PRINCIPLES OF

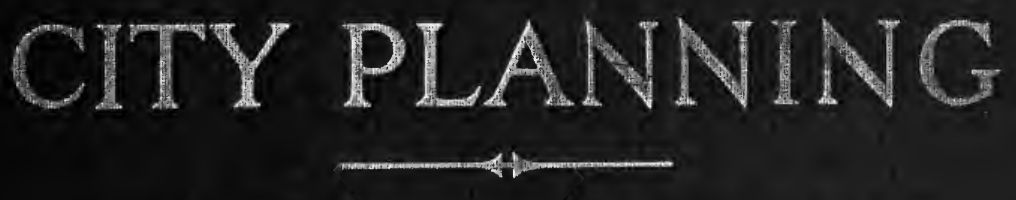
KARL B. LOHMANN 
From the collection of the

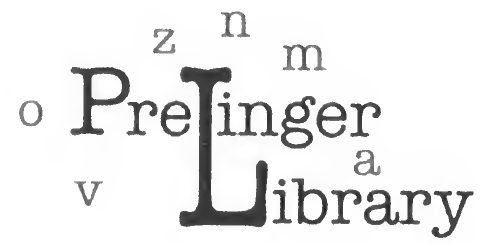
t p

San Francisco, California 2006 
dnum bo

glael. orser

univenty 



\section{PRINCIPLES OF CITY PLANNING}

This book is produced in full compliance with the government's regulations for conserving paper and other essential materials. 


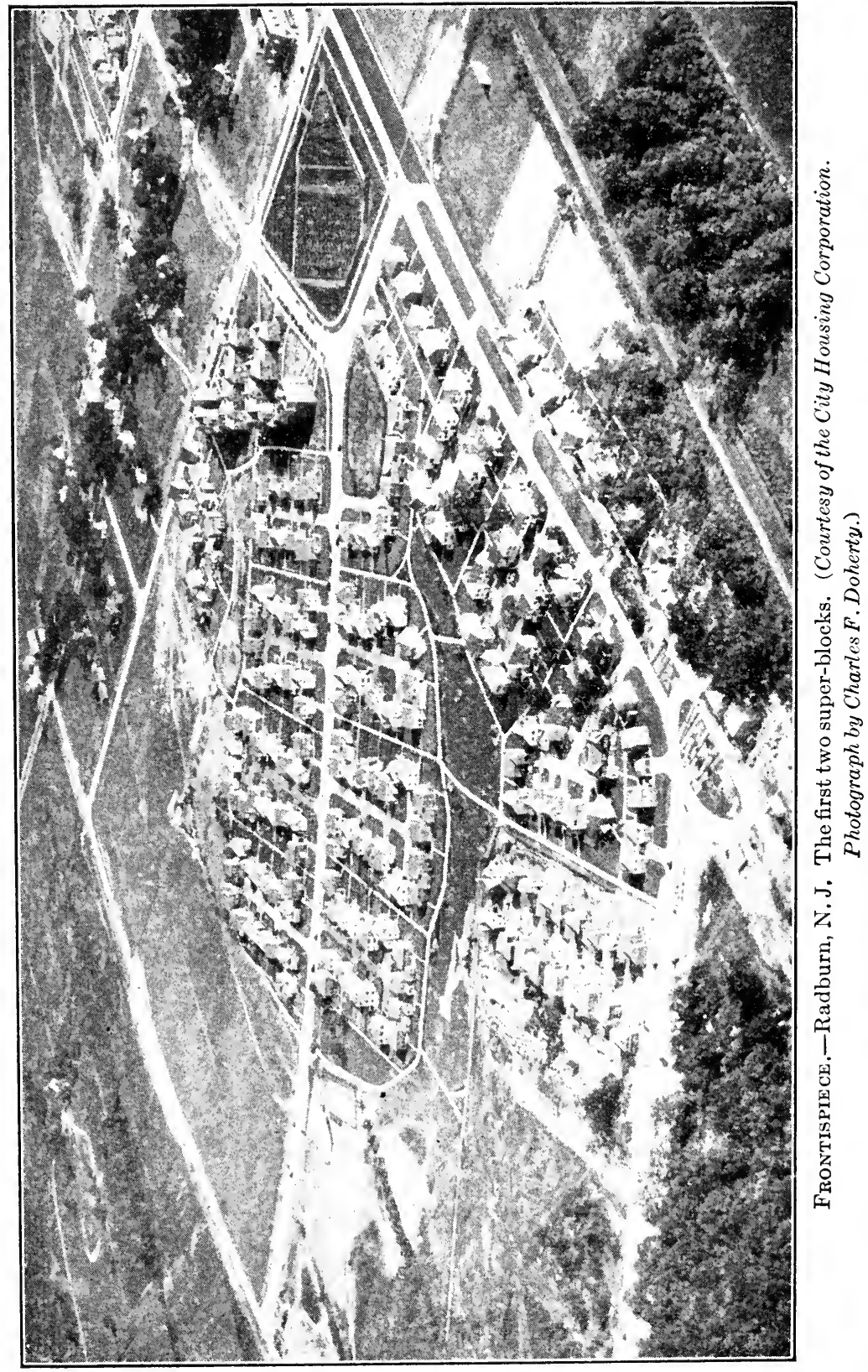




\section{PRINCIPLES OF}

\section{CITY PLANNING}

BY

\section{KARL B. LOHMANN}

Professor of Landscape Architecture, University of Illinois; Member American Society of Landscape Architects, American City Planning Institute, $N$ ational Conference on City Planning, American

Civic Association

First Edition

SiXTH IMPRESSION

MCGRAW-HILL BOOK COMPANY, INE.

NEW YORK ANDLONDON

1931 
Copyright, 1931, By the

McGraw-Hill Book Company, Inc.

PRINTED IN THE UNITED STATES OF AMERICA

All rights reserved. This book, or parts thereof, may not be reproduced in any form without permission of the publishers. 
To My Student Friends

THIS BOOK IS AFFECTIONATELY INSCRIBED

The quality of the materials used in the munufacture of this book is governed by continued postwar shortages. 


\section{Digitized by the Internet Archive in 2006 with funding from Microsoft Corporation}




\section{PREFACE}

City planning has experienced rapid growth and change during the past decade and is now occupying an important place in the public eye. Although there have been many reports and magazine articles, as well as books on special phases, there have been few books covering the whole subject. To fill the need for a single volume assembling in readily accessible form the results of various investigations and the latest discussions of important aspects of the subject, this book has been written.

This volume is intended to be of service to those who are studying and teaching city planning and to city officials, particularly to members of zoning or planning commissions. At the same time it is hoped that the book may be helpful to the citizen who is interested in the improvement of his village, town, or city, and is desirous of knowing more about this subject.

With these objects in mind the author has given special emphasis to the elements and principles of the various branches of city planning while considering also things of such general interest as the scope of the work, its importance, its possibilities, and means of accomplishment. He has tried to treat the subject comprehensively and with due regard for the practical, theoretical, and esthetic factors involved. He has endeavored to go deep enough for practical usefulness and high enough to give the reader a sweep of vision and an exercise of his constructive imagination. New as well as old ideas of planning have had the attention of the author, and the views of leaders in the field, whether conservative, liberal, practical, or visionary, have been presented.

Although now and again throughout the text, particularly in those chapters dealing with the historical development of city planning and of housing, the writer has called attention to important developments elsewhere in the world, nevertheless he has endeavored to stress the trends and accomplishments of these movements within the borders of the United States. 
These things the author has tried to accomplish by bringing together in concise form much of the material already written upon the subject and by adding results of his own experience in the past several years in teaching and practice and of his observations made during extensive travel both in Europe and in America. The present book is based largely upon notes made by the author in his teaching of a course in city planning. The manuscript has not only been put to the test of such actual use but has been examined by a score or more of nationally known specialists in the various fields discussed in the text.

For help given in the preparation of the book, the author is heartily grateful. He wishes to acknowledge particularly the kindly and valuable review of individual chapters by the following persons: Messrs. James W. R. Adams, Harland Bartholomew, Walter Blucher, Stephen Child, Arthur C. Comey, E. C. Christopher, Jacob Crane, George B. Ford, E. P. Goodrich, Everett E. King, Miller McClintock, Rexford Newcomb, John Nolen, Elbert Peets, T. Glenn Phillips, Arthur Shurtleff, Edward C. Schmidt, F. A. Cushing Smith, Lawrence Veiller, Robert Whitten, Frank B. Williams, L. H. Weir, Henry Wright, and Miss Harlean James. The author is also grateful to Mr. Tracy Augur, Miss Anna C. Glover, and Profs. Otto G. Schaffer, Stanley White, Irving Peterson, and Florence Robinson for suggestions and criticisms; to Mrs. Velma Mathews Kincaid who as librarian contributed so much of her effort during the early preparations of the manuscript; to Mrs. Josephine Smith; and to Mrs. Clarence Berdahl for her many suggestions. He is appreciative of the active cooperation of his wife, Jane R. E. Lohmann, in helping to make the book a possibility. The author owes a special debt of gratitude to Mr. Howell S. England who gave so generously of his time in helpful revision.

Karl B. Lohmann.

URBANA, ILL.,

February, 1931. 


\section{CONTENTS}

Preface. . . . . . . . . . . . . . . . . . . . . . . vii

CHAPTER I

INTRODUCTION . . . . . . . . . . . . . . . . . . 1

CHAPTER II

Physical Characteristics of Cities. . . . . . . . . . . . 6

CHAPTER III

Historical Glance at Development of Cities . . . 17

CHAPTER IV

The City Planning Movement in America. . . . . . 52

CHAPTER V

The City Plan . . . . . . . . . . . . . . . . 65

CHAPTER VI

Streets ANd Street Systems. . . . . . . . . . . . . . 71

CHAPTER VII

Traffic Control. . . . . . . . . . . . . . . . . 91

CHAPTER VIII

Transit and Rapid Transit . . . . . . . . 100

CHAPTER IX

The Railroad in the City Plan. . . . . . . . . 110

CHAPTER $\mathrm{X}$

Sea, Lake and River Ports . . . . . . . . . . . 122

CHAPTER XI

AIRPORTs. . . . . . . . . . . . . . . . . . . . . 139

CHAPTER XII

Systems of Utilities Other Than Transit and TransPORTATION . . . . . . . . . . . . . . . . 158 
CHAPTER XIII

Parks and Park Systems.

CHAPTER XIV

Playgrounds and Playfields. 185

CHAPTER XV

Subdruision of Land.

CHAPTER XVI

Housing.

CHAPTER XVII

ZoNing

CHAPTER XVIII

Public Buildings and Building Groups. . . . . . . . 274 CHAPTER XIX

The Beautiful in the City Plan . . . . . . . . 302 CHAPTER XX

Regional Planning in Metropolitan Areas . . . . 317 CHAPTER XXI

Legal Authority for City Planning. . . . . . . . . 342

CHAPTER XXII

Paying for City Planning Developments . . . . . 352

CHAPTER XXIII

Educational and Promotive Work in City Planning. . 363

CHAPTER XXIV

Conclusion . . . . . . . . . . . . . . . 373

Index. . . . . . . . . . . . . . . 377 


\section{PRINCIPLES OF CITY PLANNING}

\section{CHAPTER I}

\section{INTRODUCTION}

City planning is the effort to control, to guide, and to accomplish the physical development of towns and cities and thereby to provide for the people who are living and working in them, the best possible environment. Its concern is largely with the urban unit as a whole, inclusive of the regional setting. Interrelation and coordination, efficiency and health, utility and beauty are among its principal watchwords.

The importance of city planning is becoming more and more generally appreciated because of the phenomenal growth of our American cities, both in the multiplication of their number and in their individual increase in population. In 1860, 3 per cent of the people of the United States lived in cities; in 1930, 56.2 per cent lived in cities; and the influx appears to continue. During the 40 years from 1890 to $1930,1,748$ new cities of over 2,500 population had come into being in the United States. In 257 of our cities between 1921 and 1929, 400,000 (one-family, two-family and multi-family) dwellings on an average were erected each year, which fact explains why urban districts with their new lots, streets, and alleys are continually invading areas theretofore wholly agricultural.

Again the importance of city planning is being realized because the cost of the mistakes that result from unguided growth of cities is everywhere being impressed upon the taxpayers. At every turn in the average American city we find the congestion of both population and traffic caused by the lack of a proper city plan. This failure to provide in advance for increase in population and its attendant congestion of traffic has resulted in both inconvenience and loss of time and in numberless accidents in 
which people have been maimed or killed. In many of our cities inadequate recreational space still takes its toll in delinquency and unhappiness, and we yet see in close juxtaposition properties devoted to mutually repugnant uses. Such situations are fortunately diminishing in an ever increasing number of cities, as they avail themselves of the advantages of zoning.

The time lost because of traffic congestion is appalling, especially when we realize that such losses are in large measure preventable. In New York (the metropolitan region) the loss has been estimated at $\$ 1,000,000$ per day; in Cincinnati at $\$ 100,000$; in Detroit at $\$ 100,000$; in Philadelphia (metropolitan region) at $\$ 400,000$; and in Worcester, Mass., at $\$ 35,000$. The losses due to accidents in Chicago alone during the course of 1 year are computed to be $\$ 120,000,000$. The annual economic loss throughout the whole country from accidents upon streets and highways is over $\$ 600,000,000$. The importance of city planning is emphasized further by the tremendous cost to the municipality of rectifying these mistakes. Ten cities in the United States are now spending together a total of $\$ 465,000$ on traffic surveys. To rectify the mistakes made by the poor subdivision of land in Des Moines, Iowa, alone, has cost $\$ 2,000,000$ during the last 7 years. Reports from Chicago show that during the last 40 years $\$ 246,000,000$ have been spent in inadequate improvements in that city, improvements that had to be taken out almost immediately and done over again-with an average cost for such rectification of $\$ 6,000,000$ per year.

Through the aid of intelligent city planning, many of the foregoing losses may be averted or eliminated; through it a number of desirable achievements will be reached. By systematic and orderly development, convenience will be attained, time will be saved, congestion eliminated, working efficiency of the people increased, and both commerce and industry advanced. One of the important aims of city planning is the saving of life from the dangers of modern traffic.

The possibilities of city planning are especially striking when one considers the improved health and happiness of the inhabitants. In this connection President Hoover has made the following comment:

The enormous losses in human happiness and in money which have resulted from lack of city plans which take into account the conditions of modern lif e need little proof. The lack of adequate open spaces, of 
playgrounds and parks, the congestion of streets, the misery of tenement life and its repercussions upon each new generation are an untold charge against our American life. Our citiss do not produce their full contribution to the sinews of American life and national character. The moral and social issues can only be solved by a new conception of city building.

Maximum sunlight, pure air, extra space, and increased opportunities for physical development all contribute to the welfare of the citizens. Congestion in their living quarters and in their workshops and factories can be eliminated. All classes of people can live and work in the right kind of surroundings, under conditions that will keep them fit for work and enable them to enjoy life. Thus the aims and possibilities of city planning are hygienic, economic, social, esthetic, and ethical. City planning is seeking for a better humanity through better environment; it is foresight, common sense, and good business judgment applied to cities.

The late Charles H. Wacker of Chicago said that city planning is the greatest issue confronting the American people. This is so because haphazard city growth results inevitably in congestion, and congestion creates conditions that undermine health, foster vice and crime, and decrease the efficiency of the workers. Stuart Chase in a recent issue of the Nation writes:

What kind of community would I build to increase the count of the hours that live against the count of the hours that die? I would like to live in a community where beauty abounded; where cities were nobly planned; industrial areas segregated; where great stretches of forest, lake and mountainside were left wild and free and close at hand; where houses and their furnishings were spare and fine and colorful and there was not a single billboard in a day's march.

The improvement of our cities can be attained only by recourse to some or all of the following means of accomplishment: There must be legal authority. There must be study and analysis of the problem. One must consider both the character and the probable extent of the city's growth, how fast, how far, and in what direction it is progressing. This growth must be considered with respect to traffic, utilities, open spaces, sites for public and private buildings, and zoning. There must be that kind of somprehensive planning and replanning which adapts a city to its physical needs, -which in the new sections will involve the 
planning of separate communities and in the old sections proper adjustment to present requirements, always having in mind what the future may demand. There must be teamwork for the accomplishment of this kind of city planning - that is, cooperation of the various artificers concerned, such as architects, landscape architects, engineers, and legislators. There must be suitable financing. An orderly plan will provide for a wise expenditure of moneys over a period of years. City planning also challenges a proper balance of theory and practice, of utility and good taste, and the coordination of all future improvements. A city properly planned will therefore fit its requirements more completely than one that has grown up haphazard.

Furthermore, for the attainment of the desired results in the physical betterment of our cities, not only must there be recommendations of experts growing out of their study of the problem from all of its various angles, but also the desirability of these recommendations must by favorable publicity be brought convincingly before the people who are to pay for them. To sum up, the activities essential for the accomplishment of city planning are, to use the words of W. D. Moody, "vision and surveying, push and pull, barter and sale, education and exhortation, diplomacy and expediency, courts and iuries."

\section{Questions for Discussion}

1. Is the modern city, as we know it, the hope or despair of civilization?

2. Point out the evidences of undesirable environment in our cities.

3. What would constitute better living and working conditions as far as physical environment is concerned?

4. Explain the difference between individual and community planning.

5. What is the meaning of organic unity in a city layout?

6. Tell about the growth of population in the United States; the increase in urban and rural population; the increase in dwellings.

7. What is the penalty of the unguided growth of cities?

8. How does the growth of a city present an opportunity for intelligent conscious planning?

\section{References}

Adshead, S. D.: An Introduction to Civic Design, Town Planning Review, vol. 1, pp. 3-17, April, 1910.

Anderson, Nels, and E. C. Lindeman: City as Dynamic Stimulus, "Urban Sociology," Chap. X, Alfred A. Knopf Inc., 1928.

Hoover, Herbert: Address on need for city planning, "Plan of New York and Its Environs," pp. 13-14, Russell Sage Foundation, meeting of May 10, 1922. 
Hubbard, Theodora Kimball: "Manual of Information on City Planning and Zoning," Harvard University Press, Cambridge, 1923.

- and Katharine McNamara: "Planning Information Up-to-date," Harvard University Press, Cambridge, 1928.

James, Harlean: Introduction, "Land Planning in the United States," pp. 3-13, The Macmillan Company, New York, 1926.

Lewis, N. P.: Definitions of City Planning, "Planning of the Modern City," pp. 9-11, 1916, 1923.

Nolen, John: Introduction by F. L. Olmsted, "City Planning," D. Appleton \& Company, New York and London, 1924.

Root, Elinu: Address on need for city planning, 'Plan of New York and Its Environs," pp. 18-23, Russell Sage Foundation, meeting May 10, 1922.

Unwin, R.: Of Civic Art as the Expression of Civic Life, "Town Planning in Practice," pp. 1-14, London, 1913. 


\section{CHAPTER II}

\section{PHYSICAL CHARACTERISTICS OF CITIES}

Cities are so much like ourselves that it is no wonder they interest us and almost give us a feeling of kinship with them. Like us they live and grow and have personalities of their own. We learn to recognize and to love or dislike them because of individual characteristic traits. Most of them have certain things in common. All of them have grown from small beginnings, and as they have grown, they have served masses of people variously occupied at home, at work, and at play. As we think of them they resolve into various types. Indeed, they differentiate themselves according to size, origin, and purposes served. They are characterized by the climate under which they exist, the streets that tie them together, and their architecture. They differ also according to the kinds of people that use them.

Types of Cities According to Location.-Cities have come into being in a variety of ways and in a variety of places. Topographical influences and causes have set cities upon lake, or river, sea or ocean, mountain or plain. It is not surprising that a great many cities have originated upon rivers. Where sufficiently deep, rivers have served for navigation and often have met a land route at the point of origin of the city. Where the river is wide, the matter of crossing necessarily becomes focalized at certain points on either side of the river, and these become centers of growth of population around ferries or bridges. In cases where ocean and river join, the lines of navigation meet just as they do where a river and creek come together, or where two or more rivers unite. The deep river has resulted in Memphis and Vicksburg; the wide river has caused the origin of Terre Haute and Harrisburg; the meeting of river and ocean has given us New Orleans, New York, Philadelphia, and San Francisco; or the meeting of a river and creek, St. Paul and Richmond. The locations of Cairo, St. Louis, and Omaha were determined by the meeting of two or more rivers. 
In much the same manner as cities began upon the river banks, they became established upon the ocean shore. Ocean-going travel and land communication, export and import trade, at protected places called "harbors," result in our so-called "ocean cities" (Fig. 1). Then also there are the island cities like Galveston, New York, Boston, Paris, and the promontory cities so popular among the earlier colonies of Greece. These and the hill and mountain cities were so situated because of the ease with which

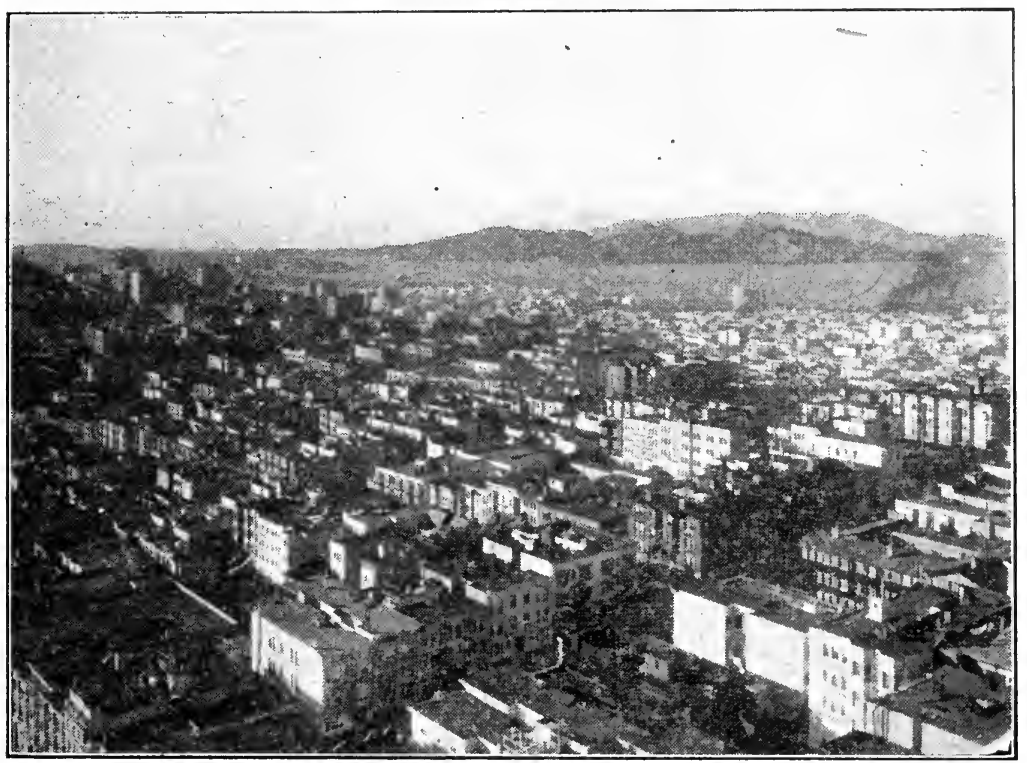

FIg. 1.-Picturesque San Francisco! From the tops and slopes of its hills one may look upon peaks to the south, upon the ocean to the west, across the bay and to the summit of Mt. Tamalpais to the north, or to the blue wall of the Berkeley hills on the east. No city in America can boast a more beautiful natural site. If only the opportunity had been seized to fit the street pattern to the locality. (Photograph by Gabriel Moulin.)

they could be protected in olden times from hostile armies by fortifications. The cities of the plains grew up naturally along trade routes either at intersections of two or more routes or along the same route a day's journey in both directions from the next villages. A good site for the buying and selling of commodities was usually found along trade routes, at the junction of highways, at points accessible by water, along railroads, and at railroad centers. Industry, too, is responsible for cities at places where much capital and labor are to be employed in manu- 
facture. The needs of industry call for proximity to raw materials as in the case of Saginaw, which is located close to lumber supplies; Pittsburgh to its foundries; Denver to its smelters. Nearness to water power caused the rise of such communities as Minneapolis, Fall River, and Spokane.

Types of Cities According to Function.-Important as the geographical and topographical characteristics of a municipality are, we have seen that they are always intertwined with the purposes and functions that have helped to determine location and development. The outstanding performance of the city or town may help to distinguish it. We have already considered the importance of defence, of commerce, and of industry in this respect. Still another activity.is that of education. The need for reasonable seclusion and beauty of surroundings played its part, no doubt, in the locations of such places as Princeton, the University of Virginia, Amherst, and others.

The function of government is responsible for such cities as Washington and Canberra; religion for Zion City, Salt Lake City, and others; residential purposes and ideals, desires for more light, air, space, verdure and comfort have fixed the location of numerous suburban cities and towns, garden cities, and villages, such as Hampstead, Letchworth, Roland Park, Palos Verdes, and Radburn: Recreational demands are responsible for such health and pleasure resorts as are situated upon the seashore, in the mountains, among the lakes, and near health-giving springs.

How the People in a Community Will Help to Distinguish It.One's impression of a city is very definitely influenced by the people living there. The density of the population, for one thing, soon tells the observer that there are too many people within a given space. If the people along the streets are dressed up for promenade, they appear to have leisure and are attractive, while those in a community of working folk, dressed and equipped for work, have a look that is very different but equally characteristic. Also, the predominant age of those who live in a city may help to distinguish it. For instance, the population of St. Petersburg, Fla., in midwinter seems largely made up of older people.

Dominant Types of Streets and Street Systems.-One of the most characteristic traits of a city is the framework of its streets and the manner in which that framework is treated. The general 
patterns into which systems of streets naturally group themselves are the rectangular and regular types, as seen in the checkerboard arrangement of Philadelphia or the gridiron arrangement of New York; the meandering and irregular type, as in Boston or London; the concentric arrangement with a common center, as in Moscow, Vienna, or Karlsruhe; and the diagonal or radial scheme as found in the plan of Paris, of New Orleans, and in Wren's study for London. These may occur in combination,

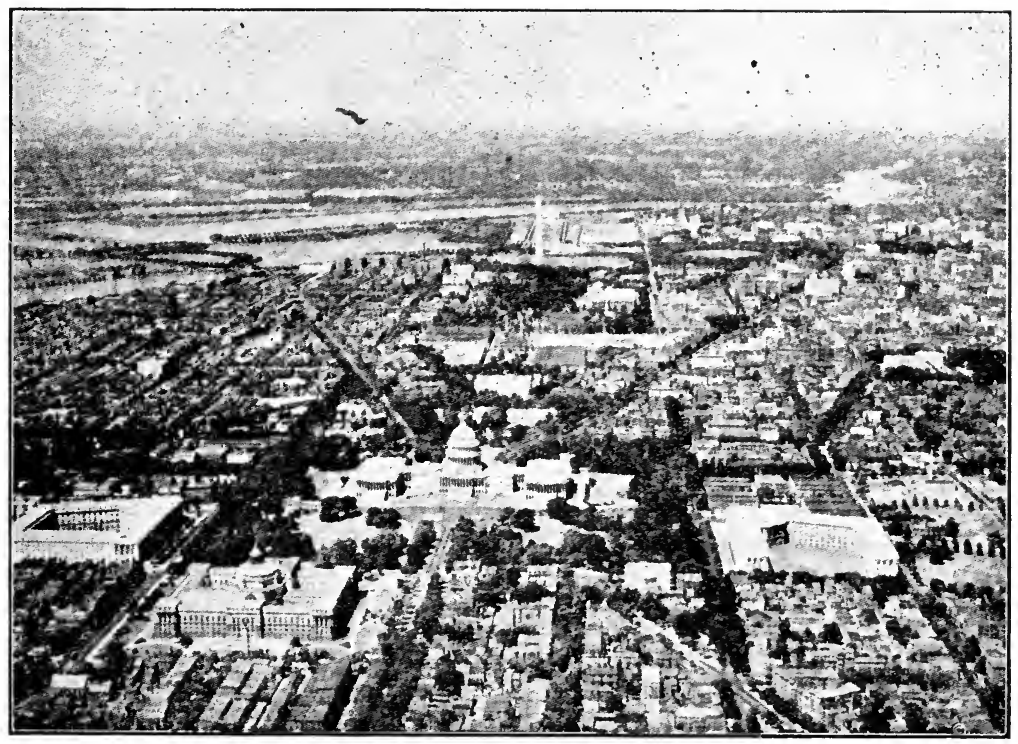

Fig. 2.- The planned city of Washington. Because of the L'Enfant plan of 1791 we are privileged to enjoy today the realized pattern of radiating avenues and the long vistas between striking focal points. We behold the vision of a city functioning in a well articulated unity and serving more and more to command the admiration of our people. (Photograph by Fairchild Aerial Surveys, Inc.)

as in Washington (Fig. 2) or Canberra. The general arrangement of the streets is obviously an important point of difference between one city and another. Of even more importance may be the treatment of the streets, their width, the disposition of the different elements, and the presence or absence of trees, telegraph poles, attractively designed light posts-all these contribute to or detract from the essential character of the city. The parks in the middle of the streets of New Orleans are among the nutstanding pleasant remembrances of a visit to that city. 
Sometimes the names of streets have much to do with creating individuality in a community and are full of eloquence. Think of such names as these in certain English communities: Rampant Horse for the name of a thoroughfare in Norwich, or Wag-a-leg in Buxton, or Endless Street in Salisbury, Parsons Pool in Shaftesbury. It is interesting to see how the names of the streets of Philadelphia have been repeated in half of our cities. Main

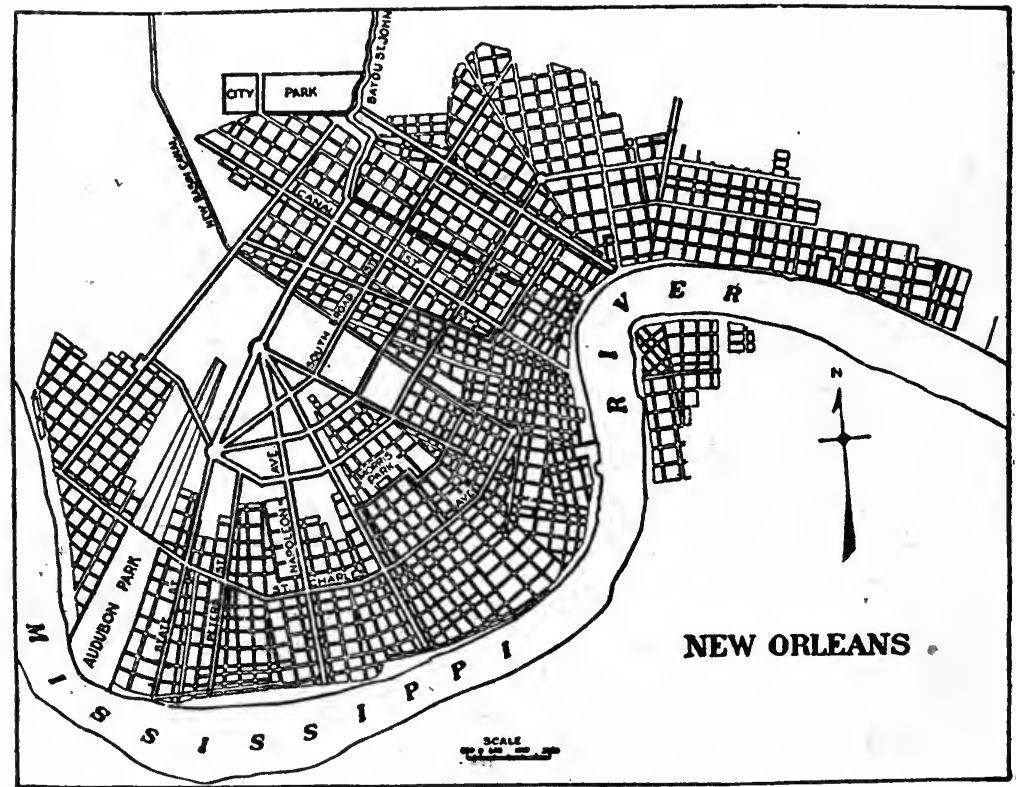

FIg. 3.-The street plan of New Orleans. There is much that is individual in New Orleans as a city. Its street system is both checkerboard and radiating, narrowed in the Vieux Carré to old time horse-and-wagon widths and broadened generously along other main ways to an extent that puts the city in a class by itself.

Street is so characteristic that it became the subject of a popular book.

Types of Cities According to the Architecture.--One can readily see how the numerous types of architecture in various parts of the world and during different stages of history have played an important part in the characteristic distinctions among cities. When considered from the viewpoint of their architecture alone, how distinctive are such cities as Athens and Rome, Nuremberg and Chester, Washington and Chicago. How distinctive the 
colonial homes that look out upon streets of Charleston (Fig. 4) and Chestnut Street in Salem, or the houses of Spanish design that are so characteristic now of Florida and California, or the French homes in parts of New Orleans (Fig. 5). Local building

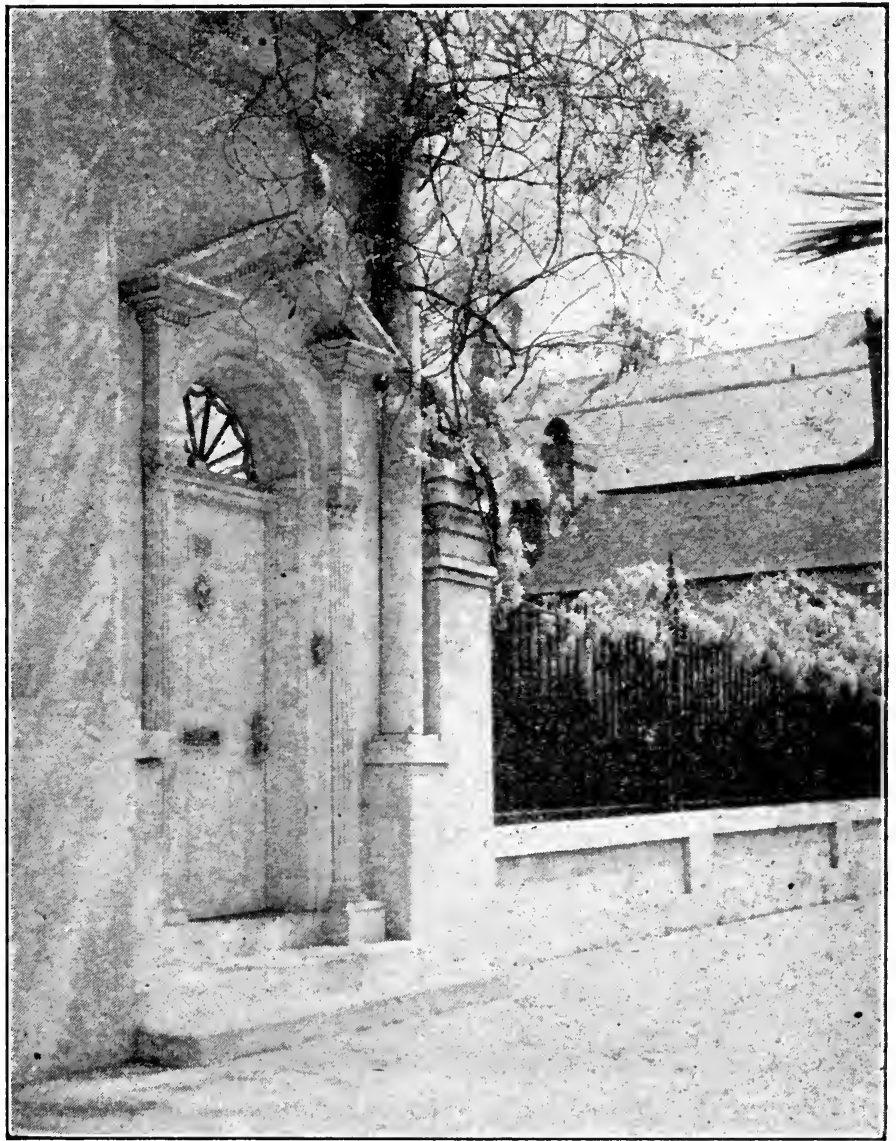

Fig. 4,- Scene along a street in Charleston, S. C. Conspicuous among the factors that determine the aspect and character of cities is architecture. Nowhere in America can one appreciate more the truth of this than in Charleston, S. C.

materials also make a great difference in the architectural aspect of the city. How characteristic such sky-piercing buildings as those in New York! Equally expressive are the different uses of buildings. The coal-mining communities, the oil cities, the agricultural towns all present particular pictures, depending 
upon the character of the industry and the consequent character of the architecture.

The effect of climate upon our cities is best reflected in the architecture. This results from the fact that either protection from the elements or the effort to make the most of the more agreeable forms of weather plays a part in determining different

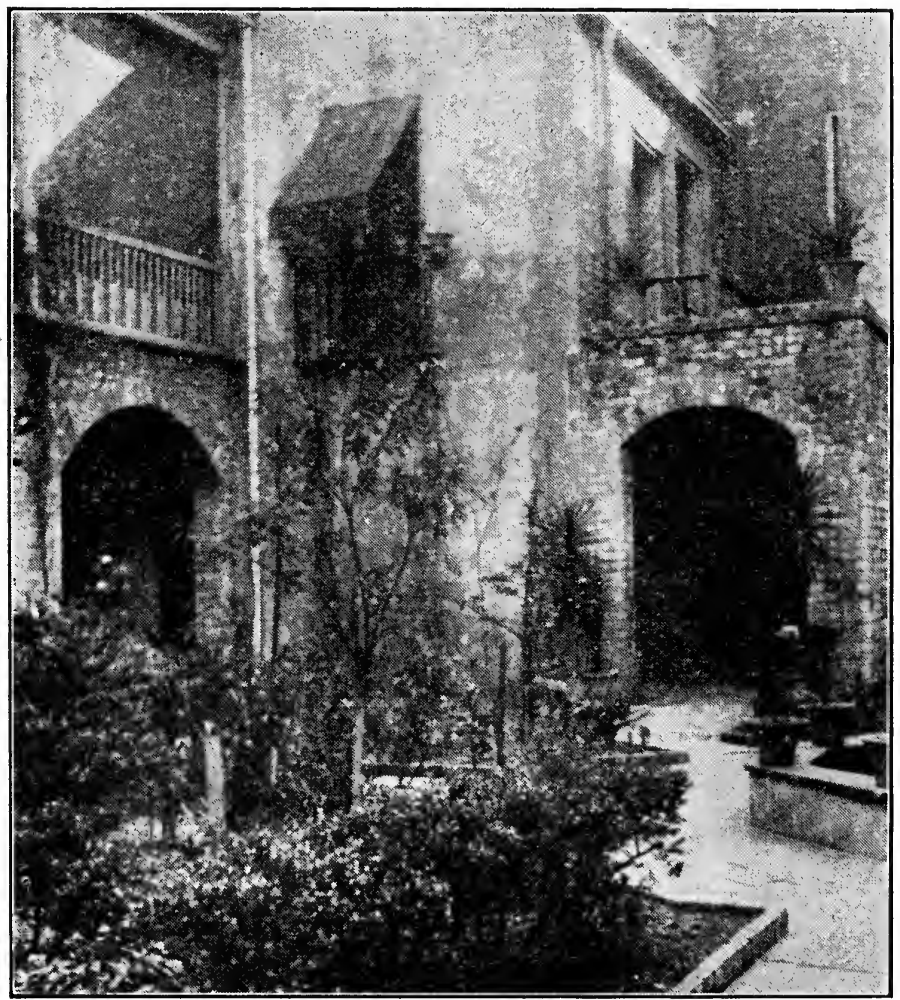

Fig. 5.-A patio of New Orleans. The architecture, the courts and gardens, the climate and habits of its people make of New Orleans one of the most unique of our cities.

types of construction as well as of architectural expression. To be sure, some of our cities are widely known by reason of their climates as such. Some are proverbially hot, others cold; the windswept streets of Chicago and San Francisco are known around the world.

Types of Cities According to Size. - The most obvious characteristic of an urban community is its size. It may be a village, 
a town, or a city. Whether it is one or the other of these in some instances might not be clearly defined, but in general we think of villages or towns as having less than 5,000 inhabitants, small cities from 5,000 to 50,000 people, and the medium-sized ones from 50,000 to 100,000 people. Centers of 100,000 people or more up to $1,000,000$ are classed as larger cities, and the largest are those of $1,000,000$ or more. In 1930 New York had almost $7,000,000$ people; London had almost 8,000,000. Apparently our ideas of what constitute the largest cities are in a state of flux. Unless newer conceptions of city planning stem the tidal drift toward ever larger centers, or unless people begin to seek homes and places of work in less populated centers, eventually we shall see cities that in size and complexity we scarcely dare allow our imaginations to picture. We may see before long the era of double- and triple-decked streets and sidewalks, and. skyscraper bridges serving other sky-piercing structures, and all forms of subsurface, surface, and supersurface types of transportation, teeming and vibrating with the motion of a hurried people, or we may see a changing drift to the open country, with industry decentralized and homes not too far away in the midst of spacious, quiet neighborhoods and close to the kind of recreational beauties that may now be enjoyed in our villages. Even though the larger metropolitan centers may continue to expand, yet they may by good planning be provided with certain advantages that are identified with the smaller communities.

Growth in the Cities. - The growth of cities in number and in size, already discussed, has been phenomenal, particularly in America. No less important than the extent of growth is the nature of it and the way it takes place within any given city as revealed in an analysis of the plan of that city. According to R. M. Hurd, ${ }^{1}$ there are two forms of growth, one of these a clustering around a central point of attraction, as, for example, some kind of business or a residence section. This is known as "central growth." The other, a main general expansion in all directions, takes place along the framework of the city, along its water courses, its arteries of traffic, its turnpikes and railroads. This growth is the result of transportation and is based on accessibility. We call it "axial growth."

The causes for the expansion of our cities have been and are numerous. Cities have grown because of the intellectual

1 "Principles of Land Values." 
advantages that they afford, libraries, schools, museums, churches, lectures, and other entertainments that are within the reach of their inhabitants. Cities have grown because of their opportunities for material gain, for work, and for the ambitious
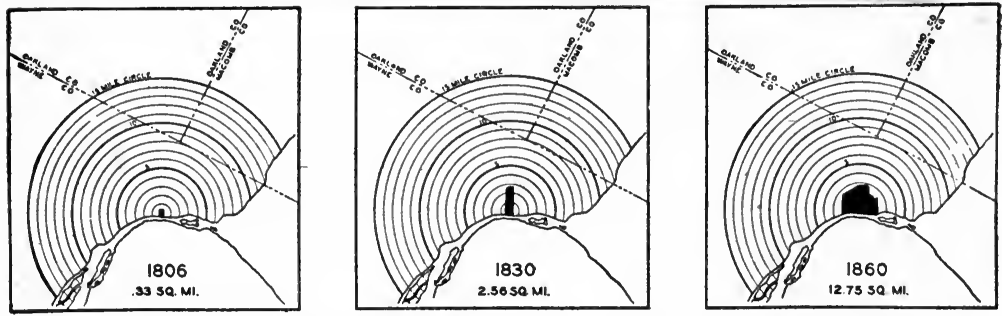

FIVE MILE CIRCLE - LMMIT OF SATISFACTORY SURFACE STREET CAR SERVICE
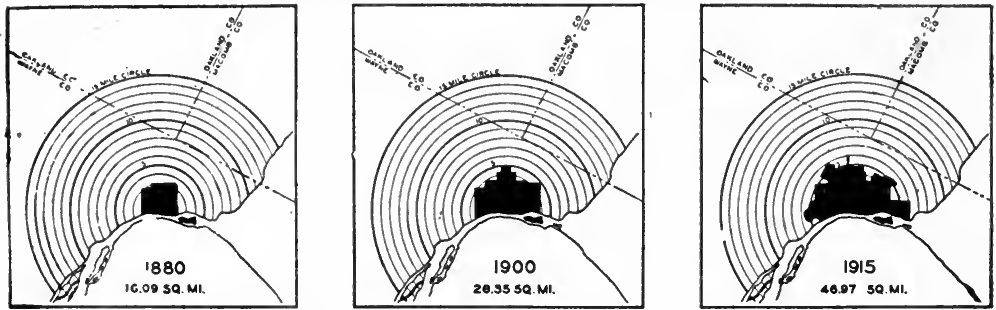

TEN MILE CIRCLE : - LIMIT OF SATISFACTORY RAPID TRANSIT TWO TRACK LOCAL SERVICE
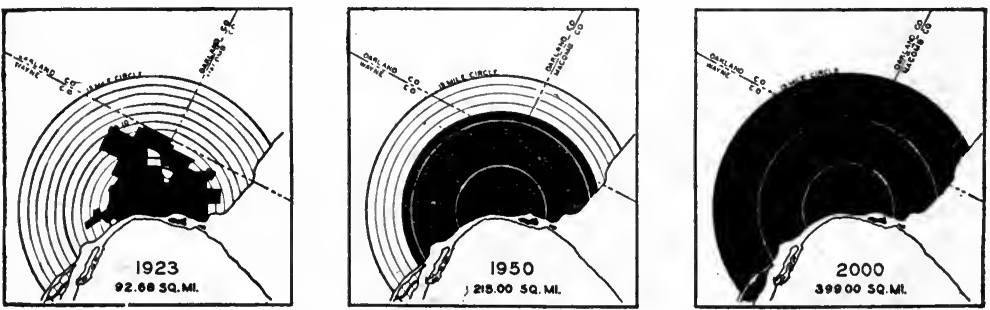

CITY OF DETROIT

EXPANSION IN AREA SINCE 1806

RAPID TRANSIT COMMISSION

FEBRUARY 1924

FIG. 6.-An illustration showing past expansion and possible future growth in the city of Detroit. How much growth has advanced or will advance is not only closely connected with the "facial" expression of the city but with the program of vital needs. The above illustration represents an. effort to study expansion and thereby determine certain future needs.

to advance. They have grown also because of the attraction of their increased facilities for the comfort of their population, their protection (as against fire, etc.), their opportunities for recreation. Another important reason for the growth of cities 
has been the improved methods of transportation (Fig. 6). So true is this that the big city of today might be thought of as the child of transportation, and particularly so in the light of developments during the last several years. Improved methods of transportation have facilitated getting food and other necessities into the city and have made it possible for the people to get in, around, and out of the city over larger areas than was possible in the past. Vertical transportation, which in the form of elevators has taken such an important place in the skyscrapers of New York and other large cities, has played its part in amplifying the vertical dimensions of the city.

\section{Questions for Discussion}

1. In what respects are cities alike and how do they differ?

2. How may topography affect the development and appearance of a city?

3. Differentiate between central and axial growth.

4. Tell what developments have stimulated urban growth.

5. What is the ideal location for a city and what city of the world approaches most nearly that ideal?

6. With the aid of plans, blackboard sketches, lantern views, etc., describe the physical layout of some one important eity of the world, noting in particular its location, size, archịtecture, and other outstanding physical characteristics.

a. Among the cities of the United States one of the following might be selected. These are arranged in the order of their population importance:

$\begin{array}{lllll}\text { New York } & \text { Baltimore } & \text { Washington } & \text { Seattle } & \text { San Antonio } \\ \text { Chicago } & \text { Boston } & \text { Minneapolis } & \text { Indianapolis } & \text { San Diego } \\ \text { Philadelphia } & \text { Pittsburgh } & \text { New Orleans } & \text { Portland } & \text { El Paso } \\ \text { Detroit } & \text { San Francisco Cincinnati } & \text { Houston } & \text { Harrisburg (Pa.) } \\ \text { Los Angeles } & \text { Milwaukee } & \text { Newark } & \text { Denver } & \text { Charleston (S. C.) } \\ \text { Cleveland } & \text { Buffalo } & \text { Kansas City } & \text { Dallas } & \text { Kenosha (Wis.) }\end{array}$

St. Louis

b. Among the cities of other countries one of the following might be selected. These too are arranged in the order of population:

$\begin{array}{llll}\text { London } & \text { Calcutta } & \text { Canton } & \text { Manilla } \\ \text { Berlin } & \text { Sydney (N. S. W.) } & \text { Birmingham (England) } & \text { Florence } \\ \text { Paris } & \text { Budapest } & \text { Rio de Janeiro } & \text { Delhi } \\ \text { Osaka } & \text { Bombay } & \text { Rome } & \text { Antwerp } \\ \text { Tokio } & \text { Warsaw } & \text { Liverpool } & \text { Canberra } \\ \text { Buenos Aires } & \text { Hamburg } & \text { Brussels } & \\ \text { Moscow } & \text { Cairo } & \text { Amsterdam } & \\ \text { Vienna } & \text { Glasgow } & \text { Prague } & \\ \text { Hankow } & \text { Constantinople } & \text { Copenhagen } & \\ \text { Peking } & \text { Mexico City } & \text { Edinburgh } & \end{array}$




\section{References}

Adams, T., and H. L. Seymour: Study in Problems of Urban Growth, Canadian Engineer, vol. 47, pp. 543-549, tables, diagrams, Nov. 25, 1924.

Anderson, Nels, and E. C. Lindeman: The City: A Geographical and An Ecological Fact, "Urban Sociology," Chaps. I, II, Alfred A. Knopf, Inc., 1928.

Elgood, F. M.: Character, Its Application in Town Planning Schemes, Town Planning Institute, London, Papers and discussions, vol. 5, pp. 79-83; with discussion, pp. 84-88, 1918-1919.

Hegeman, Werner, and Elbert Peets: City Plans as Unified Designs. The plan of Washington, "The American Vitruvius," pp. 227-261, 285293, New York, 1922.

Hurd, R. M.: Forces Creating Cities. City Growth. Ground Plan of Cities. Directions of Growth, "Principles of Land Values," illus., plans, pp. 19-21, 22-32, 33-55, 56-74, 1903.

New York, National Geographic Magazine, pp. 517-583, November, 1930.

Nolen, John: Types of City Plans, American Architect, vol. 117, pp. 213215, plans, diagrams, Feb. 18, 1920.

Reclus, E.: The Evolution of Cities, Contemporary Review, vol. 67, pp. 246264, February, 1895.

Thompson, Warren S.: "Population Problems," McGraw-Hill Book Company, Inc., 1930.

Triggs, H. I.: Types of Ancient and Modern Towns, "Town Planning," pp. 85-119, plans, London, 1890.

Unwin, R.: Of the Individuality of Towns, "Town Planning in Practice," pp. 15-114, London, 1913.

Whitbeck, R. H.: Geographic Factors Affecting the Growth of American Cities, Journal Gengrophic, vol. 21, pp. 205-207, 1922.

Wilcox, D. F.: City Growth: The Problems of Great Cities, "Great Cities in America," pp. 402-416, The Macmillan Company, New York, 1910. 


\section{CHAPTER III}

\section{HISTORICAL GLANCE AT DEVELOPMENT OF CITIES}

City planning is anything but a new science or a new art. As in the case of many other things that have their roots in the past, we can understand the present and forecast the future intelligently and sympathetically only when we have examined the precedents. The character of certain existing communities today, especially those with historic background, becomes more intelligible to us with the aid of such a study. There are, moreover, certain lessons from antiquity, particularly those in the Hellenistic and Roman periods, and also from later times that are of inestimable value to us. By a study of the historical development of cities, we appreciate more fully the fact that they are still growing and evolving to meet the changing conditions of the centuries.

\section{ANCIENT AND MEDIEVAL CITIES}

The city is as old as civilization itself. Cities existed as long ago as 5,000 to 6,000 years before the Christian era. Since then they have flourished in great numbers and variety, each characteristic of its time, country, and the race to which its builders belonged. These ancient cities grew, pulsed with myriad activities, and then finally, from one cause or another, were abandoned and fell into ruins. Although our knowledge of these early cities is incomplete, because of the perishable material of which they were built and their consequent decay and, for the most part, their disappearance, still we have sufficient evidence about the characteristics of many of the early cities of the Egyptians; Assyrians, Babylonians, and Persians to tell us what they were like. We are reasonably certain that they occupied considerable areas and in some ways resembled vast armed-eamps-and that many of them were provided with processional ways that led from one end of the city to the other, while the other streets were at right angles for ready access to the processionals. Also, the ruins indicate the part played in the plans of these-eities by important public buildings, temples, and monuments. 
It is also clear that many of these same cities had rectangular ground plans. According to the evidence, early civilizations arrived at some kind of rectangular system of streets, a system that seemed to accompany a striving for social order. The circular dwelling that is associated with the earlier stages of human habitation gave place to rectangular dwellings; then followed some kind of rectangular system of arrangement for dwellings and for the rooms within them that we associate with the earlier civilizations. It is said that barbarians were incapable of laying down a straight line or a straight street. The early cities of Britain in which we can distinguish the straight streets of the Romans from the aimless streets of the natives seem to substantiate this.

Earliest Town Planning in Egypt.-The remains of ancient Kahun, a small city that flourished between 3000 and 2500 B. C., and whose citizens were the workmen upon the Illahun pyramid, give us the oldest example we have of an early-world city-laid out on a definite plan (Fig. 7). Its dwellings are arranged along regular lines with few large homes but with numerous small ones having four to five rooms in each and steps leading to the roof. This small community had a miniature acropolis on higher ground which probably served as a center for worship and government. The streets are said to represent the earliest examples of their kind of drainage with a channel of stone for carrying the water along the middle of the streets.

The fragments of buildings that exist among many of the ancient Egyptian cities show that great temples had imposing avenues of approach. At Karnak there are still to be seen the remains of a paved approach $1 \frac{1}{4}$ miles in length, lined on each side with sphinxes. Along the Nile the periodical overflow of that river not only suggested irrigation and affected the burial customs of the people, causing them to construct tombs that the floods could not destroy, but also compelled the building of cities that were properly situated upon high and dry ground.

Early Cities of Assyria. Babylon-Founded as a sanctuary and becoming one of the most important cities of the valley of the Euphrates, Babylon first appears as a place of distinction in 1917 B.C., but it attained its greatest magnificence during the reigns of Nabopolassar and Nebonidus between 607 and 539 в. с. Although the present ruins are not sufficient to build up a picture of the layout of the city, yet from these ruins with 
the aid of existing records we can envision the greatness and splendor of ancient Babylon. The indications are that it included within its walls considerable territory on both banks of the Euphrates and that it was built on a definite plan-a huge rectangle. There were straight streets that cut each other at right angles, and a number of gates that pierced the long, thick

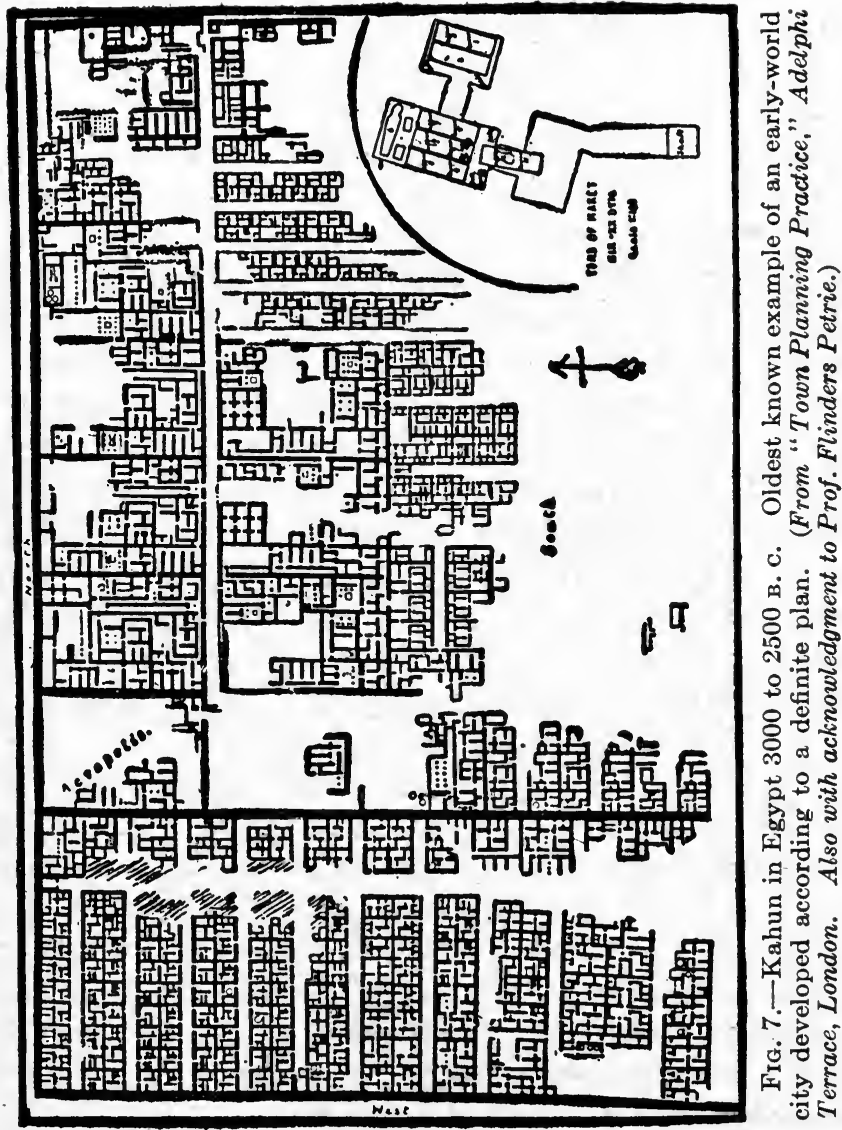

wall about the city. The Sacred Way was a broad processional road, straight for its greater part, with triumphal approaches, one of which was Ishtar's Gate that, judging from the excavations, surely must have been a crowning feature of the processional way. The city was large enough to accommodate a large population and contained woods and gardens, courts, and ter- 
raced towers. Among other features it had two palaces, one of which was on the east side of the Euphrates and contained the terraced pleasure grounds known as the "Hanging Gardens of Babylon." These were built by "Nebuchadnezzar for his Median queen who so longed for the hills of her native country that to gratify her the king erected artificial hills covered with trees and greenery in which she could imagine herself at home."

The houses, according to Herodotus, who cannot always be depended upon for his descriptions of the city, were three or four stories high. He said that there was communication between the two sides of the river by ferry but that later when the river was turned into a reservoir, a bridge was built consisting of stone piers covered with planks which were removed at night to discourage thieves. Also, according to Herodotus, the city occupied 200 square miles of territory and had a wall 50 miles long and 90 feet thick and 360 feet high, but when one considers that Chicago covers only 200 square miles of territory and that Nanking has a wall of only 24 miles in length, 30 feet in thickness and 50 feet in height, one might doubt Herodotus' accuracy.

Asshur (Assur).-The early capital of Assyria on the Tigris was a city of considerable importance. Like Babylon, it grew up around a great sanctuary, in this case the temple of the god Assur, and became the religious center of the country. There are ruins of extensive buildings and tombs which, together with the records available, give one the impression that the city was surrounded by a wall of crude brick, flanked by a deep moat. The wall was pierced by several gates. In the northern part of the city were the temples with lofty towers, one of which still stands.

Jericho was a city on a large oval-mound enclosed by massive walls and had towers at irregular intervals. The system of streets was rectangular. The interior of the city was a reserve of small houses, "threaded, as are many of the eastern bazaars, by a single thoroughfare. One of the peculiar features included many houses that were reached by passing through those of the neighbors."

Nineveh.-Despite its associations as a warrior state and the scene of every sort of merciless tyranny, the royal city of Nineveh somehow thrills us with its glamor. The city was in existence in 3000 B. C. and was destroyed in 606 B. C., but in the time of Sennacherib it appears to have reached the zenith of its spectacular beauty. Sennacherib built himself a new palace 
and surrounded it on all sides with temples and other important structures; he caused large areas of slums to be razed and in their places introduced new thoroughfares and bordered them with richly sculptured buildings. Tall, square, tower-like structures rose in successive stages. The entrances to the new temples were marked by colossi cased in bronze representing bulls and

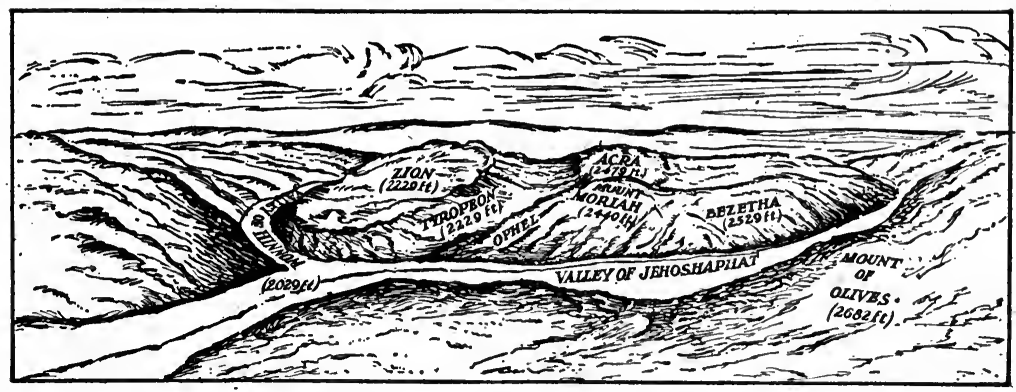

FIG. 8.-Topography of Jerusalem. (Redrawn from "The Jewish Encyclopedia.")

lions. Walls 50 to 100 feet high enclosed the city and were wide enough on their ramparts to accommodate four chariots abreast. These walls were pierced at intervals by gateways flanked by winged bulls and lions. The area of the city included some 1,800 acres and assumed the form of a gaiter, the front of it facing the left bank of the river Tigris. "The whole was cut by the river

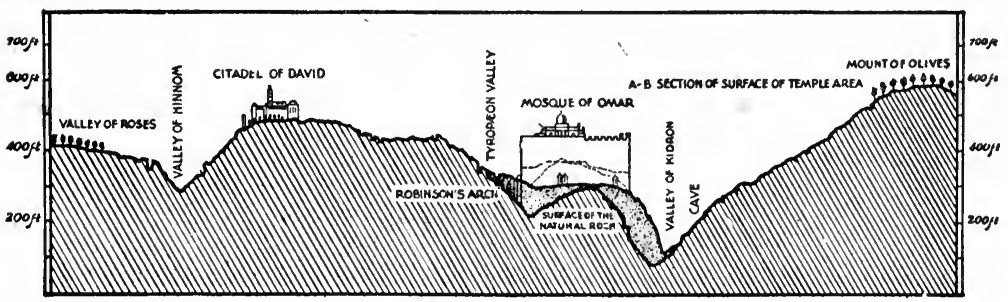

Fig. 9.-Cross-sectional view of Jerusalem (west to east) as seen from the south. (Redrawn from "The Jewish Encyclopedia.")

Khosar which at the entrance to the city on the west described a semicircle around an eminence, Kouyunjik, which was the site of a succession of magnificent palaces."

Jerusalem.-This great city of alternating glory and despair has been described as "the bride of kings and the mother of prophets." Certainly it is one of the most interesting of cities. It was situated on a watershed between the desert and the-seawhere timber was always scanty and the water supply poor. 
The site was a wedge-shaped terrain, the point of the wedge jutting to the south, and the land rose into terraced heights from deep valleys that bordered it $\mathrm{Y}$-fashion to the southeast and southwest (Figs. 8, 9). Easy access could be had only on the opposite sides, to the north. The site was furrowed with hills that have acquired world fame, Zion, Moriah, Acra, and Bezetha, the first two being the most important. Mount Zion on the southwest was not only the largest of the hills of Jerusalem but the highest and the only one that was completely isolated.

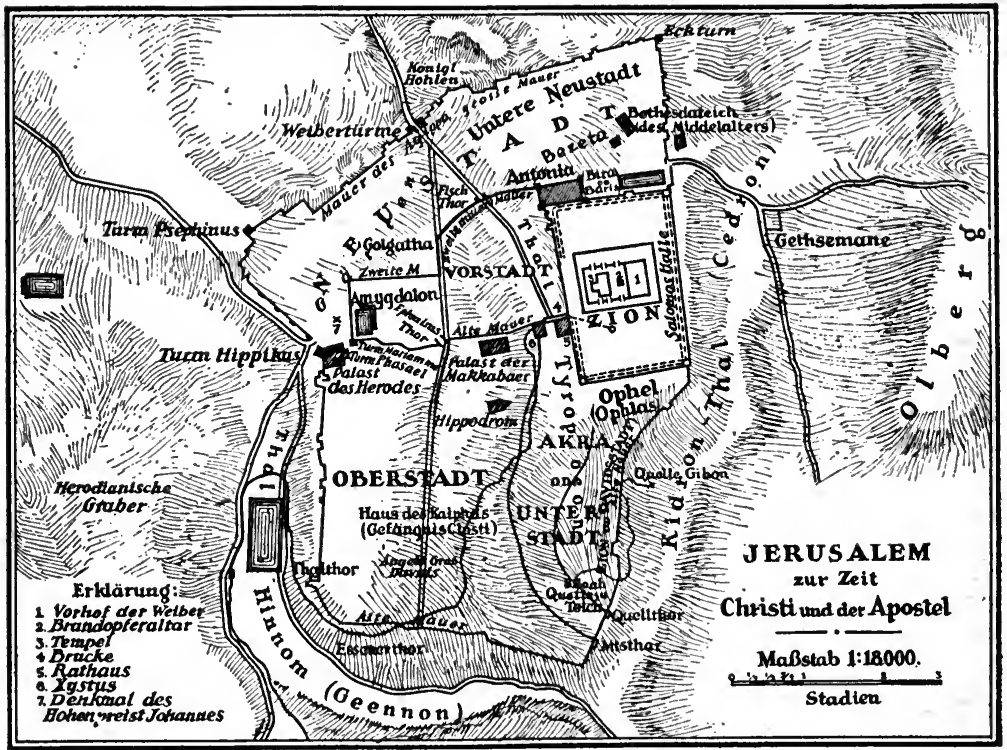

FIG. 10.-Jerusalem at the time of Christ. (Redrawn from "Brockhaus-Konversations-Lexikon.")

Upon the crest of Mount Moriah on the east the temples and palaces of Solomon were located.

In the kaleidoscope of numerous reconstruction periods to which Jerusalem has been subject, the one of Herod's-time beginning with 37 B. C. probably holds greatest interest for us, because it was during the reign of Herod that Jesus was born and because there was at that time an unusually brilliant period of building construction. During Herod's time the city lay mainly upon two opposite hills with a valley between; on Zion was the "upper city" which was much higher and longer; on Acra to the east was the "lower city" (Fig. 10). In addition there was a 
third part lower still than either of these and a fourth beyond that to the north known as the "new city." To the east of the city across the valley of Kidron and from 100 to 200 feet higher than Jerusalem was the revered Mount of Olives. Walls enclosed the upper and lower cities, but because of the easy approach from the north three successive walls were built there. In the upper city on Zion, Herod built himself among other things a splendid palace and three great towers for defence. His contribution also included the restoration of the temple of Solomon on Mount Moriah which he not only completely rebuilt from its foundations but doubled its enclosure as well; he also constructed a theater and an amphitheater, the latter containing inscriptions of the achievements of Caesar. He added to the city a town hall and the great fort of Antonia northwest of the Temple. He strengthened and beautified the defensive walls. Great new towers were added of such a character as to serve as reservoirs for water or as living rooms. Herod also introduced into the city plan a great monument to himself. It seems hardly possible that these glories were soon to pass. In $70 \mathrm{~A}$. D. the city was practically rent to pieces during a siege that lasted for 134 days.

Palmyra (City of Palms).-Another famous city of the past, Palmyra, was located 150 miles northeast of Damascus at the mountain pass into the Syrian desert. It was probably an old desert trading post long before the time of King Solomon. The interesting ruins indicate the wealth and magnificence to which it must have attained as "Queen City of the Desert" or as the city of Zenobia, that greatest warrior woman in history, she who attended assemblies of her people "helmeted, bare armed and in a robe clasped by a diamond buckle." The small streets and the large squares of Palmyra were bordered by pillared arcades. Outstanding among its buildings were the palace and the judgement hall of Zenobia. A great temple of the Sun stood upon a terrace 750 feet square surrounded by walls 50 feet high. This court was enclosed and adorned with double and triple colonnades on all sides. There are at Palmyra ruins of many commemorative towers. One of the most striking things must have been a great colonnaded street (Fig. 11). This street extended across the city from the foot of the castle heights to the principal temple for a distance of from 3,500 to 4,000 feet and had a quadruple colonnade of 454 columns, each 31 feet in height and each with a statue of some illustrious Palmyrene. The central space or 
avenue was 37 feet in width and open to the sky, while the bordering side-avenues or footways each 16 feet across,- were protected with a covering from both sun and rain. The masterly manner in which the turns were executed with the aid of triumphal arches and the way in which the junctions of the roads were arranged help to make of Palmyra one of the unique examples of city planning in history. What varied and picturesque pageantry must have passed along this triumphal thoroughfare! How proud must have been these "luxurious, silken and scented Palmyrenes" of their distinguished city of the desert!

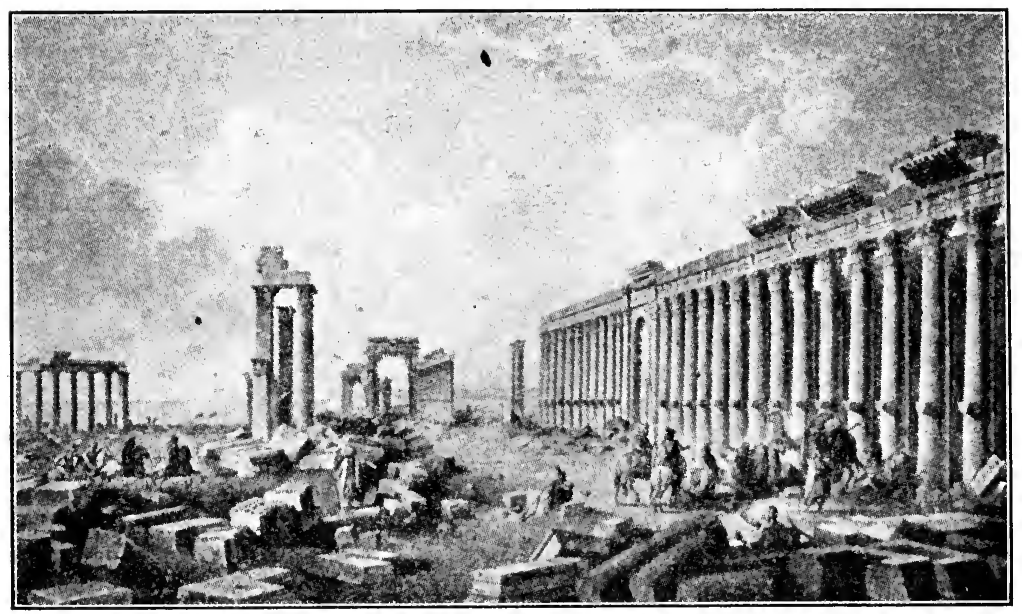

FIG. 11.-The remains of the great colonnaded street of Palmyra, the "city of palms." (From "Town Planning in Practice," by Raymond Unwin, F. Unwin publisher, London.)

The Greek Cities.-A protected location was so necessary for the earliest cities of Greece and its tributary states that they were placed in the protected hinterlands, upon the hilltops and mountain crests. With the progress of trade and with advancing civilization, the newer cities came to be located closer both to the river valleys and to the sea. These cities of Greece were not laid out according to orderly plans; city planning came later. Also there was a lack of symmetry. The sites of public buildings were cramped. The streets were, many of them, tortuous lanes, although provision was made for processional ways, for the Greeks were fond of processionals.

In the days of Pericles in the fifth century, B. c., the Greek cities passed into a period of artistic embellishment. The streets 
were built upon a scheme of rectangularity with two broad main thoroughfares crossing each other in the center of the city, where the agora or center of commercial and civic activity was located at one side with important buildings placed around it. By these intersecting streets towns were divided into rectangles and blocks. The public buildings were often magnificent, while the private homes were quite insignificant.

Athens.-Although the prehistoric period of Athens is wrapt in obscurity, yet later in the Athens of the Periclean age there is for those who are interested in the city planning contributions of history an opportunity for the free play of the imagination. No other city in the history of the world, unless it was Imperial Rome, was ever adorned with such an array of temples, public buildings, and works of art. This great city had, to begin with, an ideal location. It was far enough from the sea to avoid the attacks of the enemy, and it was close enough to be convenient to three natural harbors. It was within ready reach of the finest kind of building materials. The Attic plains adjoining furnished a supply of foodand pasturage. Near-by were several conspicuous hills and ranges of hills that contributed greatly to the beautiful surroundings of Athens. Among these hills was the famous purple-hued Hymettus.

During the Golden Age the whole territory of Athens contained almost half a million of people-a third dwelling in the city itself, and a tenth in the port nearby. In the middle of the city arose the Acropolis, a plateau (200 feet high and 1,000 by 500 feet in area), which combined the purposes of a fortress, a sacred reserve, a treasury, and a museum of art. Today it presents to visitors some of the most beautiful ruins in the world. On the western side of the Acropolis a magnificient flight of steps led to an entrance gate. To the west and north lay the town or lower city. Two parallel walls known as the "Long Walls" or "Legs,", 200 yards apart, 12 feet thick, and 30 feet high ran to the Piraeus. There was in the city of Athens an agora. There were open gymnasia and theaters and other structures to accommodate the outdoor-life-of the people.

The inadequacy of the city in some respects presents a striking contrast to the glories of Athens. Thoroughfares, for example, were woefully inadequate. One of the principal streets south of the Acropolis is said to have been but 12 to 15 feet wide, unpaved, and unlighted. We are told, half facetiously perhaps, that the 
streets were so narrow "that it was the custom for residents to knock on their doors from within before opening them to the street, in order to prevent accidents." The inadequacy in the supply of water was overcome by an aqueduct and by wells and cisterns.

There was, however, much beauty in Athens. This was due as much as anything, probably, to the Acropolis, which represented a skillful use of a great site for a beautiful group of buildings served by a stately approach. The Acropolis was not laid out originally according to orderly plans. The absence of symmetry,

- however, was quite artfully offset here and there by the use of "optical and picturesque symmetry." "The glory of the city lay in its wonderful buildings, its temples and its colonnades." "Its shame [however] was the fortuitous congestion of rude hovels and tortuous lanes." That the beauty of the individual buildings did not find similar expression in the whole scheme of things was probably due to the crowded condition of the slums the elimination of which was prevented by the preservation of the fortifications.

Ephesus was an ancient Ionian city said to be one of the 12 Greek urban developments in Asia Minor. Although its origin like that of so many ancient cities is wrapt in myth, yet the reputed founder was Androcles, the son of the last king of Athens. Ephesus was located on two hills in the midst of an alluvial plain in Lydia and near the mouth of the river Cayster. Under the Roman emperors it was the most prosperous trading city in western Asia Minor. Excavations indicate that a broad street reached from the great harbor, of Hellenistic times, past the theater, of Christian times, and terminated in a triumphal arch. Between the Hellenic agora and the Magnesian Gate the street was lined with statues of important dignitaries. Other discoveries show that there were two large market places, one Greek and the other Roman, both surrounded by colonnades and rooms.

Priene. - This Greek City in Asia Minor on the north shore of the Latmic Gulf was located on a crag that jutted out from an overhanging mountain. A high ridge of Mycale lay above it. Although during the fifth and fourth centuries B. C. it was comparatively importent as a city; its real growth occurred after Alexander's conquest of Asia (third century B. c.). This city of 400 homes had a population of 4,000 people. It was 
apparently planned with great care. It had parallel streets along the hills and narrow lanes that led uphill. The blocks were 35 by 47 meters in size. The broader streets were 23 , the narrower streets 10 feet wide. The entrances to the houses were on the side streets, while the main thoroughfares had facing them walls almost entirely blank. There were no gardens, grounds, or yards. One of the most interesting things about Priene was its spacious market place or agora with its public buildings.

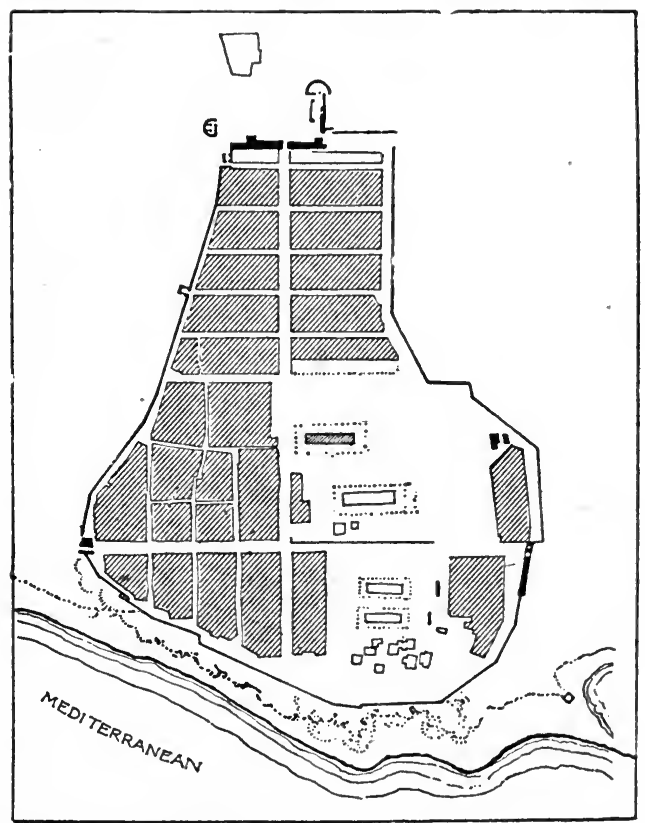

FIG. 12.-Selinus, one of the early Greek cities. (From "Town Planning," by Triggs.)

Pergamum.-F. Haverfield in his book, "Ancient Town Planning," tells us of the populous and splendid city of Pergamum, another of the Greek centers. Its chief buildings date from an age when town planning had grown familiar to the Greek world. The dominant idea was a semicircle of great edifices, crowning the crest and inner-stopes of a high crescent-shaped ridge. Below the stately semicircle of palaces, a library, shrines, and temples, was a theater hewn out of the slopes and a terrace 250 yards long held up by buttresses against precipitous cliffs. Lower yet, beneath the agora, the town of common men covered the lower 
hillside. It will be seen from this that when their abrupt hillside forbade the straight and broad processional avenues of some other Greek cities, they crowned their summits with a crescent of temples and palaces.

Selinus (648 B. C.).-This pear-shaped city (Fig. 12) is one of the earliest cities regularly laid out of which we have a trace. It occupied an entire peninsula in a Greek colony in the south of Sicily and was completely fortified. Two main thoroughfares ran from north to south and two from east to west; one of these was about 1,300 feet long and 30 feet wide. Seven or eight other streets cut across this thoroughfare.

\section{Hippodamos of Miletus, a Planner of Cities in Ancient Greece.-} Aristotle $^{1}$ describes Hippodamos as the first to introduce the fashion of laying out towns on a regular plan, which in effect is the same as giving to this famous architect of that early time the credit for inventing the art and for being the father of city planning. He was born in about 475 в. c. Although there are no direct records of his theories of planning, it was Hippodamos of Miletus, the Greek architect of the fifth century B. C., who introduced order and regularity into the planning of Greek cities. His accomplishments show that he favored broad straight streets that cut one another at right angles and that he acted with definite clear-cut principles in mind in the grouping of houses and planning of straight streets. In the opinion of one writer, he succeeded in keeping a proportionate balance between various parts of a town. He dreamed of regular and geometric cities. He desired, according to Triggs, to substitute clear, reasoned, and scientific conceptions for chance. In the opinion of Nils Hammarstrand, the city of Piræus by virtue of its scope and scale was his most outstanding accomplishment. It is likely that a first attempt was made here to subject a whole group of buildings to uniform architectural arrangement. Cities, besides Piræus, that are ascribed to the town planning genius of Hippodamos are Thurii and Rhodes. The application of his principles are observable in Selinus and Priene.

Mr. Hammerstrand feels that the evidence indicates the renown of Hippodamos and the importance of his innovations as a popular topic and to illustrate this cites a well-known passage from Aristophanes' play, "The Birds," in which Meton plans the aerial metropolis of the birds in geometric fashion,

${ }^{1}$ Aristotle's "Book" of Politics, Hippodamos, Book II, Excursus II. 
which is to be understood as a sarcastic criticism of what people no doubt referred to as the "Hippodamean innovations!"

Town Planning in the Roman World. Imperial Rome.-At the dawn of the second century A. D., when the Roman Empire was in its prime, the city of Rome had grown to great proportions and was the center of a large population. As in the case of Athens, it was a much crowded and congested city that had developed quite unsystematically. The streets ${ }^{1}$ were winding and narrow, were congested and without street lighting. Ist public buildings, of which there were many of outstanding and even spectacular architectural importance, were arranged within the limits of a toe-restrioted space-(Fig. 13). There was a use of axial lines, a respect for vistas, and, according to Hughes and Lamborn, a subordination of accessory parts of the buildings to the whole effect.

The fora were outstanding features of Rome. These meeting places of the people (exclusive of the slaves, artisans, and laborers) were open spaces and, despite the fact that they grew historically upon limited sites, contained porticos and loggias, were faced by shops, basilicas, and temples, and were variously embellished by flights of steps, fountains, and sculpture. In one instance, at least, three fora were interrelated along a principal axis for a distance of at least 1,200 feet.

The forum of Trajan was a grand colonnaded square flanked north and south by "bold hemicycles somewhat reminding one of those that adorn the Piazza of St. Peter and centered by an equestrian statue. It was entered through a magnificent arch. Basilica and colonnades and hemicycles were roofed over with gilded bronze tiles, and the pavements were of white marble." This forum was furnished with at least a hundred statues.

The Roman Forum is the most important of all historically and geographically. It was the center and heart of the ancient city and lay in the hollow between the Capitol, the Palatine, and the eastern hills and was drained by that most famous of sewers, the Cloaca Maxima. Here roads from the river and the distant mountains met. In this open space all of the famous men of Roman history have at one time or another been heard. This comparatively small and trapezium-shaped area was wider

\footnotetext{
1 There were only two streets in Rome that were designated as "vias"the Via Sacra and the Via Nova. Other streets were called, for the most part, vicus, and when they went uphill they were called clivus.
} 


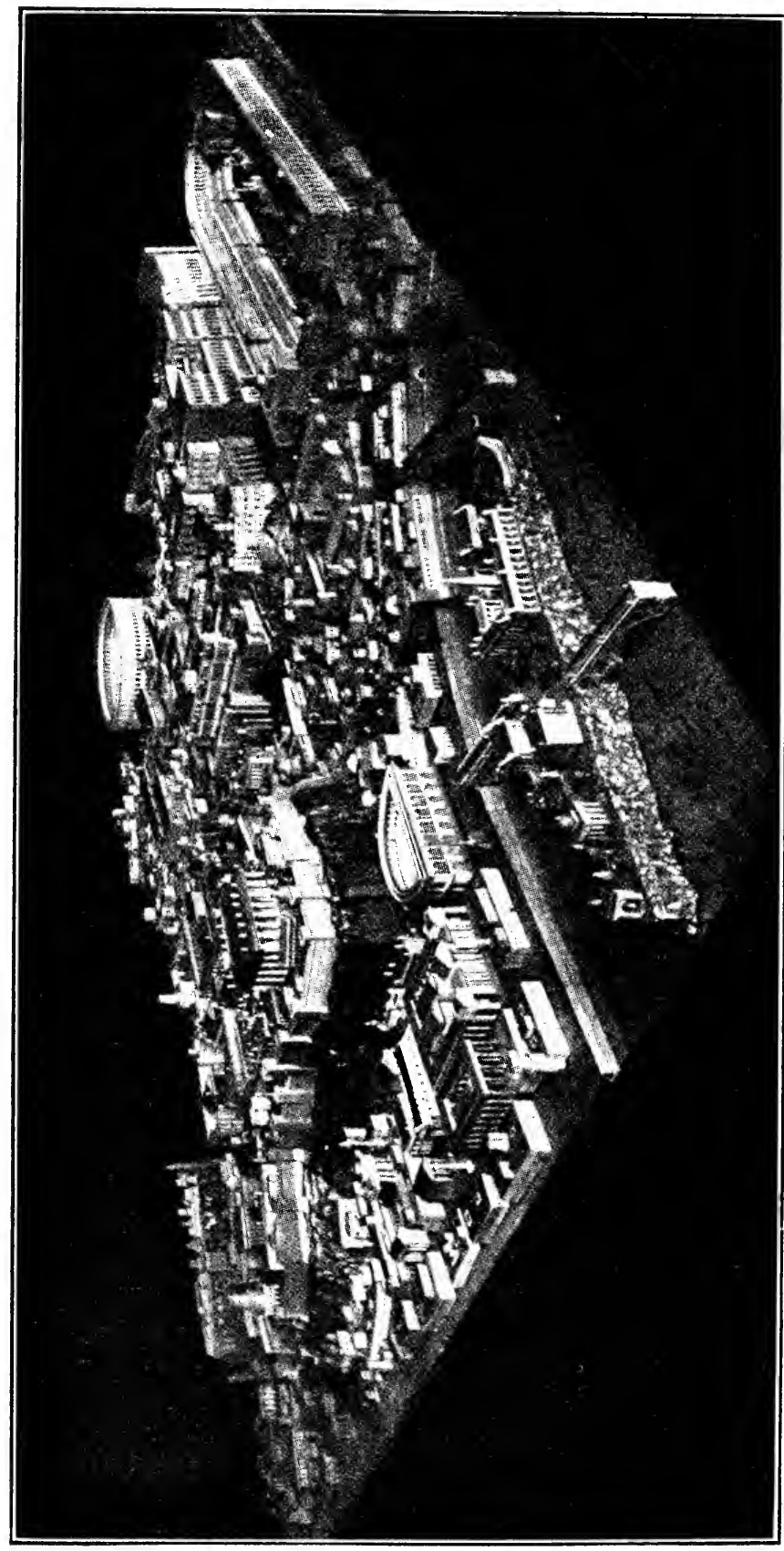

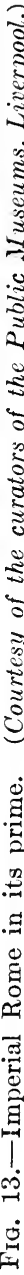


toward the Capitol than it was at the other extremity. Around it were located several basilicas, seven or eight temples, and triumphal arches. The open space was overloaded with trophies, shrines, columns, and statues. As we picture the Forum of. that time we wish perhaps that there had been a little more symmetry, a little more regularity, and considerably more extent. Yet this ensemble of structures created at various times and crowded together presented undoubtedly a kind of picturesque magnificence. As it became too small there was no effort made to enlarge it, but instead other fora were built in its vicinity.

The Palatine Hill-near-by from which one might command a view of the famous monuments of Rome became a vast pile of palaces and temples. Out over the Campagna were to be seen a number of aqueducts, one of which was the Anio Novus which brought water for a distance of 62 miles. Almost 10 miles of this conduit were above ground. The Aqua Claudia reached out for 45 miles and had $9 \frac{1}{2}$ miles on lofty arches.

Other features of the city included the Coliseum, seating 50,000 persons, magnificent baths both major and minor (800 of the latter), sculptured columns, arches, miles of porticoes as shelter from sun and rain and for business and pleasure, eight great bridges, and thousands of shrines and fountains. About the city was a chain of parks like a green girdle and beyond them the peaceful fields of the Campagna.

The main contribution of Rome to civic art was probably not the pattern of the typical Roman town that one traces in Europe and parts of Asia Minor and Africa. "The exaltation of municipal dignity" as one writer calls it, is best illustrated by those monumental works of architectural magnificence, the public buildings, the temples, theaters, baths, bridges, triumphal arches, and commemorative columns. These are the things that are the real symbols of the power and magnificence of Imperial Rome.

Roman Towns.- The ruins of many cities show that they were designed after a pattern, the influence of a city plan that was Roman. Wherever one finds the two main streets of a city meeting at right angles and leading to four gates in the surrounding walls, wherever to these streets other streets run parallel or at right angles forming square and oblong blocks or insulae, and wherever the forum is a paved, open court, the chief center of interest and importance, with its width two thirds its length 
(according to Vitruvius), it is clear that Roman influence has had something to do with it. The similarity to the Roman camp or castrum of the earlier days is interesting and suggests the possible source of inspiration for these characteristic layouts. These agglomerations of tents or huts, for instance, were divided at right angles that led to four gates and divided the camps into four sections. The prætorium or headquarters of the commandant with an accompanying open space was located near the central point at the intersection of the main thoroughfares. The sites of the typical Roman towns were chosen with a view to practical engineering results. The military advantages, the

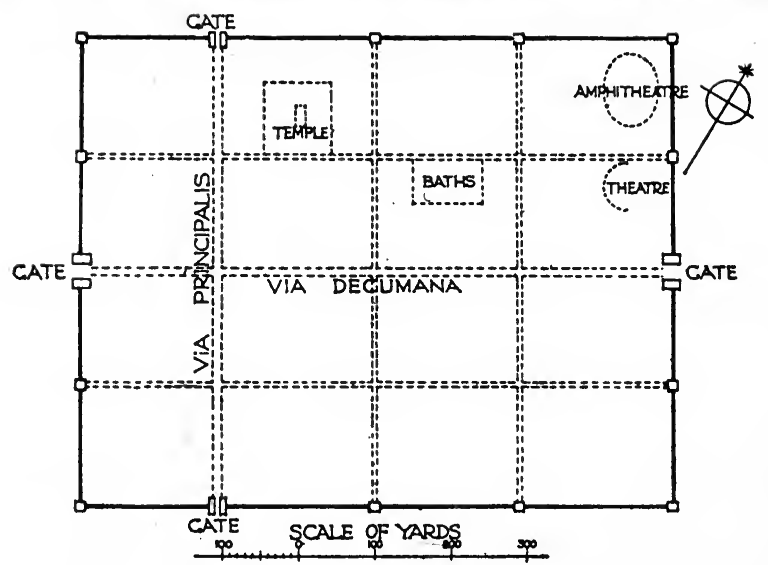

Fig. 14.-Aosta, showing the Roman influence in its plan. Founded by Augustus, 25 в. c. (From "Towns and Town Planning" by Hughes and Lamborn. The Clarendon Press.)

possibilities for commerce, the needs of traffic, of water-supply and drainage, all these things from the evidence must have been weighed in the balance when many of these cities were established. Among the most outstanding of the cities that reveal the Roman influence in their plans as described above are Turin, Aosta-(Fig. 14), Herculaneum, Naples, Spoleto, Timgad (Africa), Lincoln (England).

Although Pompeii is near Naples and was destroyed at a time when the Coliseum, the Arch of Titus, and some of the imperial palaces were being constructed in Rome, it is more representative of the town planning efforts of an earlier generation. It was one of the older cities and probably began as an Oscan community about 600 years before the Christian era. 
Vitruvius (Marcus Vitruvius Pollio).-As a personality who has contributed to the progress of city planning, the name of Vitruvius, which is associated with the first century B. c. in Italy, should be given some appropriate word. Although he holds no particular fame as a Roman architect or engineer, the influence of his writings has been great. So highly was he regarded by contemporaries that he was pensioned for life by Julius Caesar. His greatest work was "De Architectura Libri Decem" but was long lost and not rediscovered until the fifteenth century in a manuscript at St. Gaul. Particularly during the period of classical revival was he regarded as the chief authority among the architects. Such persons as Bramante, Michelangelo, Palladio, and Vignola were careful students of Vitruvius. The parts of his writings that treated particularly of city planning were his discussions on city sites and site planning, the nature and the different sorts of ground for cities, the importance of orientation, the selection of sites for theaters, the development of harbors and quays, hydraulic engineering, and the suitability of buildings for particular positions.

\section{MEDIEVAL CITIES OF EUROPE}

Of the cities that existed during medieval times in Europe, those of Roman beginnings, those that grew up around castle or monastery, or that were planned anew-all alike were inspired by war or the fear of war. It was this impetus to provide the maximum security for the citizens that constituted the main factor in city development. Every medieval town as a city of refuge was easiest to defend where its line of wall was comparatively short and pierced at few points. This necessity caused a characteristic crowding of buildings, huddled along a labyrinthine framework of tortuous, narrow lanes, a central market place of comparatively small proportions, surrounded by a ring of streets, pierced by other streets radiating from the market place. All open spaces or garden grounds were reduced to a minimum. The important buildings were erected toward the center. Sanitary conditions were exceedingly bad, water was secured from wells within the city, there was no system of sewage, and everything was thrown into the streets to await removal either by rain or by scavengers. As the streets were-without lights or patrol, the dangers at night were an ever present factor in the life of the people. 
In spite of the crowding, there must have been a certain coziness and charm about a medieval city. The beauty resulted from the collection of good-looking, individual structures that expressed the fine, common tradition of craftsmanship among the citizens. With the latter part of the Middle Ages came a period of greater prosperity, of beautification and transformation. Open spaces were enlarged, beautiful churches, town halls, markets, and guildhalls were built.

Among the outstanding cities of the Middle Ages were Venice, Genoa, and Florence. Of these, Venice, with a population of 200,000 , was the largest. In the fifth century Venice was a

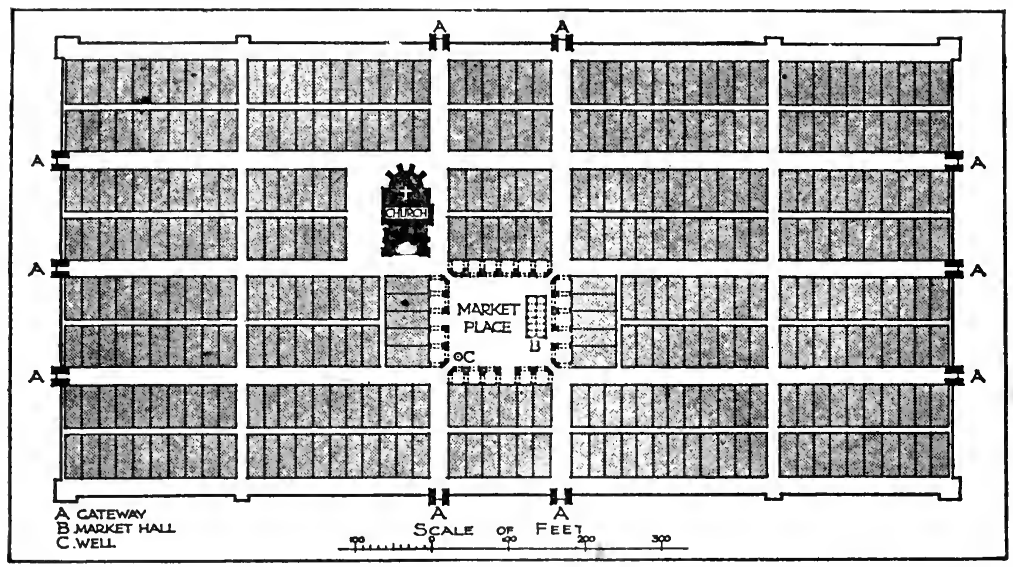

FIG. 15.-Montpazier (1284) in France, one of the 200 bastides of the Middle Ages. (From "Towns and Town Planning," by Hughes and Lamborn, The Clarendon Press.)

collection of rude huts of refugees. In the eighth and ninth centuries its galleys were defending commerce in the Adriatic. After Venice, Genoa was the most powerful of the Italian maritime cities, the great rival of Venice. Florence was the most illustrious and fortunate of Italian cities - really a republic in itself. It became a great manufacturing, financial, literary, and artistic center of the later medieval centuries. As far as the number of great men are concerned, it has been unrivaled by any other city in the woild except Athens.

The Bastides of the Middle Ages (twelfth, thirteenth, fourteenth centuries).-All of the cities of the Middle Ages did not just happen or continue to grow from earlier beginnings, nor were they all destroyed. There were brand-new cities and quite 
a number of them. These grew out of a political and economic policy that had its inception in the days before the northern conquest. Monasteries found that they possessed lands but no tenants to till them. The scheme of attracting settlers was hit upon by establishing little fortresses for them and granting to the inhabitants certain "modest immunities." With a similar idea in mind, a number of cities were laid out in like manner by St. Louis and his brother and by Edward I. There are said to be 200 of them in southern France. Montpazier (1284) is well known (Fig. 15); Saint-Foy la Grande is one of the most excellent. Winchelsea is the best example in England of a medieval town laid out on a regular plan. In some of these, medieval planning reached its highest perfection.

These communities were of various shapes but mostly square or oblong; they were protected by a wall and ditch; they had straight streets and main thoroughfares that led to gates in the walls. A feature that was also common to all the plans was the square market place, with a town hall occupying the center and arcaded streets surrounding it. Near-by the church was located.

\section{THE PLANNING OF CITIES DURING THE RENAISSANCE}

Italy.- Since the Renaissance was cradled in the cities of medieval Italy, it is natural to look to Italy for the first evidences of the Renaissance in town planning. One finds that at first there was a widening and straightening of streets; that the surroundings of churches and public buildings were made free of unnecessary encumbrances; that occasional open squares were developed; and that as much regulation and symmetry as possible were introduced into new towns and quarters. The civic group at Pienza was one of the mos' notable of the earlier schemes.

And then the spirit that characterized the later period of the renaissance took possession. Largeness of scale, spaciousness, grandiose unity and variety of form, symmetry, and dignity were some of the petals of this new flower. They indeed characterized the new city plans and the various ambitious and corrective ideas that were being put into effect in architecture. Streets were arranged to converge upon important public buildings, and appropriate forecourts for these buildings were provided. These forecourts were frequently enclosed and embellished with monuments, stairways, and fountains. The various efforts of this time, moreover, show that the conception of the city was that of a single architectural composition. 
Some of the conspicuous examples of this period include the piazzas of St. Peter's (Fig. 16), del Popolo, and di Spagna; also the Via Sistina, Trinita del Monti, the Spanish steps, and the port of Ripetta on the Tiber. One cannot disassociate these developments from several artists of the Renaissance who created them. During the last 15 years of his life Bramante (1444 to 1514) was consulted on nearly all of the great constructional undertakings in Rome. His important works reflected his

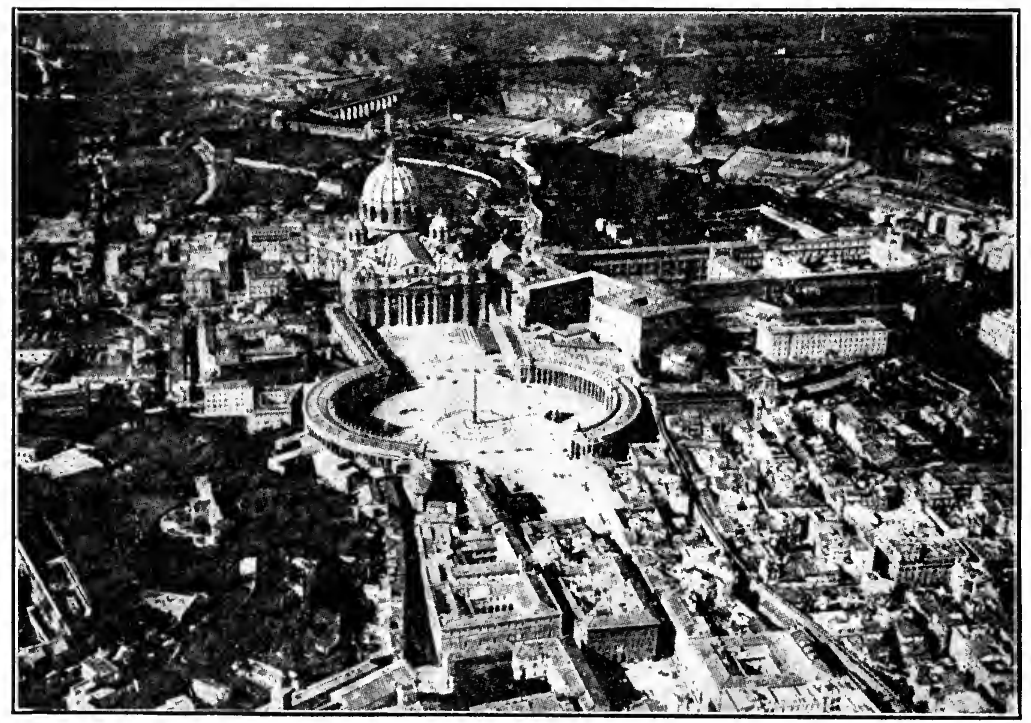

Fig. 16.-Piazza of St. Peter's, Rome. An outstanding city planning achievement of the Renaissance. (Courtesy of "The American Vitruvius," by Hegeman and Peets, Architectural Book Publishing Company.)

appreciation of scale-the monumental stateliness and the breadth of design as found in earlier Roman precedents. His scheme of courts in connecting the palaces of the Vatican shows a mastery over problems presented by irregular ground that was one of the great events of the Renaissance.

Palladio, fascinated like Bramante with the stateliness and proportion of the buildings of ancient Rome, made his impress on several town planning enterprises. ${ }^{1}$ Palladio's inspiration-as

${ }^{1}$ These include the Piazza Maggiore, the Basilica, and the bridge over the Bacchiglione, all at Vicenza; the Triumphal Arch at Venice on the occasion of Henry III's entering as King of France; the laying out of the ancient royal park at Piedmont. 
carried by Inigo Jones to England was incorporated in both the architecture of England and its town planning.

Bernini (1598 to 1680) during his 50 years as dictator of the artistic taste and achievements of the papacy, accomplished among his many efforts the creation of important fountains (such as those of piazzas Navara and Trevi), of the magnificent

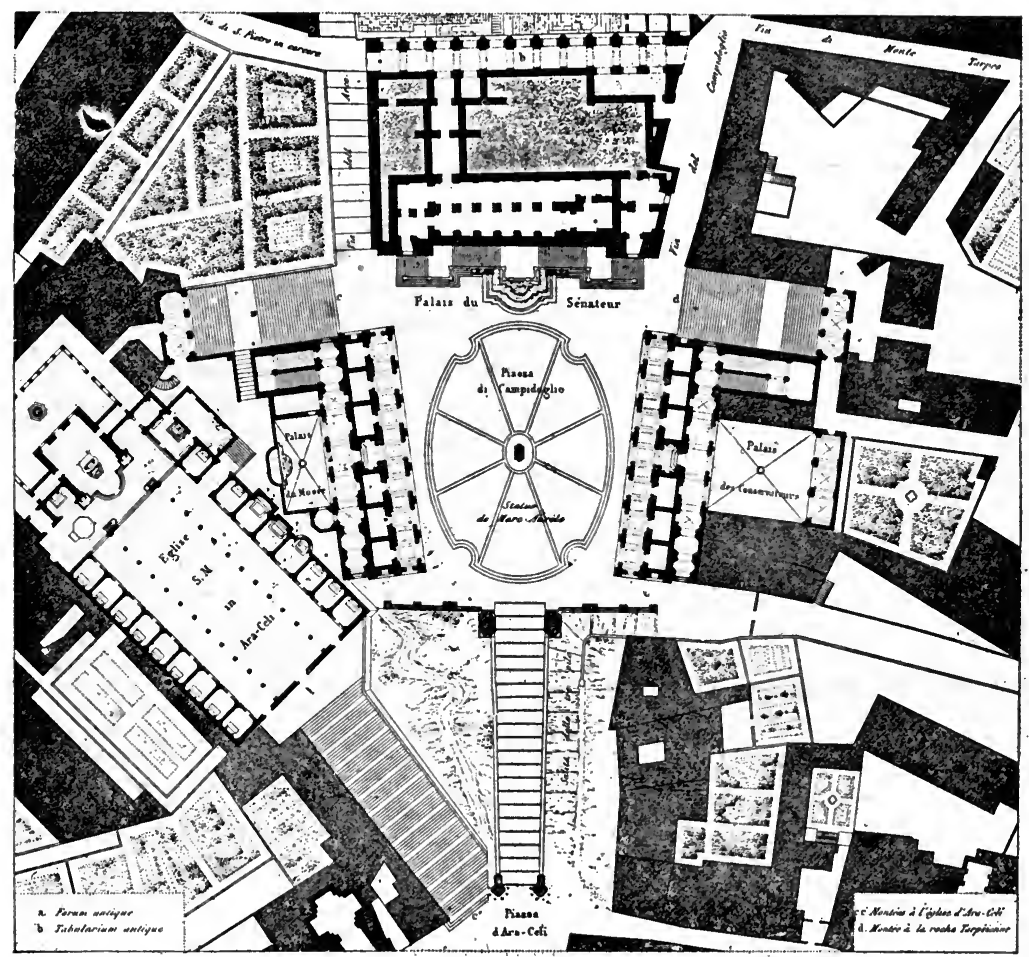

Fig. 17.-Plan of the Piazza del Campidoglio. Rome. One of the interesting city planning creations credited to Michelangelo. (Courtesy of "The American Vitruvius" by Hegeman and Peets, Architectural Book Publishing Company.)

colonnade of St. Peter's, and the restoration of the bridge of San Angelo. During a journey to Paris at the invitation of Louis XIV, so great was his reputation that he was received like a royal personage. It was while Bernini was in Paris that he met Sir Christopher Wren who was to be the creator of a new plan for London after the fire, a design which if adopted would have made a much finer city of London than it is today. 
Among those whose talents and influence contributed to the town planning of the Renaissance were of course Michelangelo, the Campidoglio Square on the Capitoline Hill being one of his interesting creations (Figs. 17, 18); and Raphael; not to mention a score of others, who are counted among the masters of art and who characterized the great period of the Renaissance in Italy.

What these men did was in part due to the opportunities that came through the patronage of the papacy. Such popes as Leo

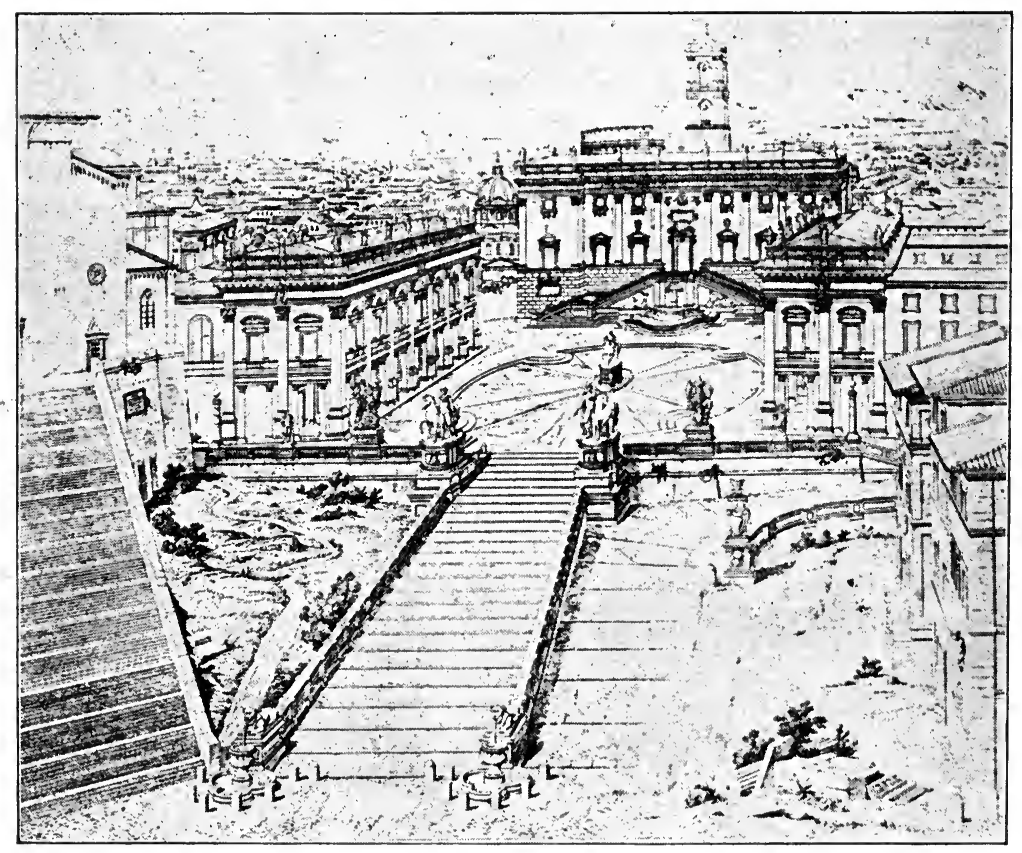

Fig. 18.-View of the Piazza del Campidoglio, Rome.

X, Clement VII, Paul III, Sixtus V, and especially Julius-II exercised a large influence upon these accomplishments.

France.-The earlier Renaissance achievements of France which were inspired by their Italian prototypes found expression in such plans as those of Vitry le François, Henrichement, and Richelieu. In the first of these founded by Francis I, there was a regular plan with a place d'armes in the center and four chief streets radiating from it. The town of Richelieu, established 
by Cardinal Richelieu, was designed as a whole and in relation to a château near-by.

A little later in the history of France it was fortunate for civic art that Louis XIV happened to look upon the architecture of his towns as a means of impressing the future with his greatness. With the aid of his autocratic power and high interest in architecture, the celebrated visit of the Italian Bernini to France was

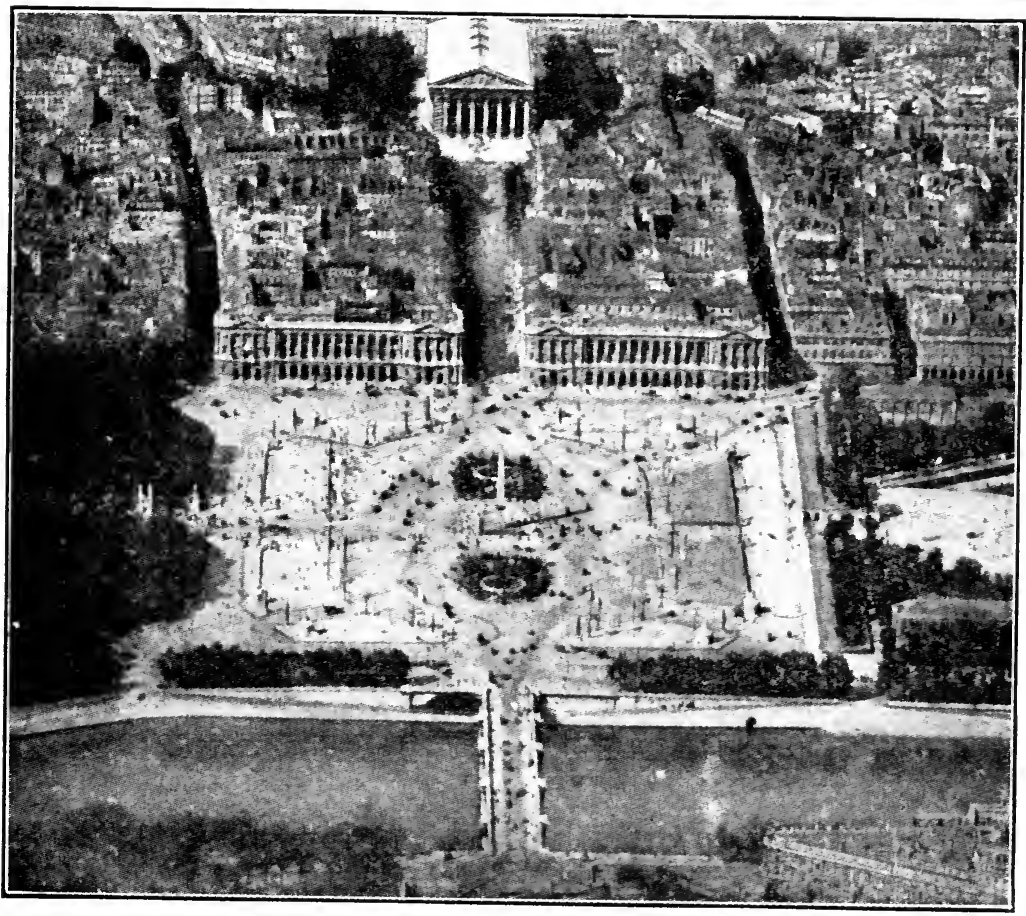

FIG. 19.-Place de la Concorde, Paris. (Courtesy of "The American Vitruvius," by Hegeman and Peets, Architectural Book Publishing Company.)

made possible, and it was the encouragement of Louis XIV that stimulated the well-known planning works of Le Notre, especially those at Versailles.

When the two squares of Paris-Dauphine and Royale--were established, they marked the beginning of an important series of plazas and other forms of city planning enterprises. One writer points to the fact that cities in the preceding ages vied with each other in the building of cathedrals, but those of the seventeenth and eighteenth centuries tried to surpass each other 
in the creation of their plazas. There was in 1748 a particular enthusiasm in this direction which developed in connection with a proposed monument for Louis XV. The descriptions of the plans, and the results of the two competitions having to do with the monument, are available in a book called "Monuments Erigés en France á la Gloire de Louis XV" (published in 1765), which is deserving of careful study. This outburst of design resulted not only in the Place de la Concorde (Fig. 19) but in others of outstanding importance, particularly the one at Nancy. This composition, in the grandeur of its monumented square, its

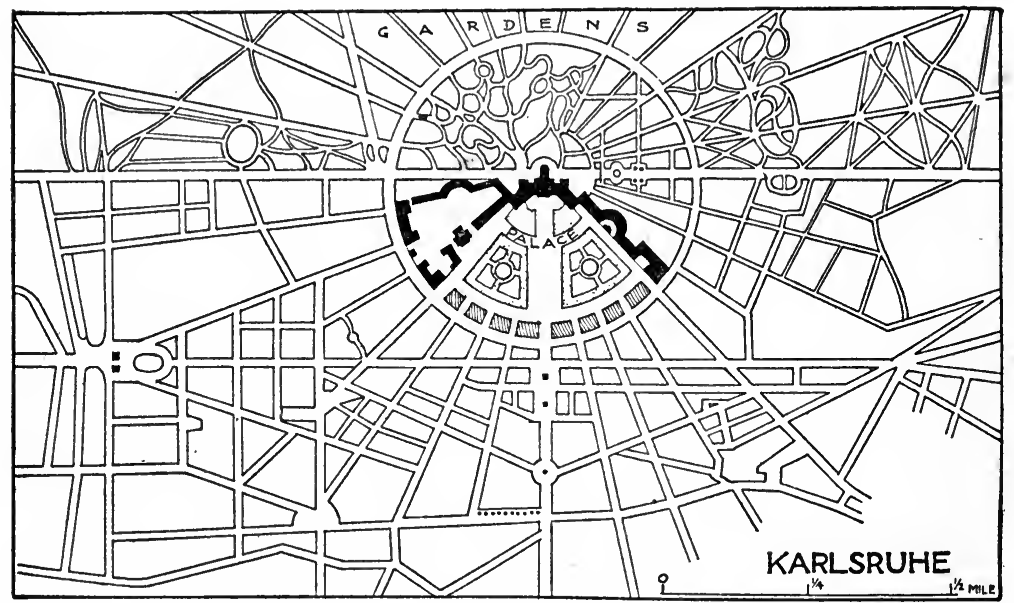

FIG. 20.-Karlsruhe, typical of the Renaissance influence. (From "Town Planning," by H. I. Triggs.)

forecourts, its long carrière and oval colonnaded area in front of the palace indeed did great honor to the memory of Louis XV.

Germany.-Following the Thirty Years' War and the celebration of the Peace of Aix-la-Chapelle, the founding of towns became the favorite occupation among princes. Such cities as Berlin, Mannheim, Karlsruhe (Fig. 20), Cassel, Düsseldorf, Coblenz, and others were planned and built.

Mannheim was planned on regular lines, with diagonals relating to the palace and wide ring streets on three sides.- Karlsruhe had the castle as its central feature, with main roads radiating therefrom and cut by a long straight thoroughfare.

England and Scotland.-The type of planning represented by the awakening spirit of the Renaissance in Italy and France 
appeared first in England at Covent Garden, through the design of Inigo Jones for a square surrounded by an arcade. This Renaissance spirit was seen also in Wren's plan (Fig. 21) for London, following the fire of 1666, a plan which provided, among

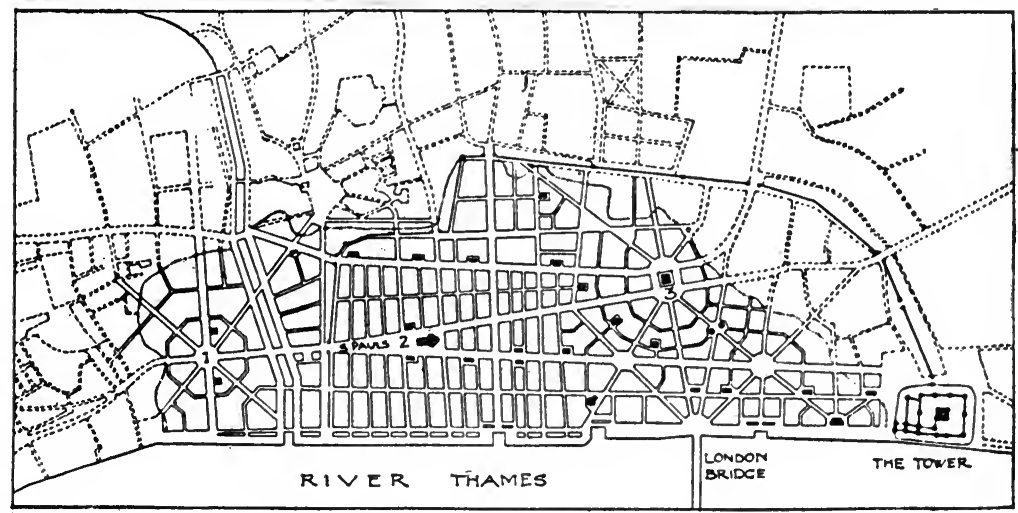

FIG. 21.- Sir Christopher Wren's replan of downtown London after the Great Fire in 1666.

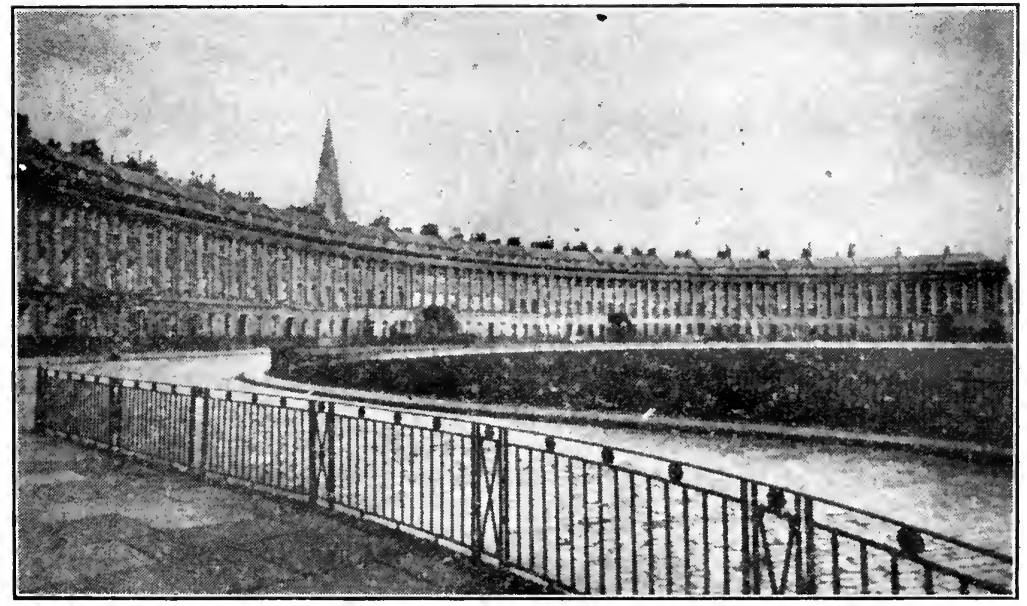

Fig. 22.-The Royal Crescent, at Bath, England. A glimpse of one of the world's harmoniously beautiful cities.

other things, open spaces and long vistas for St...Paul's, the Exchange, and other important structures. It was London's misfortune that a proposal such as this was not accepted.

Much that one finds in the beautiful city of Bath may be ascribed to the work of this period and to the vision of the 
architects John Wood and his son. The squares, circuses, and crescents (Fig. 22), with their coherent, harmonious facades and pilasters or superposed columns, give to the city an individuality that one takes keen pleasure in remembering.

Among the outstanding projects of this time (1767) in Great Britain was that of the New Town just north of Prince's Street in Edinburgh (Fig. 23). In spite of the fact that in some ways the New Town did not seem to take full advantage of the site, its George Street, with terminal squares and vistas, makes it one of the important city planning excellences of Great Britain.

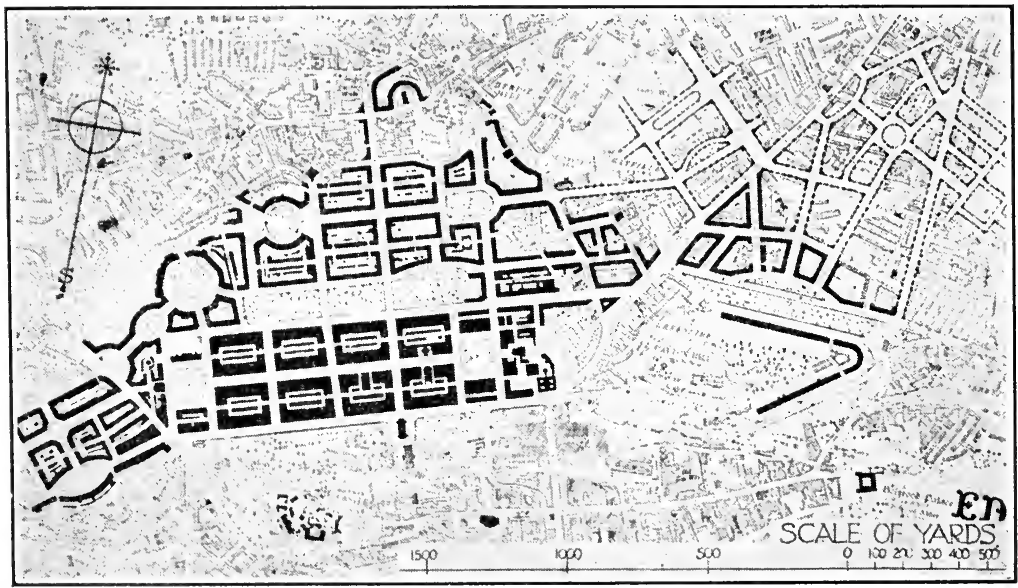

Fig. 23.- "New Town," Edinburgh, as planned in 1767 (shown in solid black). (Courtesy of "Towns and Town Planning," by Hughes and Lamborn, The Clarendon Press, and of His Majesty's Stationery Office, Prince's Street, Storey's Gate, London.)

\section{AMERICAN CITIES OF THE SEVENTEENTH AND EIGHTEENTH CENTURIES}

The settlements of early America were started either as onestreet communities, as those of New England, or as complete villages or towns. The one-street beginnings provided a site for the meeting house (which in the interior settlements would be on a hill), for the town hall, and for the common. A few crossstreets, that would give access to the near-by ranges or lots and roads radiating from the common to the nearest neighboring settlements or towns, were also provided.

The charming plan of Williamsburg, Va., reveals an effort to interrelate the capitol and college sites at opposite ends of the 


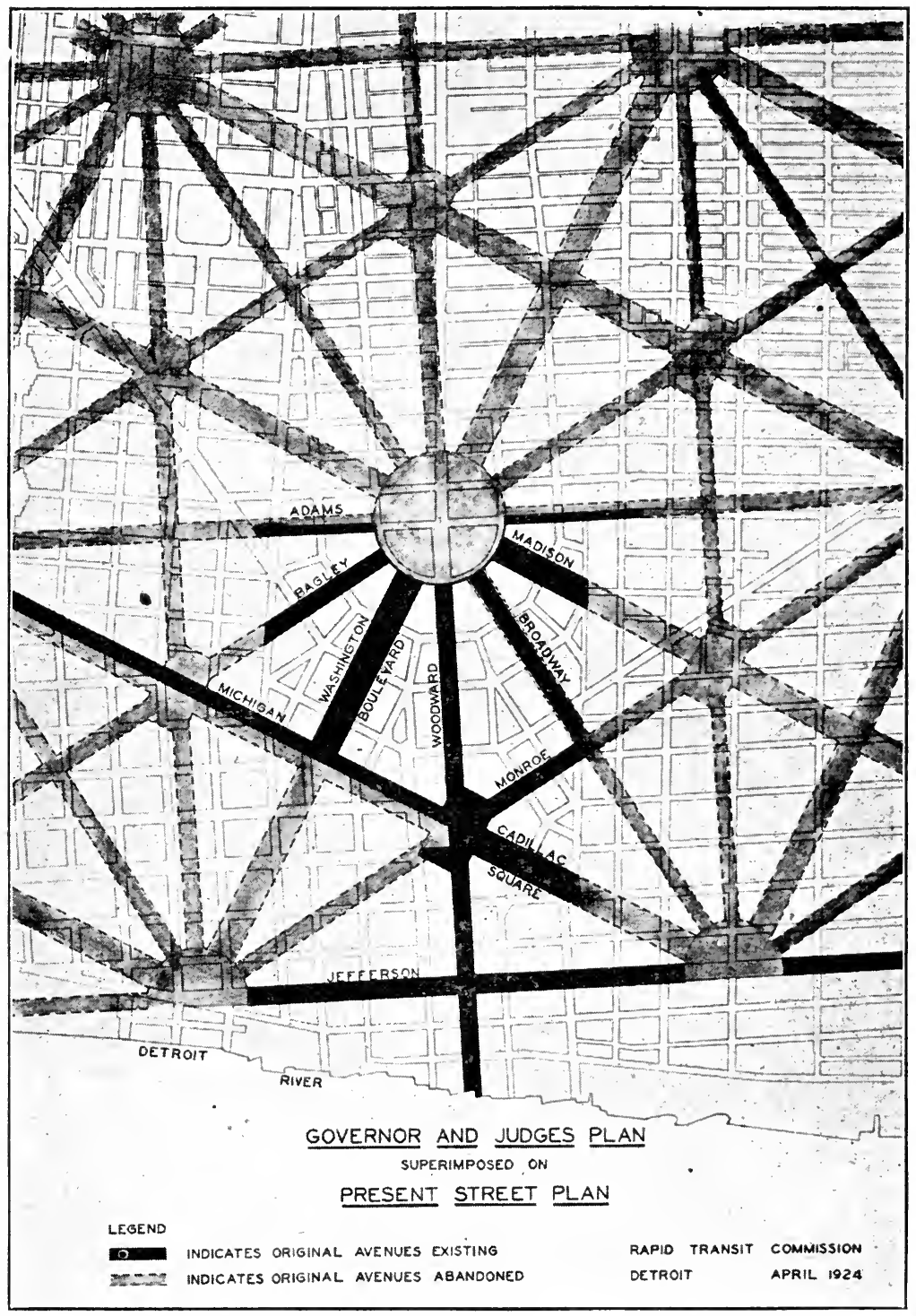

FIG. 24.-Early governor and judges plan for Detroit as compared with present streets, showing parts carried out and parts abandoned. (Courtesy of Rapid Transit Commission, Detroit, 1924 Report.) 


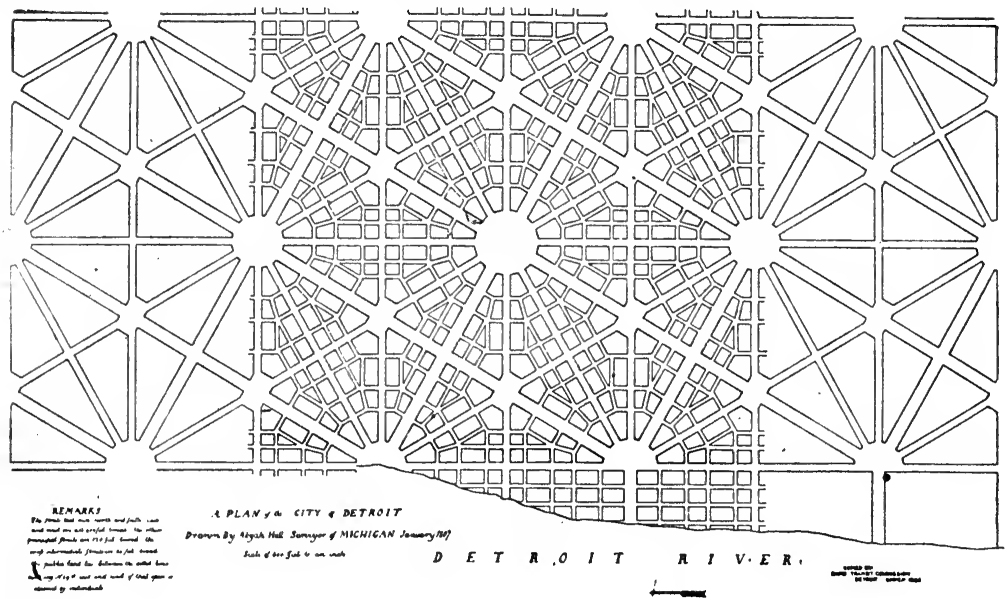

FIG. 25.--Governor and judges plan of the city of Detroit, January, 1807. (Courtesy of Rapid Transit Commission, Detroit.)

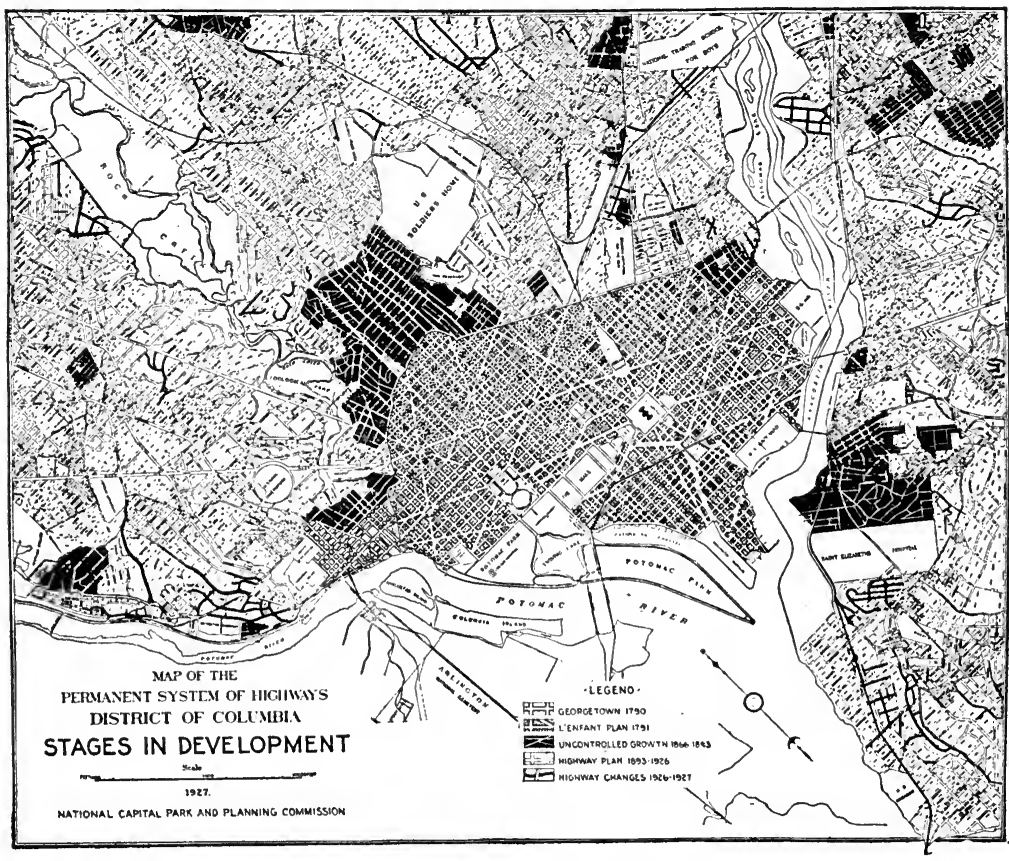

FIG. 26.-The system of highways for Washington and surroundings. The streets according to original L'Enfant plan are readily distinguishable in the center of the illustration. (National Capital Park and Planning Commission, 1927.) 
town, to provide an attractive site for the governor's palace, and to supply other public and semipublic requirements. This plan also takes into account the need for radiating streets to other communities.

Outstanding among the earlier plans for the larger towns are those of Philadelphia, Reading, Savannah, New Orleans, Detroit (Fig. 24, 25), Annapolis, and Washington (Fig. 26). The size, rectangular character, and provisions for open spaces in the first four of these present common points of resembiance and, in turn, are not so unlike certain European precedents, such as, for example, the plan of Mannheim in Germany.

The original plan of Philadelphia (Fig. 27), made by or under the direction of William Penn, provided a rectangular pattern of streets, a square at the intersection of the two main thoroughfares, and, in addition, four other open spaces. A central plaza with courthouse and markets characterized the early plan of Reading. In Savannah the rectangular plan showed provision for 2 targe park areas and 24 smaller ones. The old city or Vieux Carré, of New Orleans was planned to be 12 blocks or squares long by 6

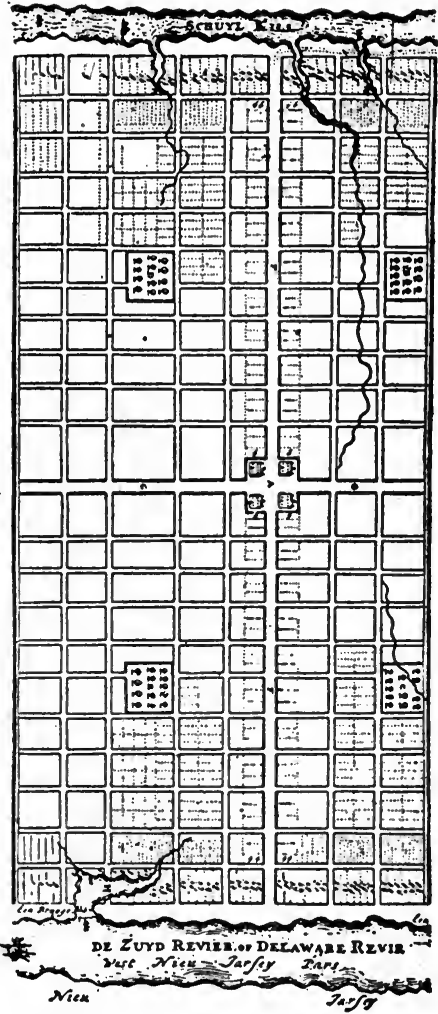

FIG. 27.-The original William Penn plan for Philadelphia. Its gridiron layout is marked by a central plaza and four other open spaces.

blocks wide and was served by a plaza in the center along the river front. The later extensions showed in their planning an intelligence characteristically absent in most gridiron plans.

Annapolis, Detroit, and Washington ${ }^{1}$ illustrate the-radiating street pattern among the earlier cities. The Annapolis plan

1 The Plan and Planner of the City of Washington, D. C.- One of the most interesting and important of our earlier plans for cities in America was that of our national eapital. Major Pierre Charles L'Enfant (Fig. 28), upon the site chosen by our first president, laid down a unique and func- 
tional framework of city development that for the most part was followed in the life and growth of the city of Washington.

L'Enfant, whom the president described as "a scientific man who had added taste to professional knowledge," and who performed so well this outstanding service as designer for the federal city, was one of the first city planners in the United States. He was born at Paris on Aug. 2, 1754, the son of a painter, received instruction as an architect and engineer, and at twenty-three years of age served as a volunteer in the American corps of engineers during the Revolution. He was wounded at Savannah. As a man of many accomplishments, after the war he was called upon to help, "whether the question was of a portrait, a banqueting hall, a marble palace, a solemn procession, a fortress to be raised, or a city to be planned."

L'Enfant was the sort of man - tall and courtly-who in appearance and manners would be outstanding in any assembly. Although he had the

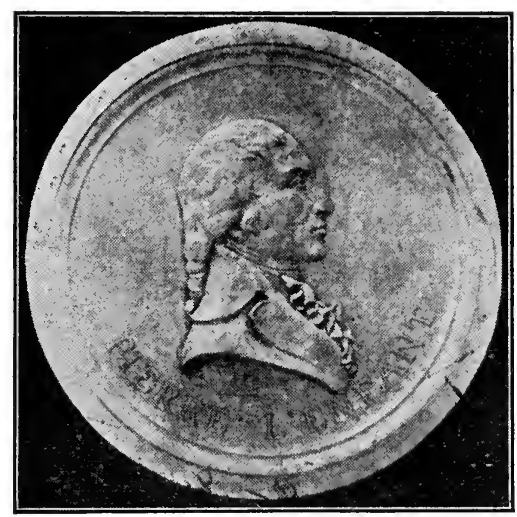

Fig. 28.-Major Pierre Charles L'Enfant, born 1754, died 1825, author of the plan for the capital city of Washington, D. C. (Taken from ' $L$ 'Enfant and Washington" by Elizabeth S. Kite, Johns Hopkins Press, 1929.)

reputation of being rather haughty, proud, and difficult to manage, yet he had a goodly share of such qualities as honesty and sincere loyalty. Not only was he a man of many accomplishments, but he was full of ideas and was able to size things up en grande-in a large way. He died in 1825 at the age of seventy-one years and his body lies buried in Arlington Cemetery near the Custis home. The grave occupies a position at an impressive high point that commands, as it should in tribute to this distinguished planner, a magnificent view across the federal city.

The plan of Washington as prepared by L'Enfant included provision for important public buildings that served as focal points upon which both rectangular and diagonal streets met. In the leftover pieces opportunity was given for monuments and parks. The Mall, a great open park 400 feet in width, stretched across the plan of the city from the capitol toward the river for a mile to serve as one of the outstanding features of the scheme. The Mall was connected in L-fashion by park with the otherfoeatcenter, the White House. These two main nuclei, the Capitol and the White House, 
also were connected by an important diagonal thoroughfare, later to be known as Pennsylvania Avenue.

As the plan of the city was being prepared, strategic places were set aside and-streets-were-loeated-for commanding views. Principal points were reserved and others were subordinated to them. Avenues were run to and from principal objectives in different directions both to lessen distance and to achieve reciprocal views. L'Enfant selected the most advantageous position at the top of a hill, 80 feet above the Potomac River, for the location of the Capitol. He also selected a site at a befitting distance from the Capitol for the "Presidential Palace," a site that would appropriately suit the demands of what was expected to become a combination convenient home, agreeable countryseat, and sumptuous palace.

The full-grown city of today, which is indeed an expression of the original plan as conceived by L'Enfant, fulfills in large measure the purposes that inspired it. No one will deny that the eity performs its mission excellently as a place for members of congress and their families and for other government officials to live or as a place in which to transact public business. All will recognize the city as a source of inspiration to visitors because of the wealth of national memorials and monuments and of other forms of civic beauty to be found in it.

With all due respect to the layout of our capital city, we must not in our enthusiasm forget one outstanding defect that detracts very seriously from the effectiveness of the plan. This results from having the gridiron system of streets superimposed upon a pattern of diagonal thoroughfares without some effort to carry streets across the latter at right angles. These intersections at angles that are acute introduce objectionable danger points for traffic and awkward and highly undesirable triangular properties for architectural purposes, especially along important avenues.

L'Enfant completed his plans in 1791 . Although in 1800 the city was still for the most part a creation upon paper, nevertheless the government was officially transferred to the new city during that year. Only part of the wing of the Capitol was completed at the time, and the home of the President was in course of construction, Much of the land surrounding the legislative building was still marshy, there were no streets worthy of the name, and even the roads were very bad. For the time being, members of Congress were obliged to live in the adjacent community of Georgetown. Then and for several succeeding years the city of Washington was spoken of reproachfully in such terms as the "wilderness city"; the "capital of miserable huts"; the "city of streets without houses"; or, the most familiar of the epithets, the "city of magnificent distances." Obviously there were those who had little imagination concerning this great city in the making and were ready even then to abandon it for another site. The British occupied Washington in 1814 and during their visit burned the Capitol, the navy yard, and the house of the President. During the following year a bill for $\$ 500,000$ for the rehabilitation of the city barely passed because of the lack of interest and of the sentiment among a great many people for a change of location for their capital city.

Both the lethargy of the nation and the general lack of interest in the city of Washington suddenly terminated at the time the Civil War broke 
was recorded in 1694; the one of Detroit, a century later (1807), proposed a quite conventional repetition of a radiating spiderweb motif over the entire original scheme.

\section{THE MODERN PERIOD (NINETEENTH AND TWENTIETH CENTURIES)}

Industry, commerce, and improved methods of transportation have all played an important part in the growth of our cities in the last hundred years. The resulting congestion that has been experienced everywhere has compelled new programs for its improvement and cure. One of the first and most striking modern efforts at such improvements was the immense program

out. The Civil War in a sense was the real making of Washington. The conflict had but started when Leroy P. Walker, Confederate Secretary of War, boasted that before May 1 (1861) the Confederate flag would float over the Capitol building. Instantly, almost, the city of Washington was transformed into a great military post. It soon became the strategic center of military operations for the North. Simultaneously the new city showed signs of growth. In fact the records indicate that during the 10 years that followed the population increased some 79 per cent. In the years after that the city experienced a steady growth and development that led not only to the making of a great city but also unfortunately to the making of serious mistakes some of which in the course of time have been corrected and some of which may never be.

The disregard for certain objectives of the original L'Enfant plan, or of any plan, was so increasingly evident that in 1901 a report was issued, apropos of the general situation, by the so-called "McMillan Commission." Those who formulated plans and recommendations for this report, namely, Burnham, McKim, Saint Gaudens, and Olmsted, emphasized the importance and value of the L'Enfant plan, regretted departures from it and suggested remedies where possible, and recommended the continuance along the major lines laid down in the original plan. The commission authorized among other things the removal of the unsightly railroad that had managed to find its way across the Mall and in turn the establishment of the famous Union Station. A few years later, in 1910, the Fine Arts Commission came into existence and as vigilantly as possible watched over the developments of Washington. It was followed by the National Park Commission, and finally, in 1926, came into being the National Park and Planning Commission that has given such broad study to improvements for the Washington region at large.

The L'Enfant plan in general has been reasonably well kept, and despite the invasion of the Mall by inappropriate structures, the rise of new problems, and new needs, all demanding constant watchfulness and careful restudy for modification, Washington occupies a position of unique beauty and character among the cities of America. 
in Paris in 1853 by Baron Haussmann under Napoleon III. Haussmann's scheme included a number of large projects, boulevard connections of importance and of great extent, roads converging at important points and public buildings located in full view down the streets, and the development of plazas and parks. The expenditure of 50,000,000 livres for these improvements helped greatly to make of Paris one of the most beautiful cities in the world.

While France was directed rather strongly by the esthetic viewpoint in the accomplishment of a more beautiful Paris, Germany was probably more concerned with matters of efficiency and economy, as represented by the effort to bring about order and to make for more economical administration. Among the leaders of city planning in the Germany of the last century are "Reinhard Baumeister, a pioneer of the science . . Camillo Sitte, a formulator of its esthetic principles, and Joseph Stübben, a practical city builder." Sitte's book, "An Architect's Reflections upon Artistic City Planning," has taken its place as a classic. Among other things:

... he not only shows appreciation for the civic work of the Middle Ages which he believes was a form of conscious, deliberate planning instead of the vegetative and accidental type, but he appreciates fully the work of the Renaissance of the seventeenth and eighteenth centuries.

When it came to modern efforts at planning, the work in England directed itself more especially to the social viewpoint. Although some of the earliest garden-city efforts, for example, were made in Germany and elsewhere, with the principal idea of trying to accomplish better social conditions, it remained for the first example to take form at Letchworth, England.

In America the city flanning activities have been guided by all three of these influences: economic, social and esthetic. During the modern period many of our American cities have burst their original bounds and have become full-grown, mighty giants. The problem of making them better has become largely one of replanning. Great schemes to reduce congestion and to make our cities more practical and more beautiful are gradually being evolved and are making our cities better, in many respects, than the best that a backward glance reveals in the cities of the past. 


\section{Questions for Discussion}

1. What is known about the plans of the ancient cities of Egypt?

2. Tell about the early urban developments of Assyria.

3. Give the outstanding features of the planning of Hellenistic cities.

4. What is known about the early planners Hippodamos (of Miletus) and Vitruvius?

5. Give a brief account of the town planning in the Roman world.

6. Describe a typical city of medieval Europe.

7. What were the bastides of the Middle Ages?

8. What were the ideals of the Renaissance as revealed in conspicuous city planning examples in the later Renaissance in Italy?

9. What were some of the outstanding city planning accomplishments in France during the Renaissance (town of Richelieu, influence of Louis XIV, plaza developments, etc.)?

10. Describe the plans of Mannheim and Karlsruhe, two of the several German cities established following the peace of Aix-la-Chapelle.

11. How was the influence of the Renaissance visible in the city planning developments of England and Scotland?

12. What were the early communities of New England like?

13. Describe the original plans of Philadelphia, Reading, Savannah, New Orleans, Detroit, and Annapolis. (Choose one or more of these.)

14. Describe the original plan of Washington and tell about the designer of that plan.

15. Tell about Camillo Sitte and his writings.

16. Who was Baron Georges Eugène Haussmann and what part did he play in the replanning of Paris?

\section{References}

Bosanquet, R. C.: Greek and Roman Towns, Town Planning Review, vol. 5, pp. 286-293; vol. 6, pp. 101-113, illus., plans, January, October, 1915.

Cities of the Past. Ashby, T.: "Rome"; P. Gardner: "The Planning of Hellenistic Cities"; F. J. Haverfield: "Town Planning in the Roman World"; A. E. Brinckmann: "Entwicklung der Stadtebau-Ideals seit der Renaissance"; discussion, Royal Institute of British Architects, Town Planning Conference, pp. 109-183, plans, London, 1910.

Green, J. R.: "Town Life in the Fifteenth Century," 2 vols., Macmillan and Co., Limited, 1907.

Hammarstrand, N.: The Ancient Builders of Cities, Journal of American Institute of Architects, vol. 11, pp. 484-486, December, 1923; The Rise of Great Cities in Classical Antiquity, ibid, vol. 14, pp.163-170, April, 1926; Urban Galaxy of the Hellenistic Age, ibid., August, 1926; Hippodamos of Miletus and Greek City Planning, ibid., vol. 16, pp. 651-3, September, 1928; Vitruvius on City Planning, ibid., vol. 13, pp. 67-70, February, 1925.

Haussmann, Baron Georges Eugène, Famous Town Planners, Town Planning Review, vol. 12, pp. 181-190, June, 1927. 
Haverfield, F. J.: "Ancient Town Planning," 152 pp., illus., plans, Clarendon Press, Oxford, 1913.

Hegemann, Werner, and Elbert Peets: Camillo Sitte and His Work. Greek and Roman Precedents, Renaissance Courts and Plazas. The American Vitruvius, pp. 7-28, 29-36, 37-48, 241-245, 245-247, the Architectural Book Publishing Co., New York, Paris, London, 1922.

"History of Sanitation," Bridgeport Brass Co., Bridgeport, Conn., 40 pp., illus., 1930.

Hughes, T. H., and E. A. J. Lamborn: "Towns and Town Planning, Ancient and Modern," 156 pp., illus., plans, Clarendon Press, Oxford, 1923.

Kite, Elizabeth, S.: "L'Enfant and Washington," 182 pp., Johns Hopkins Press, Baltimore, 1929.

Mears, F. C.: The Planning of Medieval Cities (Great Britain), Journal Town Planning Institute, vol. 10, pp. 12-21, November, 1923.

Peets, Elbert: The Geneology of L'Enfant's Washington, Journal of American Institute of Architects, vol. 15, pp. 115-119, 151-154, 187191, plans, April, May, June, 1927.

"The Federal City," American Civic Annual, pp. 83-108, 1930.

Triggs, H. I.: Types of Ancient and Modern Towns, "Town Planning, Past, Present and Possible," pp. 56-119, plans, 1909.

Unwin, R.: Individuality of Towns; with a Slight Sketch of the Ancient Art of Town Planning, "Town Planning in Practice," pp. 15-114, 1909 and later editions.

Vitruvius: "The Ten Books on Architecture," trans. by Morris Hicky Morgan, Harvard University Press, 1914. 


\section{CHAPTER IV}

\section{THE CITY PLANNING MOVEMENT IN AMERICA}

It is almost 70 years since the city planning movement in America had its real beginning, although it is less than 20 years since it assumed its more definite form. This does not mean that important activity of one kind or another did not occur in the earlier times. There was indeed much important activity that led up to this movement. Some of the activity assumed the character of plans for the improvement of villages and cities, the designing of groups of distinguished buildings and other architectural achievements, and the planning of parks and park systems. During this earlier period in America, the establishment of the first village improvement association at Stockbridge, Mass., in 1853 was of great importance, coupled with the fact that within 30 years thereafter a hundred societies of the same kind came into existence. The creation of Central Park in -1857 in New York exerted a major influence, as did also the later park systems of Chicago, started in 1869; Boston, begun in 1875; and Kansas City, begun in 1893 . The first efforts during 1857 of a commission to examine into the conditions of the slums in the cities of New York and Brooklyn marked the beginning of a great housing betterment.

The Columbian and Other Expositions.-In 1893 under the direction and inspiration of Daniel H. Burnham, architect, Frederick Law Olmsted, landscape architect, and the largest host of other artists up to that time ever gathered together in America, there developed upon the swamps and sand bars of Jackson Park, Chicago, a notable group of buildings for the Columbian Exposition. This proved to be the real beginning of the movement for city planning in America.

The Chicago exposition was indeed a wonderful creation. Because of it thousands and thousands of visitors from all over the land were able to carry back to their homes the picture of an orderly scheme of marvelous classic palaces in gleaming white, of great lagoons, canals, ponds, islands, monumental fountains, docks, bridges, towers-all of them of high architectural excel- 
lence. The whole ensemble reminded one of the monuments of other ages. It was indeed a triumph for America and an auspicious beginning of the great movement in city planning for which it was in large measure responsible.

Other expositions that followed also must have had an accumulative effect. Each in a measure tried to do the thing that was accomplished in Chicago and each reached more and more people. The Pan-American Exposition at Buffalo, N. Y., in 1901 "seemed to gain picturesqueness at the expense of orderly arrangement." The scale of the spectacle at St. Louis in 1904 gave it its greatest fame. The California fairs in 1915 and particularly the one at San Diego had the roots of their architectural style suited to the climate and to the historical background of the state in which they were presented.

City Beautiful Movement.-Little wonder that there followed soon after the exposition at Chicago so general an interest in various parts of the country, in the possibilities for improved arrangements of buildings as well as for other kinds of improvements. A wave of plans for civic centers suddenly swept the country. These included elaborate proposals for the cities of Cleveland, Denver, Springfield (Mass.), San Francisco, Baltimore, Chicago, Rochester, and a score or more of other cities. Today as a result many of our municipalities have at least some plans for the definite grouping of their public buildings.

The earlier proposals for civic centers brought the term "city beautiful" into vogue. As time went on, the realization that other necessities in the city plan were likewise calling for attention and that there was almost a reckless willingness to spend the people's money may have helped to throw the "city beautiful" idea as such, into a kind of disrepute. People came to insist upon what they termed the "city practical," rather than the "city beautiful." What they really wanted was a proper consideration for both.

War-time Cities.-One can scarcely overstate the importance of the building of emergency towns by the government under the collaborative help of engineers, landscape architects, architects, and realtors in all parts of the United States during the World War. The examples of town planning that were created and the collaboration that characterized the program have been paralleled only by similar efforts that were so outstanding in the Columbian Exposition. 
With an appropriation of $\$ 112,000,000$ the United States Housing Corporation planned 128 towns or groups, 45 of-which were executed wholly or in part, and the Housing Department of the Emergency Fleet Corporation built 27 towns and had an appropriation of $\$ 71,000,000$.

Establishment of Planning Commissions. - The growth in the number of planning commissions during this period from the first one in Hartford in 1907 to some 700 or more today is indicative of the progress that has been made. This continuous growth has been accompanied by the working together of these agencies and the development of federations and state planning organizations with a resulting exchange of ideas and a consequent building up of strength. Programs of procedure have been evolved, more power acquired, and more influenceso that the city planning commissions have gradually taken an important and recognized position in our communities (see later chapters).

City Plan Reports.-Much effort is represented by the multiplying reports of city planning commissions that have been prepared and printed since they first appeared in 1902. - These reports have been of great educational value in the communities for which they were prepared; many of them have been storehouses of information for other communities and for planners in other places faced with similar problems. The sum total of the influence of these reports is very great even if a few of them may have been permanently stored upon shelves. Among the earliest of these writings were the Senate Committee Report on the Improvement of the Park System for the District of Columbia published in 1902; the report of the Commercial Club of Chicago on the plan of Chicago in 1909; that of F. L. Olmsted on the improvement of Boulder in 1910; that of Charles Mulford Robinson entitled Better Binghampton; and that of George E. Kessler entitled City Plan for Dallas, both appearing in $\mathbf{1 9 1 1 .}$ Although one finds of necessity in these publications some degree of repetition and standardization, yet they have become increasingly attractive and valuable.

Organizations Favoring City Planning.-Nothing is more indicative of the widespread interest that our people are taking in city planning than the number of organizations that have been created to take care of such activities and to make- them a part of the regular municipal program. There have been many such 
organizations and they are as various in aims and purposes as the multilateral character of city planning itself. One of the earliest of these organizations was the American Civic Association that since its inception in 1904 has had as its object the cultivation of higher ideals of civic life and beauty in America and the promotion of improvements of cities, towns, and rural neighborhoods. This association has taken its position on important national issues affecting the welfare of the people and has many accomplishments to its credit.

Closely knit with the progress of city planning in this country has been the work of the National Conference on City-Planning, organized in 1910 along with the activities of the later more technical organization, the City Planning Institute (1917). From year to year the common problems that have arisen in city planning have been threshed out at the conventions of these two organizations and the decisions reached there have been generally followed and adopted over the country. It. has been most astonishing to note the immediate results that are to be credited to the influence of these conventions. In the same year as the Philadelphia conference, the state of Pennsylvania passed legislation permitting the creation of planning commissions in cities of the second class. The year after the Boston convention an act was passed by the state legislature making planning boards mandatory in the cities of Massachusetts with 10,000 population or over. The Cleveland Convention was followed by state-wide authorization of city planning commissions. Soon after the convention at Niagara Falls and Buffalo came the Buffalo City Planning Association and its regional program, the first in the United States. The City Planning Conference and City Planning Institute have included in their memberships the majority of those who have contributed thought and effort to the field of city planning in America.

The U. S. Department of Commerce in Washington has been doing a good work in the field of city planning. Its publications have been outstandingly helpful, and particularly is this so of the Standard Enabling Acts for city planning and zoning prepared by that department and adopted by a number of our states.

Other active and influential organizations are the National Housing Association (1911), the American-Federation of -Arts (1909), the National Commission of Fine Arts (1913), and the Federated Societies on Planning and Parks (1926).-The first 
meeting of the International Federation for Housing and Town Planning to be held in the United States came in 1925 and the encouragement given to that meeting indicated the more intelligent interest in city planning that is now being shown by the people of this country.

Other important organizations have been active in the city planning movement, including groups of architects, landscape architects, municipal engineers, civil engineers, recreational specialists, commercial and real estate men, and automobile manufacturers and dealers.

Educational Efforts and Writings.-During the same year (1909) in which the National Conference on City Planning had its first meeting in Washington, the earliest instruction in city planning in an American university was begun at Harvard in connection with the work in landscape architecture. Four years later, the University of Illinois secured Charles Mulford Robinson to serve as professor of civic design and this service he gave to the University until his death in 1917. Since that time Harland Bartholomew has been visiting professor of civic design. In May, 1923, a full technical course in city planning was offered at Harvard, leading to the Master's degree in that subject, as an option under landscape architecture, which gave Harvard the distinction of offering the first complete course of this kind in the United States. Recently the work has been organized into a separate school of city planning in a position coordinate with the schools of architecture and landscape architecture at Harvard. A number of other universities are now offering the work in the form of appreciation courses open to students with or without technical ambitions in the field of city planning. It would be a good thing if such courses were offered in more of our universities and colleges.

The importance of training citizens, as early as possible, to be sympathetic to programs of civic improvements has been recognized in the efforts to teach something of this work to the children in the grades and in the high schools. No efforts in this direction have been more outstanding possibly than that work carried on in the Chicago schools with the aid of the Wacker "Manual," which tells the story of Chicago and its early improvements, and the work in the schools of Dallas with the aid of "Our City Dallas," a book which emphasizes particularly the value of the Kessler plan for that city. Recent work among the students of 
the schools of Melrose, Mass., included as part of the regular program the preparation by the pupils of zoning plans, which it so happened were adopted by the city council. The educational efforts have not stopped with the work of the universities and the schools. Promotive efforts of all kinds are indeed educational and many of the promoters of city planning have won for themselves considerable distinction. The newspapers and magazines have played their part. The Christian Science Monitor has been one of the outstanding papers that carry city planning news. Special organs of local bodies have given over space to city planning and the periodicals of the various professions and callings have also helped. Those publications that have specialized more particularly in this subject are the American City, the Journal of the American Institute of Architects, Engineering News Record, Housing, Landscape Architecture, and City Planning. See also chapter on "Educational and Promotive Work in City Planning."

The Planners. - Whatever progress there has been in the city planning movement in America is naturally attributable to the influence and activity of the planners. Men with all kinds of training - architects, engineers, landscape architects, sociologists, economists, lawyers, writers -individually and cooperatively have come forth to solve the varieties of planning problems that have been presented. Today these persons form a considerable group, many of whom are known from one end of the land to the other, and they are largely responsible for the planning of at least 176 cities and of the zoning ${ }^{1}$ of 856 cities. It is largely due to the incessant activities of these men along these lines that city planning legislation of great importance has been enacted and favorable judicial decisions have been handed down. The decision of the Supreme Court upholding zoning in the Euclid Village case is one of the leading decisions.

In the company of those who are no longer living are men who have contributed noteworthy service to the building up of our American cities.

The name of Frederick Law Olmsted (1822 to 1903) is so important in the annals of civic development that the city planning movement as such in this country may well be said to start with him (Fig. 29). From 1855 until 1895 he was assiduously at work upon major public enterprises, starting with Central

${ }^{1}$ Survey of Zoning Laws and Ordinances Adopted During 1928 and 1929, by Knauss, Norman L., U. S. Department of Commerce, May, 1930. 
Park in New York and culminating with the Columbian Exposition in Chicago. It was said of him:

Of all American artists, Frederick Law Olmsted, who gave the design for the laying out of the grounds of the World's Fair, stands first in the production of great works which answer the needs and give expression to the life of our immense and miscellaneous democracy.

Charles Eliot (1859 to 1897) was the gifted disciple and coworker of Olmsted. This disinterested, reasonable, fair-

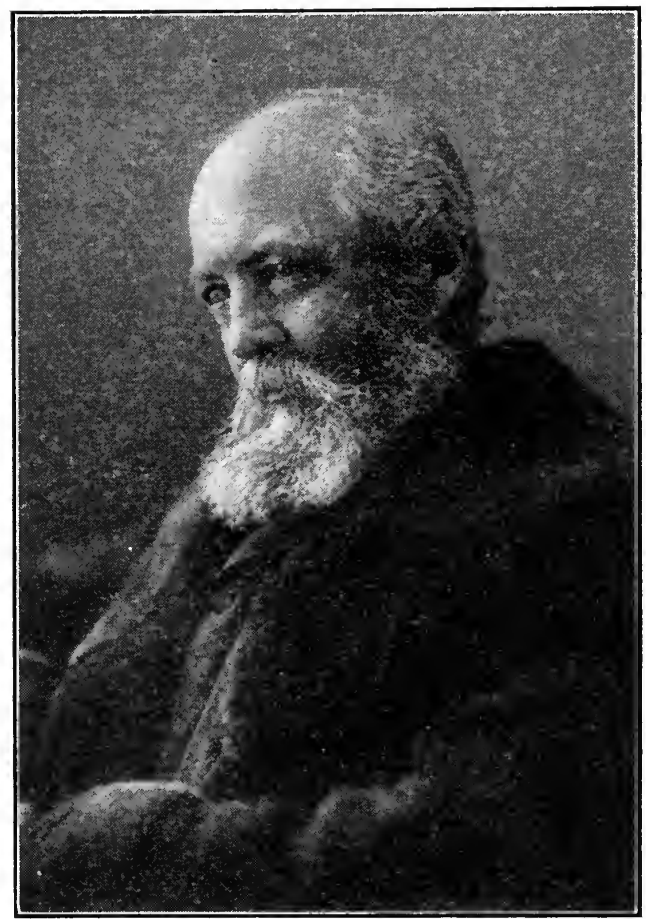

Fig. 29.-Frederick Law Olmsted, April 26, 1822, to August 28, 1903.

minded man, gentle, though persistent, modest though confident, brought to pass in "ten crowded youthful years" an astonishing number of good things. He was responsible, among other accomplishments, for the creation of the metropolitan park system of Greater Boston. This was the most outstanding of his works and at one time was alluded to by a distinguished city planner from Germany as one of the greatest city planning achievements of all time. 
Daniel H. Burnham (1846 to 1912) will be remembered both as an architect and as a planner of cities and a man of exceptional courage and imagination (Fig. 30). His accomplishments, although associated with Washington, Baguio, and San Francisco, will always be most importantly interlaced with the city of Chicago that in many of its distinguished attainments must always cherish the name of Burnham. Among the earliest personalities of the city planning movement in America stands the name of Charles Mulford Robinson (1869 to 1917). See

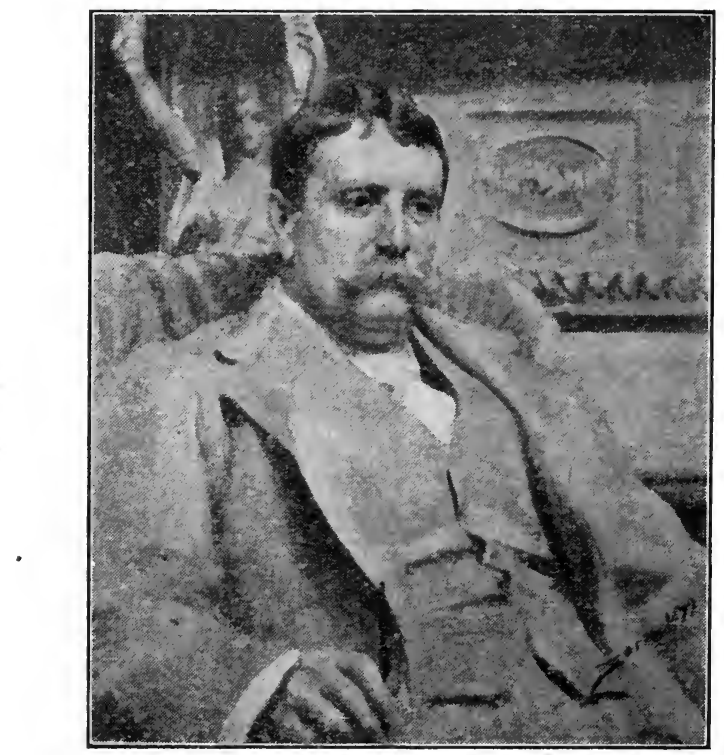

Fig. 30.-Daniel Hudson Burnham, September 4, 1846, to June 1, 1912. (From a painting by Zorn, 1899.)

Fig. 31. He was widely known as an advisor in city planning and as an author. He served as professor of civic design at the University of Illinois until the time of his death. His book "The Improvement of Towns and Cities" appeared in 1907 and was the first important one of its kind in this country. George E. Kessler (1862 to 1923) will be remembered particularly in the Middle West and more especially for the park systems of Kansas City and the Kessler plan for Dallas (Fig. 32). Nelson P. Lewis (1856 to 1924) with combined technical training, experience, and a rare character contributed greatly not only to the planning of the city of New York as chief engineer of the 


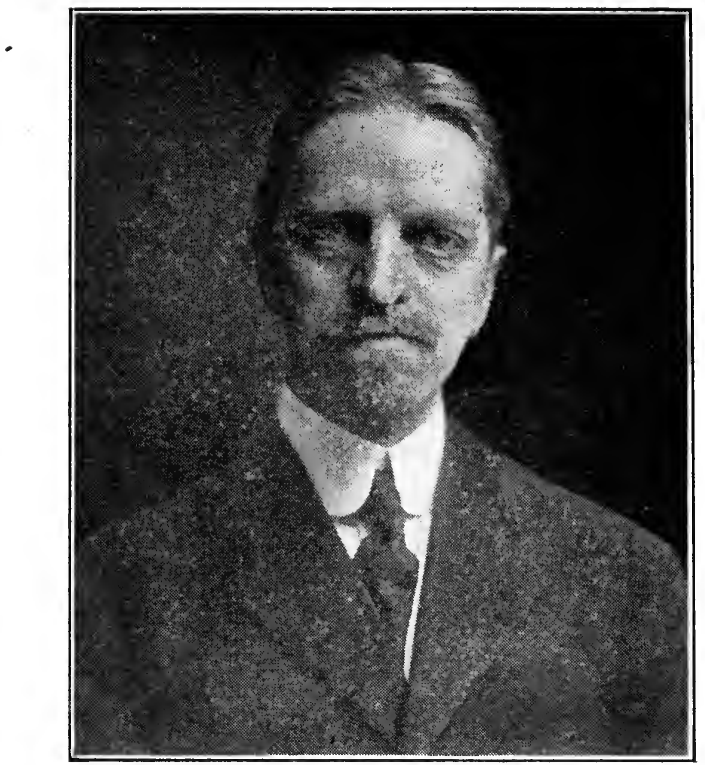

FIg. 31.-Charles Mulford Robinson, April 30, 1869, to December 30, 1917.

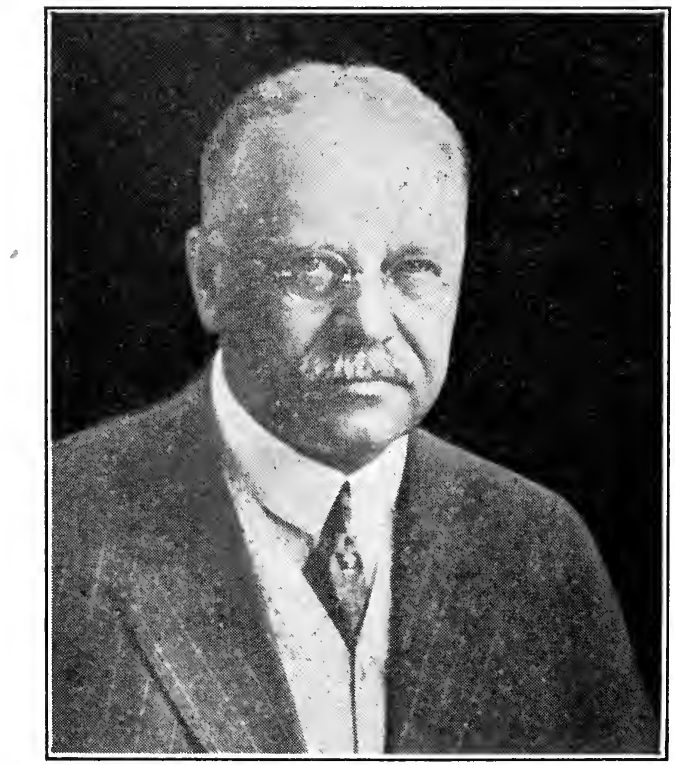

FIG. 32.-George E. Kessler, July 16, 1862, to March 19, 1923. 
Board of Estimates and Apportionment but to the planning of cities elsewhere and to the planning movement in general in this country (Fig. 33). The name of Charles D. Norton (1871-1922) will be associated with the working out of the plan of Chicago and his activities as chief of the Regional Planning Commission of New York. His objectives can be understood from his words: ". . . to bring order out of disorder; to make convenience and thrift take the place of congestion and waste;

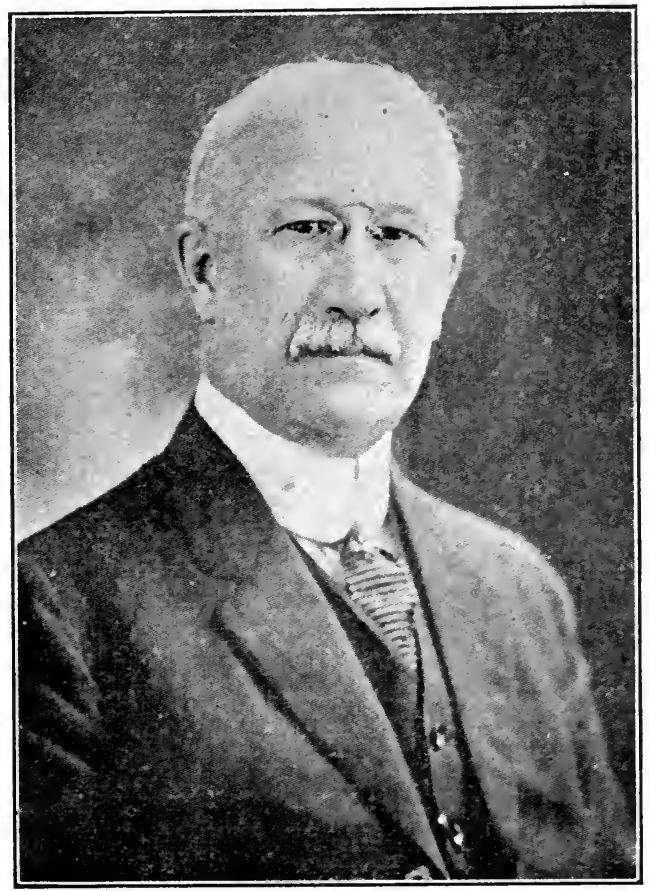

FIg. 33.-Nelson P. Lewis, February 1, 1856, to March 30, 1924.

to realize the potentialities of commerce and industry as well as of beauty, comfort and pleasure."

Charles H. Wacker (1856 to 1929) was the successor to Charles D. Norton as chairman of the City Plan Commission of Chicago and a man with the preeminent gift for translating dreams into realities. To his unceasing efforts in promoting the Chicago city plan may at least be credited the enlargement of the Chicago park system and the double-decked thoroughfare along the Chicago River named Wacker Drive in his honor. 
The progress of the city planning movement in America can never be dissociated from the splendid activities and influence of James Sturgis Pray (1871 to 1929). See Fig. 34. For 20 years Professor Pray was affiliated with the instruction of city planning at Harvard University, both as chairman of the school of landscape architecture and as teacher of city planning. He gave his first course in city planning instruction, which was

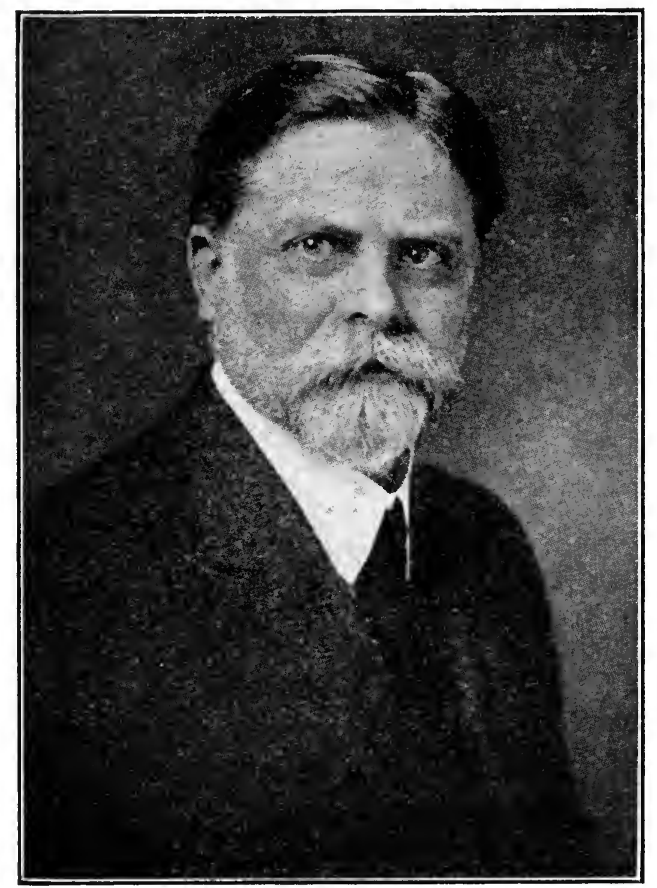

FIG. 34.-James Sturgis Pray, February 26, 1871, to February 22, 1929.

the first instruction of the kind in this country, in the fall of 1909, and in 1923 this course had developed into a full program of technical instruction leading to a special degree in city planning. Professor Pray was a leader among the educators of his profession and encouraged thorough work and an appreciation for city planning as an important field of human service.

In the passing of George B. Ford (1879 to 1930) the city planning movement has lost another of its important leaders (Fig. 35). He was trained as an architect. His service with the New 
York Commission on City Planning and the Commission on Building Districts and Restrictions, his work for the French Government in replanning Rheims and Soissons, and his influence on modern skyscraper architecture are particularly noteworthy. The Cincinnati plan prepared by his firm, the Technical Advisory Corporation, was the first comprehensive plan for a large city which was accepted as an official and legal plan. At the time

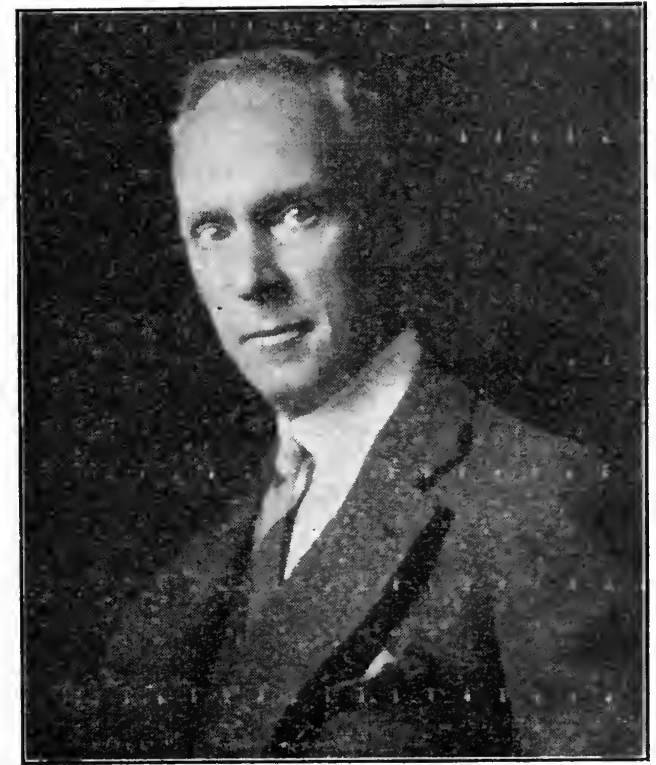

FIG. 35.-George Burdett Ford, June 24, 1879, to August 13, 1930.

of his death, Mr. Ford was the general director of the Regional Plan Association of New York. His program included a large and varied series of accomplishments in a number of our cities.

\section{Questions for Discussion}

1. Tell about the early beginnings of planning in America.

2. Describe the World's Fair of Chicago (1893) and show why it may be regarded as the real beginning of the city planning movement in America.

3 . What has been accomplished during the past 20 years of planning?

4. What were the so-called "city beautiful" activities and in what way did they tend to discredit the term "city beautiful" in the minds of many people?

5. Of what importance in the development of city planning in America were the newly created cities during the time of the war? 
6. Tell how reports on city planning were produced, planning commissions multiplied, and organizations of all kinds begun to further the ideals of eity planning.

7. Who have been the outstanding planners of the past 40 years and what accomplishments may be ascribed to them?

\section{References}

Agache, Alfred: City Planning in the United States, City Planning, pp. 264-268, October, 1930.

Howe, O. M.: Early Town Planning in New England, American Architect, vol. 18, pp. 464-469, illus., Oct. 13, 1920.

Hubbard, Theodora K.: Annual Survey of City and Regional Planning in the United States, City Planning, April, 1925-1928, covering 1924-1927.

James, Harlean: Beginnings in American Planning. Short History of City Planning in the United States; Civic Improvement and City Planning, "Land Planning in the United States," pp. 15-43, 44-81, The Macmillan Company, New York, 1926.

Nolen, John: Twenty Years of City Planning Progress in the United States, president's address, Proceedings of Nineteenth National Conference on City Planning, pp. 1-44, tables, diagrams, 1927.

Olmsted, F. L., Jr.: The Town Planning Movement in America, American Academy of Political and Social Science, Housing and Town Planning, pp. 172-181, 1914.

Shurtleff, F.: City and Regional Planning since 1876, American Architect, vol. 129, pp. 57-60, Jan. 5, 1926.

Zihlman, F. N.: History of the National Capital and Work of the National Capital Park and Planning Commission, speech in House of Representatives, 16 pp., Government Printing Office, Washington, 1927.

\section{Biographies}

Moore, Charles: "Daniel H. Burnham, Architect, Planner of Cities," 2 vols., portraits, plates, Houghton Mifflin Company, Boston, 1921.

Eliot, Charles W.: "Charles Eliot, Landscape Architect," 770 pp., illus., plans, Houghton Mifflin Company, Boston, 1920.

Kimball, Justin F.: George E. Kessler, "Our City Dallas," pp. 62-72, Kessler Plan Association, Dallas, 1927.

Nelson P. Lewis Editorial, Engineering News Record, vol. 92, p. 586, Apr. 3, 1924.

Olmsted, F. L., JR.: Frederick Law Olmsted, Landscape Architect, 18221903, "Central Park," vol. II, 575 pp., G. P. Putnam's Sons, New York, 1928.

Pond, Bremer N.: James Sturgis Pray, Landscape Architecture, Vol. 20, pp. 1-4, October, 1929.

Pray, James Sturgis: Charles Mulford Robinson, Landscape Architecture, vol. 9, pp. 180-193, portrait, July, 1919. 


\section{CHAPTER V}

\section{THE CITY PLAN}

The object of a city plan is to serve as a definite picture and program toward which the city and its environs may in the course of time grow. Its purpose is to supplant, with something better, haphazard growth, which is heedless of both the rights of neighbors and those of the community at large, and which has so generally marred the cities of the past. The aim of a city plan also is to stimulate a wider interest in community problems. By the thought which through it is given to diverse fields of activity, the city plan serves to make possible and to guide coordinated development, to stabilize property values, and to cause orderly city growth. It provides also for the intelligent spending of public funds according to their relative urgency for projects of permanent constructive value. The city plan also improves the health, safety, morals, order, convenience, prosperity, and general welfare of the urban community.

Definition.-There is coming to be more complete understanḑing among our people generally as to what a city plan really is. Misconception is not so common as in the past, when city planning was frequently thought to include administrative details, street elevations, details of installation of public utilities, and the like, all of which are thought of now, and rightly so, as the special duty of the city engineering office, of the department of public works, of the board of education, or of parks, and so on. Neither is the city plan regarded any longer as merely a portrayal of the city's advantages and resources. It is something more than that. The city plan should be a broad, comprehensive plan of the physical development- of the city and its environs. It should present the general location, character, and extent of different kinds of property, ways of various sorts, public, semipublic buildings, monuments, and parks. It should include a zoning plan for the control of the height, area, bulk, location, and use of buitdings and premises. It should contain some information about the system of subsurface utilities. As such 
the city plan may become a diagnosis of the physical ills of the community and serve either as a cure for present ills or as a preventive of those of the future. The city plan-may, moreover, become a guide for the preparation of later plans drawn in more detail and serve as a basis for avoiding legal entanglements and in accomplishing more readily the execution of proposed improvements.

Within the last few years, the use of the term "master plan" has found more and more general acceptance. This word was originally used in the sense of the "master key" to the situation. It has reference to a comprehensive scheme of development that includes the general fundamentals of a municipal plan; finality or a finished and adopted piece of work are not necessarily implied. The final scheme is the one that embodies every recommendation that can be shown graphically after an exhaustive study of the problems presented and is illustrated by accompanying maps, plats, charts, and such descriptive matter as is necessary for an understanding of the drawings.

Elements of a City Plan.-An examination of the purposes of the city plan and the nature of its physical structure reveals certain major elements into which the plan of necessity resolves itself. Broadly considered these elements relate to both public and private uses and include the following subjects: streets, transportation lines and terminals, water supply, sewage disposal, and other utilities, recreational facilities, residential and business properties, building groups and monuments. Streets prơvide both for pedestrians and vehicles the means of getting in, around and out of the city. In addition to traffic and traffic expedients, streets also force the city planner to provide details such as bridges, lighting fixtures and trees. Transportation lines and terminals constitute another of the elements of the city plan and include problems relative to bus, street car (transit and rapid transit), train, boat and airplane. The utilities of water, sewage, power, heat and light, are in themselves important enough to be regarded as an essential feature in the plan of the city. Recreational facilities embrace the whole range of squares, parks, playgrounds and parkways. Residential and business properties are not only identified closely with the problems of housing and of the subdivision of land but with the important field of zoning. A final element that carries with it immense importance is that of building groups, and monuments inclusive of other similar matters. 
Preparation.--In the opinion of Mr. Bartholomew the preparation of a city plan because it so profoundly affects the growth of a city for a half century or more, involves a great responsibility. It is one of the most important tasks to be undertaken in city planning and therefore requires and deserves the most intelligent, competent, exhaustive, and interpretive study that can be given to it. Unless the city plan is actively undertaken in a preliminary way by an unofficial civic body, the preparation of the plan must be preceded by the necessary authorization either in the form of an ordinance of the city council or by an act of the legislature. How much of the work should be done by the city itself depends upon the character and amount of talent locally available for that purpose. Since the impartial judgment of an acknowledged expert from some distant place is listened to more sympathetically than that of the prophet in his own land, as a general rule, it is well to have such an expert for the necessary analysis, vision, inspiration, and supervision associated with this work. It is the practice of professional city planners to establish one of their staff continuously upon the local work, until the completion of the project, and in the meantime supplement that local activity by frequent visits of others in the organization.

Program of Preparation.-The preparation of the city plan involves three main steps-the survey, the preliminary or master plan, and the final plan. The survey, forming the fundamental basis for study, involves a gathering together of all available data relating to existing physical conditions and future growth. The preliminary or master plan embraces a careful study of all of the elements of the city plan - streets, transportation lines and terminals, recreational facilities, etc.-as they affect the health, convenience, efficiency, and amenity of the population. The order in which these steps are undertaken depends upon the urgency of any particular phase of the problem. Sometimes it is one, sometimes it is another of these constituent steps. In fact, they are so interrelated that the order of preference is not of particular consequence. The major street plan frequently is chosen as the first of the studies in a program of this kind. As the studies progress, the results are incorporated upon the common general map which eventually becomes what is called the "final plan."

Importance of Flexibility in the Plan.-No matter how much exhaustive study and care have been devoted to the preparation 
of a city plan, it cannot be considered as altogether fixed and unchangeable. Since there are bound to be modifications, the plan must be in a sense plastic and subject to change but only where necessity compels. Where change is found necessary, an effort should be made to maintain the plan's original spirit and intention.

Maximum Power and Usefulness.-Parts of the plan may be adopted as the work progresses, or no action may be taken until it is completed. There should be some direct public contact as well as official sanction, and for that purpose at least one public hearing should be held before the adoption of any plan or of its particularly important parts. There should be "mingling of men, meeting of minds, and merging of methods." The plan playing such an important part in the life of the city should be approved and adopted both by the planning board and by the council. It is not only important to give the plan some standing, through approbation and adoption as suggested above, but it is also essential that constructive operations of the major features involved in the plan should be allowed to begin only after their location, character and extent have received the approval of those having the city plan in their keeping.

We have reviewed the important part that the piece of work spoken of as the "city plan" may play in the life of a community. We have been reminded of its purpose and function and of the elements that contribute to its structure. The importance of the program of preparation also has been emphasized, and the matters of personnel and practice in this connection, and the actual steps that are necessary for the completion of such a plan. Emphasis has been laid, moreover, upon the need for flexibility of the plan and upon the insuring of a larger power and usefulness through certification, public contacts, support of council, and necessary approval when it came to the beginning of constructive operations affecting important elements in the city plan.

The cost of such a plan depends of course upon the amount of work that is required, and this amount will vary even in cities of the same population. Local conditions, especially the amount of money available for the purpose, will enter calculations, as will also the amount of necessary foundational work already completed. Costs will sometimes run from $\$ 10,000$ to $\$ 25,000$ in a city of 100,000 , depending upon the extent to which the study is carried. Whatever the cost, at the most, 
it is small when compared with its value in terms of the human efficiency and happiness that will be realized by the population of a city that has anticipated its future in a city plan intelligently conceived.

\section{Questions for Discussion}

1. What is the value of an official comprehensive city plan?

2. What is a city plan?

3. Distinguish between a master and a final plan.

4. What elements constitute the city plan?

5. What are some of the underlying considerations that are essential in the preparation and adoption of a city plan?

6. How much does it cost to have city plans and reports prepared?

7. Discuss comprehensive studies as prepared for Cincinnati, Memphis, and other cities.

\section{References}

Bassett, Edward M.: The Co-ordination of Streets, Parks, Sites for Public Structures, Zoning Districts and Routes for Public Utilities, Proceedings 22d Annual Conference on City Planning, Denver, 1930.

"City Planning Primer." Advisory Committee on Zoning, U. S. Department of Commerce, Washington, 1928.

Crane, JAcob L. Jr.: How to Make a City Plan, National Real Estate Journal, pp. 35-39, Apr. 14, 1930.

Hodbrard and Hubbard: Technical Procedure; Comprehensive Plans in Action, "Our Cities Today and Tomorrow," pp. 101-113, 130-141, Harvard University Press, 1929.

LASker, B.: What Constitutes a City Plan? Summary Statement Embodying the Essential Principles of City Planning, Survey, vol. 45, p. 734, Feb. 19, 1921.

Lewis, N. P.: The City Plan Defined by a Municipal Engineer, Proceedings of 7th National Conference on City Planning, pp. 1-12, 1915. The Economic Value of a City Plan, "Planning of the Modern City," pp. 175-185, illus., plans, 1916, 1923.

Mathes, G. H.: Aerial Surveys for City Planning, Proceedings American Society of Civil Engineers, vol. 52, pp. 1349-1360, September, 1926.

Mitcheld, H. C.: Accurate Maps and the City Plan, Military Engineer, vol. 17, No. 91, pp. 9-15, illus., plans, January-February, 1925.

The Official City Plan of Cincinnati, Ohio, adopted by the City Planning Commission, 1925, 276 pp., Technical Advisory Corporation, consultants.

Pepler, G. L.: International Notation for Civic Surveys and Town Plans, International Garden Cities and Town Planning Federation, Report 5, pp. 70-72, conference at Gothenburg, 1923.

Reviews of recent comprehensive and special plan reports, see Annual Survey of City Planning in City Planning. 
Standard City Planning Enabling Act, U. S. Department of Commerce, 53 pp., Washington, D. C., 1928.

Ten Years' Progress on the City Plan of St. Louis, 1916-1926, including the Annual Report of the City Planning Commission, 1925-1926, 68 pp., illus., maps, and plans, St. Louis, Mo., City Plan Commission.

Weisburg, A. F.: City Planning Programs with Special Reference to the Larger Cities, Proceedings American Society of Civil Engineers, vol. 55, pp. 1429-1431; discussion, pp. 1431-1433, August, 1929. 


\section{CHAPTER VI}

\section{STREETS AND STREET SYSTEMS}

One can scarcely overestimate the importance of streets and street systems in the life of a city. Upon these permanent fixtures that form the skeleton of the city plan rest the easy direct movement of the people and their supplies and in some measure also their health, comfort, and economic growth. Although every thoroughfare is supposed to furnish light and air and access to properties abutting upon it and a suitable setting for its architecture, nevertheless its primary function is that of serving the needs of traffic. Every inhabitant is directly affected by the success or failure, the presence or absence of good circulation as represented by the streets that are provided. Since, therefore, streets, like other structures, are to be designed according to the purposes for which they were intended, it is appropriate that some thought should be given first to the subject of traffic as such and then of questions affecting its accommodation.

Principles and Character of Movement.-There can be no misunderstanding of the word "traffic," which denotes vehicular and pedestrian as well as street-car movement: Along with the idea of motion, traffic represents a double effort-to get somewhere and to return again, to attain a goal and to return to the point of starting. Since in this manner traffic flows between a point of origin and a point of destination, it is said to have a definite aim and purpose.

Traffic also has its pecularities. It may be thinly scattered or dense; it may be fast or slow, light or heavy. From the standpoint of direction it may be uptown, downtown, cross-town, around town. In terms of distance traveled it may be local or interurban. Traffic is, in some respects, quite like water which flows around or is impounded by an obstacle. Like the tide it ebbs and flows. As traffic increases in volume, again like water it requires larger channels. Traffic tends to flow into direct, wide ways and follows the line of least resistance. It is strongest 
during certain days and during particular hours of the day. Like the individuals whose minds drive it, traffic is in more of a hurry in its approach to and convergence upon a common focus. For opposite reasons, the return is somewhat slower and accompanied by comparative leisure. In the one case it is convergence of traffic, in the other divergence and dispersal of it.

Theoretical Scheme of Traffic Flow.-The nature of traffic may become more clearly pictured to us if we think of it as a system of the various types of flows and movements: It is natural for main ways to lead into a city's heart or to branch

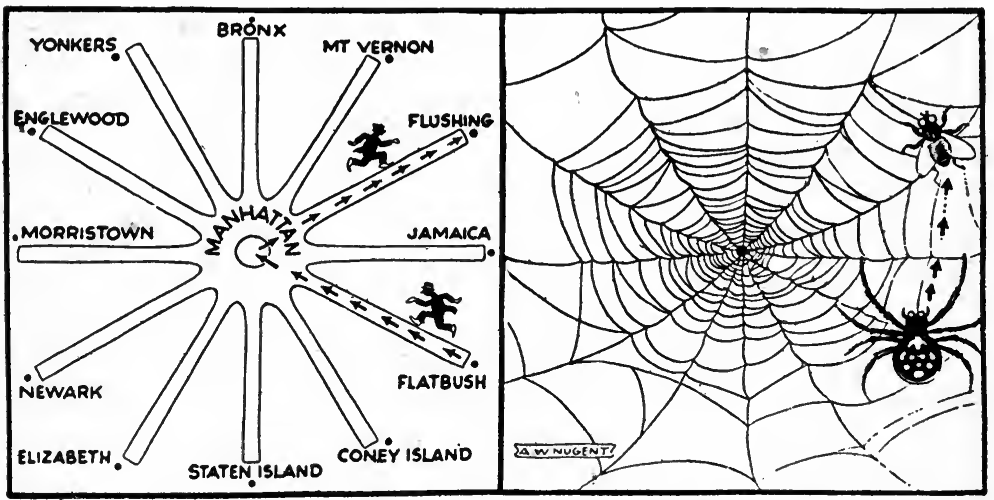

Fig. 36.-The wheel and spider-web diagram. Diagonals without connections are like wheels without rims. In connection with some studies for rapid transit by the City Club of New York this and the well set up mechanism of a spider's web were pointed out. The web of the spider makes a schematic arrangement that applies particularly to a system of streets, offering the opportunities to get out from the center of the community from which the streets radiate in all directions and to cross and to get around in general in the most direct possible manner.

outward from the nucleus and center of a city, in order to provide communication with other communities and with outlying territory. It is also to be expected that there shall be a flow of traffic along certain cross-streets intersecting the radials to permit communication between one radial and another and one part of the city and another and to allow intercommunication within the local areas served by the radials. The main lines of traffic, as represented by these radiating thoroughfares and crosstown or circumferential, distributory or by-pass ways, produce a theoretical figure like that of a spider's web (Fig. 36). Although this does not take into account special diagonal thoroughfares that may be necessary to link up certain important focal points, 
still the spider's web serves as a good theoretical representation of the natural main lines of traffic within a city.

Focal Points.-The activities of a city naturally group themselves around focal points of, special interest. Since these focal points decide the positions and directions of the principal streets, they play an important part in the city plan. The principal focus for the main arteries of the city is the downtown business center, and for that reason facilities for traffic usually are made to favor that important place. As we know too well, this may lead to the development of an overburdened and overgrown downtown center which the "vicious circle" of congestion followed by more streets and more congestion cannot mitigate. There are exceptions, as in the case of Madison, Wis., where the Capitol Building and the University group serve as major competing foci. Confusion will be minimized if traffic is carried around the business area over streets that surround that area like a belt and permit of easy access to and exit from the business section. The locations of other subordinate business centers should be determined by the location of the major streets. Such centers should be encouraged to develop at or near outlying junctions of primary ways as well as in other positions demanded by the needs of the population both within and outside the city.

Other focal points of importance are theaters, stations, squares, open spaces, and sites of public buildings and quasi-public buildings. Since these are focal points that attract and distribute traffic, they should be planned carefully as to location, size, and the proper reception and distribution of traffic.

Just as these centers become the dominant points that influence the locations of city streets, in the same manner the city itself becomes a dominant center of the county or region from which the trunk lines will be made to converge toward the city.

Types of Street Patterns.-The street plans of world cities represent a variety of arrangements. There is the meandering or irregular type (Fig. 37) with streets freely turning this way and that. Such an arrangement suggests spontaneous growth and a modeling of streets to the irregularities of land. Meandering streets that express some underlying purpose are attractive and full of interest.

A type of another kind of street is the result of the successive rings of fortifications that certain cities were obliged to construct and which were later torn down to make way for streets, as the 
need for city walls was no longer felt. The concentric arrangement of streets provides convenient accommodation for the much desired round-the-city and cross-town communication. Where these encircling streets have become pleasure ways and

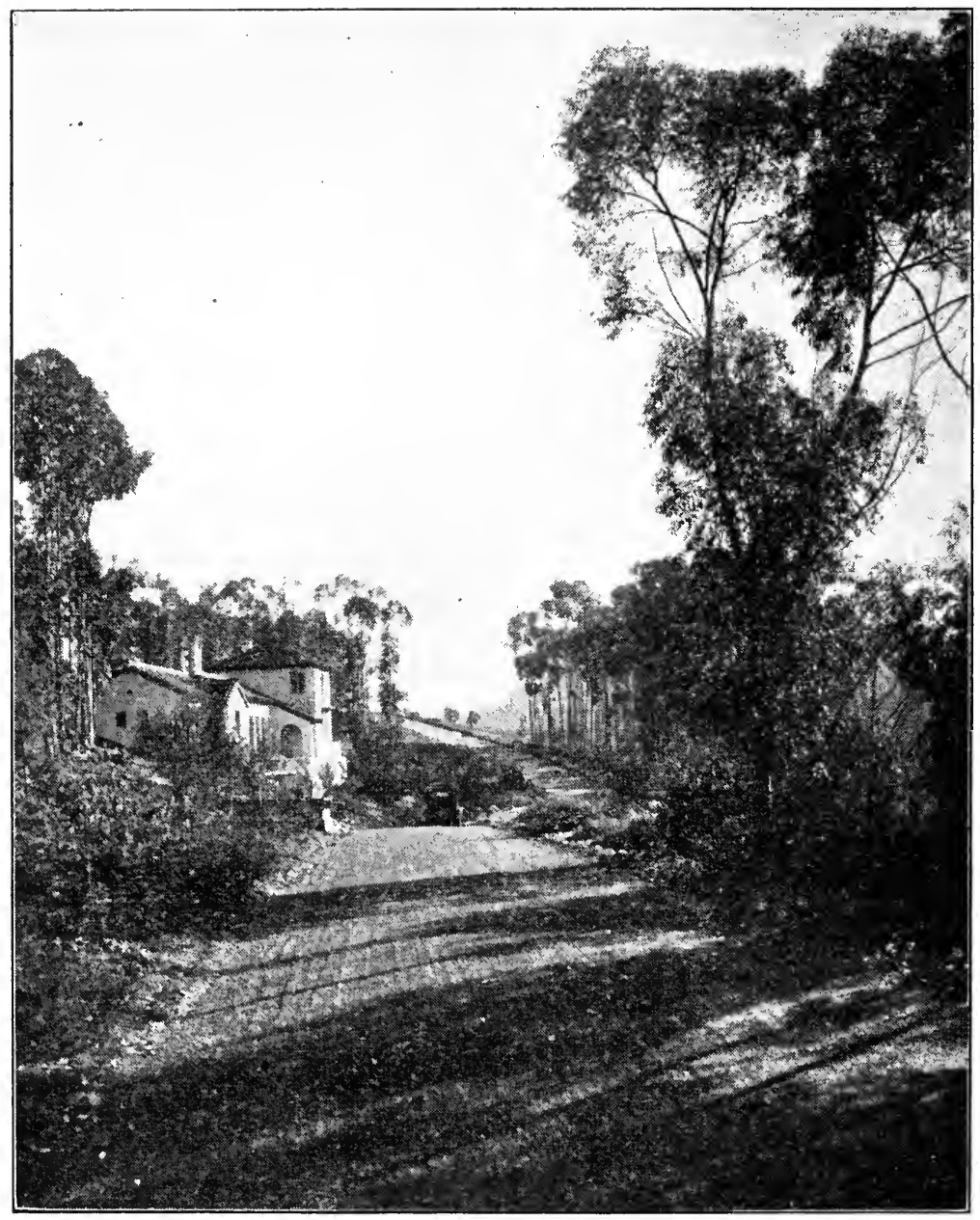

Fig. 37.-The fitting of streets to topography serves convenience, economy, and beauty. Palos Verdes, Calif. (Photograph by Padilla Company.)

have been fronted by magnificent buildings, they are sources of universal admiration.

For the diagonal or radial system of streets we are indebted to the example of the great, royal parks of France through which 
diagonals were cut for the convenience of hunting parties. These short-cut diagonals radiated from and converged upon certain focal points which resembled hubs, stars, or crow's-feet and provided sites for squares and open spaces, distribution of traffic, and locations for monuments.

We are most familiar, however, with the perpendicular, allAmerican north-south and east-west arrangement, that portrays either the checkerboard in plan, with square blocks, or the gridiron, with blocks longer than they are wide, while the streets run perpendicular to each other. This arrangement deserves examination; it. has a certain simplicity that commends it to the engineer who must plat it and record it, for the architect who must fit his buildings to the sites, and for the artist who would admire the effect of its avenues with overarching trees and long vistas, contributing to the symmetry and beauty of the street.

But it has also its disadvantages that make it anything but a model worth repeating without modification. The most objectionable feature is its straight-jacket quality and the monotony that makes impossible all requirements for diagonal traffic except at great expense.

New street patterns are being advocated, among which is a very interesting one recommended by Noulan Couchan of Ottawa. He proposes that the major areas of our cities be divided into residential hexagons. There is much of merit in this arrangement, that among other things provides good orientations for homes, affords safety and acceleration of traffic by a wide angle of vision at the three-way street junctions, and reduces the number of points at which collisions are possible. The streets in this plan are fewer and shorter than in the conventional plans and commend it from the economical side.

Another interesting arrangement of streets is found in the new town of Radburn, N. J. The plan of Radburn is notable in the effort made by its planners to cope with the requirements of a motor age. The large blocks of which the city will be. composed are bounded by major ways, but the homes within the blocks instead of facing upon the streets are arranged along culs-de-sac that open off the main highways.

In choosing a suitable system of streets, the local requirements must always be considered by the planner. "These local requirements may call for any one of the types of streets above described and, in the variety of demands to be met, perhaps all of them. 
A Street System and Plan.--Streets should be something more than a mere pattern upon paper; they should compose a wellordered system, in which each part contributes to the aggregate result of equal opportunities for improvement everywhere in

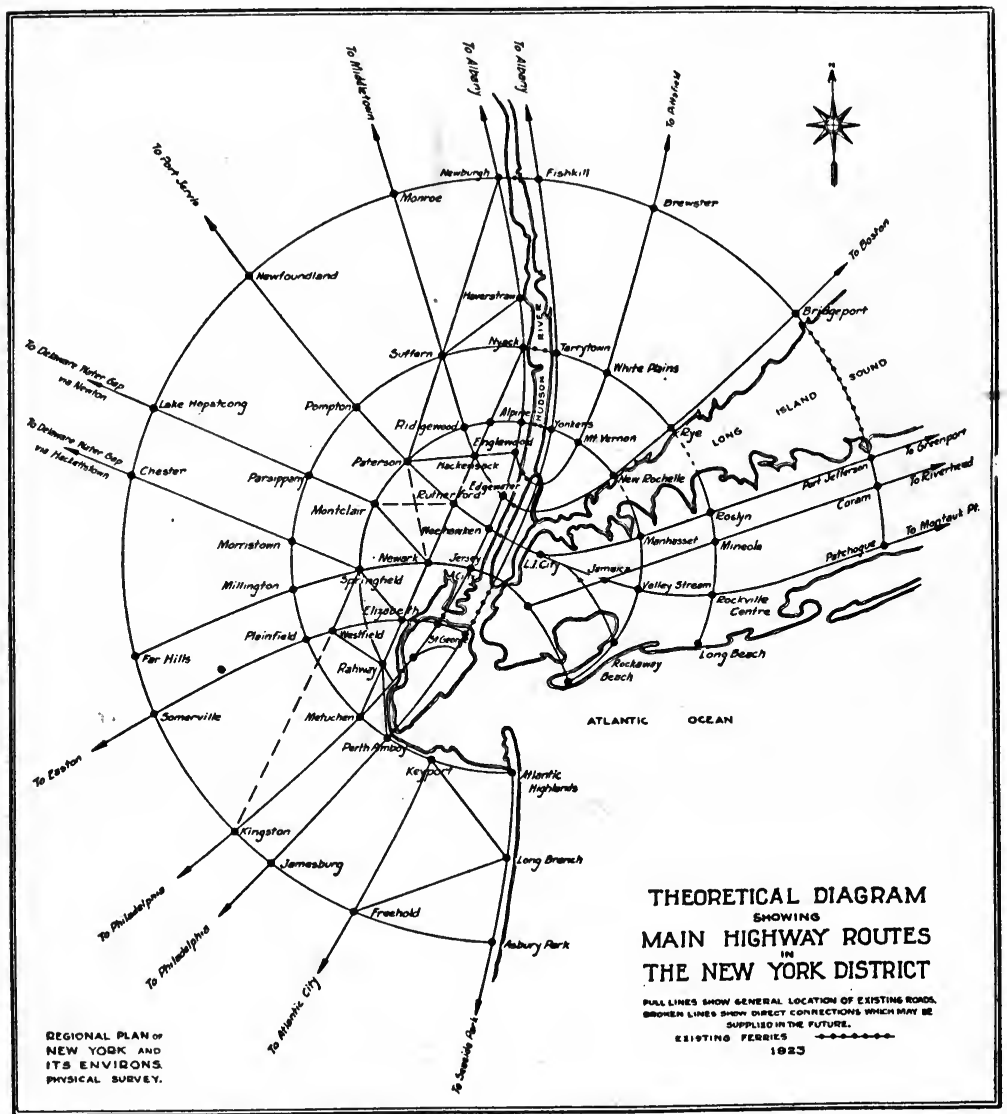

Fig. 38.- The trunk-line highways of the New York region, arterials and circumferentials, reduced to a theoretical diagram. (From Vol. III, "Highway Traffic," the Regional Survey of New York and Environs.)

the city and provides for the circulation of the population "efficiently, economically, safely, comfortably, speedily." The system should be "so planned, so spaced, so interconnected as to make for free circulation throughout the whole urban body" and the territory over which the city will eventually be spread. 
A Major Street Plan.-As a foundation for a system of thoroughfares there must be a street plan, and particularly a major street plan dealing more especially with the most important routes of travel within the city. Such a plan will serve as a guide for the progressive development of the system of streets, will help to avoid mistakes, and will set the stage for more desirable developments in the future.

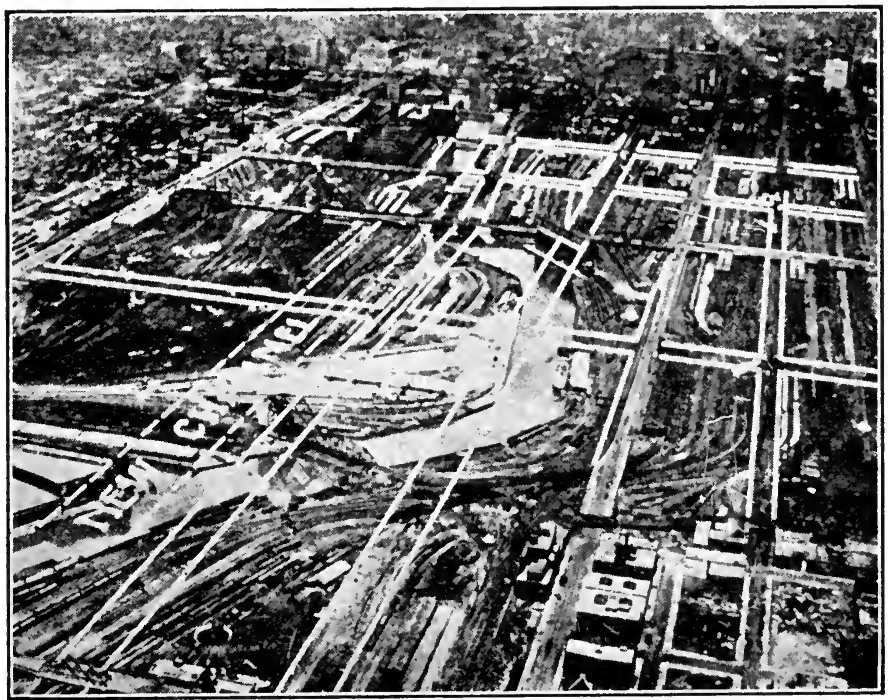

Fig. 39.-The Chicago River straightening project. After 10 years of continuous effort one of the most important projects embodied in the plan of Chicago is now being completed. The bend in the river always blocked streets west of Clark Street from extension through to the south side and much of this area was occupied by freight and passenger terminals. Only one street existed where four should be. It was a source of strangulation to the south side districts. The removal of the bend takes the river some 850 feet farther west. The improvement is destined to increase properties adjacent by hundreds of millions of dollars.

The theoretical figure of a spider's web cannot perhaps be duplicated in every plan, but at least it can be approximated (Fig. 38). There should be in effect a number of principal radial arteries for ingress and egress, leading to and from the heart of the city, broader as they approach the congested centers and less broad as they approach the periphery of the city, as the density of travel is considered to vary, approximately, inversely as the distance from the center of a community. These radial arteries should have alternate parallel streets 
or supplementary overflows where necessary. There should be cross-town or circulatory streets not so wide as the radials but set at widening intervals toward the margin of the future city. These should be supplemented by "by-pass" and distributive streets, that will tend to carry such traffic as may need to pass around centers of traffic or other points of heavy concentration.

The framework of main streets require continuity, directness, width, and easy gradient. Continuity is necessary in the sense of easy flow and freedom from such obstructions as "jogs" or "dead ends." Directness must be sought in the form of the shortest possible routes (Fig. 39). These main arteries must have adequate traffic capacity of adequate width, based upon the volume of traffic ultimately to be accommodated. Easy gradient is desirable, even at the expense of a little indirectness and a few curves of short radii.

Minor Streets.-While a major street is one that attracts and facilitates traffic, a local thoroughfare is only of local value, as it is tributary to the main arteries, is expected to serve only limited areas, to discourage through traffic, and thereby provide the safety and quiet demanded by a residential neighborhood. Considerable width, therefore, should be unnecessary in such a street, and if the topography so suggests, it may be quite curving.

Segregation of Traffic.-The pace set by a slow-moving vehicle such as a slow-moving truck is an obstacle to easy flow of traffic and particularly to the flow of those lighter vehicles that are swifter. The hazard in passing wide-bodied vehicles is, moreover, a frequent source of accident. So objectionable is this intermingling of types of traffic that the need for a segregation of them is coming to be generally realized. Different traffic ways for vehicles of light weight and for slow vehicles are being reserved or newly developed in a number of our cities. When trolleys, trucks, and buses are prohibited on certain streets and parkways, the immediate drift of the lighter vehicles to those streets is an indication of the need of such prohibition and of the appreciation on the part of automobile drivers of such protection.

The segregation of traffic into different levels is being considered as a means of accommodating the various types of traffic. Harvey W. Corbett believes that traffic by rail, wheel, and foot each belongs on a different level-that is to say, rail underground, motor traffic on the surface, and sidewalks for 
people walking lifted above the other forms of accommodation. Corbett's picture of the complete utilization of this idea is like that of a modernized Venice, a city full of canals and bridges, the canals serving the motor traffic and the bridges and arcaded sidewalks affording to the pedestrian protected views of the flowing currents below.

Elevated and "double-decker" streets have been constructed and are being proposed in occasional places in the United States. Our most notable examples are in connection with Michigan Boulevard and Wacker Drive in Chicago. Possibly the most

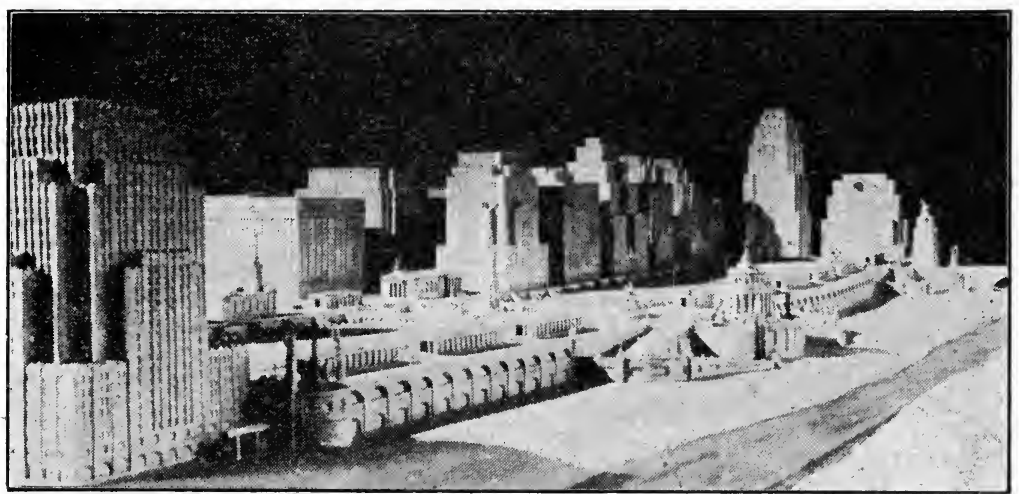

Fig. 40.-Central river-front development in St. Louis. It is proposed to change the ragged area in St. Louis between Third Street and the river along the river to a creditable monumental approach to the city. It is proposed to introduce two new thoroughfare approaches, both north and northwest and south and southwest, with elevated roadways; to widen to 140 feet and double-deck Third Street for several blocks; and to develop a river-front plaza and a highlevel mall extending from the old Court House to the river front. The total cost of the development is estimated at 50 millions. (From river-front model, size 8 by 14 inches, scale 1 inch $=25$ feet.)

outstanding proposed elevated and double-decker developments are those for the river front in St. Louis (Fig. 40) and an elevated street for purposes of express traffic paralleling the river on both sides of Manhattan Island, N. Y.

Since these expedients in themselves are after all only palliatives and however complex and elaborate may become inadequate later on, they do not constitute a final solution of street congestion and can be undertaken only where they are in every sense economically justified. John Ihlder asks this question with respect to them: "Will the property benefit enough to pay the cost of the development, and, if not, what benefit accrues to the rest 
of the city by so concentrating values?" These questions can be answered only by a careful analysis of each situation.

The Superhighway.-Another of the spectacular expressions of present-day needs of metropolitan traffic is that represented by the superhighway of Detroit (Fig. 41). This superhighway is a single-level main artery, 204 feet in width, in which four rapid-transit tracks are placed in a central reservation 84 feet

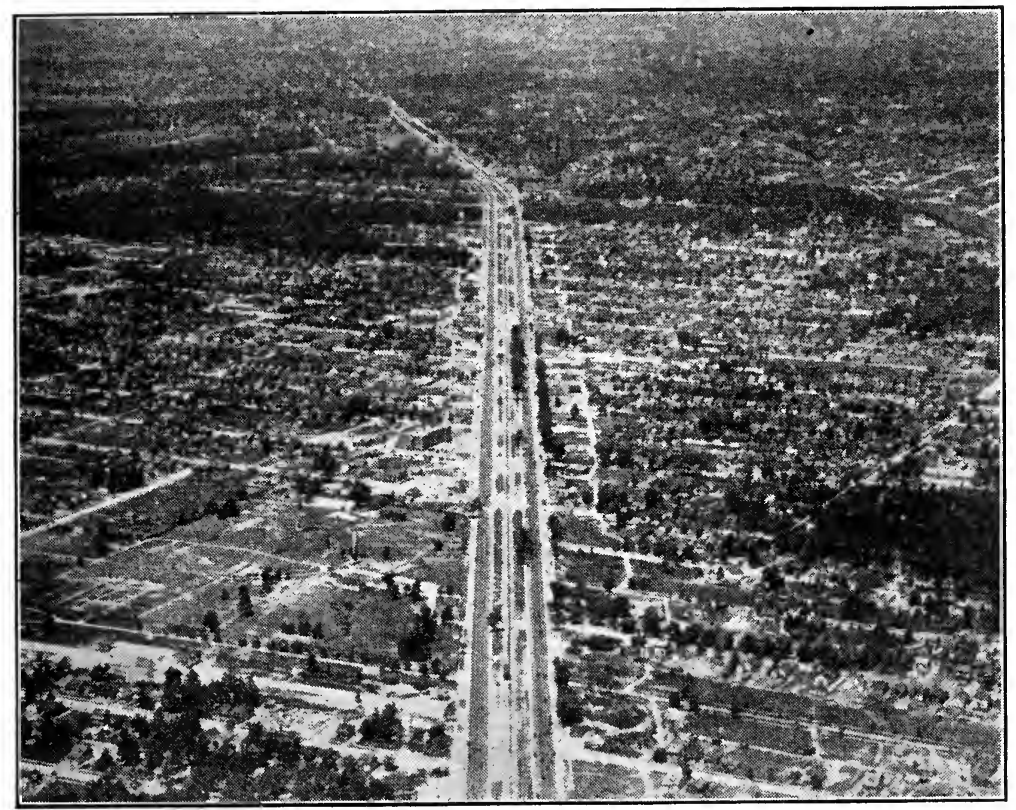

FIG. 41.-A "superhighway" of Detroit as seen from the air. The air-view comparison helps to visualize the immensity of the new superstreets of Detroit. These 204-foot ways when completed will have a central space of 84 feet for the exclusive use of rapid transit lines and planting, a 20-foot roadway for local traffic on each side, and a 15-foot sidewalk on each side. Wheel traffic may cross under at half-mile intersections, and pedestrians may pass over or under here and there as conditions warrant. (Kalec and Forster, photographers.)

wide, and the street space is split into two parts with 60 feet on each side. At the intersections of two superhighways, tracks and express roadways of one will be carried above and of the other will be carried below the former street level. The local roadways from both superhighways will meet at the intersections at normal grades. According to A. J. Brosseau:

The data so far advanced seem to indicate that the superhighway for the carrying of all types of traffic service is needed throughout the greater 
part of its route. On the other hand, where population is quite evenly distributed and there are back-lying sections in need of equally good highway service, or where there is little preference in volume of traffic to be served, then the parallel road undoubtedly should be developed.

Widths and Cross-sections (Fig. 42).-When speaking of street widths, the distance from property line to property line is meant and not from curb to curb. It is well to remember in this connection that there may be narrow roadways on wide streets and wide roadways on narrow streets. The widths of streets will vary according to the service which they are to perform. For minor thoroughfares, 60 feet is wide enough, 80 feet for major thoroughfares, and 100 to 120 feet for streets of more than ordinary importance (Fig, 43). Such widths provide average suitable room for roadways, sidewalks, and green spaces adaptable to the several needs of such classes of thoroughfare.

The detailed widths, however, and the treatment of the pavements, sidewalks, and other features of a thoroughfare will be governed by two things - the amount and nature of the traffic to be accommodated from the areas tributary to it; and the beauty of the finished work and the manner in which the various parts combine to form a well-composed picture.

By traffic count, the amount and character of traffic can be ascertained, and to some degree the amount and character of future traffic can be predicted for different streets and intersections, and the required widths of future pavements can also be foretold. Such widths of pavements, according to Mr. Bartholomew, are best as will accommodate four, six, or even eight lines of traffic. There should be the same number of traffic lanes in both directions. With four lines there will be vehicles stopping at the curbs, so that upon the basis of 600 vehicles per lane per hour there will be accommodation for 1,200 vehicles per hour along a four-line thoroughfare. Upon a similar basis a six-line thoroughfare will provide for two lines in either direction. Since on this type of street 800 vehicles per lane may pass, place for 3,200 vehicles per hour is provided. This width, however, is unsatisfactory where there are street-car lines. Of the various widths of streets so far studied, the eight-line street has been found to give the maximum capacity and also to provide satisfactorily for street-car lines as well: three lanes of moving traffic in either direction are made possible, each taking care of 1,200 vehicles per lane per hour. Minor residential 


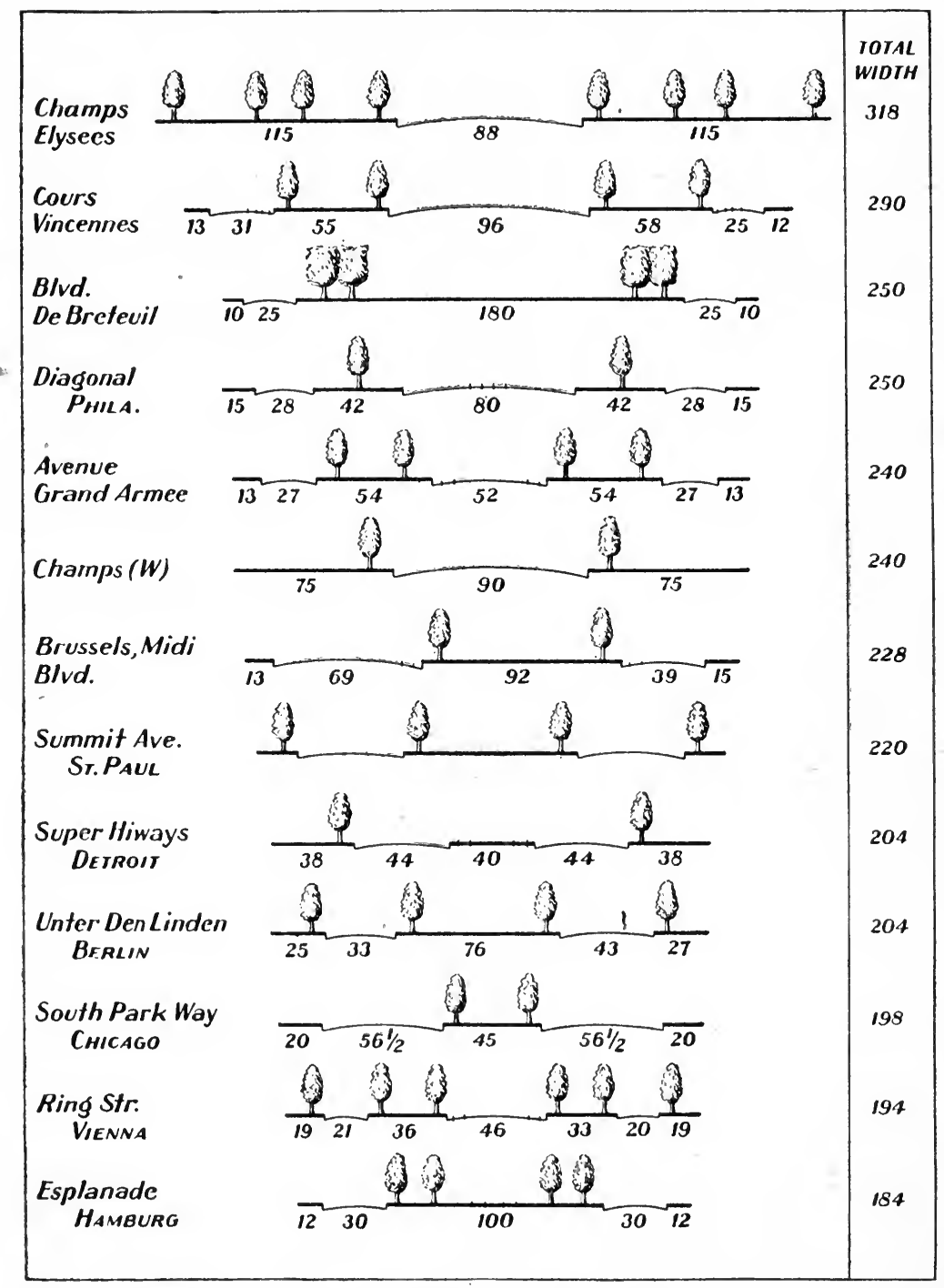

Fig. 42.-Width and space distribution of some famous American and European Streets. (Redrawn from illustration by H. W. Tiedeman in the "American City," January, 1928.) 


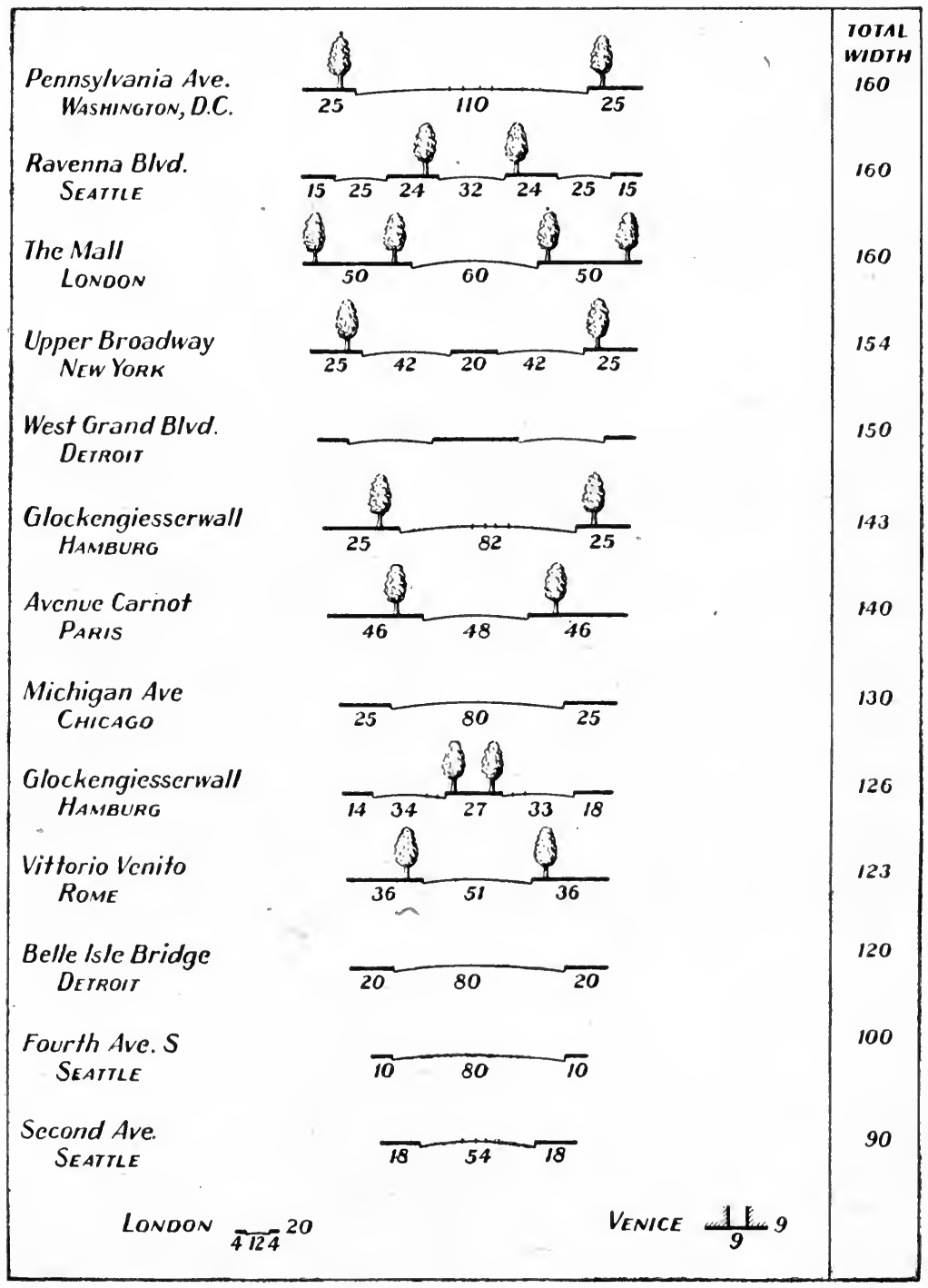

FIG. 42.-(Continued). 
streets with three lanes would tend to discourage through traffic to the advantage, it would seem, of those residential streets. Where, however, the minor streets are fronted by multiple dwellings, a width should be provided for at least four lines of traffic.

Along with the number of lanes, the width of those lanes must be considered. For moving traffic these lanes should each be

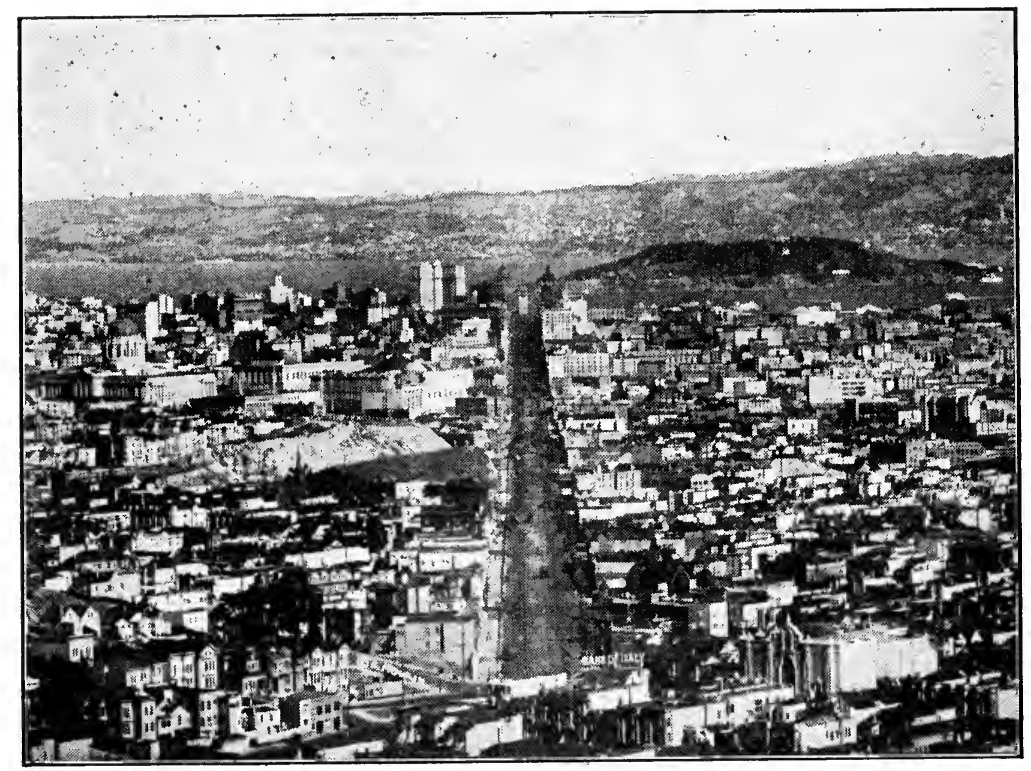

Fig. 43.-Market Street, San Francisco. This street is 120 feet wide between property lines, and 80 feet between curb lines. It is unique among larger city thoroughfares in that for its entire length through the central district it is equipped with four street-car tracks. At the end of Market Street is what is said to be the largest ferry terminal in the world. (Gabriel Moulin, photographer, San Francisco. Courtesy of San Francisco Chamber of Commerce.)

9 or 10 feet wide, allowing for reasonable speed but without much leeway for poor or careless driving.

Vehicles parked along curbs need 7 or 8 feet of space for parking purposes under ordinary circumstances, because the average automobile width is 6 feet. The occasional truck and autobus, however, with widths of 7 and 8 feet, call for a parking space of 10 feet. In cases of angle parking, 12 feet is required for an angle of 30 degrees, and 16 to 18 feet for angles of both 45 and 90 degrees. These degrees refer to the positions for the car at the curb. Since the average street car is wider than most 
automobiles or trucks, each street-car lane should be at least 10 feet wide. Sidewalks should vary in width from a minimum of 4 feet in open single residential neighborhoods up to 10 to 40 feet in business sections. A good standard width for local business centers is 10 to 12 feet, and a good minimum width for the central business sections is 15 feet. Since a sidewalk of 5 feet allows for a person to pass two others who are walking side by side, such a width should be adequate for most residential neighborhoods. Sections of the city in which apartment houses are built call for more liberal space for sidewalks. Around business blocks, where the most intensive use is found for sidewalks, the maximum widths are necessary.

No set widths can be laid down for the borders of a street set apart for grass and trees. But for the sake of appearance and safety, sidewalks in residential neighborhoods should always be separated from the pavement by spaces for grass. These spaces should be as wide as possible for effective appearance, never less than 5, preferably not less than 7 , and 10 feet is a good standard minimum. It is desirable to allow for at least 2 feet of space between the sidewalk and the property line for pipes and conduits. Where central, green spaces are used, they should be wide enough to serve as definite means of separation for traffic moving in opposite directions and also wide enough to make the street a thing of beauty. It is better to have no central strips of green at all than to have them of ribbon-like widths of 5 or 10 feet; they should be at least 30 or 40 feet in breadth, their width depending upon the size of the thoroughfare.

Street Widenings.-One of the functions of a thoroughfare plan is to reveal those improvements that are necessary to a better street system. Not the least of these functions will be the street widenings that must be undertaken. Cities everywhere in America, with Detroit and St. Louis probably in the lead, have been following large programs along this line. Many of the widenings are carried on in unimproved districts (Fig. 44). These widenings are the least difficult of all. Frequently, the freeholders on either side of the avenue about to be widened dedicate to the city enough land for the purpose, free of charge. Many widenings, on the other hand, have to be made in the built-up sections of the city. Where the widening means only the extension of the pavement, it frequently involves but a taking of some of the space alloted to the sidewalk at the expense of the sidewalk. 
Where, however, it becomes necessary to widen by appropriating land upon which structures are located, this can be done only by the award of damages and compensation to the freeholder for the taking of his land or by the establishment of new building lines. After new building lines are laid down, all new buildings, renewals, and repairs must be constructed behind such new lines.

Widening of roadways sometimes takes place also by constructing covered sidewalks on private property in the form of arcades with the existing structures overtopping them. This

\section{When is it Cheapest to Widen the Street? When like this? \\ or this?} or this?

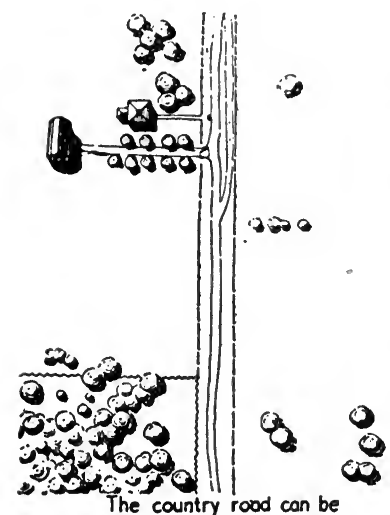

The country rood can be widened at the time the adjacent land is cut up into building lots olmost without cost

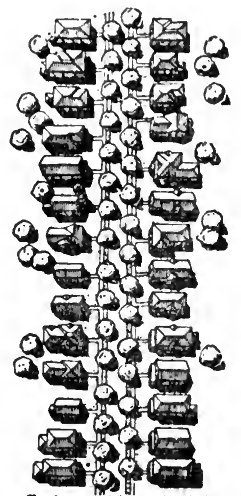

falling this a bulding line may be established that will secure its eventual widening when the residences ore replaced by stores.

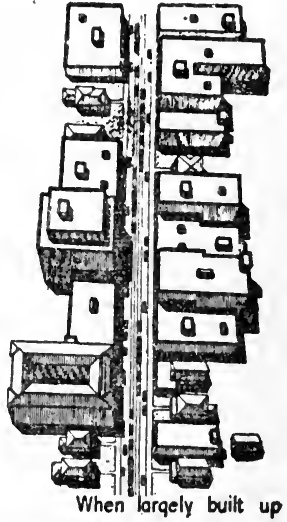

with expensive commercial buildings widening often becomes prohibitively expensive.

Fig. 44.-Street-widening diagram by Robert Whitten, city planner.

type of improvement involves only the cost for the arcade easement and the construction of the pavement. Good illustrations of arcade developments of one kind and another are to be seen at Fifteenth Street and South Penn Square, Philadelphia, at Santa Barbara, Calif., and in Miami, Fla. In the condemnation procedure necessary for the opening and widening of streets, Mr. Bartholomew reminds us of two fundamental objectives. These are expeditious procedure and equitable distribution of the cost as between abutting frontage and adjoining or contiguous areas especially benefited by the improvement and the city at large. 
Street Trees.-Too little attention continues to be paid to the large part that trees occupy in the adornment of our city streets. Trees cannot give their maximum effects unless they are carefully selected and properly arranged (Figs. 45, 46, 47). The arrangement and choice should be guided by their adaptability to the width and character of the street and by thought for future effects. The street after the trees have been set out will make a picture of great beauty. Not only will it be bordered by formal lines of trees between sidewalk and curb, but occasional spaces

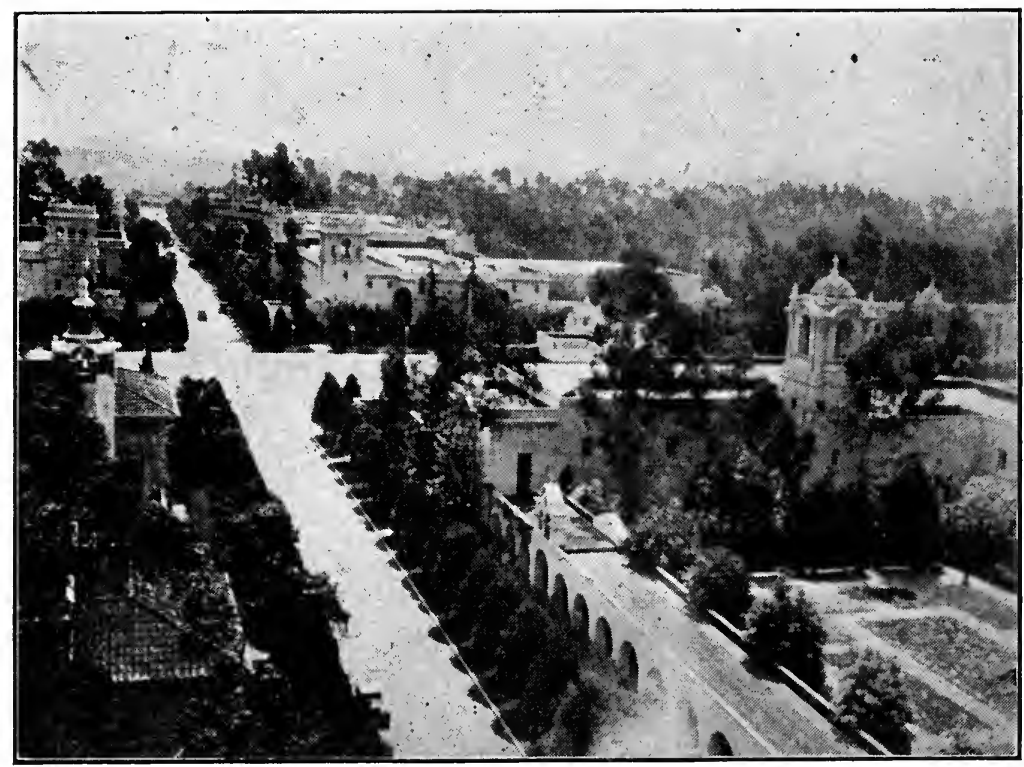

FIG. 45.-Street planting involves not merely the question of tree vigor but form, texture, color, and composition.

without trees between the sidewalk and the curb ought to be alternated with formal stretches of trees introduced between the sidewalk and the property line or inside the property line. For the sake of variety, trees planted in groups of two or three might alternate with individual trees placed with the definite purpose of painting a picture. The important thing is not to establish a monotonous standard of arrangement; there should always be an effort to create a picture the colors, forms, and texture of which are harmonious and beautiful. .

Too little consideration is given to the importance of protecting or introducing trees in the business sections. Even in the smaller 


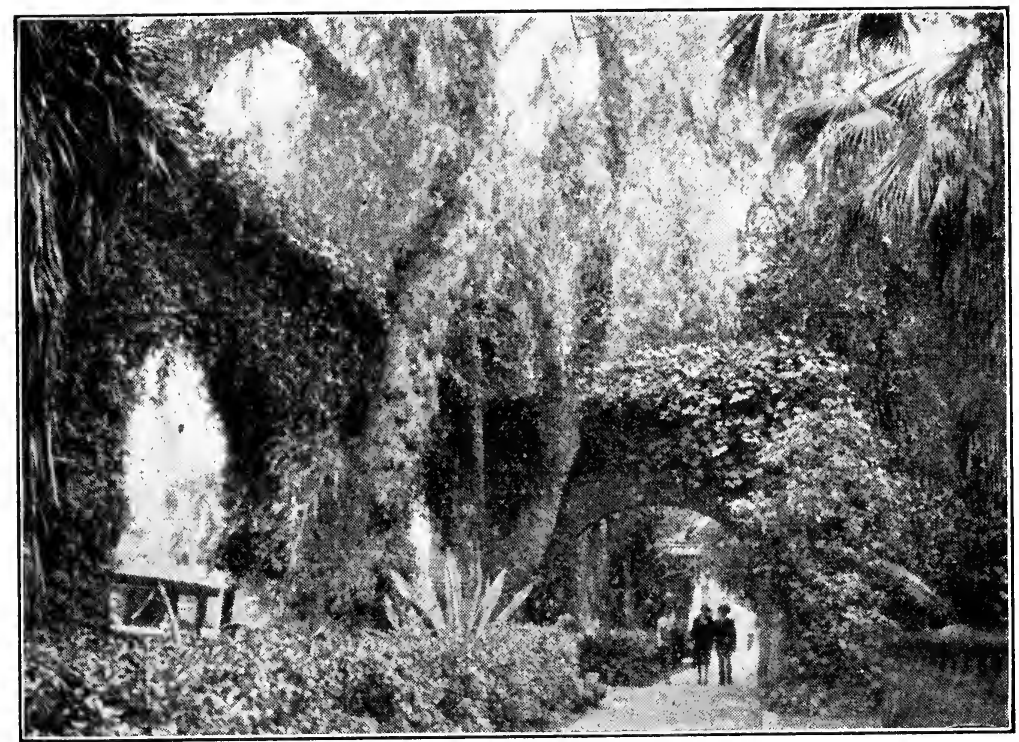

FIG. 46.-Unique sidewalk and street development in front of Mission Inn, Riverside, Calif. Similar effects or others as striking could be duplicated elsewhere throughout the country by exercise of courageous imagination and good taste.

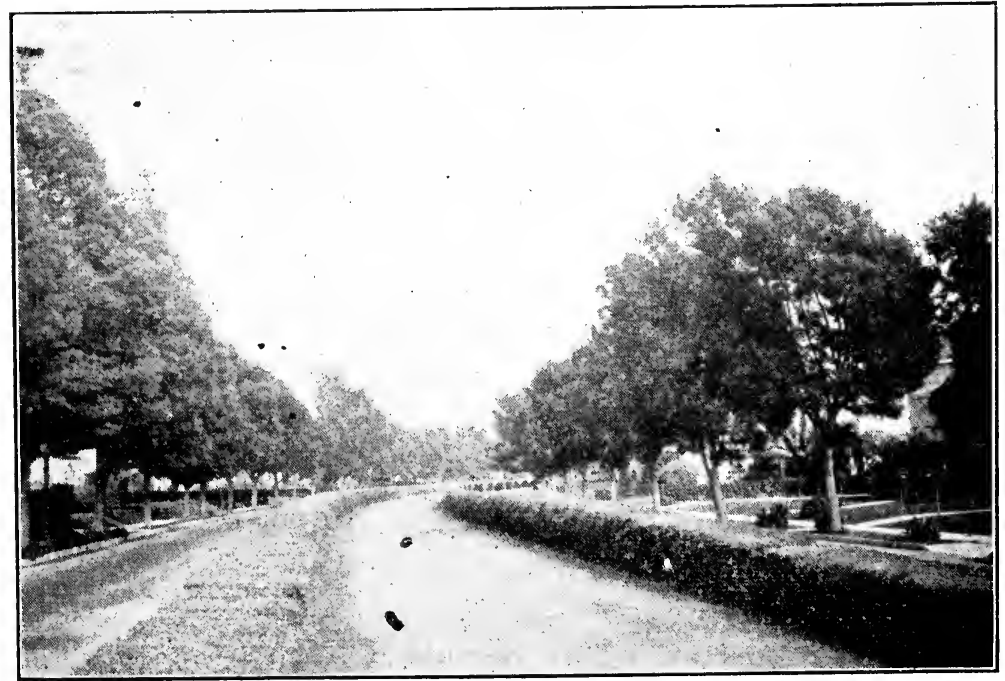

FIG. 47.- No street picture is complete without a right use of vegetation. 
towns fine tree specimens have been removed from the shopping streets with the excuse that they were thought impractical, but much to the disadvantage in both appearance and comfort of the center. In this respect the efforts made to preserve trees in the downtown sections of Washington might well be emulated.

\section{Questions for Discussion}

1. Discuss the principles and character of traffic flow, and as far as possible do so with the aid of diagrams.

2. What focal points must be considered in connection with traffic movement?

3. Discuss types of street patterns.

4. What is the meaning of a "street system"?

5. What is the value of a major street plan?

6. Consider the growing importance of traffic segregation.

7. Describe the "superhighway" of Detroit and present both its advantages and disadvantages.

8. Discuss both broadly and specifically the widths and cross-sections of streets.

9. What is the importance of street widenings today and how are they accomplished; how accomplished to best advantage?

10. Discuss the architectural, landscape architectural, and engineering aspects of street design.

\section{References}

"A.Plan for the Central River Front, Saint Louis, Missouri, 1928," 40 pp:. illus., maps, plans, City Plan Commission, St. Louis, Mo.

Bartholomew, Harland: "Major Streets, Existing and Proposed," Des Moines, Iowa.

- - Major Street Report for New Orleans, City Planning and Zoning Commission.

Hegemann, Werner, and Elbert Peets: Architectural Street Design, "The American Vitruvius," pp. 151-198, The Architectural Book Publishing Co., New York, 1922.

Hubbard and Hubbard: Street Plans and Traffic Relief, "Our Cities Today and Tomorrow," pp. 192-218, Harvard University Press, 1929.

Lewis, Nelson P.: The Street System. Street Traffic. Street Details, "Planning of the American City," pp. 86-129, 200-219, 220-246, John Wiley \& Sons, 1916, 1923.

Mawson, T.: Public Monuments; Street Equipment, "Civic Art," pp. 125-146, London, 1911.

Mulford, F. L.: Trees for Town and City Streets, Farmers' Bulletin 1208, U. S. Department of Agriculture.

Nolen, John, ed.: Local and Minor Streets, by Edward Henry Bouton, "City Planning," pp. 88-102, D. Appleton \& Company, New York and London, 1929. 
"The City Traffic Problem," 40 pp., Chamber of Commerce of the United States, Washington, 1926.

Planning for City Traffic, 264 pp., illus., plans, American Academy of Political and Social Science, Annals, vol. 133, Philadelphia, 1927.

Proposed Super-highway Plan for Greater Detroit, Report of Rapid Transit Commission, 24 pp. with diàgrams, Detroit, April, 1924.

Protecting the City Plan against Adverse Development in Future Streets, Housing Quarterly, pp. 73-78, National Housing Association, March, 1930.

Robinson, C. M.: "City Planning with Special Reference to the Planning of Streets and Lots," G. P. Putnam's Sons, New York and London, 1916.

Annual Survey of City Planning, City Planning, April, 1929.

The Traffic Problem, Proceedings of 17th National Conference on City Planning, pp. 38-107, 124-130, discussions, pp. 108-123, illus., tables, 1925.

"Thoroughfare Plan for Boston," City Planning Board of Boston, 236 pp., illus., 1930.

Triggs, H. I.: The Planning of Streets, "Town Planning, Past, Present, and Possible," pp. 213-270, illus., plans, Methuen \& Co., London, 1909.

Unwin, R.: Of the Arrangement of Main Roads, Their Treatment and Planting; of Site Planning and Residential Roads, "Town Planning in Practice," pp. 235-318, illus., plans, T. F. Unwin, London, 1909, etc.

Whitten, R.: Grade Separation, Report to the Ordinance Committee, Providence, R. I., Providence Traffic and Thoroughfare Plan, pp. 3-37, illus., maps, plans, November, 1926, reviewed in City Planning, January, 1927. 


\section{CHAPTER VII}

\section{TRAFFIC CONTROL}

Not only must the character of streets be determined and planned, but their use must be vigilantly regulated, directed, and controlled. Even well-designed streets subject the traffic over them to confusion, delay, and accidents, if some special understanding and provision for their proper use is not established.

The need for regulation for the attainment of increased capacity and safety for our streets is caused by an increase in all community activity, mass transportation, and pedestrian movements, but more especially by the increasing use of automobiles. Robert Whitten estimates that the 27,000,000 motor cars in the United States today will double in number in the next quarter of a century. Colonel Sidney D. Waldon predicts that within seven decades, which will be during the lifetime of many of our children of today, there will be in this country motor cars to the number of $70,000,000$. These estimates give us much ovêr which to pender, particularly in view of the 500,000 people who are injured and the 30,000 or more who are killed in automobile accidents every year. This, too, is apart from the immense losses in time and money that characterize inadequately regulated traffic. Since the control of traffic and the means for accomplishing its speedy and safe passage over our streets today constitute such a serious problem, let us direct our attention to the twofold problem of some of the considerations affecting traffic at rest and traffic in motion.

Parking.- Notwithstanding the fact that the fundamental purpose of a street is to provide access and egress of movement, necessity and practice have tended to make of it a place of storage for automobiles. So generally has this practice of parking cars along the curb lines of our streets come into vogue that the maximum use of streets in the business sections of our cities has been seriously curtailed. Not only does this promiscuous parking mean serious curtailment of the usefulness of the street, 
but it carries with it hardship and unfairness to the merchants in front of whose stores the automobiles are parked. The parking space in the business streets of St. Louis was found to offer an area for 2,500 cars, which represented a small part of the total registration of 120,000 cars. How much space should be available can be judged from the fact that traffic through department stores as a rule averages fifty times the personnel of the store, while traffic through office buildings averages but seven times the number of occupants of the building.

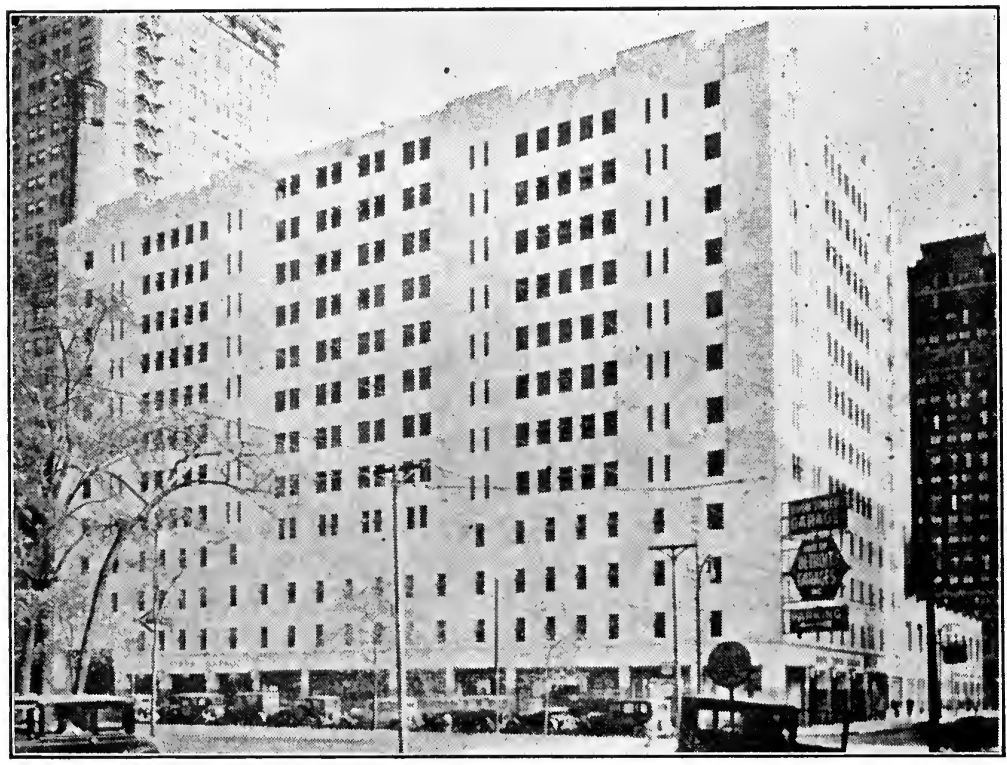

FIG. 48.- One of the many-storied structures for the parking of automobiles being erected in our larger cities. This is the Book Tower 12-story garage, Detroit. Louis Kamper, Inc., Architects. (Photograph by Nyholm.)

The ideal position for the storage for one's automobile during business hours, from the standpoint of the owner, would be in front of the building constituting his destination, but that being more and more out of the question, the nearest approximation to that ideal in another form must be found. Some cities are able to solve by a compromise, which allows for part-time parking, one or two hours at certain periods of the day possibly, or for an indefinite stay after the opening and before the closing hours of abutting stores. Other communities eliminate parking entirely in the most congested business sections. A number of 
substitutes for parking in the old sense are being encouraged. Provision for storage on vacant lots is a familiar expedient. Some buildings are being equipped with garages and with storage space for automobiles in their basements. Even roofs of buildings are being used here and there. One of the most important movements is the construction of buildings with several stories to be devoted entirely to the parking of cars (Fig. 48). Detroit has an 11-story garage with room for more than 1,200 cars. A 25-story garage in New York City is said

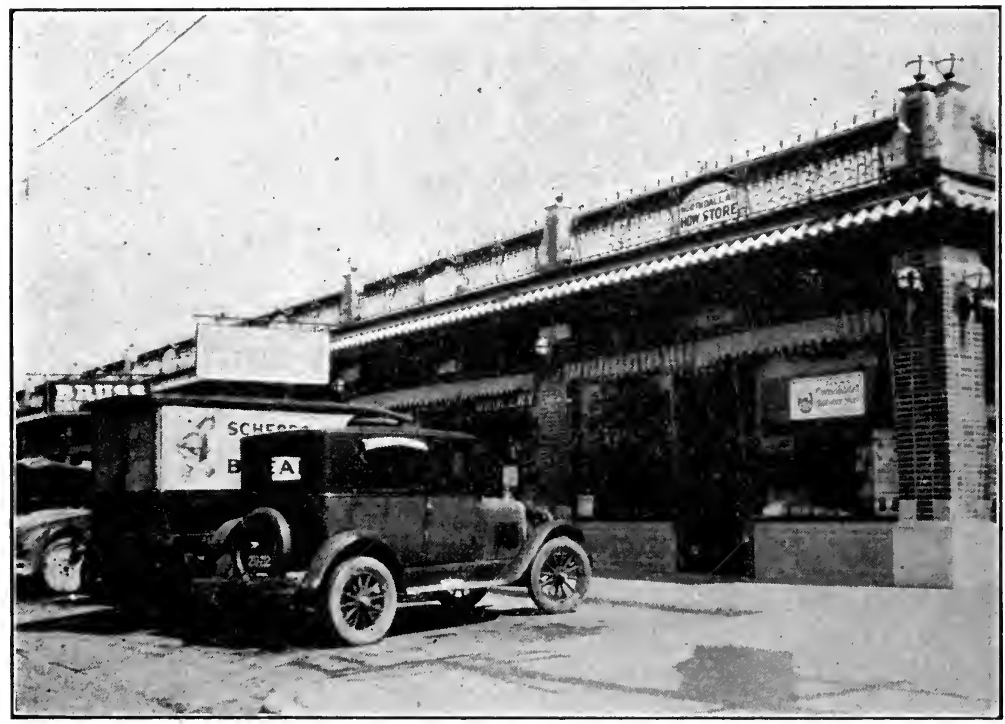

FIG. 49.- "Head-in parking" as provided in Dallas, Tex. So effective is it as a means of promoting the convenience of patrons without interfering with the traffic functions of the street that for local store use it promises rather general recognition among our American cities. (Photograph by the Author.)

to make room for as many automobiles as could be parked in 10 city blocks. The arrangement for a free driver is employed by some of our metropolitan stores. A person caring to patronize a given store is met at the entrance by a liveried chauffeur who, free of charge, takes the car to a parking structure nearby and upon notice brings it back again to the entrance.

The difficulty of parking in the downtown section has given way in some places to parking at points where rapid transit can be utilized into the heart of the city. Free bus service has been inaugurated in some such instances to gather patrons 
from outlying parking centers and conduct them to specified stores. Despite this gratuitous arrangement, the goodwill that is sought is sometimes destroyed in times of delay when patrons are obliged to wait too long for these accommodations. There are some who think that the providing of parking space is a proper public function and that to this end surface and subsurface parking spaces upon public property should be offered free as an important means of meeting the situation. One of the most important efforts at a practical solution for parking in newly developing store centers is that of "head-in parking" (Figs. 49,

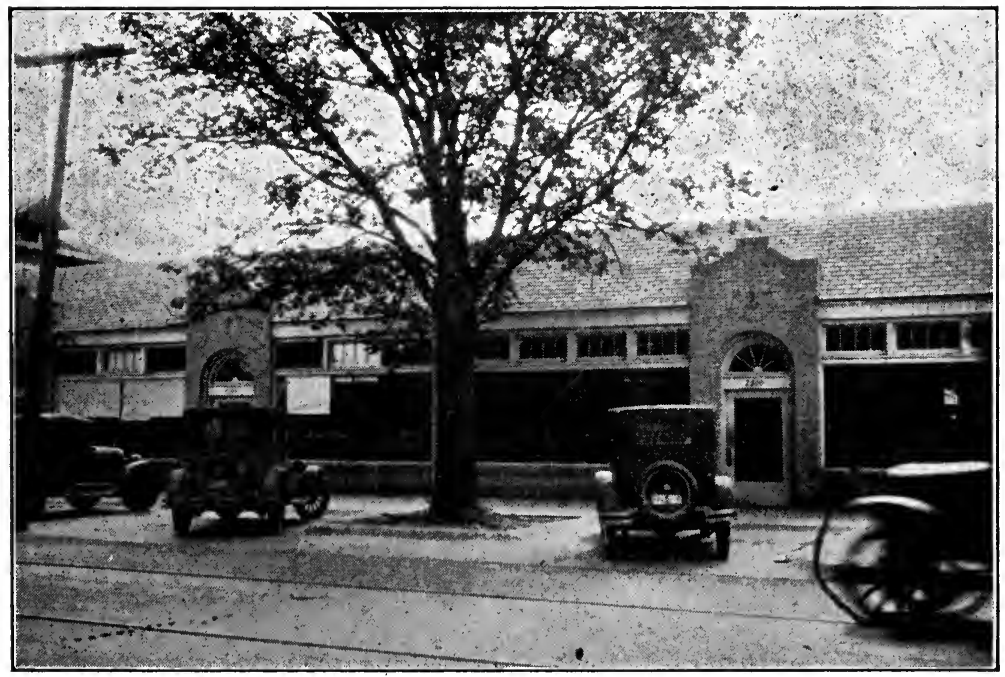

Fig. 50.- "Head-in parking" without removal of trees. (Photograph by the Author.)

50). By this plan the front of the store and the line of the sidewalk are set back to such degree as to allow additional paving space to accommodate a standard length of car-at least 14 feetand in addition to allow for a sidewalk of such width--at least 8 feet-as will allow for the projection of the fenders of a parked automobile. The cost of such parking facilities as these is borne by the abutting-property owner. According to F. A. Wood of Dallas, the practice of head-in parking of this character was inaugurated in his city about 1920 . So completely persuaded are storekeepers that this is an important means of attracting customers that the practice is generally being adopted in that city. 
Strips or open spaces running along the middle of the street are being advocated as appropriate means for alleviating the parking difficulty. Where they are used they eliminate largely the necessity for and unsightliness of parked cars in file along the curb.

Traffic at Intersections.-The attempt of many drivers to occupy the same space at the same time, while their cars are in motion, must give way to a definite system of control or of street rearrangement and particularly at intersections of streets. It is at the intersections that the most confusion and the greatest number of accidents occur. The simplest form of intersection is that of the right angle. When an additional thoroughfare meets such a crossing, the number of possible movements is increased and the capacity of the intersection correspondingly diminished. For such a type of crossing and for others of greater complexity, a central island is sometimes advantageous, in that it invites an orderly circular or gyrating movement around it. For such circles, a diameter of at least 100 feet should be provided, but larger circles up to and even exceeding 360 feet are advisable at complex crossings of streets where there is great and increasing congestion of traffic. Isles of safety should be introduced for pedestrians at intersections, and particularly on such wide streets as contain eight-line roadways. Where loading platforms for street cars are being used, other islands will be unnecessary.

The control of traffic at intersections of superhighways (Fig. 51) and other intensively used ways can be accomplished to advantage by separating the grades. One level may be reached from another by right-hand turns some distance ahead of the changed level. The control of traffic at intersections is accomplished by the aid of policemen, signal lights, and signs. The signs may take the form of painted instructions elevated to catch the eye or of signs upon the pavement. There may also be signs on movable or permanent pedestals for use in boulevard stops and the like.

According to the Committee of the American Enginęering Councils on Street Signs, Signals, and Markings to Regulate Traffic, every traffic sign should be so thoughtfully designed and so carefully placed as to convey its message quickly and clearly at the exact time and place when and where it is needed. These requirements mean simple wording and a standard of shape, color, lettering, and location. 
Signal lights are operated so as to control the movements at a single crossing in a block-movement arrangement, known in practice as the "independent control," or several adjacent intersections may be synchronized with interconnected signals so as to produce simultaneous control over a large area in a multiple block movement. In that case the control is said to be "coordinated." Coordinated control, in turn, may be either simultaneous or progressive. Under the first of these all north and south traffic along streets for some distance is halted while

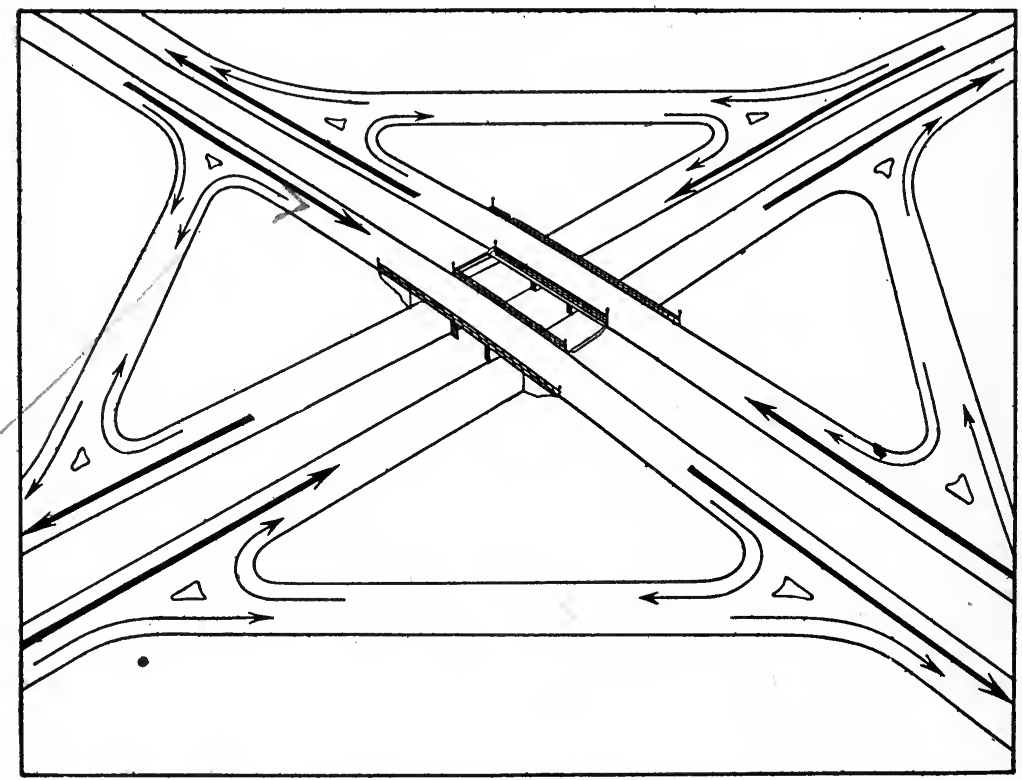

Fig. 51.-Clover-leaf grade separation.

east and west traffic proceeds in ranks. The delay for the waiting ones is succeeded by delay for the others, and so the program is carried on. This multiple block or simultaneous system has found use notably on Fifth Avenue, New York City, North Broad Street, Philadelphia, and Michigan Avenue, Chicago. Under the second form of coordinated control the signals are operated in successive waves so that traffic may follow certain set speeds and may proceed uninterruptedly for considerable distances.

Although signal lights have been practicable for crowded business sections, the same cannot always be said of them at 
intersections of lightly traveled streets. Many drivers are acquainted with the spectacle of a signal light calling for a stop but for traffic that was largely if not entirely imaginary. A newly invented device for such an intersection as this-the "traffic-actuated signal" - will operate upon a kind of self-service plan. With it a driver approaching a street intersection down a side street will be able to throw the signal automatically and give himself the right of way across the main thoroughfare. The signal system is not always desirable from the standpoint of the local street car or bus, that must make frequent stops at crossings regardless of green signals. The inconvenience thus caused can be obviated by establishing stops for buses and street cars midway of the blocks instead of at the corners.

Middle Strips and Islands for Traffic Control.-The achievement of a more effective flow of traffic commensurate with safety to both rider and pedestrian demands the removal of obstacles to free traffic motion and the causes of collision and accident. Some of these obstacles and causes are traceable to the flow of traffic in opposite directions on given streets without any segregation of that traffic; to the interruption and uncertainty of traffic at what are frequently bewildering and precarious intersections. An effective flow must permit of a larger capacity use of the streets than is seen now when short, crowded columns of cars must wait at certain points and move together at certain signals while remaining alternating stretches of streets are comparatively unused. Ideally the movement of traffic should be continuous and self-regulatory.

Head-on collisions and much of the delay that occurs where traffic moves in opposite directions along the same streets may be eliminated. This may be accomplished by introducing strips of one form or another along the middle of streets to separate the traffic flowing in opposite directions. Many persons will recognize this as a practice that has been of long standing in the United States but one that was developed because of esthetic reasons rather than for traffic requirements. On streets that carry reasonably heavy traffic these strips should be wide enough to provide adequate turning radius for the largest cars. More than one such strip may be introduced on a single street of major importance, where it is desired ta separate not only traffic headed in opposite directions but traffic that needs to be differentiated, because it comprises both through and local types. 
The interruption and uncertainty of traffic at intersections may be avoided by establishing indirect instead of direct connections as in the past. Chances for collision at intersections can be eliminated largely if traffic is made to flow in the same direction. This it can be made to do by introducing at intersections circles, ovals, squares, or variations of these around or through which cars must go. No full stops will be necessary at these corners and traffic will be in continuous flow.

For the pedestrian these central strips will be a tremendous help. Not only will they serve as safety isles, but they will enable the pedestrian to know definitely which way traffic is going and so help to eliminate the bewilderment that so frequently is fatal to persons on foot faced with the rush of machines from opposite directions.

\section{Questions for Discussion}

1. Discuss the causes of congestion in city streets.

2. What are the economic effects of street traffic congestion upon the city?

3. How numerous and of what importance are traffic accidents in a city?

4. How may we reduce or eliminate the mutual obstruction of streetcar and automobile traffic?

5. Indicate ways in which streams of traffic moving in opposite directions may be separated effectively.

6. In the interest of full-capacity use of the street, what means of control are there for aligning traffic that is moving in the same direction?

7. How may traffic at complex and irregular street intersections be controlled by proper design?

8. In the interest of safety and street capacity, what can be done with normal street intersections.

9. How can a street be designed to eliminate the necessity for restrictive control?

10. Discuss the problem of parking and both street and off-the-street methods for solving it.

11. Discuss the operation and control of traffic-signal systems.

12. What part may signs and markers play in the control of traffic?

13. How about sidewalk traffic and its need for regulation and special care? Cite various means of giving maximum pedestrian protection.

14. Present a digest of a traffic ordinance in force in one of the larger cities (Chicago, for example).

15. What is the importance of a "traffic count" and how is it undertaken?

\section{References}

Edror, American City: To Park or Not to Park, American City, vol. 35, pp. 461-462, comments, pp. 462-464, October, 1926. 
Goodrich, Ernest P.: Facilitating Traffic Flow at Street and Highway Intersections, American City, pp. 138-140, November, 1930.

MacDonald, Austin Faulks: Planning for City Traffic, Annals of the American Academy of Political and Social Science, September, 1927.

Mackall, K. W.: Operation and Control of Traffic Signal Systems, American City, vol. 35, pp. 703-708, diagrams, November, 1926.

Malcher, F.: Abolishing Street Traffic Intersections without Grade Separation: A Study of Highway Planning and Traffic Control to Meet the Needs of the Motor Age, American City, September and October, 1929.

McClintock, M.: Report and recommendations of the metropolitan street traffic survey, 292 pp., illus., plans, tables, Street Traffic Committee of Chicago Association of Commerce, Chicago, 1926.

: Report on street traffic control of San Francisco, 356 pp., illus., plans, tables, San Francisco Traffic Survey Committee, San Francisco, 1927.

: "Street Traffic Control," Chaps. II, VI, VII, VIII, IX, X, McGrawHill Book Company, Inc., 1925.

-: Preventive and Palliative Measures for Street Traffic Relief, City Planning, pp. 99-105, April, 1930.

: "A Traffic Control Plan for Kansas City," 251 pp., illus., Albert Russell Erskine Bureau, Kansas City Chamber of Commerce, 1930.

Moot, R. D.: Directional Traffic Control: the Experience of Schenectady, New York, City Planning, vol. 4, pp. 214-219, diagrams, July, 1928.

National Conference on Street and Highway Safety, 1st Report, Engineering News-Record, Dec. 25, 1924, U. S. Department of Commerce, 1924; 2d Report, 1926.

Recommendations as to Street Traffic Control Signals, p. 79, American City, December, 1928. 


\section{CHAPTER VIII}

\section{URBAN AND SUBURBAN PASSENGER TRANSPORTATION}

\section{TRANSIT AND RAPID TRANSIT}

The growth of our cities is largely a result of new methods of transportation. A hundred years ago the limits of city boundaries were determined by the distance that people could walk or that the privileged few with horses and carriages could ride. Our cities expanded and the streets were created in advance of that expansion to meet the needs of new as well as of old territories. The incentive for the enlargement of city boundaries was caused by the perfection of speedier forms of locomotion. Unfortunately the fullest possibilities of the speedier methods of locomotion have been offset by poor designs of streets and because the routes of street cars, busses, and other quicker forms of transit were laid down, without complete regard for the convenience and service of the community as a whole. Original routings were largely guided by the presence or promise of considerable patronage or, in other words, by a desire for profits rather than for service. To make matters worse, if that patronage proved attractive to other investors, a competing line might be introduced in the same immediate territory, to the exclusion of the more sparsely populated streets where the need for transportation might be very urgent.

As the development of these transit lines progressed, people were attracted by the convenience of the other streets and began to establish other transit routes to such an extent that the areas near such routes became more fully built upon than others. So intensively did the people begin to reside along or near these particular lines of transit that the new structures to house the increasing population began to pile upward as well as to spread outward. The consequent congestion was felt in a number of ways, but especially as affecting the accommodations of travel, and this in turn more particularly within certain restricted hours of the day, when the means of travel for people within these congested districts were taxed to the uttermost. 
Development of Different Kinds of Transit.-The first impetus to an enlarging circle of the living area within the city came through the horse-car lines of New York in 1832. It was not until 31 years later that another contribution appeared in the form of a rapid-transit steam railroad operated underground in London. Five years after that came the first elevated railroad in New York, and in 1873 the first surface road whose cars were drawn by cable was installed in San Francisco. Most important for enlarging civic boundaries in general was the introduction of the first street car propelled by electricity, in the vicinity of Berlin in 1881. Then followed in 1904 express trains for rapid transit by means of the subway in New York; these express trains by their speed could cover a distance of 18 miles within the period of an hour. Finally in 1906 there appeared the motor bus. The steam or trunk railway has in some cities been providing rapid-transit service for a number of years-although its primary purpose is mostly that of furnishing transportation for freight and passengers between the city and the outside world. Where such transit service interferes with the main purposes of the line, independent passenger lines for this specific function have been provided.

At present the whole question of mass transportation is in a state of flux. The business of street cars which began to decline in 1923 has continued to do so with an increasing ratio. In growing cities the use of automobiles and the cost of extensions to street car lines at the rate of $\$ 180,000$ a mile for double track, have among other things contributed to the problem. However, everyone cannot drive to town in his own automobile and it is possible that this factor combined with new types of street cars, may help to build up patronage and check the serious decline that has been apparent during the past few years.

It is difficult to say what influence the different forms of transit will exert upon the future design of our cities. In the smallest municipalities the individual automobile will doubtless continue as the most important unit of transit. In the cities of from $50,000-75,000$ population it is possible that a large percentage of individual transportation will still be popular, accompanied, however, by some form of mass transportation, perhaps the motor bus. In cities of 200,000 or more, where the use of individual transportation is weakened by traffic jams, mass trans- 
portation in the form of street cars will doubtless be utilized unless in the meantime another more successful carrier is perfected. In cities of $1,000,000$ or more the main reliance will doubtless be upon rapid transit in some such form as an elevated road or a subway.

The Automobile.-Within the last few years the automobile has played a large part in the distribution of the population. Especially is this so for streets leading to and from the heart of the city that have been sufficiently wide and where there has been ample opportunity for the circulation of traffic toward the central sections of the city. Where, however, cities have grown and have in turn over burdened their streets, driving automobiles into the congested sections under such circumstances becomes a time-consuming experience that most people prefer to avoid. Consequently the use of the automobile in larger cities is more and

STREET RAILWAY

"ELEVATED" RAILWAY

STEAI RAILIVAY

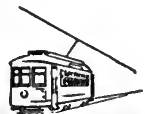

9MILES

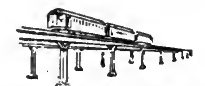

I) MILES

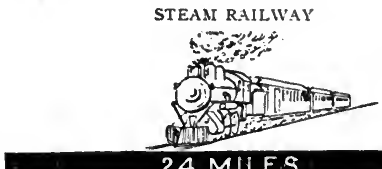

FIG. 52.-Diagram showing average speeds per hour of passenger travel in Chicago. (From "Through Routes for Chicago Steam Railroads," 1914.)

more being confined to the outskirts. Many persons would rather take a little more time on the street car in larger cities and be relieved of much of the strain involved in driving their automobiles through congested areas. Where facilities for rapid transit are available, comparatively few people think of using their automobiles for getting into the city. Recent studies, however, in a number of cities show considerable variation in this respect. In Washington, 55 per cent of the people come to the central business district by automobile; in Kansas City, 33 per cent; in Boston, 25 per cent; in San Francisco, 23 per cent; and in Chicago, 19 per cent.

Just as the limits of a community in earlier days were determined by the distance that people could walk and ride, so today a similar but more extended wall continues to surround the city (Figs. 52, 53). That wall is represented by the 40 -minute riding limit beyond which people are reluctant to go. Where cities have grown to that limit, one finds scatterings of the population gathered into suburban groups outside the city proper. 
Routings.-Few of our street systems are adaptable to the traffic needs of the people. Transit systems, many of them unchanged for a great many years, are far worse. Their routings are inadequate and inconvenient, and improvement can be hoped for only in so far as these systems comply with the needs of the community as a whole. In some form they should reach into the outlying territories as well as to the congested areas of downtown and by proper location, distribution of the lines of traffic, and a sufficiency of cars should provide for direct facilities leading into the heart of the city. Prompt and convenient trans-

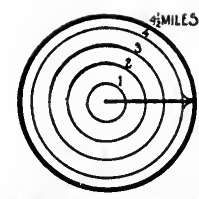

REACH OF $/ 2$ HOUR JOUR. AT STREET RAIL
WAY SPEED.
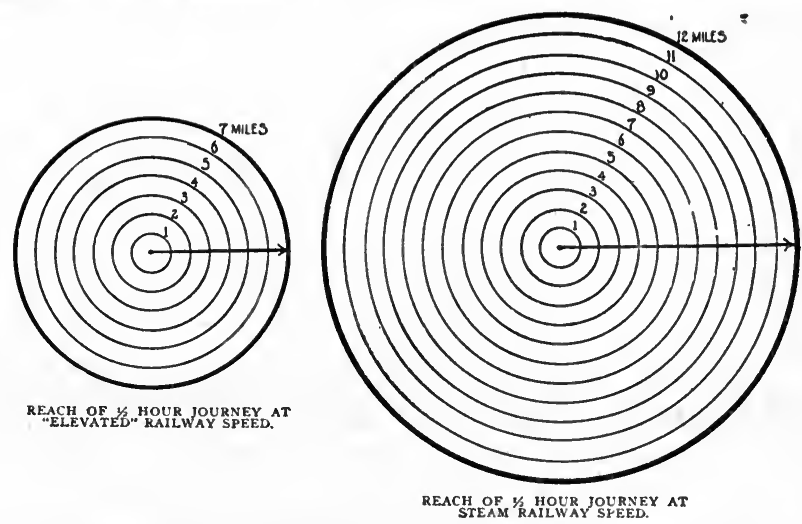

FIg. 53.-The relative reaches of one-half hour journeys by a street railway. an elevated, and a steam railroad. (From "Through Routes for Chicago Steam Railroads," 1914.)

fer privileges and facilities should be provided wherever lines of transport meet.

In the main, the requirements of service for transit systems are the same as those laid down for streets. The lines of traffic in the case of streets were diagrammatically represented by the web of a spider, with diagonal lines radiating from a center and circulatory lines intersecting at ever widening intervals toward the circumference of the web. There is a difference between the lines of streets in general and the radiating lines of transit, in that the radiating lines of transit are established as ever widening $\mathrm{U}$ routes, leading into the heart of the city, with no two overlapping each other but with all of them intersecting the cross-town or circumferential routes (Fig. 54). Although our gridiron streets make this, like other ideal arrangements, difficult of attainment, nevertheless the system of widening U's should serve 
as a guide to the planner and should be approximated by him as nearly as possible.

The practice of terminating car lines in congested districts by means of loops of various sizes and kinds interferes with efficient service. Still worse is the looping of lines across each other. In the rerouting of such lines, all turns, and particularly all left-hand turns, at busy intersections should be eliminated. In place of loops there should be consolidation into through routes that will carry cars across and beyond the congested sections of downtown. Where such consolidation takes, the place of overlapping loops, it serves to reduce street congestion and eliminates turn-

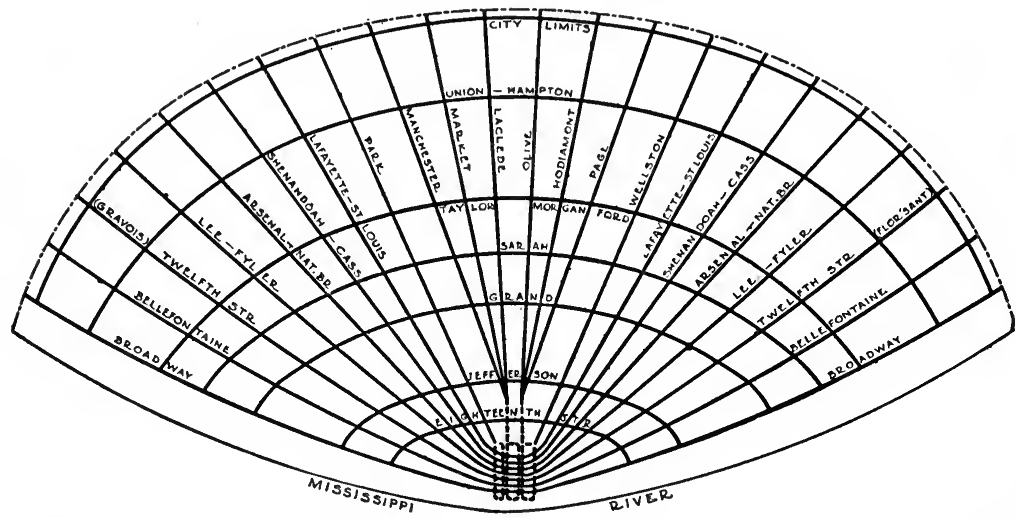

FIg. 54.-Theoretical diagram of proposed transit system for the city of St. Louis as prepared by the City Plan Commission of St. Louis. This shows a series of ever widening $U$ routes leading into the heart of the city with no two overlapping and all connecting with cross-town routes.

ings. Rerouting involves not only rearrangements but in many cases the elimination of certain unnecessary lines. Some degree of duplication of service in the congested district is not objectionable. Alternate streets wherever possible should be reserved free from car lines in the crowded areas, as a means of accelerating vehicular movement.

The Motor Bus.-The motor bus as a means of transit has. gained greatly in public favor since its first appearance in 1906, and its use will doubtless become more general in the future. Buses have many advantages that commend them for increased use. They are fast, quiet, and have unlimited flexibility in routings. In cases of unusual interruptions to the service or other unforeseen emergencies the bus system is readily sus- 
ceptible to quick recovery by diversion of routes. Buses, moreover, afford safety in the alighting and boarding of passengers next to the curb. The greatest merit of the bus is its flexibility of mobility. In the absorption of street space per passenger the bus occupies about three times the space of-street cars and for that reason cannot be expected to supplant street cars altogether especially in the larger cities. The chief use of the bus so far has been in suburban districts where it serves as a collector and distributor of passengers for existing trolley lines. A bus route finds financial justification in any territory where there are at least 250 people to the square mile within a half mile of either side of the bus route. Wherever a route will maintain bus service every 10 minutes there is sufficient patronage to make a trolley system profitable, although some cities of 50,000 population, such as Orlando, Fla., are able to get along without street cars.

Unified Control and Service.-Wherever bus and trolley lines are being used together in the same community, they should be under one general management and should render coordinated instead of competitive service. If their schedules are properly synchronized, buses will meet the street cars without delay and with the privilege of interchange of transfers. Coordination of control and the better service thereby rendered permit the more profitable routes to help support the poorer ones and assure a better service to all parts of the city. The realization of the importance of coordinated control is indicated by the fact that over 200 operating companies use buses as feeders to their streetcar and other rapid transit systems. Another justification for cooperative control is the fact that when there is a duplication of service rendered independently by buses and other transit lines, there is always a greater cost of operating such independent systems, and the burden of that cost inevitably rests upon the riding public.

High-speed Lines.- The combination of increasing volumes of traffic (Fig. 55) and of greater distances to be covered are characteristics of a growing city that call both for enlarged capacity of mass transportation (Fig. 56) and for increased speed. To provide necessary accommodations for the traveling public under such circumstances, fast-moving trolley cars have been successfully operated in some cities upon surface routes, as in the case of Los Angeles. These surface routes are satisfactory until 
the areas through which they pass become so intensively populated as to make any considerable speed impossible. Surface

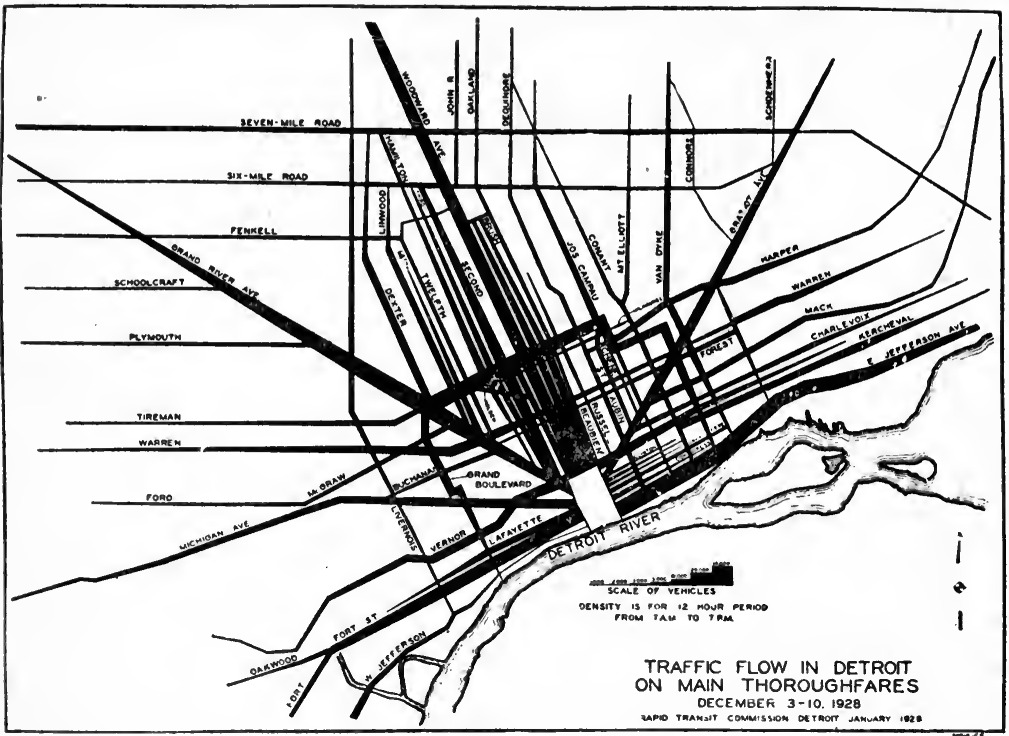

Fig. 55.-Traffic-flow study on main thoroughfares of Detroit. Such a traffic-flow study enables one to tell at a glance the story of relative traffic densities on the important streets of a city. (From April, 1929, Report on Vehicular Traffic by Rapid Transit Commission of Detroit.)

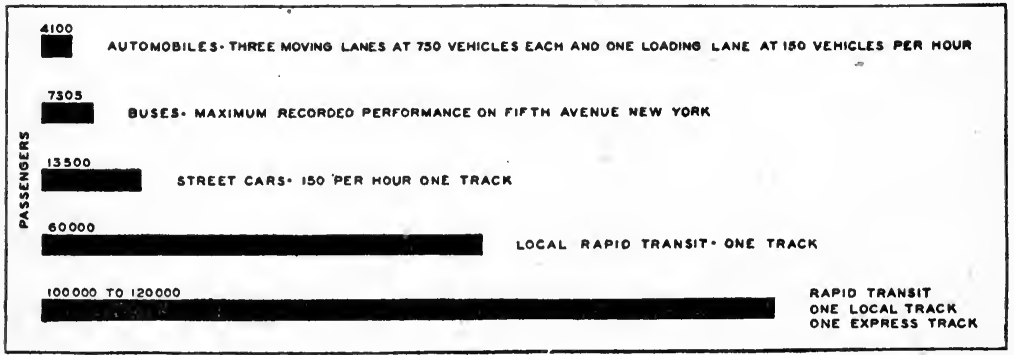

FIG. 56.-The practical capacity in passengers carried in the maximum hour on half of a 100-foot street when used by the various forms of passenger transport. This was calculated from theoretical premises, and checked by records of actual performance. A study of the chart shows the value of mass transportation, especially where streets are inadequate for the accommodation of greatest use of the automobile. (From Report of Rapid Transit Commission of Detroit for 1928.)

speed lines are so dependent upon freedom from interference of congestion and of danger to peclestrians at street crossings that grade separation has to be provided. 
For the attainment of the necessary speed, various kinds of rapid transit have been devised, such as elevated railroads, subways, and open cuts. The elevated railroad, though not so costly as subways or open cuts, is a nuisance, particularly on narrow streets. A solid floor of concrete below the tracks of elevated railroads minimizes the noise but adds to the expense. Open cuts are constructed deep enough to allow thoroughfares to be carried over them and in construction involve less cost than the subway and permit sun, light, and better air to reach the passengers. Tunnels and subways are constructed at great cost; the cost per mile of an underground double-track railroad varies between $3 \frac{1}{2}$ and $51 / 2$ millions of dollars. Such structures have the advantage of protecting passengers and equipment from the weather.

So great is the cost of these subways that few cities in America are equipped with them. New York, Boston, and Philadelphia are in some degree or in some form so equipped. Since facilities for rapid transit are practicable only within cities of at least a million population, several of our metropolitan centers such as Chicago, Detroit, St. Louis, and Los Angeles are now looking forward to the building of subways, and all of them are trying to profit by the experiences of other cities. Boston is an example of a smaller city that was obliged to resort to subways because cf its narrow streets. Delayed negotiations with the streetrailway company of Detroit caused that city to grow without the aid of surface lines and with large dependence upon the private automobile. During the controversy which finally resulted in the acquiring of the Detroit United Railroad by the city, a transit commission appointed by the city made extensive studies of the transit situation throughout the United States. These studies included a tabulation of the trends of population for cities from the 2,000 class up to and including New York City and a study of an ultimate economic unit with a radius of 16 miles.

New York is an interesting example of problems in transit already solved, and yet by virtue of the size of the city and its amazing and continuous growth, new problems in transit are always arising and pressing for solution. In spite of the hundreds of millions of dollars that new subways and elevated railroads have cost New York, she is still faced by a steadily mounting patronage of her present transit facilities and by a corresponding ever increasing congestion of her population downtown. 
The theory is generally accepted that subways are necessary in the intensively congested sections of a large city and that the outlying areas can best be served by providing grade separations at the intersections of streets. The proposals in this connection as adopted by Detroit are especially noteworthy, and particularly the system of superhighways. These superhighways provide for rapid transit along the 62 -foot centers of a great thoroughfare 204 feet wide. Where the superhighway meets other streets, its express roadways and transit lines will be carried across the other streets at a higher elevation.

There is no municipal problem that deserves more attention than transit facilities. Neither is there a better index as to the progress and enterprise of a given people than the status of their street railways, autobuses, or, in the large metropolitan centers, of their elevated, subway, and open-cut facilities. The inadequacies of the transit facilities furnished to cities in the past must give way to new and better facilities which will supply the best possible service to the urban and suburban population. Where lines of transit are owned by several companies with overlapping territories, coordination or single ownership must be enforced. If coordination be not possible under private ownership, then there must be public ownership and operation. The lines of transit must be connecting links between the houses of the people and their places of work and amusement. Lines of transit must be extended into new territories surrounding growing cities and wherever possible should precede the population, so as to encourage the building of homes, to promote home ownership, with its comfort and convenience, and to discourage concentration and congestion of the population in the heart of the city. Transit must be so aligned in the downtown business sections as to eliminate tie-ups, crowding, jamming, and waiting that are too familiar as part of the experience of the rush hour. Finally, there should be a single unit of control or, still better, of ownership, so as to provide for the community at large the cheapest, quickest, safest, most convenient and comfortable means of travel.

\section{Questions for Discussion}

1. How are congestion and accommodation for travel related?

2. Discuss the historical development of transit, i.e., urban and suburban passenger transportation. 
3. How may routings in general comply with the needs of the community as a whole?

4. Explain how far apart and how frequently transit and rapid-transit lines should occur.

5. Where rerouting of lines is required in congested districts, what considerations enter?

6. Discuss the development of the motor bus and its usefulness in serving the city population.

7. Discuss the importance of unified control and service of bus lines and trolley lines.

8. Tell about the development of high-speed lines in America.

\section{References}

AdAms, T.: City Planning as an Aid to Rapid Transit, Electric Railway Journal, vol. 66, pp. 1116-1117, Dec. 26, 1925.

Bibbins, J. R.: Rapid Transit Development and the Modern City Plan, "Planning for City Traffic," pp. 194-199, American Academy of Political and Social Science, 1927.

BסdD, B. I.: Urban and Interurban Buses, Proceedings American Society of Civil Engineers, vol. 53, pp. 813-818, May, 1927.

Damon, G. A.: Better Transit by Coordination, Community Builder, vol. 2, No. 1, pp. 21-26, diagrams, June, 1928.

Electric Railway Journal, pp. 336, 369, 372, 376, Mar. 8, 1924.

HubBard and HubBard: Rapid Transit and Mass Transportation, "Our Cities of Today and Tomorrow," pp. 219-228, Harvard University Press, 1929.

Lewis, N. P.: The Transportation System, "Planning of the Modern City," pp. 54-85, John Wiley \& Sons, Inc., 1916, 1923.

Rapid Transit in American Cities, pp. 244-264. The City of St. Louis, 338 pp. St. Louis Board of Public Service Report, 1926.

Relation of Individual to Collective Transportation, Report of Rapid Transit Commission of Detroit, 47 pp., illus., January, 1928.

Spengler, Edwin H.: "Land Values in New York in Relation to Transit. Facilities," 179 pp., Columbia University Press, 1930.

Street Traffic Economics, Report 104, 165 pp., illus., American Electric Railway Association, New York, September, 1928.

The St. Louis Transit System, Present and Future, Harland Bartholomew, engineer, 36 pp., maps, diagrams, St. Louis City Plan Commission, 1920.

Transportation in the Milwaukee Metropolitan District, Report to Transportation Survey Committee of Milwaukee, 2 vols., pp. 295, 425, 1928.

Turner, D. L.: The Fundamentals of Transit Planning for Citięs, Proceedings 14th National Conference on City Planning, pp. 104-123, 1922. 


\section{CHAPTER IX}

\section{THE RAILROAD IN THE CITY PLAN}

To railroad transportation may be ascribed much of the happiness and prosperity of our communities. Through the aid of passenger and freight service rendered by the railroads, the field of living has been extended beyond local boundaries. Railroads have made possible exchange of commodities and contact with other localities near and far. So great is the part played by the railways in shaping our urban developments that they are frequently the controlling feature of the city plan. It is quite natural that many of our municipalities should have developed around the railroads, with the latter so often constructed in advance of the cities themselves. "It is not surprising, moreover, that difficulty has resulted in the fitting of the city to the railroad. The lines of the American railroad were frequently installed as cheaply as possible with the expectation of a gradual rebuilding, as future necessity might demand. As might be expected, there resulted from this method a needless waste, a duplication of lines, and the creation of many other situations detrimental both to the railroad company and to the public interest.

The railroads came to occupy the central sections of those of our cities that grew up along railroad lines or at railroad junctions. Wherever possible, moreover, the tracks followed the water courses, in order to take advantage of the easier grades thus afforded, and this in turn caused the railroads to enter along the water front those cities that were located upon rivers. The urban communities were glad to give up their water fronts, because these were regarded as features of no value to the citizens. Manufacturing plants, moreover, were also placed upon the water front either for the purpose of using water power or, if the stream were navigable, for the purpose of receiving and shipping freight by water. The value to the community of a well-preserved and beautiful water front in the recreational life of a city was not considered at all. 
Wherever the railroad occurs in a city plan it becomes a subject of continuous modification to fit the growing needs of the community. Any program of modification or expansion of the railroad must be conditioned upon the right of way, either that already in use or another that must be obtained by the exercise of eminent domain or by purchase. There must be recognition of the fact that the needs of both city and railroad are to be met.' The railroad lines must be so arranged that both freight and passenger traffic shall be adequately served. Flexibility of transportation with opportunity to route direct by a railroad line coming into the city must be possible. There must be economy in operation, as well as rapidity in movement, and the elimination of all possible street congestion and danger of accidents at grade crossings. The work of the landscape architect ought to eliminate as far as possible the general unsightliness of the railroad. There must be transportation for a maximum of passengers and tonnage with a minimum consumption of power. As far as the city plan is concerned, the framework of the railroad must be considered in connection with the following general subjects.

Passenger Stations. - The passenger station is one of the most important contributions of the railroad to the city plan. In the smaller cities it serves its purpose easily and without any hindrance to the people's activities. In the larger cities, however, the passenger station becomes a gigantic thing, into and from which are discharged "great steam and electric caravans, sounding taxis and shuffling feet." Such a station usually occupies a downtown site because it must abut upon the railroad. Wholesale and retail stores, hotels, and theaters all cluster around the passenger station. There is in such a position, however, an interference with ready expansion which the occupation of such valuable land enforces, not to mention high rentals and taxes for the railroad company. Increasing demands for space under strictures of limited expansion cause the building of the skyscrapers that adorn or disfigure all of our larger cities. Suburban patronage also. helps to make the downtown section desirable from the standpoint of the railroad, even if grade crossings have to be eliminated, for suburban passengers are nearly all going downtown to work or shop. - Because of the expense, time, and inconvenience involved in a change of train or means of conveyance, passengers prefer to be routed direct to their 
destination. Another thing that holds the passenger stations near the business sections is the possibility of lowering the tracks, electrifying the road, and overtopping the right of way with great structures for offices. The difficulty of the railroad finding yard space in downtown sections has in part been solved by the practice of developing two-story areas. Where a new station is needed, many of the disadvantages of the crowded sections can be temporarily avoided by choosing a site in a less densely populated

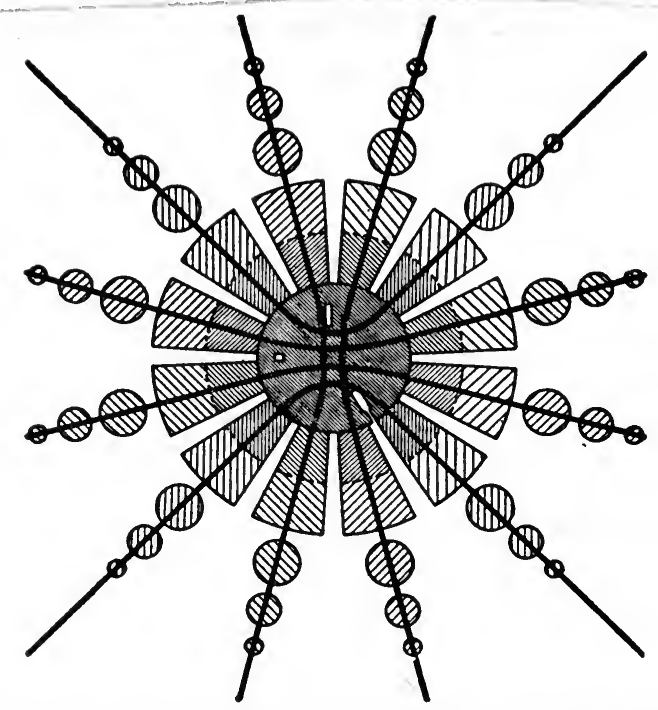

FIG. 57.-Typical plan for high-speed passenger routes of a great city. Heavy lines indicate routes (one or other depressed or elevated through center); shaded wedges and white spaces between represent, respectively, occupied and park areas of the city; outer circles typify suburbs. (From "Through Routes for Chicago Steam Railroads," 1914, Richard Peterson.)

section of the city. Business goes where the people are, however, and unless the drift is regulated, within a few years all of the old congestion will be found-simply to have been transferred to the site of the new station.

The yards of the passenger station as compared with those for the freight station are quite simple. Passenger trains are run out to the yard, there to be broken up, made into new trains, and brought back again to the passenger station for departure.

Passenger lines may lead into the central sections of the city, provided that they are not permitted to come into those central sections on grade (Fig. 57). 
Stations may be of the "through" variety past which trains may go to points beyond. They may also be of the sort in or near which the tracks may dead-end or terminate. Types of stations may differ also as to their relative levels of tracks and streets and may be single, double, or even multilevel in character.

The Union Passenger Station. - The need for a union station is obvious. It facilitates the necessary interchange of passengers among the different railroads entering the city. The demand for the elimination of grade crossings upon a number of railroads serving a city shows one advantage of a union station, because all of the railroads using it could enter it by one system of trackage laid either above or below the general level of the streets. Economy could also be effected by thus concentrating all of the railroad traffic over a single right of way and by providing for the several railroads common freight yards and common yards for the making up of passenger trains.

A new union station offers the architects designing it an opportunity to create a suitable and impressive gateway to the city, one that will make a favorable impression upon people first visiting that city. Objections are frequently made to union stations by men owning and managing railroads. In fact, such men will consent to build a union station "only under pressure of economic necessity." Such objections are apt to be heard wherever railroad lines entering a city are competitive, and particularly if their present individual facilities are adequate and efficiently operated.

The objections to the union station may be summarized as follows: complicated joint agreements, high first cost with no returns on investment, abandonment of railroad property without compensation, possible favoritism of ticket sellers and other employees, and inability for each railroad to expand independently. Whether or not the union passenger station is desirable or justified can be determined only by a careful analysis of the problem. According to the late William D. Hudson, where growth is reasonably stabilized, in cities up to 200,000 population, a union station is desirable from a public standpoint alone. For cities above 200,000 population and up to 500,000 there must be an earnest weighing of the possible effect such a station will exert upon street traffic and of what possibilities there are for new railroads and for a shifting of business. There is a feeling among city planners that for eities of 500,000 or more 
the union station is of questionable value both to the railroad and to the public, except in cases where the city marks the termination of a large number of railroad lines. There are 20 union stations in the United States. From the standpoint of architecture and size, the most outstanding are today the Union Station at Washington (Fig. 142), the Pennsylvania and Grand Central Terminal stations in New York, and the New York Central Station in Buffalo. Other great stations are being completed in Cincinnati, Omaha, and Cleveland.

The largest railway-terminal improvement underway in accordance with the comprehensive plan of the city is the development at Cincinnati. $\$ 55,000,000$ are being expended upon the various railroad developments involved. The Union Station development in Chicago, wherein adjustments to an.orderly arrangement involved expenditures of $\$ 100,000,000$, represents one of the most spectacular achievements in the country.

Freight.-The great bulk of a railroad's business is not carrying passengers but freight. In great volume and with infinite variety of commodity, freight traverses the country and must be carried to its destination as rapidly as possible so as not to suffer deterioration in transit. So important to the life, health, and comfort of our communities is the carriage and delivery of freight that the matter of facilities for passengers is dwarfed by comparison. The two main types of movement for freight are through and local. The largest percentage of the business in many cities is represented by through freight (in St. Louis 85 per cent), that is, freight in carload lots, routed from distant points to a given city but not for local delivery. Except for any necessary shifting from one road to another such freight continues through. Obviously, such carloads of freight bound for points beyond the city should not be carried at grade along or across the streets; such cars should be conveyed over belt lines constructed outside the city. All storage yards and yards for the classification of freight serving this class of traffic should be located along such outer belt lines.

There are two ways in which local freight is shipped. The first of these is by carload lots for local delivery. Wherever there are many industries and many railroads, as in our larger cities, in order to take care of this type of freight, there must be facilities for interchange and freight yards in which the sorting and arranging of the cars can be accomplished. While it is possible 
either to deliver their carload freight to the industries and manufacturies direct or to send it on its way from these points, as the case may be, the sorting and arranging of cars is a slow process, sometimes involving several days before the shipment is on its way. Belt lines passing through the industrial and manufacturing districts, or serving spurs that lead to such districts, speed up the movement of this class of freight. The other way by which local freight is shipped is in less than carload lots (LCL.) In this manner the smallest part of the freight business is conducted, but it is the most profitable although the most complicated to handle. It involves light car loading, slow movement, expensive handling, and a vast amount of machinery for the results accomplished.

There are two general theoretical arrangements for tracks serving freight of various kinds to a city. One of these is a series of tracks laid in concentric circles around the city, the inner ones to be used for local interchange of lighter freight and the outer ones for freight of the bulkier types. The inner tracks can be abandoned as municipal growth requires. As the size of the city warrants, a series of underground tunnels can be provided connecting the plants of individual shippers directly with the concentric circular tracks. The other arrangement provides for a belt system with spurs extending into the sections of the city that require it. Through freight is detoured around the city along the outer belts.

Freight Houses.-One of the most important things for the handling of freight is the freight house. In a small community a single freight station is all that is necessary. In the larger cities, however, a number of freight stations are necessary. If, when they are numerous, they are poorly located, they contribute seriously to the length of time that will be consumed in cartage of the freight from the freight station to the consignee. If the freight house be situated downtown, it has the advantage of proximity to the business sections but the usual disadvantage of occupying exceedingly valuable land, of lying in the way of street crossings, and of being subject to the intense congestion found in the downtown sections of the city. It would be better to have several union freight houses located at convenient points upon an inner belt line or to have a central freight house in which the freight could be sorted for delivery and then conducted by trucks to other freight stations situated in various parts of the city. 
Railroad Yards.-Both before freight trains are sent on their way and after they are received, they are subject to a certain amount of rearrangement, accomplished in areas known as "freight yards." The purpose of these freight yards is to keep the cars in motion, in the direction of their destination-storage becoming only "an incident and delay, an evil." Trains are broken up, made up, and then sent on their way to points beyond, and cars are sorted and classified. There are yards for receiving trains, yards for breaking up and separating them, and yards for classification. These yards for classification are most important, as in them cars are grouped, sorted, classified according to destination, route, commodity, and requirements of traffic, carriers of like commodities being placed together in separate trains or in parts of the same train.

These classification yards are long areas, preferably uninterrupted by grade crossings and located "at one side of or on the outskirts of the city, away from the probable expansion of business and main street traffic lines." They are usually located at the intersection of several tracks leading to different terminals. There are also storage yards and departure yards. In the latter the activities of the transfer engines and crews begin. Engine yards provide facilities necessary to the "maintenance, care and storage of locomotives and provide them with all needed supplies."

Within the freight yards all of the tracks are laid in parallels but are connected at both ends, while placed on the outskirts of the yards so as to avoid danger are team tracks or short stub sidings, arranged in pairs to permit unloading of the contents of the cars into wagons and trucks. No connection is made between tracks in the freight yards and the main-line tracks except at each end of the yard. The main-line tracks are located on the outside of these yards.

Relation of Railroads to Street Systems.-The arrangement of the right of way of the railroad and the plan of the city's streets should be made to fit each other. To make the streets adapt themselves more suitably to the railroads there should be certain ways of ample width leading directly from the heart of the city to the principal passenger and freight stations. Railroad terminals, docks, and industrial zones should be provided with substantial, wide pavements to withstand the impact of heavy 
hauling. Also there should be adequate space for all necessary traffic in the vicinity of the stations.

On the other hand, to make the railroads adapt themselves to the streets means that no railroad tracks shall ever be laid in the bed of a street and that all grade crossings shall be eliminated. In Europe one rarely sees railroad crossings at grade in urban districts. About 12 years ago the Pennsylvania Railroad alone had on its 11,000 miles of road 13,027 grade crossings, despite the fact that they had already eliminated 1,052 such crossings at a cost of over $\$ 66,000,000$. It costs on an average $\$ 50,000$ to remove one grade crossing, so that their elimination will have to be accomplished through a period of years and at tremendous expense. There are two methods commonly used for eliminating grade crossings - one by carrying the street by a bridge over the railroad and the other by carrying the railroad by a bridge over the street. The most expensive method is to carry the street over the railroad because of the clearance of 22 feet required $b r$ the railroad, together with an additional 4 feet, which represents the necessary thickness of the bridge. When a railroad is carried across a street there is, of course, the same or greater thickness or bridge, but there needs to be only 15 feet clearance over the street, or 14 feet in all cases in which no doubled-decked buse are to be used on the street. Where there are sidewalks only under the railroad, a clearance of 8 feet is all that is necessary" for them.

Where the surrounding territory is built up, the changes of the street level caused by these eliminations of grade crossings damage the adjacent properties. For the railroad any change in level is serious, particularly where there are adjacent yards on stations. The depression below the general level of either a railroad or a highway also causes difficulties in the matter of sewer, water, and other utility lines. The lowering of the railroad or street may require the lowering of the utility lines or even their complete removal to an altogether new location at heavy expense and inconvenience. For a built-up section of the city the depression of the railroad tracks so as to leave the street. levels undisturbed is the best solution of the problem. Whether tracks are raised or lowered, it is important to bear in mind the fact that they tend to act as a barrier or wall that separates the districts through which they lead. 
For eliminating grade crossings in any particular instance there should be prepared a comprehensive program providing for the gradual completion of the work. Certain streets may have to be relocated and new streets planned to accommodate the necessary traffic in that part of the city through which the depressed railroad tracks are laid. While the work of elimination is in progress, as long as any grade crossings must remain, signal lights should be installed and everything that would interfere with good visibility should be removed.

The city of Dayton is conspicuous for the part it is playing in the separation of its grades. It has authorized a bond issue of $\$ 8,000,000$ (in 1926) for this purpose. The entire project, which is in accordance with recommendations of the city planning commission, will involve a cost of $\$ 25,000,000$. In Pittsburgh all of the important grade crossings and in Harrisburg, Pa., all of the 15 crossings on main-line tracks have been eliminated.

Relation of Railroads to Water-front Terminals.-Convenience and economy require that steamship lines and railroads should be made to cooperate. Each railroad line should reach to every terminal on the water front, and this it can do by using beltline tracks owned jointly by all the railroads serving that port. The street serving the terminals on the water front should be set back far enough (possibly 200 feet) to allow sufficient space for the belt-line railroad to reach all of the piers. This street facing the water front should be at least 100 feet in width. Only enough trackage along the water front should be provided to serve the terminals; the railroad yards should never be placed near the terminals on the water front.

The best example of correlation between railroad and steamship is the Bush Terminal in South Brooklyn on the New York Harbor. The Bush Terminal has connection by rail with all of the trunk lines of railroad entering New York City.

Relation of Railroads to Vicinities Served.-It is to the benefit both of railroad and industry that they be in close proximity to each other. Delivery of materials to and from cars without cartage is a great advantage, and to attain that end factories and buildings for wholesale merchandizing are established adjacent to railroad yards and tracks. Heavy industry is usually segregated and is provided with an independent system of railroad tracks and switches. Farther away from the railroad than are the industrial plants, factories, and wholesale houses 
are places for conducting the various kinds of retail business, the shops, and the markets; here also are the banks, and the buildings providing offices for professional people. Most remote of all from the railroads are the residence sections of the city.

Consolidation of Lines. - No one can fail to see the disadvantages of the present wasteful and needless duplication of railroad lines, nor, on the other hand, can one fail to appreciate the hardship to which the local shipper within a city is subjected by making him dependent upon one railroad when other railroads are vainly trying to enter his city with their competing lines. It is also patent that "all spurs and industrial tracks within the city should be 'common user' tracks, served by a belt line connected with all main lines entering the city."

Such common ownership by the different railroads of the belt line gives a maximum of flexibility in the movement of freight cars that could otherwise be obtained only by municipal ownership. Common ownership of the belt line, by all of the railroads serving the city, insures a unified control over the distribution of local freight.

Planting and Improving.-Our first impression upon approaching most cities is made by their industrial plants. This impression would be more favorable if the rights of way of the railroads entering these cities were of sufficient width to provide for the planting of trees and shrubbery that would act as a shield against the stark and sordid landscape beyond. Not only can the borders of the rights of way be made more agreeable to the eye by the removal of many unsightly billboards and by the planting along their borders of trees, shrubs and flowers, but also the railway yards, bridges, viaducts, stations, and terminals can by the same means be made more pleasing in appearance. Indeed, the opportunity for landscape architecture at railroad stations is full of possibilities. The setting for the station and its adjacent buildings can be made a source of pride to the community and a means of refreshment and rest to persons who are waiting for trains. We must not overlook the fact, however, that under certain circumstances proposed planting may be difficult and even impracticable, either because of the expense or because of the difficulty of keeping planting materials alive.

The matter of attractiveness along the railroad rights of way is importantly tied up with the problem of electrification. Cleanliness and better air will be more effectively assured as our rail- 
roads more and more decide to electrify their systems. Living conditions in the vicinity of railroads that have been electrified will be made much more favorable. Because of the faster transit made possible by electrification, people will be able to live farther out from the city. The importance and value of such an improvement may be appreciated along the stretch of road that has been electrically equipped between New Haven and the Grand Central Terminal in New York City, on the New York, New Haven and Hartford Railroad. Other lines are favoring electrification and have started to introduce it. These include the Pennsylvania Railroad (between New York and Wilmington), the Illinois Central (in Chicago), and the Erie Railroad (in Rochester, N. Y.).

\section{Questions for Discussion}

1. In the location of railroad lines what general aims relating to the welfare of both city and railroad should govern?

2. Discuss relative advantages of different sites for railroad stations.

3. What are advantages and disadvantages of union passenger stations?

4. Tell about the main types of freight movements and accommodations required to handle them.

5. What theoretical arrangement of tracks is desirable for handling of freight of various kinds?

6. Explain the purpose and character of railroad yards.

7. Discuss locations of freight houses and terminals.

8. Discuss the relation of railroads to street systems.

9. Discuss the relation of railroads to water-front terminals.

10. What about the importance of consolidation of the lines for effective usefulness.

11. Discuss beautification of railroad stations and railroad rights of way;

\section{References}

Andrews, H. L.: Electricity in Rail Transportation, Engineers and Engineering, vol. 45, pp. 27-36, illus., February, 1928.

Bartholomew, Harland: The Place of the Railroad in the City Plan, Proceedings of 18th National Conference on City Planning, pp. 115$129,1926$.

Droege, J. A.: Freight Terminals and Trains, 2 d ed., 567 pp., illus., etc., McGraw-Hill Book Company, Inc., New York, 1925.

Faries, D.: Grade Crossing Elimination, Proceedings 16th National Conference on City Planning, pp. 97-104, 1924.

Hedden, W. P.: How Great Cities Are Fed, 302 pp., D. C. Heath \& Company, 1929.

Lewis, N. P.: Railroads, "Planning of the Modern City," pp. 247-259, John Wiley \& Sons, Inc., New York, 1916, 1923. 
MacElwee, R. S.: Ports and Terminal Facilities, 2d ed., 446 pp., illus., plans, McGraw-Hill Book Company, Inc., New York, 1926.

Nolen, John, ed.: Railroads, by George R. Wadsworth; Navigable waters, by E. P. Goodrich, "City Planning," pp. 264-277, 227-261, D. Appleton \& Company, New York, 1929.

Pray, J. S.: Railroad Grounds, Parks and Recreation, vol. 4, pp. 332-338; vol. 5, pp. 68-74, 156-164, illus., plans, July-December, 1921.

Railways, "Encyclopedia Britannica," vol. 18, pp. 916-952, 1929.

Sudborough, C. B.: The Terminal's Place in Transportation, Port and Terminal, pp. 11-15, July, 1930.

Transactions of the American Society of Civil Engineers. Several papers on railroads and terminals, pp. 731-863, 1924.

Transit and Transportation, Regional Survey of New York and Its Environs, vol. IV, 218 pp., illus., 1928.

Tratman, E. E. R.: Unification of Railway Passenger Terminals. Comparative Merits of One Station and Several Stations, Engineering News-Record, vol. 98, pp. 306-308, table, diagrams, Feb. 24, 1927.

U. S. Engineer Department Board of Engineers for Rivers and Harbors, port series, airplane views, maps, plans, charts, Government Printing Office, 1921, to date.

Wrlgus, W. J.: Relation of Railroad Terminal to City Plan, Railway Age, p. 1285, Apr. 30, 1920. 


\section{CHAPTER $\mathrm{X}$}

\section{SEA, LAKE, AND RIVER PORTS}

The commercial life of maritime cities is dependent upon the water-borne commerce that comes or goes through their ports. Cities located upon navigable waters should be certain to take into account the largest possibilities of the development of their harbors. At their ports, carriers of freight and passengers by land meet like carriers coming into the harbor by water. The advantages of an economical and unrestricted interchange of cargo and passengers between common carriers by land and by water should be clearly realized. Here as elsewhere movement is the life of transport and where that movement is obstructed, the port is wanting in effectiveness. The necessary facilities to be offered by the port must therefore be planned with the view of expediting the transfer of the various cargos in the most speedy and economical manner. As in the case of other elements of the city plan, ports must be so designed as not only to facilitate their purposes, but to anticipate their various needs for the future, so as to avoid costly corrective efforts in the years to come.

Our American ports in general show few signs of having been designed deliberately or of having been developed according to predetermined plans. For that reason many of them are deficient in their ability to handle diverse cargos with a minimum effort and are conspicuously wanting in coordination of their various elements. They present in this respect an unfavorable contrast with many of the harbors in Europe that exhibit results of comprehensive planning and building. Hamburg, among others, with its many piers, its basins and channels dredged out of the lowlands, and its unlimited docking facilities stands out conspicuously among the good ports of Europe. Other splendidly managed and well-built world ports in Europe include Antwerp, Rotterdam, Amsterdam, and Bremen.

American Ports.-America has its outstanding ports, however, many of them having been subjected to considerable replanning. First in America, and in some respects first in the world, is the 
port of New York, which has a shore line of almost 800 miles. Manhattan Island, its center, is bounded by an almost continuous series of wharves that project into two great rivers. These rivers join and spread out into a broad bay, that in turn is bounded by miles of wharves and dotted by a bewildering variety of craft. "There are in New York harbor 115 square miles of deep water in which vessels may lie in perfect security." Broad streets choked with traffic border the Manhattan side of the river. Although its natural advantages are unrivaled, the port of New York is faced with the immediate necessity of providing better facilities of unification and cheaper and more efficient methods for the transportation of cargoes across the harbor. With a realization of these and other weaknesses, the Port of New York Authority in 1921 submitted its plans for improvement, these were approved by the states of New York and New Jersey as well as by the federal government, and the authority given to proceed with the carrying out of these plans. The principal improvements consisted of inner, middle, and outer belt lines. In addition to these, the plans called for an underground automatic electric system for standard freight equipment to serve Manhattan Island and to connect with other points in the region. The plans also included a system of universal inland freight terminals for the Borough of Manhattan. These among the various other large port improvements that are either contemplated or underway will help to link existing units in the port development and to make possible the very much needed cheap and rapid intercommunication between all parts of New York harbor.

New Orleans has come to be known as the most important fresh-water port in the United States and holds second place among the harbors of America. New Orleans stands at the gateway to the Mississippi River, 110 miles inland, and is the focus of several railroad systems. Along the river, which here varies from $1 / 2$ to $3 / 4$ mile in width, is a succession of modern facilities. for handling freight and passengers. About 7 miles of river front is equipped with publicly owned wharves, steel sheds, cotton warehouses, and other modern facilities. The docks at $\mathrm{New}$ Orleans are served with systems of waterways, railroads, and public belt lines, and 90 to 100 steamship lines operate from these terminals. One of the large warehouses can load or unload five vessels at a time. A navigable canal that cuts through one por- 
tion of the city for a distance of $5 \frac{1}{2}$ miles and connects Lake Pontchartrain with the Mississippi forms an inner harbor, which seems to hold unlimited possibilities for development.

San Francisco enjoys great natural advantages for harbor development, as its harbor is convenient to the sea and is both landlocked and spacious (Fig. 58). The entire water front at San Francisco is owned and controlled by the state. A great

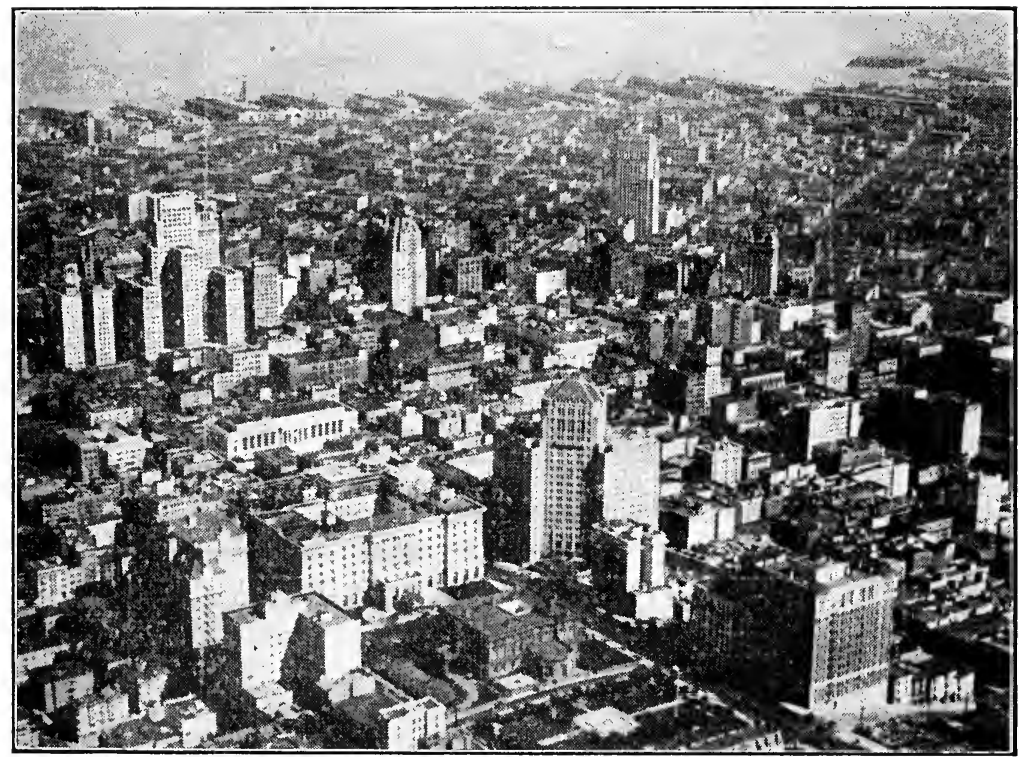

FIg. 58.-Air view of San Francisco. This outlook across a portion of San Francisco shows hotels in the foreground that occupy an eminence 300 feet above the business district just beyond them. The improvement of the commercial water front in the background on the northerly side was started in 1881 with a sea wall on the edge of marshes for about 3 miles. It is paralleled by a 200-foot street, the Embarcadero, with a belt-line railway. (Aerograph Company, Photographer.)

sea wall 20,000 feet long parallels the water front and from it the many piers project into the harbor at right angles. The water front is also paralleled by a 200 -foot street and a terminal belt line that serves all of the piers. Present indications are that if the plans for the San Francisco port are pushed to completion the port will become one of the largest and best equipped in the world.

The port of Los Angeles has had to be created practically without assistance from nature. As in the case of Athens, which 


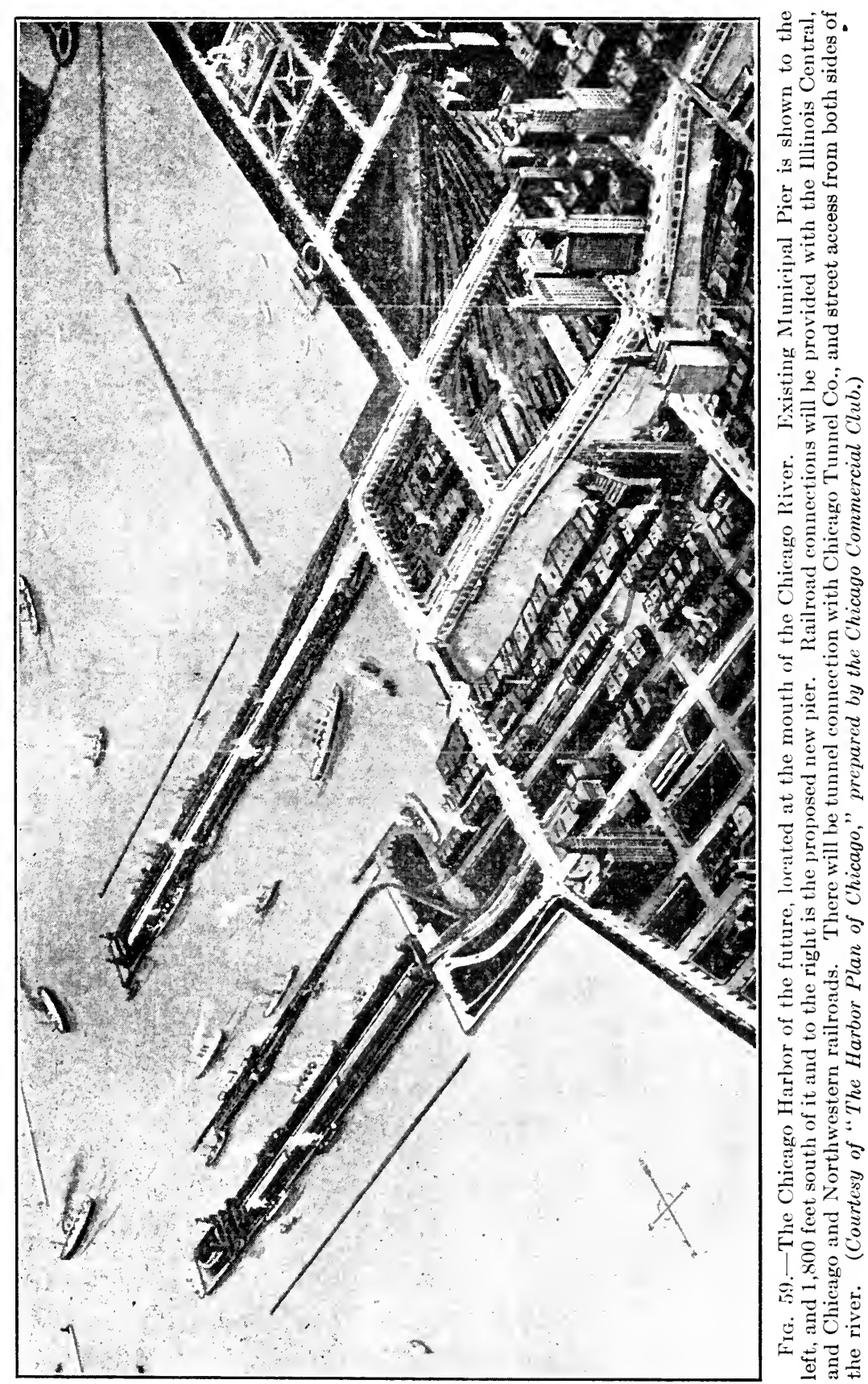


was connected with Piræus and the sea by a peninsula 3 miles in length, Los Angeles has secured a strip of land 1/4 mile wide and 22 miles long to establish her connection with the sea. Through the aid of a breakwater 11,000 feet long, an outer harbor has been created that shelters a frontage of 5 miles. The development includes a turning basin 1,600 feet in diameter and an elaborate equipment of docks and warehouses.

The harbor facilities and equipment of Seattle have no equal in America. The city is located upon a strip of land 2 to 6 miles wide with Puget Sound on one side and Lake Washington on the other, both excellent harbors. These bodies of water have been connected by a deep-water canal. A lake connected with Lake Washington is now being transformed into an important terminal.

Although the Chicago harbor is wholly artificial, it is being developed with the expectation of becoming the greatest inland port in the world. At present there are seven public and two private harbors in the Chicago Region on Lake Michigan, with 1,600 acres of sheltered water area on the lake and about 80 miles of improved interior waterways. There are in all about 72 miles of improved water front of which 40 miles are now in use. As the port authorities of Chicago look forward to the future development of their port (Fig. 59), they are keeping before them the possible completion of the Lakes to the Gulf waterway and ultimately to the St. Lawrence waterway. Comprehensive plans already prepared and adopted involve the entire region in their scope and the expenditure of enormous sums of money. The most striking of the proposals is that of another great municipal pier for ocean freight on the south side of the Chicago River and in the vicinity of and parallel to the present municipal pier. To serve an immediate need, it is proposed to construct a terminus for the waterway already nearly completed which is to connect the Mississippi River system with the Great Lakes. This barge terminal and warehouse will be located on this waterway 8 miles southwest of downtown Chicago. Proposals also call for the development of the Lake Calumet Industrial Barge Harbor to serve ships carrying heavy bulk materials and for a complete industrial and commercial harbor south of the mouth of the Calumet River to be known as the Interstate or State Line Harbor. Transhipment between vessels and railroads would largely be carried on here, new grain elevators would be built, 
and other developments would occur. There is reason to believe that this latter harbor may become the principal industrial harbor of Chicago.

Waterways and Wharves. - The character of a port is first of all dependent upon the nature of the waterway that it terminates. Upon whether or not this channel of communication is wide or narrow, deep or shallow, swift or still will depend the character of some of the most important features constituting the port. The wider waterways include the ocean, the large lakes, and the broad rivers, while the narrower ways comprise the gulfs and bays opening into the ocean, narrow rivers, canals, and canalized rivers.

Some of these bodies of water are subject to fluctuations in level, some to fluctuations in the velocity of current. Some harbors have characteristics that must not be disturbed, such as the tidal prism (the total amount of water that flows into a harbor and leaves it again with the movement of the tide). This tidal flow must not be diminished, because it is relied upon to scour and maintain at normal depth the channels in the harbors and those at the entrances to the harbors.

The natural characteristics of the harbor determine the type of structures and wharves on the water front. The wharves must fit the varying conditions of the water. The structures for loading or unloading vessels may be marginal wharves (quays or bulkheads), a type which is necessary in the case of narrow rivers or of those where the velocity of the current is excessive. The structure on the water front may be a pier, a right-angled projection into the waterway; or fairway. Between adjacent projecting piers will be open spaces of water called "slips" or "docks." The advantage of the pier-and-slip arrangement is that it gives greater length of wharfage in relation to the length of the water front (Fig. 60). Sometimes marginal wharves are placed at a distance out from the shore but connected by stemlike structures with the shore.

The width of the fairway required for the circulation of traffic also plays a part in the determination of types of wharves. In the case of piers constructed on both sides of the fairway, there should be a minimum width to this fairway of at least four times the length of a normal vessel, both to give space for turning vessels and to prevent interference of movement of the vessels in the fairway. Between the bulkheads-on both-sides 
of the waterway there should be provision for eight times the width of a normal vessel. Restricted widths may, therefore, force the building of bulkheads on one side or both sides of the body of water, where if there had been a greater area of water, piers could have been built.

The dimensions of the wharves will be affected by a variety of conditions. For example, their length will depend upon the nature of the vessels which they are to serve or upon such locally established matters as pierhead and bulkhead lines,

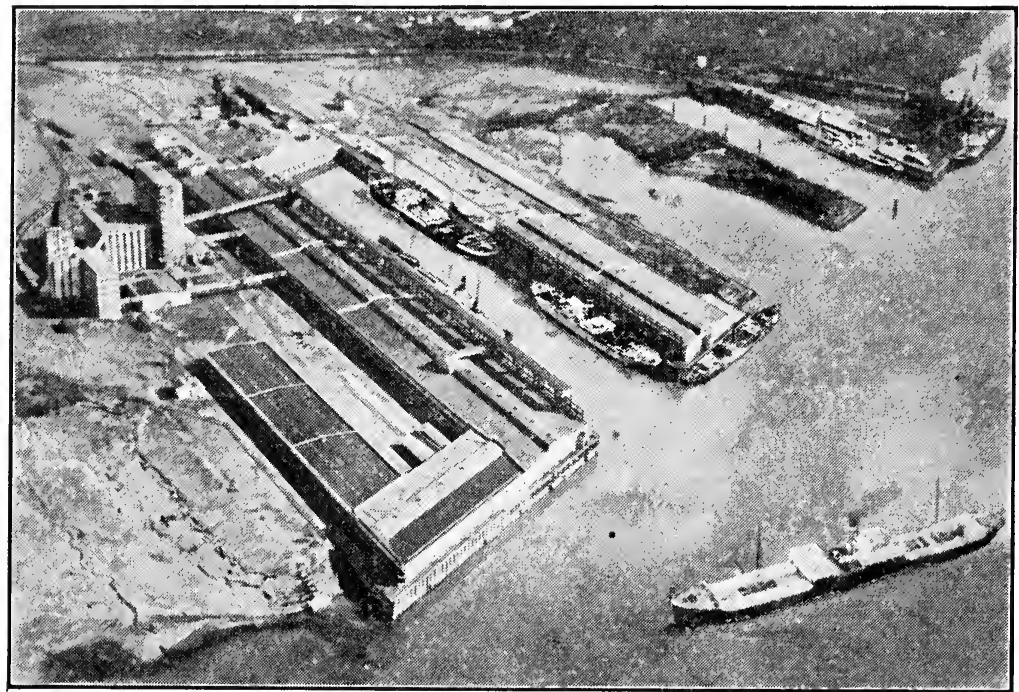

Fig. 60.-Air view of Municipal Terminal, Portland, Ore. More than $\$ 40,000,000$ are invested in the harbor and channel improvements of Portland. These constitute what is said to be the only fresh water harbor on the Pacific Coast. The air view shows the Municipal Terminal 4 in the northwestern part of the city on the Willamette River. The municipal grain elevator of $1,000,000$ bushel eapacity is also shown. (Brubaker Aerial Surveys; furnished by Portland Chamber of Commerce.)

which are fixed by the federal government. The width of the wharf will be made generous enough for the collection and distribution of the cargoes and for their sorting, inspection, and storage. It may be modified, however, by the value per front foot of the property concerned. The usual widths of piers are from 80 to 150 feet, although 400-foot piers have been built. Upon these are constructed the transit sheds and aprons. The transit sheds are usually one or two stories in height and serve to shelter the merchandise stored in them from the weather. They are 
also used as places for the loading and unloading of cargoes. They are not intended as places of general storage, however, the warehouses on the shore being provided for that purpose. The wharf apron is that portion of the wharf between the water's edge and the transit shed. Its width will be determined by the nature of the climate and the character of the cargoes and should be reduced to a minimum, commensurate with the amount of the freight handled upon it.

The space or "slips" between the piers should be adequate, the tendency having been to make them too narrow and so to cause congestion. Slips should be provided with fenders to protect the wharf from damage by ships approaching or lying at the pier.

The fluctuation in the level of the water at some ports is such that special provision must be made to accommodate the shipping. Especially is this true where the changes in level are extreme. There should be high level wharves, sufficiently high above mean high water to be still above the water at the time of the highest tides. The elevated docks, however, must not be so high as to interfere with the transference of cargoes at low water. For such conditions, there are constructed at some ports double-level bulkheads or pier facilities with the lower level under water at times of the highest tides. In ordinary sheltered harbors the docks are elevated to a height of from 5 to 6 feet above mean high water. According to Roy S. MacElwee, the rule has been that where there is a range of tide of more than 12 feet, locks and docks are necessary, but the modern tendency seems to have been to bear with the range of tide rather than to undergo the delays that are occasioned by docks. The range of tide at New York is $4 \frac{1}{2}$ feet, at Baltimore 1 foot, at Galveston $11 / 2$, and at Boston $9 \frac{1}{2}$ feet. At Liverpool and Havre the tides range from 25 to 30 feet.

In the case of rivers, floating terminals are often used, and although inexpensive to install and adapted to the fluctuations in the height of the river, these floating wharves are not readily adaptable to use by the trucks and teams necessary for the transportation of the cargoes brought to and from the ships.

Considerable range of water level forces the construction of wet docks or wet basins; these are so built that the water in the harbor can be kept at a constant level to facilitate the loading and unloading of cargoes. Boats pass through locks into and 
out of these wet basins, during the short periods when the surface of the water both outside and inside the basin is at the same level. No serious fluctuations of level are found in the water levels of lakes, so that in lake harbors, there is no need for wet docks or other similar facilities.

Where there is insufficient depth of water at the wharves or along the shore, there is at some ports an indirect connection with land, through the medium of lighters. Lighters can be used wherever the small movement of cargo does not justify the building of an expensive wharf-or they may be used in well-equipped harbors for cargoes of grain, coal, or other very heavy articles of merchandise as well as for cargoes of explosives. They are also used extensively for loading and unloading barges.

Turning basins are constructed near the inland end of a waterway in all cases where craft are carried inland along narrow channels.

With the aid of breakwaters, an artificial port can be created out of an exposed area of water and protected against heaving seas or rough lakes. These breakwaters or jetties may be in the form of a simple mound made by dumping stone into the water along the required line until the mound emerges out of the water or, before it emerges, giving it a solid superstructure of masonry or concrete. The breakwater also may be in the form of a shallow mound at considerable depth below the water with an upright wall of concrete or masonry, or there may be constructed a solid upright wall from the sea bottom up.

Kinds of Boats Involved.-The carriers to be accommodated in the port bear a very definite relation to the facilities that must be provided. The main types of carriers are those that navigate the ocean, the lake, or the river. Upon the sea are the express liners which are largely for passengers, the combination passenger and freight vessels, the cargo liners that carry freight exclusively over definitely established routes, and the tramp liners that have no fixed routes or ports of call. The lake boats include the bulk freighters, the passenger and package freight steamers, and the tankers. Upon the rivers are the packet steamers and the barges; the packets are of small capacity and are not adapted to handling freight from rail to river; the barges constitute about 99 per cent of the river traffic on many streams.

Kinds of Cargo.-The activity and facilities in a port depend also upon the kinds of persons and things that are there to be 
loaded or unloaded. These may include passengers of either cabin or steerage variety or cargoes of a general character, in bulk, or of a high-value type.

The cargoes in bulk are either solids such as coal and ore or liquids not shipped in containers. General cargoes, which make up a large amount of the commerce of the world and are the principal business of marine shipping, include standardized package freight such as coffee or sugar or perishables such as fruit. Uniform package freight is sent in uniform containers such as barrels, boxes, bags, crates, and bales. Dangerous cargoes include petroleum, cargo coal, cotton, or acids. Precious cargoes include mails, metals, and precious stones.

The manner in which the different kinds of cargoes are to be handled determines the necessary facilities. Grain, for example, may be handled by gravity or by pumping, by pneumatic elevators, or by mechanical conveyors. Ore and coal can be loaded by gravity chutes from pockets and unloaded by grab buckets or chain buckets. In the case of liquid cargo the transfer is accomplished by the aid of tank vessels, tank cars, pipe lines, pumping machinery, and other special equipment. For ship supplies it is cheaper to bring them to the vessel than to move the vessel to the supplies. The ship is "breasted off" from the wharf to allow lighters bringing coal, oil, and water to come along both sides of the ship without interfering with the loading of the cargo.

Varying Forms of Transfer Movements.-Since the activities of a port are centered around the transfer of cargo and passengers from carriers by water to carriers by land, or the reverse, a large variety of transfer movements are involved. The fewer of these movements that are necessary the better. There are varying points of destination for the freight and passengers to be moved. Local freights are for the city's manufacturies or intended for consumption within the city and may be scheduled for storage before their final delivery. Through freights are for immediate transhipment. Local passengers simply have to board or leave the ship. Through passengers must be conveyed from the ship to the railroad station, or vice versa.

Or, expressed in another way, according to Roy S. MacElwee:1

. . . the movement may be from the pier to a railway car to be switched to the trunk line railroad for the hinterland, or from the pier to the transfer yard for consolidation, or to the warehouse with spur siding 1 "Ports and Terminal Facilities," p. 15. 
for storage, or to the industrial plant with spur siding for consumption. It may be from the pier to the dray for delivery to local consignee not otherwise reached; to warehouse not otherwise reached or across the pier. The movement may be overside at the pier, cargo being loaded onto lighters for movement to warehouses or to industrial plants both with waterside delivery. The movement may be overside in stream at mooring posts into barges for the interior, into lighters and scows for local consignees having waterside delivery, and so on.

Types of carriers from the viewpoint of handling and transfer of cargoes determine the kind of movement of freight between boat and shore-that is, whether it shall be horizontal or vertical in character. "Side-port carriers" are loaded horizontally from the side, and the cargo is trucked across a gangplank from the wharf to the main deck of the vessel similar to the loading of a box car. This form of transfer occurs on coastwide as well as on lake and river vessels and also on covered "lighters." The deck-hatch vessels are loaded vertically. These boats are equipped with hatches or openings in the decks that permit the cargo to be lowered or withdrawn from the holds. On an average freight-carrying vessel there are four or five hatches which require that the cargo be hoisted vertically, swinging sidewise across the dock by crane, then lowered through the hatchway into the hold of the vessel. Obviously this operation requires the services of three gangs of laborers-one on the wharf, one at the winches, and one in the hold. Hatches are characteristic of ocean-going vessels as well as of the bulk carriers of the Great-Lakes.

Streets and the Port.-The unhampered movement of passengers and freight in a port is dependent upon the streets of the city which the port serves having been so designed as to make that unhampered movement possible. If the port means anything to the city at large, and especially in the case of the distribution of local cargo, whether passengers or freight, there should be a definite alignment of the streets of the city to fit the needs of the harbor (Fig. 61). If such provision is not made, there is sure to be difficulty of access to the harbor and of distribution of freight with a consequent congestion of traffic in the streets along the water front and elsewhere.

The pick-up and delivery of freight can best be done if a system of diagonal streets leading from the port out into the city and countryside be provided, and this system of diagonal streets supplemented by cross-connecting, circumferential highways. 
The number of streets, however, required to lead to and from the port is governed by the amount of traffic that has to be carried. In a community whose port serves almost exclusively for transhipment, fewer connecting streets will be necessary than where local distribution is the major function of the port and where the freight must be carried into or across the city. Manhattan represents the extreme of abundant streets leading to the wharves.

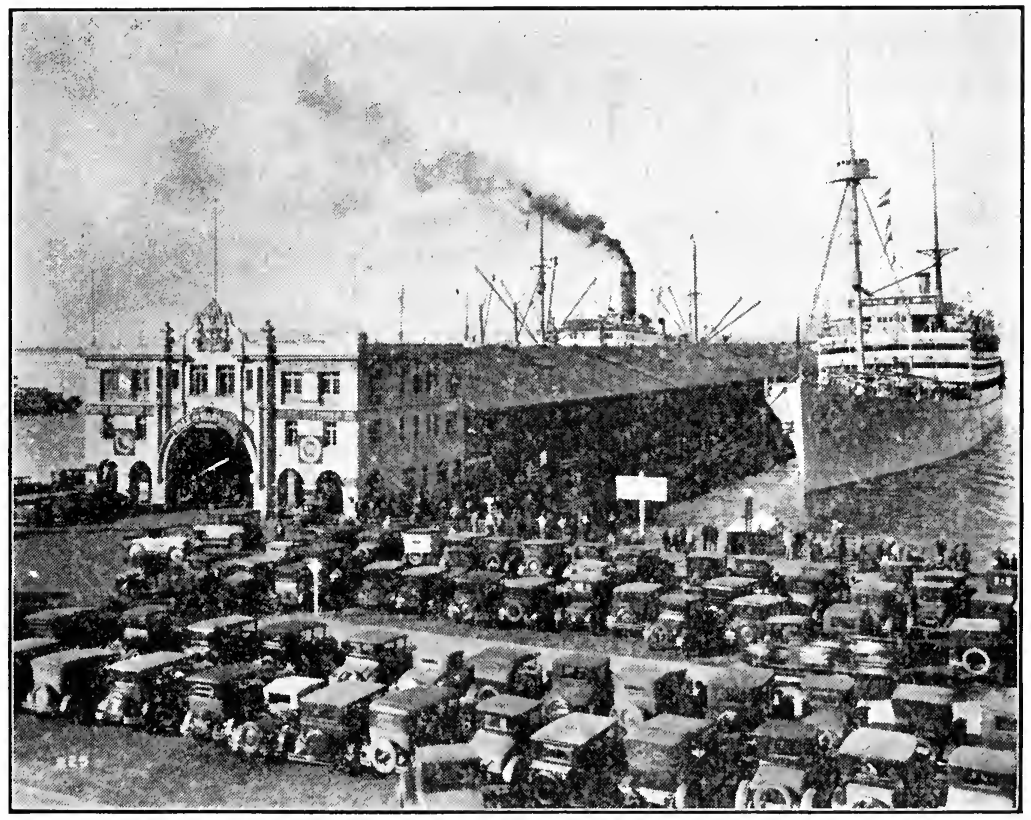

Fig. 61.-Pier 2, San Diego. Some idea of the need for parking facilities and approach requirements of a pier can be had from this picture. (Illustration furnished by San Diego Chamber of Commerce. Photographer, Lee Passmore.)

It must be remembered that whatever the destination of the cargo at the port, there must always be appropriate provision for the approach of those people who work at the port day after day and who are obliged to go back and forth by transit facilities or by automobile.

Large areas of streets are necessary along the wharves and especially where large amounts of tonnage are to be carried away from the wharf by vehicles. A street of not less than 100 feet in width should parallel the shore line and should be at least 200 feet from the water, so as to give adequate space between the 
street and the harbor line for railroads to reach the wharves, space for storage purposes and for the circulation and parking of vehicles, not to mention adequate space for the wharves, transit sheds, and handling devices.

An elevated promenade or street to accommodate the many sightseers that are fascinated in watching the activities at a port is a desirable feature, as seen, for example, along the river Scheldt at Antwerp. Elimination of grade crossings and the entire separation of kinds of traffic and particularly the separation of railroad trackage from the city thoroughfares and the facilities for freight from the facilities for passengers should be encouraged for reasons of safety and for ease of movement.

Railroads and the Port.-Ports should be provided with efficient railroad interchange. This hinges largely upon cooperation among the railroads serving the port and complete mobility between the wharf and the railroad systems. Railroad interchange can be accomplished by the so-called "combination road" or "belt line." Through such a belt line "comprehensive, economic and non-discriminating switching service can be had." So important is a belt line that some one has referred to it as the crux of the problem of port development.

This-interconnection between the wharves and the trunk lines is sometimes accomplished by an inner belt line and an outer one. The idea of the inner belt line is to bring all of the railroads and wharves in direct touch with each other. The outer belt line encircles the city, avoids centers of congestion, touches industrial sites on the outskirts, taps spurs leading into the congested parts of the city, provides classification yards that permit interchange of lines, and coordinates railway terminals.

Very few of these belt lines are to be found in the United States. New Orleans has the only municipally owned and operated belt-line railroad in the United States. San Francisco has a terminal belt line. Montreal has one of the most conspicuous examples of a publicly owned and operated harbor belt line.

The railroad tracks should connect with each pier and bulkhead by spur or siding. Upon the piers, railroad tracks may either run down the middle or along the sides. When the tracks are laid along the sides of the pier they are not covered. The tracks may be laid flush with the floor of the pier or they may be depressed so that the platform of the car is on a level with the deck of the pier. 
Port Location and the City Plan.-A number of factors enter into the decision as to whether or not there shall be one or more ports for a city. Accessibility of the port to deep water, without the interference of bridges or the navigating of tortuous channels, is one of the prime essentials. There must, moreover, be space sufficient for the largest carriers that are to be accommodated to turn around in the port. There must be protection from currents and the action of waves and from excessive fluctuations in the water level. There must, in addition, be proximity to railroad connections. Centers of population will quickly develop near the port. Separate terminals, serving industry, merchandise, or passengers exclusively, may be provided, but at each terminal some provision should be made for doing the work of the others.

An industrial harbor may be offensive or inoffensive, extensive or intensive. Where such features as chemical factories, oil refineries, or fertilizer plants are involved, they had "better be located to the leeward of business and residences, or of general cargo and passenger shipping." MacElwee objects to the spread of such larger industries along the water front as will completely block off the frontage necessary for the future development of the port. "Some of the most valuable river and harbor frontage is occupied by industries that use it for sewers and dumping places." The water frontage is too valuable for any one industry to hold in disproportionately large areas.

Centers of wholesale and retail business cluster around those ports handling general merchandise. Wherever the facilities of the ports are mainly for the transhipment of merchandise or for its storage, such ports may be remote from any business district.

The location of a port in any part of a city carries with it a burden of "extra large water mains and sewers, extra heavy pumps or engine stations."

Passenger terminals should be located with the idea of conveying to the incoming tourist a good first impression of the city and of providing for the tourist safe landing and every comfort and convenience. A railroad depot in conjunction with the port, for purposes of transference to points beyond, is a necessity.

A high-class manufacturing terminal is that of the Bush Terminal Building in Brooklyn, N. Y. (Figs. 62, 63). In this fine example of coordinated terminal planning, railroad tracks 


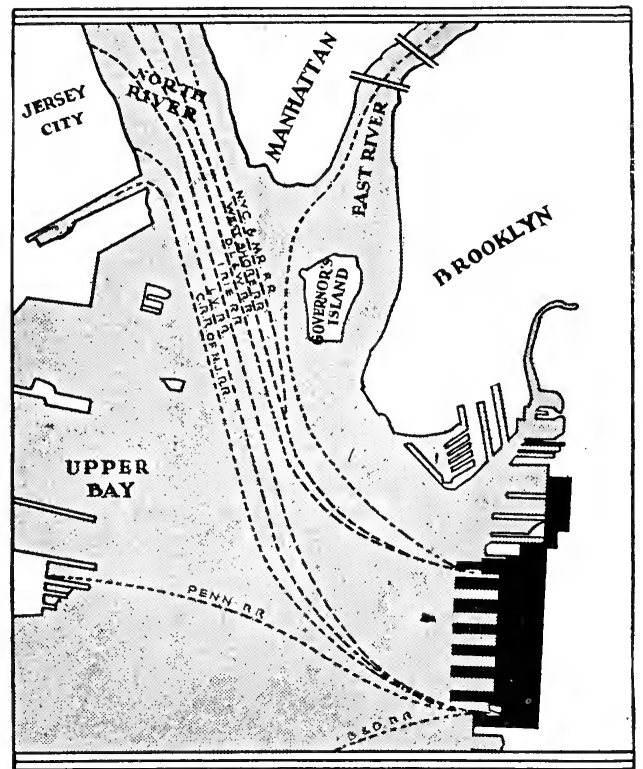

FIG. 62.-General location plan of the Bush Terminal, South Brooklyn, N. Y.

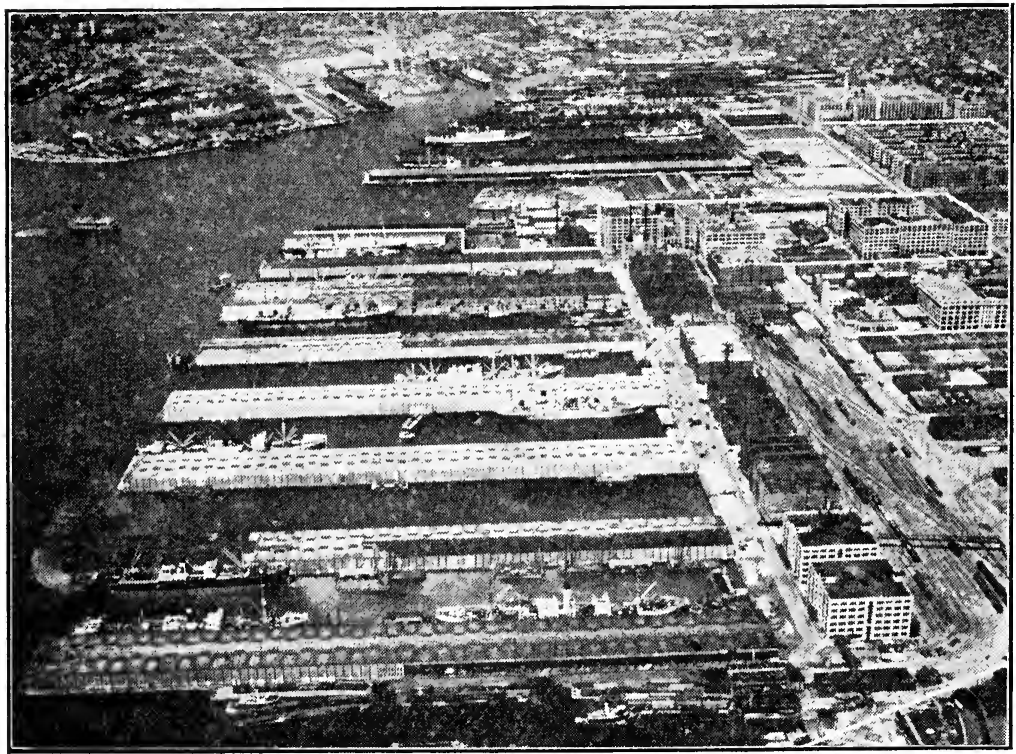

FIg. 63.-Air view of the Bush Terminal, South Brooklyn, N. Y. (Courtesy of Bush Terminal Co. Photograph by Fairchild.) 
lead through and from its seven piers to a series of adjacent large buildings. The latter are used for numerous kinds of manufacture.

The efficiency of a port is not dependent upon its size. - The port of New York with its 30,000 acres is said to cover practically as much area as the ports of Hamburg, Rotterdam, London, Liverpool, Bremen, and Antwerp combined, but each of these also has handled its share of commerce out of all proportion to its size. The efficiency of the port and the resulting economy of operation are what really count. A large volume of commerce can be handled anywhere with well-arranged facilities, but nevertheless proper thought ought always to be directed by the city planner to the need and possibilities for future expansion.

If, then, we would have our ports reflect some of the characteristics of the best-built and best-managed ports in the world, we must give to the subject of the comparative study of ports our most serious attention. We must have a good location for our port; the channel serving it must be deep enough; there must be adequate harbor space to avoid interference of vessels with each other; there must be sufficient wharfage space for loading and unloading at high or low water; there must also be transit sheds, facilities for handling the cargoes, warehouses for storage, and also ship yards and docks for overhauling vessels. Railroads on the pier and connecting belt lines for ready contact with trunk lines must be provided, as must also bordering and distributing streets. After the city planner shall have put all of these things into his plan, he must suggest the establishment of a central authority, with full power to insure the proper construction, maintenance, and operation of the port.

\section{Questions for Discussion}

1. Name and describe one or more important ports in the United States:

2. What kinds of waterways lend themselves to port development; discuss their characteristics.

3. Discuss the subject of breakwaters in relation to port development.

4. What types of wharves are there and what are some of their controlling requirements?

5. What kinds of boats and cargoes are there to be accommodated?

6. Discuss the varying forms of transfer movements:

7. How should streets and ports be related?

8. How can railroad tracks be laid down so as to further coordination of port activity? 
9. Where with reference to the city plan should ports be located?

10. Describe new or proposed new port developments of importance.

\section{References}

A Plan for the Central River Front, St. Louis, 40 pp., illus., City Plan Commission, St. Louis, 1928.

Blanchard, W. O.: "Geographic Aspects of Transportation," Henry Holt \& Company, 1930.

FitzGerald, D.: Docks, Report of Massachusetts Metropolitan Improvements Commission, pp. 155-186, illus., plans, 1909.

Great Inland Waterway Projects in the United States, 250 pp., illus., maps, American Academy of Political and Social Science, Annals, vol. 135, Philadelphia, 1928.

Lewis, Nelson P.: The Transportation System, "Planning of the Modern City," John Wiley \& Sons, Inc., pp. 55-85, 1923.

MacElwee, Roy S.: "Port Development," 440 pp., illus., plans, maps, McGraw-Hill Book Company, Inc., New York, 1925.

- : "Ports and Terminal Facilities," 2d ed., 446 pp., McGraw-Hill Book Company, Inc., 1926.

Merriman, Mansfield: "American Civil Engineer's Handbook," 5th ed., John Wiley \& Sons, Inc., New York, 1930.

Nolen, John, ed.: Navigable Waters, by E. P. Goodrich, "City Planning," pp. 227-263, illus., plans, D. Appleton \& Company, 1929.

Regional Survey of New York and Its Environs. A Study of Port and Industrial Areas, Regional Survey, vol. 4, pp. 133-156, 1928.

Schulz, Walter F.: Terminals on Inland Waterways, Civil Engineering, pp. 253-257, January, 1931.

Selected bibliography on ports and harbors and their administration, laws, finance, equipment, and engineering, compiled by W. J. Barney, secretary, American Association of Port Authorities, 144 pp., New York, 1916.

The Harbor Plan of Chicago, p. 97, Committee on Chicago Harbor and Port Survey, Commercial Club of Chicago, 1927.

U. S. Engineer Department, Board of Engineers for Rivers and Harbors, port series, Government Printing Office, Washington, D. C., Airplane views, maps, plans, 1921 to date.

Whitham, P. P.: The Port Terminal Factor of Municipal Planning, American City, vol. 15, pp. 631-638, illus., plans, December, 1916. 


\section{CHAPTER XI}

\section{AIRPORTS}

If our cities are to cope with the rapidly developing method of travel by air, they must plan at once to provide the necessary landing facilities for airplanes and dirigibles. There are already scattered over the country thousands of airports, and all of our cities not already so provided should have examined any available stretches of water or reaches of level land near enough the urban center to be used for this purpose and reserve such sites at once for immediate or future development. Unless these landing places be provided for a city, no traffic by air can ever increase the commercial importance of that place. To delay in the selection and preparation of at least one airport for every city is exceedingly unwise, because as time elapses many areas become less available by reason of their occupancy for other purposes and their resulting increase in value. Since no one doubts that aviation will develop more and more, the urgency of a forward look in this respect and a comprehensive planning of airports so spacious that they will meet all future demands can readily be understood. A universal interest among our people is now directed toward the matter of airports. They desire to plan with the best judgement available. Even though great changes in a few years may compel revision of present efforts, nevertheless these present developments may be looked upon "as an investment without which aviation cannot develop."

Number of Sites and Distribution.-The subject of airports is related to air in much the same way as the subject of harbors and docks is related to water or that of stations and yards is related to railroads. Similarly airports may become the focal points of civic development. In number airports need to be proportioned to the population to be served; in equipment they must be adequate and safe for the maximum volume of air traffic that they shall have to accommodate. Just as there are systems of highways, there will soon be air routes and systems of airports. A large in-town airport within 15 minutes of the center 
of the town and serving as a chief terminal station will constitute the hub of the system. According to Prof. H. V. Hubbard this will be supplemented by an outer circle of airports serving as the outer termini of a rapid-transit system and by local airports at suburban centers farther out. Small local ports will serve as intermediate stations every 10 miles or so to punctuate the main routes of travel. The population to be served will in every instance determine the location of the stops and their comparative importance. The chief terminals will have to be supplemented by other ports-auxiliary fields to be used i.l cases of emergency. Certain fields may be set apart for airplanes, others will be used only by dirigibles, while some will be equipped to serve both kinds of aircraft. The various facilities offered by the largest airports will need to include service for regularly organized air lines, whose airplanes are used for commercial and industrial purposes, and will also offer accommodations for other aircraft used for sight-seeing trips, for school ships, for stunt flying, or for any other possible purpose. Airplanes used in the service of the government for patrol of forests, supervision of national parks, and law enforcement will be served by airports owned by the government.

Landing spaces for aircraft will be needed, moreover, on tops of buildings in the large cities, over railroad rights of way when the railroad is electrified, and appropriate landing fields adjacent to and serving large hospitals must be provided for the landing of flying ambulances. Parking facilities for airplanes will be as necessary as they are now for automobiles. According to E. P. Goodrich, city planner, spaces of 5 acres in area will be required for the parking of 100 planes built to fly over land, and 7 acres for the parking of 100 seaplanes.

This authority, in his usual analytical manner, based upon long experience with similar estimates in other forms of transportation, comes to the conclusion that by the time the United States has reached a population of $200,000,000$, there will need to be one airport for every 2,000 of the population. Upon this basis the city of New York with its prospective population of 10,000,000 people will require 5,000 airports.

Areas necessary for future airports should, therefore, be reserved now. Until these areas are actually needed as airports, they can be used as recreational spaces. By the time that we are all flying, we shall find that "the immensely increased radius 
of travel that will be open to the reach of people in general will make recreational areas further afield attractive for them."

The Site.-The choice of a site for an airport for a city depends upon a variety of factors, chief of which are the location, the size, and the character of the lot required. The site should be as close as possible to the center of the city. Because of the difficulty in securing adequate open spaces for airports in our cities, the average distance for some several. hundred airports today is about 3 miles from the urban center. Some are as close as $1 / 4$ mile to the center of the city, and others as far out as 18 miles from that point. The larger the municipality the greater is this distance, because the difficulty of securing adequate acreage near to the heart of any city is in direct ratio to the size of that city. Famous foreign airports vary also as to distanceCroydon is 10 miles from Trafalgar Square in London, Tempelhof is 3 miles from the heart of Berlin, and Le Bourget is 7 miles from the center of Paris. There are instances of European airports having "been abandoned because too far from the city or too difficult to reach."

While a landing field for aircraft should be as close to the business center of the city as possible, it is necessary to place it in the open country. This necessity corresponds with the tendency to move the terminals of other forms of transportation farther out from the city, as is seen in the case of certain railroad terminals at Detroit and Kansas City or as in the proposed Pennsylvania railway station at Philadelphia. The airport should be not over 20 to 25 minutes' run by autom obile from the business section of the city.

The site of the airport ought to be cuccessible to and correlated with existing and probable future facilities for travel by roads, by railroad, and by navigable water. According to a paper presented by H. V. Hubbard and H. K. Menhinick before the 1930 Conference of City Planning, the airport should be easily accessible from the main highway but need not abut directly upon it for any considerable length. A location off the highway avoids automobile parking congestion. The master consideration determining the effective nearness of the airport to the city center is likely to be good highway connection for bus use. The appearance of the approach is important. A pleasant boulevard will have a value both to the airbort and to the city, 
although it must be remembered that "the airport is not a legitimate element of the recreation system."

The location for the air port directly on a railroad line aids pilots in locating the airport; facilitates transfer of passengers and freight; and facilitates airplane supply shipments. A large airport should include a spur line railroad connection. The ideal location would be an airport built directly over a railroad terminal or yards.

The airport should be bounded by streets, preferably owned by or under the control of the owners of the airport. Wide thoroughfares should lead off from the airport in all directions. The airport should have access also to various public utilities such as electricity, gas, and water. The necessary approach to the landing field should not lead across the city.

The airport should be of proper size in addition to being correctly placed. Among existing flying fields there is great variation in size from an airport the size of Mitchel Field in Cleveland covering 1,000 acres, down to 40-acre airports in Boston and Pittsburgh, and there are others elsewhere as small as 25 acres. The size of the airport is governed by the types of planes that are to utilize it, the volume of traffic that is to be accommodated, and the probable crowds that are to congregate there. Also the elevation of the property above the sea level must be considered. If helicopter planes, vertical in their rising and landing, are ever used to the exclusion of other kinds of aircraft, then the area required for the airport will be smaller. At present, however, lighter planes leave the ground in from 400 to 800 horizontal feet, the heavier ones in from 1,000 to 2,000 horizontal feet, but they all require additional space for the runway in the event of the stalling of the engine. Airports, therefore, need to be provided with certain minimum runs for the planes. According to the United States aeronautical standards, the "A" rating applies to landing areas that provide runways of 2,500 feet; and "B" rating applies to those whose runways are 2,000 feet, a distance which is sufficient for the starting of most planes. There are some planes carrying passengers that require 3,500 feet in which to make their start.

From the varieties of the shapes of landing fields the world over (Fig. 64) there is clearly no particular reason to prefer one geometrical figure to another, as better adapted to an airport. All conceivable shapes and forms of airports are in use. The 


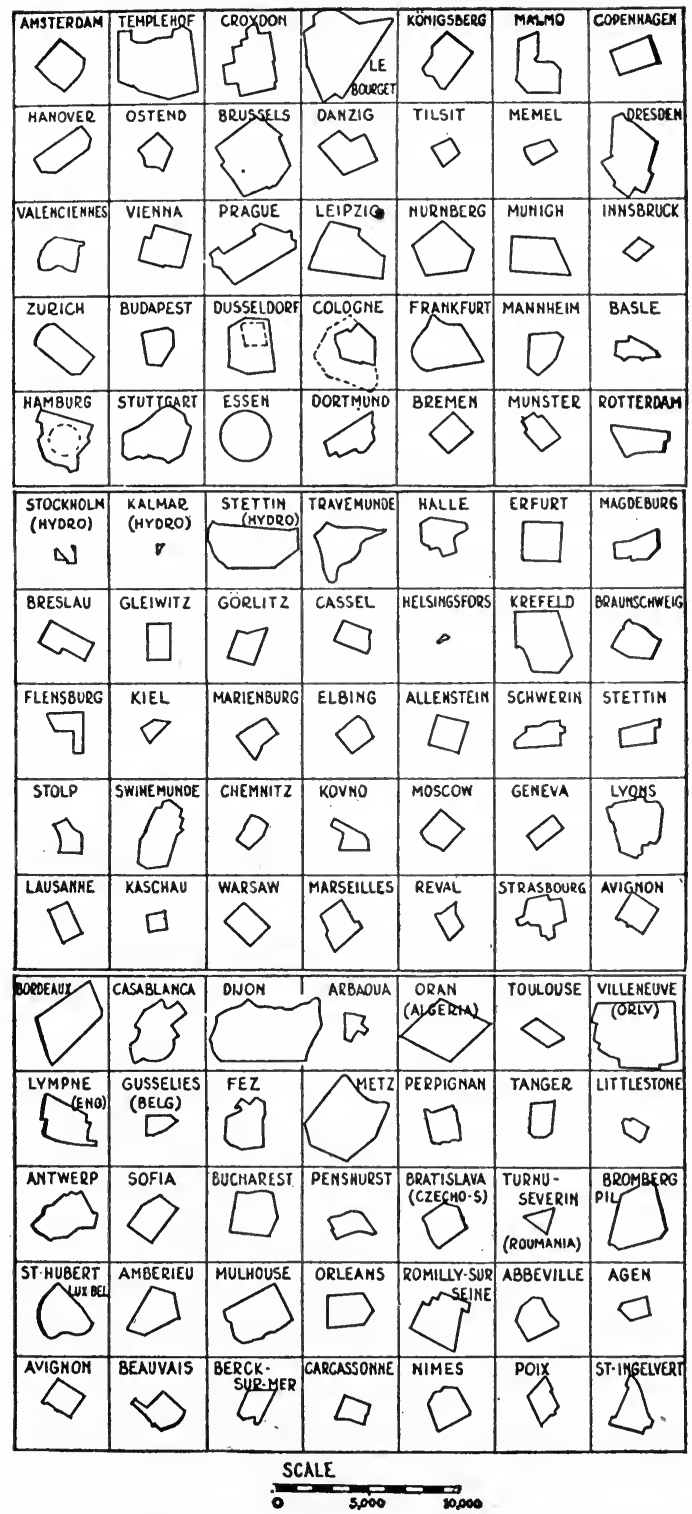

FIG. 64. - Study of comparative shapes and sizes of European airports. (Courtesy of E. P. Goodrich, Consulting Engineer, and the Architectural Record, May, 1929.) 
one thing necessary is that the airport shall provide an unobstructed runway for the take-off and an unobstructed place for landing.

European airport officials, according to Jay Downer, chief engineer of the Westchester County Park Commission, recommended circular landing fields approximately 3,000 feet in diameter, with surrounding areas 600 feet wide restricted against structures.

A piece of property 2,000 feet square when measured diagonally from corner to corner presents a length of 2,800 feet for
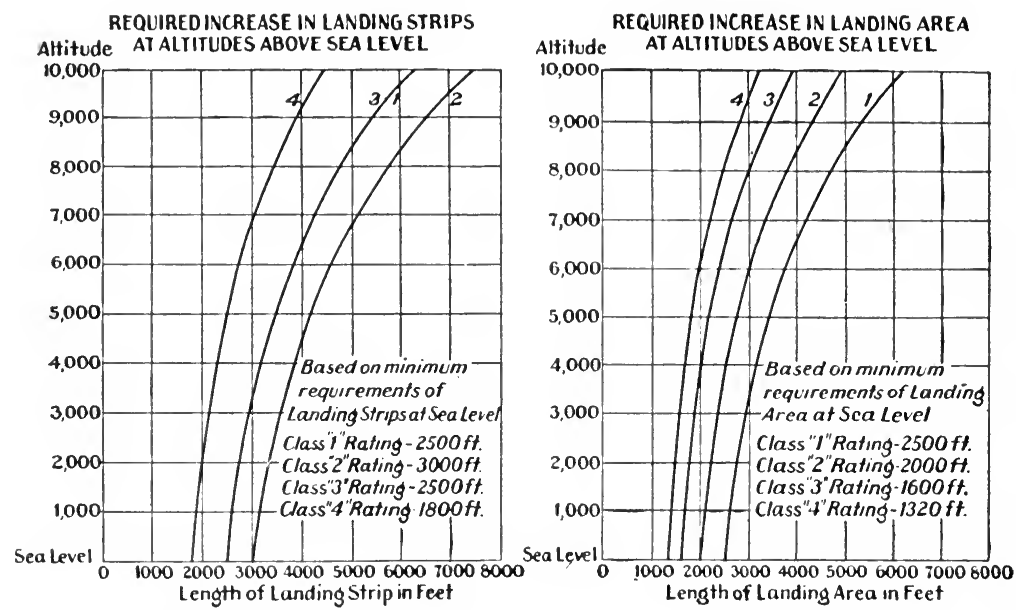

fromairportrating regulations

Dept of Commercc, May, 1928

FIG. 65.--Required increase in landing strips and landing areas at various altitudes above sea level. (From "Airport Rating Regulations," Department of Commerce, May, 1928.)

take-off and landing. Because a rarified atmosphere does not permit of the operation of an airplane at the same speed as the denser air of a lower elevation, the length required for the take-off and landing increases with the altitude, and the size of the field must be increased accordingly (Fig. 65). A take-off of 1,500 feet on a location at sea level, for example, would have to be increased to 2,300 feet at Denver (which is a mile above the sea level) and to 2,700 feet at Cheyenne.

Due allowance should be made in regard to a possible enlarging of the airport as the increasing traffic may require. It must be recognized that doubling the area of a field does not mean the doubling of its capacity. "Doubling the length may double 
the capacity if the additional area is developed as a separate field."

In calculating the capacity of a field to handle its traffic, one must keep in mind how much work a single landing strip can do. One landing strip can serve 10 incoming and outgoing planes per hour.

Climate and meteorology must also be considered when establishing an airport, and these questions must be answered: What are the velocity and direction of the prevailing winds? Are there hindering or helpful currents of air? How free is the property to be used from snowdrifts, smoke, and particularly from that greatest of all hazards, fog? The property chosen for the airport should be level ( 2 degrees preferably); its surface should be smooth and capable of being made firm under all conditions of weather; the land should have good natural drainage and be capable of sustaining a covering of firm sod. In the choice of the site, moreover, freedom from all possible obstructions must be considered. There should be nothing to interfere with the plane as it follows the necessary angles of ascent and descent, which amount to 1 foot up or down to each 7 feet of forward travel. Obviously from this calculation an adjacent building 40 feet high in the path of ingoing and outgoing planes would render useless a portion of the landing field 280 feet in radius, as far as the rising and alighting of airplanes is concerned.

The question of the surroundings and general locality of landing fields is most important. Except in cases in which they are intended to accommodate passengers, airdromes should be located close to industrial plants. Residential sections of the city need to be served by landing fields, but the noise incident to the operation of the engines in the airplanes and the flashing or rotating of the airway beacons through the night are very disturbing to overly nervous people who may have their homes thereabout. Whatever may be the use to which the lands adjacent to the airport are devoted, both the safety of the community and the full use of the landing field require that the heights of all bordering structures be restricted. The sentiment of the court as represented in the Cleveland Airport case ${ }^{\mathbf{t}}$ would lead us to believe that in crossing the property of an adjoining owner, flight must be above 500 feet; otherwise it may be regarded as

\footnotetext{
${ }^{1}$ Swetland vs. Curtiss Airports Corporation, U. S. District Court of Ohio, Eastern Division, decided July 7, 1930.
} 
trespass. "Where lower altitudes are necessary [therefore] the owners of airports must secure the consent of adjoining property owners or acquire such rights by condemnation."

The factors that affect the location of an airport have been tabulated by Robert L. Davison, ${ }^{1}$ according to their relative values, as follows:

Requirements of the flyer

Relative value

Freedom from dense river fogs.............. 8

Freedom from ground mist................ 5

Freedom from smoke conditions.............. 6

Freedom from snowdrifts................... 1

Freedom from air-travel interference............. 4

Prospective neighborhood development.......... 2

Area of field.......................... 8

Configuration of field................... 4

Freedom from objectionable air currents and eddies... 1

Approaches-satisfactory area under take-offs........ 3

Favorable prevailing winds with reference to runways. . 4

Other factors affecting safety................ 4

Total units......................... 50

Requirements of the public

Location with respect to the axis of air travel........ 8

Distance and direction from the source of air travel business........................ 7

Distance from the geographical center........... 4

Distance from center of population............. 8

Distance from rail terminals.................. 2

Distance from water terminals................. 1

Distance from post office.................... 6

Distance from hotel center.................. 5

Distance from economic center................. 3

Distance from financial center................. 3

Distance from center of airplane manufacturing industries......................... 3

Total units.......................... 50

The Development of Landing Fields.-The type of the development of a landing field depends upon the particular kind of airport that it is proposed to establish. While a terminal will require a multiplicity of facilities, an intermediate emergency

${ }^{1}$ Airport Design and Construction, Archilectural Record, May, 1929. 
field used only for casual stops will require much more simple equipment. The emergency field may be nothing more than a. pasture or a field of hay, clover, or alfalfa, subjected to frequent mowings along the runways, and its facilities for service may be limited to a filling station.

Landings and take-offs of aircraft are made against the prevailing winds, so that the direction and character of the landing strips or runways should be laid down accordingly; that is, the runways should be in line with the prevailing winds. Runways ought to be at least 500 feet wide, because occasionally the planes are carried off their course by the wind, or the pilots have to execute a ground loop upon landing. It is, therefore, customary to provide landing strips 500 feet wide that are smooth and well drained and to have them substantially paved for a width of 100 feet.

They should be so placed as to avoid approaching the airport buildings directly. If the runways intersect near the terminal building, they necessitate less taxiing than otherwise, which is an advantage. Parallel runways if not too close, in fact separated by several hundreds of feet, are useful in separating incoming and outgoing planes. A landing strip is not desirable along the perimeter of the field because of the unsteady wind currents produced against adjacent structures. Taxiways around the perimeter of the field are helpful in that they provide direct access to and from the runways. These circumferential runways, however, are so costly to build that they are not usually introduced. Where runways are surfaced with some form of paving, their construction is subject to the same general principles that govern the construction of roads. We are in fact going through the same stages as road builders with the sequence having been tried successively of grass, cinders, gravel, crushed rock, and now concrete.

Concrete for the surface of a runway is described by R. L. Davison as especially good for the following reasons: It has hard surface; it is visible at night; it is skidproof when wet; it is economical both as to first cost and as to cost of maintenance. Concrete is, moreover, able to sustain heavy loads and to withstand the high impact of alighting planes. The force of the impact of an alighting plane with a given load subjects the pavement upon which it alights to a strain several times as great as would be made upon it by the same weight of "static load." 
The same author also calls attention to the fact that in planning types of pavements for runways, the loads to be sustained, including the strain of the impact for the heaviest planes, must always be considered. According to the U. S. Department of Commerce, the heaviest planes for which runways have to be constructed are of 30,000 pounds weight. The construction at Floyd Bennett Field provides runways in a series of strips or panels 10 feet in width, 8 inches thick, and doubled together at the joints - and 7,000 feet in length of these runways are 100 feet in width.

At the intersection of the main runways, or in the heart of the best landing area, a large circle 100 feet in diameter with a 4-foot margin painted white should point out the runways for incoming planes overhead.

Buildings as well as runways are essential features in the development of the more complete airports (Figs. 66, 67). These buildings include terminals with administrative facilities, waiting rooms for passengers, also control towers, fire and ambulance stations, garages and storage facilities, sleeping quarters for travelers, bleachers for observation space, places for radios and for meteorological instruments, facilities for shopping, equipment for service of various kinds, as well as the heating plant. Also proper housing of the field personnel should be provided.

The terminal building is in some respects the heart of the airport. In connection with it or near-by will be the loading and unloading platforms; within it will be the main waiting room, ticket offices, check rooms, concession stands, the administrative offices, and a dining room. Some think that the terminal should be above the ground, others think it should be below the surface with an underground concourse and so allow for the easier flow of incoming and outgoing planes. Some think that the terminal should be located off to one side of the port in the direction of main traffic arteries. There are advocates of a central position for the terminal building. This appears questionable unless the airport has unusual dimensions or unless the central terminal is kept below ground. Such a central point involves considerable length of subway for connection with the periphery of the port.

The loading platforms may be directly outside the terminal or a little removed from it and made accessible by underground 


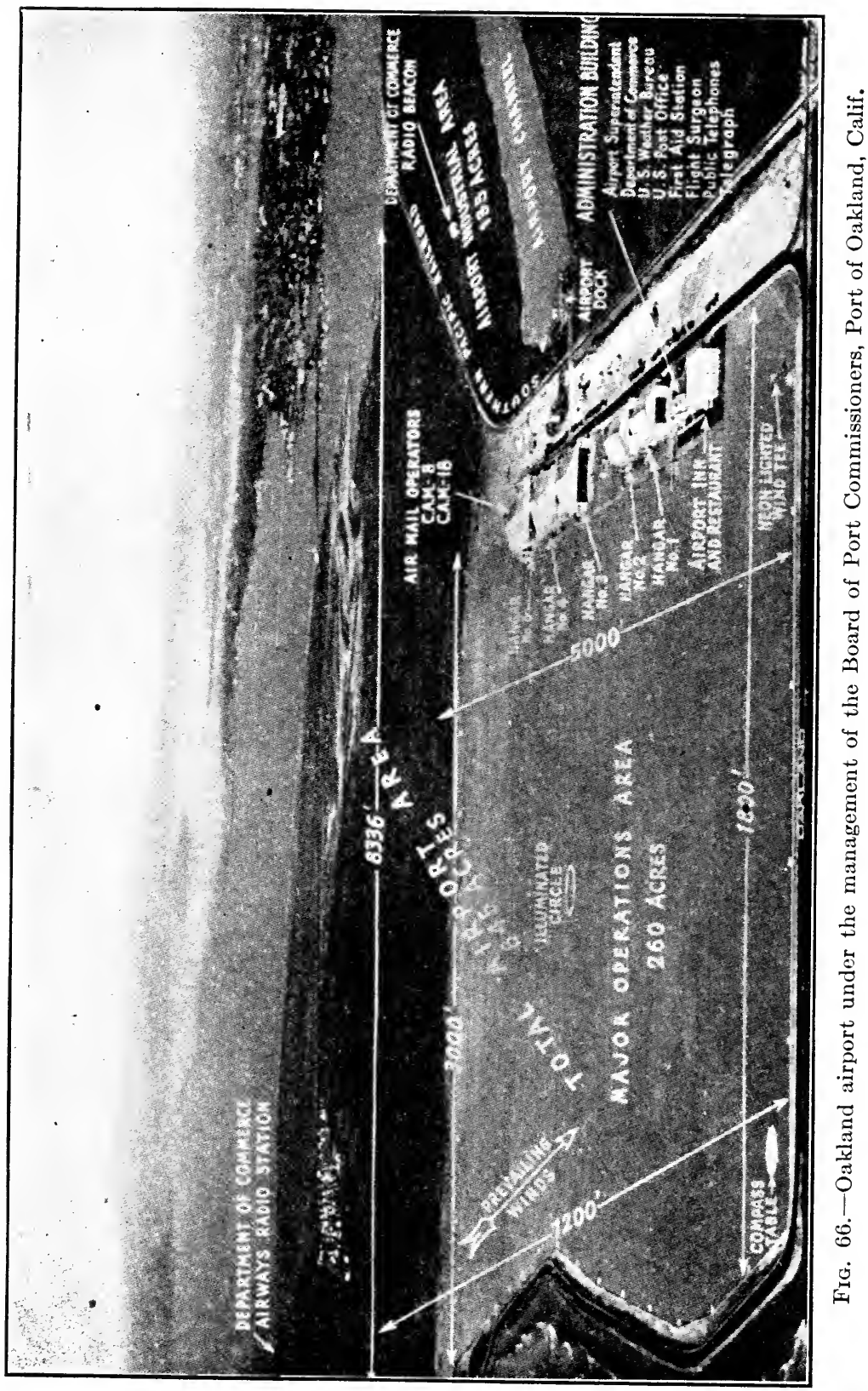


passages. Various loading platforms are being discussed. Covered loading docks are objected to because they physically

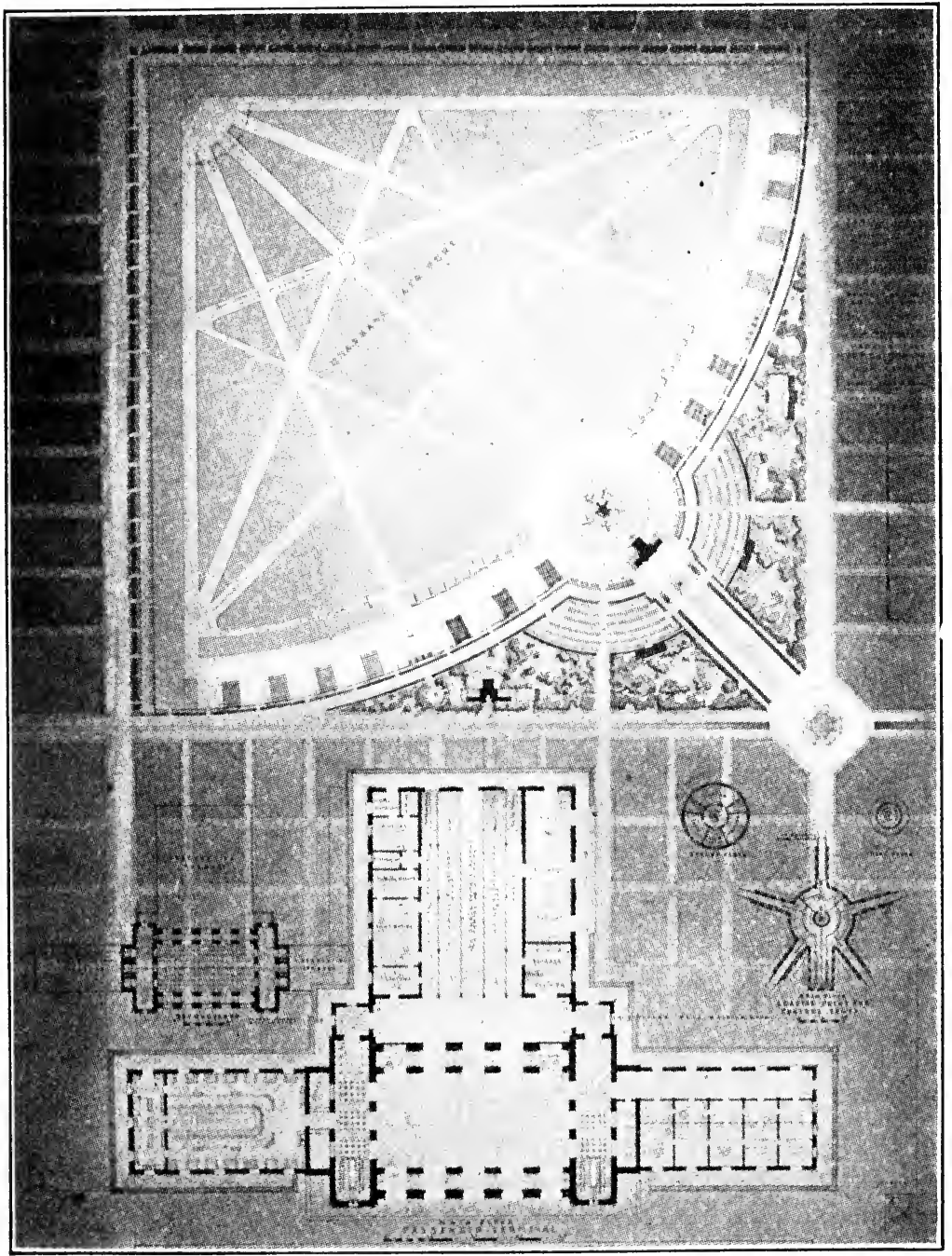

FIG. 67.-First-prize plan in the Lehigh Airports Competition, November, 1929. The jury received 257 designs for examination from 35 different states. The prize plan was designed by A. C. Zimmerman and William H、Harrison, Associated Architects and Engineers, Los Angeles, Calif.

limit the size of planes capable of using them. Turntables for handling transports beneath huge cantilever unloading bays are 
being thought of. A star-shaped platform connected with the terminal by tunnels and provided with retractable steel canopies seems to offer an interesting possible solution for loading facilities. that keep the passengers safe from the propellers of the planes.

The control station should command an unbroken view of the field and to that end should be elevated above the surrounding buildings. A place on the top of the terminal station is therefore a desirable position in this respect and for this purpose.

In number, size, and importance the hangars occupy an important position upon the airfield. It is to them that arriving planes will be moved or from them that many departing planes will be taken. They will need to be convenient of access and not too far from each other. The danger of fire makes a combination of several in one rather hazardous. They should be so placed, moreover, that they will not interfere with control-tower vision. As in the case of other buildings, they should not be placed at the end of landing strips.

In size the hangars vary from 100 by 65 feet as used for the conventional hangars for the air-mail service (costing from $\$ 22,000$ to $\$ 23,000$ ) to dimensions of 104 by 105 feet for service of the transcontinental air line like the one in Reno, which cost about $\$ 30,000$. One of the hangars of the Ford Airport in Dearborn, recently constructed, is steel framed, 300 feet long by 20 feet high, and provides a clear, unobstructed door opening on each side. Hangars are so designed as to allow for the removal of planes from one or both sides of the building. How the planes shall be removed from the hangar is dependent upon their size. The wing spread of the largest number of planes is from 30 to 40 feet and in the next largest number from 40 to 50 feet; planes, indeed, as to their wing spread vary all the way from 20 to 100 feet. They vary in height, also, from 12 or 14 to 18 feet. This does not include the planes that are being built by the General Development Company of Connecticut with wing spread of 262 feet and an overall height of $31 \frac{1}{2}$ feet.

In addition to buildings, such structures as fences and similar barriers should be erected for the protection of the public and for the purpose of operating the planes without interference. They should segregate visitors and passengers from the field. An adequate system of lights should illuminate the vicinity, these to include beacon lights, boundary lights, and night-wind indicators. They should illuminate the runways at night and 
should mark such obstructions as water towers, flag poles, and towers for transmission lines, either those that are provided upon the grounds or those that exist in the immediate vicinity of the airport.

Aspect of Field from Air.-The first impression of a city as seen upon arrival at an airport should be considered. As part of the air mosaic of the city, and to encourage good first impressions, it is essential to have an orderly arrangement of design in the airport, appropriate architectural treatment, and suitable use of grass and foliage.

Community builders must plan so that the eye of civilization, looking down upon the earth, sees order, harmony, beauty. This will not be so difficult because architects all through the ages have been planning with the bird's-eye view in mind.

This matter of impression is important also from the standpoint of the administration of the air line, as everything must be done to inspire confidence and satisfaction in the traveling public.

Value and Costs.- The cost for the acquirement of sites for landing fields and for their development varies greatly. The 45 airports studied by Hubbard, McClintock and Williams in their book on "Airports" revealed an average cost for an airport site of $\$ 974.28$ an acre, the cost per acre ranging between $\$ 50$ and $\$ 6,500$. The cost of improvements on these same airports included such important items as clearing, grading, draining, surfacing, lighting and structures. Clearing costs varied from $\$ 0.99$ to $\$ 501.54$ per acre; grading costs from $\$ 6.51$ to $\$ 9,212.50$ per acre; the drainage from $\$ 2.50$ to $\$ 1,445.09$ per acre. The surfacing where sod surface was used cost about $\$ 200$ an acre. Where, however, pavements and runways were constructed the variety of costs was found so great that these were not included in the reported costs. Upon the basis of figures from 37 lighted airports an average expenditure of $\$ 16,935.58$ for lighting equipment was obtained. The average investment for all structures was $\$ 143,417.53$ ranging from $\$ 1,000$ to $\$ 960,000$ per airport. In the above study the average cost of total improvements at 73 airports was found to be $\$ 326,000$.

Every small community cannot develop and maintain an airport of magnitude. Minimum facilities with, say, two runways 1,800 by 300 feet at right angles to each other might be sufficient for a small community. But there are notable accomplishments in the airports of such cities as Chicago, Detroit, 
Newark, Los Angeles, St. Louis, Kansas City, Charlotte, N. C., Hartford, Portland, Oregon, San Diego, and others, and still more completely equipped airports are proposed and planned for other cities.

At Newark there is to be a center serving both for the military maneuvers of the state militia and as the eastern terminal for all of the air-mail lines serving New York City. The first unit of this center is to be at first 375 acres in area, but eventually the airport will have an area of 1,000 acres. This airport is located on a man-made arm of Newark Bay, on a city-owned site, now worth $\$ 6,000,000$, upon which $\$ 100,000$ has been spent for drainage, and into which $2,000,000$ cubic yards of filling have been pumped.

A $\$ 2,000,000$ bond issue has been passed in St. Louis looking to the enlargement of an airport there from 244 to 693 acres and providing for a system of eight runways, with connecting taxi strips. $\$ 1,000,000$ has been voted for the purchase and improvement of 687 acres as an airport at Kansas City. Chicago proposes an expenditure of $\$ 2,000,000$ for her airport. Cleveland and Boston each propose to expend between $\$ 1,000,000$ and $\$ 2,000,000$ for their respective airports. In the creation of its Swan Island airport, Portland is spending some $\$ 1,250,000$.

Ownership and Operation.-While the prevailing opinion held by city planners favors the private promotion of aeronautics, there is much to be said for public ownership, maintenance, and regulation of airports and airways. At least, the public should own airports and airways that particularly affect the public welfare. Many airports will be the means of attracting new enterprises. Where only one site is available for an airport to serve a business district and that one site is privately owned, the land eventually will be subdivided for other purposes, regardless of its importance to the community as a landing field. Some city planners believe that publicly owned flying fields should be under the administration of the department of parks because these flying fields serve recreational as well as commercial purposes, and because many other open spaces are under the control of the park department, because also to some extent flying fields must be adorned with plantings, and public needs in this respect can be more easily provided by the park department.

There are others who feel that it is illogical to have airports under the control and administration of park departments, 
because aviation is primarily transportation and not recreation, that there is no more reason why the park department should administer it than that the school board should do so. "The importance of aviation, the extent of its properties, and the peculiar qualities of its technique" would seem to justify a separate public department for its maintenance and administration.

Although a certain amount of public ownership, maintenance, and regulation of airports is necessary, this should not mean the discouragement of private ownership. Because of the congestion that will be experienced on many of the fields publicly owned, the development of fields privately owned will be not only advantageous but necessary.

\section{SITES FOR SEAPLANE LANDINGS}

A site for seaplanes must be "situated on or directly connected with a body of water, calm enough for operation in ordinary weather, sufficiently large and deep to permit landing and taking-off of seaplanes and flying boats without hazard." The distance between the actual airport and the open water should not be over $1 / 4$ mile with a direct connection that allows for "taxiing" the distance. The water should be not less than 6 feet deep at mean low water, free from appreciable currents, and with a bottom of good, holding ground. There should be a minimum reach of clear water 3,500 feet in length without any bridges crossing it and without any other permanent obstructions. The port should be located near a satisfactory road and should be served by other good facilities for transportation leading into town. The land area of the seaplane landing should be at least large enough to allow for hangars and supplementary buildings located adjacent to the water.

Development.-The beach should be gently shelving and parallel with the water, there should also be a concrete or stone ramp connecting the water runways with the hangars. On the more elaborate sites, there will be one or more hangars ( 80 by 120 feet, perhaps, in size), besides equipment for making repairs, machinery for hauling planes out of the water on to a marine railway or ramp, and a boat for carrying disabled planes; facilities ior mooring planes and apparatus for fighting fire will all be provided. Buildings to furnish restaurants, waiting rooms, rest rooms, and sleeping quarters will be erected, facing the water front. 
Facilities for Airships.-Although the large airships are not multiplying with the same rapidity as the smaller ones, the time will come when landing facilities will be needed for them at important points all over the country. The principal terminals (Fig. 68) will require sufficient areas to permit of safe landing and taking off and to allow adequate space for maneuvering to and from the hangars. To this end, landing fields for large

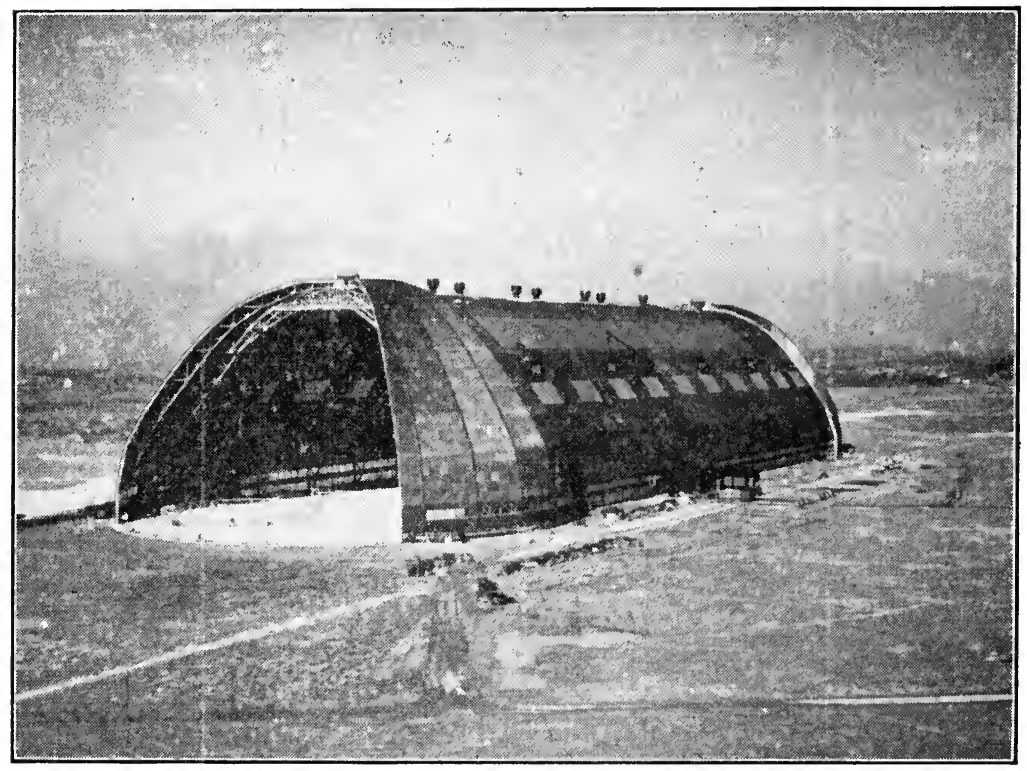

FIG. 68.-The airship dock at Akron, Ohio, is one of the largest in the world. It is 1,175 feet in length, 325 feet in width, and 197 feet in height. The huge spherical doors are most unique and operate with great hinges, with supporting trucks and a mechanism for opening and closing. (Courtesy of the GoodyearZeppelin Corporation.)

airships will have to be provided near to every city and must be constructed upon level spaces of open ground at least $1 / 2$ mile square, well-drained, and clear of all obstacles.

No forms of facility for transportation in the city plan are commanding more universal interest among our city planners today than are aircraft. The need for airports is being more and more realized, and matters of their number, size, location, and character as well as their development are occupying men's minds. It is well that this should be so, for, as in the case of all other elements in the city plan, timely anticipation of the 
future need of airports and their consequent establishment are the essence of practical and economic good sense.

\section{Questions for Discussion}

1. What is the significance of airports today?

2. How numerous should they be and how distributed?

3. What considerations should enter into the choice of a site for an airport?

4. What considerations should enter into the development of a site for an airport?

5. Explain how the appearance of the airport from the air is a factor in the development of the port.

6. How much do airports cost?

7. Discuss ownership and operation of airports.

8. Review the considerations underlying the law of airports.

9. What about sites and development of sites for seaplane landings?

10. Discuss airport rating*regulations.

\section{References}

Airport Rating Regulations, Effective as Amended Jan. 1, 1929, 23 pp., charts, Aeronautics Bulletin 16, U. S. Department of Commerce, Aeronautics Branch, Government Printing Office, Washington, 1929.

Airports, American Academy of Political and Social Science, Annals, suppl., 63 pp., September, 1930.

Airways and Airports. Regionally Planned Groundwork, 32 pp., Regional Planning Federation of the Philadelphia Tri-state District, 1930.

American Airport Designs, with analysis by Archibald Black, Lehigh Portland Cement Company, 96 pp., illus., Taylor, Rogers and Bliss, Inc., New York, 1930.

Black, Archibald: "Civil Airports and Airways," 232 pp., Simmons Boardman Publishing Co., New York, 1929.

Current Architecture, Western Architect, Airport No., Chicago, March, 1930. Davison, Robert L.: Airport Design and Construction, Architectural Record, vol. 65, No. 5, pp. 491-515, illus., plans, diagrams, May, 1929. Designing Safe and Adequate Airports, diagrams, Aeronautics Bulletin 2, Washington, Government Printing Offlce, 1928.

Duke, Donald: "Airports and Airways; Cost, Operation and Maintenance," 178 pp., illus., plans, The Ronald Press Company, 1927.

Ernst, Chardes J.: Airport Architecture and Construction in 1930, Municipal Index, pp. 773-784, American City Magazine Corporation.

Ford, G. B.: The Design of Airports, American Architect, vol. 132, pp. 561568, illus., plans, Nov. 5, 1927.

Goodrich, E. P.: Airports as a Factor in City Planning, vol. 17, No. 3, pp. 181-194, illus., suppl. to National Municipal Review, March, 1928.

Hanks, Col. Stedman S.: International Airports, 200 pp., 30 illus., The Ronald Press Company, New York, 1929.

Hubbard, H. V., and H. K. Menhinick: The Airport in the City Plan, National Conference on City Planning Proceedings, 1930. 
Miller McClintock, and Frank B. Williams: Airports, "Harvard City Planning Studies," vol. I, Harvard University Press, 1930."

Keynoe, D. E.: Construction and Rating of Airports; 2d. ed., rev., 66 pp., diagrams, U. S. Department of Commerce, Aeronautics Branch, Information Bulletin 2, 1927.

Miller, Paul D.: How Does the City Look from the Air? Pp. 125-127, American City, November, 1930.

Nolen, John: Airports and Airways and Their Relation to City and Regional Planning, 22 pp., plan, National Conference on City Planning, New York, 1928. 


\section{CHAPTER XII}

\section{SYSTEMS OF UTILITIES OTHER THAN TRANSIT AND}

\section{TRANSPORTATION}

The utilities other than transit and transportation we are perhaps accustomed to think of mostly as the invisible conduits of water, sewage, power, heat, light, and so on, that are safely concealed below the streets. While indeed large parts of these utility systems are kept out of sight, there are structures such as power houses, pumping stations, purification works, disposal plants, and reservoirs that may be not only visible but among the most interesting and attractive features in the city plan. There are, however, certain parts of these utility systems that are still much too conspicuous along our streets and alleys, and perhaps the sooner they too are made completely invisible the better.

A number of problems concerning the development of water supply, sewage disposal and other systems of utilities should be considered in connection with the development of the city plan. As with other elements of the plan, there is an interdependence that needs to be thought of and that when properly considered may eliminate largely the element of chance and so may achieve important economies in construction, operation, and maintenance.

Water Systems in the City Plan.- Some one has likened a water system, with its various works for collection, purification, and distribution, to a tree. The roots represent the collecting reservoirs (including the inflowing streams and pumping installation), the trunk represents the principal supply main, the branches the distribution system, the leaf stems the service pipes, and the leaves themselves the places of consumption. To be completely analogous, however, this tree would have its branches interconnected.

The fundamental principle of water systems is that there shall be unlimited supplies of good water. The sources may be lakes, rivers, or ground waters, near or far away. They may flow from elevated sources by gravitation or may need to be pumped to 
required heights. They may need to be stored in reservoirs, or they may need to be purified by settling, aeration, filtration, or other methods. Whatever the method, however, it must be carried out under conditions that are clean and that appear to be clean. The water plant should have ample reservations, near a

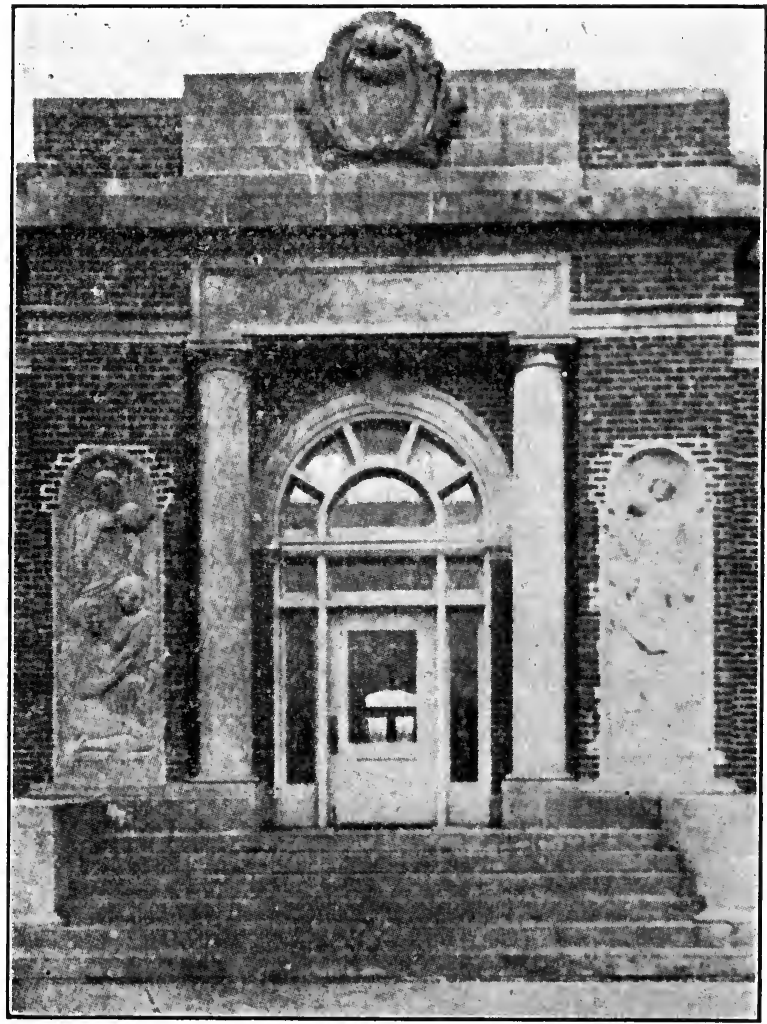

FIG. 69.-Entrance to the water purification buildings, Springfield, Ill.

forest area or in a recreational development, and may be in the vicinity of a high-class neighborhood.

The works for the collection and purification of water should as far as possible be expressive architecturally of the high purpose which a water system serves in the life of a community (Figs. $69,70)$. Water towers may well be monumental structures rather than the unsightly steel tanks of the past. Where aqueducts reach the city, there could be cascades, waterfalls, or ter- 
minal fountains, like the Aqua Paola and Trevi fountains in Rome or the Wittelsbach fountain in Munich.

The reservoir should be an important feature in the plan of the city and of the region as well, because of the large area it involves, the recreational interest that it holds, and the beauty that it affords. Where appropriate to do so, the opportunity should be availed of to fit the reservoir and its parts into natural surroundings. Whether of earth or masonry, the dam may be made to fit into the countryside and the overflow channels con-

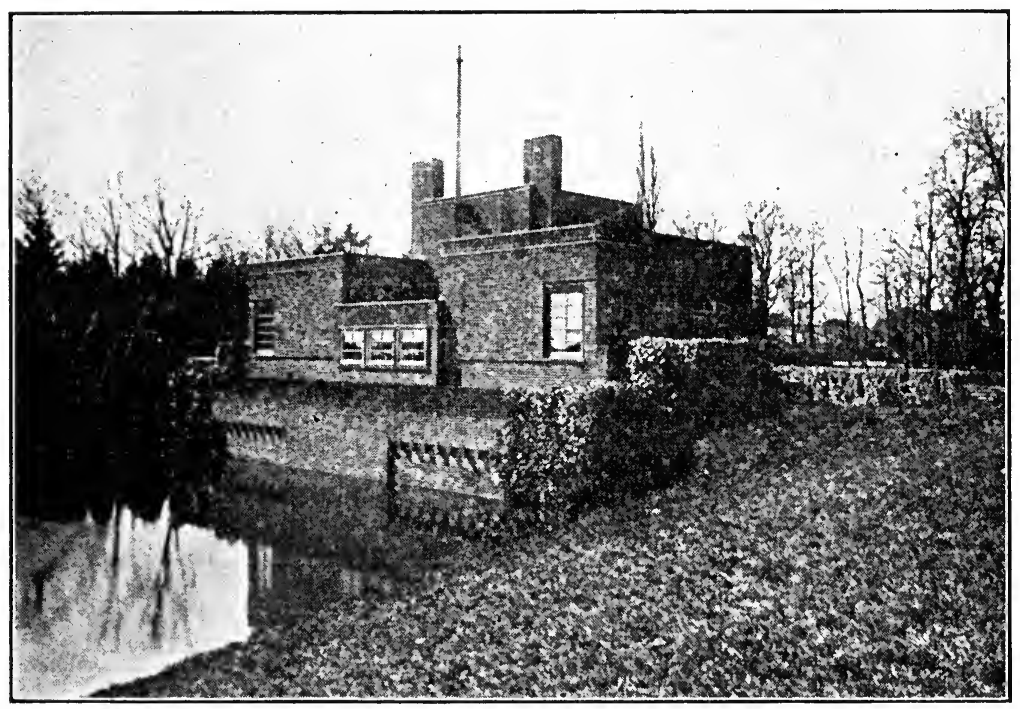

FIG. 70.-Pumping station, Hilversum. Utility structures may be both useful and beautiful.

nected with the dam may be built into fascinating points of interest where water may fall over rocky ledges or run along boulder-strewn channels. Since the marginal roads may be the principal means of enjoyment of the reservation, these should encircle the reservoir, parallel the shores but not too closely, and present glimpses from time to time through the surrounding plantations of pine, hemlock, and other evergreens. Great beauty has been attained in the reservation for water supply in the metropolitan park district in Boston. Particularly impressive is Spot Pond with a water surface of almost 300 acres. It is enclosed by rocky shores, moss-grown boulders, gravel and 
sandy beaches, and heavy growths of evergreens. In the midst of it is an island, and about this lovely reservoir are marginal roads.

The distribution of water is entirely a practical problem and one that should be governed largely by what the city is to be and in what manner its various parts are to develop. Water is distributed by means of primary and secondary feeders and distributors. The primary feeders with relatively wide spacing form the skeleton of pipes that convey large quantities of water to various points in the system for distribution; the secondary feeders form the network of pipes of intermediate size; and the distributors are the small mains serving both the individual fire hydrants and the blocks of consumers.

The necessity of applying the principles of city planning to the design of these distributing systems is becoming more and more apparent. Especially is this so in the case of transitions from one type of use to another. A residential area of small homes is adequately served by a 6 -inch main; but when this area is suddenly transformed into a district of apartments and hotels of many stories, then an entirely new set. of population and firefighting requirements are demanded of the water system. The need for these larger services is sometimes not discovered until after expensive new pavements have been laid. This results in the too familiar picture of the wasteful cutting of pavement over considerable stretches, a situation that by proper foresight might have been avoided.

If the types of residences that are to be built in the various parts of the city are known as well as the other forms of uses, then different pressures, capacities of mains, types and spacing of hydrants, all may be determined in a reasonably accurate manner in advance of development. Through the aid of coordinated planning, the uncertainty as to the trend both of building and of population will be avoided, and thus the interferences with traffic during repairs or renewals, not to mention other losses in time and money, will also be avoided.

Sewerage Systems. - With the introduction of public water supplies, the need for the removal of liquid wastes became a vital requirement in the life of the modern city. Although we do not attach to sewerage systems the same importance that we connect with the more visible developments in the city, nevertheless they serve us most vitally and contribute to the achieve- 
ment of cleanliness and the prevention of disease in our towns and cities.

These important works spread out in the city plan either in the form of a single set-up (or "combined system") to accommodate the combined flow of storm water and sewage or in the form of a double set-up in which storm water and sewage are carried away separately (in a so-called "separate system"). Whether combined or separate, the systems are laid down in a treelike pattern similar to a water system with all of the laterals connected with submains and these connected branchlike with the main or trunk sewer. The latter, in turn, leads to the point of discharge.

The choice of either system depends upon a variety of local conditions which we shall not discuss here. A combined system, according to Prof. H. E. Babbitt, should be used where the district is densely built up and where it is evident that storm and sanitary sewerage must be provided soon and where both sanitary and storm sewage must be pumped. In the opinion of W. W. Horner, the tendency has been to build combined systems using intercepting sewers with storm water overflows when it is necessary to carry dry-weather flow a long distance for treatment or disposal. To fulfill the requirements of efficient sewerage, it is necessary, therefore, to conform to various physical and human considerations.

In cities or parts of cities that are located on high ground, the sewerage problem is likely to be more simple, because the pipe lines may be arranged along streets that follow the natural drainage channels leading to the natural outfall. In cities or their parts, however, that are located upon low ground, sewage may need to be emptied into tanks and in turn pumped to heights sufficient for flow to the chosen outlet. The use of low-lying areas is an important city planning sproblem largely because of drainage and sewerage. As a rule, we should not expect to use low ground for homes because of the tendency toward inferior development on land of that sort. The expense of the drainage and sewerage relief that is necessary cannot easily be assessed against properties having low values. Because of floods, high ground water, extremely flat grades, and possible pumping requirements, low areas in time will be faced with the need for improvements that require high cost of construction, maintenance, and operation. Such localities, therefore, are much more 
adaptable to park uses or to railroads and heavy industries. These do not usually require extensive sewers and underground drainage, but when they do, the high values of the property permit the work to be done. A plan of the city in which the drainage problems of undeveloped areas have been anticipated is useful in helping to prevent premature and ill-advised extensions into areas unsuited for development.

The three factors governing the cost of sewers-length, depth, and size-are obviously affected by the type of the district served. Among other things, these factors are directly related to the density of population, the per capita water consumption, permissible heights of buildings, and the degree of imperviousness of the ground surface in the locality concerned. These are things that can be determined only after trends of urban growth and character of occupancy are known for the given city, town, or neighborhood. Here, as in the case of water supply, it makes a great difference whether an area is occupied by residences, industries, commercial houses, or recreational developments. In one- or two-family houses and in industrial buildings, the cellars, for example, are not over 4 to 5 feet below the curb and consequently require shallow sewers, whereas commercial buildings require deeper ones.

The important factor of the imperviousness of the ground surface is to be considered, too. Since it varies anywhere from 100 per cent for districts that are entirely built up to 30 per cent or less in the more suburban areas, it is essential again to know the character of developments that may be expected.

The collections of the liquid wastes are disposed of in three different ways. They are discharged directly into a river or other body of water; they are intercepted and conveyed to a point where there will be no objection to them; or they are treated so as materially to change their character before being discharged into a body of water (Fig. 71). As sites for treatment works are rather difficult to secure when a country is built up, such sites should be reserved early in the scheme of things. There can be no objection later so long as there is a complete understanding as to the use of such areas. These sites should be at points outside the thickly settled districts. On the large lakes, the works for treatment of sewage should be located in the direction of the trend of waters away from populous neighborhoods. In sections of the country where there happen to be tidal waters, 
long intercepting sewers should be introduced to carry sewage to favorable outlets.

The part that city planning should play in the design of sewerage systems is indicated in the foregoing paragraphs. W. W. Horner, sanitary engineer, estimates that from 10 to 15 per cent of the cost of the sewers in St. Louis could have been saved had a definite plan for the development of the area been adopted when the system was designed. Sewerage systems, however, should

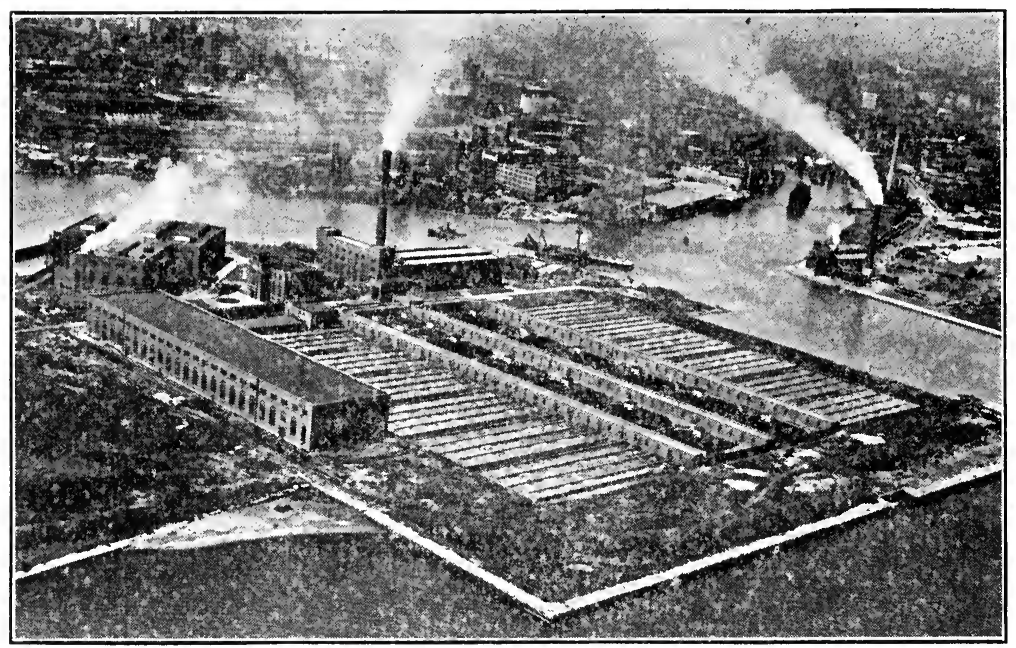

Fig. 71.-Sewage disposal works, Milwaukee metropolitan district. (Courtesy of James L. Ferebee, Chief Engineer of Sewerage Commission, Milwaukee.)

not be considered only as isolated units but should be thought of as part of a regional system. A separate consideration of them leads only to uneconomic and unsanitary results that are menacing both to municipal finance and to municipal health. Narrow political boundaries must have less of a controlling effect than they usually do. Instead the broader reach must embrace the outlying region and its communities in the fullest possible spirit of collaboration and cooperation.

Power, Heat, and Light.-The major services for heat and light are electricity and gas. Electricity is primarily used for light and power and to some extent for heat. While gas once served almost exclusively for light, it is now utilized for various forms of heating, principally for cooking, and to some extent for refrigeration. Power, heat, and light have been supplied 
principally by privately owned companies and these have seen rapid growth since 1900. At first they appeared in the form of a number of separate plants, but during recent years the tendency has been toward their consolidation into large units, with many of these large units interconnected for emergency purposes.

Among the numerous mechanical improvements in connection with electricity, none is of more significance to us perhaps in its future possibilities than that of long-distance transmission. The mass production of power, now being thought of in terms of superpower, stresses the development of the great rivers and the operation of steam-electric plants in the coal fields together with a coordination into a system of interconnected transmission lines. The cheaper supply made available by such a comprehensive superpower (or superutility) scheme will be welcomed by industry and by the friends of railroad electrification. We cannot help wondering what effect such superpower may have upon decentralization of industry, provided electricity can be obtained with equal facility throughout the entire urban region.

There are two types of manufactured gas, "coal" and "carbureted." Coal or coke is needed to make one or the other of these types, so that the plants manufacturing them must be accessible to these necessary"raw materials. For this reason, many large gas concerns are located along navigable waterways. These establishments, so objectionable because of their unsightliness and odor, should be located at a comfortable distance from any kind of residential neighborhood. Since they are, in general, considered less hazardous than many other forms of manufacture and less of a nuisance than types of industry that emit large volumes of smoke and dirt, they should be permitted in heavy industrial districts.

Telephone Systems.-In its need for proper and economical planning, the telephone system is no different from other utilities. Since customers are obliged to pay for unnecessary costs in such a system as this, it is to their interest as well as to that of the stockholders that good economical arrangement be possible. The planning of telephone systems concerns itself among other things with the growth, distribution, and character of the population. Just as there are adequate circulation routes for traffic, in the same way there are adequate circulation routes for the telephone. Just as schools must be centrally located with respect 
to the children served, in the same way certain buildings specially designed for complicated interconnecting and switching mechanisms should be economically located with reference to the wire centers. Telephone central offices are located to the best advantage in neighborhoods that are free from noise, smoke, and dirt, away from steam railroads and from street cars or heavy traffic. A system of this kind must anticipate as nearly as it can the nature of the population and its activities 25 to 50 years in advance. It must also take into account the community of interest between the town or city as a whole and its surrounding communities.

Tunnels for Utility Mains.-The interferences with traffic and the possibilities for accident are familiar to any one who has seen the disruption of streets for the purpose of repairing or making extensions and attachments to many of the utilities. As a result of such repeated obstructions to traffic, an effort is being made to put some or all of the utilities under green spaces between sidewalks and the street, under sidewalks, along alleys, or in tunnels. The savings that may be affected by installing utility galleries (or tunnels) are such that they deserve careful consideration despite the high first cost of installation. Some of the requirements for such tunnels explain their value as well as their high cost. They must be roomy, tall enough for a man to pass comfortably through them, well ventilated, well lighted, equipped with an adequate number of convenient entrances, easy of approach, and provided with tracks for conveyance of refuse and other materials. In such tunnels the electric lighting and other cables should be placed as far as possible from gas mains so that all risk of contact may be reduced.

\section{Questions for Discussion}

1. What effect has uncertainty in the trend of building development had in the past on the design of utilities, the destruction of pavement, and obstruction to traffic?

2. How may the design of a water system be affected by the consideration of the plan of the city as a whole?

3. Discuss the various sources of water for water supply; various means of purification.

4. Review the subject of reservoirs, particularly with respect to dams, shores, overflow channels, islands, marginal roads, vegetation, surroundings.

5. What are the architectural and landscape-architectural possibilities of water systems; of sewerage systems? 
6. Explain the meaning of separate and combined systems of sewerage and the circumstances under which one or the other is introduced.

7. How does topography effect the design of a sewerage system?

8. Indicate how the development of property of low elevation is related to matters of drainage and sewerage.

9. What different methods are there for disposing of sewage and where in the city plan should such disposal be taken care of?

10. What relationship is there between different intensities of population and the factor of imperviousness?

11. Does electricity promise to exert any special influence upon the layout of cities in the future?

12. Explain the importance of "coal" or "carbureted" gas in the life and plan of the city.

13. How is the design of a telephone system related to the general urban layout?

\section{References}

Annual Reports, Metropolitan Water and Sewerage Board, Boston, Mass. Annual Reports, New York Board of Water Supply.

BABBitT, H. E.: "Sewerage and Sewage Treatment," 512 pp., illus., John Wiley \& Sons, Inc., 1922.

Babbitt, H. E., and J. J. Doland: "Water Supply Engineering," 745 pp., illus., McGraw-Hill Book Company, Inc., 1929.

Eddy, H. P.: Sewerage and Drainage of Towns, Proceedings American Society of Civil Engineers, vol. 53, pp. 1603-1617, September, 1927.

Landscape Treatment for Water and Sewerage Plants, Water. Works and Sewerage, vol. 76, pp. 523-524, December, 1929.

Leavits, C. W.: Water Supplies and the Part They Play in. City and County Planning, American City, vol. 10, pp. 422-426, illus., May, 1914.

Relation of Water Supply to Zoning, American City, vol. 33, pp. 7-8, July, 1925.

Saville, C. M.: Water Supply and the City Plan, J. Nolen, ed., pp. 181199, "City Planning," 1929.

The Influence of Zoning on the Design of Public Utilities: A Symposium, Proceedings American Society of Civil Engineers, vol. 51, pp. 219-261, February, 1925; Map, tables, diagrams, discussion, pp. 447-455, March, 1925.

Water Supply and Sewerage Problems. Power, Light and Other Supply Services, "Regional Survey of New York and Its Environs," vol. VIII, 1929, pp. 34-75, 110-136. 


\section{CHAPTER XIII}

\section{PARKS AND PARK SYSTEMS}

A city may have its industries, its shipping facilities, and its labor and may be blessed with a large measure of business, but if it be wanting in those qualities of living that represent a more fruitful and happy life for its people, it falls short of its highest possibilities. There is nothing in the city plan that may contribute more vitally to this richer life of the people than appropriate provision for recreation. There is nothing that deserves more earnest consideration. This is emphasized by our increasing capacity for production that is being accompanied by an enlarging of time for leisure. Indications are that if the present tendency continues our people may indeed eventually have at their disposal more leisure than any other great nation of history. The necessity for wholesome use of expanding leisure was never greater. The need to plan for it in our towns and cities therefore takes on a new importance and should be given greater and greater consideration in all present and future planning.

Value of Recreation and Recreational Facilities.-Experience has demonstrated that where appropriate facilities for the use of leisure time are found wanting, there likewise are absent the opportunity for much needed sunlight, wholesome exercise, freedom of space, release of creative energies, and contact with nature. Under such circumstances the people are deprived of their right to health and happiness. Juvenile delinquency is encouraged by lack of recreational enjoyment, and in turn there is more vice and crime among the adults. The possibilities for the creation of wealth for the city are likewise concerned. Recreational areas suitably developed have been found to increase substantially the value of adjacent property and consequently have helped to improve the general tone of the city.

The advantages to the city that accrue from well-planned recreational areas affect so vitally the life of the community that they cannot be neglected. Indeed, the growing conviction among 
students of the subject is that recreation and the livableness of the city are one, and the response to this conviction can be seen in the growing willingness of the people to pay for parks and playgrounds. This response is illustrated by the increasing bond issues for purposes of recreation, and it is also seen in the growing practice among subdividers of apportioning the cost of the space allotted for these recreational purposes and adding it to the price of their lots. These subdividers are persuaded that the added value caused by proximity of the lots to recreational areas guarantees a greater profit upon the money invested. Another indication of this growing interest was the appropriation of $\$ 30,000,000$ recently voted by the Board of Estimate of New York for the purchase of new park sites and playgrounds. No previous appropriation has ever been made for a like purpose in New York histoy tinat has approximated such a figure, and the sum is expected to be spent within the next 3 years.

The interest of the people in parks and playgrounds in the United States goes back, in the case of parks (if we exclude the early squares and commons), to the development of Central Park, New York, in 1854, which was the first of our typically American parks. In the case of playgrounds it was in about 1885 that sand courts and an outdoor gymnasium made their appearance upon the banks of the Charles River in Boston. Eloquent of the interest of our people in this enterprise are the 300,000 acres of parks and other recreation spaces that to date have been acquired by the various cities of the United States.

Types of Recreation. - Partly because of the way in which the need for recreation has been increasingly appreciated and partly because of the character of its service, recreation divides itself into two kinds of service each of which is in some respects quite distinct from the other. One kind supplies the needs for open space and fresh air and furnishes an opportunity for the people to see and enjoy peacefully the great outdoors or "undespoiled nature." It furnishes what is so keenly missed by the people in increasingly congested quarters of the city where evidences of these things are so completely obscured. The other kind of service supplied by recreation offers the opportunity for physical regeneration through the active use of bodies and muscles in games and play of one kind and another, as provided by playgrounds and play fields. Both of these types of recreational service - the active and the passive, playground and park-have attained a 
wide range of physical, cultural, social, and civic betterment for the dwellers in cities. Although each of these two kinds of recreational service tends more and more to overlap the other, nevertheless each has attained such importance and specialization that it deserves special thought on the part of the city planner. Let us now consider the subject of parks and systems of parks, reserving for separate and later consideration the matter of playgrounds and play fields.

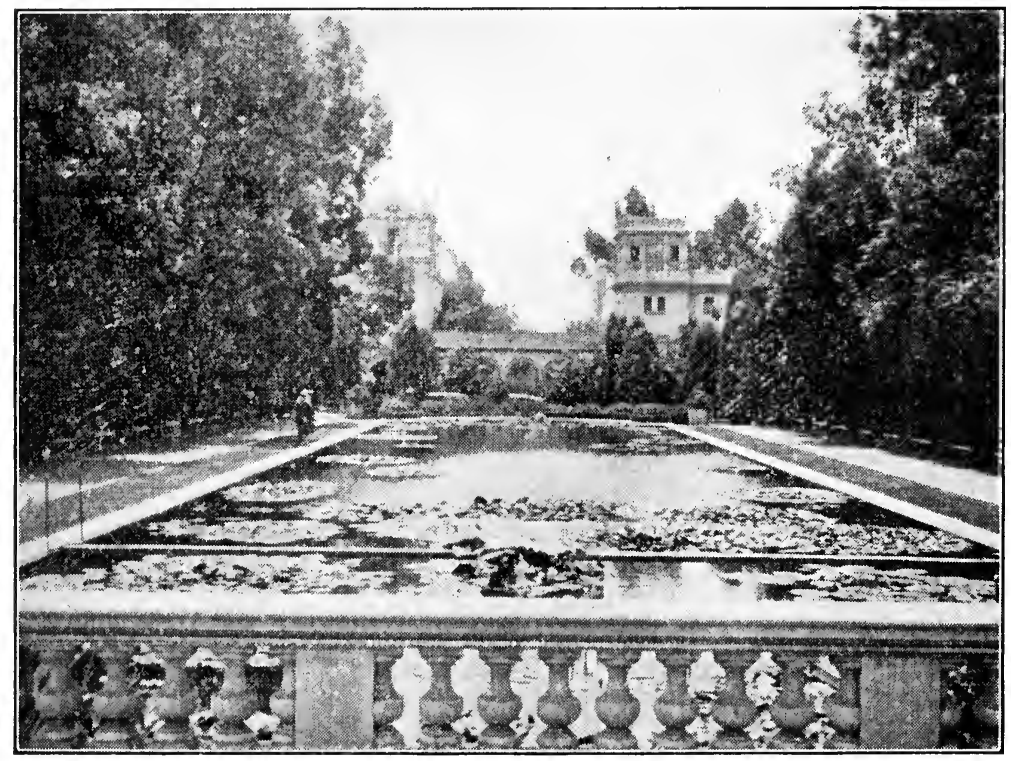

Fig. 72.- Balboa Park, San Diego, Calif. Formal features may supplement the naturalistic to advantage even in our large parks. The above center of interest, a relic of the Exposition, still remains in Balboa Park. It is one of the worthiest expressions of formal beauty among American parks. (Photograph by the author.)

Variety in Parks.-Although parks may be said to serve as breathing spaces and attractive areas for refreshment to both body and mind, they are subject to considerable variation in size, purpose, location, and character and therefore are amenable to a variety of classifications. Parks may be small or large, near at hand or far away, serving neighborhoods or entire cities. Again, parks may be recreational or educational, as when in the form of botanical and zoological gardens, or they may be historical, as when either commemorating some outstanding event in history or the life of some eminent person. Further, parks may be 
formal in character (Fig. 72) or informal (Fig. 73), abundant in artificial features of interest, or more luxuriant in the natural elements of beauty. They may provide for traffic or may exclude it and may be lavishly or indifferently maintained. Parks may be isolated and scattered or they may be tied together into an interrelated unit or so-called "system." This multiplicity of the conditions and types of parks, however, can be summarized or

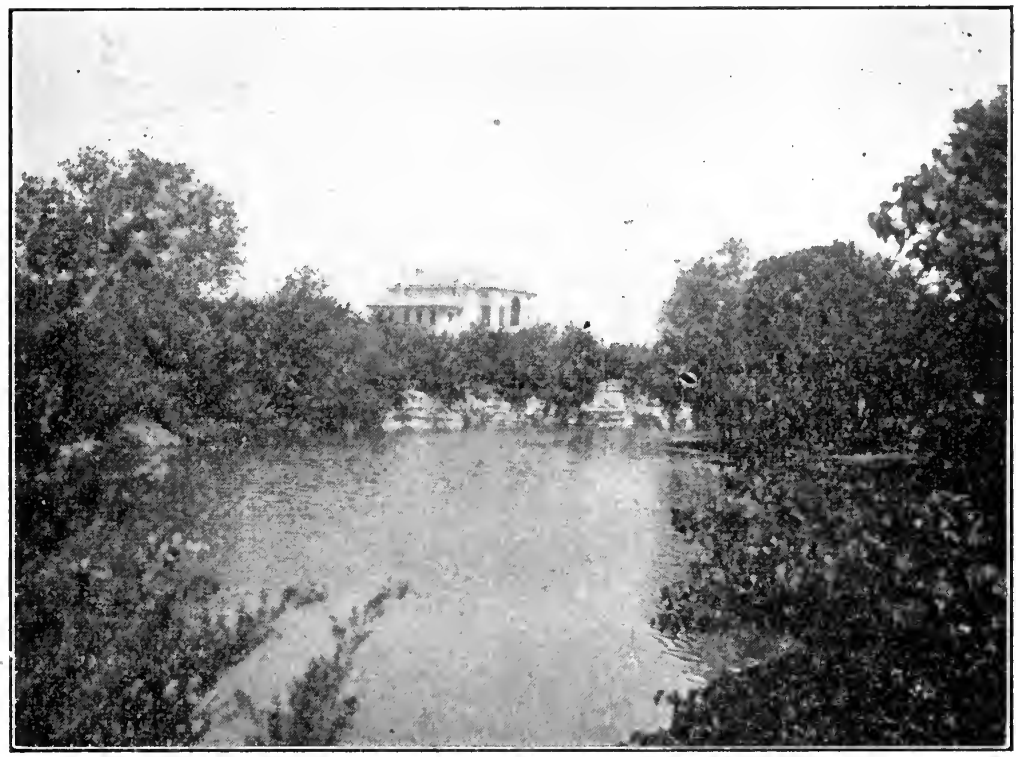

Frg. 73.-Highland Park, Tex. Upon the assumption that it is well to reserve the borders of a stream in parks and boulevards, the head waters of Turtle Creek as they flow through Highland Park, Tex. (adjacent to Dallas), have been so treated. Driveways have been introduced on both sides of the creek much to the pleasure of the people using them. (Photograph by the author.)

narrowed down for convenience into four principal kinds, namely the small-, the medium-, the large-sized parks, and the parkways.

Small Parks or Squares. - The smallest of our parks are in the downtown sections. The prices of land are highest in such territory, and too large areas for parks would be an interference with the circulation of traffic in the business portions of the city. The typical small park downtown is the "square," so called regardless of shape. This type also is representative of the oldest of the parks with which we are familiar in the United States. Although the square or plaza of Santa Fé was established as early as 1565, it serves still as a "social, dramatic, musical, 
political, rest and relaxation center to this day." In New England, town commons and village greens are familiar to us, the largest and best known being that of the Boston Common with 44 acres in public use since 1634 . The public squares of 6 -acre plots reserved at regular intervals in William Penn's plan of Philadelphia, adopted in 1682, showed important foresight on the part of the planner and had a great influence upon the arrangements of other cities in our country. In like manner, the allot-

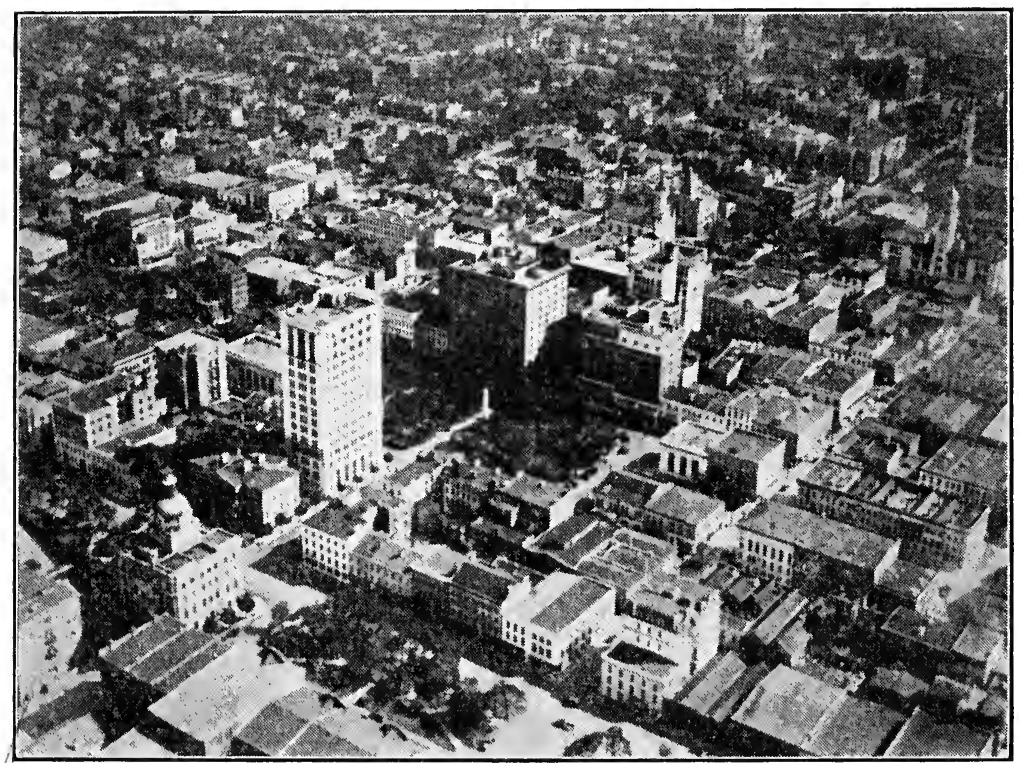

FIG. 74.- Air view of downtown parks of Savannah, Ga. The liberal distribution of parks in the business section of Savannah, is unparalleled among American cities.

ments for parks in the early layout of Savannah, Ga., in 1733 (Fig. 74), are outstanding, and the same is true of the like allotments in Salt Lake City (1847). The courthouse squares of the Middle West are characteristically familiar and interesting. These comparatively small areas in the central business sections of our cities are usually from 2 to 10 acres in size. They serve mainly as settings for adjacent buildings or for monuments and provide a haven of safety and comparative quiet for the people. in the vicinity of considerable traffic. Such parks are usually architectural in character and make possible the free and direct circulation of pedestrians as well as seating facilities for those who 
would linger and rest. Where streets meet at acute angles with resulting areas left over, these areas can be used as parks, similar to the squares. Many of these triangular plats occur in those plans in which diagonals are superimposed upon rectangular systems of streets, such as in the original plans of Washington, Buffalo, Erie, and Indianapolis.

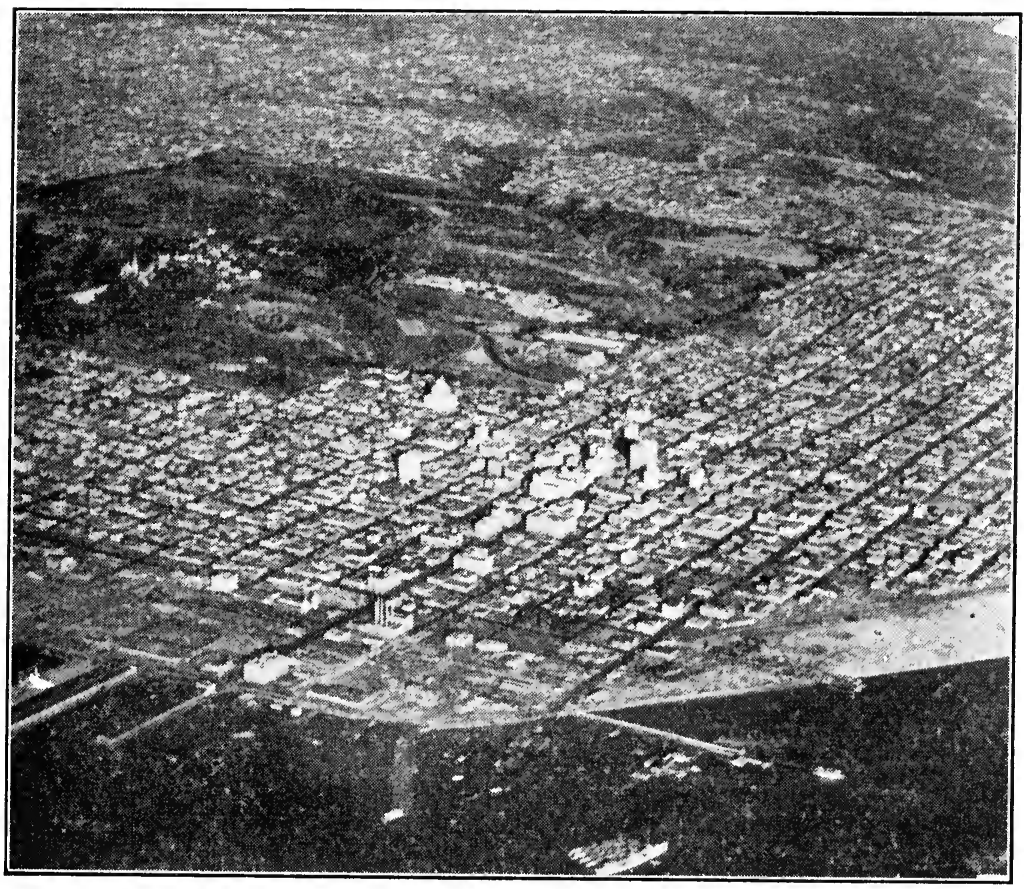

FIg. 75.-Air view of Balboa Park, San Diego, Calif. In principle it would be better to have a park-surrounded city than a city-surrounded park. Although San Diego has reason to be proud of her 1,400-acre Balboa Park, yet so large an acreage in the midst of the city may in the course of time prove to be an obstacle to circulation-unless ample provision is made for getting across the park tract. (Illustration furnished by San Diego Chamber of Commerce. Photograph by Erickson.)

Medium-sized or Neighborhood Parks. - A neighborhood park for every square mile of residential section in a city, or for every 2,500 families, brings a park within easy reach of everyone. Since such a property is likely to be generously patronized, it should contain upward of 30 or more acres. The neighborhood park should be intimate, compact, and serviceable in its equipment, giving ample opportunity for use by the people of the neigh- 
borhood. Both active play and passive recreation may be indulged in these parks. They are logical places for community buildings and thus they serve the uses of a neighborhood center both indoors and out.

Large Parks.- The park in its true and original American sense can more nearly be furnished in the large park than it can in

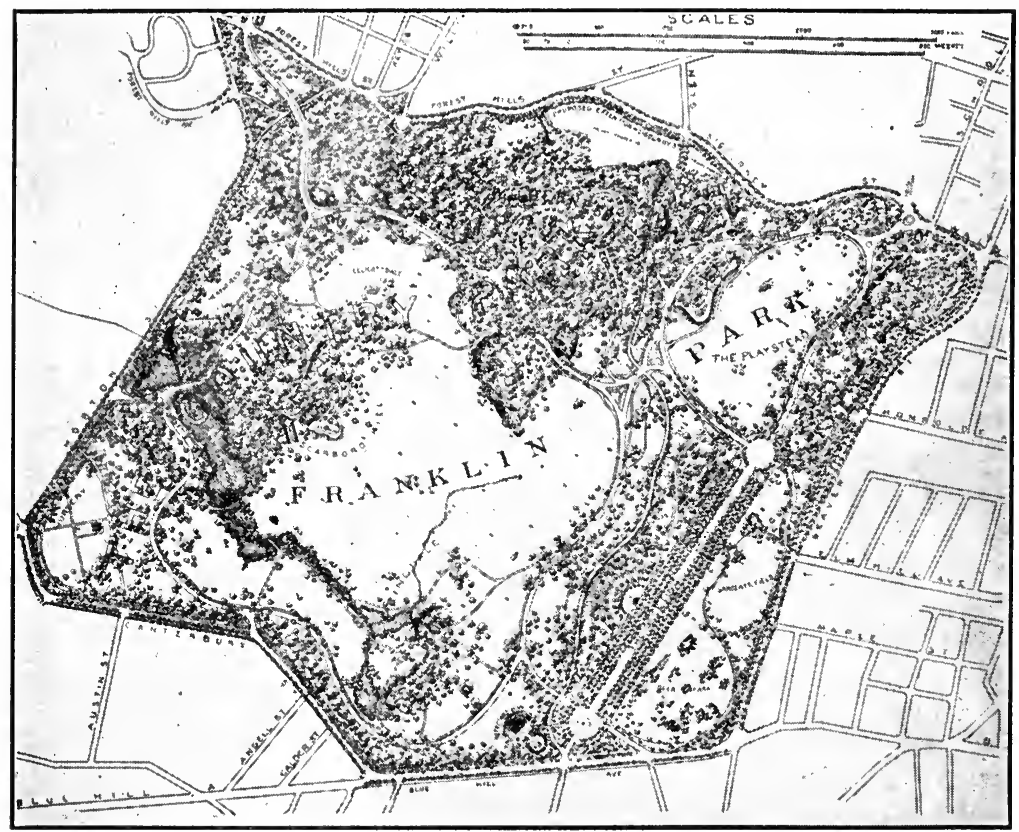

FIG. 76.-Franklin Park in Boston. This is one of the oldest and most interesting of the larger municipal recreational spots. It fulfills well its main purpose which is said to be "to adapt it in the fullest possible measure to the obtaining on the part of the multitude, of the restful, health-restoring recreation, obtained from enjoyment of beautiful rural scenery." Some 500 acres are comprised within the park and it was laid out by F. L. Olmsted, Sr.

any other. That is to say, there is opportunity in the large park to supply to the citizens frequenting it the outspreading open stretches and the enjoyment that accompanies such broad expansive outlooks, with comparative immunity from everyday urban scenes (Fig. 77). There may be a series of such larger areas, of necessity mostly outlying ones, some of them perhaps at a considerable distance from each other and from the city. These large parks may be of different types. On the one hand, they may be somewhat wild and natural, in the form of reserva- 


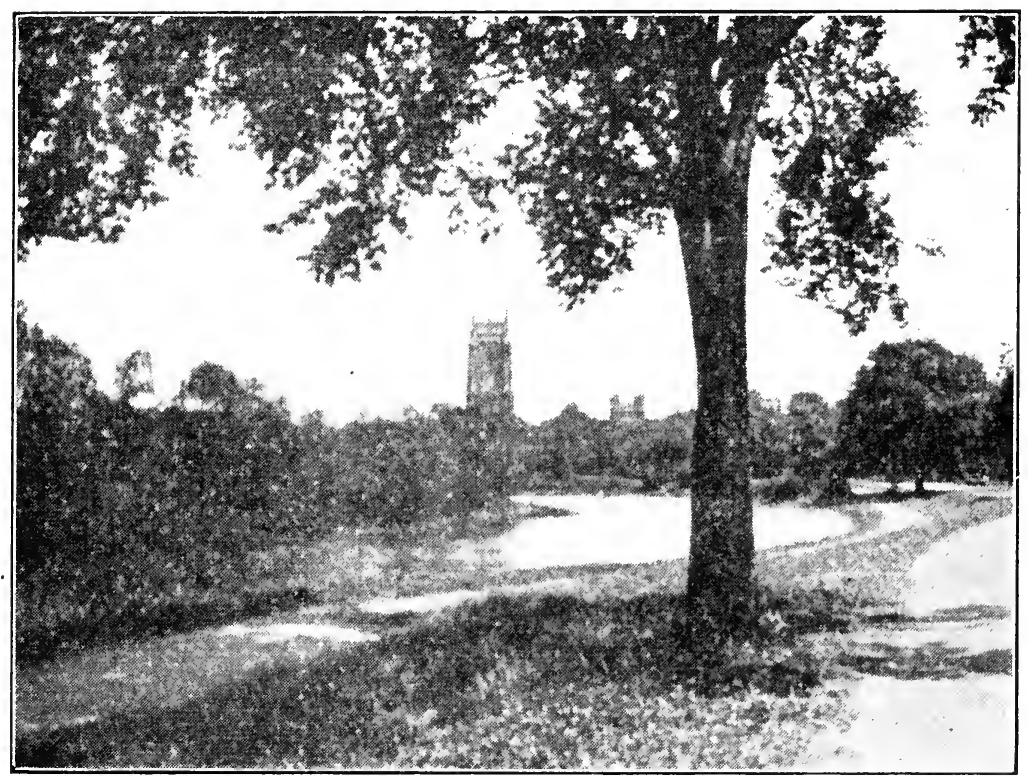

FIG. 77.- View of the lagoons, Audubon Park, New Orleans. For charm and beauty Audubon Park deserves a place close to the top among our American recreational spots. (Photograph by the author.)

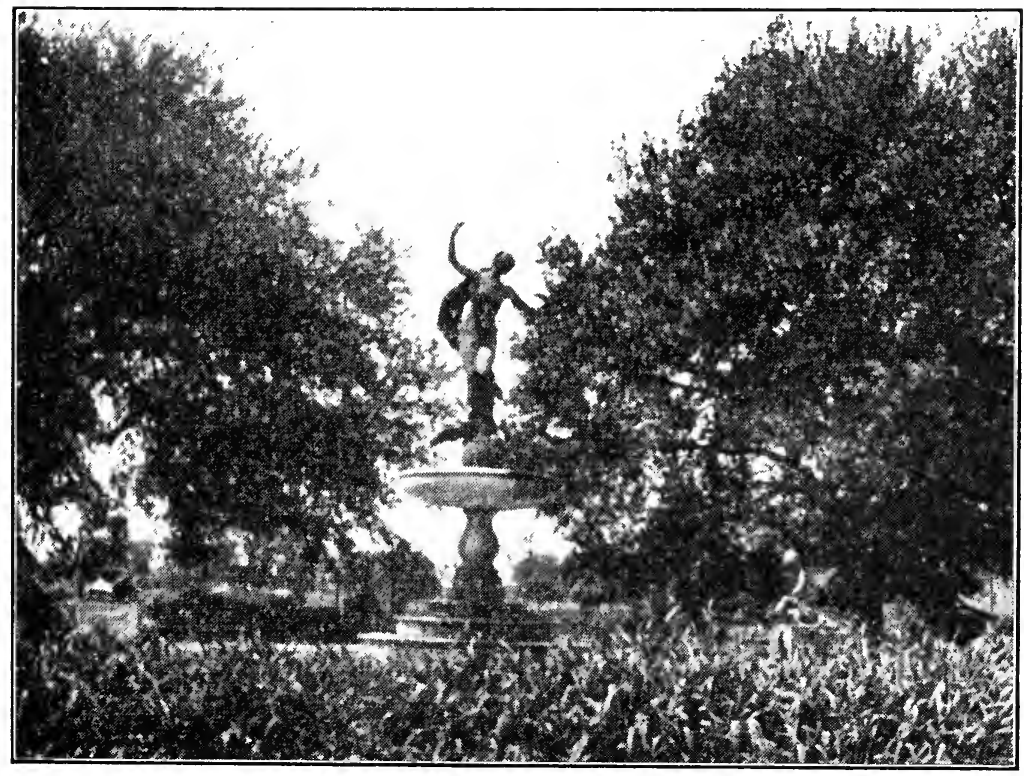

Fig. 78.-Sculptural fountain, Audubon Park, New Orleans. The architecture and sculpture in the Audubon Park of New Orleans are of a high order. The 
tions, like the Cook County Forest Preserve at Chicago (31,600 acres), the Lake Worth Reservation at Fort Worth, Tex., the Westchester County Parks of New York, or the outlying parks of Denver. Again, large parks may be somewhat artificialized and yet remain mostly naturalistic, as in the case of Franklin Park, Boston (Fig. 76), Audubon Park, New Orleans (Fig. 77, 78), or Golden Gate Park, San Francisco. Some of these large parks may be developed to some extent as a zoological or botanical

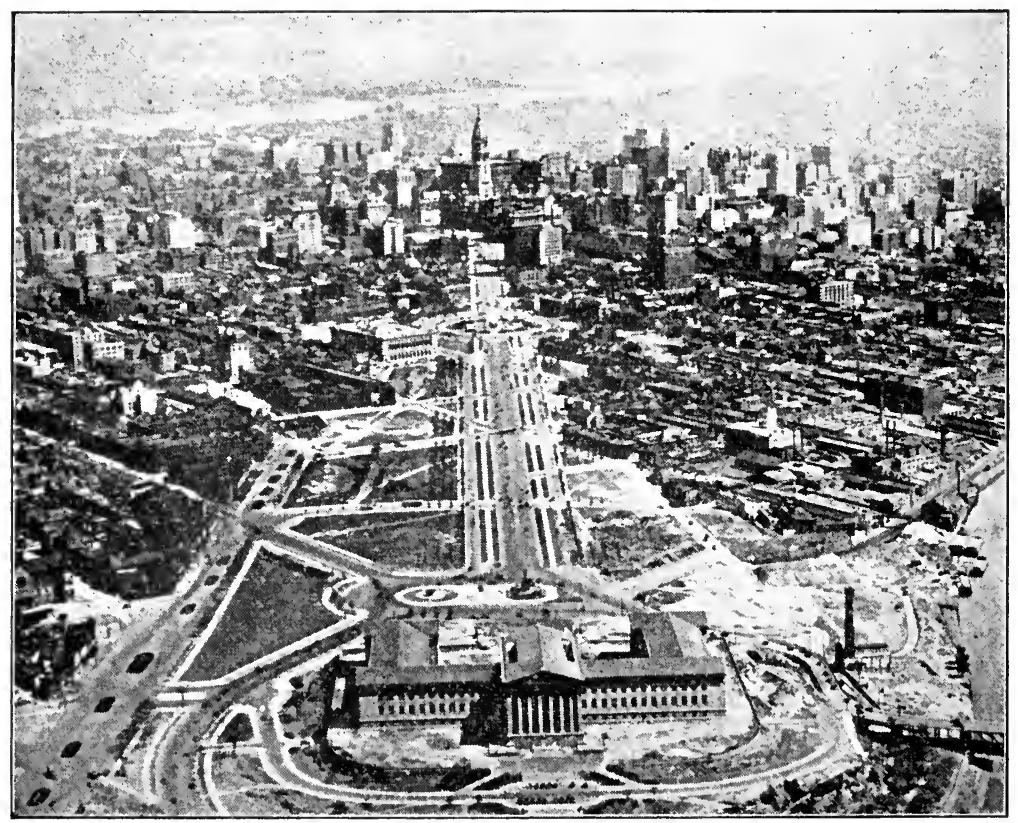

FIG. 79.-Parkway leading to the Art Museum and to Fairmount Park, Philadelphia. (From "Our Cities Today and Tomorrow.")

garden, or a golf course, or they may be given over entirely to such purposes. Certain forests, reservations for supply of water, and even sewage-disposal plants are also used as parks.

Among the municipal pleasure areas, Fairmount Park in Philadelphia with 3,881 acres (Fig. 79) and Griffith Park in Los Angeles with 3,751 acres are outstanding as to acreage among parks comprised wholly within the limits of the city. The largest allotments for parks lying in the outskirts but owned by the adjacent cities are that at Phoenix, Ariz. with 15,080 acres and the one outside the city limits of Denver with 10,000 acres. 
Parkways and Systems of Parks.-Unless parks are made readily accessible to the whole population of the city by a system

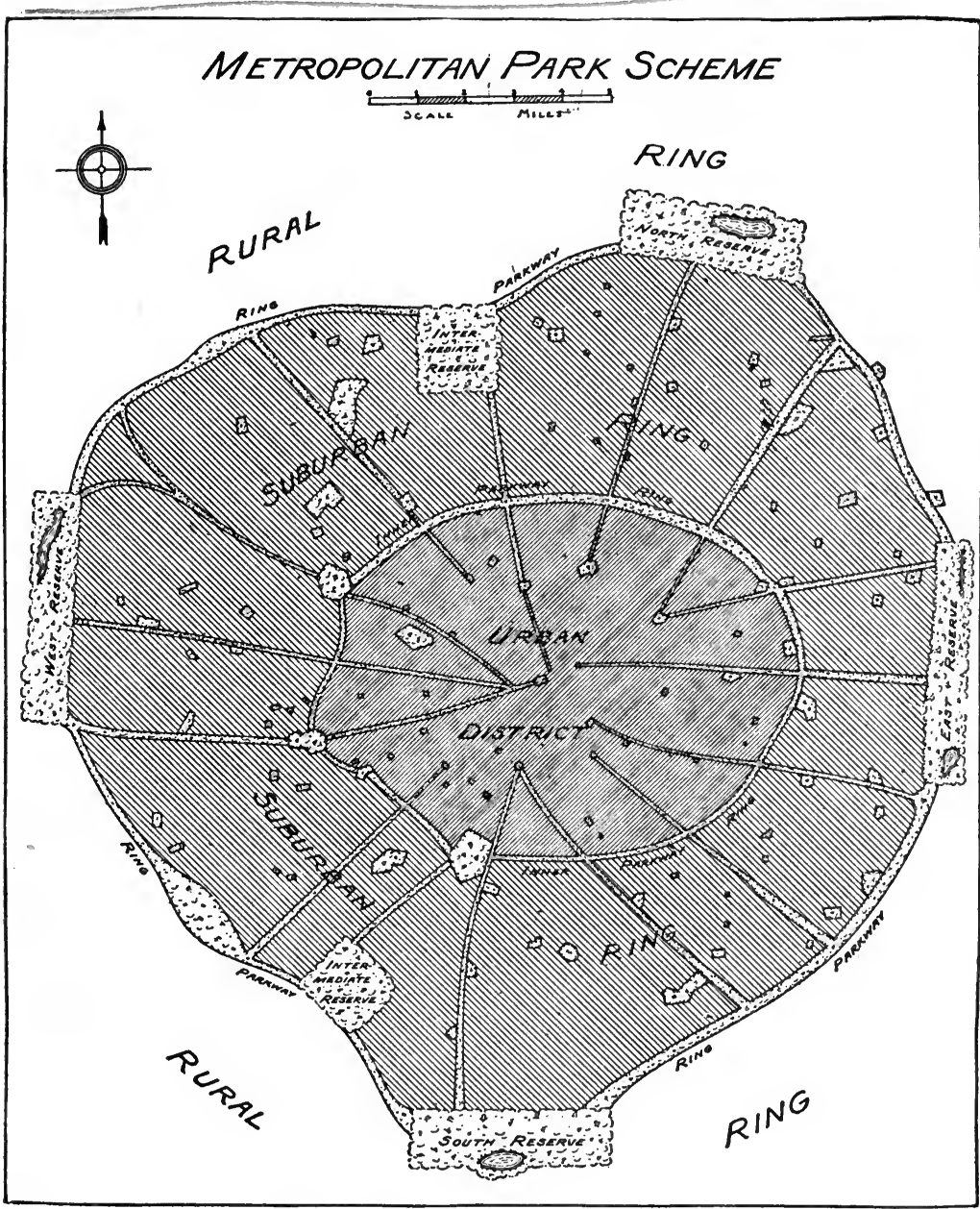

FIG. 80.-Metropolitan park scheme. The possibilities of a metropolitan park scheme are seen in this semi-theoretical plan which suggests an inner city with its quota of several parks and avenues of greenery leading out. An inner ring is suggested about 4 or 5 miles from the center with a chain of well-developed parks. More open districts follow and 10 or 12 miles from the center an outer ring connects the beauty of the high bordering hills. (From "Landscape Architecture," by Stephen Child, Leland-Stanford University Press.)

of appropriate roads leading from one park to another and to all parks of the city, they will not properly serve their purpose. The ideal arrangement of the roads serving the parks is to design 


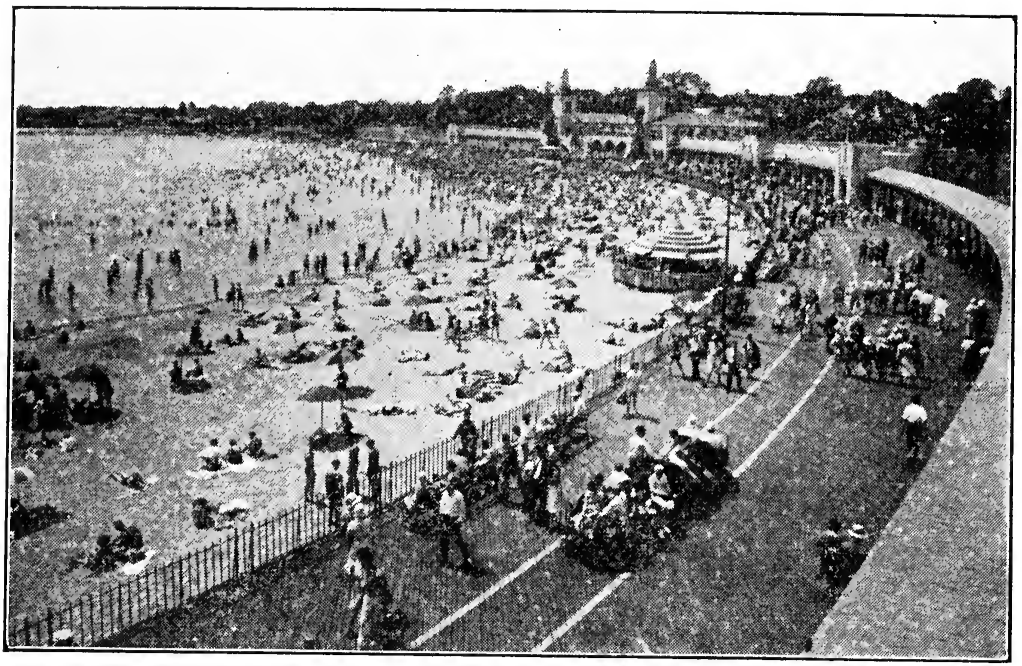

FIG. 81.- Playland at Rye Beach, Long Island Sound. This is under direction of the Westchester Park Commission, and is proof of the fact that an amusement resort need not be ugly. "About 15 acres are given over to a carefully planned grouping of coasters, caroussels, and other features along a central midway. The structures housing the devices have been planned and erected in a unified architectural assemblage. The decorative treatment is based on both lore and fairy tale motives to promote an atmosphere of relaxation and play." (From photograph loaned by the Westchester County Park Commission.)

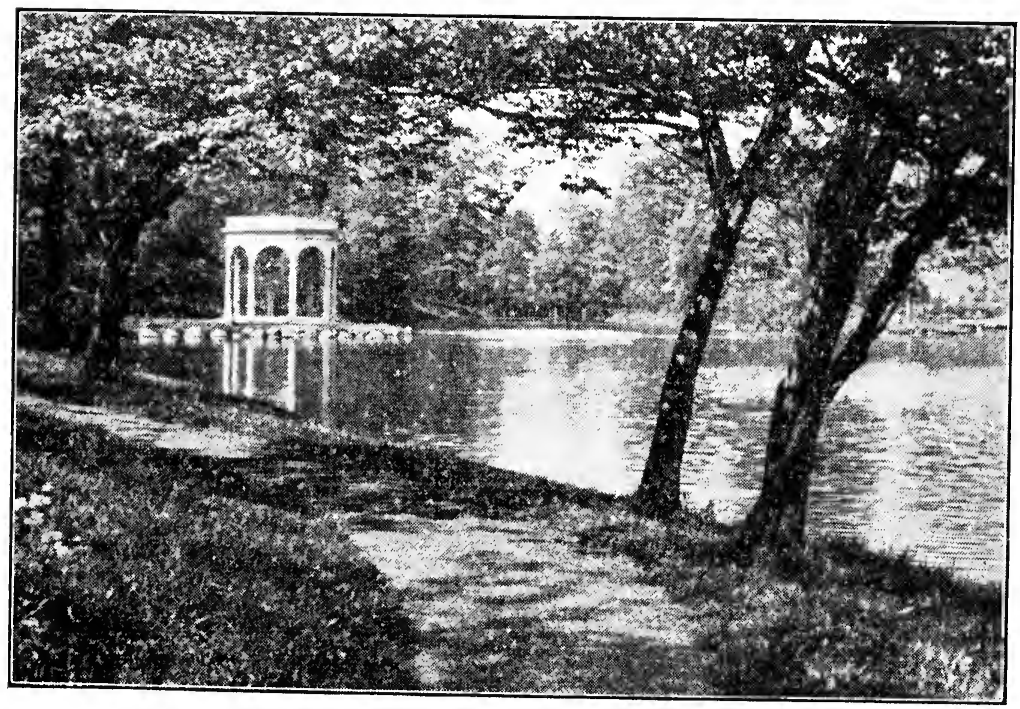

FIG. 82.- Lower lake and bandstand, Tibbetts Brook Park. (Courtesy of Westchester County Park System.) 
a system of one or more belts of parkways encircling the city, together with radiating parkways reaching all of the parks (Fig. 80). A unified system of circulation serving all of the larger parks of the city is in this way possible. These connecting parkways serve as drives with the recreative characteristics of parks. They serve to accommodate lighter forms of traffic, and by having cross-streams of vehicles separated they facilitate movement as well as provide for enjoyment of pleasing scenery. Where there must be buildings among them, such buildings should be restricted

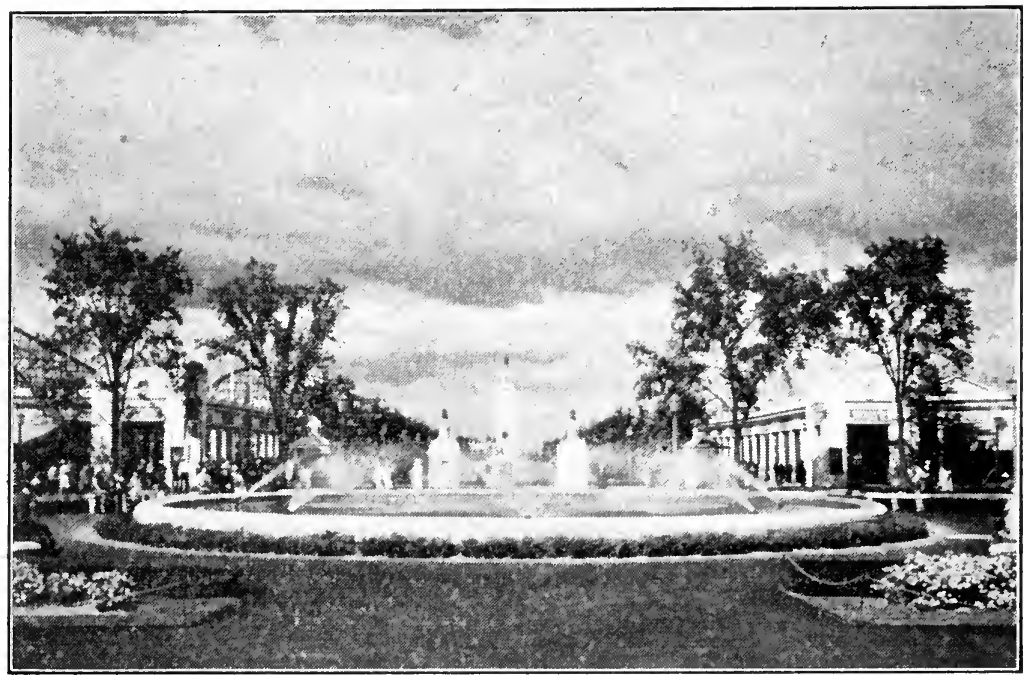

FIG. 83.-The colonnade of amusements at Playland, Rye Beach. (Courtesy of Westchester County Park Commission.)

to a uniform scheme of setback and be made to conform to a high standard of architectural excellence. One of the best illustrations of a complete system of parkways is that at Minneapolis, not only for the outstanding acreage (5,000 acres) of the parks served but for the beautiful character of its development. This system of parkways that leads seemingly from one lake to another, with the completeness of its unification as well as the quality of its maintenance, is superb. Kansas City boasts a fine system of parks, with 100 miles of boulevards and parkways. The Westchester County Park Commission of New York has one of the most extensive systems under construction, comprising 140 miles of parkways, serving recreational spaces on the water front, 
interior parks, reservations, and forest preserves. In connection with these parks and parkways, recreations of all kinds are being provided, even including a well-designed public amusement park known as "Playland" at Rye Beach (Figs. 81, 83). The Bronx River Parkway with its length of 28 miles has taken its place as one of the truly great accomplishments of its kind in the United States.

Minimum Park Requirements.-In connection with the effort to determine the appropriate amount of area for parks within any given locality, the trend of opinion among city planners favors an acreage in proportion to population rather than a flat percentage of the total area of territory to be served. A minimum of one acre for each 300 to 500 persons in any given community is a reasonable allotment for recreational spaces. For undeveloped areas, the present practice of reserving 10 per cent of open space to the gross area covered by the plan ought to be continued, unless the population of the territory concerned should exceed 300 to 500 people per acre, in which event the percentage should proportionally be increased. In addition to such reservations of minimum standard of area for urban parks, the practice is now being advocated of allowing one acre for county parks to each 150 persons of the rural population. It naturally follows that because it becomes increasingly difficult as cities grow larger to provide necessary areas for recreation, especially wherever a program of future needs has not been properly planned in advance, we cannot make the standards for the largersities a model for the smaller towns in this respect. It was found a few years ago that in the nine cities of the United States having from 500,000 to $1,000,000$ inhabitants each, there was much less acreage for parks in proportion to the population than in most of the smaller municipalities; for instance, in the case of Manhattan, although 12 per cent of its territory is reserved for parks and other open spaces, yet on the basis of relation to inhabitants, this amounts to one acre only for every 1,234 persons.

In addition to adequate space, every good system of parks should have a balanced relation to the several types of properties that are reserved for recreational purposes. The neighborhood parks (as well as the playgrounds) are the more numerous, and the larger parks and reservations, while far less in number, excel the other types in acreage. Furthermore, the requirements for parks in any given community will depend upon the extent 
of its population and the portion of the city in which the bulk of the population resides. Parks are always to be planned with reference to the types of recreation needed by the people of that particular neighborhood, as well as with reference to the general direction of the growth of the city.

Sites for Park Use.-Parks cannot always be reserved just where we should prefer to have them according to any preconceived theories. There are occasions when places of natural beauty, regardless of their position, suggest the usage for a park because if used for any other purpose, their natural beauty would be destroyed. Even if they be situated a little to one side of the actual center of the need for a park, they should be preserved. There are some kinds of topography that lend themselves particutarly to use for parks in a community, as, for example, flowing streams or lakes or rocky or steep slopes. Every effort should be made to set apart streams and Jakes as well as their margins for the enjoyment of the people at large.

Although provision for industrial and commercial communication and use should be provided along navigable streams, it is highly reprehensible to sacrifice for such use the entire bank of the stream when its possibilities for enjoyment by the people if a portion of it were reserved as a public park are so patent. Nothing affords greater delight to people than opportunity for leisure along bodies of water; there more air is always stirring during hot weather, there the outlook across the water is refreshing, and there opportunity for boating and bathing always furnishes a source of enjoyment. Promenades beside ponds, lagoons, lakes, and rivers are among the most comforting and refreshing things that a park can offer to the people. So important are such promenades that all beaches and lands lying between boulevards and stretches of water, wherever such lands may be, except in rare and occasional instances, should never be given over to the use of private individuals.

As difficult and undesirable as rocky or steep slopes may be for residential use, they adapt themselves in an eminently satisfactory manner for certain uses for parks. Such slopes suggest to the city planner possibilities for the creation of tangled thickets or forests, for trailing paths, and heights commanding extensive and beautiful views. The sites chosen for parks should be such as to interfere as little as possible with the normal growth of the city. Properties in the form of wedges that narrow toward the 
center of the city are more desirable for parks than those that lie athwart the great thoroughfares. The site for the park should include if possible an entire hill, a complete valley, an entire body of water, and so on. The boundaries of the park should coincide with streets rather than with the rear lines of lots, so that homes or other structures will face rather than back upon the park.

Park Finances.-Public opinion has not been strong enough in the past to place parks and places for public recreation upon the same plane as some of the other municipal functions, as a result of which weakness or indifference of public opinion frequent trimmings have occurred in appropriations originally recommended by competent boards for parks and recreational centers. In spite of these difficulties, however, capital invested in parks and facilities for recreation has increased until today it amounts to $\$ 1,000,000,000$ in the United States alone, while over $\$ 30,000,000$ are being spent here annually in the operation and maintenance of parks and other places of public recreation.

Parks are acquired by the public in a number of ways-by proceeds from sale of bonds, by use of current funds allotted to the park department, by installment payments out of the net proceeds from operation of the park itself, by gifts and donations from citizens of public spirit, by excess condemnation, and by special assessment. There is another rather important method of acquisition-that of "allocation," which is the transfer of property from one public authority to the park or recreation department. There are numerous examples of this method including the transfer of city farms, fair grounds, abandoned school sites, etc. The most common method of acquisition, however, the one most widely employed, is that of the proceeds from the sale of bonds.

Park Program and Administration.-The control of the parks varies according to the form of municipal government. There are in different cities park boards, park departments, or park commissions, which are all under the direct control of a city council or of a committee of the council. In some cities there is a park commissioner, who is elected by the people. In the commission form of government, the commissioner of parks and public properties actually serves as the executive, although he may and often does appoint a superintendent of parks-usually not a trained man. Under the commissioner-manager form of government, the city manager may actually take executive 
charge of parks or he may appoint a superintendent of parks to act under him. Whatever may be its form or name, the authority to plan and control parks should always cooperate with the city planning commission in the preparation of a program of and in conformance with the needs of the city for parks and recreation. This applies also to the school board. "In this day when schoolboards are tending to secure larger and larger areas for school sites" says L. H. Weir in a letter to the author, "they become a very important factor in providing two types of properties, viz., large playgrounds for children and neighborhood playfield-parks." In Seattle the school board and the park board have mutually agreed that neither of them will buy a neighborhood property without fully consulting the other. Where school boards secure as much as 75 to 100 acres for school sites, as some of them are doing now, they are getting almost into the large park class. Both the officer or board having charge of the parks and the city planning commission should consider what constitutes an adequate program for the city's parks and playgrounds and, in turn, what must be done to make such a program possible for fulfillment. There should be a scheme of activities covering the recreational requirements of the city extending over a period of at least from 5 to 10 years and so planned as to come within the financial ability of the municipality. Following such a scheme of activities and under the inspiration of its vision, there should be inaugurated an earnest campaign of education among the voters so that the needs of the city for parks and playgrounds may be adequately realized. The value of parks to the normal, economic, healthful, and moral well-being of the citizens amply justifies any such effort made.

\section{Questions for Discussion}

1. Discuss the importance of providing adequate recreational spaces where needed in the city plan.

2. Distinguish between active and passive recreation.

3. Tell about the history of parks and park systems in the United States.

4. What are the requirements and possibilities of the small park or square?

5. What are the requirements and possibilities of the park of medium size; the neighborhood park?

6. What are the requirements and possibilities of the park of large size?

7. Explain the meaning of "parkways" and "systems of parks."

8. What minimum park requirements are advised for a municipality?

9. How are park developments financed and administered? 
10. Review one of the outstanding professional reports on parks and park systems.

\section{References}

Adams, T.: What Proportion of Public Land and of Private Land Should Be Reserved for Open Spaces? American City, vol. 38, No. 6, pp. 106107, June, 1928.

Anderson, Nels, and E. C. Lindeman: Recreation, "Urban Sociology," chap. VIII, Alfred A. Knopf, Inc., 1928.

Bartholomew, Harland: Recreation Report, 54 pp., illus., plates, plans, Evansville, Ind., 1927.

Child, Stephen: Of a Rural Park for a Large City. Of a System of Parks for a Large City, "Landscape Architecture," pp. 103-142, Stanford University Press, 1927.

Hubbard, H. V.: Parks and Playgrounds, Their Requirements, and Distribution in the City Plan, Proceedings 14th National Conference on City Planning, pp. 1-33, 1922.

- - and Hubbard: Parks and Recreation, "Our Cities Today and Tomorrow," pp. 246-262, Harvard University Press, 1929.

Lewis, Nelson P.: Parks and Recreation Facilities, "Planning of the Modern City," pp. 130-148, John Wiley \& Sons, Inc., 1916, 1923.

Nolen, John, ed.: General Recreational Facilities, by Horace MacFarland, pp. 139-158; Park Systems, by John Nolen, pp. 159-178; Non-navigable Waters, by Arthur A. Shurtleff, pp. 201-225, "City Planning," D. Appleton \& Company, 1924.

Park Recreational Areas in the United States, 96 pp., illus., U. S. Government Printing Office, Washington, D. C., 1928.

Recreation Facilities Existing and Proposed, by Harland Bartholomew, 62 pp., Des Moines, 1927.

Shurtleff, Arthur: Future Parks, Playgrounds and Parkways, Report, 61 pp., illus., maps, plans, Park Department, Boston, Mass., November, 1925.

Simonson, Wilber H.: The Mount Vernon Memorial Highway, American City, pp. 85-88, October, 1930.

Stinchсомв, W. A.: The Cleveland Metropolitan Park System, National Municipal Review, pp. 704-709, October, 1930.

Weir, L. H., Ed.: "Parks: A Manual of Municipal and County Parks," 2 vols., illus., plans, A. S. Barnes \& Co., New York, 1928.

Westchester County Parks, Annual Reports from 1922, April of each year, Westchester County Park Commission, Bronxville, N. Y. 


\section{CHAPTER XIV}

\section{PLAYGROUNDS AND PLAYFIELDS}

We scarcely need to be reminded that a free use of areas for play is synonymous with the expression of a natural instinct for play. Play is promotive of health, morals, and the happiness of the community. The release of additional spare time for the people makes play increasingly important. No longer can we speak of areas for such purpose as luxuries but must list them among the prime necessities of community life. We must be aware not only of the importance of the opportunity for play but also of the need of making suitable provision for it in the plan of the city. For unless we do so, as time goes on, the adaptable open spaces for play in a town are sure to be built upon and thus are lost as sites for playgrounds. The vacant lot of the small town, serving fortuitously as a playground for children, will disappear unless appropriate precautions are taken to keep it a vacant lot. The ever widening periphery of the town places such vacant lots farther and farther from convenient reach of those living in the town. The space for play once supplied by grounds adjacent to the home will be supplanted by an intensive residential occupation in the form of either small space for yards or even the entire absence of any yards. "As vacant lots become fewer the demand for playgrounds becomes greater." All of these changes will occur, unless there is a vision of possibilities for play in the mind of the city planner that will make such changes impossible, a vision correlated with a comprehensive modern plan for the city.

The Play Movement.-Although the evolution of areas for playgrounds in the city has taken place in the last half century, the strides made have been tremendous, and the recognition among our people of the importance of this evolution has been striking. As we survey the activities of the period we recognize a- series of developments that present themselves somewhat as follows: First came the sand gardens sponsored by settlement houses and churches (1885 to 1895), then the earlier examples 
of playgrounds (1894 to 1900) and the beginning of using parks for these purposes (1900 to 1905). Then appeared the extensive development of recreational centers as in Rochester and Chicago (1905 to 1912) and the burst of interest in the civic art and musical phases of play, accompanied by the preparation of important recreational surveys as exemplified by Detroit and Cleveland and the inauguration of some important recreational legislation (1912 to 1914). A characteristic tendency toward "localized play participation" made its appearance (1915 to 1918), and finally there came a far-reaching vision of a universal establishment of playgrounds so as to save the world, so to speak, through the agency of play. In this connection so important has been the part played by the National Recreation Association for several years past, in stimulating interest in playgrounds and in their guidance and leadership, that one must think of that association as among the outstanding features of the playground movement.

Within this comparatively short period of time, the ideals and purposes behind the establishment of playgrounds are seen to change and widen. We think now of play areas prepared for organized play, not only for the slums as in the earlier days of the play movement but also for the more suburban areas, and in fact for all of the residential sections of the city. We think of them now as legitimate, indispensable features in the city plan, features that are entitled to liberal public support and not matters solely for private philanthropy. So great a hold has public interest taken upon the subject that statistics prepared by the Playground and Recreation Association of America in 1930 showed a total of 13,397 separate areas for play, under trained leadership, in almost as many different cities of the United States, a number which represented the decided increase of 1,137 over those reported for 1929 . The importance of playgrounds and the growing interest taken in them by the general public point to the necessity for allotments being made in the city plan. What, then, are some of the considerations that must be weighed by the city planner? No sooner do we think of areas for play than we wonder about the specific groups of the urban population that are to be accommodated by these several areas and also about the kinds of developments as to size and character that the citizens will demand. How numerous should the playgrounds be and where located in the framework of the city? 
Kinds and Distribution.- - The types of areas for play and their distances apart from each other will depend upon the ability of the persons served to reach the specified places and the interest of these people served in making the requisite journeys. In other words, the problem of the kinds and distribution of playgrounds narrows itself to a consideration of the ages of the groups of people that are to be accommodated by any particular playground.

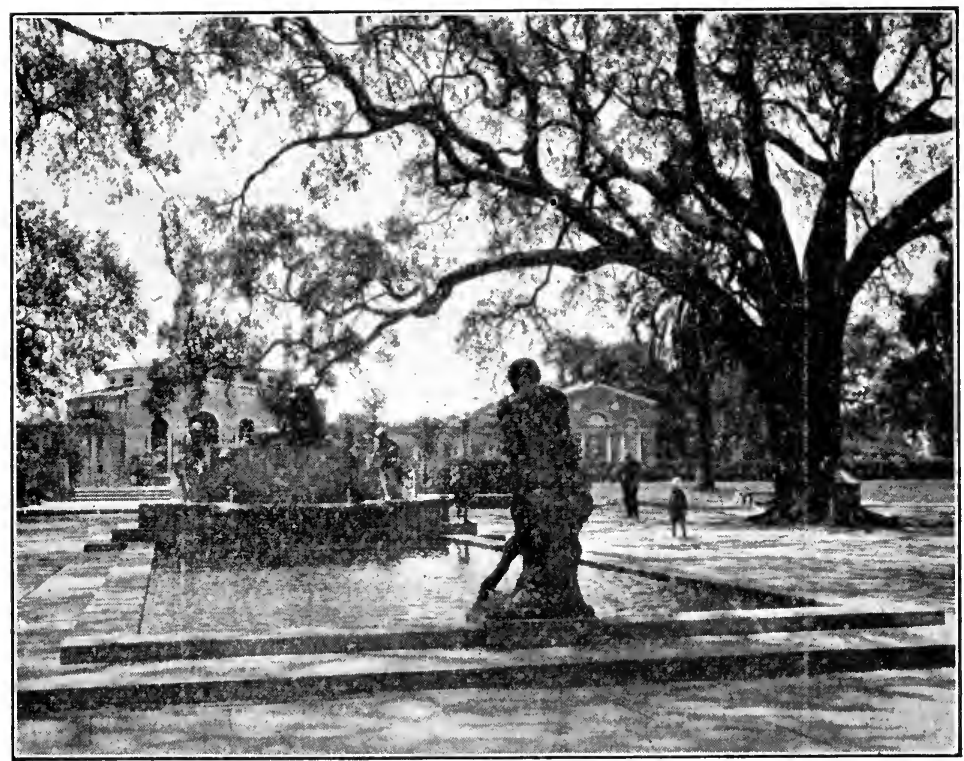

Fig. 84.-Wading pool, New Orleans. Not only children but artists everywhere would revel at the sight of two exquisite wading pools (identical design) that occupy places in two parks of New Orleans. These were presented by Sara Lavinia Hyams. (Photograph by the author.)

Location of Playgrounds. For Preschool Children.-The first of these groups of people is composed of children from one to five years of age. Such children require facilities for play (Figs. 84, 85, 86) close to their homes, as in their own back yards, or upon areas near-by, which may be playgrounds in the interior of the block, surrounded by individual houses or blocks of tenements, or reservations of vacant lots within the block, or perhaps spaces upon roofs of apartments. The playground in the center of the block may consist of the rear ends of the two tiers of lots that meet, these consolidated into a single area for 


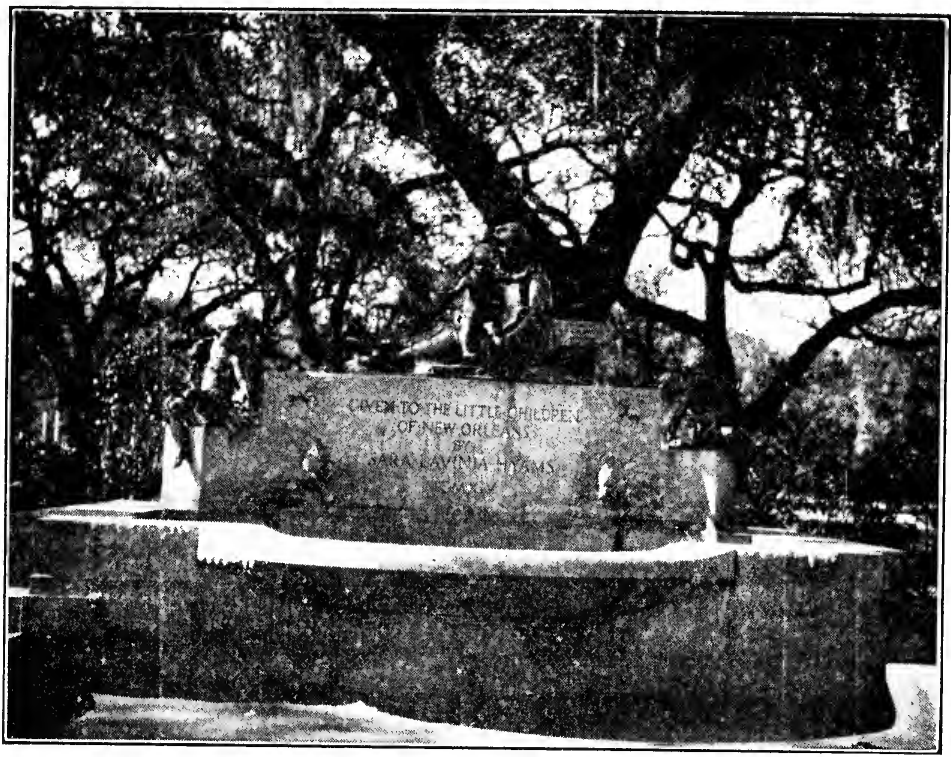

FIG. 85.-Wading pool, New Orleans. The heavily shaded fountain end of pool. (Photograph by the author.)

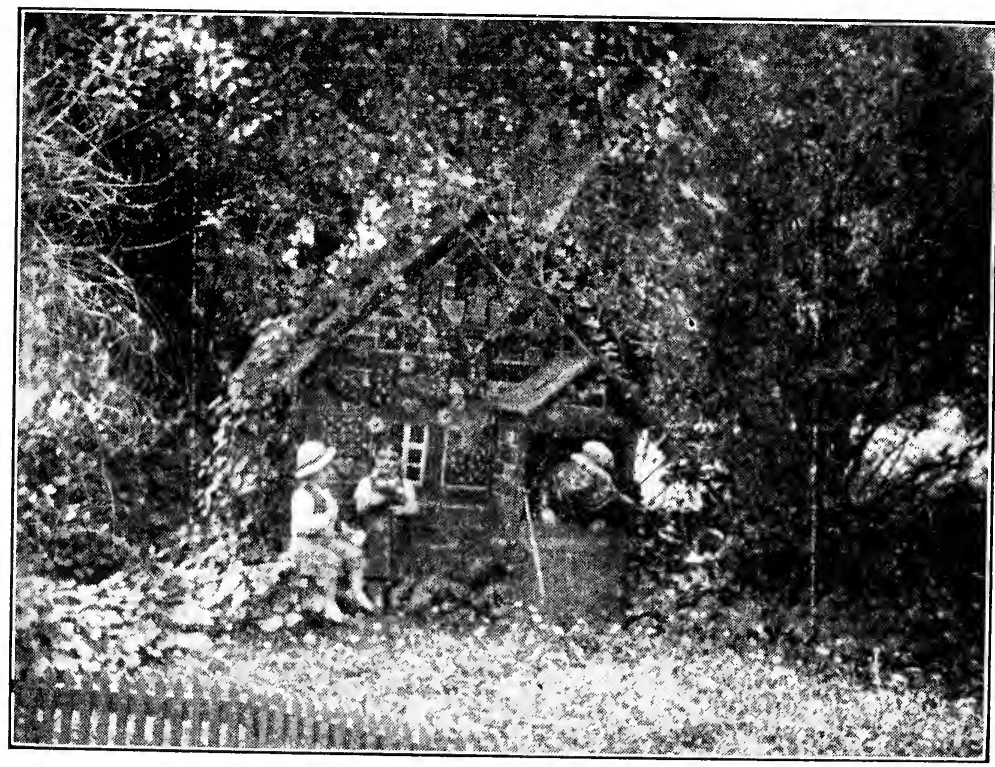

FIG. 86.-Miniature setting, Busch Gardens, Pasadena. Groups of storybook characters in characteristic pose hold unlimited possibilities for amusing and interesting children in parks and playgrounds. The above represents a Hansel and Gretel episode. (Photograph by the author.) 
play for small children. Such interior areas for play are excellent from the standpoint of access, convenience, and safety and yet the difficulty of maintaining and supervising them must be overcome, if they are to be regarded as altogether practicable. A vacant lot somewhere in the block facing the street could be reserved for a playground with practically the same effectiveness but with fewer complications, as far as arranging it for the children's play is concerned.

For the School Group - The school children ranging from six up to fifteen years of age require facilities of their own, although they share their grounds in part with those of other groups. In the case of school children, the facilities near at hand, previously described, are used only incidentally, because the organized playground or the larger play fields suit the requirements of these older children much better. Although school children enjoy such special exercises as swimming, coasting, etc., their major interests are provided for on the playgrounds connected with the schools that they attend (Figs. 87, 88). School grounds if properly located are logical centers for playgrounds; and playgrounds "in the main should coincide with the distribution of the grade schools." From the standpoint of supervision, athletic leadership, and maintenance, facilities for play enjoyed by school children upon playgrounds surrounding the school house are the most economical. The selection of a location for a public school should be made only after full consideration of such location as a suitable place for a playground.

It is important to keep in mind in this connection that there is a present tendency toward the construction of larger school buildings than in the past, buildings that may house from 800 to 1,000 or more pupils. This tendency may have the effect of widening the radius of distance in the case of sparsely populated and open districts. Mr. Weir states that where the density of population approaches 50 per acre a school building will probably be required in each quarter section ( 160 acres) and that except in parts of very large cities with an extremely high density of population, school buildings will probably not be provided more thickly than every quarter section.

For the Elementary School Group.-The first six years of schooling are offered in the elementary school, and a site should be set apart for such a school at a maximum radius of (but preferably less than) $1 / 2$ mile from the most distant homes of the attending 


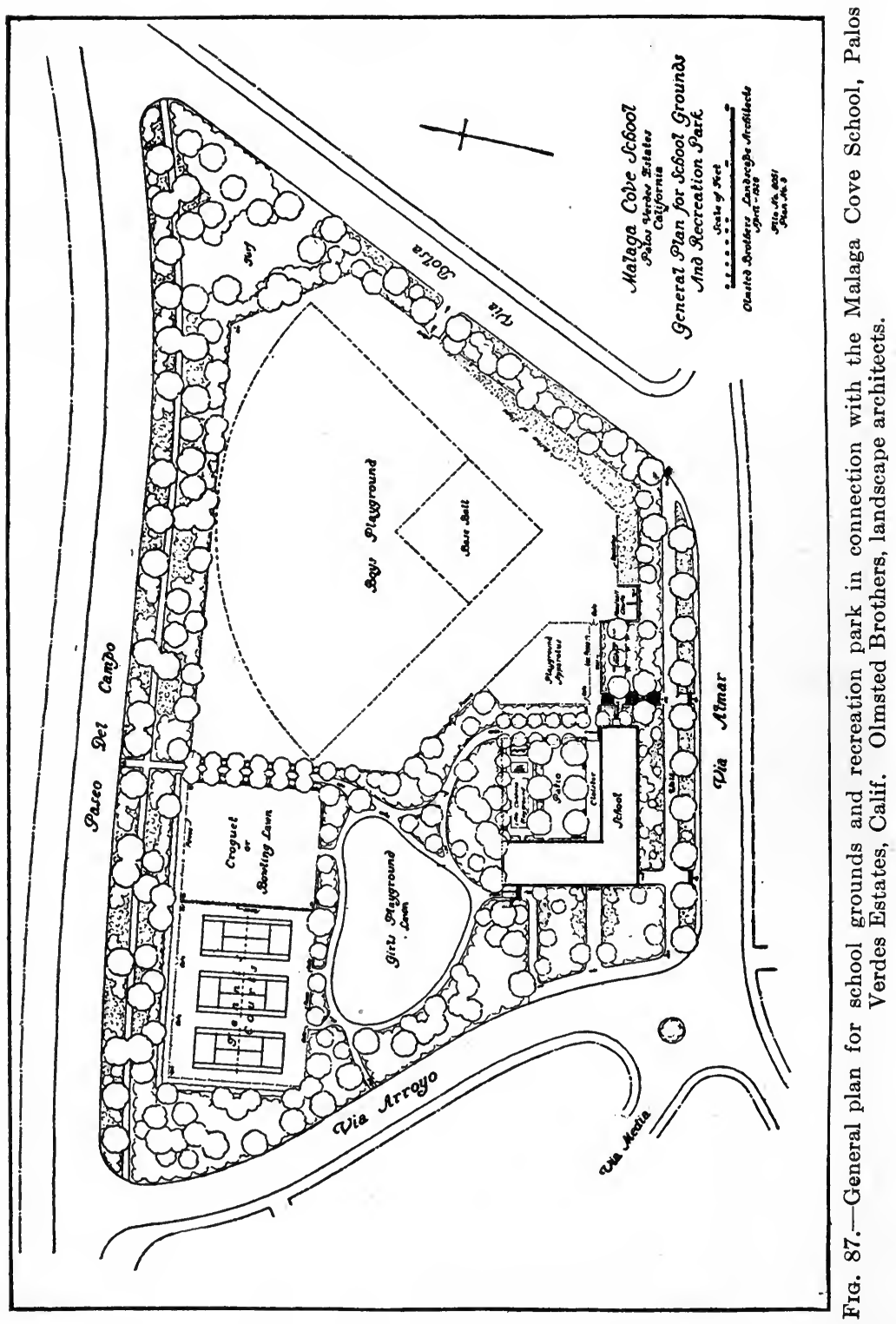


children. The number of sites required for the location of elementary schools in any city makes of the play park surrounding the elementary school the foundation of the whole structure of municipal playgrounds. Upon these playgrounds of average size that are the most numerous of the organized play areas are facilities for athletic exercise of both boys and girls attending the school together with some provision as well for the play of smaller children of the neighborhood (Figs. 87, 88). In the interest of

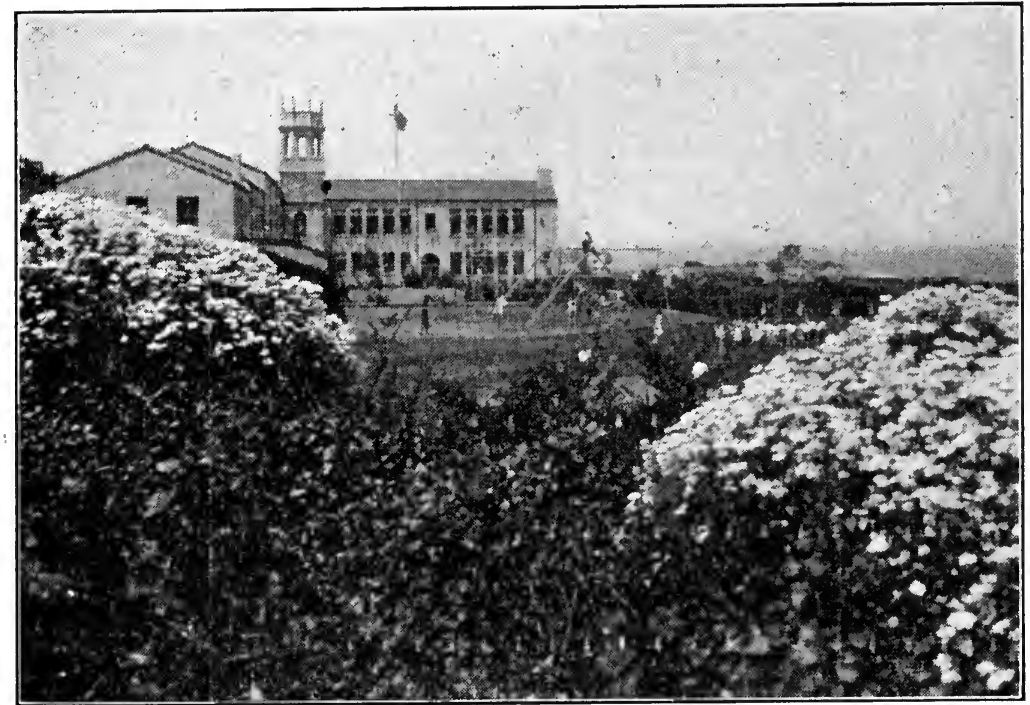

Fig. 88.-Glimpse of the school and grounds at Malaga Cove, Palos Verdes, Calif. Not only may school grounds provide for active recreational needs but they may also serve the requirements of good order and beauty. (Photograph by Padilla Company.)

safety to the children, these spaces surrounding our elementary schools should be located well away from any major streets, car lines, or railroads. This has special reference to the danger involved in going to or coming from the playgrounds.

Location of Play Fields for the Intermediate School Group.In the case of grammar schools, junior high schools, or intermediate schools for boys and girls between twelve and fifteen years of age, the maximum radius of distance from the home to the play field should be one mile. The children of this group are larger than those attending the elementary school and prefer games that occupy relatively greater space, so that their scene 
of activity is known as a "play field" rather than a playground. Better still, perhaps, is the name "play-field park." A combination of an athletic field, tennis courts, and a swimming pool should occupy the larger divisions of the play field for the intermediate school, while provision to some extent should be made for smaller units of play, with also a few facilities for smaller children.

Eocation of Athletic Fields for Youth and Adults.-The high school group and the other young folk within the range of fifteen

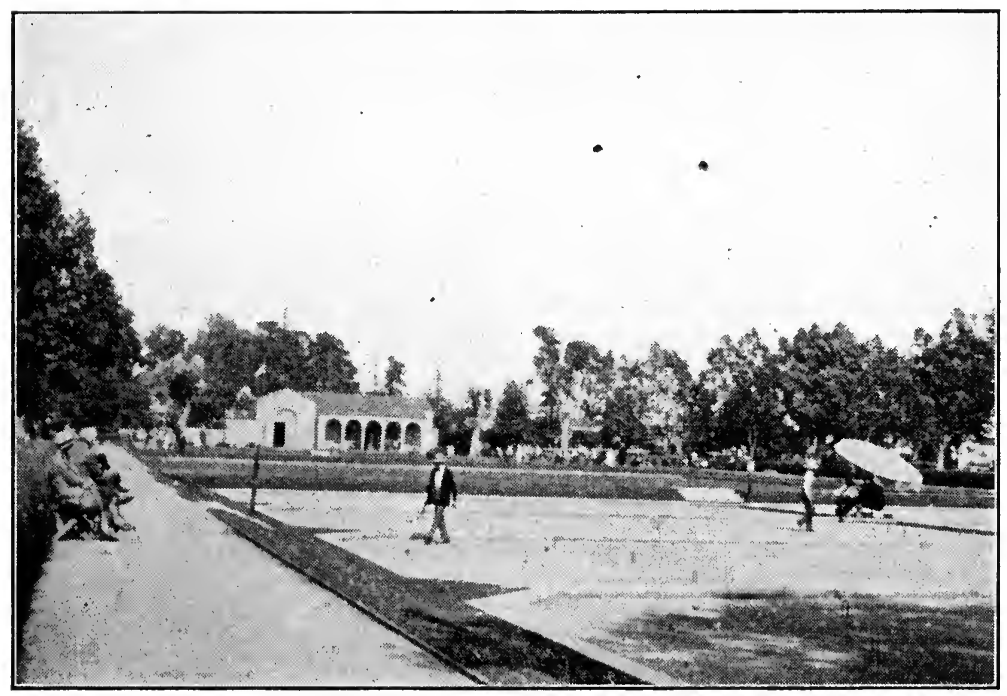

Fig. 89.-A game of roque in Exposition Park, Los Angeles. Too little is still being done to organize the leisure time of old and young through the aid of properly equipped recreational areas. (Photograph by the author.)

to twenty-five years of age (and upward) may be thought of as one body, as far as physical play is concerned. The needs of this group can be provided in play-field or neighborhood parks that should occur at the rate of at least one for every square mile ( 640 acres) of residence area, with 5 per cent of that residence area (about 30 acres) reserved for play purposes. Also, the needs of this group can be provided, in part at least, in conjunction with the grounds around the high school. A radius of $1 \frac{1}{2}$ to 2 miles from the most distant home of the students there attending is not too great for the site of a high school. Since the high school may be an elaborate plant, a site of considerable acreage may be necessary not only to accommodate the groups of build- 
ings that at times are as extensive as those upon the campus of a small college but as well to take care of the various athletic facilities that are needed. Provision should be made that the adult population of the neighborhood may share with the youngsters the facilities of the play field or athletic field; in the case of these adults, however, there will have to be supplied a goodly assortment of the less strenuous games, such as croquet, roque, throwing horseshoes, or quoits. Regardless of grouping by age, there are occasions when the different features of the system of recreation will be shared alike by people of all ages (Fig. 89). The more nearly that the development for play designed by the city planner accomplishes this general purpose of recreation for people of every age the more nearly it becomes an indispensable feature of the neighborhood. Such facilities for a neighborhood are sometimes provided not only in conjunction with neighborhood parks, or as part of certain larger parks, but also as sites for branch libraries.

Sizes of Playgrounds and Play Fields.-How large a playground should be is determined by a variety of factors including such things, for example, as the school population of the district, the location of existing facilities for recreation, the type of playground required, and the minimum areas for the different kinds of sports for which provision must be made upon the given playground. A great variety of the standards of the space required for playgrounds and play fields have been advocated by different persons, and perhaps the most various of these standards are those that concern the space required by each individual engaged in play. These recommendations have varied anywhere from 35 up to 200 square feet for each child in the neighborhood concerned or for those playing at any given time on the playground areas.

Another method of determining the amount of space required for playgrounds or play fields is through the medium of the kind of school to be served, as experience has demonstrated that each kind or grade of school has its own particular needs in this respect.

Comparatively little space for recreation is required for the preschool age group, their principal requirements being plenty of shade, shelter, toilet facilities, some equipment for games, free open space, and a fence around the whole playground. This enclosure should include at least 2,000 square feet. Since 
the average playground is planned in conjunction with a primary school, there should be a total of not less than from 5 to 8 acres in the plat, depending upon whether it is developed in a section of single- or of multiple-family houses. From 1 to $1 \frac{1}{2}$ acres of this area must be used for the school building, its setting and service and the rest of the acreage should afford a section for the older boys, one for the older girls, another for apparatus, open space, areas for shelter houses, a shaded space for handicraft, places for quiet games, and accommodation for those of preschool age. This type of combined play and school site adequately cares for the play needs of boys and girls from five to fifteen years of age.

The intermediate type or the play field for the grammar school and junior high school should have an area of from 8 to 15 acres. Such an area will give opportunity for major games for the older boys, movable bleachers, and a grandstand on the west side. Upon such an area also can be planned a place for the games of the older girls. This place ought to be somewhat isolated and screened from view by the aid of plantings. An accessible area ought also to be prepared for the play of younger children in the neighborhood whether or not they attend school. Where such a type of play field for school children is situated at a distance from the school, a recreational building, or field house, must be provided on the play field. An enlargement of the acreage would not only give larger opportunities for play but also would give a chance to set apart a portion of the area strictly as a park. The athletic field in connection with the high school should contain at least 20 to 25 acres of land both for the buildings and for recreational uses, but in all cases where the high school buildings are not erected upon the athletic field, 10 to 20 acres for athletic purposes will suffice. A large acreage is essential wherever there must be a football field, a $1 / 4$-mile track, tennis courts, a number of baseball diamonds, and places for other forms of active recreation. Ample facilities for the parking of automobiles must also be provided.

While designing his athletic field it will prove helpful to the planner to have. before him the requirements of space for the various organized games and sports for which he is endeavoring to provide. Since in the case of laying out the grounds for some games the necessary area is less for children than for adults, the 
following tables showing all possible areas required for the sports enumerated are here presented:

Space Requirements for Organized Games and Sports for Adults 1

\begin{tabular}{|c|c|c|c|c|}
\hline Name & $\begin{array}{l}\text { Dimensions of play } \\
\text { areas, feet }\end{array}$ & $\begin{array}{c}\text { Use } \\
\text { dimensions, } \\
\text { feet }\end{array}$ & $\begin{array}{c}\text { Space } \\
\text { required, } \\
\text { square } \\
\text { feet }\end{array}$ & $\begin{array}{l}\text { Number of } \\
\text { players }\end{array}$ \\
\hline Baseball... & 90-foot diamond & $\begin{array}{c}300 \text { by } 325 \\
\text { (or more) }\end{array}$ & 97,500 & 18 \\
\hline 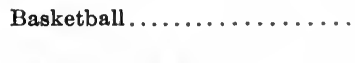 & $\begin{array}{l}50 \text { by } 94 \text { (max.) } \\
35 \text { by } 60 \text { (max.) }\end{array}$ & $\begin{array}{l}60 \text { by } 100 \\
\text { (av.) }\end{array}$ & 6,000 & 10 \\
\hline Basketball (women's)......... & 45 by 90 & 50 by 100 & 5,000 & 12 to 18 \\
\hline Boccie............ & 18 by 62 & 30 by 70 & 2,100 & 2 to 4 \\
\hline Bowling green ${ }^{2} .$. & 14 by 110 (one alley) & 120 by 120 & 14,400 & 32 to 64 \\
\hline Clock golf ................ & Circle 20 to 24 diam. & 30 -foot circle & 706 & $\begin{array}{c}\text { Any number } \\
\text { (4 to } 8)\end{array}$ \\
\hline Crivket. . & Wickets 66 feet apart & $\begin{array}{l}420 \text {-foot } \\
\text { circle }\end{array}$ & 138,545 & 22 \\
\hline 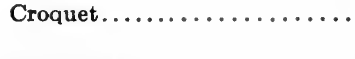 & 30 by 60 & 30 by 60 & 1,800 & $\begin{array}{c}\text { Any number } \\
\text { (4 to } 8)\end{array}$ \\
\hline Field hockey.............. & $\begin{array}{l}150 \text { by } 270 \text { (min.) } \\
180 \text { by } 300 \text { (max.) }\end{array}$ & $\begin{array}{c}180 \text { by } 330 \\
\text { (av.) }\end{array}$ & 59,400 & 22 \\
\hline$\ldots \ldots \ldots \ldots$ & 160 by 360 & 180 by 420 & 75,600 & 22 \\
\hline Handball. & 20 by 34 & 40 by 50 & 2,000 & 2 or 4 \\
\hline 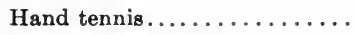 & 16 by 40 & 25 by 50 & 1,250 & 2 or 4 \\
\hline Horseshoe pitching.... & Stakes 40 feet apart & 10 by 50 & 500 & 2 or 4 \\
\hline Lacrosse...$\ldots \ldots \ldots \ldots \ldots$ & $\begin{array}{l}210 \text { by } 450 \text { (min.) } \\
255 \text { by } 540 \text { (max.) }\end{array}$ & $\begin{array}{c}250 \text { by } 500 \\
\text { (average) }\end{array}$ & 125,000 & 24 \\
\hline Paddle tennis............... & 18 by 39 & 30 by 60 & 1,800 & 2 or 4 \\
\hline Playground ball...... & 35 or 45 diam. & $\begin{array}{c}150 \text { by } 150 \\
\text { (or more) }\end{array}$ & 22,500 & 20 \\
\hline 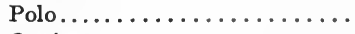 & 600 by 960 & 600 by 960 & 576,000 & 8 \\
\hline 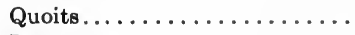 & Stakes 54 feet apart & 25 by 80 & 2,000 & 2 or 4 \\
\hline 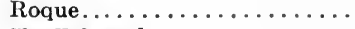 & 30 by 60 & 30 by 60 & 1,800 & 4 \\
\hline Shuffleboard............... & 10 by 40 to 50 & $\begin{array}{l}15 \text { by } 50 \\
\text { (or longer) }\end{array}$ & 750 & 2 or 4 \\
\hline Soccer.... & $\begin{array}{l}150 \text { by } 300 \text { (min.) } \\
300 \text { by } 390 \text { (max.) }\end{array}$ & $\begin{array}{c}210 \text { by } 360 \\
\text { (average) }\end{array}$ & 75,600 & 22 \\
\hline Tennis...... & $\begin{array}{l}27 \text { by } 78 \text { (single) } \\
36 \text { by } 78 \text { (double) }\end{array}$ & 60 by 120 & $\dddot{7}, 200$ & $\begin{array}{l}2 \\
4\end{array}$ \\
\hline $\begin{array}{l}\text { Tether tennis } \ldots \ldots \ldots \ldots \\
\text { Volley ball. } \ldots \ldots \ldots\end{array}$ & Circle 6 feet diam. & 20 by 20 & 400 & 2 \\
\hline Volley ball. & 30 by 60 & 50 by 80 & 4,000 & 12 to 16 \\
\hline
\end{tabular}

1 From "Play Areas: Their Design and Equipment," copyright 1928 by the Playground and Recreation Association of America, Inc. Used by permission of A. S. Barnes and Co., publishers.

2 Most bowling greens in areas for public recreation are 120 by 120 feet, which provides eight alleys. The amount of space required for a single alley would be 20 by 120 feet. 
Space Requirements for Organized Games and Sports on Children's Playgrounds ${ }^{1}$

\begin{tabular}{|c|c|c|c|c|}
\hline Name & $\begin{array}{c}\text { Dimensions of play } \\
\text { areas, feet }\end{array}$ & $\begin{array}{l}\text { Use dimen- } \\
\text { sions, feet }\end{array}$ & $\begin{array}{c}\text { Space } \\
\text { required, } \\
\text { square } \\
\text { feet }\end{array}$ & $\begin{array}{l}\text { Number } \\
\text { of } \\
\text { players }\end{array}$ \\
\hline Baseball. & 75-foot diamond & 250 by 250 & 62,500 & 18 \\
\hline Basketball...... & 35 by 60 & 50 by 75 & 3,750 & 10 to 12 \\
\hline Clock golf....... & Circle 20 to 24 diam. & $\begin{array}{l}30 \text {-foot cir- } \\
\text { cle }\end{array}$ & 706 & $\begin{array}{l}\text { Any num- } \\
\text { ber (4 to } 8)\end{array}$ \\
\hline Croquet. . & 30 by 60 & 30 by 60 & 1,800 & $\begin{array}{l}\text { Any num- } \\
\text { ber ( } 4 \text { to } 8)\end{array}$ \\
\hline Field hockey.... & 150 by 270 & 150 by 230 & 49,500 & 22 \\
\hline Football........ & 160 by 360 & 180 by 420 & 75,600 & 22 \\
\hline Handball........ & 20 by 30 & 35 by 40 & 1,400 & 2 or 4 \\
\hline $\begin{array}{l}\text { Horseshoe pitch- } \\
\text { ing }\end{array}$ & Stakes 30 feet apart & 10 by 40 & 400 & 2 or 4 \\
\hline Paddle tennis.... & 18 by 39 & 26 by 57 & 1,482 & 2 or 4 \\
\hline Playground ball & $\begin{array}{l}\text { 45-foot diamond } \\
35 \text {-foot diamond }\end{array}$ & $\begin{array}{l}125 \text { by } 125 \\
100 \text { by } 100\end{array}$ & $\begin{array}{l}15,625 \\
10,000\end{array}$ & 20 \\
\hline $\begin{array}{l}\text { Soccer.......... } \\
\text { Tennis.......... }\end{array}$ & $\begin{array}{l}150 \text { by } 300 \\
27 \text { by } 78 \text { (single) } \\
36 \text { by } 78 \text { (double) }\end{array}$ & $\begin{array}{r}150 \text { by } 360 \\
50 \text { by } 120\end{array}$ & 54,000 & 2 or 4 \\
\hline $\begin{array}{l}\text { Tether tennis.... } \\
\text { Volley ball...... }\end{array}$ & $\begin{array}{l}\text { Circle } 6 \text { feet diam. } \\
25 \text { by } 50\end{array}$ & $\begin{array}{l}20 \text { by } 20 \\
40 \text { by } 60\end{array}$ & $\begin{array}{r}400 \\
2,400\end{array}$ & $\begin{array}{c}2 \\
12 \text { to } 16\end{array}$ \\
\hline
\end{tabular}

'From "Play Areas: Their Design and Equipment," copyright 1928 by the Playground and Recreation Association of America, Inc. Used by permission of A. S. Barnes and Co., publishers.

\section{Questions for Discussion}

1. What is the value of play?

2. Discuss the play movement in America.

3 . What are the general requirements of playgrounds for children of preschool age?

4. What are the general requirements of playgrounds for children of elementary school age?

5. What are the general requirements of playgrounds for children in the intermediate grades?

6. What are the general requirements of playgrounds for children of high-school age?

7. Discuss sizes of playgrounds and play fields.

8. What are some of the major construction requirements that must be considered in the development of playgrounds and recreation fields?

9. Outline the possibilities of beautification in play areas.

10. Review a city planning report that deals particularly with the recreational facilities of any given city. 


\section{References}

Bartholomew, Harland, and Associates: A Plan for the Systematic and Economical Development of Recreational Facilities for Des Moines, Iowa, 62 pp., illus., plans, City Plan Commission, Des Moines, Iowa, 1927.

Bassett, Hubbard, and Ford: Small Parks for Playgrounds Considered in Their Relation to City Planning, Parks and Recreation, vol. 10, pp. 437-446, May, June, 1927.

Butler, G. D., ed.: Play Areas: Their Design and Equipment, 206 pp., illus., plans, Playground and Recreation Association of America, A. S. Barnes \& Co., New York, 1928.

Butterworth, William S.: The Economic Values of Recreation, The Playground, vol. 22, No. 9, pp. 495-499, December, 1928.

Child, Stephen: Of Playgrounds, "Landscape Architecture," pp. 91-102, Stanford University Press, 1927.

Engelhardt, N. L., and F. Engelhardt: "Planning School Building Programs," Columbia University, 574 pp. 117 diagrams, 1930.

Ford, G. B.: Schools and Playgrounds, "City Plan and Twenty-year Program of Public Improvements for New Rochelle, pp. 75-80, 1929.

Hadden, G.: Athletic Facilities to Meet Modern Needs in Towns and Cities, American City, vol. 34, pp. 529-536, illus., plans, May 1926.

Hanmer, L. F.: Planning for Play, Survey, vol. 54, pp. 444-447, illus., July $15,1925$.

Kennedy, Louise Venable: "The Negro Peasant Turns Cityward," pp. 270, Columbia University Press, 1930.

Lohmann, Karl B.: Construction and Beautification of Playgrounds and Recreation Fields, The Playground, vol. 20, No. 4, pp. 205-208, July, 1926.

Strayer, George D.: The School Building Program an Important Part of the City Plan, Proceedings, pp. 46-64, of the National Conference on City Planning, June, 1922.

Weir, L. H., ed.: "Parks: A Manual of Municipal and County Parks," 2 vols., illus., plans, A. S. Barnes \& Co., New York, 1928.

: Standards in Planning for Recreation, pp. 155-169, National Conference on City Planning, Proceedings, Buffalo, N. Y., 1929. 


\section{CHAPTER XV}

\section{SUBDIVISION OF LAND}

The platting of land for purposes of subdivision is undertaken with the idea of providing places upon which people shall live or work or play to the best advantage and with the expectation of giving a profitable financial return to the promoters of the enterprise. As long as our population continues to increase, as long as older residential sections become more and more out of date and newer means of transportation make it possible for people to live farther out from the centers of business and manufacture, the demand for the laying out of lands hitherto unbuilt upon or purely agricultural will continue. Practically every city in the United States is an outgrowth or a composite of large and small subdivisions that have in the course of time been planned and one after the other added to the area of the city. It is unfortunate that in an examination of these subdivisions we find so little evidence of foresight in their plans and so little regard for the needs and comforts of the people obliged to live upon them. We are now, however, seeing the beginning of a different tendency. People are looking for and expecting better subdivisions, and the more reliable real estate men are finding that greater profits can be made from sites that are conveniently and attractively planned. Many eity planning commissions, moreover, are keeping watch over new subdivisions and are helping to guide their planners along better channels of development.

The residential subdivision may occur either as an extension to an existing city plan or as the establishment of an independent suburb or neighborhood. In the planning or the control to which we shall give our special attention with reference to such developments, the principles that have been advanced for the whole city will very naturally apply to the parts or to what may be the nuclei of future cities. Although some degree of restatement and duplication will be met with, yet at the same time, this phase of . the subject calls into play details that were inappropriate for the 
larger unit of the city as a whole and which could not conveniently be presented in that connection.

Subdivisions Planned.-Within recent years we have had a good many examples from which to profit in connection with the planning of subdivisions. The numerous industrial communities that developed during (1917 to 1918) the World War were important object lessons, as were also the activities of city plan-

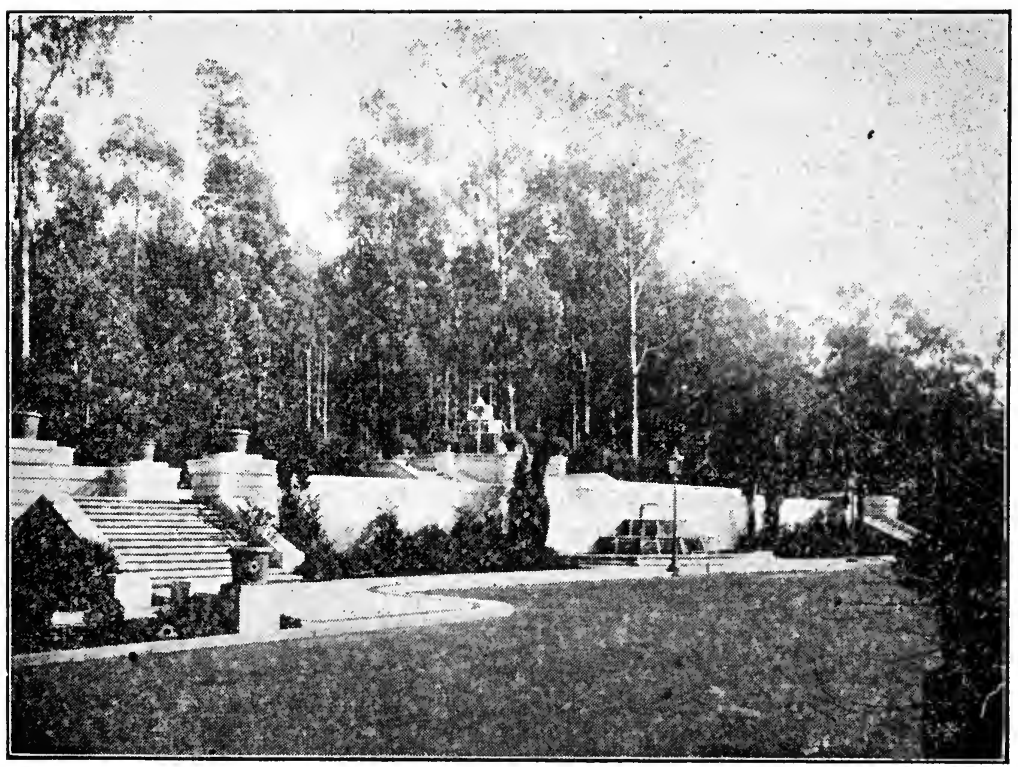

FIG. 90.-Monumental fountain feature, St. Francis Woods, San Francisco. It takes but 20 minutes from the heart of San Francisco by rapid transit tunnel under Twin Peaks to reach St. Francis Woods, a high-class subdivision. At the high point of the subdivision looking down a boulevard out to sea is this interesting monumental fountain feature.

ning during the recent boom in real estate in Florida. The activity in the creation of subdivisions in Florida was the most outstanding example of such work in our history, at least as far as number and variety of the subdivisions planned were concerned. Here and there over the United States are examples of subdivisions of a high class that are a credit to their promoters. Among the most notable are Roland Park, Baltimore; Shaker Heights, Cleveland; Kansas City Country Club district; Palos Verdes, St. Francis Woods (Fig. 90), Rancho Santa Fe, Calif.; and Coral Gables, Fla. (Figs. 91, 92, 93, 94, 95.) More recently 


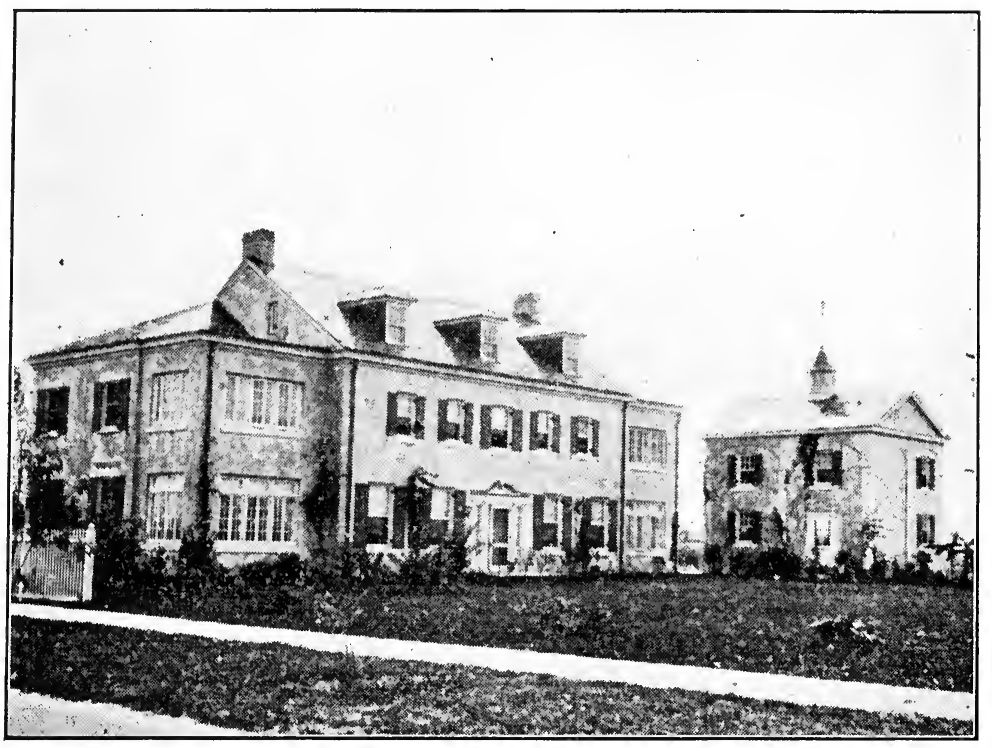

FIG. 91.-The segregaton of different types of homes, in Coral Gables, Fla. An example of the colonial homes. Despite its reverses Coral Gables must be considered one of the notable subdivision developments of our country. Among other things it can boast regulation in type and design of architecture. Although the predominant style of the whole development is a modified type of Spanish architecture certain portions of the "Gables" have been reserved for Chinese, French, Italian, Colonial, and other forms. (Photograph by the author.)

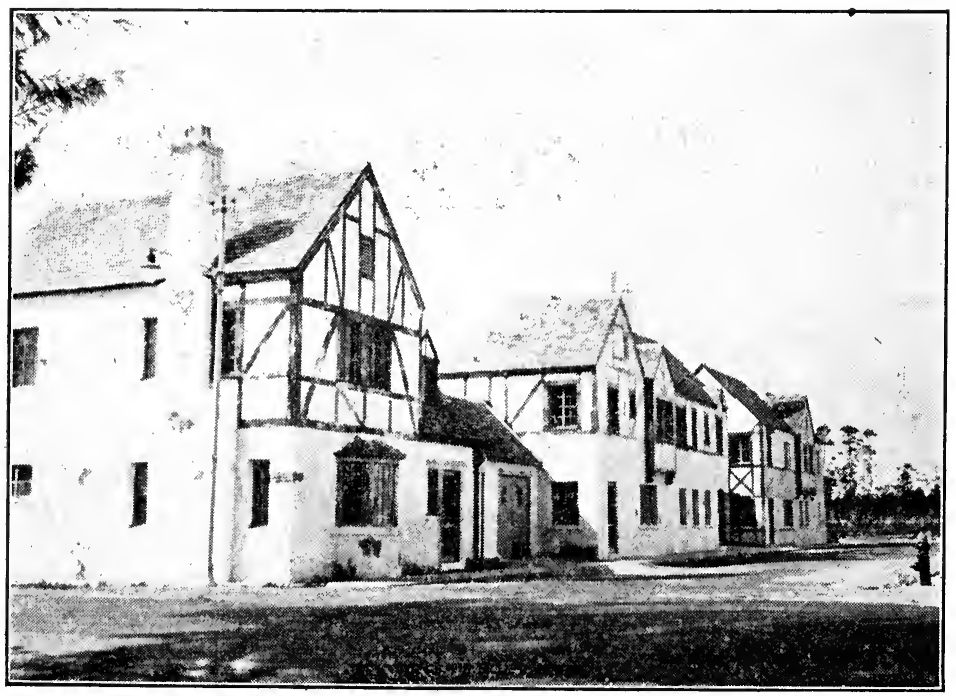

FIG. 92.-The French village, Coral Gables. (Photograph by the author.) 


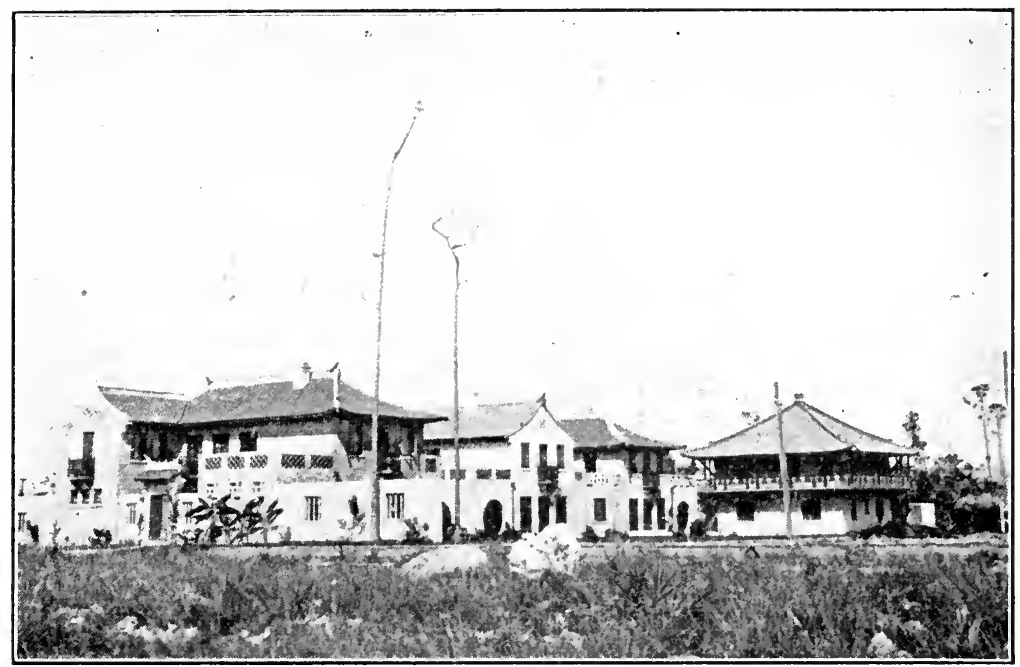

FIG. 93.-The Chinese village, Coral Gables. (Photograph by the author.)

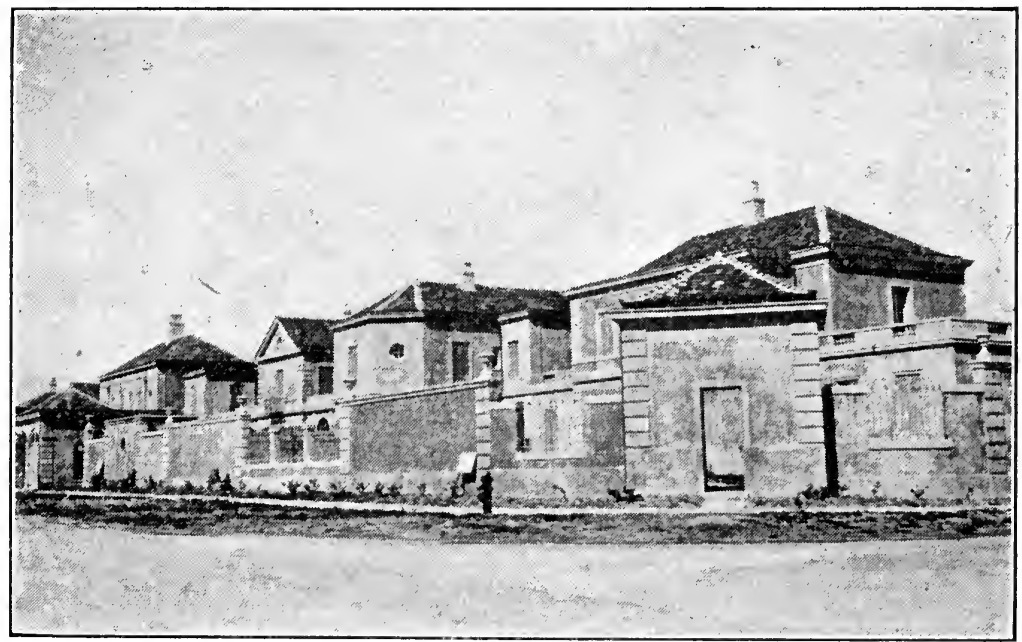

FIG. 94.-The Italian village, Coral Gables. (Photograph by the author.) 
in Radburn, N. J., just outside New York, an effort has been made to interpret the need of our age of automobiles for safety and quiet by a use of streets planned as culs-de-sac around blocks of immense size which contain central recreational areas. The blocks are made safely intercommunicating by means of underpasses. This Radburn scheme as a whole is commanding so much interest that it promises to be the model for many new subdivisions and the inspiration for new departures in the design

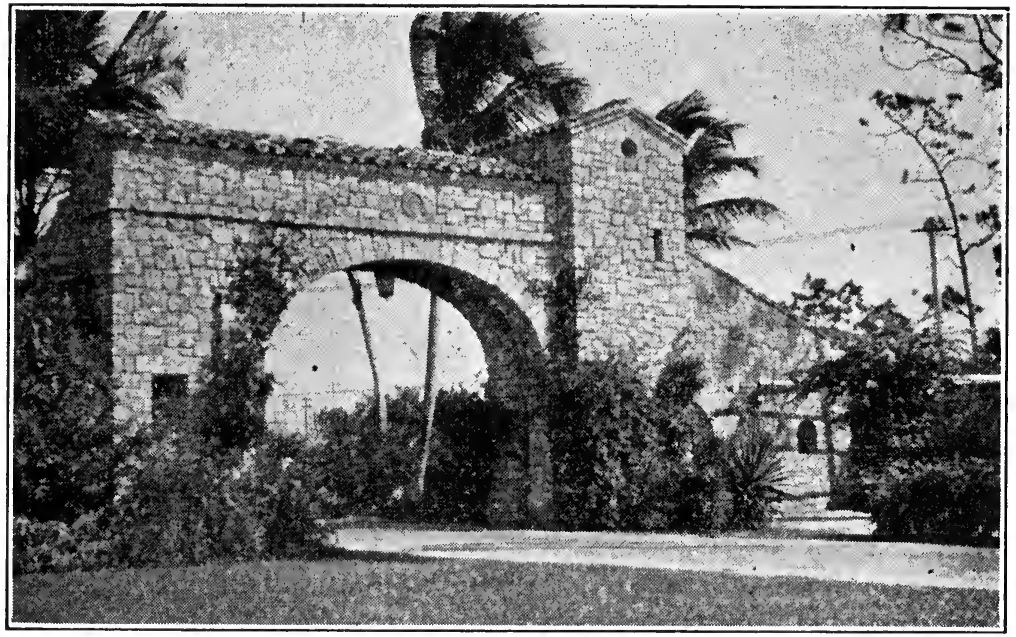

FIg. 95.-Douglas Entrance. Amazing, delightful, and unique among American subdivisions, are the entrance ways into Coral Gables. Similar of type but distinctly various in design they frame vistas and mark the entrances. They are made of coral-like native material and blend with the vegetation into striking pictures.

practices of the future. Even now a number of new developments are being patterned after Radburn.

Peculiarities of the Site.-As the site of a subdivision may be a very real factor in determining important phases of the design, it should receive the most careful analysis. The peculiarities of a site are matters of location, physical condition, and size of grounds.

Location of a Subdivision.-The choice of a good location for a subdivision should be governed by the relation of the site to the places of business as well as to the general facilities necessary to the life of the community. The property for a residential section that is close to the place in which its inhabitants must work 
accomplishes for these inhabitants a saving of their time, money, and energy and obviates the annoyance that they might otherwise suffer in trips back and forth between the home and place of employment day after day. On the other hand, remoteness of the residential section of the subdivision from the business section has its advantages in affording a change of environment for workers of all kinds and freedom of the homes from the smoke of the factories as well as from other nuisances incident to any location in close proximity to the factories. The land and the rents of the houses are both cheaper the farther away their location may be from the factory or center of business, and more open spaces are there available for the enjoyment of the resident population. Whether the property be far removed or near to the center of business or manufacture, the framework of the scheme for the subdivision should be built up with proper regard for the tendencies of traffic, by the provision of main highways leading from and toward the factories, mills, and commercial centers. If a railroad or trolley line shall pass through the plat to be subdivided, the right of way for this public utility will help to determine the site or the centers of business and manufacture in the future community and also the arrangement of its major streets.

Schools for the community and the supply of water, electricity, and gas to the community must be given careful consideration, as must also a system of sewers and sewage disposal. Where systems of public utility need to be relied upon, their capacity for extension should be definitely determined. Laws relating to local plumbing, health, and buildings will need to be taken into account as well as every possible regard for the present and future development of the community at large.

Physical Conditions to Be Considered.-The peculiarities of the soil as affecting the health of the people or economy in the construction of buildings, the different elevations of the land, the nature of the water supply, the natural vegetation, all of these things have an important bearing upon the development of any given property. Low, level land, for example, will mean the problem of deep sewers; and steep, rocky areas may involve a prohibitive cost for the construction of any sewers.

Size of Property as a Factor.-The amount of land available for a given project will very materially determine its character. If the land be plentiful and cheap, there will be no necessity and no justification for intensity of development, as there may be 
where the land is scarce and the price of it is high. Experience in this connection shows that providing for less than 6 families to the gross acre (inclusive of streets and exclusive of parks and open spaces), except on high-class subdivisions, is an extravagant use of land. Like experience also shows that a density of over 12 families to the gross acre, unless apartment houses or houses built in rows are provided, brings about congestion.

\section{THE PLANNING OF THE SUBDIVISION}

Only after the site of the proposed scheme for subdivision has been carefully examined and studied from these various angles is the designer ready to begin the problem of actual development. At this stage he needs to be informed about the further problems that are to be encountered as he proceeds, including the apportionment of areas for different purposes, the design of streets and systems of streets, of blocks, of buildings, and of lots and open spaces.

Allotment of Elements of the Scheme.-Here, as well as in other developments, one of the first things that arrests the attention of the designer is to see to it that things that go to make up the scheme of the subdivision in general are located to the best advantage in relation to one another. He will find that valleys frequently offer the most adaptable places for streets. Space for factories, if required, he will reserve upon level ground near transport lines, and play fields he will place upon low, flat areas. Sections that are not well adapted for other uses, such as steep hillsides, ravines, areas covered by water, or woodlands, he will dedicate to the public for use as parks.

An attempt should be made by the city planner to produce a complete residential neighborhood or a pattern of several such units, to encourage the enjoyment of neighborhood life (Fig. 96). These residential neighborhoods should include, among other things, one or more shopping centers, local streets to discourage through traffic, small parks, playgrounds, and sites for schools. For the creation of one of these residential neighborhoods, Robert Whitten suggests an area of a size that would ordinarily serve one elementary school, a tract of, say, 160 acres, located between two main thoroughfares $1 / 2$ mile apart and serving a population of 6,000 people. This area should be walled in by arterial highways in such manner as not to invite traffic through the area. At least 10 per cent of the entire area should be 
devoted to parks, a civic center of one kind or another should be provided if possible, and shopping districts introduced at the intersections of traffic about the periphery of the tract. In limited zones the area might consist of a parcel of 40 acres lying between main streets set at intervals of $1 / 4$ mile apart, and in the case of sections for apartment houses such an area will serve from 5,000 to 10,000 persons.

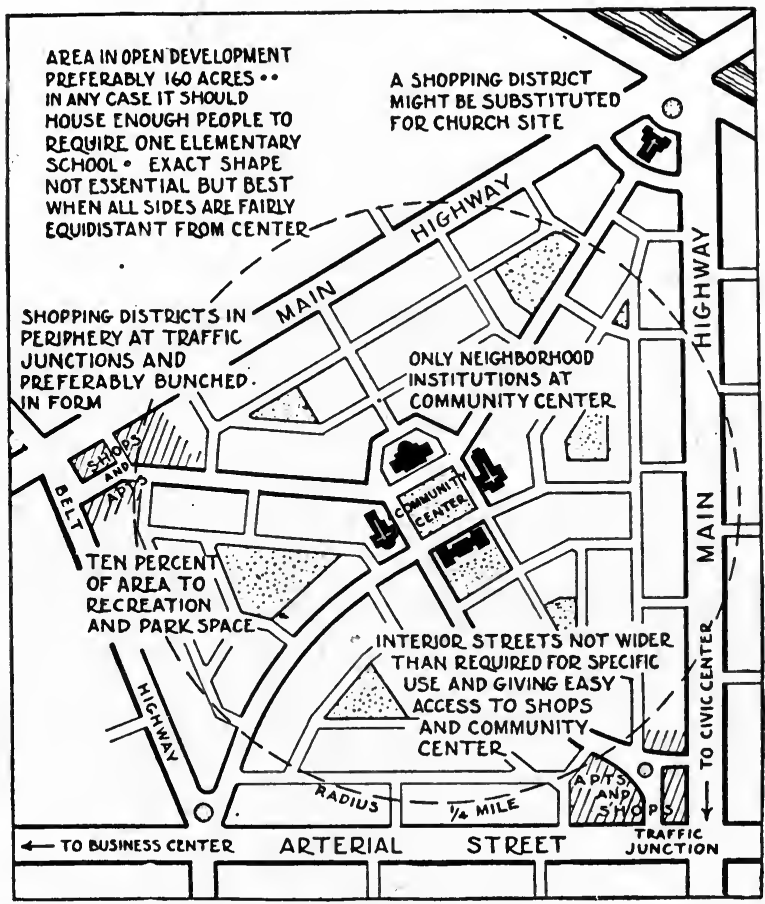

F1G. 96.-Diagram showing neighborhood-unit principles. (From the Regional Plan of New York, Vol. VII, p. 88.)

The difficulties of creating self-contained units of such size as these are the great amount of capital required and the difficulty of welding a sufficient number of small tracts of land into the requisite single area. The idea of designing complete residential neighborhoods is so commendable, however, that in most cases it should be approximated as nearly as the local conditions of the tract to be subdivided will permit.

Center Locations.-As in the case of the city at large, the location of a center is another element in the scheme of sub- 
divisions that calls for thought. This central feature or hub around which the life of the community may be said to revolve should lend itself to particular expression in the plan. Nothing else so completely endows the subdivision with organic unity. These central features of the subdivision are various in character. The center may be nothing more than a grocery store or drug store, serving the local residence section, or it may be an assemblage of public or semipublic buildings that are the pride of the

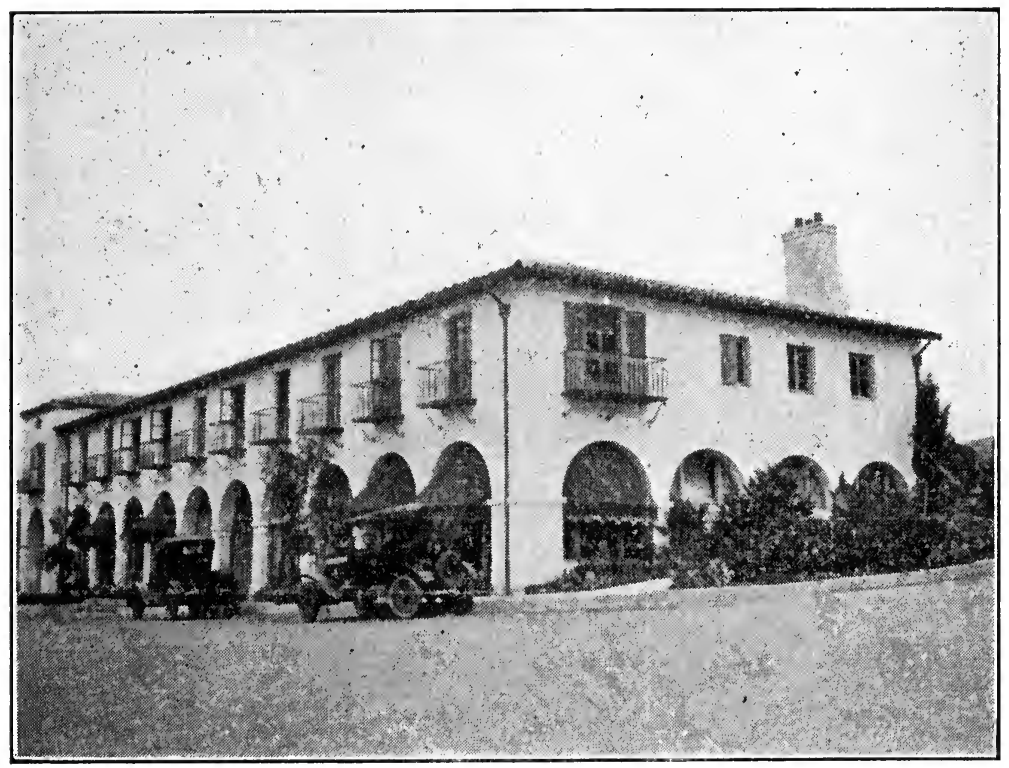

FIg. 97.-The first completed unit of the business plaza in Malaga Cove, Palos Verdes, Calif.

region. The small business centers (Fig. 97) that are common to the average subdivision should be close to the main road, streetcar line, or railroad station and thus easily accessible to the people on their way to and from work.

Centers for stores at the intersections of important streets are logical. In the 160-acre community which Robert Whitten advocates, the stores are proposed to be located at the corners of the subdivision where main highways cross. To concentrate the retail stores together at the ratio of 25 front feet for stores to every 100 of the population served is much better than to have the stores strung along every main highway, disproportionately to the needs and very much to the disadvantage of the community. 
The central commercial section for a larger community development should be concentrated into a compact unit. The more leisurely types of shops may be provided around quiet inner courts like El Paseo of Santa Barbara, and the more active types may be introduced along the streets, in proximity to convenient and adequate parking areas for automobiles.

Schools do not group well with other public and semipublic buildings, because they require so much space around them for play. To incorporate a place for worship into a center of publicly owned structures is a delicate undertaking, as it may lead to jealousies where other religious sects happen to be numerous in the same locality. A church, however, when desired with its related buildings, should occupy a site of some prominence or of reasonable quiet, perhaps across from a park. It is conceivable that a number of churches well designed with a common architectural note might be gathered together into a single group.

Streets (Underlying Considerations).-Careful attention should be given by the city planner to the design of the streets in the development of his subdivision. He cannot know how to provide for streets unless he have an understanding as to what they are supposed to do. He finds that some streets serve the needs of important traffic for the general public, while others merely open up a site locally for direct access to certain individual homes. The accommodation of traffic is the most important function of streets, and the devising of the best ways to take care of this traffic constitutes one of the important problems of the city planner. The solution of this problem lies in a complete conformance with the needs of the community that their traffic be accomodated in a manner which may prove to be safe and in conformance with the needs of the traveler, that while passing through he may be comfortable, free from anxiety and delay, and supplied with a succession of attractive views along the streets. Needs of traffic require, therefore, that streets must have adequate width, few crossings, and indeed no bad crossings or dangerous curves. Streets must be easily accessible to traffic, especially the major ones that must be so planned as to be direct and free from all unnecessary windings. Streets must be economically designed, not too narrow, else the growing demands of traffic will involve costly condemnation proceedings in the future for the purpose of widening them. Streets must provide 
comfortably and attractively for traffic, their grades must not be too steep, especially upon important thoroughfares, and there should be in all cases only easy vertical curves. There should be no abrupt changes in the direction of a street unless to discourage through traffic as in a residential neighborhood or to avoid a complicated street intersection. The streets should be well proportioned, not only to accommodate the necessary traffic but to look well in the relative scale of pavement, sidewalks and parking strips. The value of central parking strips is being advanced as a successful means of directing and controlling traffic. For practical usefulness as well as for looks these should be at least 40 feet in width. The sides of the streets should be interestingly planted and properly shaded, not only by trees occupying the strips of grass but also by rows of trees upon adjacent properties or by groves planted to adorn individual buildings or groups of buildings. The appearance of the street may be immeasurably improved, moreover, by a careful establishment of front lawns for the houses facing upon it.

An intelligent accommodation for traffic in every street involves a detailed study of the needs of that traffic. Streets that carry a considerable burden are found to require greater width than others not so encumbered, and the width of every street depends upon the number of measurable or predictable lines of traffic that will traverse it and the consequent space that will, for this purpose, be required. Upon the basis of the width of a roadway now accepted by eity planners as being 9 feet for moving vehicles and 8 feet for parked cars standing parallel with the curb, the space necessary for the required number of traffic lanes and therefore for the width of the paved street may be determined.

There are four types of streets, from the point of view of serving traffic, necessary in the development of a subdivisionthose that carry considerable through traffic, those that provide for the main circulation of traffic within the limits of the subdivision, those that are purely local and concern only access to the residences facing them, and those designed purely for purposes of pleasure. In other words, streets are arterial, secondary, residential, or park ways.

Arterial Streets in Subdivisions.-Since the function of an arterial highway is to conduct important streams of traffic for relatively long distances, special concern should be had by the 
city planner for the needs of the city in designing arterial streets or of the surrounding region at large-rather than any special concern for the needs of the given subdivision through which or beside which the arterial street must extend. The arterial street demands directness, easy gradient, freedom from unnecessary curves, few cross-streets, and ample width. Such a street should not be less than 80 nor, as a rule, more than 120 feet wide, within which limit (say, for 100 feet in width) four lines of traffic can be provided (36 feet), two lines of parked vehicles (16 feet), 2 car tracks (20 feet), and two sidewalks inclusive of parking strips (28 feet). In this emergency we must not overlook the plan of 204-foot super highways that in the Detroit regional plan are called for every 3 miles square.

Secondary Streets in Subdivisions.-The purpose of this class is to connect streets and centers within the given property and generally to make one part of that property convenient of access to the other parts. Secondary streets, therefore, call for a greater regard for the immediate scheme of the subdivision than do the arterial streets. Secondary streets are provided to divert traffic from residential thoroughfares and to form more important public highways than the residential streets, and accordingly they require a fair amount of directness. The standard width of secondary streets is between 50 and 80 feet. Assuming an average width of 68 feet for a secondary street, such provisions as the following can be made: two lines of traffic (18 feet), two lines of parked vehicles (16 feet), and two sidewalks inclusive of parking strips (34 feet).

Residential Streets.-The purpose of residential thoroughfares is mainly to serve as access to residences. Since the requirements of traffic and quietness in a residential section make through traffic objectionable, systems of residential streets that are indirect and uninviting to traffic are being introduced. These streets, too, may vary in importance, some being longer and more generously patronized than others, so that there may be a variation in their widths of from 40 to 60 feet. On a residential street with a width of 50 feet there will be provision for two lines of traffic (18 feet), one line of parked vehicles ( 8 feet), and two sidewalks, including strips of grass (24 feet). The purely residential streets as provided at Radburn, N. J., take the form of a series of spurs from the main roadways, streets wide enough for two vehicles to pass but terminated by dead ends. The houses are 
grouped along these and face in the opposite direction upon green stretches of enclosed yards or upon open parks, depending upon their position in the scheme (Figs. 98, 99).

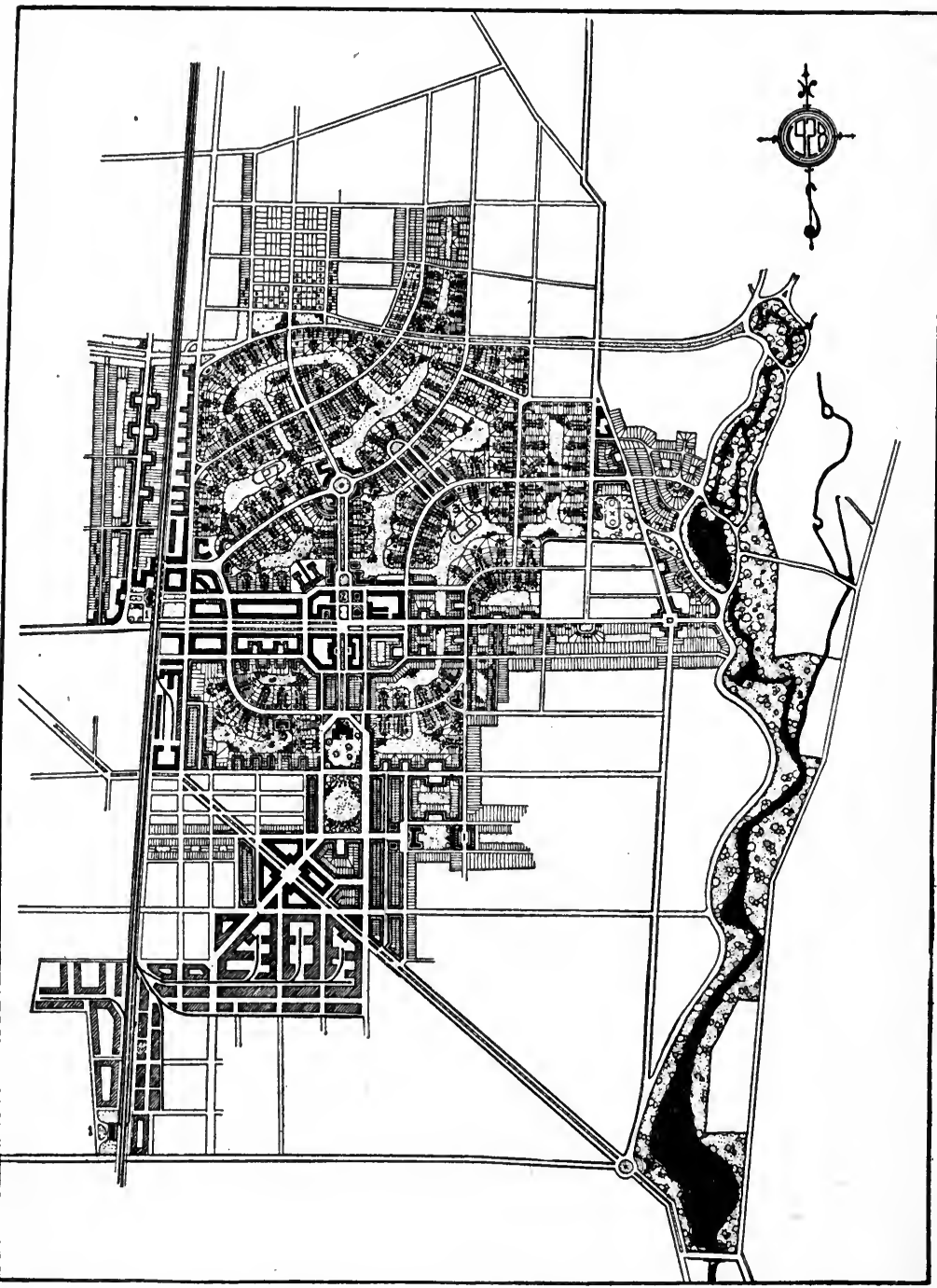

Fig. 98.-A plan of Radburn, N. J. Attention is called to the immense blocks, the dead-end streets with homes grouped along them, and the inner block parks.

Boulevards and parkways are provided principally for the pleasure of the people walking and driving and are both of use 


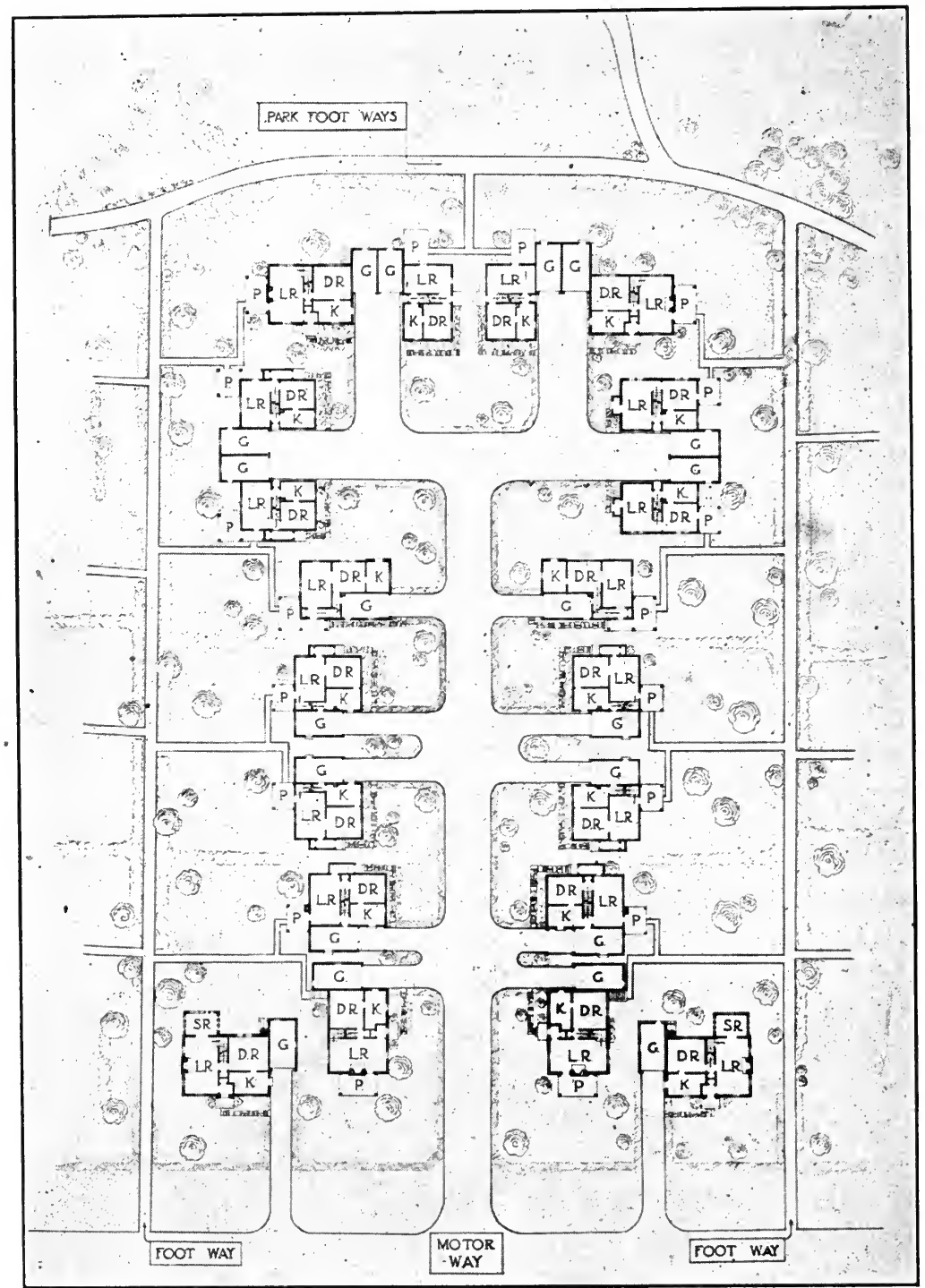

Fig. 99.-Radburn, N. J. Plan showing placement of houses on closed-end street with motor way and pedestrian path. 
in linking up some portions of a system of parks with another or in making available narrow strips of property of some particular interest to the people. Boulevards and parkways are subject to considerable variation of treatment by city planners but are usually characterized by a generous width and by the free use of trees and shrubbery and the inclusion of other features of beauty along their margins.

Blocks.- The design of streets cannot proceed intelligently without an understanding of the blocks of buildings around which the streams of traffic are to flow. The sizes and shapes of these blocks will depend upon the topography, the requirements of traffic, the use for which the blocks are intended, and the economic considerations involved. A hilly site, which introduces difficulties of construction and utilization, obviously will produce a different effect upon the character of blocks than a level one. The necessity for convenient access from one street to another makes blocks of indefinite length undesirable, although considerable latitude in this respect is permissible, where separate cross-walks are introduced at convenient intervals.

Their maximum use at minimum expense in land and road and loss of frontage has an important bearing upon the size and shape of blocks. When they are too small, they add to the amount of area of the streets necessary, add to the cost of street construction, and subtract from the amount of available frontage for the lots. Blocks of conventional size have different potential values according to their individual shapes. According to recent studies of Henry Wright, those that approach most nearly the rectangular or square appear to be the most economical.

The loss of frontage at the junctions of roads also has an important bearing upon the shapes of blocks. The least amount of frontage is lost in right-angled junctions, while the most frontage is sacrificed where two roads meet at acute angles.

It has been the practice to lay out blocks with their longer sides parallel with the main roadways, in order to give maximum frontage upon these main highways. The value of longer sides along the main ways, with fewer resulting cross-streets and intersections of streets, is also being recognized now as an important means of promoting traffic flow and safety. Larger blocks are placed to best advantage in the better class of residential neighborhoods. The average of convenient length for a block may 
reach to as much as 1,000 feet and more, provided cross-walks are introduced.

The practice of utilizing frequent cross-streets and shorter blocks is gradually giving way to larger blocks and fewer crossstreets, which satisfies not only the needs of street circulation today but also the needs for economy in reduced street area and utility lengths. It is apparent, and may readily be demonstrated, that the larger a block happens to be the more economical it is in regard to the construction and maintenance of cross-streets and intersections and the more comfortable it is for traffic in the fewer obstacles to progress and the fewer causes for collision that are present. Henry Wright says of the large square block that it is the most efficient in the relation of usable frontage to endblock waste and in minimum street maintenance per lot. In the matter of reduced street area it is important to know, and at first thought it seems almost unbelievable, that "in almost any plan of subdivision on land at average suburban costs, where two short blocks have been plotted adjacently . . . by omitting the dividing street the remaining frontage can be produced at little more cost and frequently at a saving." This is immensely important because it brings within sight the possibility of introducing more spaciousness in our blocks in the form of common open space without extravagance and without disregard for economic factors involved in the working, out of a practical development.

The extreme of large blocks is to be found at Radburn where they are at least $1 / 2$ mile long by $1 / 4$ mile wide and cover an average of about 35 acres. The introduction of these large blocks at Radburn has reduced the amount of area in streets and the lengths in utilities by 20 to 30 per cent as compared with the provisions in the normal block layout.

Lot Sizes.-It is not surprising when we consider the numerous influences that help to determine the size of lots, that such an infinite variety in their sizes is to be found (Fig. 100). Among the influences that play a part in producing this variety in the size of lots are local custom, the improvement of lots, and the topographical requirements of the subdivision.

Local custom has made it easier in the past to provide lots of a size familiar to the people who are to buy them. In order to secure a fair measure of financial return to the subdivider, the cost of the land to be subdivided determines either a development of fewer and more expensive properties on the one hand or a 
development of more numerous and cheaper properties on the other. The cost of improvement of the streets and the cost of improvement of the lots, including their grading and planting,

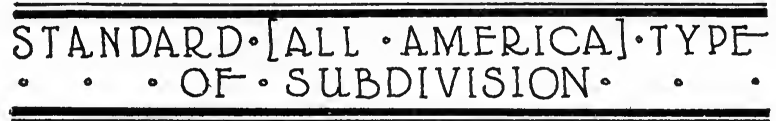

-TWO - EXTREMES
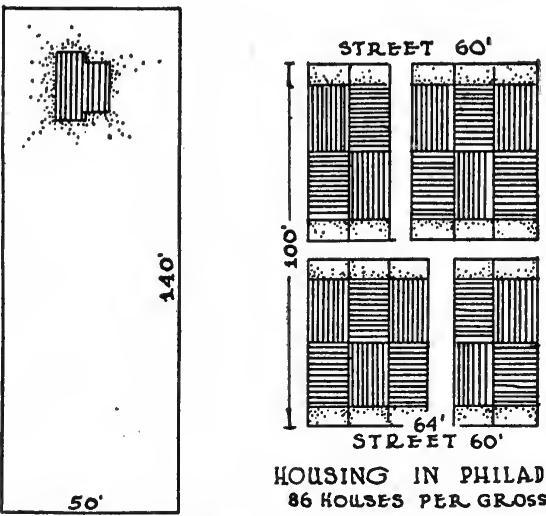

HOUSING IN PHILADELPHIA

86 HOLSES PER GROSS ACRE

HOUSING IN IVYANDOTTE

3.75 HOULES PER GROSS ACRE

\section{THE・VARIETY・IN・STANDARDS}
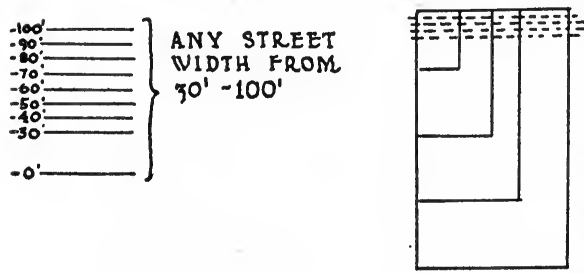

ANY SET-BACK
FROM $O^{\prime}-5 O^{\prime}$

ANY LOT DEPTH

FROM $40^{\circ}-300^{\prime}$

ANY LOT WIDTH

FROM 15'-100'

ANY ALLEY

FROM $10^{\circ}-20^{\prime}$

Fig. 100.-Standard (all-America) type of subdivision. This is intended as a ready answer to the common question as to what constitutes the width of a street or the depth of a lot, etc. The variation that may be found is self-evident in the above illustration, which was originally suggested several years ago by Henry Wright, community planner. (Drawn by Clarence Baughman.)

their fences, hedges, and their walks leading to individual houses, as well as utilities, are important factors in determining the price that the subdivider must receive for his lots. 
The requirements of the ground determine the sizes of lots, and in this connection nothing is more important than to know how much space is necessary for the structures to be built upon the lots and the uses to which these structures will be devoted. The width of the lot is determined by the depth and width of the house that is to be erected upon it. Detached houses (25 to 30 feet) require lots of from 40 to 50 feet wide; semidetached houses ( 20 to 25 feet to each unit) require lots 25 to 30 feet wide, with at least 16 feet between the buildings upon adjoining lots; and dwellings in groups 15 to 16 to 20 feet in width for each unit require lots 15 to 16 to 20 feet wide. Wide lots are generally assumed to be more advantageous for detached homes than narrow deep lots.

The depth of the conventional lot should be the summation of the depth of the front yard at least 10 to 20 feet, the depth of the house and the depth of the back yard requiring 35 to 40 feet at least where a garage is to be included. More than 130 feet as a total depth for the lot cannot be used efficiently in the case of an industrial community. It must be kept in mind that lot depth is not so important because of actual use as it is for separating and obscuring the view of rear ends of buildings that occupy the opposite side of the same block: Where interior block spaces are introduced, this need for deep lots disappears.

Lot Shapes.-Good shapes of lots facilitate the advantageous use of streets and public utilities, the survey of the lots and their description for purposes of record, and the maximum use of the lands and offer the best sites upon which the buildings can be erected. In the blocks and lots with which we have been familiär in the past, more lots in a given area are served by a given lengty of street and by its utilities when the narrow sides of the lots face the street. This explains why there are so few wide lots in spite of their advantage for single homes. Along streets upon steep hillsides, it often proves both necessary and desirable to have the long sides of the lots extend parallel with the thoroughfare. By simplifying the lines of the lots, by keeping them uniform and equally spaced, and by running them through the block from the street, the work of the engineer at least is greatly lightened.

Lots of similar size should lie together, because uniform sizes of lots are fundamental to the planning of a neighborhood, intended to be rather uniformly developed. Irregularity in the shapes of lots prevents the best use of the property, and therefore all angles in the outline of the lots that are less than right angles 
should as much as possible be avoided. "Pie-shaped" lots are always more difficult to plan to good advantage than rectangular ones.

By having lots conveniently shaped, the best sites are provided for the buildings that are to occupy them. The best way to devise lots and the shapes of lots is to locate the buildings or groups of buildings first according to the ideals of community planning and then make the lots to fit the proposed buildings. This method of work suggests the necessity, when engaged in the task of formulating the shapes of the required lots, of keeping in mind the kinds and positions of the buildings intended to be erected.

Since a house on a small property looks best, as a rule, when located in a line perpendicular to the street upon which it fronts, be the street curved or straight, the lines of the lot also should be drawn perpendicular to the same thoroughfare. Since houses often serve as interesting and beautiful terminal features to certain streets, the lot lines should be so arranged as to encourage the placement of houses for such desired effects.

Where the construction of the residences as well as the layout of the lots proceeds under common ownership, there are many desirable effects attainable in the arrangement of both buildings and lots. Houses may be grouped in well-considered units in some instances facing inward upon a block of gardens. Those erected at street corners may have special treatment, and others may be so grouped as to take advantage of a green, a meadow, or a park.

The disposition of a portion of the lots at least should be governed by the growing need for apartments and particularly those in groups and blocks. The normal house lot cannot be expected to serve the needs of apartments. These cannot and should not be confined to cramped quarters. Unlike solid, compact, individual homes, apartments are likely to be large in bulk and require internal courts of some size. Apartments should be not more than two rooms deep and in the form of a perimeter building around an ample courtyard. Where the block is large enough to do so, the perimeter at intervals can be recessed in the block in the form of reentrant courts with the resulting advantage of setback from the street for numerous rooms and frontage upon an outer court instead of upon the street.

Parks and Interior Open Spaces.-The number and kinds of parks and interior open spaces that may be provided in a sub 
division depend upon how many similar facilities are to be enjoyed upon adjacent properties, upon the size of the given subdivision, the density of its proposed population, and the value of the land. It is desirable to reserve at least 10 per cent of the total area of the subdivision for purposes of parks. In some instances this would need to be exceeded; in others, because of a compensating acreage near-by, it could be reduced.

The development of internal areas and open spaces set aside in the middle of blocks is ideal in purpose and is becoming more popular. Unless, however, proper supervision and control are exercised and maintenance is afforded by the municipality, the subdivision, or the block concerned-and there is no reason why this cannot be arranged-these areas will soon degenerate into centers of unsightliness. The importance of appropriate care of such areas must be properly understood, but the difficulty of securing that care should not be permitted to eliminate the excellent idea of central recreational areas.

Alleys.- Now that homes in our newer developments are being reversed and are made to face upon the alley side and to back upon the street, the alley is becoming the dignified front walk which leads past the gardens of the neighborhood. Even in the old sense the advisability of providing alleys with the main purpose of serving the rear entrances of homes is sometimes open to question. Alleys are necessary upon occasion, especially where local custom requires them and where there are rows of houses with no other way of getting to the rear. Alleys, however are unnecessary where there is an open development of detached and semidetached houses. The main objections to alleys are that they are depositories for rubbish and are an added expense when it comes to paving them. Where alleys are used they should be paved, that they may be easily kept clean, and they should be well lighted, not curved, and should always have the supervision of the police. They should be at least 16 feet in width, to accommodate the passing of one automobile and a pedestrian. The alleyway may also be used to advantage for accommodating such public utilities as poles and wires.

\section{SUBDIVISION CONTROL}

Subdivision control is that authority which may be exercised over new subdivisions, under the direction of a city planning commission, in behalf of better conservation of the health, 
safety, and general well-being of the people. That authority is exercised largely under the police power with the fundamental purpose of preventing unhealthy, ugly, and wasteful conditions. It can be made effective only by the power delegated by legislative act. Commissions with only advisory power can accomplish but little. The Standard City Planning Enabling Act as prepared by the U. S. Department of Commerce and being adopted by a number of our states contains ample provision for adequate public control. Under this act no plat may be filed or recorded until it has been approved by the planning commission. Although the planning commission cannot prevent a person from selling his land, it can at least, under this act, prevent the purchaser from making any use of that land that would mar the city plan already adopted. The act, however, provides that no such control of plats can be undertaken until a major street plan covering the whole territory under consideration has been adopted by the planning commission. There should be at least a major street plan. It would be better if there were plans also showing the general layout and intercoordination of the various basic systems of public facilities and control, water and sewer, transit and transportation, recreation, and zoning. Into all of these preferably the proposed subdivision should fit.

Then, too, before exercising these important powers, the planning commission must prepare for itself a set of regulations so "as to reduce as far as possible the field of arbitrary discretion." A number of cities have adopted regulations that carry out these purposes. The regulations adopted detail in outline the requirements for preliminary plans, provide the manner in which these plans shall be presented to the commission, describe how much information the plans shall include, fix the scale at which the map of the subdivision must be drawn, and provide that there shall be shown plainly on that map the lines of all of the lots included in the subdivision and the grades of all of its streets. Similarly, these regulations indicate the nature of the final plan (scale 50 to 100 feet to the inch) and the number of copies of that final plan that must be made (a tracing and three prints). The regulations should also include the demand that some statement be made by the planners showing the width of the streets and alleys, the width and depth of the lots, the length of the blocks, and the percentage of space to be dedicated for parks and open spaces throughout the subdivision. 
A regulation as to the giving and acceptance of a bond to secure to the municipality the actual construction and installation of utilities and other improvements, together with power to enforce such bond, is a salutary feature in connection with the control of subdivisions by the city planning commission. Unfortunately there are too few cities today that make all of these requirements. Subdividing should be allowed to proceed by the city planning commission only after an explicit understanding shall have been had with the subdividers that the subdivision in question must fit the proposed human occupancy. In the light of their many unfortunate experiences in the past, cities before long will have to adopt this principle of assured improvements and thus eliminate "wild cat" subdivisions.

There are certain arrangements, appropriate types of buildings, and so on, in the development of a subdivision that may be controlled and made more enduring either by restrictions in deeds or by general community "zoning." Restrictions and zoning may prevent the further dividing of the lot; may govern the use of buildings and land, the value, the style of architecture and position of the house, as well as the location of the garage, fences, walls, and telegraph poles. The restrictions in a deed extend over only a limited period of time, from 20 to 30 years, although they can be made renewable automatically, but the control exercised through "zoning" ordinances continues indefinitely.

Another method of insuring a high order of beauty in the design of the house is through an inspection of the proposed design by an architectural board of review. This method was tried succesfully as far back as 1893 in the case of Roland Park, Baltimore, where all of the plans for fences, buildings, and other structures, as well as their color, had to be approved in advance of their adoption by a competent appointed committee. In 1922 appropriate machinery for this kind of thing was set up at Palos Verdes, Calif., with the aid of an endowment of $\$ 300,000$ expressly made for the purpose. This endowment has the distinction of being permanently established (Fig. 101).

Other organizations for the subdivision of property throughout the country have reserved the right to pass upon all proposed plans of buildings to be erected within the boundaries of their subdivisions but have not set up the necessary permanent machinery to carry out their intentions, have not been properly 
financed, and have not been equipped with power sufficient to prevent the erection of any buildings to which the subdividers might object. If an art committee is to function satisfactorily for the development of any given subdivision, it must be composed of persons with a correct judicial attitude toward their work and with full power to enforce their decisions.

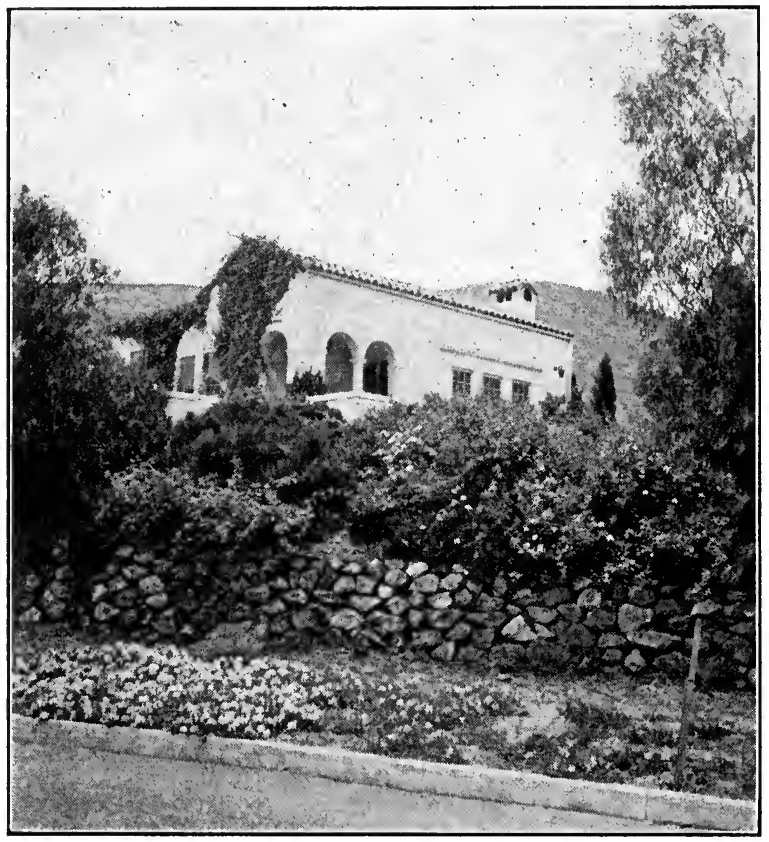

Fig. 101.-House and lot, Palos Verdes, Calif. Not only is the situation of Palos Verdes difficult to match but everything possible is being done to make the most of it, roads are fitted to topography, houses to lots and views, and appropriate standards of architecture and planting to suit the needs of the picture are maintained. (Photograph by the author.)

Homes Associations.-Where a new subdivision is undertaken outside an incorporated city, there is some difficulty in bridging the time until enough people under the law are permitted to organize some form of town or city government and carry on the needs of the community. The selling agency often tides over this difficult period in a somewhat paternalistic manner, which leads to undesirable concessions for purposes of sale. This difficulty can be avoided by organizing a homes association from the beginning of the development of the subdivision, primarily for the 
common benefit of all the owners of property in the subdivision in order to bring about the most attractive, convenient, and satisfactory development. The Homes Association as perfected at Palos Verdes and Rancho Santa Fe is successful.

Such an association may be incorporated as a non-stock-issuing and non-profit-making corporation, in which the owner of every building site has a vote. The duty of the organization may be made to include the maintenance of parks, street planting, and other affairs of the community and to perpetuate the restrictions provided in the scheme of the subdivision. Under the control of the homes association vacant lots may be kept free from weeds and rubbish, ornamental lighting of streets may be provided and supervised, and a fire department and protection by police may be afforded. Taxes or assessments may be levied by the homes association, but the power of the association to levy these taxes must fall within the rate specified in the charter. Any other features that may contribute to the welfare of the people may also be incorporated in the charter creating the homes association.

\section{Questions for Discussion}

1. How may the subdivision of land affect the physical development of a city?

2. Discuss the control of land subdivisions.

3. How may the "home association" be of value?

4. Name and describe some of the notable subdivisions of recent years.

5. How may factors of location, physical condition, and size of the tract affect the development of a subdivision?

6. What elements of a subdivision are to be located and where must they be located?

7. What is the meaning and value of a complete residential neighborhood?

8. What considerations are involved in the layout of streets in subdivisions; arterial streets; secondary streets?

9. Discuss the requirements of blocks and lots.

\section{References}

Control of Land Subdivision and Building Development: An Outline of Practices and a Statement of Principles, City Planning, vol. 4, pp. 251255, American City Planning Institute, July, 1928. Also repr.

Crane, J. L.: Interior Block Playgrounds. New Features on an Indiana Townsite Subdivision, Landscape Architecture, vol. 14, pp. 188-193, illus., plans, April, 1924.

Harmon, W. E.: Playgrounds in New Land Subdivisions, City Planning, vol. 2, pp. 85-86, April, 1926. 
Hegemann, Werner, and Elbert Peets: Land Subdivisions and Residence Groups, "The American Vitruvius," pp. 263-284, Architectural Book Publishing Company, New York, 1922.

HUBbard, H. V.: Land Subdivision Restrictions, Landscape Architecture, vol. 16, pp. 53-54, October, 1925.

-: The Influence of Topography on the Layout of Subdivisions. Landscape Architecture, vol. 18, pp. 188-199, plans, April, 1928.

Monchow, Helen C.: "The Use of Deed Restrictions in Subdivision Development," Institute for Research in Land Economics and Public Utilities, Chicago, 1928.

Morris, Warren L.: Cleveland's Miles of Respectability, National Municipal Review, pp. 690-694, October, 1930.

Olmsted, F. L.: Palos Verdes Estates, Landscape Architecture, vol. 17, No. 4, pp. 255- 275, July, 1927.

Propper, Henry M.: A New Town Planned for the Motor Age, American City, pp. 152-154, February, 1928.

Swan, H. S., and G. W. Tuttue: Land Subdivisions and the City Plan, Suppl. to National Municipal Review, vol. 14, pp. 437-462, illus., plans, diagrams, July, 1925.

Thомpson, F. L.: "Site Planning in Practice," 258 pp., illus., plans, Oxford Technical Publications, H. Frowde and Hodder and Stoughton, London, 1923.

Unwin, R.: Of Site Planning and Residential Roads. Of Plots and the Spacing and Placing of Buildings and Fences. Of Cooperation in Site Planning, "Town Planning in Practice," pp. 289-360, 375-386, illus., plans, T. F. Unwin, London, 1909, etc.

Whitten, R. A.: With Particular Reference to a Complete Neighborhood Unit for Low or Medium Cost Housing, 72 pp., School of Citizenship and Public Affairs of Syracuse University and Regional Plan of New York and Its Environs, New York, 1927.

: Land Subdivision: The Effect of Density on Acreage Values and on Lot Values, City Planning, pp. 259-263, October, 1930.

Wright, Henry: Exploiting the Land, Journal of American Institute of Architects, vol. 15, pp. 305-306, October, 1927.

-: Platting City Areas for Small Houses, 16 pp., illus., suppl. to Journal of American Institute of Architects, August, 1920.

-: Sunnyside and Radburn, Playground, vol. 22, pp. 682-684, plan, March, 1929.

: Some Principles Relating to the Economics of Land Subdivision, Paper 1, 20 pp., illus., American City Planning Institute, ser. 1930. 


\section{CHAPTER XVI}

\section{HOUSING}

A program for city planning that fails to facilitate in every way possible the attainment of good housing fails in one of its most vital purposes. It is essential not only that we plan good sites for good homes but also that we do the reverse, that we plan good homes for good sites, for only by so doing can we solve the problem of housing which has confronted all past generations of people, and which now faces us.

Good housing means that there shall be enough homes in any given city to satisfy the needs of all classes of people dwelling within it and furnish to all of these people good living quarters with plenty of light, air, and conveniences for comfort and happiness. Good housing suggests homes accessible to the work and play of the people, suitably controlled by the municipality as to occupancy and upkeep, and within the financial reach of the occupants. Good housing is synonymous with the safety, health, convenience, and privacy of the people living in a city and with the agreeableness of their surroundings.

To take care of the people at large, good housing must include accommodations that are suitable for families with children, for persons of advanced age who have reared their children and are now left alone, and for the unattached, homeless man and the wage-earning woman. To meet these needs a diversity of types of homes is necessary in every city-houses built for one family and occupied from cellar to roof by that family; semidetached houses; houses built in rows; houses for two families (one above the other); and (Fig. 102) multifamily homes (or apartments). Of the various requirements of good housing the most essential is the building of a house that will fit the needs of a family with children (the house for one-family serves children best of all); and such houses or their nearest equivalent, must be brought within the reach of all classes of the population-poor and rich alike. It is not only unfair that appropriate houses in which to live be denied to anny of the city's population, but it 
is unwise as well in that the consequences of bad housing juvenile delinquency, immorality, and disease-are always felt both directly and indirectly by the whole community.
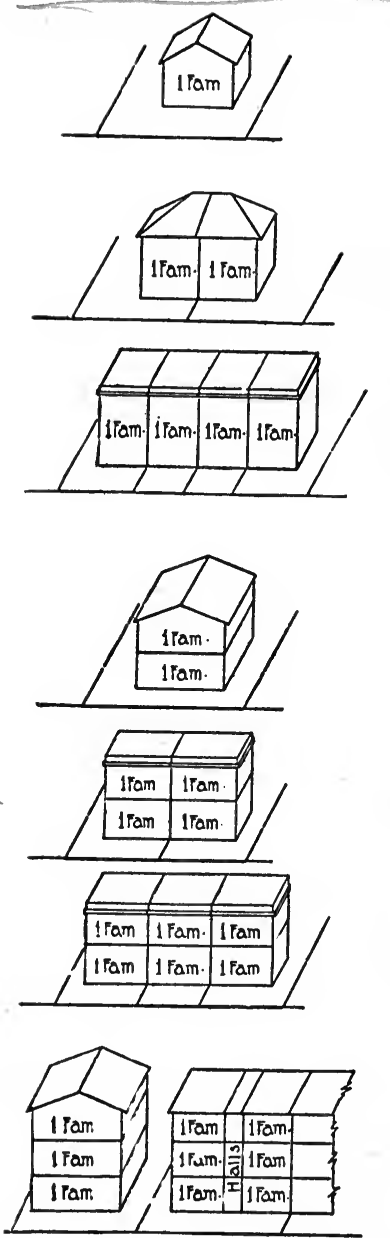

Detached house.-(The "single house," one family in a building.)

Semidetached house.-(A one-family house having one party wall only in common with an adjacent house. Each half of the building is a "semidetached house," the whole building is a pair of semidetached houses.)

Row house.-(A one-family house attached with two or more others to form a continuous row or group in which the several houses are separated from adjacent houses by party walls.) This type may be divided according to location in the group or row into: row end houses and row inside houses.

Detached two-flat house.-(The "duplex house," two families in a building, one over the other.)

Semidetached two-flat house-(A two-flat house having one party wall only in common with an adjacent house; normally one-half of a building containing four families, one in each story in each half.)

Row two-flat house-(A two-flat house attached with two or more others to form a continuous row or group, in which the several houses are separated from adjacent houses by party walls.) This type may be divided according to location in the group or row into: row end two-flat houses, and row inside two-flat houses.

A partment house.-(The "tenement house," containing three or more families, normally one or more families on each of three or more stories, served by a common hall or stairs.)

Fig. 102.-Diagram of house types. (From Report of the United States Housing Corporation, Vol. II, 1919.)

\section{HOUSING LEGISLATION AND BAD HOUSING}

Unsatisfactory living quarters in cities are with us still, as they have always been through the centuries. The condition of the housing in New York City was formerly deplorable and much of the legislation in other cities has followed and has been 
patterned after the attempts to improve housing conditions in our largest American metropolis. Although some agitation for public control of the housing situation was started in New York City as early as 1842 (with a report by Dr. John H. Griscom), and although a council of hygiene and public health to deal with the housing difficulty was formed there in 1864, the first law to regulate tenements was enacted by the legislature of New York in 1867 and this law was followed by another enacted in 1879 . No successful attempt was made to deal in a comprehensive way with the housing evil in America, until the opening years of the twentieth century. Housing conditions were investigated thoroughly by a commission in New York City during 1899 to 1900, with Lawrence Veiller and Robert W. de Forest in charge of the inquiry. Several years prior to that important investigation, the importance of the need for immediate remedial legislation was notably stressed by the writings of Jacob Riis and other philanthropists. By the passage by the legislature of New York, in 1901, of the tenement house law, a milestone in the pathway of the regulation of tenement houses was established.

New York City is not alone among our municipalities in suffering from the defects of its housing. All our larger cities in America are subject to the same affliction, and many of them have tried to affect cures.

In other countries, too, there was an early realization of the need for housing betterment. In England, for example, the famous study and report by Edwin Chadwick appeared in 1842, a report that is said to be the beginning of all sanitary science in this country. Public regulation of housing in Creat Britain began with the act of 1857 . The epoch-making studies made in London by Charles Booth and presented in his "Life and Labor of the London People" were begun in 1886.

The first comprehensive and scientific investigation of urban housing conditions in Germany was carried on from 1880 to 1888. This investigation was conducted in Berlin by the authorities of that city. As a result of that investigation, it was found among other things that in a group of 15,000 families, each of which was then occupying but a single room, the death rate was thirtyfive times as high as it was among families occupying four rooms or more. In other words, the investigation revealed the startling fact that 6 per cent of the population was contributing 50 per cent of the deaths occurring in the city. Following this study, 
Berlin enacted a comprehensive law regulating tenement houses.

Just on the heels of the investigation in Berlin, a somewhat larger survey of the conditions of housing and living was conducted in the poorer sections of London (1887 to 1895). So great was the impression made upon the people of England by the facts discovered during this survey and by the revolting pictures that were painted in its report of the overcrowding, poverty, and squalor then existing in London that one of the great achievements in housing reform came out of it-and that was the Housing and Working Classes Act of 1890. A few years later the Housing and Town Planning Act of 1909 was enacted by the British Parliament which, among other things, authorized with appropriate financial help the building of new homes.

Since 1909 the range of public authority to control the housing situation in England has been broadened by other acts of Parliament such as the Town Planning Acts, the Slum Clearance Act, and others stimulating the building of houses to meet the shortage that was caused by the World War.

\section{BAD HOUSING CONDITIONS IN THE UNITED STATES TODAY}

In spite of the efforts in our various cities made to overcome unsatisfactory conditions of housing, there are existing today, in all of our large cities, conditions detrimental to the public welfare. There is a great shortage of houses that can be rented for less than $\$ 30$ a month. Many of our laboring people are living in unfit and unsanitary areas of our cities and in antiquated and outworn buildings; some are living in dark or windowless rooms, in unsanitary, dilapidated, and congested quarters, with inadequate and defective plumbing. Old frame buildings, mere fire traps, are allowed to remain standing and to be occupied by thousands of people, because there is no attempt made to enforce the local ordinances passed to prevent the commission of this great crime against our common humanity. Such slums occur in most of our large cities, like cancers in the human body, and like cancerous growths they should be removed.

According to Lawrence Veiller, as many as one-third of the people of New York City (that is to say, 2,000,000) live under unsatisfactory and disgraceful conditions of housing.

Chicago, too, has its difficulties of housing and is without any effective or comprehensive plan for their correction. Most 
of the foreign-born population of Chicago is living in tenements, and a large percentage is occupying houses built in back yards. Its worn-out one-family homes are occupied intensively, as are many of its three-story flats that are likewise swarmingly overpopulated. Cincinnati has 12,000 tenements at the present time, and these house a high proportion of its population. Although Philadelphia is outstandingly free of tenement houses and has a large proportion of one-family dwellings and a high ratio of home ownership, yet the condition of the housing in the quarters

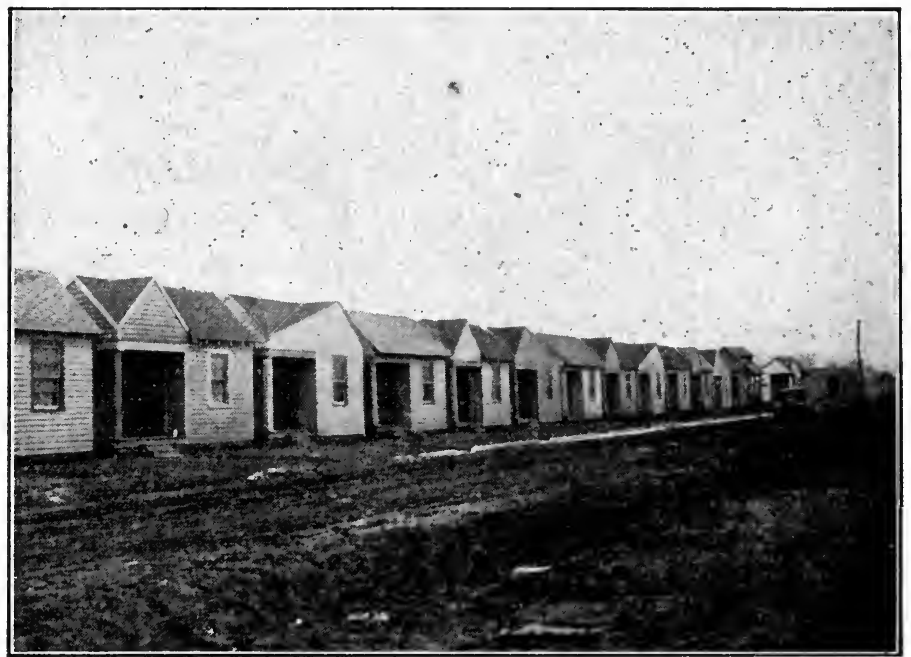

FIG. 103.-A row of shacks intended for homes. Freedom to build atrocities like these in a city is a reflection upon the good sense of the city.

occupied by negroes is anything but commendable. The negroes in Philadelphia are packed in their homes four times as closely as are the whites, and as a result of such congestion the cases of tuberculosis among them are from three to five times as numerous as among the white population. Boston and the mill towns of Massachusetts have witnessed the construction of three-decker frame tenements erected upon narrow streets, while other American cities (Fig. 103) are having thrust upon them similar problems of their own.

"With all of the wealth and power and vigor of the United States," writes Louis H. Pink, "we are woefully behind in providing decent, respectable, sanitary, cheerful, livable dwellings for those who toil." 
Reasons for Bad Housing.-Among the contributory causes of bad housing are the concentration of population, scarcity of accommodations, high rents, and the exploitation of obsolete buildings, not to mention the elemental and most important cause of all-poverty. In relation to the poverty of our working people, the distribution of their incomes and the cost of building are such that only a third of our whole population can afford to buy or even to rent a new home.

Overcrowding of houses is prevalent over our entire country, in both the larger and the smaller cities. This overcrowding is partly due to the desire of workmen to be-close-to their work (present employment or potential) and to their desire to be free from long, tiresome rides and the cost of transportation.

Accomplishment of Good Housing. - The attainment of more habitable places of living for our laboring people resolves itself into the problem of the repair and improvement of existing dwellings, the replacement of houses that are no longer usable, and the creation of new and more ample accommodations.

The replacement of existing and outworn structures (unhealthful and unsanitary buildings) is a thing that has been done in this country in a small way but not at all to the extent possible, as is shown by a comparison with the similar accomplishments in the leading cities of England during the last 50 years. In order to clear out our slums, as we must plan to do, according to Lawrence Veiller, we must have the authority of law and must have some kind of functioning body upon which the responsibility for the work will devolve and which must establish an equitable basis of compensation to the landlord for the loss of his buildings. Some understanding must also be had as to what use the land will be put after the destruction of the present dilapidated structures, whether new buildings shall be erected upon the land or parks and open spaces shall be provided upon it. Mr. Veiller proposes a plan, first suggested 30 years ago by I. N. Stokes, architect of New York City, by which the city shall acquire a whole block, raze all buildings on it, and sell off strips 30 feet in width on each side of the tract to a company paying limited dividends, the company to build new houses upon these strips. These strips are to be occupied 100 per cent by houses two rooms deep and facing the central area, which could then be maintained by the city as a park. 
The accomplishment of better housing, whether by salvaging homes worth saving, by the removal of homes not worth saving, or by the building of new dwellings that conform to high standards, depends upon a number of things.

John Ihlder has pointed out that although speculation has played a great part in producing dwellings in America, it has likewise played a great part in destroying them and thus has helped to increase the evils of housing. Dwellings of an inferior type of construction, that have followed in the path of speculation, have deteriorated all too soon and taken their untimely places as outworn homes. It is these types of run-down living quarters that have helped to produce much of the bad housing of today and that give similar promise for the future, unless the owners of these dilapidated houses are compelled to put their old buildings into a more habitable condition. If residential areas were improved and the cost of the improvements of streets lessened, conditions would be stabilized, and much of the difficulty in finding homes of the right sort would be eliminated.

Adequate public control of the housing situation by the aid of city planning and zoning, housing acts, and building and sanitary codes will assist materially in the building of better homes, as will also street improvements, including paving and the installation of utilities. The opportunity for a larger use of excess condemnation will, in certain instances, increase the possibilities for better housing. The right of eminent domain put into the hands of housing corporations paying limited dividends will, under proper safeguards, provide a means of acquiring land suitable for low-cost housing. Tax exemption, state credits, municipal ownership, new methods of construction, more economical financing arrangements, improved architectural design, and better planning of the sites are some of the many things suggested by students of the subject to bring about better housing.

\section{MODEL HOUSING IN EUROPE}

Addressing himself to the Garden City and Town Planning Association of London in February, 1928, George Hicks, secretary of the Amalgamated Union of Building Trade Workers, said:

I am not in favor of establishing little town paradises, while the most hideous aspects of life in our big industrial oenters remain untouched, and thousands are compelled to dwell in black and squalid regions of 
misery and desolation. I want these little town paradises to arise as a direct consequence of our dealing with the worst conditions in the big towns and in the rural districts.

Fortunately, attempts have been made in Europe to carry out the suggestions of Mr. Hicks. As already stated in this book, clearance of slums and model enterprises of housing planned upon unoccupied land both inside and outside European cities have been attempted. Owners of factories have been forced to erect houses for their workers, but such forced action has not brought the best results. As early as 1818, a working men's village that was widely adopted elsewhere was developed ai Mons, and another, in 1883, at Verviers, both in Belgium. After 1850, a number of model villages adjacent to factories appeared in various parts of Europe but unfortunately became all too soon only instruments for securing for the builders and owners high rents and large profits.

Holland.-Within recent years, a number of interesting attempts to provide better housing for laborers have been and are still being made in all parts of Europe. In Holland, Niewendam and Hilversum are perhaps the most outstanding of such attempts. Niewendam is the newest and largest of Amsterdam's garden suburbs, while Hilversum is a rapidly growing community in which have recently been built a number of municipal cottages that achieve a distinctive architectural effect.

Germany.-The efforts to improve housing in Germany have commanded considerable interest among city planners. The garden village of Hellerau, north of Dresden, was started in 1908 upon a tract of 530 acres with ultimate provision for from 10,000 to 15,000 people. It is reported to have 460 houses at the present time and a population of 2,100. A number of little villages are being developed throughout the rural belt surrounding Cologne, the city widely famous for its great cathedral. Over 100 building operations have been underway in these communities around Cologne since 1924, with a phenomenal increase in the number of multifamily homes and a marked tendency toward a new school of architecture inspired by the American architect Frank Lloyd Wright. The accomplishments of good housing at Frankfort am Main, more than those of any other city in Germany, show the adoption of that same simple modern style of architecture that is commanding such universal interest at the present time. 
Austria.-Vienna holds the distinction of erecting some of the finest apartments for workers in the world. Some of the enterprises, however, are based on socialistic premises, and the tenants live practically rent free at the expense of the taxpayers: According to Louis H. Pink, these apartments are "characterized by cheerfulness, architectural beauty, wide courts, balconies, play spaces, kindergartens, laundries, fountains, flowers and statues." In Freihof, near Vienna, one of the largest and best developments of cottages was started in 1924 and when completed will accommodate a population of 10,000 people.

\section{MODEL HOUSING IN ENGLAND}

Within recent years we have heard a great deal about the various developments of model housing in England; some of these have exerted a world-wide influence. The building of the village of Bourneville, 4 miles northwest of Birmingham, in 1879 was caused by the transplantation of the Cadbury chocolate factory from Birmingham into the country. The 1,700 houses now occupied in Bourneville shelter a comfortable community in a very attractive village, built mainly for the workers in the adjacent chocolate factory. Port Sunlight, near Liverpool, was developed in 1888 by Lever Brothers, upon a tract of 547 acres. It is built upon ideal rather than economic lines; the gardens in front of the cottages are maintained by the company's gardeners, and the back yards take the form of several allotments separated from the respective houses by alleys. To be a tenant at Port Sunlight one must be a worker in the Lever Brothers' soap factory. Earswick, near York, was developed in 1904 by the Joseph Rountree Cocoa Works, upon a tract of 120 acres. There are in Earswick 700 houses and a population exceeding 3,000 .

Letchworth.-Upon the theory that if you cannot bring the country into the city, you must take the city into the country, Sir Ebenezer Howard conceived and successfully promulgated the idea of the garden city. His first work was the booklet "Tomorrow" published in 1902 . In 1903 a company was incorporated for the purpose of putting his dream into material form, a site of 4,500 acres 34 miles from London was bought for the purpose from 14 different owners of land, and plans for the development of Letchworth were drawn by Unwin and Parker, architects (Fig. 104). The size of the town was limited to house 
a population of 35,000 people; houses and industries were provided. The inhabitants now represent all classes. The whole city is owned by its citizens and is held in trust for future residents. Any surplus of the moneys derived from rents above the interest upon the capital invested in the project is used in paying off debenture stock, paying off a sinking fund, and improving the town. All unearned increment is preserved as the most valuable

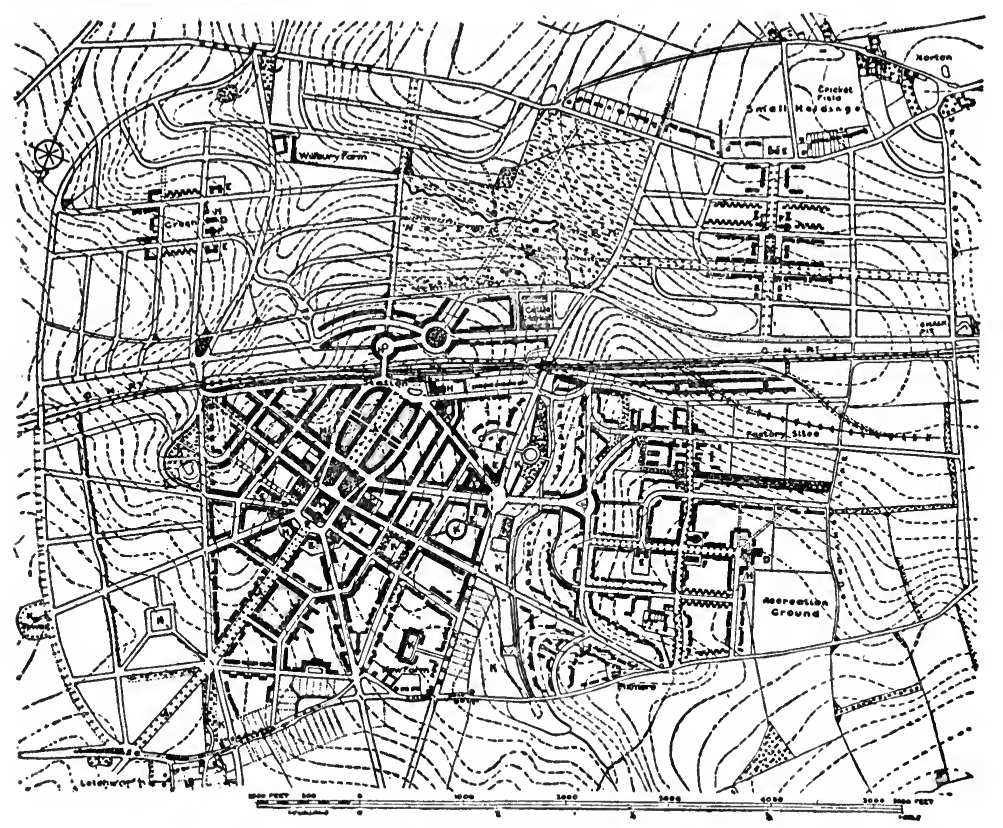

FIG. 104.- The original plan of Letchworth Garden City, England, submitted by Unwin and Parker in April, 1904. The realization of the dream of Sir Ebenezer Howard as described in his booklet, "Tomorrow."

of the company's assets, and the whole town is surrounded by an open agricultural belt of 3,000 acres. After a score or more of years, one finds in this garden city today 3,349 buildings, including 157 shops, 39 factories, 62 workshops, and a population of 13,500 . Such progress is phenomenal and promises well for a city designed from the outset upon such a unique basis.

Welwyn.-Welwyn, the second development of a garden city, was begun in 1920, along lines similar to those of Letchworth. Welwyn covers 2,383 acres and is prepared to house, when completed, a population of 40,000 . It is being financed by govern- 
ment loans and is going ahead very rapidly. In 1926 there were 1,675 buildings erected in Welwyn, 78 of which were for industrial and commercial purposes, and the population of the town had reached 5,020. Welwyn is situated in the midst of a beautiful country, has distinctive centers and broad parkways intersecting at the town square, and one of its outstanding sources of charm is the use made of streets designed as culs-de-sac. Unlike Ietchworth, the parent, Welwyn profits by its increased values of land and retains control of its public services.

Other Housing Developments in England.-In addition to garden villages and cities and the very fine Hampstead Suburb, there are in England other important postwar schemes of building, such as those carried on by the London County Council.

Great Britain is carrying out in England, Wales, and Scotland a 15-year program for the building of 2,500,000 small homes, financed by government loans. According to Dr. Edith Elmer Wood, over 1,000,000 of such homes are already built or are now being built throughout England and Wales, and over 100,000 in Scotland. This is indeed a huge project, as compared with the 6,000 homes that to date have been built at Letchworth and Welwyn.

\section{HOUSING ACTIVITIES IN FRANCE}

Since more than $1,000,000$ of the people in Paris live under conditions which are either unsatisfactory or unsanitary, the passage last summer of a new act by the Chamber of Deputies of the French Republic shows that the French people are resolved to do what they can to correct their bad urban housing. The new act provides a program of home building and makes provision for the construction, between the years 1928 and 1933, of 200,000 houses which are to be offered to the people for sale at reasonable prices and of 60,000 like houses for lease at average rentals for such properties in their several neighborhoods.

\section{MODEL HOUSING IN THE UNITED STATES}

There have been a number of housing projects in this country. Mr. Veiller estimates that there are as many as 730 of them. They include efforts to correct unfavorable conditions within the cities or to carry residential developments (sometimes residential and industrial developments combined) to the outskirts of the city. Some of these housing projects have been planned in con- 
nection with an industry; some plans have been paternalistic or non-paternalistic in character; some company owned, and some government owned or privately owned. The purposes behind

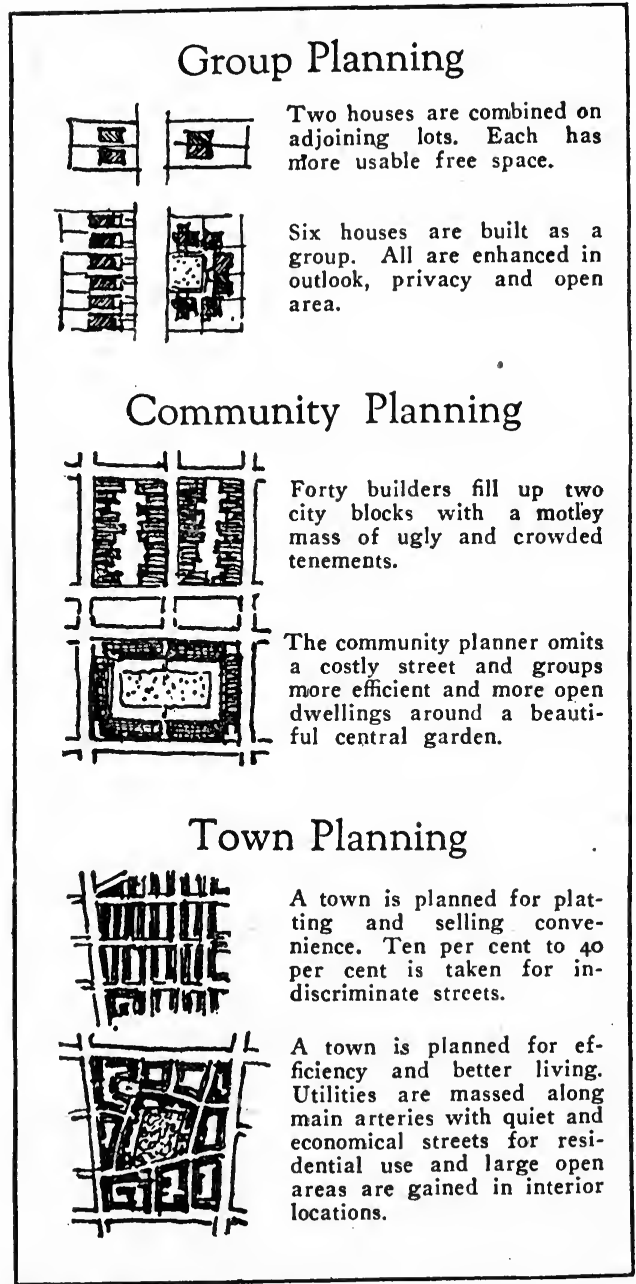

FIg. 105.-The attainment of better housing is directly related to group, community, and town planning. (From Road to Good Houses, by Henry Wright, city planner, Survey Graphic, Vol. VII, May, 1925.)

these housing projects have been to promote good housing and city planning (Fig. 105), to furnish labor to the unemployed, to increase contentment among employees, to reduce the turnover 
of labor, and to promote business. In some cases the accomplishment of all of the above objectives has been considered in establishing a single housing project.

The earlier and decidedly disagreeable tenement houses in the mill towns of New England (1835 and later) and the shacks and shanties of the mining and lumber camps throughout the country are types of the employing of company-owned residences for laborers. Although in recent times (1881) Pullman, Ill., was developed by the employer in the hope of providing for the employee conditions of better living, yet the ownership by the employing company of everything in Pullman and the spirit of paternalism that that ownership produced provoked against the scheme an unforgettable antagonism among the employees and made of Pullman an outstanding example of the mutual ill feeling and misunderstanding between capitalist and laborer that such a housing project can create.

In the newer enterprises for industrial housing that have benefited from such examples as Pullman, the paternalism is avoided and everything possible is done to make the housing project fit the interests and wishes of the workers. Goodyear Heights at Akron, Ohio, is an example illustrative of the more recent attempts to avoid all paternalism in the establishing of a housing project.

War Housing.-The abnormal need for ships and other products requisite to the carrying on of the war and the coincident dearth of adequate housing at the new industrial centers caused the United States government to establish a number of housing projects in the vicinity of industry in key parts of the country. These new towns were developed under the auspices of the United States Housing Corporation and by the Housing Division of the Emergency Fleet Corporation. The United States Housing Corporation planned 128 towns or groups of houses for laborers, 45 of which were developed either in whole or in part, while the Housing Division of the Emergency Fleet Corporation built some 27 different housing projects. Of necessity, all of these housing projects were carried forward with great haste, and as a result many were planned like conventional towns. Such developments as Bridgeport, Atlantic Heights, and Fairview; also Buchman Tract (Chester) and Union Gardens (Wilmington, Del.) were among those that for one feature or another had special merit. The Fairview (or Yorkship) development near Camden 


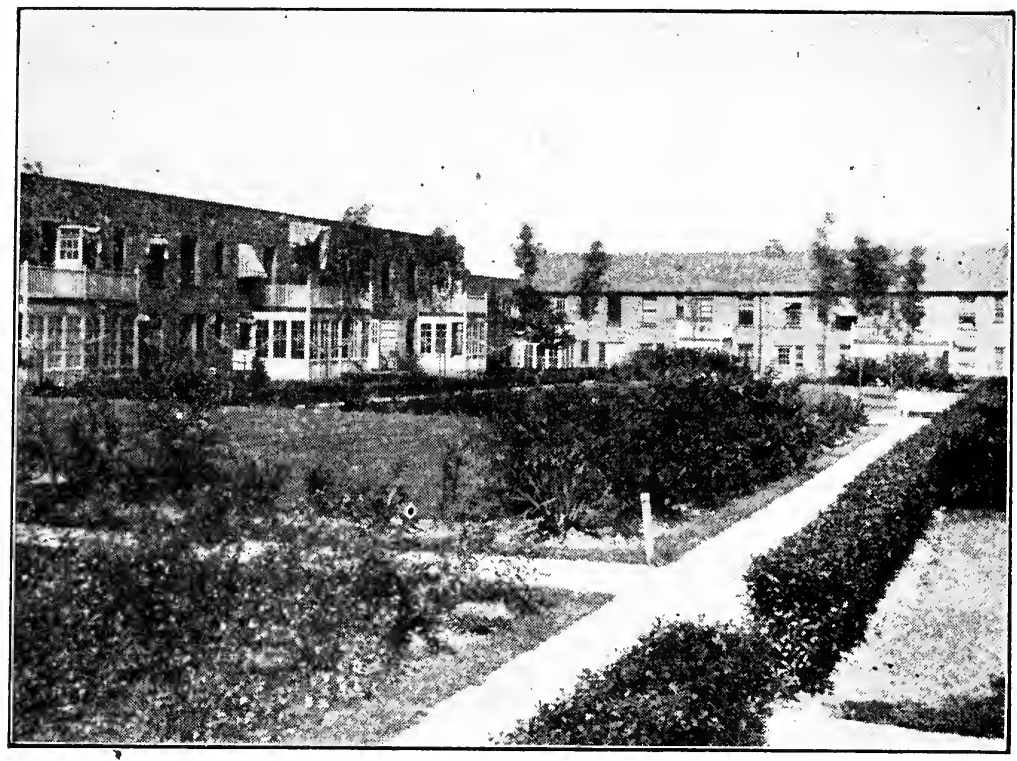

FIG. 106.-Sunnyside. View of backs of houses, facing on a central court. Architects, Frederick L. Ackerman, Clarence S. Stein; Associate Architect, Henry Wright. (Photograph by Richard Southall Grant.)

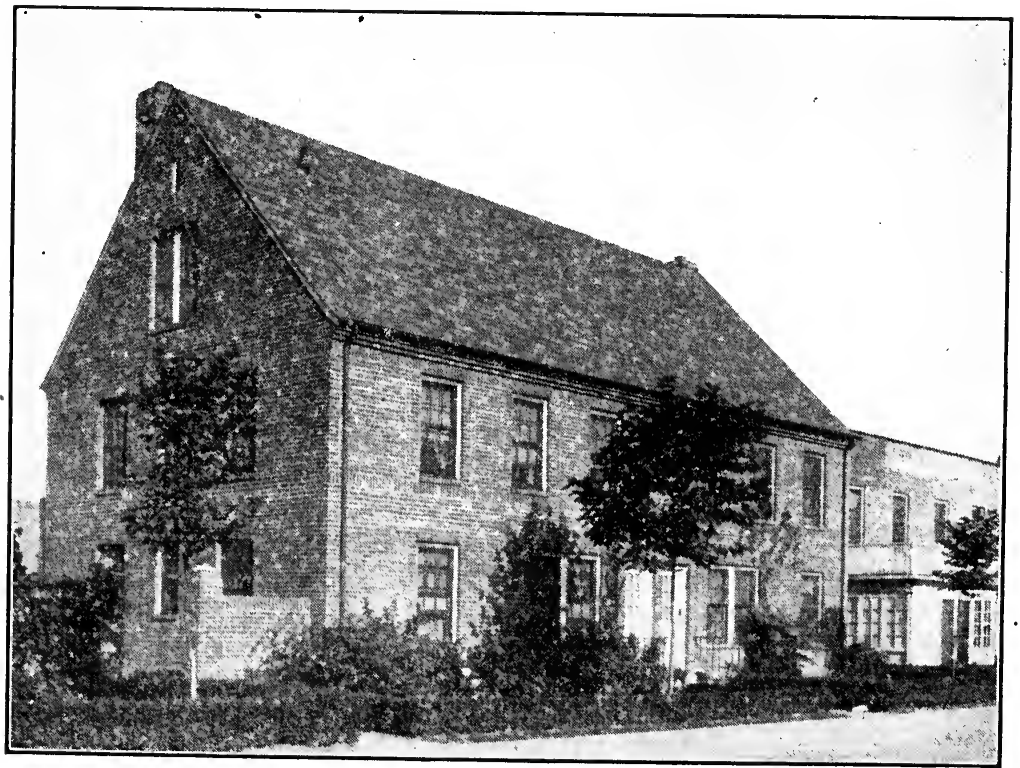

FIG. 107.-Sunnyside. View of homes from the street. Architects, Frederick L. Ackerman, Clarence S. Stein; Associate Architect, Henry Wright. (Photograph by Richard Southall Grant.) 
assumed the appearance of a New England town, and its colonial architecture, despite its overgenerous plazas and streets, made it one of the most interesting of the housing projects resulting from the war.

Sunnyside.-Outstanding among the strictly residential projects erected at low cost is the development of Sunnyside Gardens, 15 minutes from Manhattan (Figs. 106, 107). Sunnyside Gardens was planned and built upon 70 acres of low-cost land, close to a

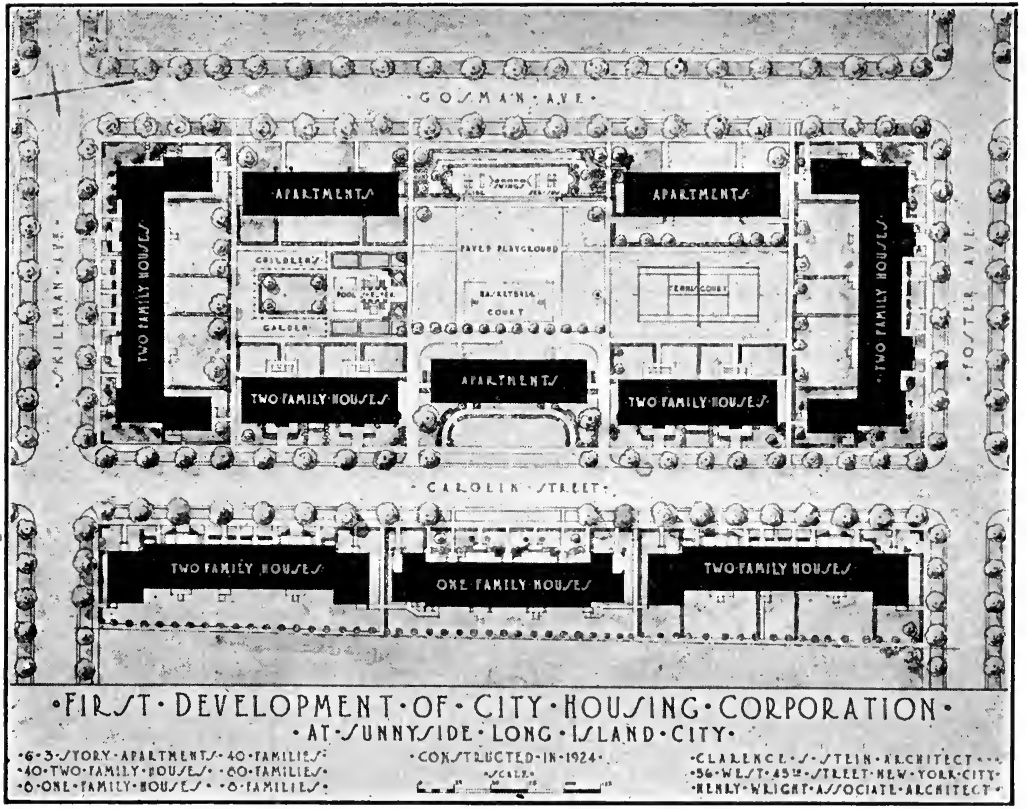

FIg. 108.-A diagram showing the openness of the development at Sunnyside as compared with conventional apartment efforts elsewhere. When contrasted with a characteristic tenement arrangement in the Bronx the difference is striking. (Courtesy of City Housing Corporation, Sunnyside, Long Island City.)

subway station, in 1924 by the City Housing Corporation. Among the men associated with the project are Alexander $\mathbf{M}$. Bing, a far-sighted real estate operator, president of the City Housing Corporation; Frederick L. Ackerman, Clarence S. Stein, architects; and Henry Wright, community planner.

The first units of Sunnyside Gardens were laid out on the principle of one-family homes, two-family homes, and apartments, surrounding a central open garden space. The homes 
occupy only 28 per cent of the property as compared with the 73 per cent occupancy by buildings in the case of characteristic tenement blocks (Figs. 108, 109). The houses at Sunnyside Gardens are two stories high, and the apartments three stories, and neither houses nor apartments are more than two rooms deep. The garages are provided on a separate tract nearby.

Sunnyside Gardens already provides homes for 1,000 families, and the houses are sold to the tenants at the rate of $\$ 12.50$ per

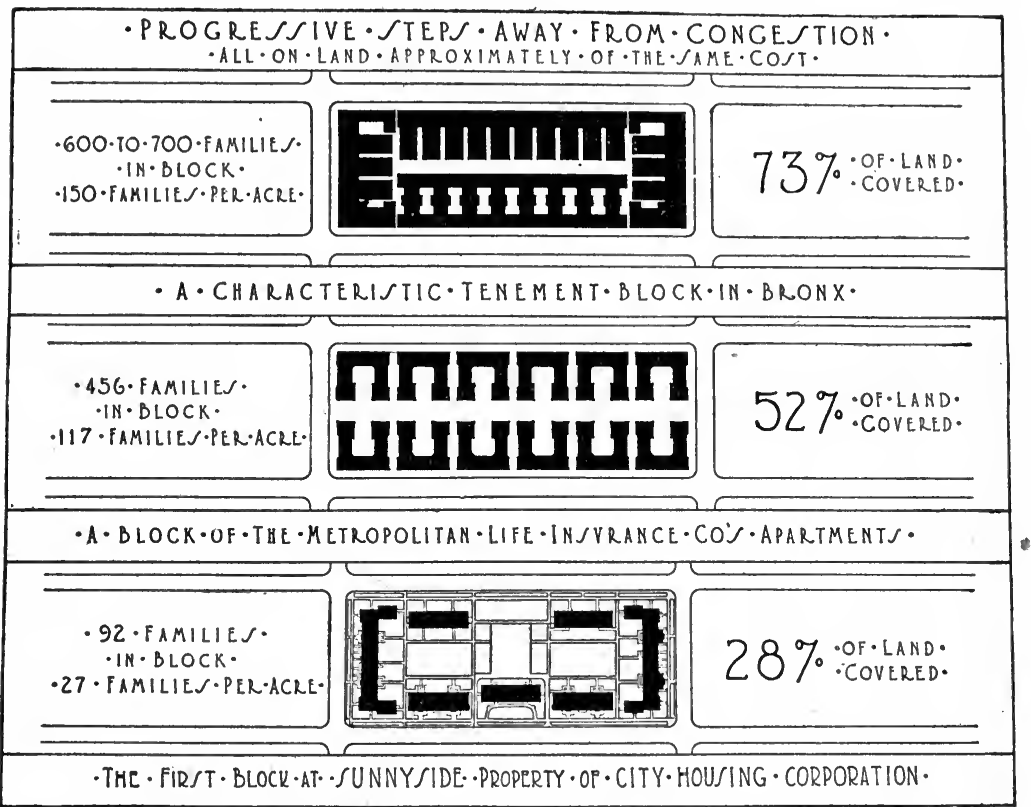

FIG. 109.-General plan of a Sunnyside block development and comparison with other more congested forms of housing. (Courtesy of the City Housing Corporation.)

room per month. The first mortgage bonds issued by the City Housing Corporation are being disposed of to large foundations and other institutions and to a number of fire insurance companies. The commercial soundness of the development at Sunnyside is shown by the uninterrupted payment of 6 per cent dividends upon the capital stock since the company was organized and by the accumulation from its earnings of a surplus in excess of $\$ 300,000$.

Rockefeller Housing Developments.-With the realization of the importance of the need for better housing, John D.-Rocke- 
feller, Jr., has expressed his interest in the subject to the extent of investing $\$ 6,000,000$ in four different housing projects. He has developed one of these, which accommodates 149 families, at Bayonne, N. J. This housing project is designed in the form of $\mathrm{H}$-shaped units and is provided with out-of-door facilities for play. Another housing development financed by Mr. Rockefeller is located at 265th Street and Avenue A in New York City, overlooks the East River, and provides for 82 families.

The Thomas Garden Apartments at Mott and Sheridan streets surround large gardens and take care of 175 families. One of the most important of Mr. Rockefeller's housing ventures is the Paul Laurence Dunbar group of dwellings for colored people (149th Street and Seventh Avenue, New York City). This housing project is especially important for the reason that colored families usually have to live in slums of frightful squalor and have to pay extortionately high rents for their quarters. The Dunbar Apartments are a splendid group of buildings, accommodating 513 families, are grouped around central gardens and playgrounds, and cover above 50 per cent of the land embraced in the project. All four of these housing projects financed by Mr. Rockefeller are wholly cooperative in character.

Different as to both character and extent is the latest housing venture of the Rockefellers, which promises to command widespread interest in the field of city planning and of housing. It is destined to develop into a city of 20,000 people. This enterprise is going forward upon the old Rockefeller Forest Hill estate, which comprises several hundred acres of wooded rolling terrain in Cleveland. The program is to be something greater than a real estate project, and there is to be nothing philanthropic or charitable about it, according to announcements. At least $\$ 5,000,000$ has already been spent (exclusive of the land values); electric lighting and telephone wires have been placed underground; 10 miles of sewers, 10 miles of separate sanitary sewer, $12 \frac{1}{2}$ miles of water line, and almost 100 miles of streets have been started in the development. Eighty-one houses and a block for business costing $\$ 750,000$ constitute the first unit of the housing project to be completed. The homes are priced to sell for about $\$ 25,000$ each.

Chicago Model Housing.-There is now in Chicago a model tenement similar to the developments in the vicinity of New York. The project at Chicago is developed around a central 
garden, the buildings are two rooms deep, and the structures occupy 50 per cent of the required property. These tenements are located on the north side of Chicago, two blocks away from Lincoln Park and are enclosed by Blackhawk, Sedgewick and Connor's Streets, and by Hudson Avenue. They were constructed by the Marshall Field Company with Andrew J. Thomas of New York City as consulting architect.

Another development, the Michigan Boulevard Apartments, has been completed in Chicago. It represents an attempt to provide housing facilities for colored people and to prove that modern, healthful, and attractive accomodations can be provided at moderate rentáls, while being operated upon a strictly business basis. These apartments, built by Julius Rosenwald, with the assistance of Klaber and Grunsfield, architects, and Henry Wright, consultant architect, are located between Michigan and Wabash avenues, and Forty-sixth and Forty-seventh streets. Although the development covers an entire block, the buildings occupy 40 per cent of the property and they enclose about 3 acres of gardens, courts and a playground. The rooms of every apartment are open to sunlight and fresh air, and every apartment is equipped with modern appointments such as built-in bath, automatic refrigerator, built-in kitchen cabinet, and so on. The two nursery schools comprised within the development provide on the one hand for the mother who works and who wishes to leave her children while she is at work and on the other for the one who desires to give her children the best in modern care and education such as a well-regulated modern nursery school affords. A community room provides the opportunity for group meetings. Not least of the interesting provisions, especially for those who occupy the upper apartments, is the roof promenade.

Housing Venture by Amalgamated Clothing Workers (Fig. 110).-Of tremendous importance in the field of future housing development is the housing project of a large labor union in the Bronx, New York City. This housing project was developed by the Amalgamated Clothing Workers upon a delightful site, opposite Van Cortland Park and adjoining a property to be occupied by Hunters College. The group is composed of six buildings, containing in all 303 apartments, and was constructed through a subsidiary body of the Amalgamated Clothing Workers in December, 1927. The apartments are two rooms deep, the 
rooms are large, with high ceilings; each apartment has a tiled bath, a built-in kitchen cabinet, a garbage incinerator, and the apartment is warmed by oil-burning furnaces. Most of the basement is exposed to the sun and provides indoor playgrounds. One-third of the tenant owners are members of the Amalgamated

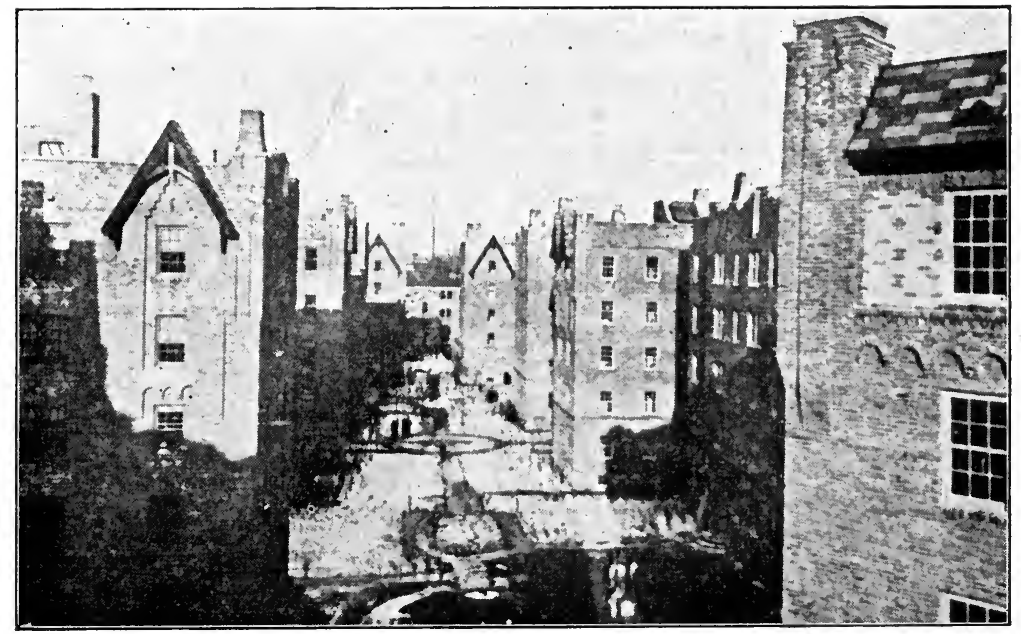

Fig. 110.-The tenements of the Amalgamated Clothing Workers, New York City.

Clothing Workers Union, which is planning to erect several similar groups of apartments where they may be needed elsewhere in New York City.

\section{THE GARDEN CITY IDEA IN AMERICA}

The wish to have in America a garden city planned along the lines of Letchworth in England has often engaged the attention of American planners, but so far no one has as yet established in the United States a real garden city. There have been attempts made by city planners to introduce some of the features of such a city into some of the projects for model housing that have been adopted here, and yet many of the most important features of Letchworth have been absent from these American housing plans. The truth of the matter is that Letchworth in many respects is difficult of exact duplication in this country. The term "garden city" is, however, often used for housing projects in America.

To establish an independent new community like Letchworth, with both residences and industrial plants, would require a like 
site of from 2,000 to 10,000 acres, near a large city; such a site must have natural beauty and wooded areas, together with a river or lake. To build a Letchworth would require an expenditure of capital estimated at between $\$ 10,000,000$ and $\$ 25,000,000$. Further, the venture would yield no income during the first few years of the city's existence. Factories must be built on the site, and homes for the people who must work at those factories. To build a Letchworth here would mean a voluntary limitation of return to the investors. The principle of community ownership of the land would also be difficult to accomplish in America.

There are many things about a garden city as represented by Letchworth that are worthy of imitation in America, and our city planners can reproduce in our American housing projects these many worthy things, even if it be impossible to duplicate Letchworth here. These difficulties of duplication explain why there are not any real garden cities in America.

Mariemont. - The new town of Mariemont, Ohio, however, can be described as a species of garden village, in the sense that it is an independent, preplanned community, equipped with residences and industries, and with ample adjacent open land and reservations for parks. Mariemont lies 9 miles east of Cincinnati, along the little Miami River, and was founded Apr. 23, 1923 , by a wealthy widow in memory of her husband. The town is developed upon 420 acres of rolling terrain, is intended to accommodate a self-contained community of 9,000 people, and is primarily intended to furnish homes and places of employment for wage earners.

The plan of Mariemont was made by John Nolen, and the buildings were designed with the help of more than 30 well-known American architects. The development is intended to serve as a demonstration "to show the advantages of city-planning, the proper relation of buildings to environment, the value of many small parks, and as an example of the way American cities ought to grow." The plan of Mariemont provides for a town square, radiating streets and boulevards, a village green, a civic center with sites for public buildings, and a concourse along the bluff, commanding a view. Today there are 350 dwellings and 1,500 people at Mariemont, and the average rent there per dwelling is $\$ 75$ per month.

One million dollars has been spent in the installation of underground utilities at Mariemont, to obviate the necessity for over- 
head poles and to make possible a central heating plant whose services are available by most of the buildings in the town. Mariemont has 50 acres of parks and playgrounds, a near-by hospital, and a model farm. The municipal administration of Mariemont is still under the control of the memorial company, but it is planned eventually to turn the government of the city over to the inhabitants. All of the buildings now are only rented; ultimately they will be sold to private owners, and the money realized from the sales will be used for establishing other similar model communities.

Kingsport, Tenn.-An independent industrial community of another type is that of Kingsport, Tenn. Kingsport is a town that in 1915 was developed with the idea of creating business for a railroad. It was deliberately planned, and laid out in advance of any local need whatever, to accommodate diversified industries and to provide for the educational, recreational, and social life of the people. The entire project has been under the direction of the Kingsport Improvement Association, a corporation that builds, rents, and sells houses there. Kingsport grew from a scheme drawn upon paper to a city with a population of 10,000 in the short period of 4 years. One of Kingsport's especially interesting features is the development of a portion of the city for the residences of negroes and as such is probably one of the first attempts to build an attractive and well-ordered village for negroes.

Forest Hills, L. I.- One of our earliest housing enterprises purely residential in character was Forest Hills, L. I., begun in 1913. Forest Hills was intended to provide attractive residences for persons of modest means, was undertaken with the backing of the Russell Sage Foundation, and was one of the first efforts of that organization.

Forest Hills is a project covering 200 acres of land and is 17 minute's ride from New York City. The plan for the development is a product of the Olmsted office, and the architecture is in charge of the Grosvenor Atterbury firm. There are two 80-foot. avenues running east and west and two winding 70 -foot streets, as well as courts and many curving local streets. There are small wooded parks. A harmonious predominantly English style of architecture characterizes Forest Hills, as does also a particularly picturesque and interesting plaza adjacent to the railroad station. It was designed to furnish an example of how 
homes should be developed in pleasant surroundings with proper regard to architectural beauty and the amenities, and it seems to fulfill this purpose admirably.

Radburn, N. J.-Among the housing experiments in America, none will be looked upon with greater interest in the years to come than Radburn, N. J. Radburn is located about 17 miles from Manhattan (near Patterson, N. J.), and is being developed

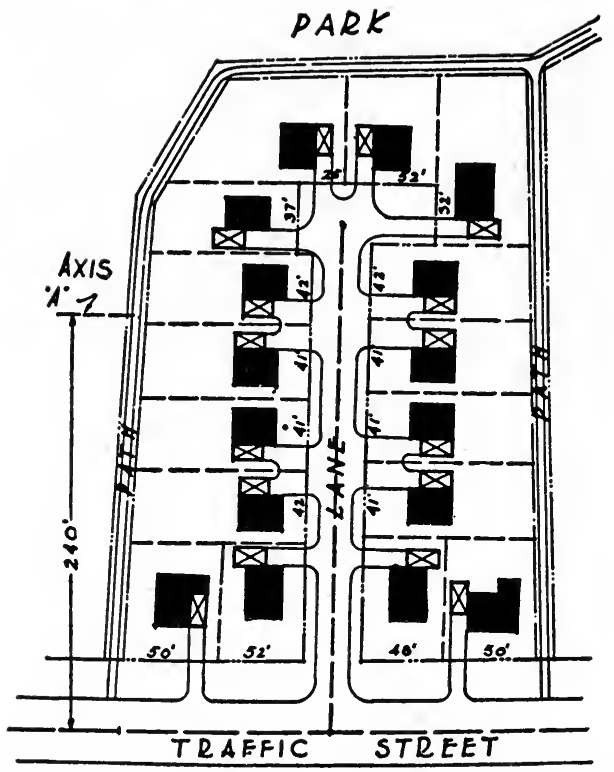

Fig. 111.-Plan of group of houses at Radburn, N. J. No housing development in America has commanded a larger interest than the development at Radburn. The illustration indicates the grouping of the homes along the deadend streets that lead from the traffic streets in to the superblocks.

by the City Housing Corporation (Clarence S. Stein and Henry Wright, associated architects, in association with F. L. Ackerman and Robert D. Kohn). The City Housing Corporation is the same company that planned and financed the $\$ 10,000,000$ Sunnyside project in Queens. Radburn is frankly an attempt to comply with the special requirements of our age of automobiles. The town is planned so that children will not be run over while on their way to school, so that there will be passages from block to block tunneled under the streets, and so that the noise of traffic will be reduced to a minimum. Radburn is to be a city 


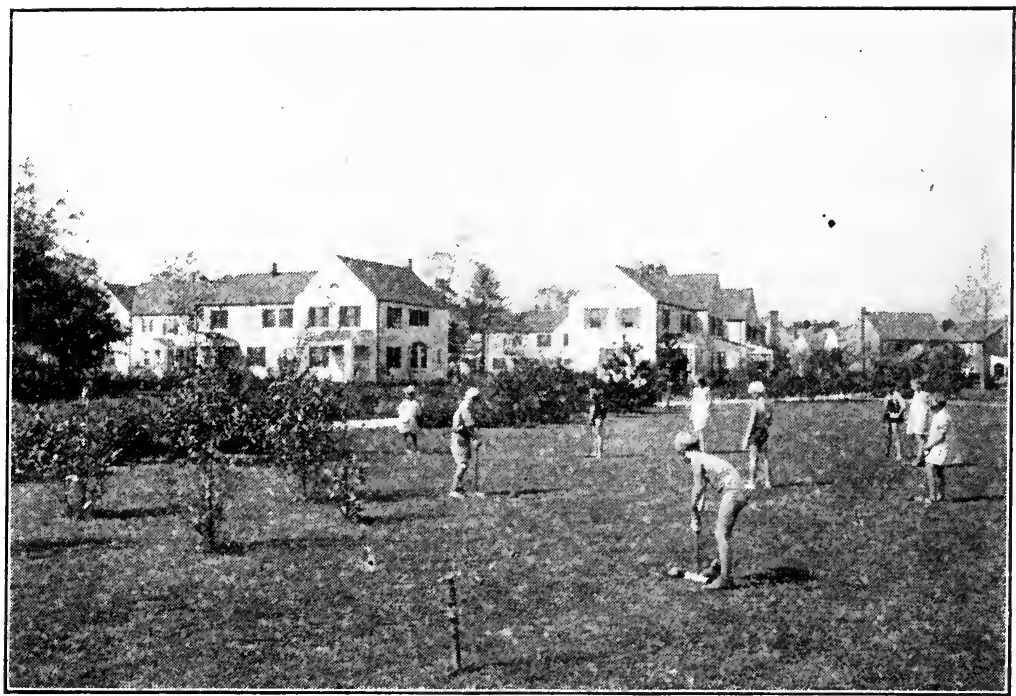

FIG. 112.-Children playing in the large parks in the center of each block at Radburn, N. J. (Courtesy of City Housing Corporation. Photograph by Heinrichs.)

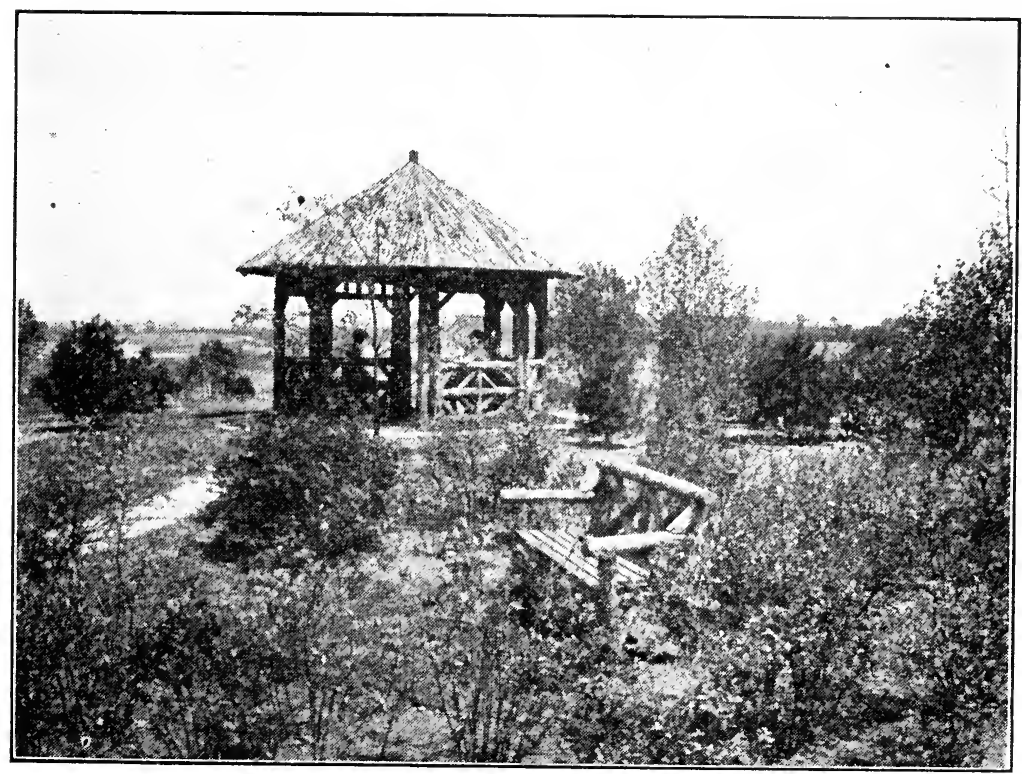

FIG. 113.-View in a central park area of one of the superblocks at Radburn. (Photograph by Mattie Edwards Hewitt.) 
with large blocks enclosed by main roads, from which a succession of narrow lanes or culs-de-sac (Fig. 111) lead into and accommodate a succession of groups of homes with garages attached. Within the blocks (Figs. 112, 113, 114) are parklike areas and paths upon which the residents will be able to take a 2-mile walk from block to block, using the underpassages, without having any contact with a motor car.

The homes at Radburn are being built on the basis of mass production, although they will not be all alike. In a normal

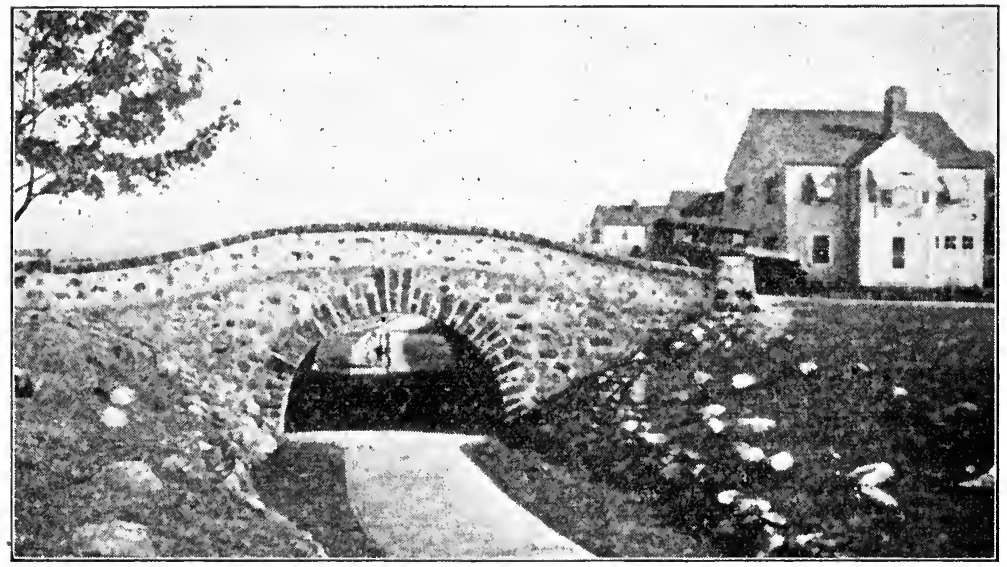

FIG. 114.-Underpass at Radburn. This helps to separate pedestrians, and particularly children, from automobile traffic.

town from 35 to 40 per cent of the total area is given over to streets and alleys, while in Radburn only 20 per cent is so used. Although there is land along the railroads reserved for industry, most of the population of Radburn will commute between the home town and New York City.

The importance of the Radburn example is illustrated by the new plans in different parts of the country that are incorporating some of the major features of this pioneer, independent, and successful effort to cope with the requirements of our age.

\section{Questions for Discussion}

1. What is the meaning of good housing?

2. Discuss types of houses that should be planned for in the development of a city.

3. Review the past history of bad housing and of legislation for better housing. 
4. What is the status of housing in the United States today?

5. What are some of the reasons for bad housing?

6. How may good housing be accomplished; what about slum clearance?

7. Tell of model housing in Europe (France, Holland, Germany, etc.).

8. Describe and discuss Letchworth; Welwyn.

9. Discuss outstanding examples of model housing in the United States, such as Sunnyside, the Paul Laurence Dunbar group, the housing project of the Amalgamated Clothing Workers, Mariemont, Kingsport (Tenn.), Forest Hills (L. I.), and Radburn (N. J.).

\section{References}

Anderson, Nels, and E. C. Lindeman: Social Pathologies of City and Urbanizing the Home, "Urban Sociology," Chap. XV, XVI, Alfred A. Knopf, Inc., 1928.

Bing, A. M.: Sunnyside Gardens, National Municipal Review, vol. 15, pp. 330-336, June, 1926.

Buttenheim, Harold S.: Where City Planning and Housing Meet, Proceedings National Conference on City Planning, pp. 114-123, 1929.

Ford, J.: Housing and City Planning, Community Builder, vol. 1, No. 6, pp. 7-15, illus., also repr., May, 1928.

Gries, J. M.: Housing in the United States, Journal of Land and Public Utility Economics, vol. 1, pp. 23-35, January, 1925.

Hare, S. H.: Planning of Industrial City of Longview, Washington, Proceedings American Society of Civil Engineering, vol.. 53, pp. 1177-1183, August, 1927.

Housing Problems in America, Proceedings National Conference on Housing, 1st, 8th, 8 vols., 1911-1920.

Kennedy, Louise Venable: "The Negro Peasant Turns Cityward," Columbia University Press, 270 pp., 1930.

Knowles, M.: "Industrial Housing," 408 pp., illus., plans, MeGraw-Hill Book Company, Inc., New York, 1920.

Munro, William Bennett: "Municipal Government and Administration," The Macmillan Company, New York, 1923.

Newman, Bernard J.: "Housing in Philadelphia," 48 pp., illus., Philadelphia Housing Association, 1929.

New York State Board of Housing Report to Governor Alfred E. Smith and Legislature of State of New York, 43 pp., illus., tables, diagrams, legislative doc. 1928, p. 76, Albany, N. Y. Feb. 29, 1928.

Nolen, John: New towns for old. Kingsport, Mariemont, etc., (Marshall Jones Co., Boston, 1927).

Pink, Louis H.: "The New Day in Housing," The John Day Company, Inc., Publishers, New York, 1928.

Purdom, C. B.: “The Building of Satellite Towns," 368 pp., illus., plans, J. M. Dent and Sons, Ltd., London, 1925.

Stein, Clarence S.: The President's Housing Conference-A Challenging Opportunity, The American City, pp. 141-143, November, 1930.

The World Movement for Better Housing for Families of Small Income and for the Abolition of Slums, Journal of the Town Planning Institute of Canada, vol. 8, No. 2, April, 1929. 
Veiller, Lawrence, ed.: Housing, quarterly, National Housing Association, New York City.

-: The Housing Problem in the United States, Town Planning Review, pp. 228-256, December, 1929.

Wright, Henry: Sunnyside and Radburn, Playground, vol. 22, pp. 682-684, plan, March, 1929.

: The Modern Apartment House, Architectural Record, vol. 65, No. 3, pp. 213-245, March, 1929. 


\section{CHAPTER XVII}

\section{ZONING}

There is no phase of city planning that has greater possibilities for municipal benefits than zoning. Unlike the subjects streets, transportation, and recreation, which represent the more public aspects of city planning, and which we have already considered, zoning is directly concerned with private properties, which cover 60 per cent of the areas comprising the city plan. The confusion and turmoil that result from the mixed uses and conditions of

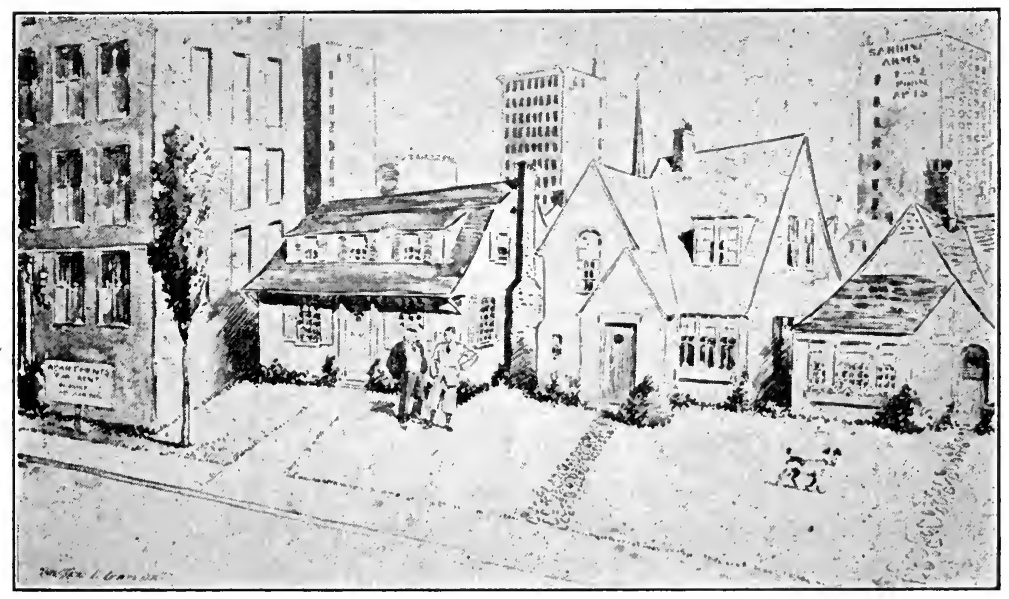

FIG. 115.- "The great open spaces in an unzoned suburb." (American City. February, 1929, and from Saturday Evening Post.)

private property in a city make the need for its systematic regulation and order an insistent one. Where there is no zoning the development of the city is left entirely to the individual builders (Fig. 115). Business centers beeome congested, transit and street facilities are overwhelmed, high apartment houses are built without front yards along the street lines, factories invade business sections and intrude into residential areas. The whole city becomes a patchwork of mixed uses, disorder, and chaos. 
Through the use of zoning early in the life of the city, this pandemonium can be avoided (Fig. 116). Through it there may be regulation by districts of the use, area, and height or bulk of buildings. Under zoning the city can be divided into districts or zones, in each of which uniform regulations govern the proper location and development of residential, business,

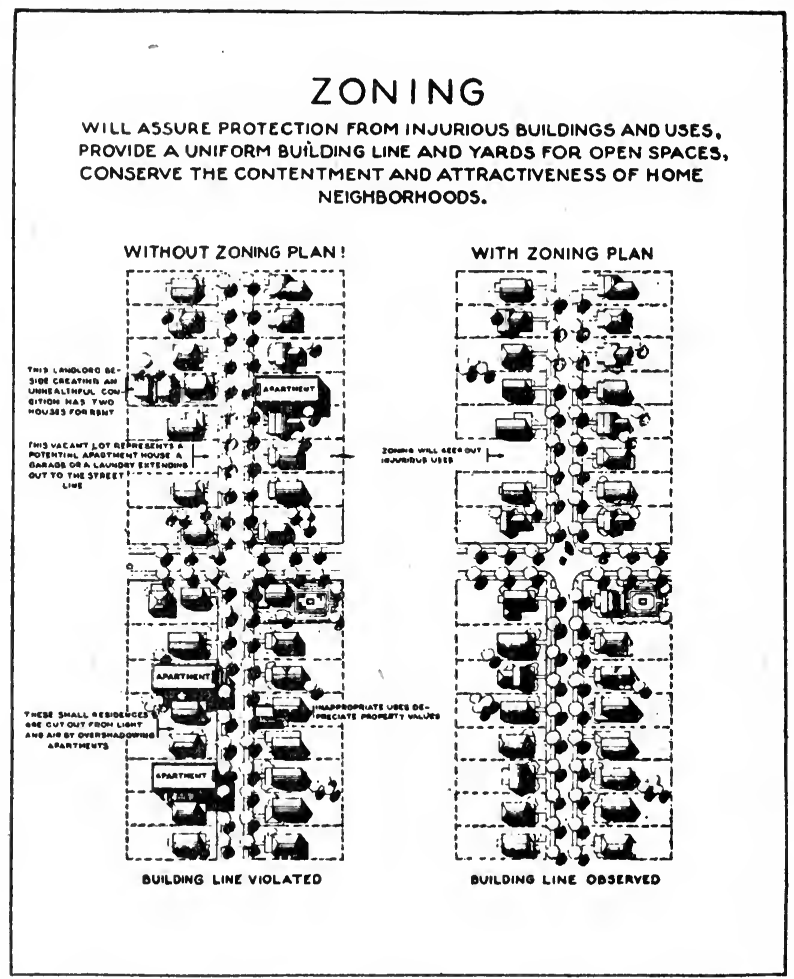

FIG. 116.-Comparison of street conditions where zoning is wanting and where it is in effect. (From Report of Tentative Zoning Plan for Akron, 1921.)

and industrial sections, the height above which the buildings in each section may not be built, and the area that may be covered by an individual building. Hand in hand with these, the density of the population in the residential sections can also be controlled. By zoning, the congestion in the streets may be lessened, the danger from fire can be minimized, and the noise and impure air of the districts devoted to manufacturing may be diverted from the residential districts in which peace and quiet will then 
be possible. Properly regulated growth of the community by zoning prevents the undue concentration of the population. To such an extent can the future needs of the community be foretold by the city planner by the means of zoning that every form of transit and transportation may have a place in his plan, every utility and requirement may be located to the best advantage, and the several sections of the city may be outlined in so clear and distinct a manner that there need be no indiscriminate invasion of industries and stores into residential neighborhoods. Industrial areas also may, by zoning, be made secure against undesirable mixed uses, and blighted districts with their unsightliness may be avoided. The manner and direction in which the city shall grow will not be left to chance nor to the selfish whims of individual property owners if the city shall have been comprehensively and reasonably zoned. Under zoning the health, safety, morals, convenience, order, prosperity, and general welfare of the people in a community are promoted. Zoning can be done, moreover, without cost to the taxpayer except for the expense incident to the drawing up of the ordinance.

There are limitations beyond which the benefits of zoning cannot go, but these limitations are greatly outweighed by the advantages. Zoned cities will be found to be as President Hoover has described them, cities whose residents enjoy "reasonable, neighborly agreements."

Zoning Movement in United States Prior to 1916.-While zoning had its beginnings centuries ago, its first real development occurred in Germany in 1894, and from Germany, zoning spread to all parts of the civilized world. The earliest efforts at zoning in America were of a piecemeal character; that is, the zones did not cover the entire city. The attempts at zoning in Boston and Los Angeles established the most important earlier American instances. Because of its narrow streets and its closely placed buildings, Boston, in 1903, was authorized by the state legislature of Massachusetts to regulate the height of its buildings. The zoning ordinance passed subsequent to this enabling act by Boston's aity council specified 125 feet as the maximum height of buildings on wide streets, and elsewhere throughout the city the maximum height was fixed at 80 feet. In the course of time, all of these zoning regulations were contested by suits at law, but the zoning ordinance was sustained by the courts. 
Los Angeles was the first city in the United States to be fully, although not systematically, zoned. In 1909, to protect its residential districts from the invasion of Chinese laundries, the city was divided into residential and non-residential districts, and these zoning regulations were made retroactive in character. Of the protests that arose against this ordinance, two concerning Chinese laundries resulted in suits at law, which were carried on appeal to the Supreme Court of California, which sustained the city ordinance. A third suit was brought to test the ordinance by persons who owned land that was used as a brickyard. This land, which had been outside the city at the time of the passing of the zoning ordinance, was afterward taken in by annexation and was said to be worth $\$ 800,000$ as a brickyard but only $\$ 60,000$ for purposes of residence. The Supreme Court of California, and upon appeal the Supreme Court of the United States, sustained the ordinance upon the ground that "cities must grow, and if individual rights interfere with the majority, those of the individual must give way."

The first important achievement in zoning in the United States was the adoption in 1916 by the Board of Estimate and Apportionment of the celebrated New York zoning regulations. These regulations are, in fact, one of the most important of our achievements in the whole field of city planning, including as they do a systematic, comprehensive, and complete plan that covers practically the entire city. The reports of the city planners, their plans, and the ordinance itself show the result of exhaustive, painstaking, and scientific research. The New York "regulations" became in structure and machinery a model for many another city in this country in framing its own special zoning ordinance. The "regulations" provide for residence sections, business sections, and sections unrestricted as to use; limit both the height and bulk of the buildings in certain districts; and are not retroactive in character.

Zoning Since 1916. - The progress of zoning in the United States during the last 12 to 15 years, and more especially during the last 2 to 3 years, has been remarkable. Public sentiment in regard to zoning has changed from apathy and misunderstanding to interest and enthusiasm. Our courts have dealt both pro and con decisions with regard to the details and phases of zoning that have been the subject of litigation. The real triumph for zoning, however, in the United States came when reasonable 
zoning was decided by the Supreme Court of the United States to be a proper exercise of the police power (Euclid vs. Ambler Realty Co.).

\section{ZONED MUNICIPALITIES IN THE UNITED STATES BY STATES - JULY I, 1930}

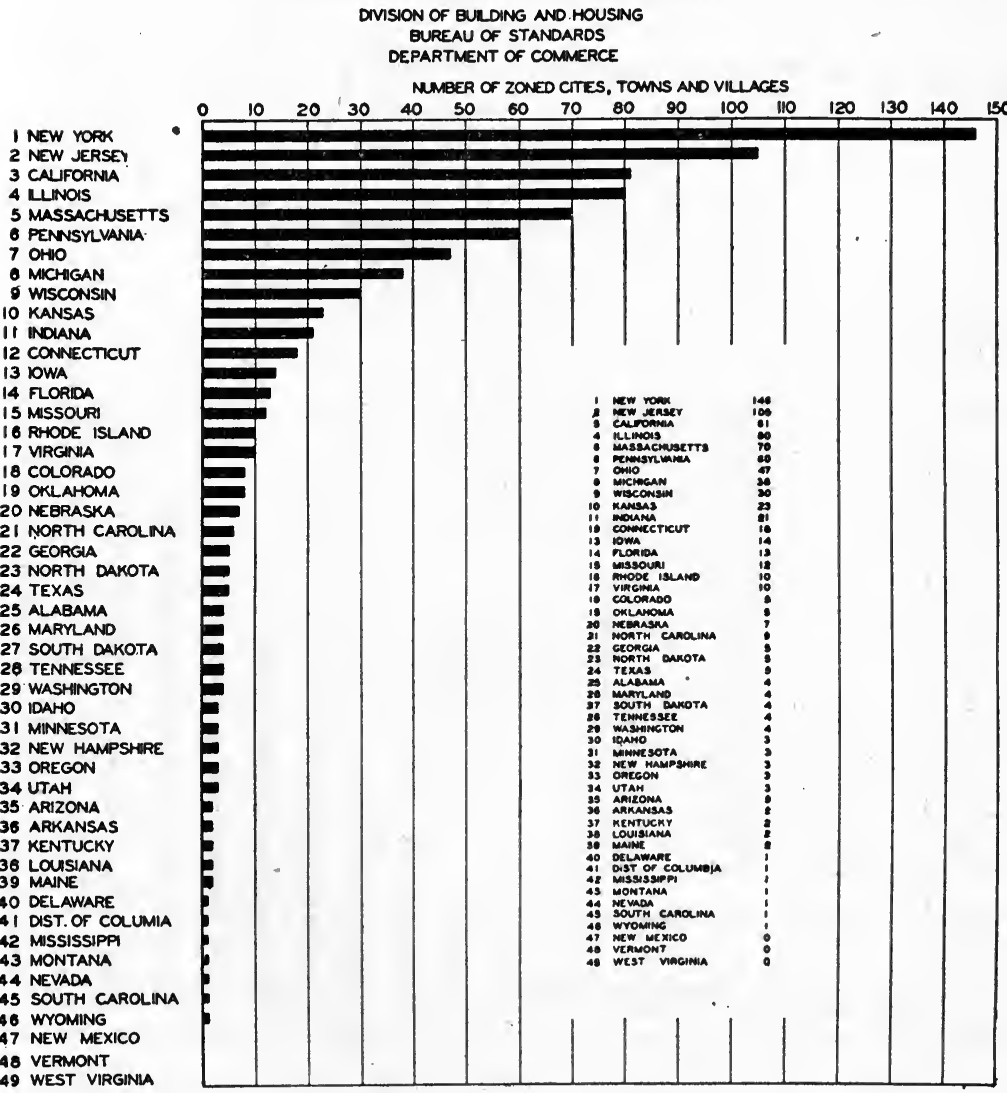

FIG. 117.-Analysis of the number of cities according to states having zoning ordinances in operation July 1, 1930. (Division of Building and Housing, Bureau of Standards, U.S. Department of Commerce.)

The part played by the U. S. Department of Commerce in advancing the cause of zoning has been most conspicuous, as the Standard State Zoning Enabling Act, which up to 1930 had been adopted as a whole or in part by 35 state legislatures, was drawn by the executives of this department. To date zoning 
laws have been enacted by the legislatures of 47 states and by Congress for the District of Columbia. The number of municipalities zoned in the United States (January, 1930) is 856, with a total population of more than $39,000,000$ inhabitants, or threefifths of the whole urban population of the United States. The greatest center of zoning at the present time is New York State (Figs. 117, 118).

Other Means than Zoning for Regulating Private Property.There are other methods besides zoning to regulate the use of

ZONED MUNCIPALITIES IN THE UNITED STATES

BY YEARS. 1904-1930"

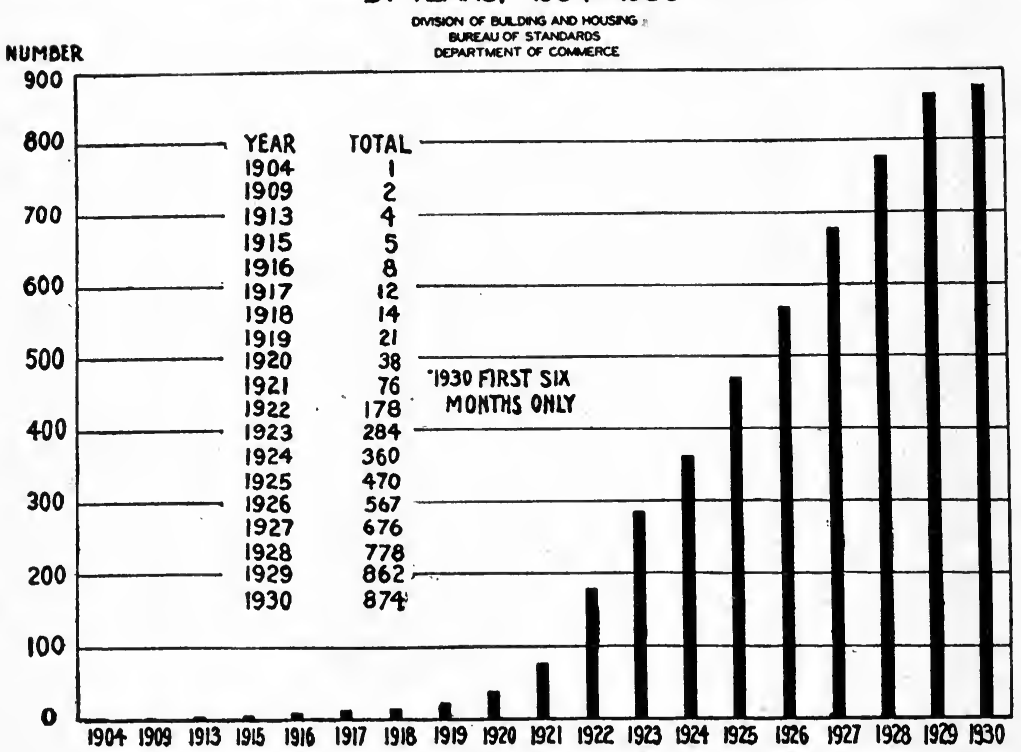

FIG. 118.-Zoned municipalities in the United States by years, 1904 to 1930.

private property in cities. Ordinances are passed to prevent obstruction of highways, owners of abutting property being forbidden to place obstructions across sidewalks or to stage shows upon the sidewalks that might attract crowds and thus make congestion upon the streets, to the annoyance of pedestrians. Also, there are ordinances regulating the overcrowding of buildings, such as tenement houses and factories, by requiring minimum space per capita. There are ordinances, both of prevention 
and of suppression, relating to nuisances, upon the assumption that a man cannot so use his property as to injure that of another. There are building codes dealing with requirements to prevent fire and to secure the necessary strength and stability of construction of all buildings to be erected in the city. Building codes also contain provisions for proper plumbing, sunlight, and ventilation in rooms, all things calculated to insure good standards of living and working among the people. These building codes are uniform in character covering the entire city so that by them it is impossible to achieve the orderly condition that can be accomplished by establishing different requirements for different districts as in zoning.

Restrictive covenants imposed in deeds of conveyance (in which case every buyer of the land takes title subject to all of the reservations in his deed) are useful. They relate to the character and location of buildings to be erected upon the property and to objectionable or offensive utilization of the property but are not altogether practicable.

When buildings are once erected upon unrestricted lots, it is practically impossible to get the owners of such lots to agree to establish any restrictions whatever. Mr. Bassett, speaking of restrictive covenants, says:

They are not of sufficient long-time protection from an all-city point of view (running on an average from 20 to 30 years), are not adaptable to changing requirements, and sometimes are in the way of normal and material improvements. Zoning regulations, however, may properly be supplemented by restrictions in deeds, based upon purely esthetic reasons or for the purpose of creating a uniform residential development, or for other purposes.

Eminent Domain and Zoning.-Zoning is the latest and most practicable method for the regulation of private property and has been declared by our courts to be but a proper exercise by the community of the police power. The police power is defined as a community power, or the whole reserve power of the community, to legislate for persons and things in the interest of the health, morals, safety, and convenience of the public at large. Because

. . . carried out under the police power of the state, zoning therefore must be reasonable and impartial and the authority to impose its restrictions on property must be delegated to the municipality by the state. Zoning, enforced upon the citizens as a proper exercise of the 
police power, must not be confused, however, with "eminent domain" which is "the power of the state to take property of a private citizen only for a public purpose and on payment of compensation.

Eminent domain is used in abolishing grade crossings, in cases of street widenings, and for other kinds of community improvement that involve the taking of private property for public use.

Gathering of Facts in Zoning Survey.--The establishment of zoning districts and the writing of a zoning ordinance can be accomplished only upon the foundation of a careful gathering of facts by the city planner and an interpretation of them. The survey should begin with good-sized prints of the map of the city, drawn upon a scale of, say, from 400 to 600 feet to the inch. One such print should become the map showing the uses of the different sections of the city-one color indicating tha residential, another the commercial, and another the industrial section, as the same are now existent. This map should indicate the positions of the one-family dwellings, the duplexes, rows (terraces), flats, apartments, and stores (those stores with residences above them should be noted). Also upon the map should be marked the position of all manufacturing plants, public properties, parks, institutions, churches, and schools.

Another map should indicate the height of all of the buildings in the city, according to stories; and yet another should portray in color the density of the population in the form of square feet per family. One of the most important maps is one giving information as to the assessment value of all land in the city. This value must be taken from the assessment books and is important because the most valuable land is that which is put to the most intensive use. The front yards (setbacks or building lines) of the entire city should be depicted upon another map, which would also show the sizes of lots, particularly their widths. A map showing the location of new buildings would be valuable to the city planner for the purpose of indicating the character of new developments. All of these maps are useful to the city planner but ought to be supplemented by other studies; for example, zoning can scarcely be attempted without some thought as to the requirements of the plan of the city's streets.

Establishment of Zoning Districts.-In a comprehensive study, the city is divided by the city planner into districts representing the use of the buildings, their height, and their required area. 
These districts are not necessarily concentric or uniform but may assume shapes and sizes as irregular as the existing conditions of the city require. These various districts need not be identical with their eoterminous boundaries but may overlap one another. The location, character, and number of these districts and their subdivisions depend upon the peculiar requirements of each city. These requirements can be determined and interpreted by the city planner only from a careful study of the existing uses, heights, and areas of the buildings already erected, together with his conclusions as to the proper density and distribution of the local population. The study of zoning must proceed with a very definite idea in the mind of the student as to its relation to other elements of the city plan. The widths of the streets in the city and the appropriate types of the buildings abutting upon the streets, the extent and location of recreational spaces and privately owned space, the land values, and the permissible intensities of building - all of these things and numerous others must be constantly taken into consideration by the city planner and show the interrelationship that exists between zoning and the eity plan in general.

Use Listricts in General.- The classes of use to which the private properties of a city are put are mainly those of a residential, commercial, and industrial character, and these form the major framework of the study of zoning. Residences are permitted in districts devoted to business, and both residences and places of business are allowed in light industrial districts. There is, however, some question as to the propriety of allowing residences in heavy industrial localities, and if built at all these residences ideally should be separated by belts of park. Actually the provision of belts such as these is difficult to accomplish. As to the area requisite for the city's activities, from 40 to 50 per cent is likely to be occupied by residences, 2 to 5 per cent by stores, and from 2 to 25 per cent by industrial plants.

The inclusion of public and public utility buildings within the zone plan and map is logical and essential and these buildings should be subject to such conditions as to appearance, height and location as will tend to minimize detrimental effects upon properties in the vicinity.

Residential Use Districts. - The character as well as the location of residential districts will depend upon such matters as easy accessibility to the heart of the city, freedom from nuisances 
and smoke, and proximity to park areas and to pleasant outlook. They will depend also upon the value of land. Frequently and in large degree such value is a reflection of the easy access of the land to the heart of the city.

The practice in city planning has been to approximate a sequence of types of buildings from the center of the city outward, a sequence in which apartments, flats, rows of houses (terraces), semidetached, and detached dwellings for single families follow one another in succession from the center of the city to the periphery. The new thought regarding the development of neighborhood units over the plan of the city and the possibilities for comfortable, economic, and attractive multifamily homes threaten to change conceptions of the past in these matters.

It may be that the proposed neighborhood "safety" or "cell" units, or whatever they may be called, are to be enclosed by arterial streets of the future and that along these boundaries of at least a few of the new civic units are likely to appear groups of multifamily homes, with both parks and single and semidetached homes distributed throughout the breadth of the cells. It is assumed that the important streets upon which the apartments are to face will be made as safe and agreeable as possible by having the main central pavement depressed between flanking trees and strips of grass, while two minor streets, exclusively for local use, are carried along and adjacent to properties on both sides of the main traffic way.

Residential districts therefore may be defined as districts for single-family dwellings exclusively, or they may be understood to include also multiple dwellings, duplexes, and small and large apartments. Incidentally, in connection with apartments it should be noted that in spite of the interest in this form of building, studies and observation in various cities uncover the fact that not more than one per cent of the area devoted to the residential sections of our cities is occupied by apartments. This must not mislead us, however, for there is at the present time a trend toward increasing the number of apartments, and this increase must be seriously considered by the city planner in the preparation of his zoning plans. There are those who believe that the multifamily dwelling in time may so grow in public estimation as to be the most popular place to live in. 
Commercial Use Districts. - The commercial necessities of the city are taken care of in districts that are centers of traffic, the whole district being compact, convenient of access to the shopper, and preferably free from factories. These commercial districts are either local in character, in the form of outlying groups of stores, or central, as part of the downtown portion of the city. The most efficient plan in general for the central district is one that provides for blocks approximately 300 feet square. The amount of space to be set aside by the city planner for stores is a very important matter, and particularly must he avoid any excess of commercial frontage. Studies by the Los Angeles Regional Planning Commission show, for example, that the practice of reserving for business all properties in Los Angeles facing existing highways of 100 feet in width would result in sufficient commercial frontage to support more people than the present population of the entire United States.

Measurements of actual business developments in 40 cities and villages in the region of Chicago show a ratio of 50 feet of business frontage to every 100 people (the lowest ratio was 22 and the highest 90.7 ). This ratio is fairly reasonable, as applying to stores largely downtown. More recent observations in other parts of the country point to the lesser ratio of 35 feet per 100 persons for the whole area of the city downtown, and a ratio of 25 feet per 100 people for the outlying commercial centers.

The amount of space given over to commercial uses will probably not greatly exceed 2 per cent of the total municipal territory.

Industrial Use Districts. - Industrial districts may be either restricted or unrestricted. Districts for the lighter sort of manufacture may have within them some intermixture of commercial houses. Districts for the heavier kinds of manufacture must be equipped - with larger yards and buildings, and the factories must be provided with devices for eliminating the dust, noise, and odor that would otherwise annoy the citizens. Those industries emitting noxious odors should be located far away from any city, village, or other aggregation of houses. No form of industry, however, needs to continue as a nuisance (Frg. 119). Experience shows that there is much that can be done to minimize the smoke, dust, and odors in connection with any industry, and that should be done, not only for the sake of the community but in the interest of the business itself. 
For the-sake of better conditions in the residential areas, the industries should be confined to the edge of town. By segregating them at the outskirts instead of distributing them between the residential areas and downtown, the distance between the residences and downtown is considerably lessened. This is true for the homes that supplant the land otherwise occupied by industry, as it is true for the homes farther out in the town that are freed from the intervening traffic that industry might otherwise introduce. In a new district such features as yards

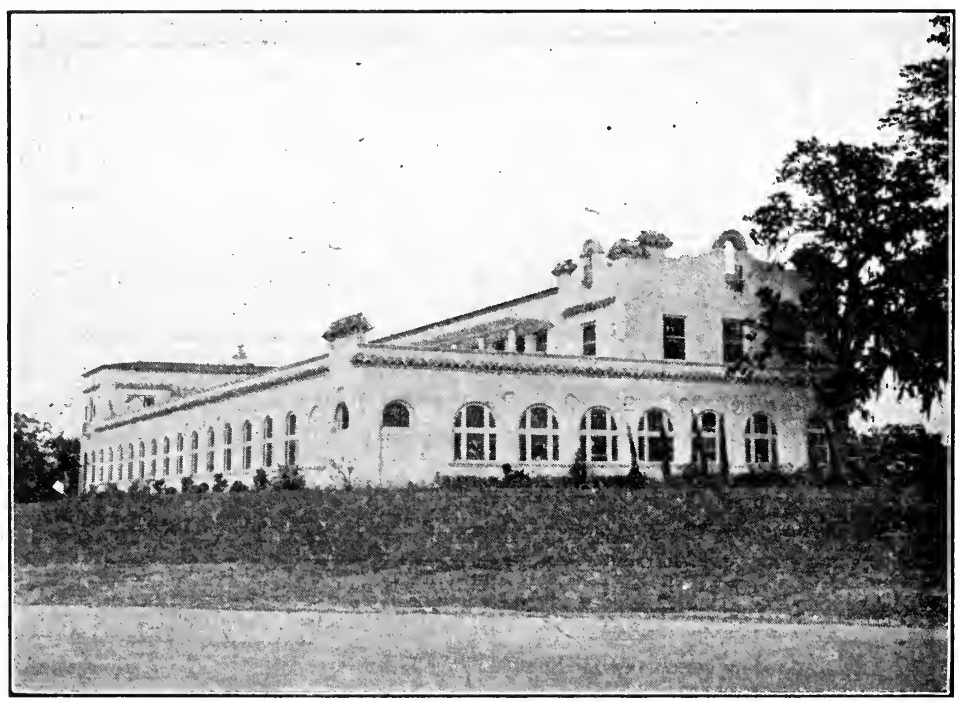

FIG. 119.-Printing establishment overlooking Buffalo Drive, Houston, Tex.

for local materials (lumber, and so on) might be temporarily permitted while the area is being built, with the understanding that after a period of years they be brought within the group of non-conforming uses. In this way space is released in a part of town where houses ought to be located. No residences should be situated near the manufacturies unless separated from them by belts of woodland. As stated before, this is desirable but difficult to accomplish.

In determining the amount of space to be given over to industry it will be helpful to keep in mind the observation of $\mathrm{Mr}$. Goodrich, that it takes about 2,000 square feet of factory land per worker and that, on the average, eventually about 10 per cent of the population will probably be employed industrially. 
This, however, must be determined separately for each specific community.

Non-conforming Uses.-Reasonableness requires that uses of land that do not conform to the purposes of a given district as devised by the city planner when the zoning ordinance is put into effect may continue to exist as non-conforming uses. Any changes or alterations of such non-conforming uses, however, must be conformable to the requirements of the district. No enlargement of such non-conforming uses should ever be allowed. The zoning regulations should never be retroactive, should never operate backward and affect things done in the past, although in one or two states there are reported cases in which retroactive claims relating to zoning have been upheld by the higher courts.

Districts for Different Heights.-It is because the uncontrolled and mixed heights of buildings in any given district of the city are a menace to the health and safety of the people, impair the values of property by depriving the surrounding buildings of light and air, and increase the congestion of traffic in the streets that regulations with respect to the heights of buildings are established.- The different kinds of buildings in a city normally resolve themselves into the following classes as far as height is concerned: dwellings and flats (35 feet or 21/2 stories high); small apartments ( 35 and 45 feet or $2 \frac{1}{2}$ and 3 stories); large apartments ( 85 feet or 8 stories); industrial buildings ( 85 feet or \& stories); sections for commercial houses or hotels (125 feet or 10. stories to 150 feet or 12 stories). The whole matter of the regulation of the height of buildings and its details is, however, for local determination.

The most general method of expressing heights of buildings is that of expressing a height limit in feet for each districtfor example, such heights as 35, 45, 85, 125, or 150 feet. Another method is to grade the buildings in each district according to the number of stories - that is, $2 \frac{1}{2}, 3,8,10$, or 12 stories.

How about the Skyscraper?-Much is being said both for and against the skyscraper. To some the skyscraper seems necessary for the purpose of earning a fair income on high-priced property, as well as a means of providing expansive views and maximum light and air to the tenants. The skyscraper also provides greater convenience for people occupying offices in large cities by its concentration of the activities of business to a relatively small area and makes for the city a more interesting sky line. 
To some city planners skyscrapers are thieves of sunlight, sources of increased congestion, and means of overtaxing transit and street facilities. The mounting assessments and other economic effects of skyscrapers on properties near-by are such as to compel similar utilization or replacement. Skyscrapers mean "higher rents, higher overhead, higher prices, and increased cost of living." They are also possible sources of catastrophe in case of fire and panic. One city planner speaks of skyscrapers as being "theatrical"; another thinks that they may be a monument, an advertisement, or a failure. Still another city planner boldly advocates a further concentration of them into tremendous cubages with no limitation as to height save that of the sky. The immensity of these great structures can be readily imagined from the fact that one New York building occupies an acre of land and serves 10,000 people, while another casts a shadow that at noon on the twenty-first day of December covers $71 / 2$ acres. Regardless of these varying opinions of the city planners quoted above, there is no doubt that many of these high buildings are individually beautiful (Fig. 120). In fact it is entirely conceivable that every town might have its skyscraper appropriately surrounded by open space and treated as a tower-like feature, the center of general interest, and the pride of the community and serving conveniently certain specified business or professional needs of the municipality.

Methods for Controlling Extreme Height.-Some control of the height and character of skyscrapers is without doubt necessary. Effective methods of control, other than those of zoning, include jncrease of taxes according to the height of the building or in proportion to their cubage. The height of skyscrapers might also be controlled by the assessment of the benefits conferred on such buildings by subways and other similar improvements.

With the aid of zoning there are various methods for regulating the "height" of skyscrapers in the downtown districts of our large cities. One method is the adoption of a certain height limit ("dead limit"). This method is in many cases desirable from the standpoint of the city planner, but it is not generally adopted. Another method is to regulate the height of the abutting buildings by certain multiples of the width of the street. This is a good method in view of the fact that a height limit for abutting buildings based on the width of the street bears a direct 
relation not only to its available supply of light and air but to the congestion of traffic upon the street. The height of a build-

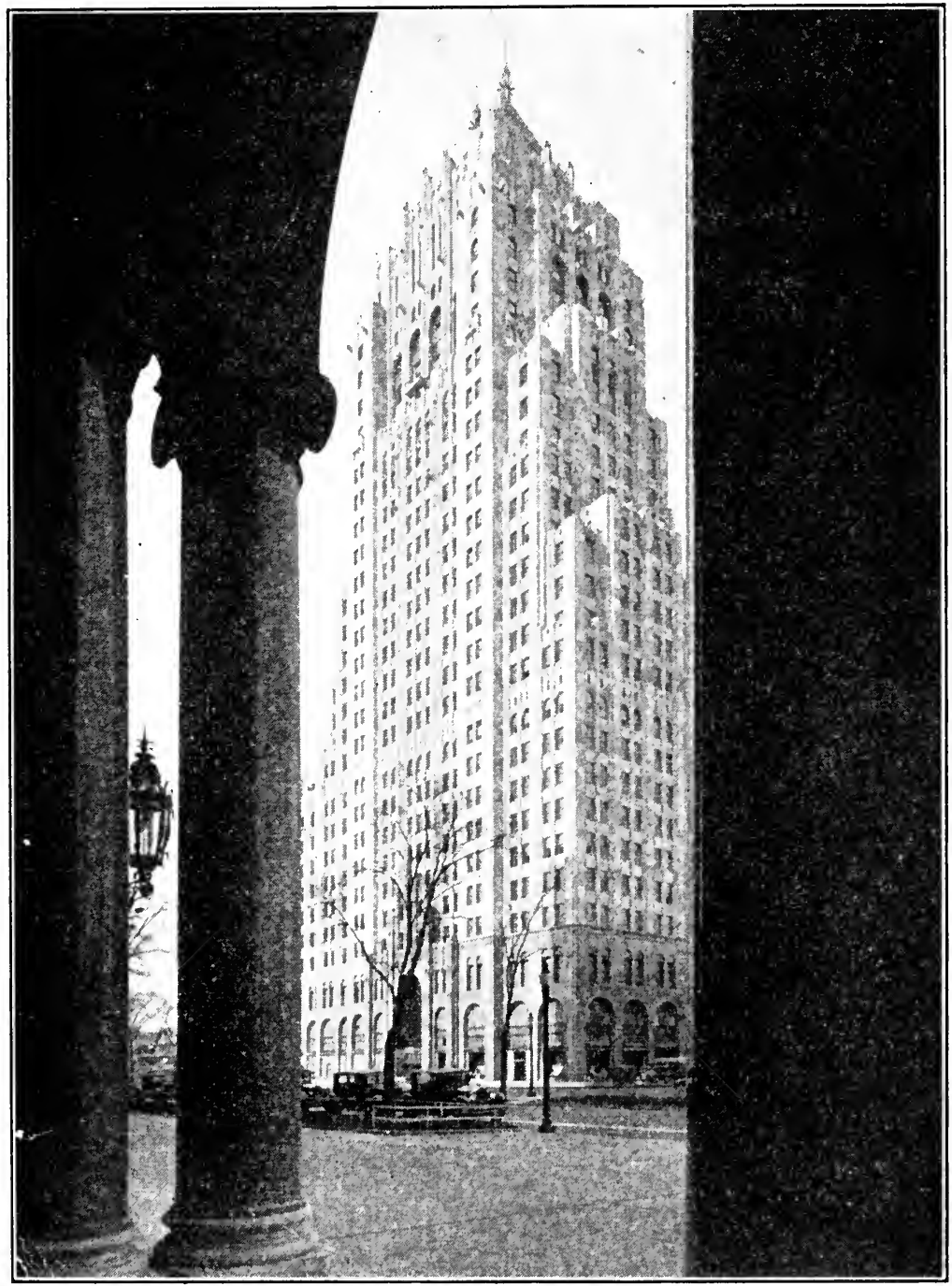

Frg. 120.-The Fisher Building, Detroit. The most outstanding contribution to Detroit's fast-growing skyline is the Fisher Building. It rises to 440 feet and is constructed almost entirely of granite and marble. (Courtesy of Fisher Building Corporation, Herbert A. Fisher, Manager.)

ing determines in large measure the size of the building, and the larger it is the more people it will accomodate and obviously 
the greater will be its demand for street services of every kind. One can readily understand why the height of a building, which has been called the "third dimension in city planning," should be thought of in large degree in terms of street width. In the New York ordinance are found the following multiples; one, one and one-quarter, two, and two and one-half times districts; that is, the city is zoned so that in the different zones the buildings may rise up vertically on the lot lines to as many times the widths of the abutting street as above indicated. Beyond these heights the buildings step inward at specified angles and intervals, and upon a restricted area a tower may rise to an unlimited elevation. Similarly, some freedom is given to the limitation of the height of cornices, parapets, chimneys, flues, grain elevators, etc.

A recent method of regulating the height of the buildings in a city is a combined calculation as to both the height and the bulk of the buildings, accompanied by proper setbacks. As for the "bulk-and-volume" methods of zoning, there are at least three distinct types, each type having its advocates among city planners. The zoning ordinance of St. Louis provides for the creation of an ideal prism, made by the multiplication of the number of feet in the base of the building multiplied by a certain fixed height. The highest building that one can build under this method at St. Louis and cover the land 100 per cent is 200 feet, and "all you cut off you may pile on top." When setbacks are introduced below the 200-foot limit on buildings having a frontage on intersecting avenues, the volume of the buildings may be exceeded by an amount equal to the volume of the building taken out of the ideal prism which is used for reference, provided that the total volume of the building does not exceed by more than 25 per cent the volume of the ideal prism, of 200 feet in height. The ordinance of Pontiac, Mich., is a bulk-andvolume provision of another type. At Pontiac the volume of the abutting building is calculated by multiplying the area of the lot in square feet by the greatest width of the street upon which the building fronts and includes the setback principle for all buildings above a certain fixed height. The ordinance says (in a commercial or light industrial district):

No building shall be erected to such height that the cubical content above the reference level exceeds the volume of a prism having height equal to the width of the widest street or public alley upon which such 
building abuts (but in no case shall such height exceed 120 feet) and a base equal to the area of the lot measured to the lot lines or to the center lines of any abutting public alleys.

The Detroit City Plan Commission has perfected a third bulk-and-volume type of zoning. This plan is based upon the calculation of the volume resulting from the area of the lot in square feet measured to the center line of the abutting street, multiplied by a fixed height in linear feet, and there is no restriction as to the design of the building affected by that cubage. Detroit's type of zoning offers a distinct advantage to the owners of the lots on wide streets and of corner lots, and it is found to be disproportionate for certain shallow lots.

Districts for Various Degrees of Land Coverage.-Not only is a control of the height of buildings essential to a reasonable provision of light and air for the inhabitants, but provision for adequate space around the buildings in yards, courts, and other open spaces is also necessary. Because of the nature of the buildings and their uses coupled with the value of the land upon which they are built, it is assumed by the city planner that the greatest percentage of the occupancy of the lot by the building erected upon it will be found in the central parts of the city and in those parts of the outer stretches of the city that are occupied by factories, mercantile establishments, or apartment buildings. The area of the lot occupied varies generally from 100 per cent in the central districts to 30 or 40 per cent in the detached districts. There is also a general increase of 10 per cent of occupancy for corner lots in all districts. The area districts of many zoning ordinances reveal considerable variation in both classification and treatment. While many ordinances have general regulations as to yards, courts, and areas of buildings, some have separate rules for front, rear, and side yards, and others have rules for both inner and outer courts. Still other ordinances provide for restrictions in the number of families per unit.

Controlling the Depths of Front Yards.-The front yards, which are provided for purposes of "recess from odors, noise and dirt of the street, for grass, trees and general amenity," have their requirements expressed usually in terms of depth, which may be, say, 12 to 30 feet for all types of houses. Front yards are not, as a rule, required in commercial or industrial areas. They can frequently be used to advantage in such areas, however, and 
particularly in local business centers, as in the case of Akron, Ohio, or Kenosha, Wis. Vision clearance or setback of business buildings at corners for safety in street turns, as exemplified in Kenosha, has much to be said in its favor (Fig. 121). Front yards should be established with some reference also to future street widenings. Setback regulations in zoning are front-yard regulations, as Mr. Bassett has so often pointed out, and they should be so named.

Although the depth of front yards is often determined in the case of residential sections by taking advantage of the front yards already established on one side of the street between any

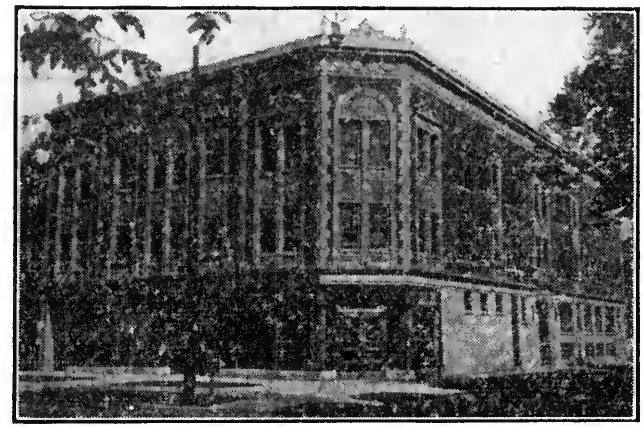

FIG. 121.-An illustration of the setback principle applied to corners for better vision and greater safety of traffic. (Courtesy Kenosha City Planning Commission.)

two intersecting streets, the exact distance will have to be determined by considerations of the character, height, and use of the buildings as well as by the nature of the streets themselves in the given district. There are occasions when variations in front-yard depth allowing for groupings of homes may be a blessing as compared with an unbroken uniformity in line. The depth of the front yards is sometimes expressed by percentages, which in the more restricted districts are of a required minimum depth of, say, 20 per cent of the depth of the lot.

Controlling the Depths of Rear Yards.-The important thing about rear yards is that they shall be large enough to allow-for light, air, and outlook and for access and egress. Their dimensions are frequently based on sunlight projection and are related to the height of the buildings which they are intended to serve. The variety in requirements for the depth of rear yards is numerous and is equaled only by the variety in every possible manner 
of their expression. The most common methods of computation are by percentages of the depth of the lots or by a flat figure covering the maximum requirement of the depth. In the case of one- and two-family homes, this percentage may be 25 feet, with 15 feet as a minimum. There may also be a limit to the depth of the yards stated in feet, for one- or two-story buildings, with additional feet required for the depth of the lot for each additional story of the building. Sometimes, as in the case of the more congested districts, the depth of the rear yards may be at the rate of so many inches, say 1,3 , or 4 inches for every foot of the height of the building. Additional area for the yard can be provided according to the number of the families to be accommodated.

Widths of Side Yards. - Side yards are introduced for the purpose of securing light, air, and access. The widths of side yards should depend largely upon the sizes of the lots and upon the character of development that is proposed. They are usually related for light and air to the height and length of the building. Side yards are not required in the case of commercial or industrial buildings. Care should be taken not to interfere by restriction with development that might be more satisfactory and successful without restrictions. Narrow lots are likely to enforce long, thin houses that are not so desirable as houses only two rooms deep. It has been the custom to express the widths of side yards by a fixed minimum in linear feet. For restricted districts a good common minimum for the width of the side yard is set forth as 8 feet, while for less restricted areas from 3 to 5 feet is common.

A lot 40 feet in width, for example, should provide enough space for a driveway of 8 feet along one side of the house and 5 feet on the other side, which would leave 27 feet of width for the house. Instead of picturing the requirements of the side yards in feet, they may be stated as a percentage of the width of the lot. They may also be expressed as so many inches to the foot of the height of the building or so many inches to the foot of the length of the building or yet, again, in so many feet for a twostory building plus so many additional feet for all extra stories. Sometimes the sum of the areas of two side yards must reach a required minimum.

Exceptions Applying to the Requirements of Side and Front Yards. - There are occasions when homes may be arranged in architecturally homogeneous and livable groups in a manner that 
is ill suited to the conventional requirements for front and side yards. In this day of growing popularity of multifamily homes and the demand that is likely to come for the groupings of such homes around generous open courts and over the stretch of complete blocks, it should be possible to depart occasionally, at least, from the uneconomic and unesthetic as well as unlivable arrangement that so frequently attends the placement of separate homes in accordance with the requirements of narrow. lots. In order that a sensible departure from this practice of the past may not be unduly hampered, the properly designated authority should be permitted to waive all side- and front-yard restrictions in such cases, provided that "open space in the form of courts, deeper rear yards, and so on, as great as or greater than the total area of the side and front yards so waived is provided in lieu thereof.

Widths of Inner and Outer Courts.-Minimum sizes as to the widths of courts also are specified by the city planner. These too are provided to assure light and air and are determined according to the proposed height of the building and of the needed sunlight projection.

In cases of inner courts that are surrounded on all sides by walls, 10 feet is a common minimum width in the most restricted districts of the city. Here, too, the requirements are sometimes stated in so many inches for every foot of height of the buildingpossibly not less than $1 \frac{1}{2}$ inches per foot of the height of the building will be the proper ratio in the least restricted districts of the city. In the case of outer courts which extend to an opening upon a street or alley or yard, the requirements are similar to those of side yards, with an additional limitation of their width in terms of the length of the court.

Control of Population Density.-The attempt to prohibit the overcrowding of land is accomplished by regulating the density of population or the number of families per unit that may occupy the given area. The number of families so accommodated may range from 8 to 25 families per acre in the restricted portions of the city up to from 110 to 140 families in the least restricted ones. For practical purposes, this estimate is better accomplished by establishing a standard of so many square feet of dwelling to be occupied by a family or of a certain number of square feet of the open space on the lot per family. This requirement should be supplemented by regulations involving height of buildings, 
percentage of lot coverage, and yard requirements, because density of population is largely determined by the size of buildings.

Zoning Transition. Since the types of the development upon the opposite sides of any street should be similar, zones should be bounded by alleys or by the rear lines of the lots and not by the streets. Local centers for stores at the intersections of streets occupied by residences should conform to the requirements of the front yards in the vicinity. Heretofore multiple dwellings (apartment houses and duplex types) have been suggested as buffers between the local centers of stores and residences. The provision of such buffers in the form of more families seems like an aggravation rather than an extenuation. Better still would be to reserve a strip of park between store and home, but this, too, is difficult to accomplish, especially in an existing development. Generally speaking, the transition has always been thought of as progressing from the more completely occupied and more densely populated areas of the center of the city toward the more open of the outer portions or from the higher buildings of the central sections to the lower buildings farther out.

Obviously such transition will differ considerably if the pattern of the city, as already described, is eventually to be, as some think it must be, a collection of cell-like units. Around several of these units may be developed apartments both small and tall, while the interior of the cells are occupied by single, semidetached homes and by parks.

Form and Content of Zoning Ordinance.-Although there is as much variation in the ordinances for zoning as in the number of cities and towns for which they are prepared, yet there does exist some degree of uniformity among zoning ordinances. The ordinance will include a section for definitions which in some instances will be quite lengthy. The districts into which the city is to be zoned will be specified. The kinds of districts into which the city is to be divided by the city planner will be fixed, as well as the appropriate regulations that are to be enforced regarding them, and the whole scheme will be made to accord with the comprehensive zoning plans. A section of the ordinance will be devoted to the applications and permits for construction and occupation. In most cases, provision will be made for a board of appeals to take care of special permits. The manner by which the ordinance may be amended, supplemented, 
or changed and in which the ordinance is to be interpreted in general, for what purpose and to what end, will also be included. The application of the ordinance with regard to easements, covenants, or agreements will be made clear in the instrument, as well as what is to happen in the event of any conflicts with other ordinances. Finally, the manner of enforcement and the time when the ordinance is to take effect will be stated.

Board of Appeals.-After ordinances are put into operation they need adjustment, modification, and some practicable means for the handling of exceptional cases. Since it would be too slow to have these matters corrected by amendment in council, a board of appeals makes a very convenient body for this purpose. Before this board, which usually consists of from three to five members, grievances can be aired and reviewed, and from it special permits can be secured. The purpose of this board of appeals, however, is "not to change the zoning ordinance, but to authorize such variance as will not be contrary to the public interests. It must assume the correctness of every part of the zoning ordinance and restrict itself to the narrow, though important field of adjustments." It is an administrative and not a legislative board. It is not a court and has no judicial powers, and the hearing before it is not a judicial proceeding. "The hardship that justifies a variation must be that of the individual lot and not shared by other properties in the neighborhood."

The board of appeals therefore "becomes a convenient remedy against arbitrary or unreasonable exercise of the police power." In most states no appeal to the courts can be made until the matter at issue has already been taken to the board of appeals.

Zoning Program.-The steps in the accomplishment of a zoning program are as follows: First, a comprehensive state enabling act is necessary to be passed by the legislature. After that, a representative body of men constituting a zoning commission should be appointed with clearly defined-duties and responsibilities. Under the sponsorship of this capable and honest group, assisted by persons trained in the work, there should proceed a careful collection and interpretation of all pertinent facts and a thorough discussion of every problem involved in the scheme. The approval of the common council should also be secured by proper ordinance. Frequent hearings of objections offered by any interested taxpayer should be arranged, followed by approval of all changes by the council. 
The board of appeals should be charged with the duty of hearing and taking care of any unusual conditions that may arise and produce unnecessary hardships.

In closing, a quotation from Will Irwin appropriately appears to sum up the preceding discussions:

The movement for sane zoning . . . carried forward by thousands of business or civic organizations over the United States is blending into a nation-wide movement for more convenient, more economical arrangement of our cities. It is not possible to estimate in cold cash the enormous benefit . . . conferred on our industrial commonwealth. But when it comes to this high endeavor for the comfort, permanence and beauty of our future America, one must abandon even guessing. Though it has eliminated much waste in tearing down cities, one must measure it chiefly in spiritual terms of security and contentment and happiness.

\section{Questions for Discussion}

1. What is the value of zoning?

2. Review the history of zoning in the United States (Boston, Los Angeles, New York, etc.).

3. What is the "police power" and how is it related to zoning?

4. Discuss the requirements, respectively, of residential, commercial, and industrial use districts.

5. Explain the meaning of a non-conforming use.

6. Should the skyscraper be regarded as a blessing or an evil?

7. Why must heights of buildings be controlled; what classes of buildings are there according to height; according to what methods are the heights of buildings expressed?

8. What zoning methods are advanced for the control of bulk and volume of skyscrapers (St. Louis, Pontiac, Detroit); what non-zoning methods?

9. Discuss the requirements of area districts (front, rear, and side yards; inner and outer courts; population density).

10. What should the boundaries of zones be like and how is the transition from one zone to another effected?

11. Explain the function of a board of appeals.

12. What maps are essential to a zoning study?

13. Outline the contents of a typical zoning ordinance.

\section{References}

Advisory Committee on Zoning: “Zoning Primer," 10 pp., illus., rev. ed., Government Printing Office, Washington, D. C., 1926.

Anderson, Nels, and E. C. Lindeman: Occupational Areas and Their Types, "Urban Sociology," Chaps. IV, XIII, 1928, Alfred A. Knopf, Inc. 
Apartment Houses or Dwellings—Which? Housing, pp. 179-181, September, 1930.

A Standard State Zoning Enabling Act, with notes. Government Printing Office, Washington, D. C., 1926.

BAKer, N. F.: "Legal Aspects of Zoning," 182 pp., Chicago University Press, 1927.

Bartholomew, Harland: Plant Location and City Planning, Factory and Industrial Management, vol. 76, pp. 489-490, illus., September, 1928.

- - What Is Comprehensive Zoning? Proceedings, 27 pp., National Conference on City Planning, 1928.

BassetT, E. M.: Zoning, rev. ed., National Municipal League, Technical Pamphlet ser. 5, pp. 315-341, 1922.

_._. : Fundamentals of American Zoning with Special Reference to Court Review, Proceedings 17th National Conference on City Planning, pp. 423-430, 1925.

- : Humanitarian Institutions, City Planning, pp. 291-293, October, 1930.

Betrman, A.: The Decision of the Supreme Court of the United States in the Euclid Village Zoning Case, University of Cincinnati Law Review, vol. 1, pp. 184-192, March, 1927.

- : The Present State of Court Decisions on Zoning, City Planning, January, 1926.

Chamberlain, Joseph P.: Zoning Progress, American Bar Association Journal, pp. 535-539, September, 1929.

Clatk, W. C., and J. L. Kingston: "The Skyscraper, A Study of Its Economic Height," 164 pp., American Institute of Steel Corporation, Inc., New York, 1930.

Constitutionality of Zoning Laws Is Sustained by Supreme Court, (U. S. Daily 23, p. 15, discussion and full text of decision, Euclid, Ohio, 1926). Factors in the Zoning of Cities: A symposium, Proceedings American Society of Civil Engineers, vol. 51, pp. 153-217, February, 1925.

Goodrich, E. P.: Sunlight and the City Plan, American City, vol. 39, pp. 121-122, July, 1928.

Hubbard, H. V., and Hubbard, T. K.: Zoning, "Our Cities Today and Tomorrow," Chap. XI, pp. 162-191, Harvard University Press, 1929.

Kingery, R.: Determining the Size of Retail Districts in Zoning Cities and Villages, American City, vol. 36, pp. 246-248, February, 1927.

Krusen, Wilmer: Zoning and the Public Health, 4 pp., Philadelphia, Housing Association, 1930.

Legal decisions on zoning and city planning, Municipal Index, American City Magazine Corporation, pp. 132-150, 1930.

Report of Heights of Buildings Commission, 278 pp., Board of Estimate and Apportionment, New York, 1913.

Nichols, J. C.: The Planning and Control of Outlying Shopping Centers, Journal of Land and Public Utility Economics, vol. 2, pp. 17-22, January, 1926.

Nolen, John, ed.: Zoning, "City Planning," pp. 404-429, D. Appleton \& Company, 1929. 
Pepler, G. L.: Proportion of Area Required for Industry, Town Planning Review, vol. 12, pp. 122-124, 1926.

Regional Plan of New York and Its Environs, Zoning, etc., Survey, vol. 6, 1928.

Report on zoning standards and principles, American City Planning Institute, 12 pp., March, 1929.

St. Louis Zone Plan, pp. 12-43, City Plan Commission, St. Louis, Mo.; Harland Bartholomew, engineer, Nixon-Jones Printing Co., 1919.

The Influence of Zoning on the Design of Public Utilities: A Symposium, Proceedings American Society of Civil Engineers, vol. 51, pp. 219-261, February, 1925.

Williams, F. B.: The Principles of Building Regulation and Zoning, "The Law of City Planning and Zoning," Part IV, pp. 191-356, The Macmillan Company, New York, 1922.

Zoning and the Courts, Housing, pp. 211-240, September, 1930.

Zoning in Practice, Proceedings 17th National Conference on City Planning, pp. 423-497, 1925. 


\section{CHAPTER XVIII}

\section{PUBLIC BUILDINGS AND BUILDING GROUPS}

Public buildings and groups of buildings play a significant part in the life of the community and in the framework of the city. When they occupy commanding sites and are adequately, efficiently, and beautifully designed, they interpret the purposes and ideals of the community, focus the city's activities, and symbolize civic aspiration and achievement. For any city to

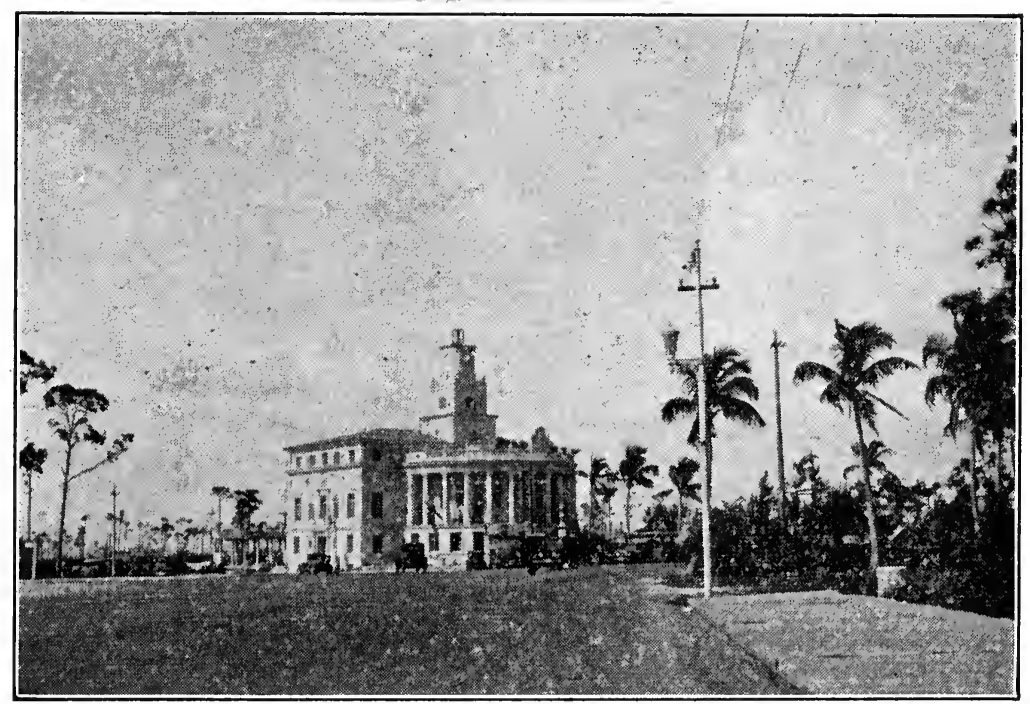

FIg. 122.-The city hall, Coral Gables, Fla. Public buildings should be located with every regard for views to be had of them from adjacent plazas or approaching streets as well as for views from them. (Photograph by the Author.)

be without its important public and semipublic structures is to have that city miss a vital service to the people. Because of their significance, public buildings and groups of buildings demand that adequate provision be made for them in the city plan. Such adequate provision is determined by the city planner taking cognizance of the usefulness and beauty of the buildings themselves and of their relation to the plan of the city at large. 
This adjustment of the public building or group of buildings to the plan of the city calls for the conferring of as much benefit to the community as possible and without any interference with the other normal features of the city plan.

Location of a Public Building That Is to Stand Alone.-In choosing a site for a public building, as distinguished from the location of a group of such buildings, it is necessary to exercise care that the site be one of easy access to the people and suited to the purpose for which the public building to be erected upon it is intended. The zoning regulations of the locality in which the site lies will help to determine the height and proportions of the building. Factors affecting the matter of appearance should, moreover, be weighed, such as the desirability of a site at the terminus of a thoroughfare (Fig. 122) or at an intersection of streets at which traffic converges. If the site chosen is upon an eminence, it gives an opportunity for a more satisfactory monumental type of approach. If the eminence chosen for the site should overlook a park or the water front or afford a view along a river or across a lake, so much the better. The site selected should be large enough both to insure to the building plenty of light and air and to prevent any overdominance by other structures in the neighborhood. Upon a large site, undesirable adjacent structures may be screened from view by planting trees and shrubbery. Every site for a public building gains an advantage when it offers opportunity for fronting or surrounding forecourts or open areas. ${ }^{1}$. Where the building is to be set facing a street,

1 "In order to see at its best a building as a whole (i.e., leaving aside the detailing) the observer should be separated from the building by a distance equalling about twice its height, which means he should see it at an angle of 27 degrees. In this latter case the building will fill the entire field of vision of an observer who holds his head motionless. If the observer wants to see more than just the one building, if for instance he wants to see this building as a part of a group, say a civic center group, he should see it at an angle of about 18 degrees, which means he should be separated from the building by a distance equal to about three times its height." Hegemann, Werner, and Elbert Peets, Plaza and Court Design in Europe; "The American Vitruvius: An Architect's Handbook of Civic Art."

"If we examine a series of ancient places, we shall see that, whether from accident or design, the entrances to them are usually so arranged that they break the frame of buildings very little, if at all. This enclosure is not only important because it gives a sense of completeness and repose to the place itself, but also because of the importance of providing a proper frame and background to the public buildings; if we examine the various places, 

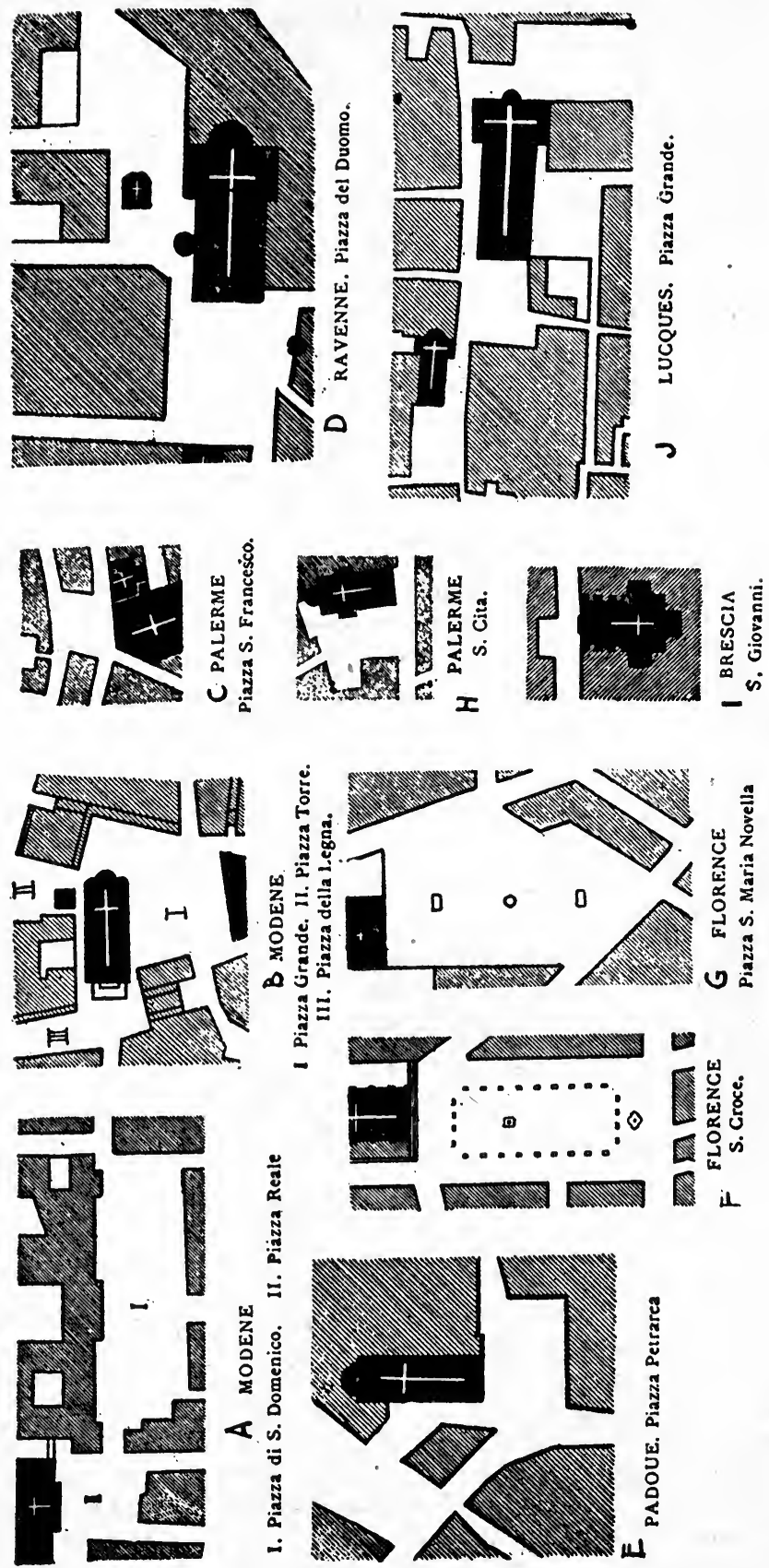

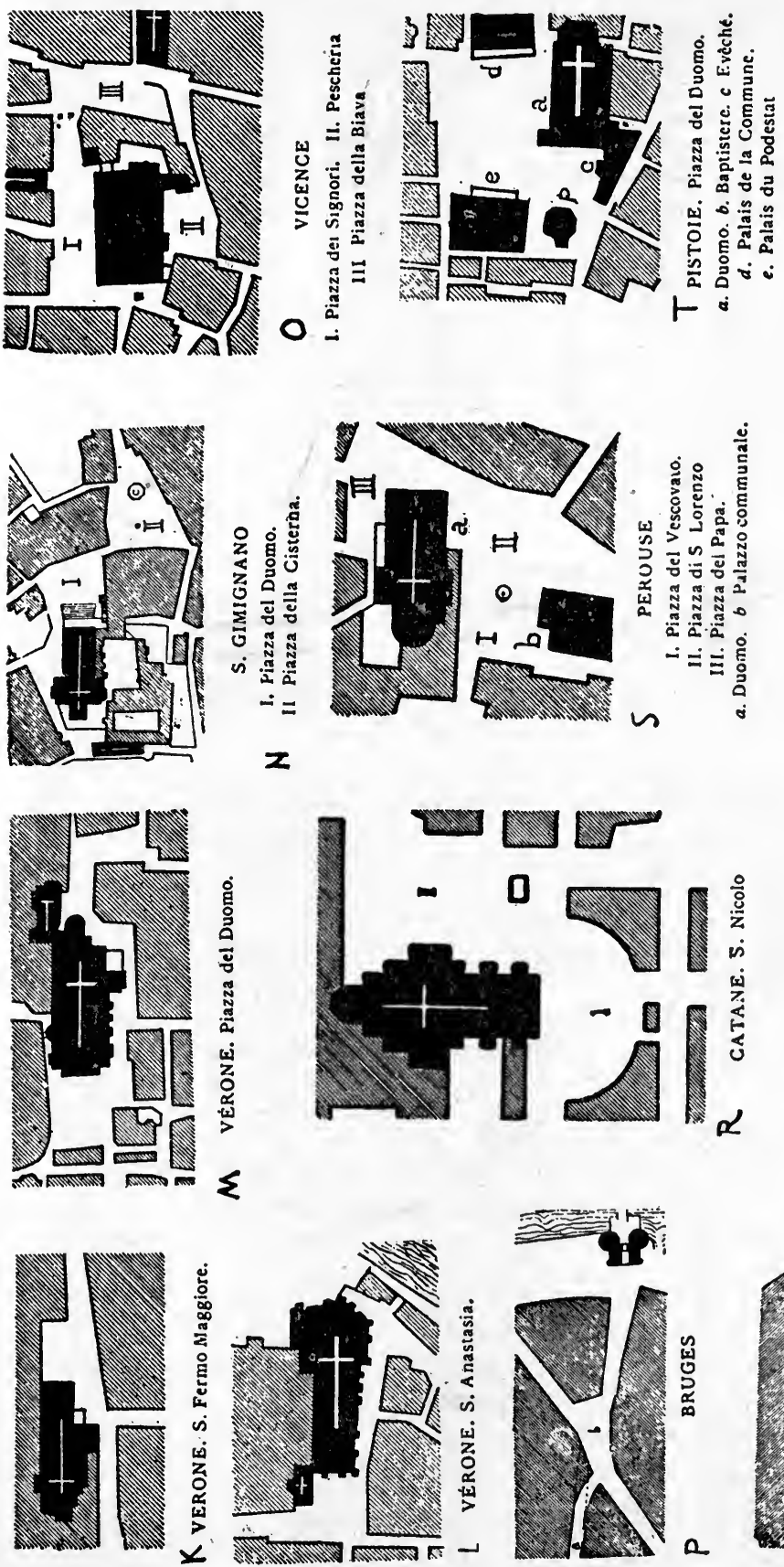

s。 8

啳

\% ठี

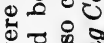

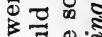

형

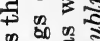

象.

융류 훙

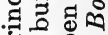

a. 용

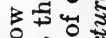

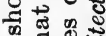

ఫ正

สี 용ำ

ส. कू

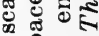

a

पे

药 ํㅜㅇ

需

은. ह ह

ह

ه

政

क क

$\circ .4$

월

ปี

田. 兽

.$\Xi$ ฮ็

or

$\checkmark$ \&

녕

on.

on $\Rightarrow$

दै द

क.

훙:

ه

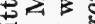

in 0 क

욜.

है

Оू.

g $n$

을

둥 웅

윸용

은

$\triangleq$

บ क

15

政

N

응

s. 
such a forecourt may be a square or quadrant separating the building and street or located upon the opposite side of the street. The shape of such forecourt or plaza should be preferably rather oblong and in length from one one-half times to twice the height of the public building or following some other equally good proportionate relation, in order to provide a view pleasing to the beholder.

An enclosure should define the boundaries of this forecourt, making it a picture set in a frame and giving to both the building and its forecourt an air of picture-like repose (Fig. 123). In the old Gothic towns, in which the streets were narrow, the public buildings were successfully screened from sight by having the streets approach the plaza at right angles to the main line of view of the buildings or by constructing arches across the streets from the public buildings to adjacent structures.

Some control of the character and size of the buildings abutting upon the forecourt and plaza or other approach to the public

we shall find that in nearly all cases the public buildings are not in the center but on one side; very often they are actually attached to their surrounding buildings or are separated from them by such narrow openings that when viewed across the place the gap between them is not evident.

"It has become the custom to build our churches and other public buildings in isolated positions on comparatively large sites. This is not the way to produce satisfactory pictures or to show buildings to the best advantage. In a picture so very much depends on relation to surroundings, on the contrast of one part with another, and it is the same with street views. For one thing, size is not in itself appreciated. It is only apprehended by its relation to some known standard, by a comparison, or by contrast.

"Definite rules for the size and proportion of places cannot be laid down. They should bear some relation to the size of the buildings likely to surround them. An overlarge place will tend to dwarf buildings. Sitte points out also that tall buildings, narrow in proportion to their height, such as the west ends of cathedrals, seem to require places deep in the dimension at right angles to their front; while wide buildings of lesser height, such as are many town halls, picture galleries, and the north and south fronts of cathedrals, seem, on the other hand, to show best on places wide in the direction parallel to the building, and shallow in the direction at right angles to it. He also recommends that places should not usually be square but rather oblong, the length and the width bearing some definite proportion one to the other. Usually the length should not be greater than three times the width. Such rules, however, can at best only indicate one method likely to prove successful. Proportion in town planning, as in architecture, is a matter that cannot be reduced to figures, but must be judged of in each case according to the circumstances." Centers and Enclosed Places, Unwin's "Town Planning in Practice." 
building must be exercised by the municipal authorities. For example, in the case of the architecture of all buildings bordering the approach to a building surmounted by a dome, the importance of keeping the lines of the cornices of these bordering buildings nearer to the earth than the drum of the dome can easily be appreciated. The effect that can be produced upon a public building by having it overtopped by surrounding skyscrapers can similarly be understood.

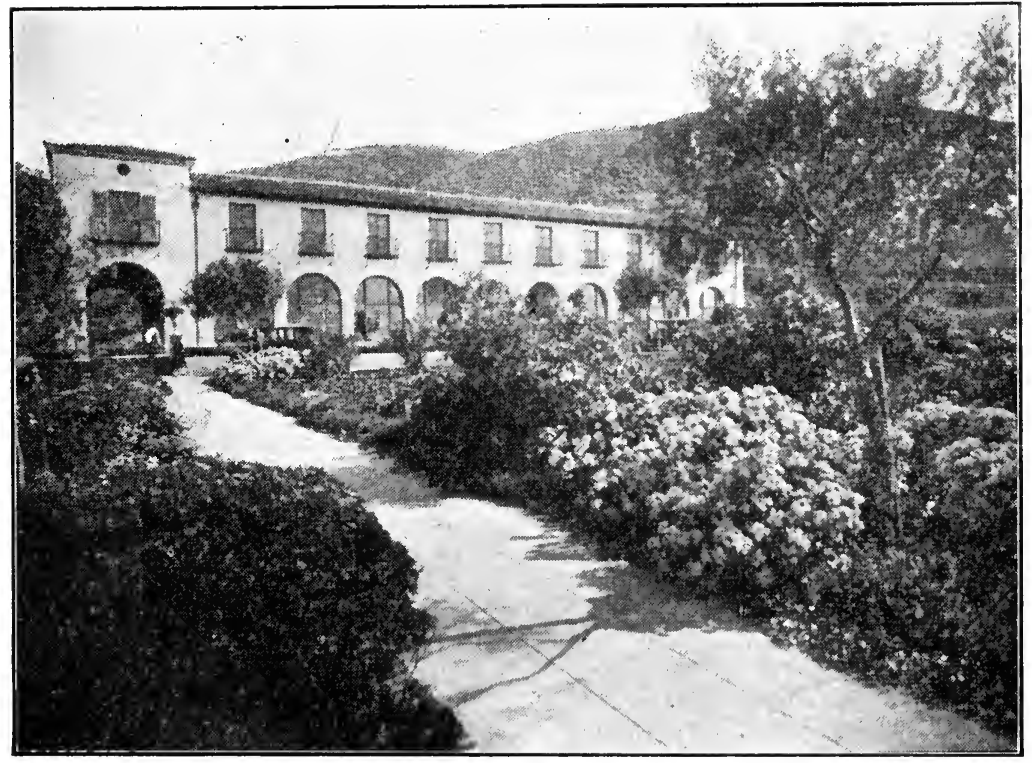

FIG. 124.-Offices and stores in the first unit of the business plaza in Malaga Cove, Palos Verdes, Calif.

The problems of locating and designing a public building are many. The site selected must be accessible to the people as well as suited to the building to be erected upon it, and the design of the building must measure up to high standards of architectural excellence.

Groups of Public Buildings. Civic Centers and Subcenters.Effective though individual buildings may be, a group of public buildings serving kindred uses is apt to be more impressive. Assemblages of public buildings may form civic centers, community centers, centers for the study of industrial or dramatic art or music, of groups of churches, public markets, or retail stores or buildings housing some institution. 
Civic centers may be governmental (federal, state, county, municipal), cultural, and educational in character. Occasionally they may include semipublic buildings "to help support or complete the effect of architectural composition." They may be downtown, central schemes serving the entire city or local community developments any where in the city. They may include such building units as the city hall, the courthouse, or joint city-county building, as in Milwaukee and Wilmington,

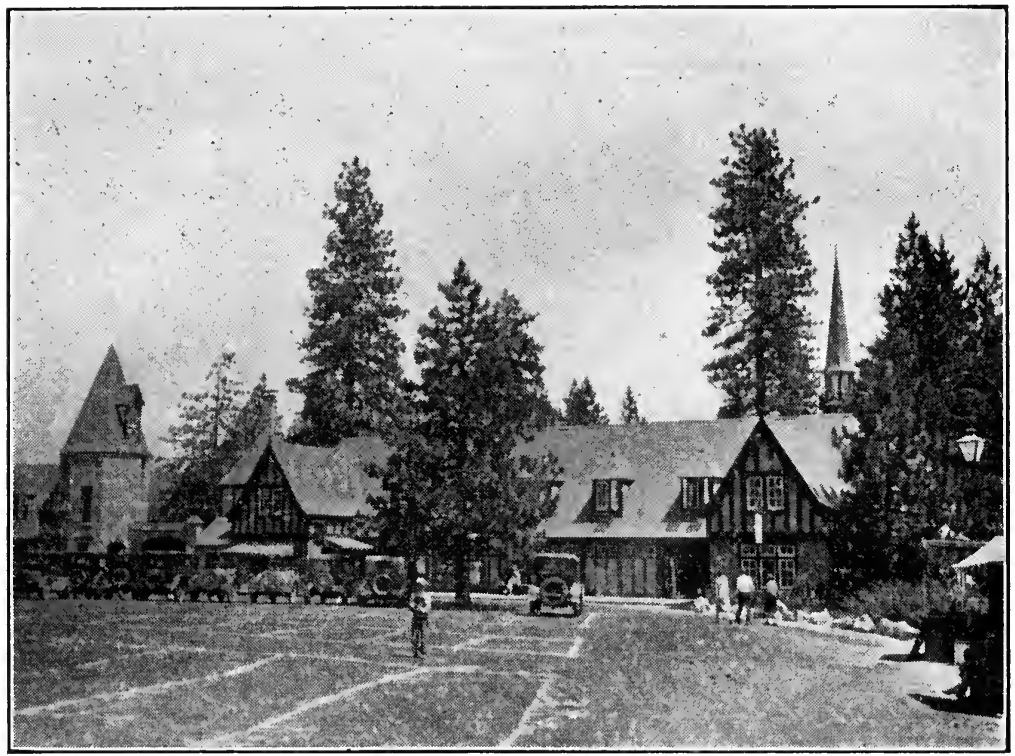

Fig. 125.-Shop center, Arrowhead Lake, Calif. (Photograph by the Author.)

the hall of records, the post office, the public library, the public auditorium, the headquarters of the police and fire departments, the art museum, and the churches. They may also include an armory, an open-air theater or other recreational buildings, a hotel or a bridge or a water front. Where they are composed of stores and shops (Figs. 124, 125) they should be situated as closely as possible to the center of population.

Civic centers should be in a convenient location. They should be near the centers of business but not amidst a chaos of sordid surroundings or with too much movement within their boundaries. They should not lie within the heart of the business district so as to be an interruption to business, nor should they 
lie within the path of commercial expansion. They should be close to good transportation facilities. They should be chosen with due regard for the needs of the individual buildings that are to compose the groups, such, for example, as the space and the approach demand. This is particularly so in the case of an auditorium with its requirements of a more leisurely but ample approach. Civic groupings should permit of a dominant central building that will give character to the scheme as a whole. The areas selected for civic centers, moreover, should contribute to good composition with few or no bisecting streets to interrupt the continuity of line and mass in the groups. If possible, a commanding location should be sought out, for there is much to be said for having civic buildings higher than all others and on the highest land so that they may easily and frequently be seen and so contribute constantly to the inspirational interest and beauty of the city.

Building Groups in the Old World.-The value of grouping public buildings, as distinguished from scattering them amidst commonplace surroundings, was appreciated in the days of Athens. The successful achievements of the Athenians in this direction show their extraordinary civic pride and their devotion to their common public interests. The climax was reached in the developments on the Acropolis during the Periclean period. Upon an inaccessible rock of irregular conformation a worldfamed group of structures was picturesquely fitted. The ruins alone are a never ending source of inspiration to the artist today, suggesting former glories of the Propylaea, the Erechtheum, and the Parthenon. The value of the grouping of buildings was likewise appreciated in Rome, to such a degree, in fact, that one thinks of that great city as a civic pattern of closely fitting building groups. The examples of the early times that stand out in bold relief are the Roman Forum and the many other fora, notably those of Trajan and Nerva, that were developed by the emperors, as the old central meeting place seemed to grow smaller with increasing demands made upon it. Not only the Rome of the Empire but the Rome of the Renaissance had its stately plazas and building groups, including, among others, the Piazza di San Pietro, Place du Capitol, and the Santa Maria Maggiore. Elsewhere there are such notable groupings to be seen as Piazza di San Marco, in Venice, the Louvre and the Tuileries and the Place de la Concorde, of 
Paris; Place de la Carrière and Place Stanislaus of Nancy; the assembly of buildings close to and in connection with Unter den Linden in Berlin; Trafalgar Square in London-all of these and many others reveal the variety of possibilities, the principles, and the results that are to be associated with the building up of public structures in the city plan.

Building Groups in the New World.-Our first realization as a nation of the possibilities of civic groupings of buildings came with the beautiful ensemble of structures at the World's Fair at Chicago in 1893. We had some other notable groups of buildings erected before that time, to which, however, we never gave sufficient recognition, such, for example, as the group known as Independence Hall at Philadelphia.

Soon after the World's Fair many of our cities recognized the desirability of planning their public buildings after some particular choice of architecture and scale appropriate to the character of the community, of placing them in a group, and of building them with one kind of material, thus adding greatly to the beauty of the center and the beauty of the municipality. The old American practice of scattering the public buildings all over the city has now been generally abandoned in a number of our cities, and as a result we see magnificent groups of public buildings approaching completion in conformance with programs conceived several years ago, as, for instance, in Cleveland, Denver, St. Louis, Detroit, and Los Angeles. The conspicuous examples of civic centers underway also include Buffalo, Baltimore, Des Moines, Duluth, Kenosha, Los Angeles, Milwaukee, Springfield, (Mass.), San Francisco, Washington, and Wilmington.

San Francisco shows astonishing progress in the completion of its outstanding civic center; even now it has a development that may well be a source of pride to its citizens, and it is marvelously impressive to visitors (Fig. 126). The lands and buildings for this accomplishment have cost the people of San Francisco $\$ 20,000,000$. The group of public buildings includes an architecturally beautiful city hall at one end of the group, crowned by a dome of commanding height (300 feet), and along the sides of the city hall an exposition auditorium, which seats 12,000 persons, and which has already been the scene of many national conventions; a public library and a State Building of California are also prominent members of the group. One may gain some idea of the size of the San Francisco civic center from the fact 
that four city blocks are given up to the plaza alone. Plans are now under consideration for the addition to the group of two buildings as war memorials and a proposed federal building. The Springfield, Mass., civic center is being developed around an attractive park between the main business street of the city and the river. The city hall and the municipal auditorium with a high bell tower rising between them occupy one side of the park and inspire in the beholder admiration and enthusiasm. The

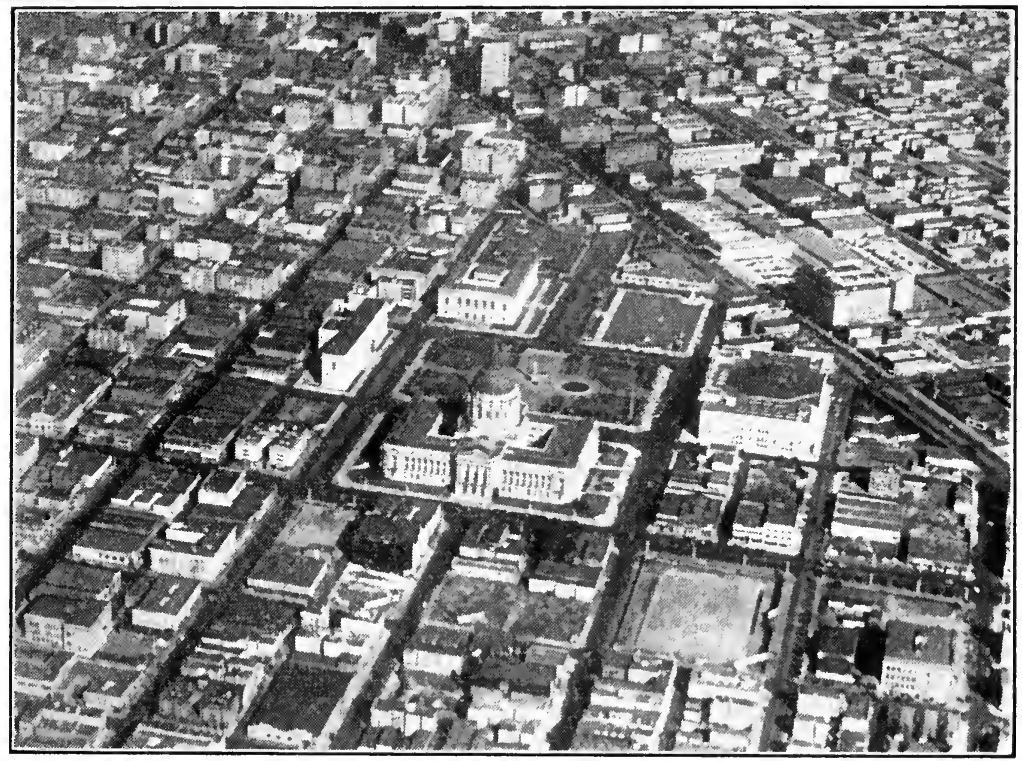

FIG. 126.-Air view of the civic center of San Francisco.

county building, situated across the park from the group above described, also forms an interesting part of the plan. The old First Church now blocks the view from the new groups of buildings toward the river and because of its architectural charm will probably be removed but retained in some other portion of the square. This development at Springfield represents a notable accomplishment among the cities of 200,000 population or less.

Santa Barbara is now leading the country in efforts to develop unique and beautiful groups of stores and offices. Outstanding among these is the Paseo, which is designed so as to provide facilities for shopping and conveniences and refreshment for the shoppers within the block and away from the noise, heat, dirt, 
and confusion of the streets (Fig. 127). A succession of passageways and enclosed open spaces at different levels with architecture so conceived as to furnish picturesque views to the shoppers at every turn is an idea in architecture never before so successfully put into material form in this country.

The location of civic centers depends upon the individual needs of the buildings that are to be included within them. The

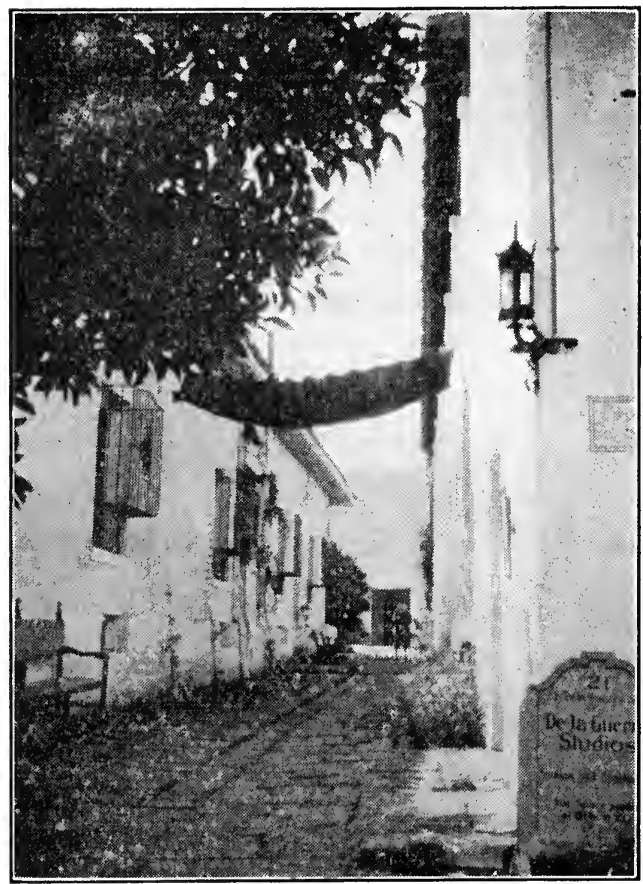

FIG. 127.-The De la Guerra Studios of Santa Barbara, Calif. They are entirely off the main street and open upon covered and uncovered passageways and upon open courts of changing level. One feels as though he were wandering through a separate picturesque village.

city hall and courthouse need to be centrally placed. Police stations and fire-engine houses (Fig. 128) should be in close proximity to important thoroughfares in order to give quick access to the territories served. Public auditoriums should be near the focus of many main lines of communication from all parts of the city, near the downtown hotel and shopping district, and should allow for considerable parking space in the vicinity without interfering with general traffic. For such a public 
auditorium alone several acres of land are necessary. It is coming to be the practice now to locate post offices near to the railroad stations and within easy walking distance from the center of the city. A central public library should be readily accessible to the downtown business district for use during the noon hour and should therefore be within easy walking distance of the central business section of the city and convenient also to lines of transit. The library should be located in a quiet

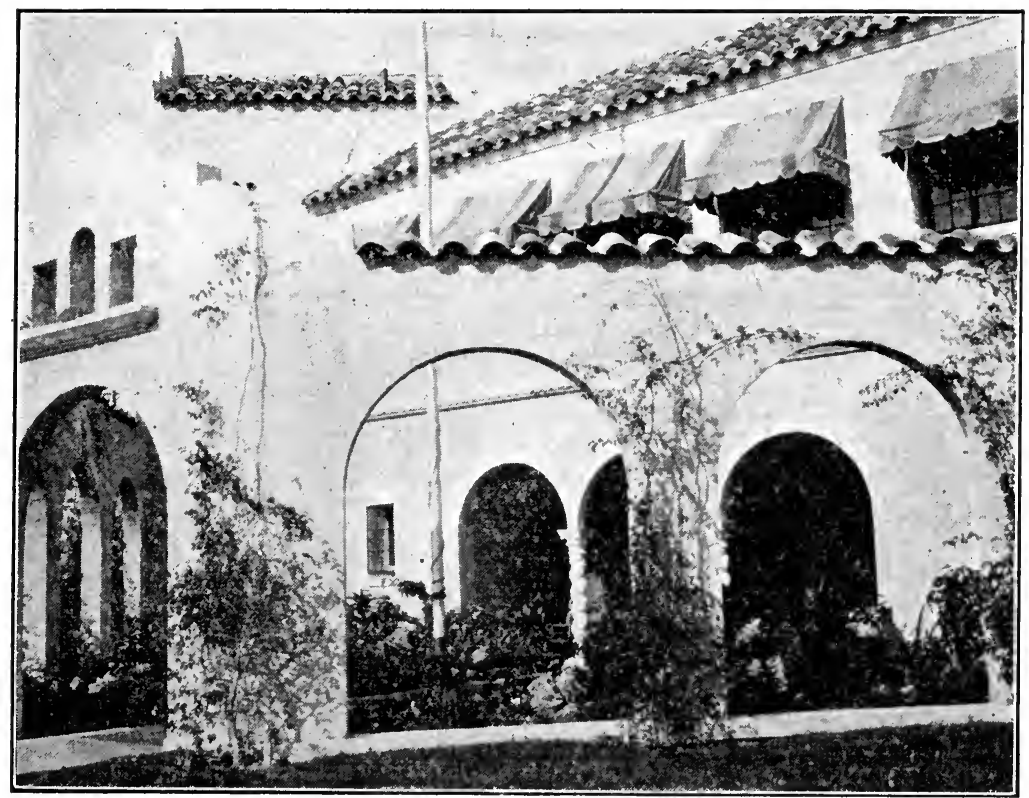

Fig. 128.-Fire-engine house, Miami, Fla. The opportunity to make public buildings a credit to the community is not always so nicely realized as in the case of this fire-engine house. (Photograph by the Author.)

place and have ample open spaces around it. Places of worship, singly or in a group, should be so placed as to serve as terminal features to the view along approaching streets and should be so designed as to provide a feature of beauty for the surrounding district.

No public building should be built in such a location that its activities could interfere with the use of any other public building. For instance, a fire-engine house should not be situated near a library, a schoolhouse, or a museum. 
Institutional Groups of Various Kinds.-Of great importance are institutional groups in a city. Colleges and universities protect us from illiteracy; hospitals from disease; criminal courts and jails from crime, misery, and various other forms of unhappiness. These institutional groups many, in number and possibilities, come before us in a great panorama of schools, colleges, universities, homes, asylums, hospitals, jails, and other correctional institutions.

The location of institutional buildings depends upon their necessity for pleasant surroundings and access to the population served, as well as upon the allowance of sufficient surrounding area for future extensions. The location must be chosen so as to interfere as little as possible with lanes of traffic, areas for parks, and the general growth of the community. For many types of institutions, that property which lies open to the sunlight, is bathed with an abundance of fresh air, free from noise and dirt coming from factories, switching yards, and other sources, and that helps to display the buildings to the best advantage ought to be chosen as the best location.

The Hospital and the City Plan.-Among the service-giving institutional groups of the city, the hospital is the most important. Two years ago, statistics showed that there were 6,893 hospitals in the United States-4,041 general hospitals, 589 for nervous and mental disorders, 466 for tuberculosis, and 1,797 for the treatment of miscellaneous ailments. New hospitals are constantly being built. Although all of these may be located within the limits of the city, the general hospital, at least, should be there, so as to be accessible to the population at large, to visitors, out-patients, and physicians. Where large areas are not available for them within the city, all other hospitals can be located in the suburbs. In general, perhaps, hospitals are moved to the suburbs to save money and for the sake of prettier surroundings, but for the actual convenience of the people it would be better if they were in the closely inhabited areas provided they had the necessary open spaces around them.

The size of the hospital's grounds depends upon the scope of the institution, the size of the city, and the character of the surrounding country. Important institutions for their proper setting require from 10 to 100 acres. Sites for hospitals need to have agreeable surroundings, to provide plenty of light and air, and opportunity for the proper orientation of the buildings and 
for possible expansions of the institution. They should offer as little interference as possible with the growing residential districts. An adjacent square or plaza may offer a foreground or entrance that will adapt itself to a striking civic vista of the buildings. Since they require much sun, quiet, and as little congestion as possible for their highest usefulness, hospitals as a rule should be placed in residence districts of high class. Despite the hardship on the neighborhood of numerous parked cars, deliveries of food, taking away of waste, and the depressing influence of a hospital, nevertheless such an institution must be located where conditions contribute to its maximum serviceableness. Proper consideration should be given by the city planner to the availability of sewers, water, gas, and electricity and to any possible need for the extension of a thoroughfare that might eventually have to penetrate the grounds and ruin their effectiveness.

Hospitals for the insane for many years were built as a vast building from which radiated long galleries and which resembled jails. Since 1880 accommodations for the insane have improved, and now one finds these hospitals well designed in institutional groups, with separate buildings, fitting the different kinds and conditions of cases and set amidst beautiful grounds. In some hospitals the dormitories are similar to ordinary dwelling houses or cottages, varying in size to accommodate from 6 to 20 or more patients each. Sometimes these dormitories are built in groups in connection with some kind of industry and are arranged as a village, having streets. In such hospitals the acute cases are confined in special cottages somewhere in the vicinity. So that while the insane in former times were "tolerated, tormented, laughed at, and even executed as criminals," today the institutional group that accommodates them is meant to effect cures by occupational, educational, and medical means.

A site that permits some isolation for the development of the hospital is to be preferred to the type that subjects its activities to the almost perpetual public inspection of people passing along the streets.

Penal and Correctional Institutions.-Our penal system in the United States is said to vary between the most advanced and the most backward in the civilized world, so that we have the very greatest variety in the buildings and groups of buildings to which the offenders against our criminal laws are committed. A 
prison is a place of confinement or involuntary restraint for the safe custody of criminals and others committed to it by due process of law. The prisons for the detention of persons accused of crime are known as "jails," while the prisons for those convicted and sentenced are called "penitentiaries," "workhouses," "houses of correction," and "reformatories." Although jails are usually built in close conjunction with our city halls, sometimes on the top floors of the newer ones there are county jails, like the new one for Cook County, Ill., occupying several acres of land and having a capacity to house 1,500 prisoners. In Utah a new prison is being built which combines a walled prison with one without walls.

For many of those convicts capable of learning a trade or of receiving an education, reformatories and correctional institutions are provided. A correctional institution for women at Alderson, W. Va., provides for the inmates two campuses at different levels. It is built along the lines of a cottage institution, with a reception cottage, two decreased-privilege buildings, a cottage for drug addicts, an industrial building with well-lighted schoolrooms and workrooms, a power-serving plant, a laundry, and also a farm and dairy conducted by the farmer, who is a woman. This institution is two miles distant from the nearest town and its grounds are surrounded by a mesh-wire fence more to bar intrusion from the outside than to prevent the escape of the prisoners.

Educational Groups and the City Plan.-Nothing gives larger returns on the investment than the money spent upon educational groups. Not only are ádequate facilities made possible for life training, body building, and the pursuit of high ideals, but the beautiful group of buildings itself, built amid parklike surroundings, is a constant source of enjoyment to the community at large.

If the educational institution is meant to serve a population largely within the city, the matter of its location with respect to the population it is to benefit is of great moment. Educational institutions that provide dormitories for the students may, however, be located anywhere amidst suitable surroundings. The amount of property required depends upon the extent to which it is expected to develop the institution. Considerable variation is to be found in the size of university grounds; for example, the University of Illinois has 305 acres in campus; Alabama, 40; Kentucky, 65; Delaware, 88; Indiana, 138; Massachusetts Institute of Technology, 80; Idaho, 40; Michigan State, 


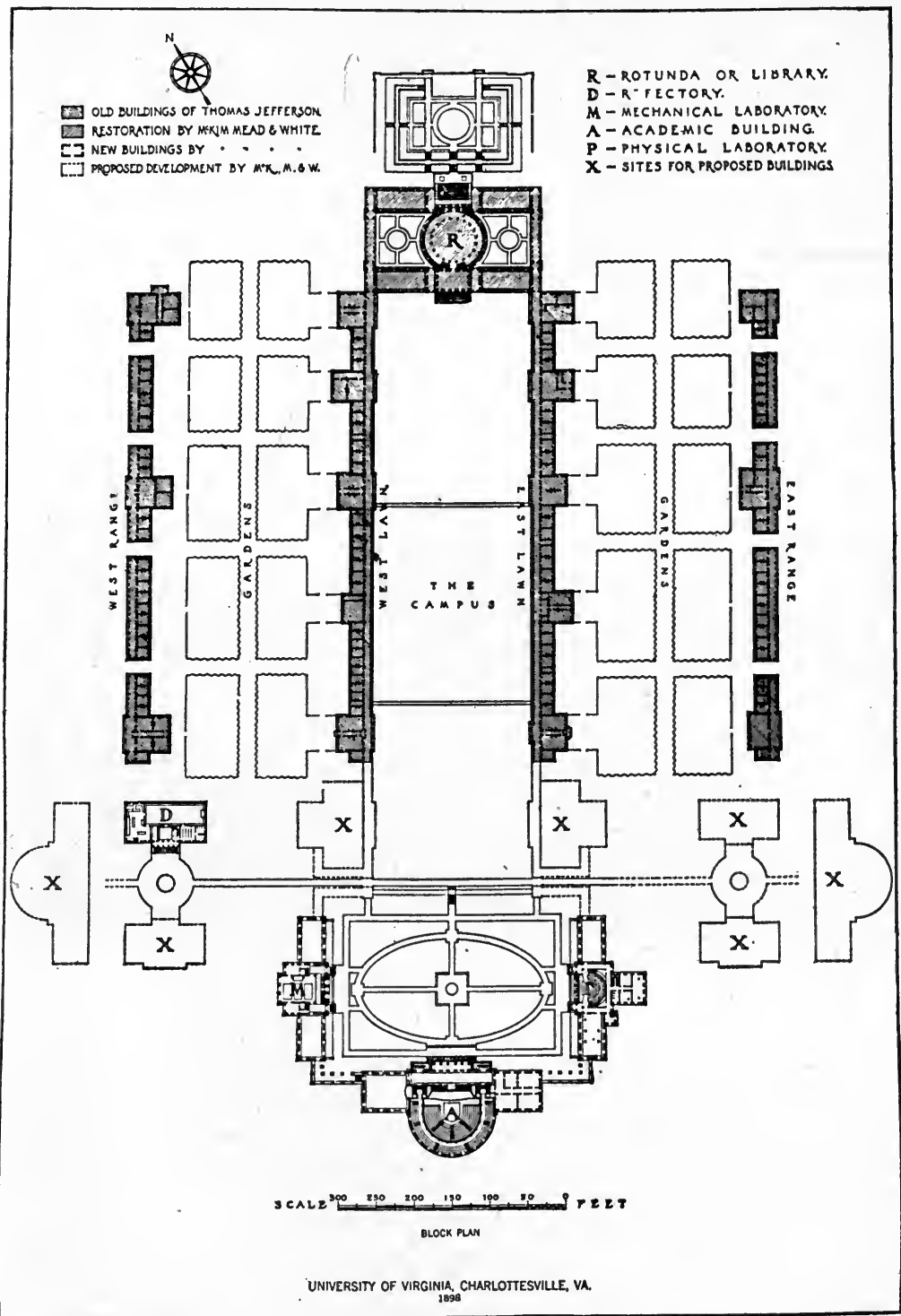

FIG. 129.-Plan of the University of Virginia. One of the most interesting institutional developments in the United States is the University of Virginia. Original scheme by Thomas Jefferson, later proposals by McKim, Mead, and White. (From monograph of the works of McKim, Mead, and White.) 
103; North Carolina, 30; Rutgers (downtown campus), 40. For a fair-sized university there should be not less than 75 acres. Appropriate surroundings are highly important. An educational group should be located away from noisome railroads or industries. In the case of a large university, however, a spur from a railroad may be used to good, economic advantage, for carrying coal and other freight into the grounds of the university. A desirable residential section, a park, or a plat of land whose topography is of distinct natural beauty adapts itself to the

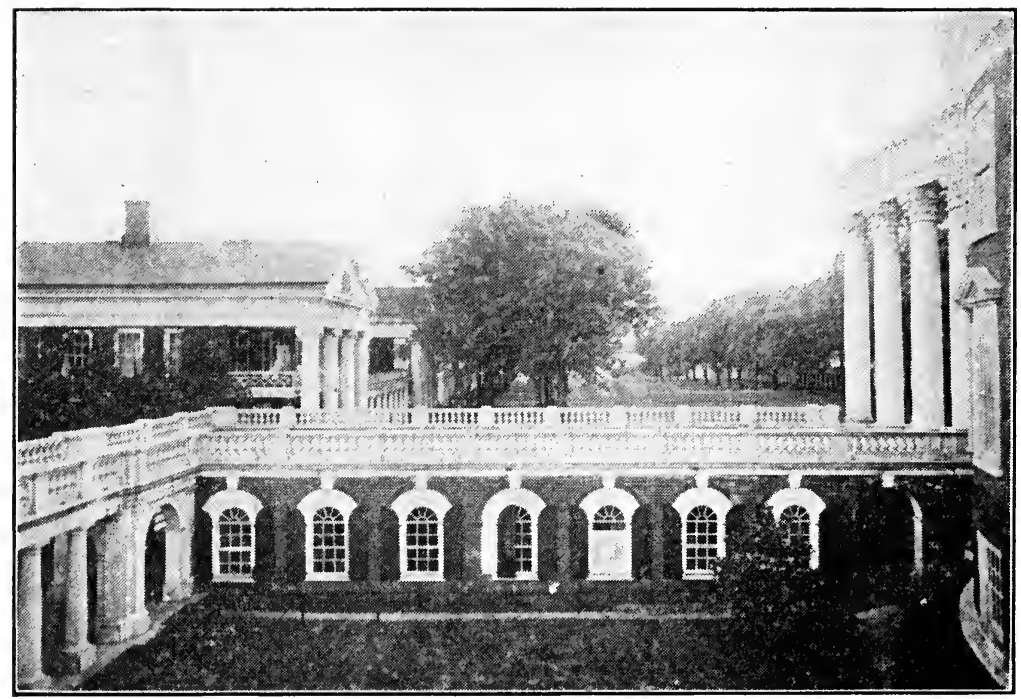

FIG. 130.- University of Virginia. View to northeast into the campus. (Photograph by Holsinger.)

development of educational buildings. There must be sufficient level space for the grouping of the buildings, for athletic fields, and for the parking of automobiles and also other ground, preferably hilly, upon which can be designed secluded, parklike places.

The University of Virginia (Figs. 129, 130), Rice Institute at Houston, Tex., and Leland Stanford University at Palo Alto, Calif., all have groups of educational buildings that attract attention. The University of Virginia was designed by Thomas Jefferson and is conspicuously impressive. It gives the pleasing and harmonious effect of an enclosed forum. A rotunda (the library) looks across the quadrangle from the north. The teachers' residences on the east and west sides are connected by 
colonnades. Directly in back of these are gardens, and beyond them an outer frame of buildings that parallel the main campus and are known as the "ranges." Rice Institute gives promise of becoming one of the attractive college campus developments. Its balanced plan of several courts and Byzantine detail are to be credited to Cram, Goodhue, and Ferguson. The design of Leland Stanford came from a study of the mission architecture and a blending of this with a vision of the Moorish and the Romanesque. The original plan by Charles Allerton Coolidge provided for three groups of quadrangles. The inner one consists of long, low buildings, wide colonnades, and an open court of the old mission inspiration but on an imposing scale. The buildings are connected by a continuous open arcade facing the court. A large stone church commands this inner quadrangle and is seen for some distance upon the approach to the University group. The "yard" at Harvard is an interesting and beautiful example of an earlier work. The newer dormitories at Yale and Princeton and the additions to the buildings at the University of North Carolina and at the University of Illinois all indicate an awakened interest among our people in the importance of groups of educational buildings that are architecturally beautiful.

Representative of a brand-new turn in college architecture is the skyscraper cathedral of learning at the University of Pittsburgh. There are undoubtedly advantages that may be credited to such a new departure as this. It may prove to be a tower of convenience and comfort, provided changes in classes can be accommodated without confusion and without too much reliance upon flights of steps. Such a university structure should possess something of inspirational quality associated actually as well as spiritually with the heights. It may well be a magnificent picture, particularly if it is surrounded by adequate open space. It remains to be seen if the tower-like creation will in some way compensate for the physical exercise and fresh air that are derived in going to and from classes in the horizontal types of universities. It remains to be seen if there can be the same kind and amount of mingling and between-class discussions that are frequently so pleasant and valuable to students. It remains also to be seen whether or not it is a vital architectural sacrifice of the opportunity for individual expression of different departmental buildings by massing all into one individual structure. 


\section{INSTITUTIONAL BUILDINGS}

Grouping.-The grouping of institutional buildings, as distinguished from their haphazard scattering throughout the city, involves a composition of the units by the city planner that provides for open space in and around the group of buildings to give them plenty of light and circulation of air; all of the buildings for harmony of effect should be built of one style of architecture; the site chosen should be easily accessible to the people and ought to be on an eminence sufficient to afford an outlook over the city and the surrounding country.

Functions and Kinds.-Among so many possible types of institutions, there is considerable variation as to the style of architecture that will best suit the buildings that compose any particular institutional group. And yet there is bound to be some similarity, schematically at least, because of the necessary quarters common to all-administration buildings, for example, or dormitories and dining halls. Buildings for service, such as power houses, kitchens, and laundries, occur in nearly all institutional groups. The dormitories may, however, take different forms in different institutions and may be either arranged in large halls or in separate cottages, providing accommodation for the students, patients, or inmates, as the case may be; the dining rooms also may be provided either in large halls or in separate cottages.

Depending upon the kind of institution to be designed, there may be buildings for class rooms and laboratories, hospitals, infirmaries, cell blocks, isolation wards, gymnàsiums, chapels, auditoriums, libraries, and museums. Many of these various requirements often have to be provided in one structure, at the beginning of the life of an institution. Vision and foresight are requisite to be exercised by the planner when one building must serve so many diverse uses, to anticipate what buildings will be needed in the future to house separately all of these necessary activities; and sites for all of the buildings that the future may demand must be marked upon the institutional plan.

Arrangement for Convenience.-To lessen the distances between the buildings in an institutional group of buildings reduces in large measure the steps. that the officers and servants must take and thus conserves their energy and saves their time, 
thus facilitating the business and other activities that are necessary to make of the institution a practical machine. There are two ways of lessening distance: One is by selecting the site of the buildings either within the city or upon adjacent territory; and the other is by setting the buildings of the group near to each other. In case the site has a considerable acreage, the buildings may be placed either near to or far from the entrance, depending upon the nature of the institution and the topographical conditions at the entrance. It is desirable for jails of every kind, and for hospitals for the insane, to be isolated and to have the buildings placed in a position upon the grounds remote from the entrance.

A compact arrangement or concentration of the buildings housing any kind of institution is economically desirable, architecturally effective, easy of supervision, and renders every department of the institution convenient of access from all of the other departments. Such concentration of the buildings is subject, however, to the disadvantage of affording less light and air than can be provided in plans in which the buildings are erected at a distance from one another. When the buildings of an institution are set at a distance from one another, the hazard from fire is reduced, and any concentration of the buildings also concentrates the noise attendant upon the activities of the institution. A reasonably extended grouping of the buildings is therefore desirable, although the matter ought to be determined in accordance with the nature and purposes of the institution which is planned. Where there are separate structures housing the institution, the buildings serving similar functions should be placed together, as in the case of civic centers. In civic centers, the city hall and its city departments, the museums, schools, and libraries all should be erected in one group. In institutions, the dormitories and union buildings, the engineering buildings and power houses ought to form one group. Buildings to adjoin certain outdoor spaces that particularly serve them should by their proximity and position express that relation; for example, gymnasiums should be built adjacent to recreational spaces or athletic fields. One of the most important buildings of all institutions is the administration building, which should be so located as to be convenient of approach from every direction.

Consideration of Existing Conditions in Layout of Institutions.-Familiarity with the site selected and knowledge 
of the advantages that will result therefrom are essential. The lead of the topography of the site must be followed by the designer in his plans, for the reason that he will thus attain a more economical result, avoid much cost in grading, and at the same time secure a group of buildings much more attractive in appearance. Buildings existing upon the chosen site must always be considered by the planner, although some of these may be so bad that they will have to be removed. There may be some existing buildings that, regardless of their condition, will have to remain in place for sentimental reasons, and there are at some institutions certain buildings, treasures of architecture, that ought to be preserved and embodied in the new scheme of development that is to be designed. Important streets must be considered by the city planner in connection with designing groups of buildings. It often happens that one of these streets will determine the grouping of the buildings as well as the situation of the main entrance to the grounds.

Finally, great care should be exercised by the designer to preserve all natural features of beauty afforded by the site in question and all features that have possibilities for beauty. By shifting the location of a building or of a road in his plan, the designer may save a magnificent tree; by retaining boulders and ledges of rock, he may convert them into objects of beauty. Ponds, lakes, streams, and ravines, each with its peculiar beauty, become great sources of pleasure to the observer and ought, therefore, to be carefully protected from injury or destruction.

Grouping for Beauty.-The arrangement of buildings should be undertaken with a due consideration to their appearance and with the idea of securing a maximum of attractiveness. Satisfying all of the demands of convenience and of the site must be attempted, and, in addition to that, the architectural style of the buildings must receive equal attention. In constructing pictures, the elevations of the buildings must always be considered by the designer in making his plans; he should strive for mass effects, subordinating the subsidiary to the dominant architectural features. He should make of his grounds and buildings a harmonious and balanced picture and then set that picture in a frame. All of these things he may accomplish by a proper distribution of the buildings.

But pleasing pictures cannot be made by the artist designing institutions without the aid of open spaces and proper surround- 
ings for his buildings (Figs. 131, 132, 133). Public and semipublic buildings are sometimes grouped in rows facing streets. This grouping is objectionable, except where the street is flanked by a broad plaza. When important buildings face directly upon an average thoroughfare, the effect of their scale and their apparent importance in relation to their surroundings are destroyed, while the narrowness of the street makes a full appreciation of the buildings impossible because there is no place from which they can be viewed in perspective. It is more effective to have the buildings facing a park or to have them grouped within or around a parklike area. Open spaces from which they can be observed determine how buildings appear, how much sunlight they shall have, and what outlooks there shall be.

These open spaces surrounding the buildings of institutions take a variety of forms; when irregular they must be so solved as to bring out in best relief the buildings that face upon that particular irregular tract (occult or picturesque balance). Most of these open spaces are, however, squares, rectangles, or semicircles, and the designer can create a symmetrical balance between such tracts and the structures facing upon them (Fig. 134, 135). Again, these open spaces may be used for special requirements, such as for parade grounds, band concerts, or commencement exercises, dependent upon the kind of institution that they serve.

Organization of Roads and Paths.-Convenience of circulation for people and traffic upon the grounds and between the buildings of institutions brings up the question of roads and paths. The point or points at which roads and paths penetrate the grounds is not so important upon a large property as it is upon a concentrated development in a restricted area. As it is desirable to emphasize one main entrance, regardless of the number of others, this main entrance should become the main axial line upon which the entire scheme of the grounds is balanced (Fig. 136). The road and path at the entrance should be located by the designer in the direction of the approach of traffic and should be adorned by architectural features that are in keeping both in style and in scale with the architecture of the buildings of the institution. The development of the roads will depend upon the manner in which the buildings are to be arranged. In the case of a quadrangular plan, the drive-should lead to the administration section 


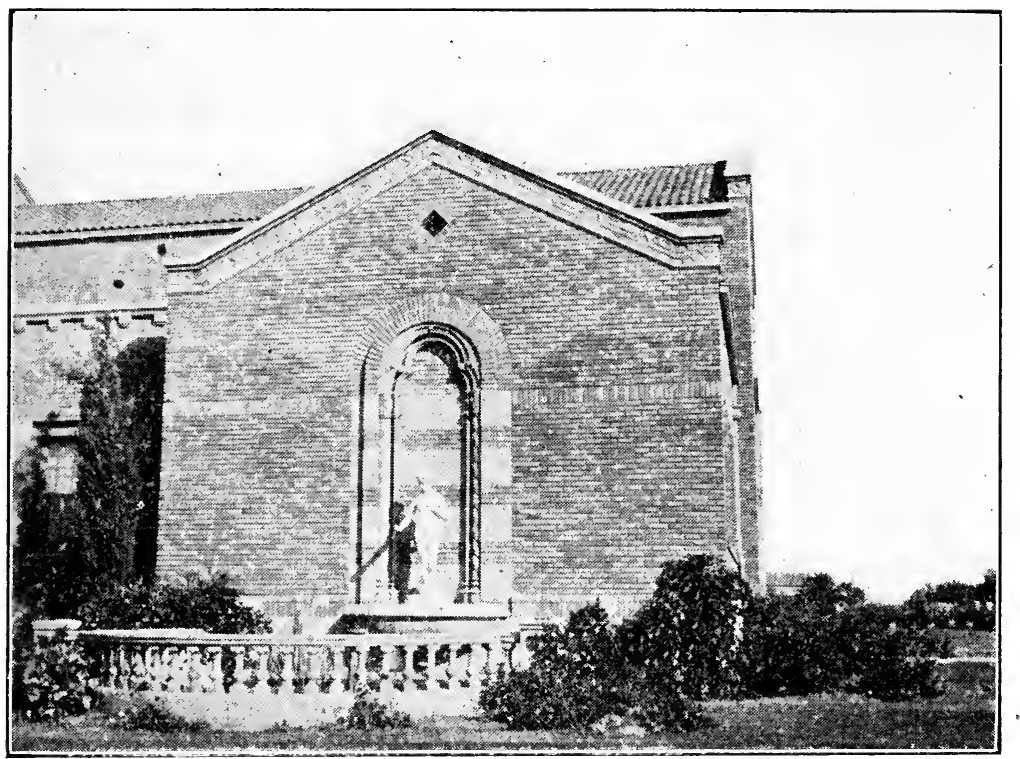

FIg. 131.-Use of sculpture at high school of Venice, Calif. The writer knows of no other school that has given the same successful thought and care to the development of its setting and especially to the use of sculpture in its scheme of improvement. (Photograph by the author.)

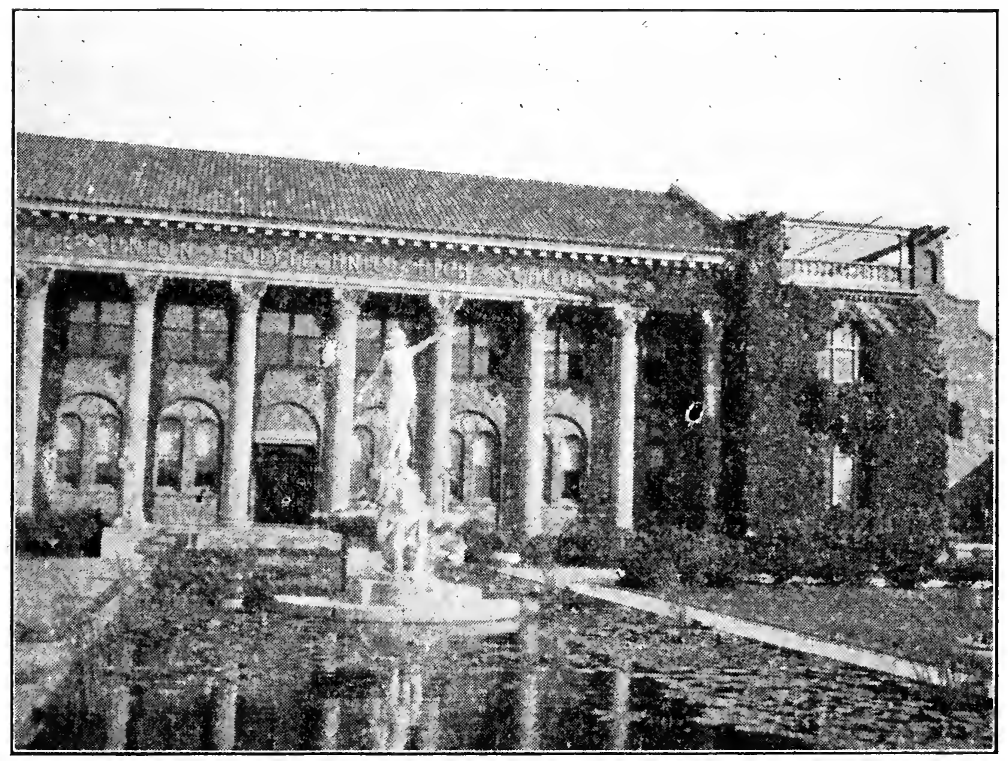

FIG. 132.-A view of another portion of high-school facade, Venice, Calif. (Photograph by the author.) 


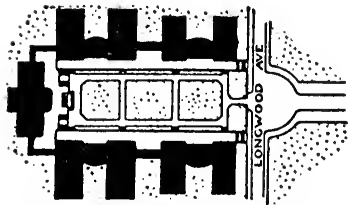

HARVARD MEDICAL SCHOOL
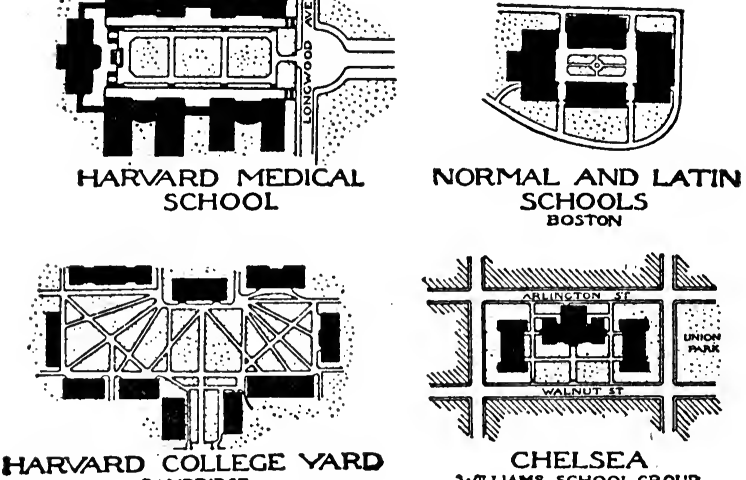

CHELSEA

WTUAMS SCHOOL GROUP

FIG. 134.-The variety of possibilities in building arrangement as suggested by four plans of educational institutions. (From Report to Metropolitan Improvements Commission, 1909, by A. A. Shurcliff.)

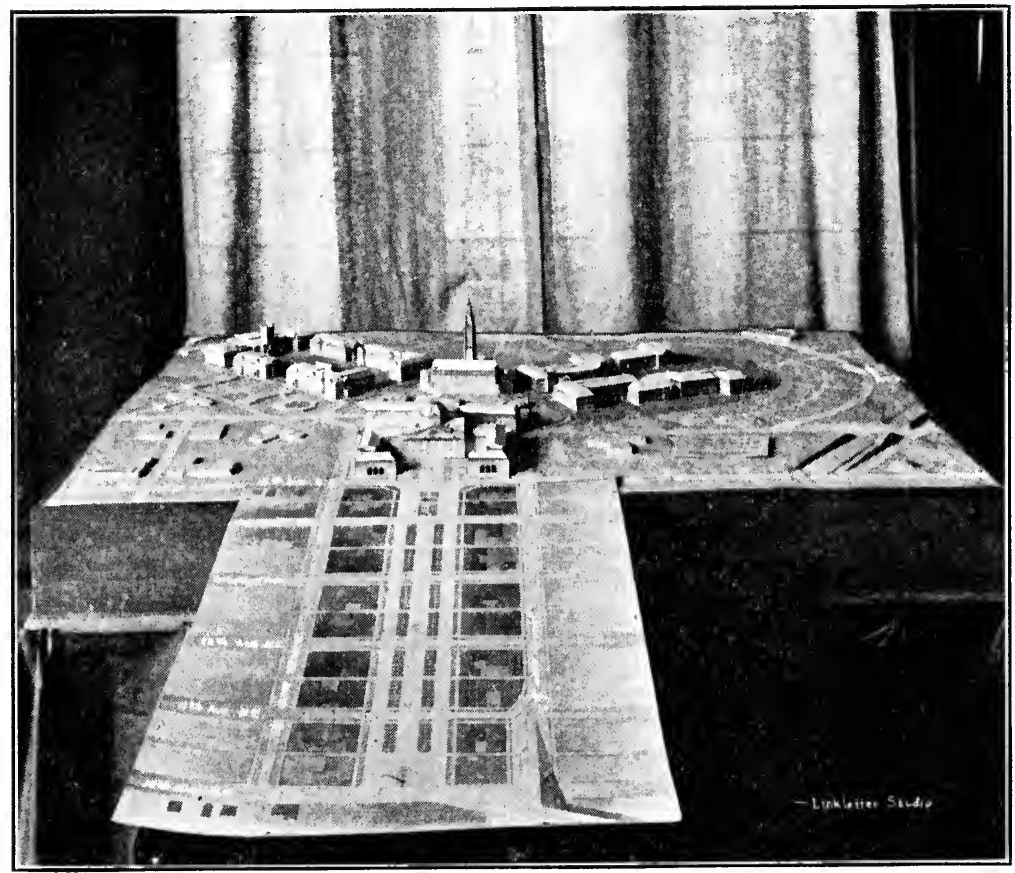

FIG. 135.-A model of the campus plan of the University of Washington, Seattle. 
but should pass behind the buildings, thus keeping the drive out of the quadrangle, so as to preserve for the quadrangle seclusion and quiet. In an extended arrangement of the buildings, each structure requires its own main service road. Care,

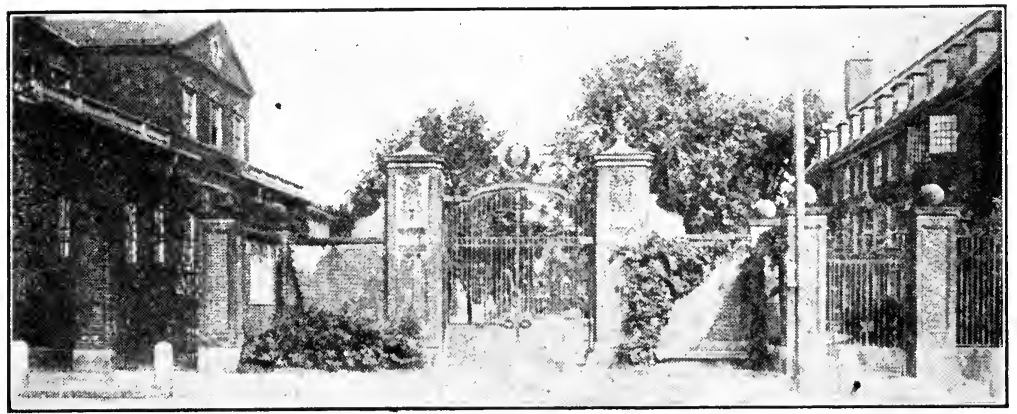

FIg. 136.-One of the entrance gates at Harvard. Some of the building groups of a city require complete enclosure. The gates should be in keeping with the character of the architecture and expressive of the important service that they perform.

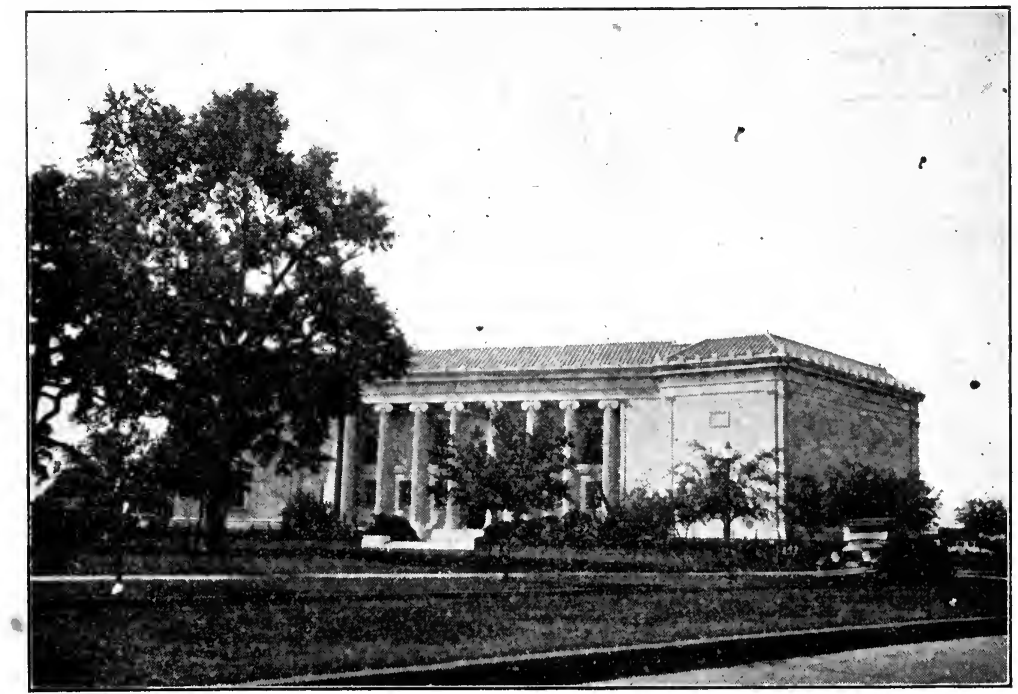

FIg. 137.-The Art Museum, Houston, Tex. (Photograph by the author.)

however, must be taken not to encircle any building completely with a drive.

Paths are very important features in connection with institutional grounds and should be made to serve the convenience 
of pedestrians. The persistent cutting across lawns by pedestrians, where there are no paths, shows that walks should be placed there.

Pictorial Effects through Planting.-Buildings and open spaces, roads and paths should all be supplemented by planting of trees and shrubbery. The planting should be done with the same good taste, moderation, and sincerity that mark the architecture of the buildings of the institution (Fig. 137). Overhanging trees to the side and to the rear of buildings beautify the resulting landscape. Upon no occasion should a continuous foundation of shrubs encircle a building. In fact, few shrubs should ever be used, excepting for some definite purpose, such as to create a compositional effect particularly desired. More and more should be stressed the value of vines upon the buildings if the use of them is governed by restraint.

The larger unbroken open spaces around which the buildings are grouped should be outlined by trees. The entire establishment may to advantage be enclosed by a fence or wall, supplemented by trees and shrubbery. The stretches of green lawn should not be defaced by placing upon them dazzling, circular flower beds. Other positions much better than a lawn may be found for bedding plants. Such plants as petunias and geraniums should not be mingled with shrubbery, although there is no objection to the use of old-fashioned perennials set in masses against a group of shrubs. There should appear a succession of pictures to the person who is passing over the grounds of the institution. Each of these pictures should be a complete composition in itself, made beautiful by masses of foliage, and each picture should be related harmoniously to those adjacent to it.

\section{Questions for Discussion}

1. How are public buildings and groups of buildings important in the life of a city?

2. What are the requirements of sites for public buildings standing alone?

3. Describe some of the plazas of Europe and point out a few of the underlying principles of design.

4. Discuss the requirements of location and design for a civic center and describe some outstanding examples of civic centers in the United States.

5. Discuss the relation of the following building groups to the planning of the city: hospitals; penal and correctional institutions; educational groups.

6. What are the possibilities for more attractive business centers?

7. How must convenience and beauty be considered and served in the drranging of buildings in groups? 
8. What thought must be given to the roads, paths, and planting about public buildings and building groups?

\section{References}

Abercrombie, P.: The University in Relation to the Planning of the City, Papers and discussions of the Town Planning Institute, vol. 9, pp. 3350, with discussion, pp. 51-54, illus., plans, London, 1922-1923.

Brunner, A. W.: The Civic Center, National Municipal Review, vol. 12, pp. 16-19, January, 1923.

Curtis, H. C.: Elements and Rules of Composition. Building Arrangements, "Architectural Composition," parts 3, 6, 7, J. H. Jansen, Cleveland, 1926.

Engelhardt, N. L., and F. Enghlhardt: "Planning School Building Programs," Columbia University Press, 574 pp., illus., 1930.

Githens, A. M.: The Group Plan, Brickbuilder, vol. 15, pp. 134-138, 179182, illus., plans, July, September, 1906.

Hegemann, Werner, and Elbert Peets: Plaza and Court Design in

Europe. The Grouping of Buildings in America, "The American Vitruvius," pp. 37-98, 99-150, New York, 1922.

Klauder, Charles Z., and Herbert C. Wise: "College Architecture in America and Its Part in the Development of the Campus," 301 pp., illus., Charles Scribner's Sons, New York, 1929.

Mawson, T.: Civic Centers, "Civic Art," B. T. Batsford London, 1911, pp. $97-124$.

Robinson, C. M.: Architecture in the Business District, "Modern Civic Art," pp. 123-137, G. P. Putnam's Sons, New York, 1909.

SaArinen, E.: Architecture and City Planning, City Planning, vol. 1, pp. 143-155, illus., plans, October, 1925.

The Public-building Group Designs of 54 Cities, Municipal Index, American City Magazine Corporation, pp. 159-175, 1930.

Tilton, L. D., and T. E. O'Donnell: "The Illinois Campus Plan," 245 pp., illus., University of Illinois Press, Chicago, 1930.

Unwis, R.: Of Buildings, and How Each Must Be Dominated by the Harmony of the Whole. Centers and Enclosed Spaces, pp. 360-374, 175-233, "Town Planning in Practice," T. F. Unwin, London, 1909, etc. 


\section{CHAPTER XIX}

\section{THE BEAUTIFUL IN THE CITY PLAN}

\section{(COMBATTING THE SOURCES OF UGLINESS)}

While successful attention to practical needs in the layout of a city may fill us with keen satisfaction, never can it inspire in us the same hearty, soul-stirring enthusiasm that is enkindled by a conformance to both the esthetic and the practical urban needs. In the truly beautiful city there is not only an implied high regard for utilitarian necessities but that attention to esthetic requirements of fitness, proportion, symmetry, and order that produces a reciprocal association among the elements composing the city and an effect of charm, dignity, even magnificence. Taken together the aggregate of beautiful effects thus to be enjoyed symbolizes in a fitting manner the finer aspects and aspirations of the community life.

Such a picture might seem to take us beyond the reach of civic purse strings, and yet by the importance increasingly attached by people to the element of beauty in the ordinary things of life, by their willingness to pay for appearance in automobiles, washers, and furniture, they are betraying an esthetic interest that forecasts a demand for the same liberal expression of beauty and attractiveness in the fabric of their city.

Beauty, after all, is in a large measure identical with utility; in the words of Frederick Law Olmsted, Jr.: "They [beauty and utility] differ merely in demanding closer approach to practical perfection in the adaptation of means to ends than is required to meet the merely economic standard." There was a prevalent notion not long ago that civic beauty was external and attached rather than something incorporate. This misconception combined with the appearance of plans that in some instances were suitable neither to civic needs nor to the purses of the communities concerned brought about a certain degree of discredit for civic beauty that luckily in the course of time has largely disappeared. 
Today we no longer think of attractiveness in the community as a luxury but rather as a need and an asset. The results of it are measured not only in increased business and property values but in the added loyalty and happiness of the people. This being so, no city can afford to neglect steps that lead to the achievement of beauty. How, then, and in what ways may we add to the comeliness of a community? The accomplishment of it will depend upon creative, preventive, and destructive effort; creative in the sense of building up and enriching the city plan pictorially;

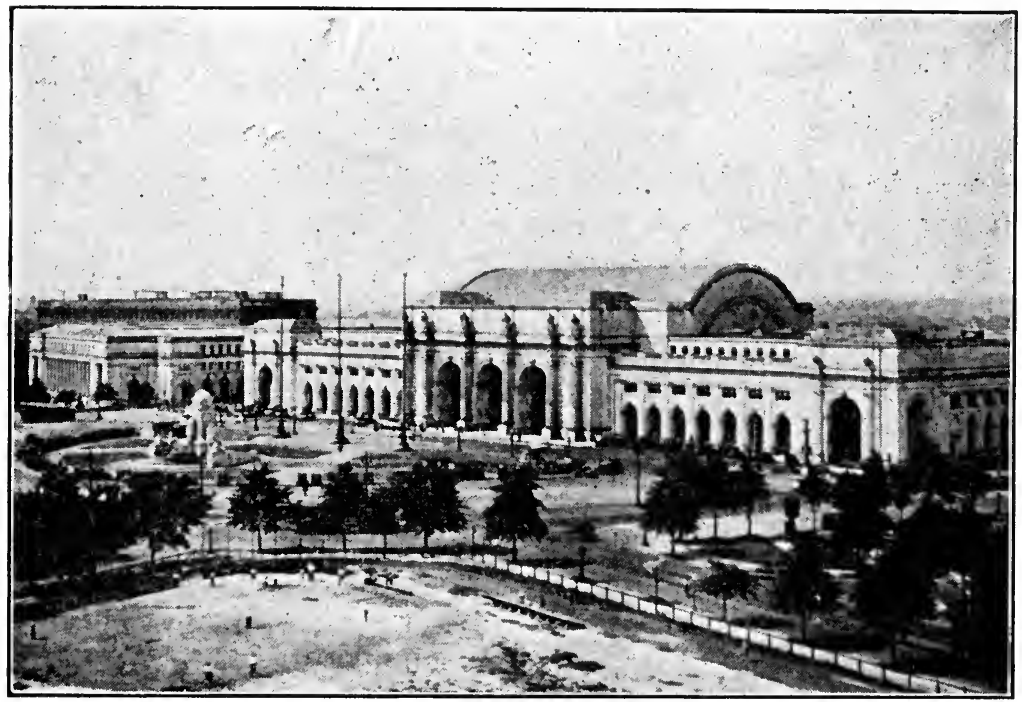

FIG. 138.-The plaza and Union Station, Washington, D. C.

preventive by way of regulation and control; destructive through the removal of blemishes that are unbecoming to the civic countenance.

Building Up the City Pictorially.-There is scarcely a physical detail in the layout of the city that does not lend itself to some expression of beauty, unless we except, of course, features that are hidden from view. There are some portions, however, that seem to offer themselves particularly to artistic execution because they occupy rather conspicuous places in the municipal layout. Entrances and approaches to the city by water, rail, highway, or air contribute to lasting impressions-and should accordingly be made to measure up to high artistic standards. This applies also to the various transportation terminals and their plazas 
(Fig. 138). Bridges may accommodate themselves to interesting and fine architectural and sculptural enrichment and serve, too, as suitable approaches to the city (Fig. 139).

The streets are not merely matters of utility but may be thought of also in terms of art. Each part, pavement, sidewalk, green space, and tree must be well proportioned to the one next to it and to the whole picture, including such adjacent features as widths of front yards and heights of buildings. One of the elements of the street-the tree-contributes most conspicuously

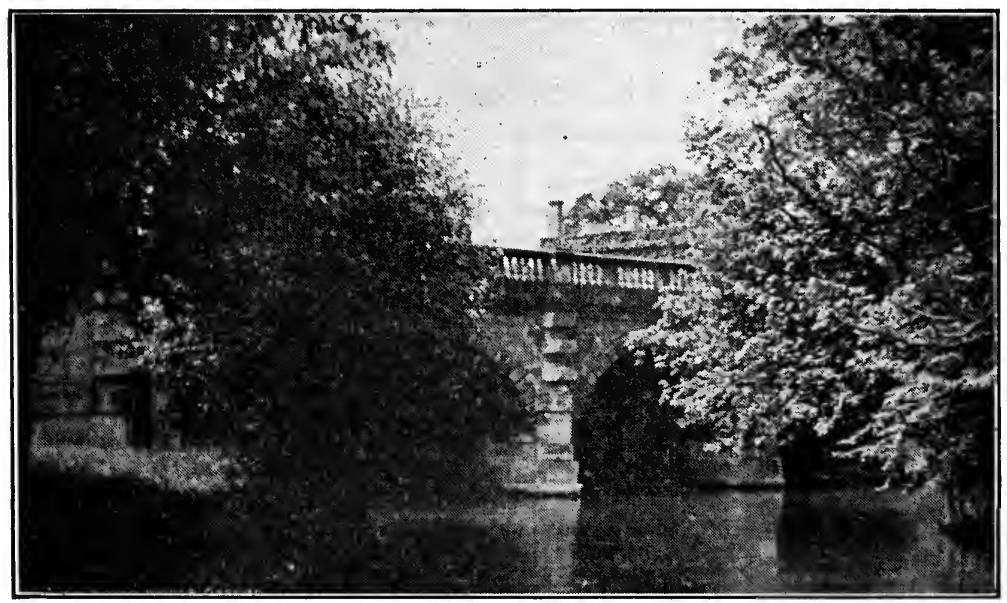

FIG. 139.-Magdalen Bridge at Oxford, England.

to beauty of effect by its stateliness, symmetry of growth, ample foliage, its light and shadow, and the arched views that it may enframe. Although the value of it is universally granted in connection with residential neighborhoods, it should be regarded as of no less importance in areas downtown. Every effort should be made in our store districts to preserve trees or to introduce them because of the increased comfort and beauty that they give. The importance of artificial light as a source of civic beauty is not so thoroughly realized as it might be. Illumination at night helps to give a fairyland aspect not only to certain parts of the city but to the city as a whole. Indeed, there is considerable magic in civic illumination. How beautiful are the trees with the lights showing through them, the facades of buildings in their silver glow, the luminous curves of the seaside or the riverside, or the glimmering lights of a metropolis viewed from a 


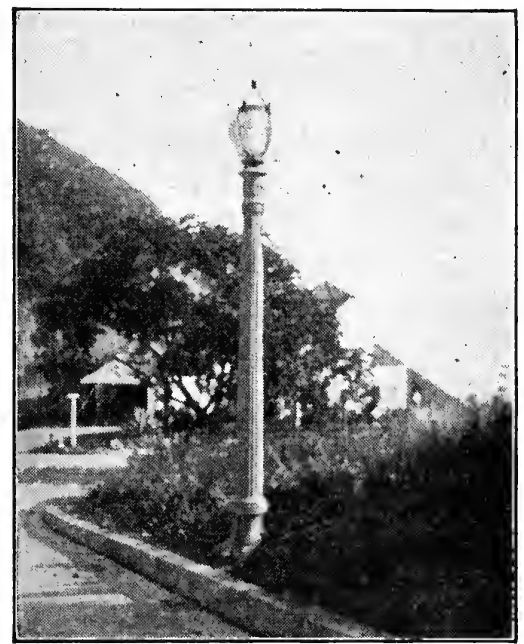

FIG. 140.-Lamp post in Los Angeles. (Photograph by the author.)

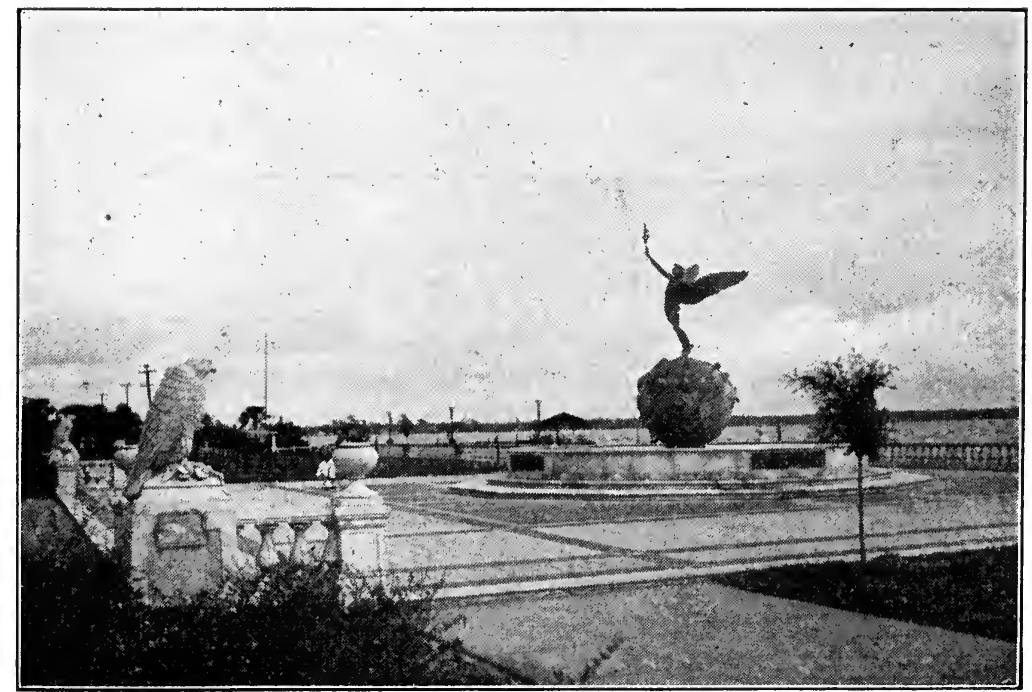

FIg. 141.-Wilson Park, Jacksonville, Fla. (Woodward, photographer.) 
high elevation. Each light standard that plays its part in this luminous effect at night should by its chaste and simple design take its place also in the picture by day (Fig. 140).

Then, too, there are the focal points of a city that contribute conspicuously to its beauty. These may be street intersections or other open spaces around which important structures may be assembled and within which civic sculpture and fountains may be placed. While the groups of public structures present various possibilities for dignity and impressiveness, they reach their crowning glory, perhaps, when they interpret the spirit and beauty of the city in an appropriate civic center. Street intersections and other similar types of open spaces offer excellent positions for fountains and sculpture. Most of our cities have too little sculpture of any kind, let alone good sculpture. Statuary should be symbolic of "the poetic, the romantic, the dramatic, or the decorative" and should if possible be located near salient civic elements that are reminiscent of the subjects portrayed. Each sculptural piece should be introduced with a full regard for scale and for setting and should be related to the important civic member near which it happens to be placed (Fig. 141). While the poetic transcriptions have frequently been confined to the more retired locations or to the parks and the warrior and political monuments have been assigned the more prominent civic positions, this need not be so. The whole matter of staging statuary, monuments, or fountains should be undertaken only in the fullest degree of collaboration of sculptor, architect, landscape architect, and any other artistic or practical mind necessary to the most completely well-considered result (Fig. 142).

Focal spaces in the city may also be used for fountains. These, like statues, are diversified in their character and must be located and designed with equal regard for site and environment. Parks and playgrounds are certainly conspicuous elements of beauty in the city plan and should be regarded as works of art.

The City Plan as an Essential to the Achievement of Beauty.The vision of civic physical possibilities can best be represented and focalized through the means of a city plan. Dr. John Nolen insists that there can be no such thing as a beautiful city without an urban plan conceived and executed not only so as to serve all the practical requirements of a city, but also to provide abundant opportunities for the proper expression of the beautlful. The city plan, according to Dr. Nolen, provides 


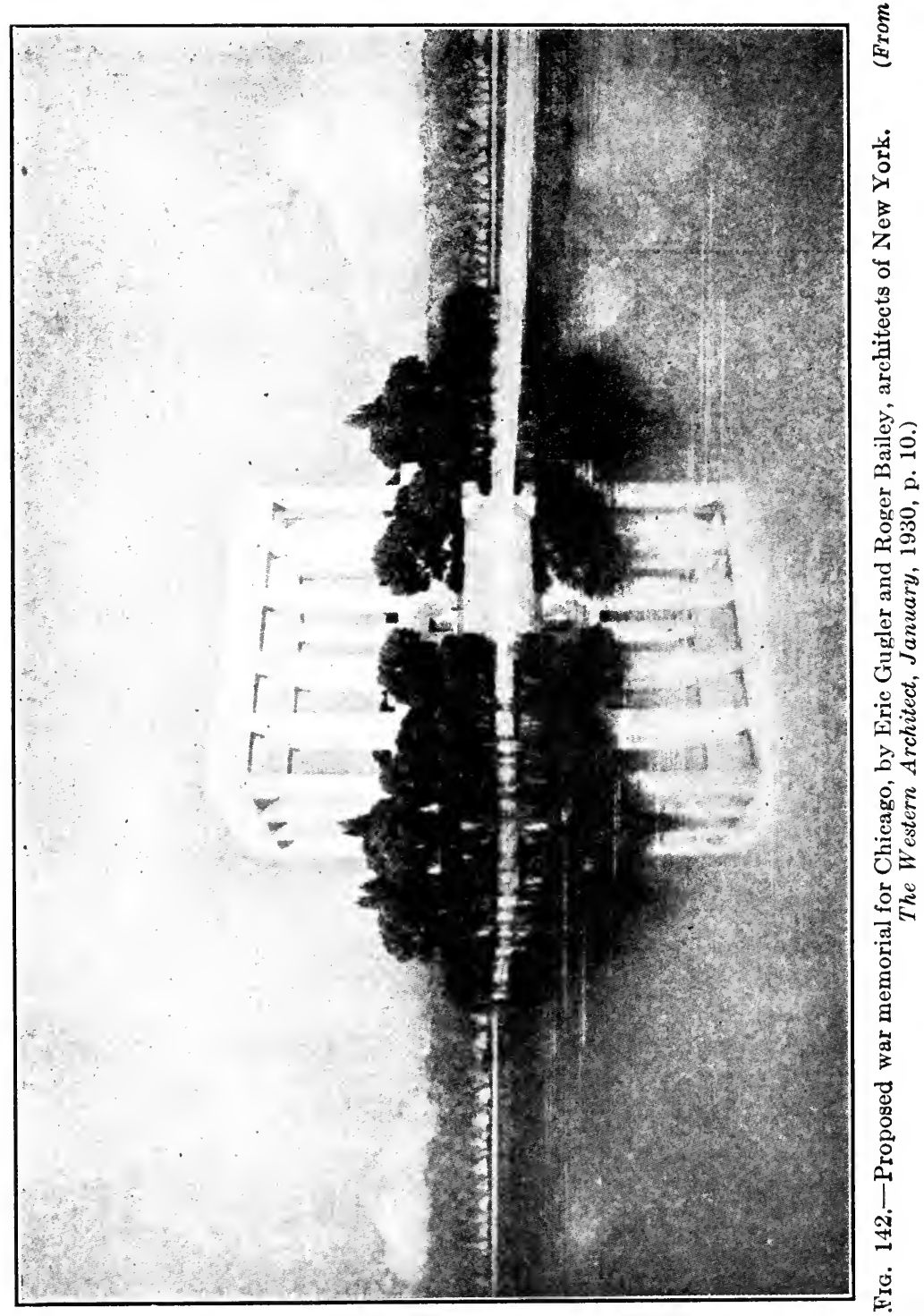


. . . the location and the arrangement, the elevation or gradient, the foreground and background, the vistas, balance, and symmetry, the street scenes; it provides a proper sense of scale, the broad relationships, the environment, and the opportunity for the grouping, assembling, and composition of such works under conditions that make them truly and permanently beautiful.

Further, according to "Cities of Tomorrow":

... the time is ripe for comprehensive plans to relate these details [the various elements of the city plan] to a convenient and effective organic structure, which through its own pervading orderliness achieves a fundamental beauty never to be attained through superficial embellishment.

Architectural Control as an Essential.-As nothing adds to or detracts from the appearance of the city more than its architecture, every consideration should be given to achieving a high standard for it. In this connection Harry B. Brainard makes an interesting comment: ${ }^{1}$

. . . it seems reasonable that inasmuch as every residential or business structure is largely dependent for its revenue on the community in which it is located, such a building owes something to the community supporting it. In other words, if the building does not enhance the appearance of its street, the building, to that extent at least, is parasitic.

No less interesting in this connection is the following statement: ${ }^{2}$

Once planted, the idea seems to be growing that in a modern community it can no longer be the inalienable right of every individual to build on his own land whatever type of structure his fancy pleases. The Supreme Court of the United States, in recognizing the constitutionality of the general principle of zoning, has pointed out how far public opinion and the gradual growth of new needs have extended the legitimate use which communities may make of their so-called "police power." Pretty well rooted as it has come to be in our thought and practice, the idea of public control is here and there beginning to put out a new kind of branch. It is coming to be realized that if it is against the common welfare to permit the building of a public garage in a good residential section, it may well be against the general common property values and right to permit the erection of structures that are architecturally out of key.

${ }^{1}$ American City, October, 1929.

${ }^{2}$ From an editorial in the National Real Estate Journal, Jan. 21, 1929. 
An effort to control and guide the architecture of a city along lines of beauty is being made through the medium of art commissions and juries in various of our cities. The art jury of Palos Verdes Estates in California has an endowment of some $\$ 300,000$ for the continuance of its activities. During 1928 the Los Angeles Commission considered 527 plans representing an estimated valuation of more than $\$ 10,000,000$. These, however, were mostly plans of public buildings. The Board of Review of Santa

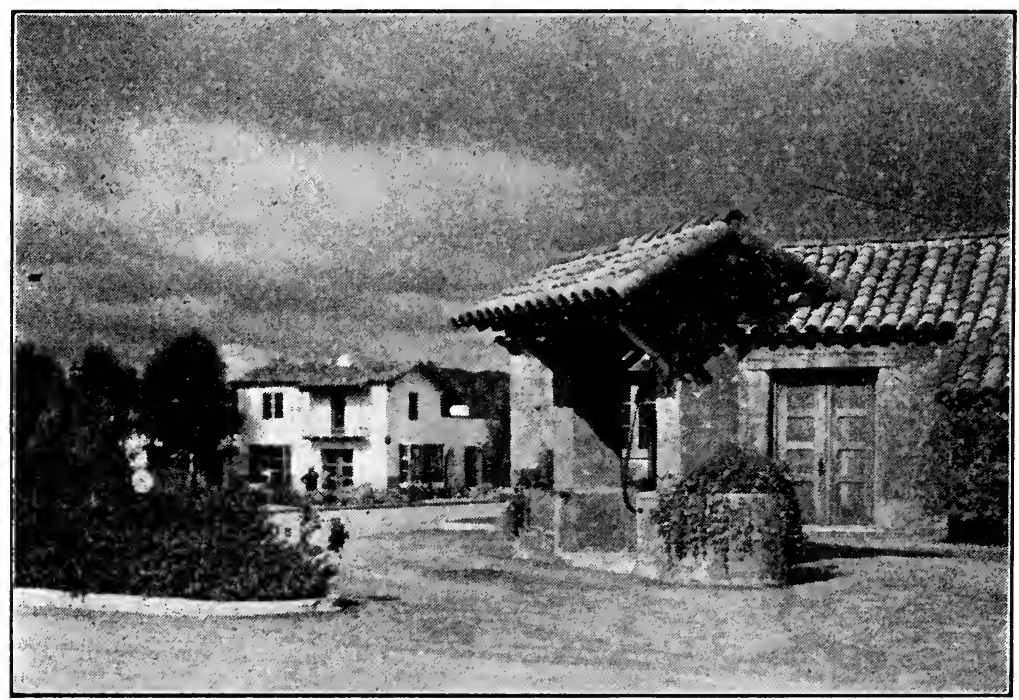

Fig. 143.-Evidences of architectural control. Rancho Santa Fé, Calif. (Padilla Company, photographers.)

Barbara held up a uniformly high standard of design in their city after the earthquake a few years ago when two-thirds of the principal street-Estado-had to be replaced. Both Palos Verdes and the Rancho Santa Fé (Fig. 143) are exercising control over their architecture. A recent ordinance in New Orleans prohibits the modification, alteration, or construction of any facade out of architectural harmony with the Vieux Carré, the old French quarter of that fascinating city.

Elimination of Ugliness. - To attain beauty in the layout of the city we must see to it that the blotches and blemishes are removed from the civic countenance. Many existing architectural atrocities and other features may need to be removed, improved, or may have to be tolerated until time works the miracle of 
change. There are some things spreading their ugly wings across the city that by well-organized effort, regulation, and control may be avoided and eliminated. The most outstanding of these are smoke, poles, and wires and, in some respects one of the worst, billboards.

Smoke as a Nuisance to Be Reckoned With. - City planning efforts are useless as long as rays of the sun may be obscured freely by smoke or the air polluted by soot. Further than this there are in various ways tremendous losses that result from smoke and soot that are sometimes not thought of, as, for example, in the increased expense of laundry work, the decreased durability of clothing, the tarnishing of silverware, the injury to the health of people and of vegetation, the more frequent necessity for the painting of buildings or the cleaning of stone, brick, and cement structures, and the destruction of real estate values. It is estimated that 17 tons of soot settle on every square mile of the city of Detroit annually. This condition is at its worst in cities where high-volatile coals are used for industrial and residential purposes.

According to a recent report of the Fuel Research Laboratories, smoke from soft coal and from improper combustion of other fuels in heating and power plants causes damage amounting to more than $\$ 500,000,000$ a year in the United States. Of this sum it is estimated that $\$ 90,000,000$ constitutes the loss from fuel wastage due to improper combustion, $\$ 270,000,000$ due to bad hygienic conditions caused by smoke and $\$ 140,000,000$ are charged against damage to merchandise and the additional cost of cleaning buildings.

A statement from the Smoke Abatement Committee of the Department of Health in New York City seems to indicate that smoke control hinges on the education and cooperation of the individual. Owners must be approached on a business basis and shown that smoking chimneys mean incomplete combustion and resulting waste of fuel. An active system of policing is necessary-alse. Much of the excess smoke is found to be due to outmoded heat equipment, so that the solution of smoke abatement involves the perfection of appliances by which industry may burn any type of fuel without creating smoke. The program also may include the effort to get domestic users to pledge themselves to use smokeless fuels. 
Rising Tide against the Billboard.-There is a growing sentiment against the signboards and billboards, and particularly those that clutter the approaches and exits of our cities in the open country, that intrude themselves obnoxiously into residential sections, and that project over sidewalks in the commercial districts of our cities. In spite of the efforts of the national advertisers to improre their displays, the latter are still regarded as things that obstruct the view, distract the attention, and are both a fire and storm hazard. They depress land values and frequently prevent the ready sale of home sites. They are not only detrimental to public safety and welfare and detract from the appearance of the street or road, but by helping to multiply the signs they help to defeat the very purpose for which each sign is erected.

Advertising which is introduced against public properties as a background is strongly attacked in a Bulletin of the Municipal Art Society of New York (1928), which says:

The faces of buildings, which are turned toward the world, are obviously of interest to the public, and all citizens have a property in them. The spectator is, in fact, part owner. No man builds to himself alone. General interest and intelligent appreciation of public arts are a necessity of civilization. Civic alertness, honest pride or firm protest are not matters of taste for a few, they are essential activities of the urban mind. In cities, buildings take the place of fields, trees and hedgerows. Buildings are an artificial form of nature. We have a right to consideration and some politeness in buildings. Our cities do not alone belong to profit-lords, .railroad companies and to advertisers.

This Society is in no way hostile to legitimate advertising, which is universally acknowledged to be one of the greatest forces of progress and civilization. But those advertisers who use public places as their background have, it seems to us, failed to grasp the rights of the public in those public places, and it also seems to us that they fail to sense the growing irritation and hostility of a very large part of the public toward the unnecessary intrusion of advertising where it does not properly belong.

It is strange that modern merchants and manufacturers and producers who use billboards or roof signs seem not to realize that they are spending enormous sums of money to buy public ill-will and detestation of their products. The outdoor advertiser is like an unwelcome caller who invites himself and who becomes more hateful the longer he stays. How can rational men continue to spend money on street advertisements which produce in the spectator contempt for the advertiser's taste, 
uislike for his product, and doubt of his civic pride? Is it a good investment which yields these returns?

The following comments by William J. Pedrick, presented at a hearing before the Welfare Committee of the Aldermanic Committee of the City of New York, likewise emphasizes the need for eliminating signs and especially the projecting variety along our city streets:

A multiplicity of signs, in addition to detracting from the appearance of the street and from the stores, defeats the very purpose for which each sign is erected.

Every person who erects a projecting sign must outdo his neighbor to carry out his intention of making his sign conspicuous.

Mr. Pedrick contended that the elimination of signs enhances the beauty of the streets and thus aids the realty and business values. He said projecting signs interfere with light, "become an eyesore, a nuisance and a danger" to pedestrians.

We believe that the proposed amendments will cause the sign industry no hardship but will, on the other hand, by helping to eliminate the existing projecting signs, encourage merchants on these streets to go ahead with their plans to erect artistic flat wall signs, either in wood or bronze.

The antipathy of our people to billboards is indicated by the numbers of states that have introduced laws of one kind or another affecting their use and representing efforts to lessen their number and to keep them off the highways. Roadside advertising is now controlled by as many as 41 states. The regulations are various, some prohibiting any commercial advertising on any highway or right of way, some confining the regulation to state highways only, some attempting to keep the signs 15 feet away from the highway, as in Connecticut, or to regulate them even up to 500 feet away, as in Massachusetts. Some require licenses, others annual fees and bonds, and still others taxes upon advertisers.

City ordinances likewise have provisions affecting the matter of billboards. Some are regulating them by zoning, and a great many, probably the majority, have done nothing to control them. Indianapolis refuses to permit them within certain distances of boulevards and restricts them mainly to first- and second-class industrial zones. Chicago has an ordinance which prohibits 
billboards on the roofs of buildings and requires a majority consent before they are erected in residential districts.

The decision rendered by the Indiana Supreme Court on June 27, 1930, represents a victory for antibillboard sentiment. It upheld the constitutionality of an Indianapolis ordinance which prohibits the erection or maintenance of advertising billboards within 500 feet of any park, parkway, or boulevard and directs that all such existing structures within the city be removed. The suit is reported to involve more than 160 billboards, about half of which are electrically illuminated. The degree to which the opinion recognizes the evolution of the law with regard to esthetics is particularly interesting.

It has been often held that a city may not prohibit billboards therein merely because such boards are unsightly and under the law as it exists today aesthetic or artistic considerations are not considered sufficient to warrant the exercise of the police power to prohibit advertising billboards generally throughout the city, because such considerations, of themselves, are not such a necessity as justifies the taking of private property without compensation.

But aesthetic considerations enter in, to a great extent, as an auxiliary consideration where the regulation has a real or reasonable relation to the safety, health, morals or general welfare, and where the regulation of billboards does not apply to an entire city, but merely applies to billboards in close proximity to public parks and boulevards it may properly have a relation to the public health, comfort and welfare which it would otherwise possess.

Parks are set aside and maintained by cities as places conducive to the health, pleasure, comfort and amusement of the public. An enjoyment of fresh air and sunshine, and also the grass, flowers and trees, is most important in securing the social, physical and moral well-being of the people, and parks as a means of providing these bounties of Nature for all the people have come to be considered as essentially necessary.

Parks are usually laid out, ornamented and embellished in such a way as to afford pleasure to the eye as well as to furnish a place of resort of the public for recreation and exercise, and it is only reasonable that the surroundings of a park should be kept in harmony therewith if practical to do so.

Under a liberalized construction of the general welfare purposes of State and Federal Constitutions, there is a trend in the modern decisions (which we approve) to foster, under the police power an aesthetic and cultural side of municipal development - to prevent a thing that offends the sense of sight in the same manner as a thing that offends 
the senses of hearing and smelling. But this trend must be kept within reasonable limitations, for citizens must not be compelled under the police power to give up rights in property solely for the attainment of aesthetic objects.

Five ways of regulating billboards by law are suggested by Frank B. Williams of New York. These are, first, by securing the passage of laws for the constructional stability of billboards and incidentally covering their appearance. Second, by forbidding advertising on public property; third, by making it a crime to place advertisements on private property without written consent of the owner; fourth, by passing state laws authorizing zoning by all the local governments within the state and seeing to it that proper zoning regulations under which general advertising is confined to business and industrial localities are enacted by all these governments. Fifth, by seeking to find occasions (as was done in New York) in which objectionable advertising can be regulated or forbidden on private property. ${ }^{1}$

Overhead Wires. - There was a time when tangles of wires along our streets were regarded as evidences of civic progress. The more there were the more progressive the community was supposed to be. We are getting far away from that point of view, however; the fewer wires there are in evidence for us now the better. They are gradually disappearing in our business sections where they are being replaced in underground conduits. In fact, many of our cities report wires largely or completely removed from central business districts. In the residential sections of some of our cities they are frequently introduced along the alleys or rear lines of property. This, however, will no longer be regarded as satisfactory while people try to build up attractive views in their gardens.

St. Louis has an ordinance that compels the removal of at least 4 miles of poles and wires annually. In Buffalo overhead wires are being removed from 2 miles of street each year. In the newer parts of Cincinnati wires are no longer in evidence. On all new or improved major streets in Toledo wires are being placed underground. In Washington, wires and poles have been removed over the entire city practically, and in all high-class subdivisions over the country wires are being put out of sight.

${ }^{1}$ From Bulletin 25, Municipal Art Society of New York, February, 1926. 


\section{Questions for Discussion}

1. What are the value and importance of civic beauty?

2. How are beauty and utility related?

3. Discuss esthetic factors that apply to the approaches to a city, i.e., by road, rail, water, and air.

4. Explain the layout of terminals and surroundings from a pictorial viewpoint.

5. What elements contribute to the attractiveness in a bridge?

6. Discuss factors governing the choice and placement of trees along the city streets.

7. How may the lighting of a city contribute to its interest and appearance?

8. Discuss other factors contributing to the appearances of streets.

- 9. What considerations help to make buildings and groups of buildings focal points of beauty?

10. Discuss the placement of civic statues, monuments, and fountains.

11. Explain why parks and playgrounds may well be regarded as works of art.

12. How is a city plan essential to the achievement of civic beauty?

13. What is architectural control; where and how has it been exercised?

14. Explain the importance of smoke abatement and what efforts are being exerted in that direction.

15. What is the status of present-day billboard regulation?

16. What progress is being made in the elimination of poles and wires from our cities?

17. How does the expression "prevention is less costly than cure" apply to the planning of our cities?

18. In connection with our subject, explain the significance of the following by Ruskin: "You may have thought beauty is expensive. You are wrong-it is ugliness that costs."

\section{References}

Ackerman, F. L.: The Architectural Side of City Planning, Proceedings 7th National Conference on City Planning, pp. 107-120, 1915.

Bennett, E. H.: Buckingham Memorial Fountain, Parks and Recreation, vol. 11, pp. 181-185, illus., plans, January-February, 1928.

Cheney, C. H.: Architectural Control of Private Property, Proceedings National Conference on City Planning, 1927.

Crawford, A. W.: The Sheer Cost of Ugliness, Proceedings 16th National Conference on City Planning, pp. 141-145, 1924.

Emerson, W.: Bridges as Memorials, Architectural Forum, vol. 45, pp. 337344, illus., December, 1926.

Ford, G. B.: Planning the Attractive Town, Proceedings 13th National Conference on City Planning, pp. 195-203, 1921.

Fitzgerald, M.: Cleansing the Sky: Part 1, The Case for Smoke Abatement; Part 2, The Way to Smoke Abatement, Garden Cities and Town Planning, vol. 14, pp. 60-62, 73-75, illus. diagrams, March, April, 1924. 
Goodrich, C. S.: Regulation of Billboards, Professional Engineering, vol. 14, pp. 12-13, September, 1929.

Hegemann, W., and E. Peets: "The American Vitruvius: An Architect's Hand Book of Civic Art, 298 pp., illus., plans, Architectural Book Publishing Co., New York, 1922.

Hewes, L. I.: Control of Roadside Advertising and Utilities, Roads and Streets, vol. 69, pp. 346-347, October, 1929.

HogG, J. E.: Billboardless Hawaii, Nature Magazine, vol. 15, pp. 387-390, June, 1930.

Holsworth, W. C.: Street Trees Planting in Relation to City Planning, Parks and Recreation, vol. 7, pp. 314-322, 422-432, 538-546, 650-654, January-February, March-April, May-June, July-August, 1924.

Hood, O. P.: Progress and Possibilities in the Abatement of Smoke, American City, pp. 125-126, September, 1930.

Hubbard, H. V., and Hubbard, T. K.: The City's Appearance, "Our Cities Today and Tomorrow," pp. 263-280, Harvard University Press, 1929. Kemper, E. C.: Effective Restriction of Outdoor Advertising Urged by American Institute of Architects, American City, vol. 42, p. 147, February, 1930.

Leavitt, C. W.: Vista in the City Plan, American City, vol. 38, pp. 119-120, June, 1928.

Mawson, T. H.: "Civic Art," 375 pp., illus., plans, B. T. Batsford, London, 1911.

Meller, H. B.: How Cities Can Control the Smoke Nuisance, National Municipal Review, vol. 15, pp. 270-276, chart, May, 1926.

Menhinick, Howard K.: Municipal Art Commissions, City Planning, pp. 269-281, October, 1930.

Monnetr, P.: Smoke Abatement, U. S. Department of the Interior, Bureau of Mines Technical Paper 273, 31 pp., illus., plates, Government Printing Office, Washington, D. C., 1923.

Newсомв, R.: The Bridge as Architecture, Architectural Forum, vol. 44, pp. 73-78, 243-248, illus., February, April, 1926.

Nolen, J.: The Place of the Beautiful in the City Plan, Proceedings 14th National Conference on City Planning, pp. 133-147, 1922.

Realtors Endorse Zoning against Billboards in Residential and Scenic Districts. American City, vol. 36, p. 389, March, 1927.

Robinson, C. M.: "Modern Civic Art," 381 pp., illus., 4th ed., G. P. Putnam's Sons, New York, 1918.

Unwin, R.: Of Civic Art as the Expression of Civic Life, "Town Planning," pp. 2-14, illus., plans, 1909, etc.

: The Art of City Planning, City Planning, vol. 1, pp. 71-76, July, 1925.

Williams, F. B.: Planning for the Promotion of Beauty, "Law of City Planning and Zoning," pp. 381-442, The Macmillan Company, 1922. 


\section{CHAPTER XX}

\section{REGIONAL PLANNING IN METROPOLITAN AREAS}

Not until recent years have city planners realized that the theories and practices applying to the city may be extended into the outlying areas into which the city is growing, and within which areas other municipalities are gradually taking form. So expansive may be these outlying areas and the multiplicity of the communities involved, and so large in scale the problem as a whole, that in a very real sense we may think of regional planning as a glorified application of the principles of city planning.

The area surrounding a central city and the cluster of municipalities that lie within that area require, for the purpose of their systematic and orderly development, a simultaneous and coordinated planning of their common public improvements and utilities and of the uses of land. They require the cooperative consideration of all of their common physical problems.

The main difference, perhaps, between urban planning, on the one hand, and regional planning, on the other, lies in the fact that urban planning is concerned so largely with the reconstruction and replanning of built-over areas. The planning of a region deals with territories in a large measure undeveloped and, instead of being limited to a single urban unit, must provide for all of the interrelated activities of a number of municipalities, clustering around a central city.

Value of Regional Planning and the Regional Plan.-Faced with but relatively few such evils of the past as are associated with developed territory, regional planning offers unlimited opportunity to the city planner for the prevention of regional difficulties and the accomplishment of better regional conditions. Such unlimited opportunity opens the way for the creation of the regional plan.

The regional plan forms a composite of the studies and conclusions of the city planner, dealing with the different physical aspects of the metropolitan area. The regional plan when 
adopted must be one upon which there is a general agreement among the citizens. Such a plan, if efficiently prepared and administered, will perform an inestimable service in the development of the region. It will do this by correlating the urban with the suburban developments and taking care of all of those conditions and problems that are beyond the powers of any isolated municipality to control.

Furthermore, the regional plan will provide wider and more direct thoroughfares wherever needed, "by-pass roads" around centers of congestion, and continuous boulevards. The regional plan also will include an appropriate setback of all buildings and a safer and more effective routing of all street-car lines and railroads. The coordinated regional plan will capitalize the avoidance of any unnecessarily high cost of doing business through one or another avoidable cause, as in the expenditures for purifying drinking water that has been unnecessarily polluted by some other community near-by. The regional plan will also provide for the citizens abundant means of recreation in the valleys along the streams, along the shores of any lakes, and in any woodlands and so preserve for the people their precious heritage of natural beauty.

The regional plan will provide for the normal and desirable growth of a city and its surrounding area into a region that will be so improved as to protect its inhabitants in the enjoyment of their homes and preserve for them all of the natural advantages of their location. By regional planning, the congested cities of today will be supplanted by the more spacious cities of tomorrow. It will point out the physical, economic, and legal means whereby this form of development may be realized. In short, a coordinated plan for any region will promote the health, safety, morals, order, convenience, efficiency, prosperity, and general welfare of the people who live there.

Scope and Character of the Region.-Although the metropolitan region with which this scheme of planning is concerned is a decidedly variable unit, depending upon its location and other things, yet in a general way it includes all of that territory subject to the influence of the central or mother city and lying within easy commuting and one-day shopping distance, and over which the central or mother city may eventually spread its boundaries. The occupied territory of the region may comprise a group of municipalities - satellites of the central city-lying 
in close juxtaposition to it and to each other and owing their livelihood, social life, supply of commodities - in fact, their very existence-to the chief city of the region. All of these smaller municipalities will be subject to common, overlapping, and interrelated interests and problems.

With respect to the differences in the radii of these metropolitan regions, the distance at New Haven is $\mathbf{1 5}$ miles from the center of the city to the boundary of the territory included in the plan. The region around Norfolk, Va., has the same radius. For Boston, Buffalo, St. Louis, Cleveland, and Toledo (Lucas County), the radii extend as far out as from 20 to 25 miles; and for New York City, from 40 to 50 miles. These outlying areas represent the outlines of the territory covered by the normal retail trade of the central city and correspond to the outlying points at which the customers who have charge accounts in the local department stores live.

Equally various are the square miles of the involved territory. The region around Boston includes 400 square miles; that around Chicago, 8,000; Los Angeles, 4,115; New York, 5,528; Niagara Frontier, 1,550; Philadelphia, 4,000; Santa Barbara, 2,740; and Washington, 450 square miles; while, for the sake of comparison, the Ruhr Basin in Germany includes 1,482 square miles.

It is interesting to bear in mind that a metropolitan region can cover a territory too large for its best interests. In this connection Alfred Bettman contends that in the same manner as we have been trying to build up in our cities a consciousness of the organic nature of the city's problems and interests, so now in the case of the metropolitan region, we are faced with the need of building up what he calls the "regional mind," meaning by that term a consciousness of the organic nature of the region. Mr. Bettman feels, however, that it is easily possible to spread out the interest in the unit amidst the people of too large a territory.

On the other hand, it is important for the regional planner to keep in mind that for the purposes of comprehensive study of a subject of this kind, the metropolitan region need not be limited to any single political jurisdiction, such as sanitary districts, school districts, cities, villages, townships, or counties, although boundaries might well be political. The multiplicity of these can be understood in part when one considers that the region around Boston has 39 municipalities; that around Los Angeles, 91 incorporated and unincorporated cities and towns; Phila- 
delphia, 357 different, political subdivisions, of which 129 are cities and boroughs; the Niagara Frontier, 28 villages and cities; not to mention other numerous divisions.

The character of the metropolitan (one might also call it the "polypolitan") region varies not only in size, shape, and the number and forms of the municipalities and other local political units of which it is composed but also in the density of the population and in the extent of its urban, suburban, and agricultural territory. Each metropolitan region will possess its individual financial, economic, social, and political situation. Its traditions may be strongly historical, and its people may be tenacious of old methods, or the metropolitan region may be new, too young to have acquired any traditions, and accordingly with a population easily susceptible to new ideas. It may have needs that must be met immediately or needs that will not be particularly important until some time in the future.

The area of a well-developed region has been appropriately likened by the Regional Plan of New York to the floor space of a factory in which arrangement has been made for the best use of that surface. As a result, the aisles of that factory are kept free from jamming by goods, and the different departments of the factory are planned according to their several needs. The metropolitan region, like the factory, may have to compete with efficient rivals whose plants are better and more efficiently planned.

The metropolitan region has also been likened to a network of cells of different sizes and shapes, all of which gradually enlarge until they eventually overlap.

A Regional Theory of Population Distribution.-Before we plan for the future expansion of cities or the development of new municipalities within any metropolitan area, we must arrive, at least, at some provisional understanding of what the future distribution of population of the region will be. Hitherto the general trend of regional planning has been toward anything that will contribute to increase the profit to be made by the promoter from the values of his land, without any regard to the general well-being of the people. Any development of a region that will force a congestion of the population, as Thomas Adams, city planner, has said, although excellent for profit making in the value of land, is both destructive of human welfare and economically unsound. In the long run, congested development is not even in the interest of the owners of the property. 
We must count upon either a continuance of the concentration of the population, as in the past, or upon-a redistribution of the population over the countryside according to a process of decentralization and recentralization. Which shall it be: a solid city expanding without limit to the end of time, with the accompanying intensification of the evils of congestion; or an infinite number of complete, independent, smaller centers, distinguished by the spaciousness of their internal arrangements and by the orderly planning of their outlying or surrounding areas?

At the present time, the decentralizing influences at work seem to point to the latter of these two types of developments as the one that will ultimately prevail. Studies in New York City show that "manufacturing is not more than holding its own in the center of the city and that it has probably already begun to be crowded out." Some of the leaders of manufacture and industry, such as Henry Ford, are advocating the decentralization of industry, which of course will be understood to include the decentralization and appropriate recentralization of the homes of the workers. There is, furthermore, a continued acceleration of growth in the suburban areas adjoining the larger cities, but areas not yet included within the city's limits; the rate of increase in population in the city of New York was recently found to be 24.2 per cent while in the adjacent suburbs the increase was 57.4 per cent. ${ }^{1}$

In connection with commutation fares, which are related to the question of decentralization, it must be remembered that such fares are based upon the distance traveled by the commuter and that the best way to overcome the cost involved in commutation as well as the waste of energy by the commuter resulting from long rides is either to place the home near the work or to bring the work near the home.

This bringing of the people close to their work can best be accomplished.by having the regional planner provide a number of "satellite towns" that are independent and self-sufficient yet maintain some kind of relationship to the mother city. Such communities will naturally develop somewhere along the great arterial thoroughfares penetrating the region. The nearer they are to the parent city the greater is likely to be the attraction that

${ }^{1}$ Boston increased 4.8 per cent during the last 10 years, its suburbs grew 25.2 per cent; Philadelphia 7 per cent, its suburbs 42 per cent, Cleveland 12 per cent, its suburbs 118 per cent. 
the larger city will exert upon the population of the satellites, and the farther from the central city are the satellites the less that attraction will be. From this it follows that the farther away from the central city the satellites are situated the more completely and independently equipped these centers of population will have to be.

Our theory, then, requires that the growth of the population be distributed among a number of suburban or satellite towns

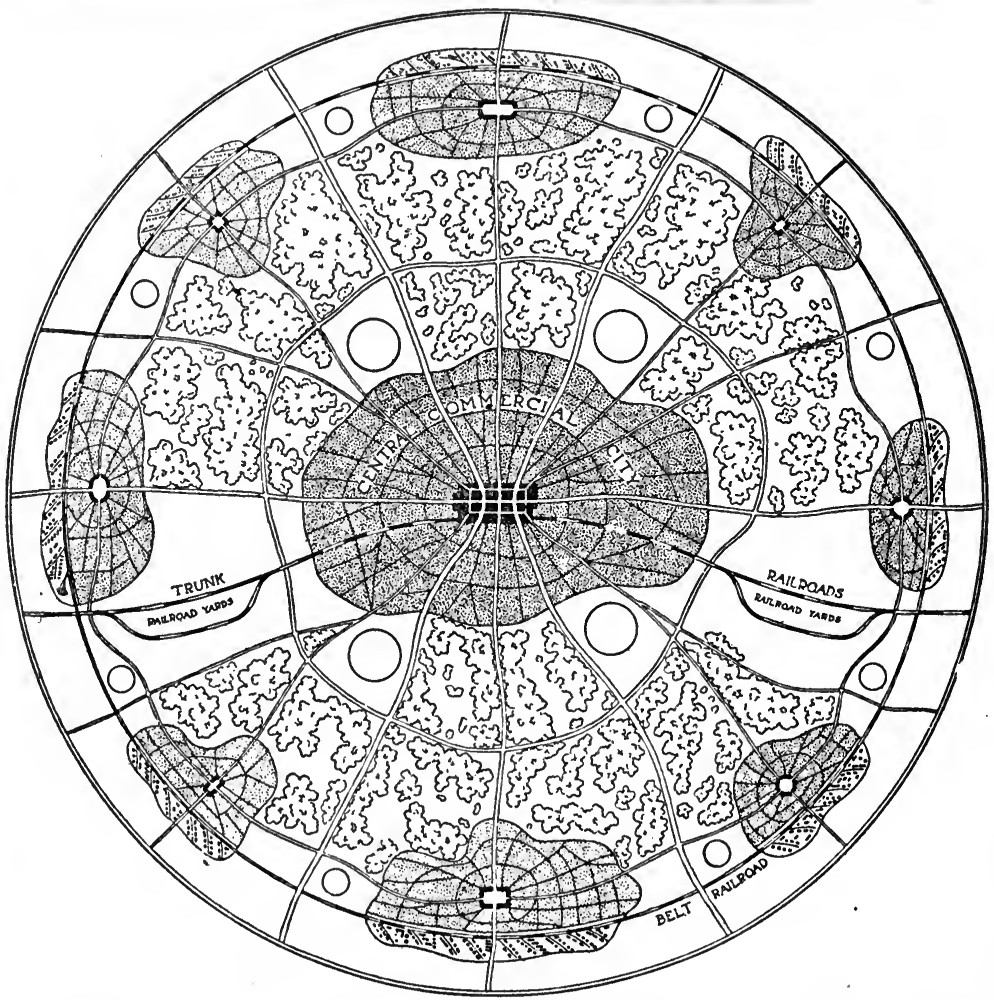

FIG. 144.-Theoretical scheme for regional development by Robert Whitten (1923). "The central city would be surrounded by numerous separate and selfcontained suburbs or satellites; the permanent separate existence of these secured by broad, open development areas separating them from each other and from the central city."

that can accommodate that growth and provide the necessary activities of the community in a reasonably self-sufficient degree and that these suburban towns be spacious in their character and be separated from the central city and from one another by generous open areas (Figs. 144, 145). 
How, then, can we accomplish these various purposes of regional planning of which we have treated? First, we must have a regional planning commission, with authority, purpose, and the

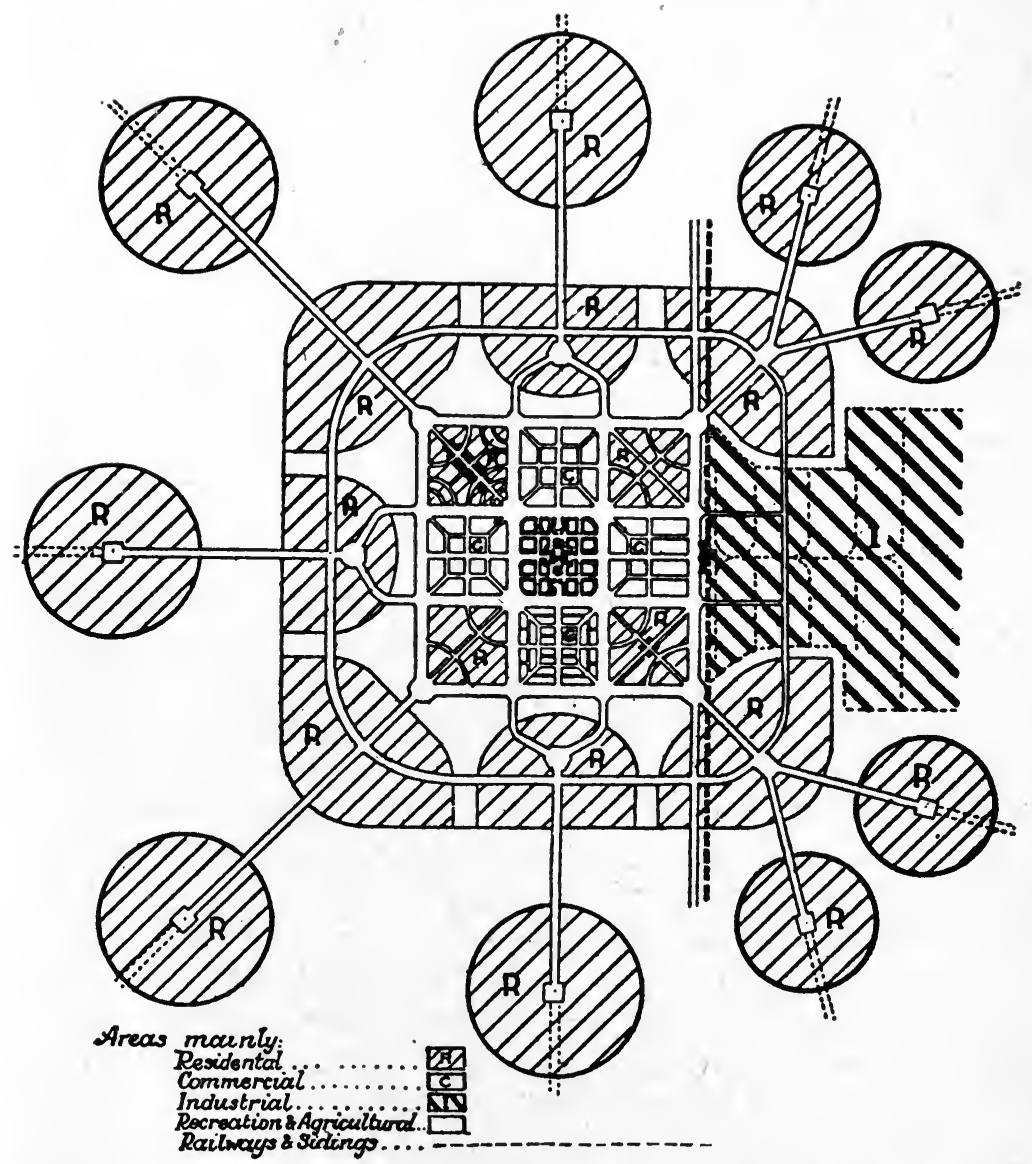

Frg. 145.-A diagram showing how town extension should progress. It suggests growth by "means of detached suburbs grouped around some center and separated from the existing town by at least sufficient ground to provide for fresh air, recreation, and eontact with nature." (Designed by Raymond Unwin, 1922.)

necessary facilities and finances. Second, the commission must prepare studies, plans, and recommendations. Finally, it must see to the carrying out of the plans by enlisting the collaboration and active interest of the various municipalities or other 
jurisdictional bodies concerned. Let us consider some of these things a little more at length.

Regional Planning Commission.-Before the conception of the regional planning commission was accepted, restricted phases of the regional work were undertaken by special governmental agencies, such as the metropolitan park commission, the sanitary district, or the transit commissions. These governmental agencies, of course, went ahead without any master plan, bearing u.pon the regional plan as a whole, to guide them.

Today there are both official and unofficial or voluntary bodies, that have been created to deal with the regional problem as a whole; the official bodies are those of Boston, Los Angeles, Lucas and Milwaukee counties, Niagara Frontier, Santa Barbara, and both the Washington and Maryland National Park and Planning commissions; the unofficial or voluntary bodies are those of Chicago, Cleveland, New York, and Philadelphia (Tristate).

The Standard City Planning Enabling Act, prepared by the U. S. Department of Commerce, contains recommendations and suggestions relative to the establishment of regional planning commissions. In regard to a method for bringing into being such a commission, the act provides that the governor or other state officer, upon the request of the voters of any county, or of any 100 citizens of a county, and following a hearing upon the request, in case the request proves to be to the public interest, shall grant the application, define the boundaries of the region, and appoint a regional planning commission. There is also an alternative or cooperative method provided, by which the enterprise may be initiated by both the planning commission and the county commissioners, who are empowered to cooperate in the creation of a regional planning commission. The members of the regional planning commission and of the county commission are authorized further to get together, decide upon the boundaries of the region, and determine the share of costs of various kinds.

According to the standard act, the commission shall consist of nine persons, each appointed to serve for a term of 6 years, and the members of the commission are to serve without compensation except that their expenses incident to the work of the commission are to be paid. The organization of the commission, its rules, procedure, miscellaneous powers, and duties are much the same as those applying to a city plan commission. The 
finances for the commission are raised as provided in the act, and the act also prescribes what staff of expert city planners shall be hired by the commission. The amount of money to be spent by the commission is subject to the approval of the governor. Councils and commissioner in each political subdivision are authorized to appropriate their respective share of the expenses of preparing the regional plan and carrying it into effect, expenses which are first paid into the state treasury and then paid out, on authorization of the regional plan commission.

The powers and duties of the regional plan commission consist of preparing, with the aid of its own engineers and technical staff, a master regional plan. This master plan includes all necessary studies, maps, charts and diagrams, showing the general location, extent, and character of the streets, parks, and other public ways and open spaces, the public buildings, public properties, and public utilities, as well as the general location of all forests and areas for agricultural purposes, open development, and for various purposes of the conservation of all resources and for the protection of the people. The master plan includes also a zoning plan.

The powers and duties of the commission are further set forth in the Standard Enabling Act. After the adoption of the plan, no street, park, or other public way, ground, or open space, no public building or other public structure, and no public utility whether publicly or privately owned or operated shall be authorized or constructed upon private property within the region, until the plans for the same shall have been submitted to and approved by the commission.

Many other provisions relative to the powers, functions, and jurisdiction of the regional plan commission, its raising of the money, and so forth, can be defined to best advantage after the plans have been completed, rather than before.

Planning the Region.-Although the law to authorize the preparation and official establishment of the plans and the recognition, encouragement, and financial support necessary to maintaining an organization for carrying on the work of regional planning is necessary, after all, the work of regional planning, as such is the real thing with which we are here concerned. We have already touched upon the general scope of the subject, the territory involved, and the general principles and theories that underlie the planning of a region. Let us now consider 
in a little more detail some of the things that must be made to function normally and healthfully if the best results are to be had from our regional plan. In every case there is involved an inventory of the resources and assets of the region, the topography, geography, population, natural resources, agriculture, industry, and trade of the region which must all be considered, also an analysis of the uses of the land, to the end that the highest and best results can be obtained. Serious thought, in every case, must be given to the basic factors that affect the physical development of the region. All of these basic factors must be examined broadly and applied to the plan for the accomplishment of the predetermined objectives.

Regional Highways. - The system of regional highways should provide for the free and easy circulation of traffic, for well-built, direct arteries between various important points. The system of highways should comprise trunk lines, "by-pass" routes (around congested centers), old roads made better as to width, grade, and alignment, and the planning of new highways ahead of the increasing population. Such a system of regional highways is expressive of the natural needs of traffic and embodies the great radials, diagonals, or auxiliary routes that must reach out into the surrounding regions. The system of radial and diagonal highways should be supplemented by ever widening circuits that serve as cross-connecting links. The points of intersection of a major system such as this will mark the nuclei of centerswhich will become the satellite towns of the future metropolitan region (Fig. 146):

Instead of a well-ordered scheme or even its approximation, an analysis of existing conditions may reveal a tangled network of indirect, broken, incomplete, tortuous, narrow ways, with no by-passes around congested business centers and no means for any direct connection of one needed kind of street with another. On the other hand, now and then we may find all of the elements of a good system already existing, the fragments of which need only to be tied together to serve beneficially the inhabitants of the region. In such an instance, the elements of a good system may be the result in part of an early seeking by the people to avoid natural barriers to streets and to follow the lines of least resistance in the establishment of the highways-circumstances that may have predisposed the suburban growth along rational 
lines. Such an instance is found in the new planned diagonals leading out into the metropolitan region of Philadelphia.

The study of regional highways must be accompanied by an analysis of traffic, including both that kind of traffic which originates and travels within the region and that which originates

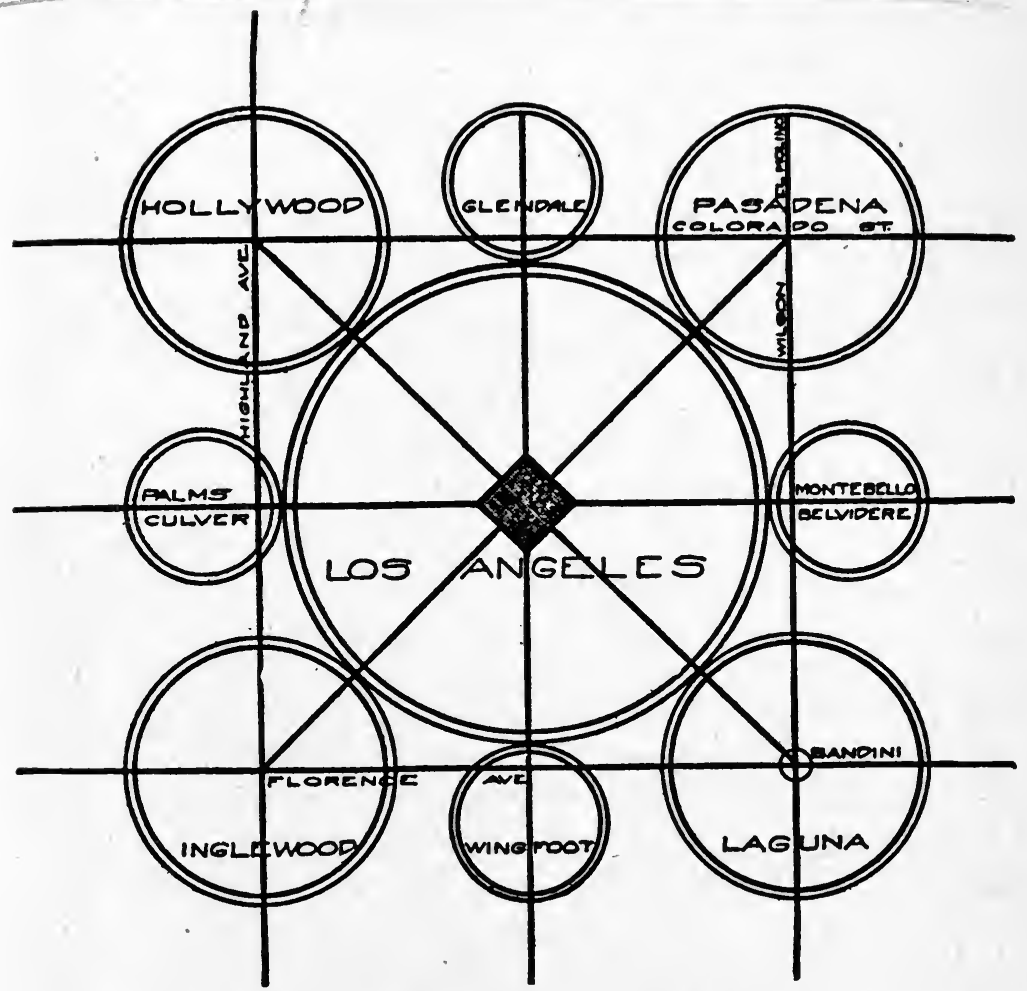

FIG. 146.-Program showing satellite cities of Los Angeles. It is to be expected that as the mother city grows the outlying sub-centers will become more important. Such satellite towns from 6 to 10 miles from Los Angeles have their own "character and identity which must be encouraged and maintained." (Diagram from the Proceedings of the First Regional Planning Conference of Los Angeles County.)

out of the region and passes into it or through it. There must in addition be a study of motor registration, inasmuch as an increase in the use of automobiles may become a barometer of the growing demands of the highway system, an unprecedented increase in the number of automobiles traversing the streets suggesting the need for the immediate consideration of new planning. The maximum loads of trucks, computed by day and 
hour, must be determined. Estimates of the future possibilities of traffic must be evolved by the city planner and compared with the present facilities and may suggest both wider pavements and parallel routes. The number of vehicular accidents and grade crossings in the region should be discovered, for these things may emphasize the need for a particular kind of planning, either immediately or for the future.

The matter of the width of regional highways can be determined much more easily when the principal directions and quantity of traffic have been examined and some understanding had with respect to the major system of the regional plan. On thoroughfares upon which the principal directions of traffic are in evidence, the construction of highways can be conducted along more generous lines than upon those highways upon which the principal direction of traffic cannot be determined. This skeleton framework of the more important roads and streets should be differentiated upon the map into major county roads of from 80 to 120 feet in width between property lines, primary routes of 140 feet, and superhighways of 170 feet or more. In some regions the practice is followed of making roads 100 feet wide along section lines and secondary roads 80 feet wide every $1 / 2$ mile apart, where the topography will permit.

Regional Transit and Transportation.-Like the principal highway system of a region, the transit and transportation lines should spread out and serve the regional area in a direct and wellcoordinated system of intercommunication between the different suburban communities or between the suburbs and the city. This they should do with as little cost in time and energy as possible and with a minimum of jeopardy to human life. The transit and transportation ways should be in the nature of radial trunk lines leading out through the independent and separate communities and also in the form of circumferential lines that serve the purposes of cross-connection. Good regional facilities require supplemental cross-highways with lines of buses and railways all coordinated, so as to facilitate transit and transportation over the region. Freight lines as well as those that accommodate passengers should be constructed around the principal city.

Wherever regional planning is used as the basis for action, the control of the location of transit lines may, according to Arthur C. Comey, be made to distribute the population about 
a great city in the form of a star, with relatively open land between the points, instead of concentrically, as is likely to be the case under unrestricted or undirected growth. This less accessible land will remain comparatively cheap and economically available for open residential development, parks, farming, and even forests on the rougher areas, thus preserving such amenities close to the more compact urban development along the transportation lines.

A study of the railroads of the region will involve a consideration of the principal connecting railroads and of the railroads that serve only the district. This study will necessitate some thought as to passenger lines, as to the number of passengers who use them, the riding habits of the patrons, and the rates for commuting. Similarly, the facilities of the port for the handling of freight will have to be analyzed.

In connection with transit and rapid transit, the existing lines will have to be plotted by the city planner; the population to be served and the density of that population will also have to be considered by him together with all of their interrelations. The riding habits of the people living in the region and the number of fares per capita on all surface lines will have to be included in the study, as well as an analysis of the means of transportation according to the number of persons entering the city or leaving it. The routes of motor buses must also be similarly considered.

With the extension of urban development into the open country, the number of crossings of railroads at grade also increases, and these crossings at grade become more expensive to eradicate as houses and other structures are built in their vicinity. Important regional thoroughfares especially should be as free as possible from grade crossings, and a comprehensive program of grade separations should be included by the city planner as a part of the regional plan. This is especially important because timely grade separations are instrumental in avoiding much unnecessary expenditure by giving thought to the question while much of the territory is as yet unoccupied.

Important thought should be given likewise to facilities for aviation in the region (see also chapter on airports). A policy for providing sufficient airports should be settled and adequate reservations made for them while such reservations are available and sufficient to serve the needs of this growing form of transportation. 
Regional Water Supply and Sewage Disposal.-In no phase of the regional plan is the need so urgent for cooperative and joint responsibility among the municipalities of a metropolitan region as in the matter of water supply and sewage disposal. Many communities are found to be without any facilities for disposal of public sewage, and those communities that have such facilities are equipped for the most part but poorly. Some cities practice dumping their raw sewage into streams that are potential sources of recreation or of water supply; in the case of some cities the sewage is first treated, while another community farther upstream is discharging its raw sewage into the same stream untreated.

Furthermore, with these multitudinous systems of sewage disposal, there are duplications of disposal plants and an unnecessary paralleling of water lines and sewers. Much of this unnecessary duplication and futility of effort can be avoided by a realization of the interdependence of neighboring cities in this respect and the creation for them of common facilities for the disposal of their sewage. Sewers and sewage should be made to accord with the natural areas of drainage and watersheds. It is obviously much more economical, as M. S. Hill, consulting engineer, suggests, for two adjoining communities within a common drainage area to install a common sewerage system and thus to carry their sewage away by gravity, rather than to have two systems in this same drainage area and to pump the sewage from its natural outlet into some other drainage area. To solve the question from the standpoint of political boundaries alone is a matter of waste and possible damage. The cooperation as to sewage disposal among neighboring municipalities permits in addition the serving of many other communities not adequately equipped today, because of the cost of having to construct a separate system for each town.

The availability of sources of water supply, according to Morris Knowles (civil engineer and city planner), is determined largely by locations of sewerage outlets. If nuisance would be avoided, the extent and character of the treatment of sewerage depend upon the prospective use of its resources of water for purposes of water supply. The sources of water are always limited in number and capacity, moreover, so that a city may do lasting injury to the surrounding region by developing its supply of water without regard for the like needs of its neighbors. 
The supply of water for a regional group of cities should be protected, preserved, developed, purified, and utilized according to the needs of the region considered as a whole. "Any act therefore creating water or sewer districts should be along broad lines, giving a board or a commission ample powers to enable it to execute proposed work in a prompt and efficient manner."

Regional Parks.-With our increasing knowledge of the need for open space and for plenty of it, we should exert every effort that we can to preserve acreages for parks in generous proportions, while such acreages are still available throughout the breadth of a comparatively undeveloped region. If all the space needed for reservations of water supply and for forestation is provided, and all other areas not adaptable for residential uses and yet highly effective for purposes of parks are reserved, there would be ample open space in every community, according to Thomas Adams, city planner.

In addition to all this, we should keep in mind the desirability of separating the various future towns by reserving encircling, open spaces of from $1 / 2$ to $3 / 4$ mile in width. Mr. Bassett (the well-known legal authority in city planning) calls our attention to the fact that any two neighboring cities, growing toward each other, almost always develop a depressed or blighted district at the place at which they finally meet. If this be true, then the encircling open area will prevent such a meeting of the two communities and avoid the resulting depression of values at their common outskirts. Open spaces around a city include not only "outer parks, parkways and forest preserves," but "cemeteries, aviation fields, large acreage institutions, fairgrounds, railroad car storage, railroad classification yards, private estates, country clubs."

Again, according to Thomas Adams, there should be at least one acre of regional park to every 150 persons of the urban populafion, and in the outlying communities, not less than 10 per cent of the gross acreage should be devoted to regional parks. In the outlying towns, there will be one acre of regional parks provided by the city planner for every 300 or, at the least, for every 500 of the urban population (see chapter on parks).

The various areas for the parks of any region should be accessible to one another by parkways and thus be tied together into a great system of recreational areas. 


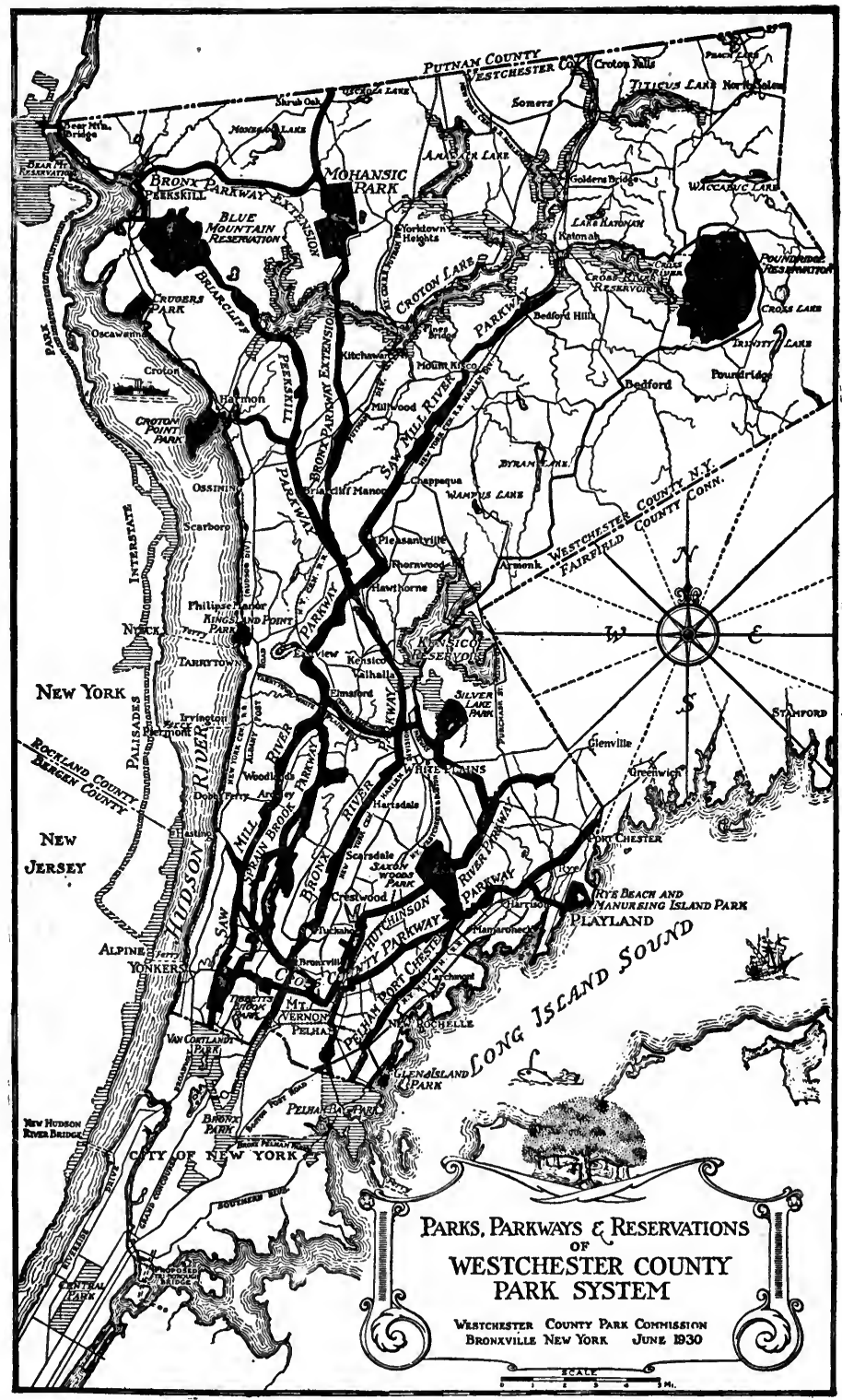

FIG. 147.-Plan of the parks, parkways, and reservations of Westchester County Park System, 1930, (Courtesy of the Westchester County Park Commission.) 
The Westchester County Park System.-One of the most important regional park enterprises in this country is the Westchester County Park System of New York (Fig. 147). Since 1922 the total appropriations by the Westchester County Board of Supervisors for this county park work have exceeded $\$ 60,000$,000. The Westchester County Park System embraces an area of 17,152 acres of land and has a total length of parkways of 160 miles. The Bronx River Parkway, which was developed along the line of one of the commuting railways into New York, is one of these. It was the first project of the system to be completed and cost $\$ 16,000,000$. It is built wholly within Westchester County and covers 1,088 acres. The beauty of this parkway, which represents the transformation of a mass of unsightly ash heaps and a disordered river valley into broad, gracefully sweeping roadways that lead under bridges (in perfect keeping with their apparently natural surroundings) and afford views into scenes of created loveliness that seem natural, is surpassing. This great regional enterprise has attracted world-wide attention, has improved valleys through which streams flow, has conserved unspoiled sections of the landscape, and has included among its features facilities for boating and bathing, golf courses, picnicking trails, bridle paths, and ponds for skating.

One of the most interesting amusement parks in the country has been developed at Rye Beach. This park is especially interesting because it demonstrates that amusement parks, as such, need not be centers of ugliness and vulgarity and that they can be administered directly by a department of county parks.

The economic soundness of the entire Westchester County Park System becomes apparent when we compare the total assessed valuation of taxable properties in Westchester County for 1922 , which was $\$ 733,007,069$, with that of 1929 , which was $\$ 1,644,114,324$. In 1929 the accomplishment was achieved by the Park Commission of operating the park system without cost to the tax payers. In place of an outlay the total receipts of 1929 exceeded the total cost of operation and maintenance by almost $\$ 40,000$.

\section{REGIONAL ZONING}

Aims.-The development of any territory by means of regional zoning carries with it the potential development of all of the activities that will characterize that territory in the future. 
It determines whether the welfare of the region at large shall be disregarded and that of each individual community alone shall be considered or the interdependence of all of the individual communities. The ultimate maximum efficiency, stability, and beauty of the region must ever be held in mind, while we must never forget the protection of the people who must live there. Gaps in any pattern of zoning are like the missing links of a chain and completely destroy its effectiveness. What good are any regulations applying to the uses of properties inside the boundaries of a city when any use can be made of any property immediately beyond those boundaries?

Regional zoning should effect the regulation of the use of all properties throughout the region at large. It should provide a varied assortment of public services for the people and set aside places for all legitimate private activities. This it should do so that every industry may prosper without perpetrating damage upon any other. We must keep in mind the fact that misplaced uses produce economic loss. We must reserve all factory sites for their greatest economic and social advantage and must recognize their dependence upon transportation facilities and leve] lowlands. We must avoid the creation of excessive business frontage and must encourage an occupancy of all buildings that will allow plenty of rooms for the people rather than force their congestion-we must allocate everything as far as possible on the canvas of the region, according to its economic, topographic, health-giving, and esthetic fitness.

Factors to Be Considered.-The region to be planned will have to be studied and appraised with respect to all existing conditions and all probable future trends that can be foreseen. The positions of its future business centers can be fixed at the intersections of its main arteries of traffic, and frontage for business can be restricted reasonably as to both amount and location, thus avoiding the prevalent practice of creating an excess of business frontage in undeveloped regions.

The reservation of space for any purpose-by the city planner must be governed by his information as to the character of the soil, which may show certain fundamental needs of the region and certain possibilities. The potential economic and occupational activities of the people, whether they be "those that create or those that follow" a concentration of population, should also be analyzed and considered. 
The reservation of recreational spaces should be kept in mind as well as the distribution of the population, the density of the traffic and its direction, the relation of all developments to facilities for transportation by rail, the requirements of sufficient space for various economic activities, and a comparison of the importance of the things crowding with that of the things crowded, to determine which shall have to give way to the other. The amount and character of the planning and zoning throughout the region must be carefully analyzed, with a view to the coordination of all of the several activities of the territory in hand.

Standards. - The spirit of cooperation that makes people zone their territory regionally requires also their use-of certain universally understood symbols and practices. There must be a set of rules to be used universally over the region. There must be a reasonable uniformity as to the basic zones, and these must be founded upon the utmost simplicity-the fewer the number of subdivisions in a region to be zoned the better. The Los Angeles Commission suggests as the five major basic divisions of the region, residential $(R)$, commercial $(C)$, manufacturing $(M)$, parks $(P)$, playgrounds $(P l)$, and recreational $(R e c)$ areas. According to the commission, residential uses are expressed by $R 1$ for single residences, $R 2$ for two family, $R 3$ for multiple, $R 4$ for unlimited families; commercial uses: $C 1$ for apartments and restricted business, $C 2$ for neighborhood business, $C 3$ for unrestricted; manufacturing: $M 1$ for factory use, $M 2$ for industrial use, $M 3$ for unrestricted manufacturing use.

Likewise uniformity and simplicity in the use of the colors upon the map are necessary. The Los Angeles Commission has agreed upon variations of yellow for residences, red for commercial districts, blue for manufacturing, and green for parks and other recreational areas.

\section{REGIONAL CONTROL OF SUBDIVISIONS}

The method of dealing with the subdivision of unoccupied territory into streets and lots as if each subdivision were to form a separate unrelated entity is full of possible, dire consequences. Cities of certain classes, in some of our states (Pennsylvania, Virginia, Ohio, North Carolina, and Oregon), have been authorized to control all subdivisions within from 3 to 4 miles of the city limits, and this control has been a great help to those cities 
in achieving, to some extent at least, a harmonious urban unit. Most of the states, however, do not grant this privilege to their cities, and without such regional regulation, the outlying areas are likely to become a patchwork of non-coordinated streets, blocks, and lots.

Subdivisions in any region should not be allowed to proceed in this fragmentary manner and according to the whim of the individual subdivider. There should be some regional agency that, with a comprehensive plan of the region as a guide, may evolve a set of standards into which all plats of new subdivisions must fit. No subdivider should be given the license to lay down his plan at will and without regard to the effect of his plan upon neighboring tracts. The plan of every subdivision within its borders vitally concerns the future life of the regional area of which it is a part.

\section{METROPOLITAN ORGANIZATION}

To secure the endorsement and active support of the multitudinous agencies that are interested in the progress of a regional plan involves unending contacts and the spreading broadcast among the general population of the region involved of complete and accurate information as to the purposes of the planning organization. This advertisement must go on in two principal ways-one directly to the people through newspaper stories, illustrated articles in magazines, and the medium of a regularly published bulletin by the commission, which must be sent to officials and civic workers of all kinds throughout the region. Public hearings also accomplish this purpose of reaching the people directly and give to all concerned an opportunity to express their views upon the various questions raised by the proposed improvements.

The other important vehicle of contact and coordination is through meetings with persons and agencies of various kinds, both official and non-official, within the region. Contact should also be had by the city planners with individuals of responsibility and with committees and commissions that include within their supervision any phase of regional planning. An advisory body ought to be organized among the various planning professions of the region. Most important, however, is an association of city planners from among the official planning bodies of every community. Such an association as this is outstandingly alive 
and successful in the Los Angeles region, where it is known as the Association of City Planners of Los Angeles County. This association comprises a membership of 900 persons, representing city plan commissions, city councilmen, city engineers, city attorneys, and all others interested in city planning. The association meets once a month, and each month in a different community. The writer attended one of these meetings that had an attendance of some 200 enthusiastic persons, with about as many women as men in the group.

\section{REGIONAL PLANNING PROJECTS IN THE UNITED STATES}

The importance of regional planning has already been recognized in several parts of the United States, and the most notable places in which that importance has been recognized, if judged by their activity and accomplishments, are the following: ${ }^{1}$

The Boston Metropolitan Planning Division of the Metropolitan District Commission is the result of the creation of the Metropolitan Sewage Commission in 1889, the Metropolitan Park Commission in 1893, and the Metropolitan Water Board in 1895. Boston's regional area covers 400 square miles, and its activities have included metropolitan highways, systems of rapid transit, and parks. It is now composed of 40 cities and towns and covers 392 square miles.

This Division has limited its planning work primarily to problems of highway transportation and transit, to water supply and sewerage, and to parks and parkways. The construction of circumferential and cross-town arteries has been its major concern.

The Chicago Regional Planning Commission is a voluntary organization and was created in 1923 probably under the impulse of the regional activities of the forest preserves. Chicago's metropolitan area covers a tristate region of 8,000 square miles and involves a population of $5,000,000$ people. Certain highways and proposals for parks have been carried out as recommended by the commission. This association is "an outstanding example of actual results secured through the participation of a very large number of county and local officials and through education of the communities involved."

${ }^{1}$ See Summary of Regional Planning Activities, Report, American Civic Association, April. 1929. 
The Los Angeles Regional Planning Commission of the County of Los Angeles includes a metropolitan area of 1,200 square miles, while the whole county covers an area of 4,115 square miles and boasts a population of $2,271,151$. From this commission, which was the first of the separate county regional planning commissions, came the first county-wide zoning ordinance in the United States (September, 1927). The work of this enterprising and active commission has been carried on more especially in the direction of major highway projects, zoning endeavor, and improved land subdivisions. It has successfully built up public opinion through its important educational program.

The Milwaukee County Regional Planning Department has within its jurisdiction 240 square miles, with a population of 700,000 . The activities of this department cover major highways, parkways, parks, platting, and zoning.

The activities have proceeded in cooperation with the Board of Land Commissioners of the City of Milwaukee. During the past few years the department has secured the adoption of county use-zoning, started a system of county parks and parkways, established the routes and widths of a system of county major thoroughfares, and promoted better control of platting and coordination of local business centers with future lines of transportation.

The New York Regional Plan is an unofficial and advisory organization, working under the financial guarantee of the Russell Sage Foundation. The area studied by this organization covers 5,528 square miles and involves a population of $10,000,000$. The New York Regional Plan has issued 12 volumes of "Surveys" dealing with the economic, social, and physical conditions of the region, and the results of the work were publicly presented on May 27, 1929. The region assumed comprises 400 municipalities, portions of three states, and an area of 5,528 square miles. Its activities have cost over $\$ 1,000,000$ and represent one of the outstanding contributions to the subject of regional and city planning.

The Niagara Frontier Planning Board and Niagara Frontier Planning Association is an official organization with two names, its regional area covers 1,550 square miles, and the population involved numbers 850,000 . The organization has issued bulletins setting forth its progress, has prepared a number of maps, and has executed parts of its plans for rectification and development. Through its influence local planning and zoning bodies have been 
established throughout the region, park and highway plans prepared, water supply and sewerage districts developed, and bus transportation improved.

The Regional Planning Federation of the Philadelphia Tristate District covers an area of 4,000 square miles in Delaware, New Jersey, and Pennsylvania and is concerned with a population of $3,402,805$. This organization, which involves 340 cities and boroughs and 3,500 square miles, is unofficial and has thus far carried forward by private subscription its surveys and researches, which include 30 diagrammatic maps. It has already been the means of furthering intercommunity plans. This organization has secured by private subscription $\$ 500,000$ in a recent financial campaign for use during the current 3 years.

The Santa Barbara County Planning Commission has under its control a county plan covering 2,740 square miles. The population of the region is 65,000 . "The Commission is conducting educational work and initiating comprehensive studies which look to an allocation of uses which will not damage the attractiveness of the county as a scenic resort."

The Toledo (Lucas County) Plan Board controls an area of 40 square miles, with a population of 400,000 Its activities so far have covered major highways and parkways:

Since, in Ohio, a county may adopt a master plan, the recently published comprehensive report on a proposed system of major highways and parkways for Lucas County, not adopted by the county commissioners, becomes binding so far as it relates to non-municipal territory.

The Washington National Capital Park and Planning Commission was appointed (1926) by the federal government. The area under its supervision is 450 square miles, and the population served is 680,000 . The activities of this commission cover a comprehensive plan, dealing with the highways, parks, and playgrounds, within the region; also the commission has in hand special projects of zoning and transit. The work of the commission also has contributed greatly toward bringing before the people of the United States the needs of growth, development, and improvement, in connection with our great capital city.

The Maryland National Park and Planning Commission, with authority to plan, etc., was established in 1927. It is working in close cooperation with the Washington Commission, and already zoning has been adopted in the counties concerned and comprehensive regional studies are underway. 


\section{Questions for Discussion}

1. What is the meaning of regional planning and of what value and importance is it?

2. Indicate how regional and city planning are alike or different.

3. Discuss the subject of metropolitan regions with reference to their scope and character.

4. Describe a regional theory of population distribution and how it may be accomplished.

5. What are the powers, functions, and jurisdiction of a regional plan commission.

6. Discuss the planning of regional highways; regional transit and transportation; regional water supply and sewage disposal; regional parks and park systems; regional zoning.

7. What is the importance of the regional control of subdivisions; of metropolitan organization.

8. Name and describe the outstanding regional projects in the United States.

\section{References}

Abercrombie, P.: Regional Planning, Town Planning Review, May, 1923, vol. 10, pp. 109-118, map.

Adams, T.: Forecast: The Regional Community of the Future, Proceedings American Society of Civil Engineers, vol. 53, pp. 1533-1543, September, 1927.

"America's New Frontier," The Middle West Utilities Co., 1929.

Anderson, Nels, and E. C. Lindeman: The City and Its Hinterland, "Urban Sociology," Chap. III, Alfred A. Knopf, Inc., 1928.

Basic Information Needed for a Regional Plan, pp. 1056-1095; Housing and the Regional Plan, pp. 1109-1121; Cultural Opportunities in Regional Planning, 1122-1143; Forecast: The Regional Community of the Future, pp. 1146-1179, Transactions American Society of Civil Engineers, vol. 92, 1928.

Child, Stephen: Of Metropolitan Parks, in his book, "Landscape Architecture," Stanford University Press, pp. 142-162, 1927.

Comey, Arthur C.: "Regional Planning Theory," pub. by author, 1923; also in Landscape Architecture, vol. XIII, pp. 81-96, January, 1923.

County Parks, Report of study of county parks in the United States, Playground and Recreation Association of America, 150 pp., 1930.

Douglass, Paul Harlan: "The Suburban Trend," The Century Company, New York, 1925.

DUFrus, R. L.: "Mastering a Metropolis," pp. 292, illus., Harper Brothers, New York, 1930.

Ford, G. B.: Regional and metropolitan planning, principles, methods, cooperation. (In Proceedings of National Conference on City Planning, 1923.)

Greensfelder, A. P.: Supervised Regional Expansion. (Paper before American Society of Civil Engineers, St.Louis, Oct. 1, 1930. 19 pages.) 
Hubbard, H. V. and Hubbard, T. K.: Agencies for Regional Planning, "Our Cities Today and Tomorrow," pp. 46-64, Harvard University Press, 1929.

Hubbard, Henry V.: Planning the City and the Region-Then and Now, American City, pp. 99-100, September, 1930.

Hubbard, T. K.: Annual Survey of City and Regional Planning in the United States, City Plcnning, April issues, 1925 on.

Kenr, Cyrus: "A Nation Plan," Oxford University Press, 1926.

Knowles, M.: Engineering Problems of Regional Planning, Proceedings 11th National Conference on City Planning, pp. 115-138, repr., 1919.

Lewis, N. P.: The Environs of the City, "The Planning of the Modern City," pp. 296-308, illus., plans, 1923.

Nolen, John, ed.: Residential and Industrial Decentralization, by James Ford, pp. 333-352; Regional Planning, by John Nolen, pp. 472-494, "City Planning," D. Appleton \& Company, New York, 1924, 1929.

Plan of Highways Improvement in the Regional Area of Cleveland, Ohio, 187 pp., diagrams, etc., Report, Bureau of Public Roads, U. S. Department of Agriculture, and County Commissioners of Cuyahoga County, Ohio, 1928.

Purdom, C. B.: “The Building of Satellite Towns," J. M. Dent and Sons, Ltd., London, 368 pp., illus., plans, 1925.

Regional Plan for Nation's Capital, American City, pp. 166-168, February, 1930.

Regional Plan of New York and Its Environs, Regional Survey 1-8, Regional Plan 1-2, prepared by the Staff of the Regional Plan, published by Regional Plan of New York and its Environs, 1927-1929.

Regional Progress, American Civic Annual, American Civic Association, pp. 109-122, 1930.

Studenski, PaUl: "Government of Metropolitan Areas," National Municipal League," 400 pp., New York, 1930.

Unwin, Raymond: Regional Planning with Special Reference to Greater London Regional Plan, Royal Institute of British Architects Journal, vol. 37, No. 6, January, 1930.

Whitten, R.: The Organization of a Metropolitan Community, Landscape Architecture, vol. 14, pp. 77-80, map, January, 1924. 


\section{CHAPTER XXI}

\section{LEGAL AUTHORITY FOR CITY PLANNING}

No accomplishment of city planning can be obtained under our system of government without the necessary constitutional right. This is true either as regards the granting of such right by law or by the more liberal interpretation of existing law. Our cities as creatures of the state and conducting their business under charter must be duly empowered by legislative enactment to accomplish certain objectives of city planning. This is quite different from the continental cities of Europe, where they may do almost anything they wish along this line.

In the past few years there have been a number of additions to our statute books bearing upon city planning and a more liberal interpretation by our courts of existing laws, both of which have made possible a greater diversity of activity in city planning. Despite the fact that there are things yet to be accomplished that are awaiting constitutional right or broader construction of present laws before realization, there are today various main forms of power in relation to city planning through which the state exercises guidance and control. These include the power to take land and to regulate property as well as to administer other activities of city planning and to finance projects for city development.

Power to Take Land (Eminent Domain and Excess Condemnation).- The extension and widening of streets and the acquiring of parks or of sites for public buildings and other public uses involve the taking of private land for public uses. Such taking of land is accomplished under the fundamental law of our country. The fourteenth amendment to the Constitution of the United States reminds us that no state may deprive any person of life, liberty, or property without due process of law and that no private property shall be taken for public use without just compensation. The taking of land for public uses, therefore, must be accompanied both by due process of law and by compensation to the owner. This compulsory surrender of land for a public purpose 
is accomplished under what is known as "eminent domain." The taking of private property by right of eminent domain carries with it variously hearings before appraisers, commissions, and courts and a final report of the appraisers as to the amount of damages that must be paid to the private owner.

The power to take land should include excess condemnation. ${ }^{1}$ We are coming to recognize more and more the advantage it would be to a community to be able to acquire land in excess of that actually needed for an improvement, to sell such excess land at its increased value, and to control the development of the excess land. Such a method of acquiring extra land and of controlling development is known as "excess condemnation." It gives the community the advantage of increase of value resulting from a given improvement, it provides a way to utilize advantageously remnants of land that are too small for independent development and prevents such use of land fronting an improvement as will lessen the value of the improvement.

Excess condemnation, according to Frank B. Williams, has been used but little in this country, in spite of the fact that the need of it in numberless instances has been clear. ${ }^{2}$ Reasons advanced for the failure to use it more generally include undue conservatism of city attorneys, impractical procedure too frequently provided, interference of the debt limit and financial conditions of many cities, unwillingness to give authority to officials to enter into what is in some respects a business transaction, and the lack of knowledge of the advantages of city planning and the evils of unregulated growth.

Power to Control Land Platting.-Many of our cities are composites of subdivision plats. Many of these plats have been drawn to serve the owners' wishes, without reference to or agreement with adjacent plats or with respect to the city as a whole. They have time and again shown little if any regard for

${ }^{1}$ See also chapter on Paying for City Planning Developments.

2 The history of excess condemnation in this country as pointed out by Mr. Williams (1925) reveals that it was provided for and considerably used in the state of New York under a statute enacted in 1812 but was held to be unconstitutional by the New York courts in 1834 and virtually ceased to be practiced until revived by statutes in Massachusetts and Ohio in 1904 and subsequently in other states. These statutes were so criticized by the courts that little use was made of them, and constitutional amendments for the purpose were passed, first in Massachusetts (1911) and then in Ohio (1912), in New York (1913), and in Rhode Island (1916). 
standards of health, convenience, and beauty. The effort on the part of the public to control this situation has varied in the different states. It has varied in both the amount and the kind of control. Public control is exercised largely through the instrumentality of the planning commissions, so that the most important thing has been the power to appoint such a body and the delegation to that body of the power of approval or disapproval of the proposed plans for all new subdivisions. This power should apply not only to newly developing lands within the city but also to all future expansions outside the city for at least 5 miles beyond the municipal limits. A competent commission will be provided with the necessary plans, especially a "major street plan" and a "master plan," with which to direct the future growth of the city. Into these plans all new schemes for development must fit.

The commission must also prepare a set of regulations to

... serve as a convenient, useful guide to those who are in one way or another concerned with the platting of land, in or close to the city, to prevent possible favoritism, unfairness or misunderstanding regarding the different steps and phases involved; to avoid as far as possible the kind of planning which is inimical to the public welfare and, instead, to promote conditions that are favorable to it.

These regulations often provide that a distinct statement as to what must be done in the way of grading and improving the property, especially setting forth every possible detail of the installation of utility mains, must be made to the commission as a condition precedent to the approval of the plot. Appropriate penalties for cases of non-conformance to the regulations are also included.

Power to Regulate Property (Police Power).-To have a city function well involves the coordination of all of its composing parts. There must also be some regulation of private property if disorder and chaos are to be prevented in the community, despite the fact that each person thinks himself ruler of his own domain. Fortunately for the city at large, some measure of jurisdiction known by the term "police power" has been provided for the accomplishment of this purpose. The inherent sovereignty in a community "to satisfy a public need in a reasonable way" held by the state and delegated to the cities has not been completely defined. It is generally described, however, as a 
power of the community, or a power inherent in the government, which allows the enactment of laws promotive of order, safety, morality, and the general welfare. This regulation of private property by the police power has been particularly useful in the platting of new subdivisions, the establishment of setback lines, and the promotion of zoning. 'The police power is also being used as a possible means of improving the appearance of the city, but only incidentally.

Power to Regulate Setback Lines.-The setback or front building line is defined by Frank Williams as one "beyond which on his own land the abutter must not erect buildings," the land owner retaining the right to use his land for all other purposes.'

The evidence of such a regulation is seen where there exists some degree of uniformity of positions in the buildings facing a street. Such a result may follow conformance with private restrictions that have been written into deeds by the owner of a large tract, or may represent an agreement among a number of individual owners of homes, or may follow a general requirement established by the city. In the instance last named, the setback may have been made for the purposes of widening the street, in which case it involved, of course, the law of eminent domain with compensation to the owner or owners.

Setbacks also are ordered for the purpose of providing more light and air and freedom from fire hazard by allowing more space between opposite buildings or for the purpose of keeping the noise and dust of the street away from the buildings abutting thereon. Setback lines also prevent the creation of blind corners at the intersections of streets and maintain open spaces. The police power can properly be used to effect a setback wherever such a provision bears directly upon the health and safety of the population. Building lines, as representing front yards, are expressions of the police power; street widenings are expressions of eminent domain.

Building lines are sometimes fixed by ordinances passed by the common council as general provisions covering a whole section of a city without reference to any particular street. The provision of building lines, merely by means of a written text, is not altogether satisfactory, because such a text is not so easily visioned as when the whole scheme is graphically presented in the form of a comprehensive map upon which all of the building lines are shown. 
A comprehensive, consistent "setback plan" tells its own story at a glance, as in it each street has been carefully studied in plan and upon the ground. The widths, depths, and shapes of lots have been considered as well as the abutting streets, and greater setbacks have been provided in the residential sections than in those devoted to business. The narrower the streets the more generous relatively are the setbacks. The nature and scope of future developments have to be taken into account as well as future traffic and the effect of the proposed building lines upon the use and value of the abutting property.

Even such comprehensive plans for building lines as above described will never be adopted by the city council without first having given to any taxpayer who may feel aggrieved ample opportunity to appear before a board of appeals and there to state his objections.

Power to Prevent Buildings in Mapped Streets.-The removal of houses that stand in the path of extensions of streets is a frequent source of delay and of additional expense to the city. The presence of such houses can be avoided in large measure by having the streets mapped and letting the people know that they are so mapped. The cost of aquiring the land and of laying out streets in unused portions of the city in advance of their need often prevents the development of those streets, but the fact that they are to be developed should be anticipated in a plan of future streets. Until the time when a given street is to be developed, owners of property always feel that they should be permitted to use their property as they choose, regardless of future plans and should be allowed to locate their buildings where they desire, and frequently such owners feel that if they refrain from using their land as they wish, they ought to be compensated by the city for their sacrifice. It is an important thing, however, for the city to exercise its power to prevent an owner from building a home in the path of a future street already mapped but not as yet opened, as by so doing it may not only remove an obstruction to the development of the future street but also avoid the possibility of protests and misunderstandings and the payment of damages that would otherwise be sure to follow and lead to delays and even to a change in the direction of the proposed street.

The remedy for all of these difficulties lies not only in planning the streets intelligently, definitely, and permanently but also in 
providing in the building department of the city regulations that will prevent any construction of buildings within the lines of a future street when once mapped. The municipal rules should require that the intending builder must file a notice of his proposal before the proper board, so that the city will be given opportunity to prevent the building and even to acquire the land at that time, if such a course be deemed desirable by the executive officer or board having authority in such matters. All this can be accomplished by taking an easement in present buildings or by forbidding them under the police power.

Power to Zone.- - That power which aims to regulate the uses and intensity of uses to which properties within a city shall be put, the heights to which structures upon them shall ascend, or the area that such structures shall occupy-namely, the power to zone-must come from the state. The delegation of that authority to the various cities is made possible through what is called an "enabling act," which grants this jurisdiction to cities. Most of our state legislatures, with varying provisions, have delegated that power by such enabling acts.

The scope of these acts can best be shown by an examination of a recent model or standard State Zoning Enabling Act as prepared by the U. S. Department of Commerce. This model, which has been followed with some modification in the laws of several of our states, bases the grant of power upon the ground of promoting the health, safety, morals, and general welfare of the community. It provides for dividing the municipality into districts of varying number, shape, and area. It sets forth a method of procedure and provides for future modifications. The power to appoint a zoning commission is given and the powers and limitations of that commission are set forth. Finally, it creates and outlines the powers of a board of appeals and provides penalties in cases in which provisions of the act are violated.

Power to Control Appearance.-The question of legal authority for the control of esthetic effects centers around private property. The city has absolute control over its own property and with the aid of eminent domain can acquire private lands and transform them into esthetically gratifying pleasure ways, parks, and playgrounds or can build upon such acquired land memorials, halls, monuments, or statues. Improvements, however, that depend upon compensation for their accomplishment must needs be 
limited when it comes to the regulation of beauty upon the private property which constitutes so large a portion of the area of the city.

To force upon the individual freeholder an esthetic improvement, the police power is drastic, especially when one considers that the individual must bear his expense alone, whatever cost such an esthetic improvement may happen to impose. Although the courts have been slow to place any such burden upon the freeholder, at the same time they have been rendering their decisions upon other grounds by making a broader, more liberal interpretation of the terms " order," "safety," " health," "morals," and "public welfare." As an example of this, although billboards have not been forbidden on account of unsightliness, they have been forbidden on account of hazard from fires and windstorms, concealment for dumping grounds or for the criminal, and because of serving as an obstruction to light, sunshine, and air, which are conducive to the health and comfort of the people.

In Santa Barbara the accomplishments through an architectural Board of Review, following the earthquake of a few years ago, represent the first and most outstanding municipal attempt to exercise control over private property. Today the beautiful buildings in the business section of Santa Barbara testify to the desirability of such a public control if well supervised. Entirely different from public control has been the architectural control exercised over some of our prominent subdivisions. This control has been accomplished through covenanted agreements between the corporation owning the land subdivided and the individual purchasers of lots within the subdivision.

The trend of the courts in the direction of esthetics is well stated by Newman F. Baker in his "Legal Aspects of Zoning":

It is predicted that the time is not distant when the courts of our country will hold that reasonable legislation affecting the property of the individuals will be considered constitutional if passed to promote the well-being of the people by making their surroundings more attractive, their lot more contented, and by inspiring a greater degree of civic pride. The decisions denying that the suppression of ugliness is a necessity do not settle the question for all time. As soon as the average person may be thought to have developed an appreciation of the beautiful, the courts will, no doubt, sanction legislation for esthetic purposes. Whenever things once considered luxuries become, in the course of progress, necessities, the courts may be depended upon to treat them as such. 
Power to Administer the Activities of City Planning.-The destinies of a city planning program are in the hands of officers or boards duly appointed for that purpose. It is indispensable to have a permanent, impartial, and highly respected official commission, lipon which shall rest the responsibility and the planning for the city. Such official commissions receive no remuneration but may hire a corps of assistants and receive the advice of trained consultants. It is common to create commissions of nine members, including three exofficio representatives of the city government.

The commission is required to adopt rules of business, keep records, and elect its chairman from among the appointed members and is allowed to hire employees necessary to carrying on its work.

The main duty of the commission is to make and adopt a master plan for the physical development of the municipality or for those outside areas that are important to the life of the city. The commission should, as time goes on, have the right also to restudy, amend, extend, or add to the plans.

Construction of streets, parks, public buildings, and other public utilities should be made to await the authorization of the commission. The commission further should have the power and the necessary funds to employ publicity men and to use other means of an educational nature to arouse public interest in its work.

Power to Finance City Planning Projects.-The power to raise money for projects of public improvements is essential to the conduct of the affairs of every city. There are four common methods of exercising this power, all of which are further discussed in other chapters.

1. To take the money from the current revenues.

2. To issue and sell municipal bonds.

3. To assess the owners of abutting property for the increased value of their lands, alleged to be due to the public improvement in question.

4. To exercise, the power of excess condemnation, which, however, is less important as a means of reimbursement than it is a means of controlling development.

Taxation is the principal method for the raising of current revenues but is not so frequently employed for the financing of improvements in city planning as are the second and third 
methods. Since the future receives its share of benefit and the improvement is intended to serve the people for many years there is ample reason for municipal borrowing in the form of bonds. The debt limit of such borrowing varies from 1.5 to 10 per cent of the assessed valuation of the real estate in the city. Municipal bonds are usually repaid to the lender in installments over a period of years and bear interest at a specified rate upon all unpaid balances.

One of the most important means of financing for projects of city planning is by the assessment of benefits upon the owners of abutting property or of other contiguous property. By this procedure the land in the neighborhood of an improvement is presumed to receive a special advantage. If the owner of abutting property is the sole or main beneficiary of the development, he will be obliged to pay the major cost. If the other lands in the neighborhood share the good of the project, the cost is spread over the whole area by a graduated assessment.

Standard City Planning Enabling Act.-Most of these necessary powers above outlined and others mentioned later are included in the Standard City Planning Enabling Act. This act, like the Standard Zoning Enabling Act, was submitted for the use of the states by the U. S. Department of Commerce. Within that commendable act, which has since been enacted by the legislatures of a number of our states, provision is made for the appointment, powers, procedure, and duties of both city planning and regional planning commissions; for buildings located in mapped streets; and for control of subdivisions. The act is fully annotated and explained and carries behind it the experience and best thought of the country. Although modifications in the phraseology and even in the substance are to be expected, as this act becomes incorporated into the laws of our various states, the fact remains that together with its sister act providing for standard zoning, it is one of the chief grants of authority for city planning in this country.

\section{Questions for Discussion}

1. Explain what is meant by the term "eminent domain."

2. What is excess condemnation?

3. Discuss platting laws and regulations in the United States.

4. Explain the meaning of "police power."

5. How may "setback" ("front building") lines be regulated?

6. How prevent the construction of buildings in mapped streets? 
7. What is meant by the power to zone?

8. What has been the progress of architectural control?

9. What is meant by the power to administer the activities of city planning?

10. What is meant by the power to finance city planning projects?

11. Give an analysis of the Standard City Planning Enabling Act.

12. Discuss outstanding recent city planning legislation, local and national.

\section{References}

. Advisory Committee on City Planning and Zoning, U. S. Department of Commerce, A Standard City Planning Enabling Act, 54 pp., Government Printing Office, Washington, D. C., 1928.

Augur, T. B.: Platting Laws and Regulations in the United States, Landscape Architecture, vol. 14, pp. 15-26, October, 1923.

Baker, N. F.: "Legal Aspects of Zoning," 182 pp., Chicago University Press, 1927.

Cheney, C. H.: Progress in Architectural Control, Proceedings 19th National Conference on City Planning, pp. 248-268, 1927.

Excess Condemnation in City Planning: A Symposium, Proceedings American Society of Civil Engineers, vol. 51, pp. 1416-1452, September, 1925; with discussion, pp. 1861-1872, November, 1925; pp. 2073-2074, illus., plans, December, 1925.

Lewis, Nelson, P.: Restrictions, City Planning Legislation, "Planning of the Modern City," pp. 260-285, 320-337, John Wiley \& Sons, Inc., New York, 1916, 1923.

Nolen, John; ed.: "City Planning," Public Control, by Frank B. Williams, pp. 48-85, D. Appleton \& Company, New York, 1929.

Sheridan, L. V.: Building Line Zoning, Proceedings American Society of Civil Engineers, vol. 51, pp. 214-217, February, 1925.

Williams, Frank, B.: "The Law of City Planning and Zoning," 738 pp., The Macmillan Company, New York, 1922. 


\section{CHAP'TER XXII}

\section{PAYING FOR CITY PLANNING DEVELOPMENTS}

In the last analysis, city planning is directly dependent upon the finances available for the purpose. The city plan must first be made, and if it be adopted by the city, it must be carried out. That costs money, and all of this money has to be raised. The permanent improvements involved in the plan may have a service value, as, for instance, in the case of public schools, and yet make no financial return. If, however, the permanent improvement be a public utility such as a supply of water or a system of transit, a revenue can be derived from the service rendered.' Permanent improvements may have only a local use, or they may be of general importance to the life of the whole urban population. The character of the service supplied by these permanent improvements will govern the way in which the money necessary for their installation and upkeep will have to be raised. The cost of permanent improvements may be charged, in whole or in part, against the tax levy of the city, or the necessary money to pay for such improvements may be raised by an issue of municipal bonds. The cost of such buildings as libraries and schools or such structures as bridges that serve the whole city equally is met by the city at large. The costs of such permanent improvements as pavements or streets are often met in whole or in part by a special assessment made against those who own the properties abutting upon the improved streets.

Taxes and Bonds.-American cities derive the great bulk of their revenues from taxes. If taxes are too high, they help to pyramid the expenses of living and of conducting business; and when they are too low, the public improvements necessary for the welfare and progress of the city cannot be made. There is much variation in the rate of taxation, as every city has its own policy in this regard and conforms to its individual limitations as to the purposes for which its taxes shall be levied, the amount that must be collected, and the methods of collection. In fact, the limitation of the taxing power of the city council is so frequent 
that cities resort to all kinds of subterfuges in order to secure the funds needed for permanent improvements. City taxes should be used only to meet the current expenses of the city's administration. To make costly permanent improvements and to pay for them entirely out of the current taxes is to impose upon the taxpayers of the city too heavy a burden. It is only just that the cost of an improvement that is built to last from 10 to 50 years should be shared by the generations that will use it in the future as well as by the people who build it. Such sharing by succeeding generations of citizens of the cost can be accomplished by borrowing the sums needed for the permanent improvement upon an issue of municipal bonds and paying these bonds gradually through a period of years that will not exceed the usefulness of the improvement. That is, the cost can be borne by the issuance of municipal bonds, the entire issue of which matures at once, or of bonds which may be called in and retired before maturity, or of serial bonds which will mature in installments.

Several years ago, Nelson P. Lewis deplored the short-sighted and reckless use of municipal bonds for financing permanent improvements, the adoption of a scheme of improvement, for example, the money to pay for which was borrowed for a term of 50 years, while the improvements for which the bonds were issued could be of service for only 10 years. Mr. Lewis says that the city's credit is improperly used when any municipal improvement is paid for with money borrowed upon bonds issued for a period longer than the possible or even probable life of the improvements to be made.

Limits of legal debts upon the issuance of municipal bonds are provided by state statute or charter provision in many of our cities and vary anywhere from 1.5 to 10 per cent of the assessed valuation of the urban real estate at the date of the issuance of the bonds. This limitation is intended to check extravagant and reckless borrowing, since excessive borrowing, according to F. B. Williams, may become more injurious to the progress of a city than excessive taxation.

Special Assessment (Betterment or Local Improvement Tax).The obstacles set up by the legal limitations on the borrowing and taxing power of cities can be overcome in large degree by special assessments. Philip H. Cornick speaks of a special assessment as a tax proportioned to the unearned increment that will accrue 
to adjacent properties as a result of an improvement (Figs. 148, 149). Special assessments are based on the principle of putting the burden of the cost of the contemplated improvement upon the properties that are directly to be benefited by that improve-

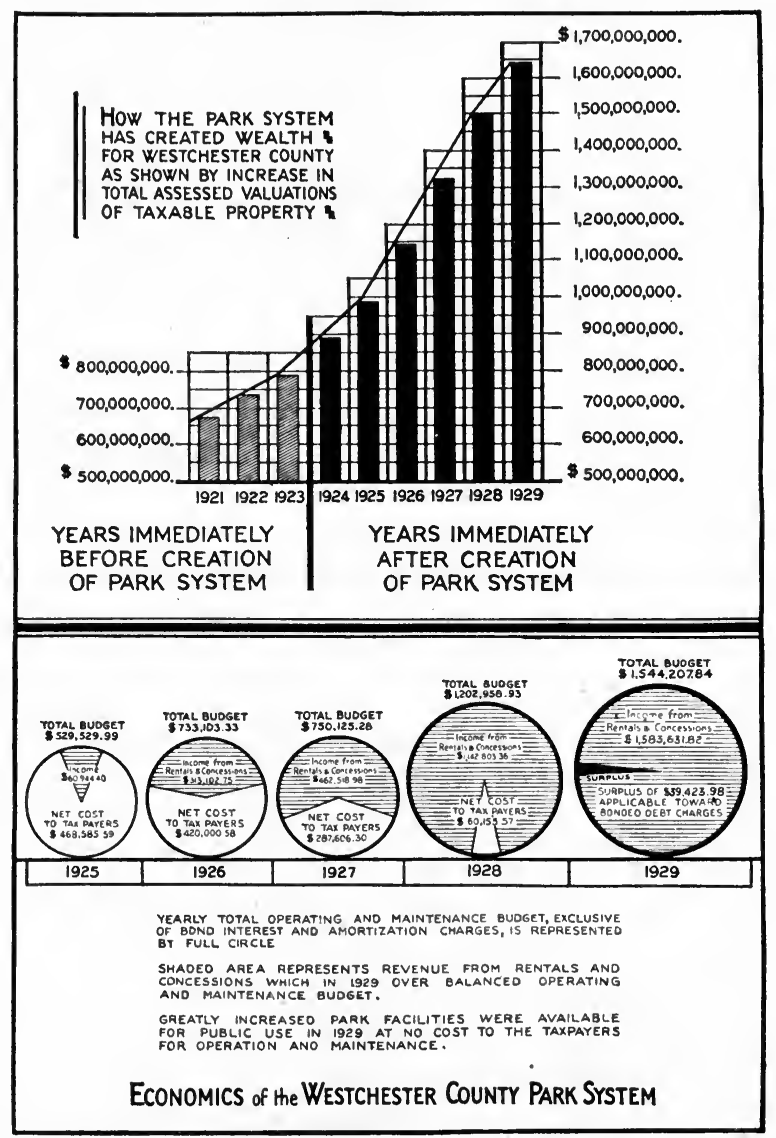

FIG. 148.-Diagram indicating how a park system has created wealth. 1930 Report, Westchester County Park Commission.)

ment and are particularly adapted to local needs and local improvements. William Anderson ${ }^{1}$ believes this form of financing to be eminently just, as it permits of public improvements in any given locality withoue holding up or endangering other public projects and without increasing unduly the tax rates or 1 "American City Government." 
the city's debt. Special assessments reach much property that is exempt from ordinary taxes and relieve the burden of general taxation. They are as certain of collection, moreover, as ordinary taxes.

So well did Nelson P. Lewis think of special assessments that he wrote: "To the degree that the assessment plan is adopted, to the same degree will the city place itself upon a cash rather

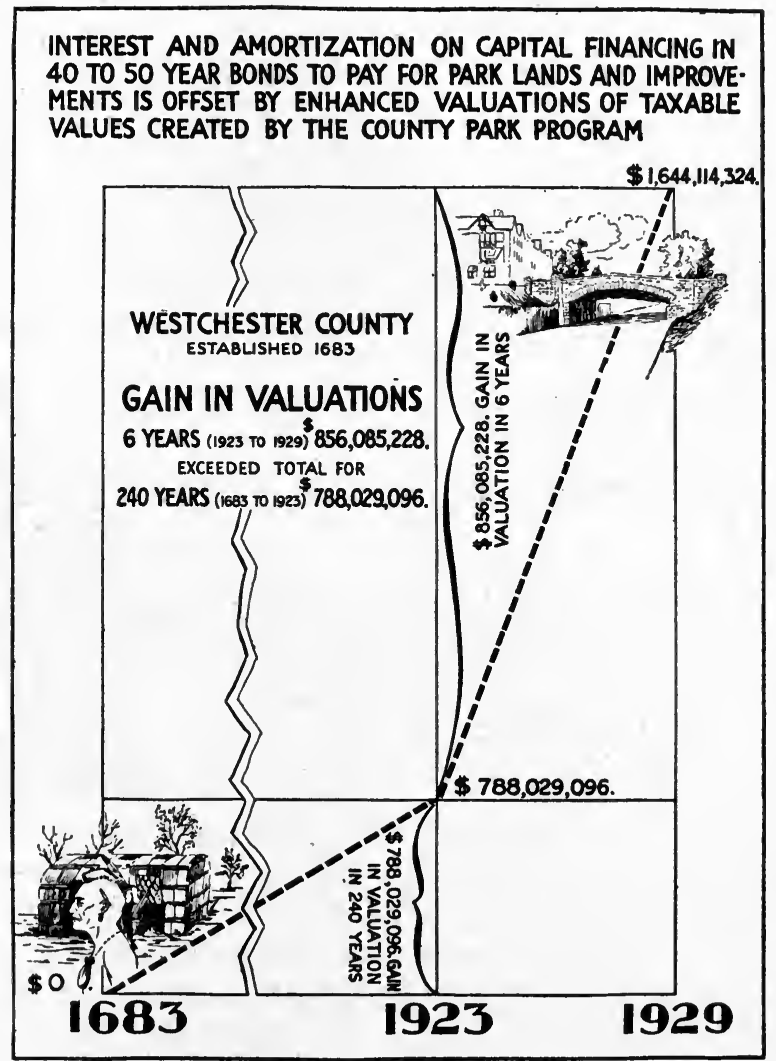

Fig. 149.-Gain in valuations. (Courtesy of Westchester County Park Commission.)

than upon a credit basis," and he made the important pronouncement that where there is local benefit, there should always be local assessment. Those whose property gains in value.by a public improvement ought to contribute proportionately to the cost of that improvement. The assessment against each prop- 
erty that will be benefited should be in direct proportion to but not in excess of the benefits conferred by the improvement.

Principles Underlying Assessment of Cost.-There should be some agreement as to the underlying principles of the special assessment to pay for the proposed improvement. Special assessments are employed in an attempt to make an equitable distribution of the costs of the improvement upon the land directly benefited thereby and of the diminishing benefits to other lands that while not facing the improvement are still to some extent so benefited. It is an effort to take account of the variations in benefits, from an improvement over a given area-benefits that decrease as the distance from the improvement decreases.

L. W. Hoelscher observes in this connection that where property is of fairly uniform value, the variation in benefit seems to be in accordance with a square-root curve that varies inversely with the distance from the improvement. Where there is a great difference in the value of the property, this rule will not hold, and the only one that will is that assessments should be proportionate to the benefits.

Harland Bartholomew mentions three things of special importance that need to be considered in connection with improvements of streets. First, that the values of land increase in proportion to the intensity and volume of traffic over the street upon which it abuts; second, that the establishment of an artery of traffic tends to stabilize the values of land in the district traversed by it; third, that the value of land is increased, to a large extent, by its proximity and access to certain established focal points. In connection with the first of these notations, it is not amiss perhaps to emphasize also the importance of the kind and character of the traffic. In addition to these, factors such as the area, topography, normal fair value of each piece of property before improvement, and probable fair value of the property after improvement ought also to be considered.

\section{SPECIAL ASSESSMENTS}

Streets.-For the improvement of streets, primarily residential, it is fair to assess the entire cost against the abutting property. The total cost of local streets in unbuilt areas and a part of the cost of the major highways should be charged against adjacent properties, so great is the benefit to the property affected. It 
would be obviously unfair to the taxpayers in general to improve these local outlying areas at the expense of the entire city. The right to assess against properties in the neighborhood the cost of improvements which involve no taking of land is universally recognized in the United States.

Parks.-Small parks, like minor streets, are more especially a source of local benefit. The light and air that they afford to neighborhoods make them so. Large parks also afford a certain

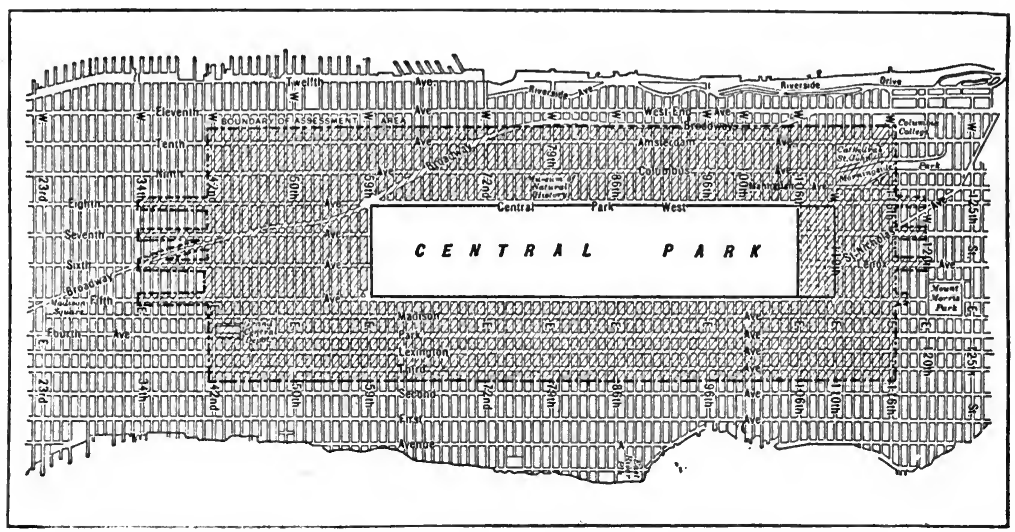

FIG. 150.-Diagram showing area over which cost of Central Park, New York, was spread; 32 per cent of the cost was spread over the cross-hatched area surrounding the park. (Illustration from Planning of the Modern City, by Nelson P. Lewis.)

measure of local benefit, but the radius of that benefit depends upon the size and shape of the park as well as upon its proximity to residential sections of the city and its accessibility to the people. The assessments for the park will bear most heavily upon the abutting properties and will decrease with the distance, according to Mr. Lewis, in what should be a geometrical ratio.

Districts for parks can be organized for purposes of assessment, as in New York City (Fig. 150) and many other cities. The entire expense of the parks within Kansas City has been borne by assessment against adjacent properties without cost to the city as a whole. The expense was assessed upon the abutting properties in the six park districts in Kansas City according to the benefits enjoyed. Since the adoption of the so-called "inside Elwell law" in Minneapolis, more than 241 improvements connected with the construction and improvement of parks, at a total cost of $\$ 3,139,000$, have been carried out under its provisions. 
Area of Assessment.-There is no fixed rule of laying down areas for assessment, any more than there is a fixed rule for the distribution of the expense of planning and maintaining improvements involved. Careful study and investigation of the local problems in every case must be made. As the small town pushes out its boundaries, it multiplies its possible areas of assessment. In place of the one square and the one main street with which the small town started, several squares and centers, fed by a multiplicity of important thoroughfares, appear when that small town becomes a metropolis.

In the case of a major highway:

... the assessment area may run to a line midway between it and the next street of more than residential width. In the case of an arterial way in undeveloped territory the area of benefit may be correspondingly enlarged.

The area for such special assessment for the building of rapidtransit lines or for extensions to such lines already existing may extend for some distance on either side of the line and even to a greater distance beyond the terminals.

The boundaries of the areas to be reached by special assessments are established either by state statute or by ordinance or resolution of the city council. A city official or a special commission appointed for that purpose may also establish these boundaries. The areas over which the special assessments shall extend are, when large, divided into zones parallel with the street to be improved, and to each zone is assigned the proper percentage of the total cost of the improvement.

Methods.-The fact that no one rule of applying methods of special assessment will fit all cases and that no two special assessments can be spread in the same way explains why no standard rules of procedure have as yet been established. One method, called the "front-foot method," has been quite generally used; this assumes that the benefits conferred upon the property abutting upon the street that has been improved vary directly in proportion to the frontage of each lot upon the improved street. In certain cases in which the abutting lots are regular and at right angles, this method works out satisfactorily, especially if there be no widenings of streets and no new streets opened. The front-foot method is not satisfactory in cases in which parcels of land to be assessed are not abutting, neither is it satisfactory 
when applied to tracts of irregular shape, or for residential lots facing upon diagonal streets, when such streets produce triangular and trapezoidal lots. The "area method" of making special assessments is to compute the assessment upon each lot to be benefited by the improvement, in direct proportion to the area of that particular lot. This method can be used in assessing lots of equal frontage but of varying depth. Where, however, the costs to be met by the assessment are distributed over a large area of land, where matters of the varying and diminishing benefits to be conferred upon the several lots by the improvement must be carefully calculated, the area method must be used by dividing the area to be covered into "zones," as described above.

At times, both the front-foot method and the area method are used in attempting to solve a single problem of special assessment.

The method of procedure in making special assessments suggested by Harland Bartholemew is that we must determine the extent of all of the benefits that will accrue to each lot of land within the given area from the proposed improvement. The benefit resulting from the increased capacity of the street widened and from the greater intensity and volume of the traffic upon it will be limited to the abutting property; from the standpoint of the stability of the value of land, the benefit will spread over an extensive zone or belt with the widened street as its axis. Benefits arising from accessibility to the widened street will extend to all districts served either directly or indirectly by the wider artery created, and the special assessment ought to cover all of these districts.

Mr. Bartholemew enumerates four general rules to follow in this connection:

1. Property abutting upon the streets widened and coming within all three of the zones laid down for the purpose of making the special assessment constitutes the district of primary benefit and should bear the heaviest assessment. Property affected by but two factors-stability and accessibility-should bear a secondary assessment only, while districts still more remote by virtue of their lesser accessibility to the widened street would bear so light a special assessment as to be negligible.

2. For any given project, the benefit conferred upon the surrounding properties varies inversely as the square of the distance of these several properties from the improvement. 
For example, the benefit to property at a point 400 feet from the improvement would be one-fourth the benefit to property at a point 200 feet removed. Exceptions to this rule are strategic corners which will bear a heavier assessment and property barred from access to the improvement by natural barriers, which will not be assessed at all.

3. There may be harmful effects of a widening upon a major street extending parallel with the street improved.

In this connection let us answer the question, To what extent does the establishment of a new artery for traffic create a competitor to older traffic-bearing thoroughfares?

4. Four other factors-the frontage, area, land value, and strategic position of each lot-must also be considered in arriving at a proper special assessment.

There are those who feel that there are so many exceptions to a definite rule such as that under the above section 2 that the only true method of determining a special assessment is to find out actually how much the property is benefited, and that cannot be done by any set rule.

Graphical Analysis.- The whole project of special assessments can be facilitated for those intrusted with the work by a suggestion from the late William D. Hudson, city planner of St. Louis, who recommends a graphical presentation upon a sectional map of the following information: the value per front foot of the property affected; the total amount and number of special assessments for other improvements levied against the same property within the last five years; the ratio of the total amount of all special assessments to the assessed value of the property in question; and the probability as to whether the property in question will hereafter increase or decrease in value $\mathrm{Mr}$. Hudson suggests as further information to be spread upon the map for ready use by the assessors: the number of petitioners who asked for the improvement, the names of the owners of the property benefited, and the character of the proposed improvement.

Excess Condemnation. ${ }^{-}$-Unlike special assessment, excess condemnation (called by one writer "marginal eminent domain") is a means of securing to the city the whole of the increase in value of the abutting property instead of only a part of it. Excess condemnation permits a community to acquire private

${ }^{1}$ See also chapter on Legal Authority for City Planning. 
property in excess of that actually needed for the proposed improvement. Further, it gives to the city the power to sell such excess of land at its increased value, to aid in the accomplishment of the improvement.

Excess condemnation is of particular importance wherever there are remnants of land adjacent to an improvement left unused after the construction of a diagonal thoroughfare in any given neighborhood. These remnants, which when considered each by itself are too small for improvement, can, if combined with others, become both useful and valuable. Excess condemnation is also desirable because it prevents any inappropriate use of properties adjacent to the public improvement. Where considerable increase in the value of the abutting properties is expected, moreover, excess condemnation offers to the city a chance to condemn land in excess of that needed for the proposed improvement in order that such excess land may be sold by the city to pay or help to pay for the improvement under consideration. Excess condemnation has seldom been used in the United States. There are, however, 14 of our states that grant such authority to cities.

Long-term Financial Program.-Many of our cities are using a budget, which is intended to keep the contemplated expenditures within the limits of the expected revenues. We are coming to understand more and more the need of preparing a financial program that will cover the necessary expenditures by the city, extending over a long period of years. City planners are recommending such budgets to the taxpayers and to the officials of the cities. Such budgets show that it is possible to carry out a complete program of public improvements upon a comprehensive scale and indicate how these public improvements can be realized according to their relative urgency. The making of improvements not actually needed at any given time can be postponed. Although a financial program extending over a long term of years may have been adopted by the city, the authorization for the expenditure of money need not go beyond an amount sufficient to pay for one year's work, so as not to bind subsequent officials and so as to provide for unforseen contingencies.

\section{Questions for Discussion}

1. Of what importance are taxes and bonds in the carrying out of civic improvements?

2. How are improvements financed by means of special assessment and what are the underlying principles of special assessment? 
3. Discuss the application of the above to streets and street improvements.

4. Discuss the application of special assessments to parks.

5. What methods are employed in spreading special assessment costs?

6. Explain the meaning and importance of excess condemnation; of a long-term financial program.

\section{References}

AgG, T. R., and J. E. Brindley: Methods of Apportioning Special Assessments, American City, vol. 36, 637-639, May, 1927.

Bankson, Paul A.: Distribution of the Cost of Acquiring Streets, American City, pp. 103-104, November, 1930.

Bartholomew, Harland: Street Widening Methods with Particular Reference to Distributing the Cost, Proceedings 16th National Conference on City Planning, pp. 166-187, 1924.

Bldcher, Walter H.: What We Don't Know about Special Assessments, City Planning, pp. 291-296, October, 1928.

Buck, A. E.: "Public Budgeting," 612 pp., incl. 52 charts and tables, Harper \& Brothers, New York, 1929.

Ford, G. B.: “Can a City Plan Serve to Reduce Taxes or Debt?" National Conference on City Planning, 11 pp., New York, 1928.

- : Long Term Capital Budget Helps Carrying Out of City Plan, American City, pp. 123-124, April, 1930.

Godward, A. C.: Financing Park Acquisitions and Improvements, Parks and Recreation, vol. 5, pp. 501-503, May-June, 1922.

Hoelscher, L. W.: Assessment Principles for Street Widening, American City, pp. 108-109, July, 1930.

James, H.: Paying for City Planning Projects, "City Planning Procedure," pp. 25-31, American Civic Association, 1926.

Lewis, N. P.: Financing a City Plan, "Planning of the Modern City," pp. 367-396, John Wiley \& Sons, Inc., New York, 1923.

Purdy, L.: Financing Improvements by Special Assessments, "City Planning Procedure," pp. 19-24, American Civic Association, 1926.

Special Assessment Procedure, Special Report, State Tax Commission of New York.

Spengler, Edwin H.: "Land Values in New York in Relation to Transit Facilities,” 179 pp., Columbia University Press, 1930.

Swan, H. S.: The Administrative and Financial Machinery for Carrying Out the City Plan, American City, vol. 26, pp. 579-589, illus., plans, June, 1922.

Wrlliams, F. B.: City Planning Finance, "Law of City Planning and Zoning," pp. 357-379, The Macmillan Company, New York, 1922. 


\section{CHAPTER XXIII}

\section{EDUCATIONAL AND PROMOTIVE WORK IN CITY PLANNING}

An aroused and cultivated public interest is most important for the accomplishment of city planning. When properly enlightened as to the scope and cost of the work, the citizens are much more easily persuaded to favor a high standard in the improvements proposed, if the same be set before them by the city planner frankly and fully, than would have been the case if the voters had not been so educated. The public must always be made to understand what the proposed improvements are, their scope, their meaning, their advantages, and their cost. "One must remember that permanent progress is achieved only by educating from the bottom up, rather than by supplying plans from the top down."1

Public Education.-Arousing the interest of the community and educating the public are accomplished in many ways: Articles in newspapers and magazines, reports of conventions of city planners, circulars spread abroad, lectures by city planners either before a local audience or broadcast over the radio, exhibits and pictures of plans already adopted to improve other cities, as well as courses in city planning offered by schools and colleges are some of the means adopted.

Within the city, the work of educating the community is undertaken by the local city planning commission, although much assistance can be given to the commission by self-constituted committees of citizens. For example, a city planning committee, organized solely for the purpose of arousing public interest in the matter, can recommend with great force that the voters adopt the improvements suggested by the city plan commission, because the voters will all know that such a committee has no selfish interest in the general improvement of their city.

Among the many educational efforts in our various cities, a few are cited below', quoted in part from a report by Dr.

${ }^{1}$ A. P. Greensfelder. 
Nolen upon the subject of citizens' committees before the National Conference on City Planning held at Los Angeles in 1924.

A citizens' committee at Cleveland has included among its purposes the diffusion among the citizens of a knowledge of comprehensive city planning. This citizens' committee has carried on publicity and has raised funds for the local city planning commission and has served as a means of contact between the official commission and the people of Cleveland.

The Chicago Commercial Club, in its educational campaign in favor of civic betterment, has distributed 165,000 booklets describing the official city plan and has published 150,000 copies of Wacker's "Manual of the Plan of Chicago." The same club, moreover, published cartoons and articles favoring the plan in the daily press, distributed pamphlets prepared by the city plan commission, and conducted lectures explaining the purposes of the proposed improvements. In addition, the Chicago Commercial Club had a motion picture prepared, entitled "A Tale of One City," and exhibited the picture in all of the motion-picture theaters of the city as part of the educational campaign. A book by Walter D. Moody entitled "What of The City?" was published and distributed all over Chicago by the Commercial Club.

Outstanding educational efforts have produced the accomplishments in city planning at Dallas. These educational efforts began as early as 1902, under the leadership of George B. Dealey of the Civic Improvement League. A series of letters was published in the local newspapers in 1909, and clippings from these letters were sent to a selected list of citizens. A campaign in the News for suggestions as to the most important work of improvement for Dallas to undertake aroused the interest of the citizens in the proposed city plan. A very interesting book, moreover, "Our City Dallas" (1927), by Justin F. Kimball, which deals in large measure with the work proposed by the Kessler plan, has been made available to the school children without cost.

A United City Planning Committee was organized at Cincinnati in 1915 and started a movement for the adoption of a city plan. It sponsored educational campaigns for which it raised the necessary funds, it served as a means of contact between the public and the planning commission, and it lobbied 
before the state legislature to obtain the passage of an act giving the city of Cincinnati full power to put the proposed plan into effect.

The educational work at Johnstown, Pa., unlike the others mentioned, was conducted by the City Plan Commission itself and was characterized by the interest aroused among the pupils in the public schools. These pupils were encouraged to give illustrated lectures on city planning, and the same subject also formed a leading topic for discussion in the papers read by the graduates of the high schools at their commencement exercises. The adolescents of Johnstown were thus made the instructors of

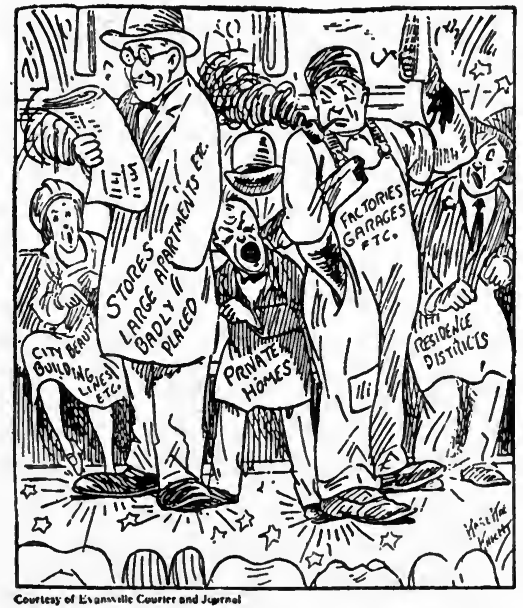

FIG. 151.-An appeal to the public. A cartoon used in the zoning publicity campaign at Evansville, Ind.

the adult population in the benefits that city planning can confer upon an urban community.

Keeping the Psychology of the Public in Mind.-In considering the various means of educating the people in their need for city planning, it is helpful to keep in mind some suggestions by Prof. H. A. Overstreet of the department of philosophy, College of the City of New York. Professor Overstreet points out that the average person is visually minded and can see more quickly than he can think, so that the visual appeal is instantly effective upon him. Where pictures are used to illustrate a lecture, the most significant and arresting ones obtainable should be used. 
Where statistics are to be employed in the lecture, they can be put into a picture in such a way as to startle and convince the beholder. Furthermore, to get the idea of city planning into the head of the average citizen at all, a dingdonging repetition of the purposes and aims behind the educational campaign is indispensable. A dramatic presentation of the facts, so shaped that those who run may read, is useful (Fig. 151). The appeal, moreover, should be made not to a single individual but to the people in groups, as people are social animals, and things shown to them when they are gathered together in assemblies much more effectively arrest their interest. If we want to persuade people to do things, we must get them in the midst of their social groups and arouse their emotions en masse.

Professor Overstreet makes the further suggestion that city plans in any stages of their development should never be presented to the people for approval but rather should be submitted to the voters for their consideration and for any constructive suggestions. The people are in that way asked to contribute their wisdom to the project, which arouses in them a spirit of friendliness toward the proposals. Both the leaders of the people and the people themselves in their social groups are thus educated in city planning, pleased with its promising improvements, and finally persuaded to adopt the project presented.

Instruction on City Planning in the United States.-The widespread and growing interest in city planning throughout the United States is being reflected by the courses now offered in the subject by our colleges and universities. Both general and technical courses in city planning are being given in at least 87 different institutions of learning in the United States, although there was until recently only one university in which city planning could be made a major subject. That university was Harvard, which until recently offered a course of 3 years in the School of Landscape Architecture, in the form of an option in city planning. With the aid of the Rockefeller Foundation it has now been organized into a graduate school of city planning and is coordinate with the schools of Landscape Architecture and of Architecture at Harvard.

The function of the school is not only to train men to be professional city planners but to give a sound conception of city planning to men who are going to be architects, landscape architects, engineers or leaders in various public endeavors, so that they may be efficient co-operators 


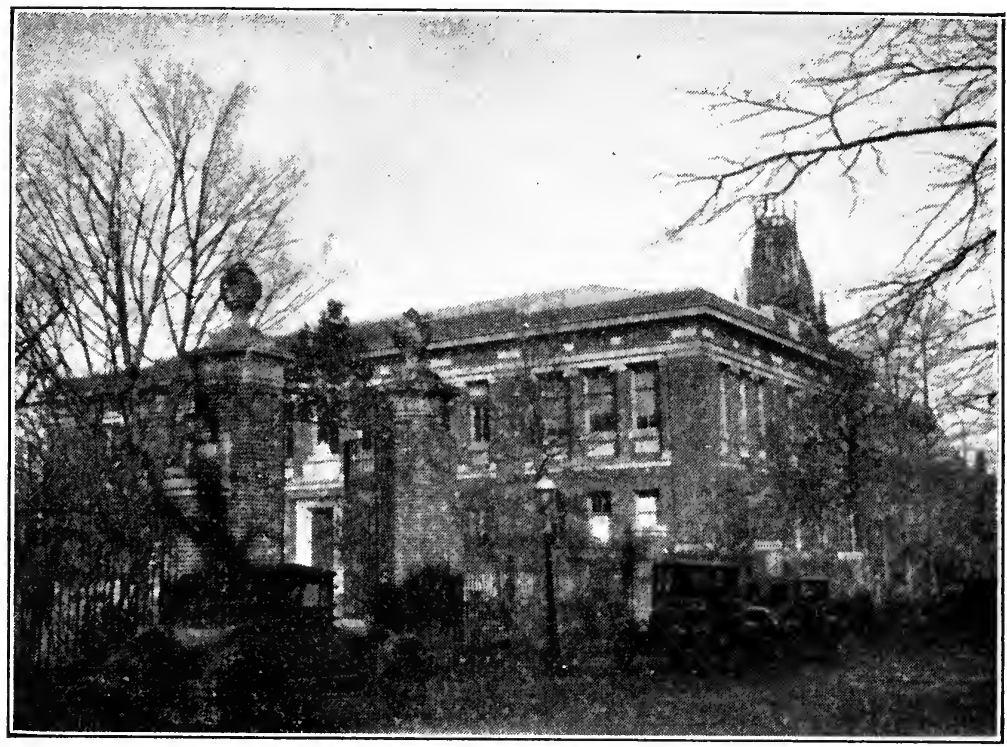

FIG. 152.- For several years the center of graduate instruction in city planning. Robinson Hall, Harvard University. (Photograph by the author.)

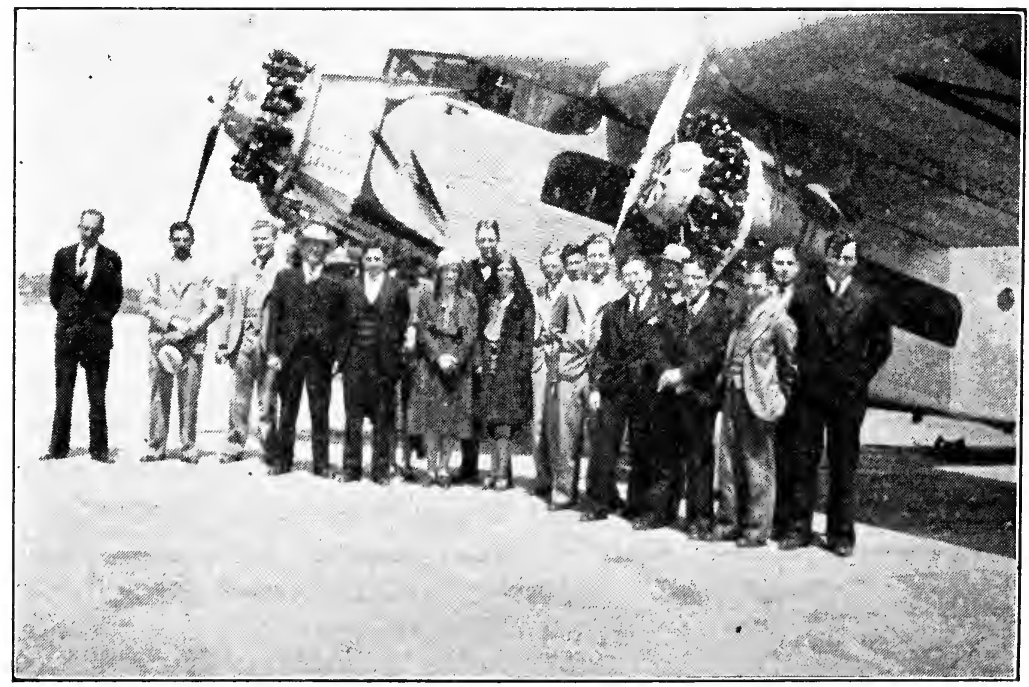

FIG. 153.- Under the auspices of the Division of Landscape Architecture at the University of Illinois, the four-day inspection tour in the general appreciation course in City Planning was completed on May 3, 1930, by an ascent into the air of sixteen of the group for a view of the Chicago region. As far as known, this was the first time that any class of City Planning, as such, included this experience in their itinerary. (Photograph by S. H. Huntington.) 
in the comprehensive field of city planning. Also, the school hopes to help many other people to be more useful members of the community as voters or as city officials or in their everyday life. The carrying on of research and the publication of information directly useful in city and regional planning will be among the principal activities of the school.

The other courses in city planning over the country are being conducted in connection with schools of architecture, landscape architecture, civil engineering, political science, sociology, etc., thus indicating the breadth of the subject and the manner in which it overlaps many related fields of work. With a realization that the work may be approached from at least two different angles on one campus, a plan has been adopted at the University of Illinois whereby options in city planning may be had in either landscape architecture (Fig. 153) or civil engineering. Perhaps the architects, political scientists, and others will as time goes on insist upon giving to city planning a similar recognition.

It seems to be the general opinion among city planners that persons training for the work of city planning should have a special training in one or more of the important phases of the subject and, for purposes of collaboration, some knowledge of the related professions.

One of the important instrumentalities for arousing public interest in city planning is the offering of general courses in the subject in a great many, if not in all, of our universities and colleges. Through the opportunity offered by such courses men and women in ever larger numbers will be fitted to become members of city planning commissions and committees, as well as writers upon the subject and promoters of it. At least people so trained will supply much valuable leaven in the civic masses of which they shall thereafter become a part.

The difference between such general courses in city planning and those of the so-called "professional type" is that they offer less technical and a little more popular information, or, as Prof. George B. Zug of Dartmouth has described it, "a comprehensive course with a general appeal." Such a general course will not, however, teach how to pave streets, or how to build private houses and city halls, or how to finance the enlargement of systems of water supply. Such general courses should comprehend a logical and cumulative arrangement of topics, a 
sequence of lectures leading to a climax, each theme taught being accompanied by certain required readings in substantial books upon the subject, the readings being afterward tested by quizzes or examinations. In all likelihood, such general courses in city planning will fit best into the junior, senior, or graduate years at the universities, although there is no particularly good reason why they should not be offered in the freshman year when so desired by the student. It is entirely possible that such courses might also be introduced into the secondary schools.

State Participation.-Outstanding among the efforts of states to promote interest in city planning are those made in California, Iowa, Indiana, Massachusetts, New York, Ohio, Pennsylvania, and Wisconsin. The Massachusetts Federation of Planning Boards has been functioning since 1915 with annual meetings and the publication of bulletins and has been cooperating with the Division of Housing and Town Planning of the State Department of Public Welfare.

The Conference on City Planning in California has published bulletins to promote city planning and zoning in that state. The California Commission of Immigration and Housing, however, is the official state agency to promote the work of city planning.

Pennsylvania has two unofficial bodies-the Pennsylvania Housing and Town Planning Association and the Pennsylvania State Association of City Planning Commissions. The official body in which the city planning activity of the state is vested is the Division of City Planning and Municipal Engineering of the Pennsylvania State Bureau of Municipal Affairs, and under its direction much interesting activity has been initiated among the municipalities of Pennsylvania.

Ohio has its State Conference on City Planning, which has conducted several annual conferences and successful campaigns. Indiana has its State Conference on City Planning. The Iowa Town Planning Association has been active and successful. In addition, other state, work has been accomplished by the extension activities in city planning that are being conducted by Iowa State College, at Ames, Iowa.

The activities in New York State include a Bureau of Housing and Regional Planning (1923) in the New York State Department of Architecture. Educational activities in city planning have been listed among the programs of the New York State Conference of Mayors and other city officials. 
A Wisconsin City and Regional Planning Association is also among the state educational agencies concerned directly with city planning activities.

There are leagues of municipalities in some of the states such as in Illinois, Michigan, Minnesota, and Texas that are furthering city planning as part of their work.

National Organizations Furthering City Planning Education.A number of national organizations formed primarily for promoting interest in engineering, the arts, architecture, landscape architecture, housing, parks, recreation, civic and municipal welfare, commercial interests, and the sale of real estate are comprised among those that are promoting city planning. The most important of these national bodies are the National Conference on City Planning, devoted solely to the promotion of city planning; the American City Planning Institute, composed of those engaged in the work of technical planning; and the $U$. S. Department of Commerce, which last-named organization does the very useful job of collecting and disseminating information about city planning and zoning. The National Housing Association, the City Planning Division of the American Society of Civil Engineers, the Committee on Community Planning of the American Institute of Architects, and the American Society of Landscape Architects should all be included because of their special contributions to the subject.

City Planning Periodicals.-There are 24 important periodicals in the United States that offer space to matters of city planning and zoning. Outstanding among these are City Planning (City Planning Publishing Company, 9 Park Street, Boston, Mass.) and the Amprican City (443 Fourth Avenue, New York City). The organs of the various professional organizations interested in this field and magazines covering the various related subjects give space and important thought to the matter. The engineering, architectural, landscape architectural, and housing magazines are also particularly useful.

Several important publications are to be had in England. Among these are the Journal of the Town Planning Institute (11 Arundel Street, London) and the Garden Cities and Town Planning Review. The Journal of the Town Planning Institute of Canada (Ottawa) is also important.

A few city planning magazines are to be had in foreign languages. These are published in Belgium, Holland, Mexico, 
Cuba, France, and Germany. Der Städtebau, a German monthly (31 Markgrafenstrasse, Berlin, W 8) is an interesting and worthwhile periodical.

Local Civic Publications.-As part of the program to enlighten the people and gain their support for enterprises of city planning, a number of our cities have assumed the task of issuing publications pertinent to the promotion of civic betterment. Among these are to be noted the following: ${ }^{1}$ the Baltimore Municipal Journal (issued twice a month); Current Affairs, a weekly put out by the Boston Chamber of Commerce; Buffalo City Facts, distributed now and then by the Buffalo City Planning Association; Greater Cleveland, sent around once a week by the Citizens League of Cleveland; Denver Municipal Facts, which appears twice a month under the joint sponsorship of the city of Denver and the county of Arapahoe; Civics for Houston, a monthly magazine published by the Forum of Civics; Regional Planning Notes, a weekly publication issued by the Regional Planning Commission of Los Angeles; the Bulletin of the City Club of New York, a monthly; Greater New York, likewise a monthly and published by the Merchants Association of New York; Progress, a monthly periodical published by the Pittsburgh Citizens Committee on City Planning; and Plan-it, a mimeographed monthly prepared by the City Planning Commission of Portland, Ore.

\section{Questions for Discussion}

1. Discuss means of gaining the public support for a city planning movement.

2. Tell how the city planning committee (as distinguished from a city planning commission) may further a program of improvements.

3. Cite educational efforts undertaken by several of the cities in this country and by several of the states.

4. What national organizations, what city planning periodicals, and what civic publications are furthering city planning?

5. To what extent and in what way are the centers of learning offering the subject of city planning?

6. In arousing the public interest how must the psychology of the public be considered?

7. Outline a program and plan of procedure for the improvement of a city.

\section{References}

Adshead, S. D.: Town Planning Education, Journal of Town Planning Institute, vol. 14, pp. 95-99, with discussion, pp. 100-105, March, 1928. 1"Planning Information Up-to-date," Hurbard and McNamara, 1928. 
City Planning. Instruction in Schools and Colleges of the United States, by the Secretary of the National Conference on City Planning, City Planning, January, 1929.

Dealey, G. B.: The Newspaper as a City Builder, American City, pp. 129130, September, 1930.

James, H.: "Civic Improvement in Your Town, a Program and a Plan of Procedure," 40 pp., illus., plans, American Civic Association Series, vol. 3, No. 2, Washington, D. C., May, 1927.

Kimball, J. F.: "Our City-Dallas. A Community Civies," 384 pp., illus., maps, Kessler Plan Association, Dallas, Tex., 1927.

Kingsley, S. C.: Methods of Winning Public Support for a City Planning Program, Proceedings 14th National Conference on City Planning, pp. 174-181, 1922.

Moody, W. D.: "What of the City?" 441 pp., illus., plans, A. C. McClurg \& Co., Chicago, Ill., 1919.

Moody, W. D.: "Wacker's Manual of the Plan of Chicago," for use in public schools, Chicago Plan Commission, Calumet Publishing Co., Chicago, Ill., rev. 1916.

Overstreet, H. A.: Arousing the Public Interest in City Planning, American City, vol. 38, No. 6, pp. 85-89, illus., June, 1928.

Robinson, C. M.: Popular Education in Art, "Improvement of Towns and Cities," pp. 237-252, The Knickerbocker Press, 1913, etc.

W Acker, C. H.: Gaining Public Support for a City Planning Movement, Proceedings National Conference on City Planning, pp. 222-243, 1913. -: Perseverence in City Planning, City Planning, vol. 1, pp. 3-5, April, 1925.

ZUG, G. B.: City Planning as a Subject for Undergraduate Courses in Colleges, Proceedings 18th National Conference on City Planning, pp. 191-196, 1926. 


\section{CHAPTER XXIV}

\section{CONCLUSION}

As the miracle of change continues to transform our countryside into urban centers and our towns into supercities, more and more must we look to the services of the city planner to guide us in fashioning these towns and cities. As the growth of our urban population continues, as the new means of transportation on land and in the air become practical, as the problems of providing satisfactory living quarters and adequate recreational facilities for our city dwellers become ever more pressing, the need for skilled advice and guidance becomes more urgent.

The profession of the city planner is necessary, either to correct mistakes in the designs of our cities that are already built or to prevent such mistakes in cities about to be built. As for the cities already built, so resistlessly have many of them moved in the direction of concentration, that much effort will still be needed to counteract the evil effects of the intensive pyramidal building to ever greater heights. The effort needed to counteract these increasing evil effects will include an inevitable retinue of remedial devices, multiple-decked streets, and sidewalks as well as countless other features of which we have not as yet even dreamed. While the trend of city building continues in this manner, corrective city planning will be obligatory to prevent as much as possible the evils coming from the constant pouring of people into areas already oversaturated, with the resulting increase in the values of land, exploitation of the population, and aggrandizement of a handful of landlords.

The help of city planning, however, can be much more effectively applied in preventive activities. Rather than encourage the upward-reaching process of the city's growth, how much better it is to promote the outward-spreading type of city, either by restriction in the height of the buildings or by recentralization, which involves the distribution of the population into smaller self-contained communities outside the central city.

A more rational provision for the development and expansion of our cities will substitute spaciousness of area for our present 
congestion; the ordinary activities of urban life will then be coordinated. so that the citizen may live in safety and have around him plenty of sunshine and open stretches of land. Work as well as wholesome recreation will in the future be near at hand. Under such circumstances the country will penetrate the town, and the town the country, and the art and science of comfortable human existence will be mastered. All of these promising possibilities will furnish for our communities an environment that will provide for our city dwellers the real satisfactions of life.

In our discussions of the various topics of city planning in the foregoing chapters, we have tried to discover both the past and contemporary achievements in city building. We have given thought to the problems of traffic movement and circulation, of homes spread out where air and sunlight may bathe them, of work effectively located, of parks and playgrotends close at hand, of the interdependence of communities and activities in metropolitan regions, of order and beauty as a contributing element in the enjoyment of the people.

We have noted the lesson of beautiful location as represented by San Francisco or Chicago; of a splendid system of parks as shown by Boston, Minneapolis, and Westchester County; of advanced ideas in the layout of subdivisions as in Palos Verdes, Coral Gables, or the country club district of Kansas City. We have considered successful housing enterprises, as represented by the achievement at Sunnyside Gardens; fine buildings well located, as in Washington; and arrangements for streets and homes, devised to fit our motor age, as exemplified by Radburn. We have been interested in the distinct beauty of a business district, such as one may see at Santa Barbara; and in the charm of the architecture and gardens as well as in the quaint individuality of New Orleans, Charleston, and Salem. Although these scattered excellences have not as yet been combined into a single picture or into a number of separate urban pictures, yet there is a possibility that by the use of an imagination both practical and courageous, some future planner may accomplish such a result.

The greatest lesson, however, to be derived from a study of city planning is the realization that the city is something more than an inert and lifeless thing. We find it to be a complex organic structure that pulses with life. The city is so constituted as to carry on its activities automatically like a living thing. 
Because the city is a living organism, no one of the mutually dependent activities of a city is more important than another. All of them must work together, if the great living organism is to function effectively for the efficiency and happiness of the people who have created it. Thus art and engineering must not and cannot sit in judgment upon each other on opposite hilltops. They must meet at a common trestle board as copartners in a common task.

The task of creating or replanning cities is the job of no one man and of no one profession but of many men working in many professions. This task should be entered into by the student who has the largest spirit of cooperation with the students of cognate fields of work and also a sympathetic understanding of those cognate fields. City planning demands of its students an active imagination and an ability to make adequate and effective plans and demands from the public an understanding and a support of the execution of these plans. City planning embodies research by its students into misunderstood and unexplored phases of the work and a larger exchange of the results of these researches than is now common.

Just as city planning in the past has contributed of its best to civilization, let us hope that its results in the cities of the future will justify these words of the novelist:

But who can tell of the fullness and pleasure of life; who can number all of our new cities, cities made by the loving hands of men for living men, cities men weep to enter, so fair they are, so gracious, so kind. ${ }^{1}$

\section{Questions for Discussion}

1. Why is the profession of the city planner more and more necessary?

2. How can the help of city planning be applied to preventive activities?

3. Why is the conception of the city as an organism important or the whole city more important than its parts?

4. Why is one mutually dependent phase of city planning as important as another?

5. Outline a theory of rational development and expansion for cities.

\section{References}

Baker, M. M.: Interest of the Engineer in City Planning, City Planning, vol. 1, pp. 41-42, April, 1925.

Betrman, A.: Relation of Lawyer to Other Professions Engaged in City Planning, Proceedings American Society of Civil Engineers, vol. 55, pp. 667-669, March, 1929.

${ }^{1} \mathrm{H}$. G. Wells, "In the Days of the Comet" 
Bigger, F.: Relationship of Architecture to City Planning, Journal of American Institute of Architects, vol. 15, pp. 155-158, May, 1927.

Child, Stephen: Of City Planning, "Landscape Architecture," pp. 163210, Stanford University Press, 1927.

Ferriss, Hugh: "The Metropolis of Tomorrow," 142 pp., illus., Ives Washburn, Inc., New York, 1929.

FlagG, E.: City of the Future, Scientific American, vol. 137, pp. 238-241, 334-337, September, October, 1927.

Giant Power: Prospect of Electrical Superpower Systems and the Probable Consequences for City and Country, Survey Graphic, vol. 4, No. 6.

Hubbard, H. V.: The Profession of City Planning, City Planning, vol. 3, pp. 201-203, July, 1927.

Ihlder, J.: The City of Tomorrow, Nation's Business, vol. 16, pp. 18-20, September, 1928.

LeCorbusier [Jeannert, Charles Edouard]: “The City of Tomorrow and Its Planning," 301 pp., illus., Payson \& Clarke, Ltd., New York, 1929. Mumford, Lewis: "The Story of Utopias," Boni \& Liveright, New York, 1922.

Nolen, Jонn: Town Planning and Its Relations to the Professions Involved,

Proceedings American Society of Civil Engineers, vol. 52, pp. 16121618, October, 1926; with discussion, pp. 1873-1875, 2049-2050; vol. 53, pp. 121-123, November, December, 1926, January, 1927. : "The Next Twenty Years in City Planning," pp. 45-58, National Conference on City Planning, 1927.

The Scientific City of the Future, Forum, vol. 76, p. 823, December, 1926. Solon, Leon V.: Titan City Exhibition, vol. 59, pp. 92-94, Architectural Record, January, 1926. 


\section{INDEX}

(Boldface numbers indicate illustrations)

A

Abercrombie, P., 301, 340

Accidents due to motor cars, 91

Ackerman, F. L., 244, 315

Acropolis (Athens), 25

Adams, T., 16, 109, 184, 340

Administration of city planning, 349

Adshead, S. D., 4, 371

Agache, Alfred, 64

Agg, T. R., 362

Air trip by class in city planning, 367

Airport structures, 148

administration buildings, 148

ambulance stations, 148

control stations, 151

fences, 151

garages, 148

hangars, 151

housing of personell, 148

lights, 151

loading platforms, 148

meteorological department, 148

shopping facilities, 148

terminal buildings, 148

Airports, 139-157

airship dock, Akron, 155

airship facilities, 155

aspect of field from air, 152

cost, 152

development of landing fields, 146

distribution, 139

number of sites, 139

operation, 153

ownership, 153

prevailing winds, landings, and take-offs, 147

prize plan, 150

seaplane landings, 154

sites, 141
Airports, sites, comparative shapes and sizes, 143

value, 152

Akron, Ohio, 155, 266

Albert Russel Erskine Bureau, 99

Alleys, 217

Altitude regulations, diagram of, 144

Amalgamated Clothing Workers, apartments, 241

American City Planning Institute, 55,370

American Civic Association, 55

American Federation of Arts, 55

Amherst, 8

Amsterdam, 122

Ancient and medieval cities, 17-33

in Assyria, 18

in Egypt, 18

in France, 35

in Germany, 10, 49

in Greece, 24

in Italy, 29, 276, 277

Anderson, Nels, 4, 16, 184, 247, 271, 340

Anderson, William, 354

Andrews, H. L., 120

Annapolis, 45

Antwerp, 122, 137

Aosta, 32

Apartments, Amalgamated Clothing

Workers, 241

Chicago, 239

exceptions to zoning requirements

in favor of, 267

neighborhood units, 205

perimeter arrangements, 216

residential zoning, 257, 258

Rockefeller developments, 238

Sunnyside, 237 
Apartments, trend toward increasing apartments, 258

Appeal to public, 365

Appearances, 308, 347

Aqueducts, Aqua Claudia, 31

Anio Novus, 31

Arcades, 86

Miami, 86

Philadelphia, 86

Santa Barbara, 86

Arch of Titus, 32

Architectural control, 219, 308, 345, 347,348

in Rancho Santa Fé, 309

Architects, general, 4, 5ิ2, 53, 57

(See also Planners.)

Aristophanes' play "'The Birds," 28

Aristotle, 28

Art juries, Los Angeles, 309

Palos Verdes, 309

Santa Barbara, 309

Vieux Carré, 309

Art Museum, Houston, 299

Ashby, T., 50

Aspect of airport from air, 152

Assessment methods, 353-360

area method, 359

Bartholomew method, 359, 360

front-foot method, 358

Asshur (Assur), 20

Assyria (early cities of), 18

Athens, 10, 25, 281

Atlantic Heights, 235

Atterbury, Grosvenor, 243

Audubon Park, New Orleans, 175, 187

Augur, T. B., 351

Automobiles, how numerous, 91

use of, in Boston, 102

in Chicago, 102

in Kansas City, 102

in San Francisco, 102

in Washington, 102

B

Babbitt, Prof. H. E., 162, 167

Babylon, 18

Baguio, 59

Baker, N. F., 272, 351, 348, 376

Balboa Park, 170, 173
Baltimore, 129, 282

Bankson, Paul A., 362

Bartholomew, Harland, 56, 67, 86, $89,109,120,197,272,273,362$

Bassett, E. M., 69, 197, 272

Bastides of Middle Ages, 34

Bath, Royal Crescent, 41

Baumeister, Reinhard, 49

Beauty in city plan, 302-316

approaches, 149, 150, 152, 303, 304, 311

architectural control, 308 .

billboards, 311, 312, 313, 314

bridges, 304

building upcity pictorially, 303, 304

city plan as essential to achievement of beauty, 306

elimination of ugliness, 309

focal points, 306

fountains, 199, 306

illumination, 304, 305, 306

interest in things beautiful, 302

overhead wires, 314

parks, 168-184

smoke, 310

streets, 304

trees, $75,85,87,88,89,208,300$, 304

value, 303

war memorial, 307

zoning, 249-273

Belt lines, 134

Bennett, E. H., 315

Berlin, 40, 141

Unter den Linden, 282

Bernini, 37

Bettman, A., 272, 376

Bibbins, J. R., 109

Bigger, F., 376

Billboards, 3, 311, 312, 313, 314

Bing, A. M., 247

Black, Archibald, 156

Blanchard, W. O., 138

Blocks, 212

Blucher, Walter H., 362

Board of appeals, 270

Boats, kinds of, 130

Bonds, 353

Bosanquet, R. C., 50 
Boston, airport, 142

automobile travel, 102

Common, 172

Franklin Park, 176

island city, 7

metropolitan region, radius, 319

park and park system, $52,58,374$

plan, 9

planning convention, 55

playground, 169

regional planning commission, 324

regional territory, 319

suburban trend, 321

subway, 107

tenements, 227

tide, range of, 129

water supply, 160

Boulder, 54

Bourneville, 231

Bramante, 33, 36

Breakwaters, 130

Bremen, 122, 137

Bridge, Magdalen, at Oxford, 304 of San Angelo, 37

Bridgeport, 235

Brinckmann, A. E., 50

Brindley, J. E., 362

Brooklyn, 52, 135

Brosseau, A. J., 80

Brunner, A. W., 301

Buck, A. E., 362

Budd, B. I., 109

Buffalo, 173

civic center, 282

exposition, 53

overhead wires, 314

plan, 173

radius of metropolitan region, 319

railroad station, 114

Building arrangement, 298

Harvard College Yard, 298

Harvard Medical School, 298

Normal and Latin Schools, 298

Williams' School Group, 298

Building groups, 274-301

civic centers, 53, 279-281, 283

in new world, $282,283,284$

Baltimore, 282

Buffalo, 53, 282
Building groups in new world, Chicago, 53, 282

Cleveland, 282

Denver, 282

Des Moines, 282

Detroit, 282

Duluth, 282

Kenosha, 282

Los Angeles, 282

Milwaukee, 282

Philadelphia, 282

St. Louis, 53, 282

San Francisco, 282

Santa Barbara, 283

Springfield, Mass., 283

Wilmington, 282

in old world, 281, 282

Athens, 281

Berlin, 282

Louvre, 281

Nerva, 281

Piazza di San Pietro, 281

Piazzo di San Marco, 281

Place du Capitol, 281

Place de la Carrière, 282

Place de la Concord, 281

Place Stanislaus, 282

Roman forum, 281

Santa Maria Maggiore, 281

Trafalgar Square, 282

public buildings, 279

sub-centers, 279

Buildings (see also Building groups).

standing alone, 275

background, 275

relation to surroundings, 278

to see them as a whole, 275

Burnham, Daniel H., 48, 52, 59

Bush Terminal, 118, 135, 136, 137

Business, 205, 206, 207, 257, 259,

260, 266, 269, 279, 284

Buttenheim, Harold S., 247

Butterworth, William S., 197

Buxton, 10

C

Cable cars, 101

Cairo, 6 
California, 11

Camden, 235

Canberra, 8, 9

Cargo, 130

Carriers, types of, 132

Cassel, 40

Central Park, 52, 169, 357

Chamberlain, Joseph P., 272

Charles River, 169

Charleston, S. C., 11, 374

Charlotte, N. C., 153

Chase, Stuart, 3

Checkerboard and gridiron plan, 75

Cheney, C. H., 315, 351

Chester, England, 10

Chester, Pa., 235

Cheyenne, 144

Chicago, airport, 152

architecture, 10

automobile use, 102

billboards, 312

Burnham, Daniel H., 59

business frontage study, 259

civic center, 53

climate, 12

commercial club, 54, 364

comparison with Babylon, 20

double-decker streets, 79

educational work, 56

exposition of $1893,52,58,282$

Forest Preserves, 176

harbor, 125, 126

housing, model, 239

inadequate improvements, 2

location, 374

Michigan Boulevard Apartments, 240

Norton, Charles D., 61

parks, 52

plan of Chicago, 54

regional planning body, 324

regional territory, 319

routings, 103

Rosenwald Apartments, 240

river straightening project, $\mathbf{7 7}$

subways, 107

traffic system, multiple blook, 96

Wacker, C. H., 3

"Manual," 56
Child, Stephen, 184, 197, 340, 376

Christian Science Monitor, 57

Cincinnati, plan, 63

poles and wires, 314

railroad station, 114

tenements, 227

traffic losses, 2

United City Planning Committee, 364 ,

Cities, American, of the seventeenth and eighteenth centuries, $42-48$

Annapolis, 45

Detroit, 45

New Orleans, 45

Philadelphia, 45

Reading, Pa., 45

Savannah, 45

Washington, 45

types according to architecture, 10

City beautiful movement, 53

City Hall, Coral Gables, 274

City plan, 65, 70, 306

definition, 65

elements, 66

building groups and monuments, 274-301, 302-316

recreational facilities, $168-197$

residence and business properties, 198-222, 223-248, 249273

streets, 71-90

transportation lines and terminals, 100-109, 122-138

water supply, sewage disposal and other utilities, 158-168

essential to achievement of beauty, 306

flexibility, 67

maximum usefulness, 68

program, 67

City planning, definition, 1, 3

City planning committees, for educational purposes, 364

City Planning Enabling Act, 55, 218, $324,325,350$

City Planning Institute, 55

City planning movement in America, 52,63 
City planning movement in America, city beautiful movement, 53 educational efforts, 56 establishment of planning commissions, 54

expositions, 52

organizations, 54,55

planners, 57,63

Burnham, Daniel H., 59

Eliot, Charles, 58

Ford, George B., 62

Kessler, George E., 59

Lewis, Nelson P., 59

Norton, Charles D., 61

Olmsted, Frederick Law, 58

Pray, James Sturgis, 62

Robinson, Charles Mulford, 59

Wacker, Charles H., 61

reports, 54

war-time cities, 53

writings, 56

City planning organizations, 54, 55

“City Planning Primer," 69

Civic centers, 53, 279, 280, 281

San Francisco, air view, 283

Clark, W. C., 273

Cieveland, airport case, 145

Citizens Committee, 364

city planning convention, 55

civic center, 53, 282

metropolitan region (radius), 319

Mitchel Field, 142

suburban trend, 321

Union Station, 114

Climate, 12

Clover-leaf grade separation, 96

Coblenz, 40

Coliseum (Rome), 32

Collaboration, 375

Cologne, 230

Columbian Exposition, 52

Comey, Arthur C., 328, 340

Commercial Club of Chicago, 54'

Committee of American Engineering

Councils, 95

Conclusions, 373-376

cities about to be built, 373

cities built, 373

city as organism, 374
Conclusions, contributing professions, 373

outstanding excellences, 374

past and contemporary achievements, 374

spaciousness, 374

in what way should growth proceed, 373

Control of appearances, 347,348

of land platting, 343

of setback lines, 345

Corbett, Harvey W., 78, 79

Cornick, Philip H., 353

Couchan, Noulan, 75

Courses, general, in city planning, 368,369

Courts (see also Apartments).

inner and outer, 268

patio, 12

Santa Barbara, 207, 283, 284

Covent Garden, 41

Crane, J. L., Jr., 69, 221

Crawford, A. W., 315

Croydon, 141

Culs-de-sac, 75

Curtis, H. C., 301

D

Dallas, Texas, 54, 56, 93, 94, 364

Damon, G. A., 109

Davison, Robert L., 146, 156

Dayton, 118

Dealey, G. B., 372

Denver, 8, 53, 144, 176, 282

Des Moines, Iowa, 2, 282

Detroit, airport, 152

Book. Tower Garage, 92

civic center, 282

D. U. R., 107

early plan of, 43, 44, 45, 48

Fisher Building, 263

governor and judges plan, 43, 44

growth, 14

railroad terminal, 141

smoke, 310

street widening, 85

subways, 107

superhighway, 80 
Detroit, traffic, losses in, 2 traffic flow study, 106 zoning for height, 265

Diagonal or radial system of streets, 74

Doland, J. J., 167

Douglass, Paul Harlan, 340

Downer, Jay, 144

Droege, J. A., 120

Düsseldorf, 40

Duffus, R. L., 340

Duke, Donald, 156

Duluth, civic center, 282

Dwellings constructed per year, 1

\section{E}

Earswick, 231

Economists, 57

Eddy, H. R., 167

Edinburgh, 42

"New Town," 42

Educational groups and city plan, 288

Educational and promotive work, 363-372

city planning periodicals, 370

educational efforts and writings, 56

instruction in city planning in United States, 56, 366

keeping psychology of public in mind, 365

local civic publications, 371

national organizations, 370

public education, 360,361

state participation, 369

Electric cars, 101

Electric Railway Journal, 109

Elevated and double-decker streets, 79

Elevated railroads, 101

Elgood, F. M., 16

Eliot, Charles, 58

Eliot, Charles W., 64

Emerson, W., 315

Enabling Act, Standard City Planning, 55, 218, 324, 325, 350

Engelhardt, F., 197, 301
Engelhardt, H. L., 197, 301

Engineering News Record, 57

Engineers, 4, 53, 57

(See also Planners.)

Ephesus, 26

Erie, 173

Euphrates, 19

\section{F}

Fairmount Park (Philadelphia), 176

Fairview, 235

Fall River, 8

Faries, D., 120

Federated Societies on Planning and Parks, 55

Ferriss, Hugh, 376

Finance, 349

Financial program, 361

Fire engine house (Miami), 285

Fitzgerald, D., 138, 315

Flagg, E., 376

Floating terminals, 129

Florence, 34

Florida, 11

Focal points, 730

Fora of Rome, 29

Roman, 29

Trajan, 29

Ford, George B., 62, 63, 156, 197, $315,340,362$

Ford, J., 247

Forest Hills, N. Y., 243

Fort of Antonia, 23

Fort Worth, 176

France, Renaissance, 38

Francis, I., 38

Franklin Park (Boston), 174

Freight, freight houses, 114, 115

Freihof, 231

Function, types of cities according to, 8

G

Galveston, 7, 129

Garage (25-story), 93

Garden city efforts, 8, 49, 231, 232

Garden city idea in America, 241, 242 
Garden city idea in America, difficulties, 241,242

Forest Hills, L. I., 9, 243

Kingsport, Tenn., 243

Mariemont, Ohio, 242

Radburn, N. J., 244, 246

Genoa, 34

Githens, A. M., 301

Godward, A. C., 362

Goodrich, C. S., 316

Goodrich, Ernest P., 99, 138, 156, 272

Goodyear Heights, 235

Grade crossings, 117, 118

Grade separation, clover-leaf, 96

Greece, 7

Greek cities 10, 24, 25, 281

Green, J. R., 50

Greensfelder, A. P., 340, 363

Griffith Park (Los Angeles), 176

Group, community, town planning, 234

Groups of public buildings, 279, 281

Grow th in cities, 13

\section{$\mathrm{H}$}

Hadden, G., 197

Hamburg, 137

Hammarstrand, H., 28, 50

- Hampstead, 8

Hanging Gardens of Babylon, 20

Hanks, Col. Stedman s., 156

Hanmer, L. F., 197

Harbor (see Ports).

Hare, S. H., 247

Harmon, W. E., 221

Harrisburg, Pa., 6, 118

Hartford, 153

Harvard, 56, 62, 298, 299, 366, 367

Haussmann, Baron Georges Eugène, 49,50

Haverfield, F. J., 50, 51

Havre, 129

Head-in parking, 93-94

Heat systems, 158

Hedden, W. P., 120

Hegemann, Werner, 16, 51, 89, 222, 316

Heights of buildings, 11, 15, 261, $265,318,320,324,373,375$
Hellerau, 230

Henrichemont, 38

Herculaneum, 32

Herod, 22

Herodotus, 20

Hewes, L. I., 316

Hicks, George, 229

High school, use of sculpture, (Venice, Calif.), 296

High-speed lines, 105, 107

elevated, 107

fast-moving trolleys, 105, 106

open cuts, 107

subways, 107

High-speed passenger routes of a great city, typical plan for, 112

Hilversum, 230

Hippodamos of Miletus, 28

Historical glance at development of cities, 17,51

American cities of 17 th and 18 th centuries, $42-48$

ancient cities, 17-33

Medieval cities, 33-35

Modern period, 48-50

Renaissance cities, 35-42

Hoelscher, L. W., 362

Hogg, J. E., 316

Holsworth, W. C., 316

Homes associations, 220

Hood, O. P., 316

Hoover, Herbert, 2, 4, 251

Horse-car lines, 101

Hospital and the city plan, 286, 287

House types, diagram of, 224

Housing, 223-248

(See also Garden city idea in America.)

bad legislation and, 224

reasons for, 228

in United States today, 226

good, accomplishment of, 228

Housing Department of Emer-

gency Fleet Corporation, 54

model, in Europe, 229

Austria, 231

England, 231-233

France, 233 
Housing, model, in Europe, Germany, 230

Holland, 230

in United States, 233-235

Amalgamated Workers, 240

Chicago, 239

Rockefeller developments ,238

Sunnyside, 237

war housing, 53, 54, 235

United States Housing Corporation, 54

See also Forest Hills, Kingsport,

Mariemont, Radburn, and under Subdivisions.

Howard, Sir Ebenezer, 231, 232

Howe, O. M., 64

Hubbard, H. V., 141, 156, 184, 197, 222,376

Hubbard, Theodora Kimball, 5, 64, 341,371

Hubbard and Hubbard, 69, 89, 109, $184,272,316 ; 340$

Hudson, William D., 360

Hughes, T. H., 29, 51

Hurd, R. M., 16

Hymettus, 25

Ihlder, John, 79, 229, 376

Illinois, University of, $56,367,368$

Illumination, 151, 304, 305, 306

Importance of city planning, 1-4

Improvement, means of attaining, 3

Indianapolis, 173, 313

Industry, 135, 259

Institutional buildings, arrangement for convenience, 292

existing conditions respecting, 293 functions and kinds, 292

grouping, 292

for beauty, 294

organization of roadsand paths, 295 planting, 300

Institutional groups, 286

educational, and city plan, 288

hospital, and city plan, 286, 287

penal and correctional, 287

Instruction in city planning, 56,366 , 367
Interior block spaces, 216

International Federation for Housing and Town Planning, 56

Intersections, 78, 95, 96

Irwin, Will, 271

Ishtar's Gate, 19

Isles of safety, 95

Jackson Park (Chicago), 52

James, Harlean, 64, 362, 372

Jefferson, Thomas, 289

Jericho, 20

Jerusalem, cross-sectional view, 21 plan of, at time of Christ, 22 topography of, 21, 22 .

Johnstown, Pa., 365

Jones, Inigo, 37, 41

Journal of the American Institute of Architects, 57

\section{K}

Kahun, 18, 19

Kansas City, airports, 153 automobiles, use, 102 parks, 52, 179 assessment, 357 railroad terminal, 141

Karlsruhe, 9, 40

Karnak, 18

Kehr, Cyrus, 341

Kemper, E. C., 316

Kennedy, Louise Venable, 197, 247

Kenosha, Wis., 266, 282

Kessler, George E., 54, 59, 60

Keyhoe, D. E., 157

Kidron, 23

Kimball, Justin F., 64, 364, 372

King Solomon, 23

Kingery, R., 272

Kingsley, S. C., 372

Kingsport, Tenn., 343

Kingston, J. L., 273

Kite, Elizabeth S., 51

Klauder, Charles Z., 301

Knauss, Norman L., 57

Knowles, M., 247, 341

Kohn, Robert D., 244

Krusen, Wilmer, 272 
Los Angeles, exposition park, 192

Griffith Park, 176

Lamborn, E. A. J., 51

harbor, 124

Landing fields, development of, 146-152

Landscape architects, 4, 52, 53, 57, 58

(See also Planners.)

Landscape Architecture Magazine, 57

Lasker, B., 69

Lawyers, 57

Leavitt, C. W., 167, 316

Le Bourget, 141

Le Corbusier (Charles Edouard Jeannert), 376

Legal authority for city planning, $3,342-351$

power to administer activities, 349

to control appearances, 347,348

to control land platting, 343

to finance, 349

to prevent buildings in mapped streets, 346

to regulate property (police power), 344

to regulate setback lines, 345

to zone, 347

L'Enfant, 9, 45, 46, 47, 48

Le Notre, 39

Letchworth, 8, 231, 232

Lewis, Nelson P., 5, 59, 61, 64, 69, $89,109,120,138,184,341,351$, 353,362

Light systems, 158

Lighting, lamp post (Los Angeies), 305

Lincoln, England, 32

Lindeman, E. C., 4, 16, 184, 247, 271,340

Liverpool, 129, 137

Location, types of cities according to, 6

Lohmann, Karl B., 197

London, Croydon, 141

population, 13

port, 137

Trafalgar Square, 282

Wren's Study, 9, 37, 41

Los Angeles, airport, 153

association of City Planners, 336

Los Angeles, civic center, 282 regional planning commission, 324 regional territory, 319

- subway, 107

zoning, 252

Lots, 213-215

Louis XIV, 37, 39

Louis $\mathrm{XV}, 40$

\section{M}

MacDonald, Austin Faulks, 99

MacElwee, R. S., 121, 129, 131, 138

MacFarland, J. Horace, 184

Mackall, K. W., 99

Madison, Wis., 73

Magnesian Gate, 26

Malcher, F., 99

Mannheim, Germany, 40, 45

Mariemont, 242, 243

Mathes, G. H., 69

Mawson, T. H., 89, 301, 316

McClintock, M., 99, 157

McNamara, Katharine, 5, 371

Mears, F. C., 51

Medieval cities of Europe, 33-35

Meller, H. B., 316

Melrose, Mass., 57

Memphis, 6

Menhinick, H. K., 141, 156, 316

Merriman, Mansfield, 138

Metropolitan organization, 336

Metropolitan park scheme, $\mathbf{1 7 7}$

Miami, 86

Michelangelo, 33, 38

Middle strips and islands, 97

Miller, Paul D., 157

Miniature settings, Busch Gardens, 188

Minneapolis, 8, 282, 357, 374

improvemenis and "Inside Elwell Law," 8, 357

Mitchell, H. C., 69

Model housing in England, 231

Bourneville, 231

Earswick, 231

Letchworth, 231 
Model housing in England, other developments, 233

Port Sunlight, 231

Welwyn, 232

in United States, 233, 234

Amalgamated Clothing Workers, 240

Chicago, 239

Goodyear Heights, 235

Pullman, 235

Rockefeller developments, 238, 239

Sunnyside, 236, 237, 238

war housing, 235

Emergency Fleet Corporation, 235

United States Housing Corporation, 235

See also Forest Hills, Kingsport,

Mariemont, Radburn and under Subdivisions.

Modern period in city planning (nineteenth and twentieth centuries), 48, 49

Baumeister, Rheinhard, 49 economic viewpoint, 49 esthetic viewpoint, 49

Haussmann, Baron Eugène, 49

Napoleon III, 49

Sitte, Camillo, 49

social viewpoint, 49

Stübben, Joseph, 49

Monchow, Helen C., 222

Monnett, P., 316

Mons, Belgium, 230

Montpazier, 34, 35

Monument, proposed war memorial (Chicago), 307

"Monuments Eriges en France," etc., 40

Moody, W. D., 4,

Moody, Walter D., 364, 372

Moore, Charles, 64

Moot, R. D., 99

Morris, Warren L., 222

Moscow, 9

Motor bus, 101, 104

Mount of Olives, 23

Mulford, F. L., 89
Mumford, Lewis, 376

Munich, 160

Munro, William Bennett, 247

\section{$\mathrm{N}$}

Nabopolassar, 18

Names of streets, 10

Nancy, 282

Nanking, 20

Naples, 22

Napoleon III, 49

National Commission of Fine Arts, 55

National Conference on City Planning, 55, 370

National Geographic Magazine, 16

National Housing Association, 55

National Recreation Association, 186

Nebonidus, 18

Neighborhood parks, 173

Neighborhood-unit principles, 205

Newark airport, 153

Newcomb, Rexford, 316

New Haven, 319

Newman, Bernard J., 247

New Orleans, Audubon Park, 175, 176

belt-line railroad, 134

diagonal scheme of streets, 9,10

early plan, 45

French homes, 11

harbor, 123

individuality, 374

location, 6

patio, 12

street plan, 10

wading pool, 187, 188

New York, airports, future, 140

Aldermanic Committee, 312 apartments, Amalgamated Clothing Workers, 240

assessment district for parks, 357

building heights, 264

Bush Terminal, 118, 135, 136, 137

Central Park, 52, 169, 357

decentralizing trend, 321

electrification, 120

elevated railroads, 101

elevated streets, 79

Ford, George, 63

gridiron streets, 9 
New York, harbor, 123

housing commission, 225

housing condition, 226

island city, 7

Lewis, Nelson P., 59, 61

location, 6,7

Municipal Art Society, 311

park appropriation, 169

population, 13

port, 137

railroad stations, 114

range of tide, 129

region, radius of, 319

regional planning body, 324

regional territory, 319

skyscrapers, 11, 15, 93, 262

slums, 228

smoke abatement, 310

spider-web diagram, 72

subway, 101, 107

Thomas, Andrew J., 240

traffic, 2, 96

transit, 107

trends of population, 107

Westchester County Park system, $176,179,333$

zoning, 252

Nichols, J. C., 272

Niewendam, 230

Nineveh, 20, 21

Nolen, John, 5, 16, 64, 89, 138, 157,

$184,242,247,316,341,351,376$

Norfolk, Va., 319

Norton, Charles D., 61

Norwich, 10

Nuremberg, 10

\section{$\mathrm{O}$}

Oakland, airport, 149

O'Donnell, T. E., 301

Olmsted, F. L., 52, 57

Olmsted, F. L., Jr., 54, 64, 222, 302

Olmsted office, 243

Omaha, 6, 114

Orlando, Fla., 105

Oscan Community, 32

"Our City Dallas," 56

Overhead wires, 314

Overstreet, Prof. H. A., 365, 372
$\mathbf{P}$

Palatine Hill, 31

Palladio, 33, 36

Palmyra, colonnaded street, 23, 24

Palos Verdes, 8, 101, 199, 219, 220, 221,309

Pan-American Exposition (Buffalo), 53

Paris, Bernini's visit, 37

Haussmann, Baron Eugène, 49

island city, 7

Le Bourget, 141

Louis XIV, 37, 39

Napoleon III, 49

Place de Ja Concorde, 39

Place Dauphine, 39

Place Royale, 39

radial plan, 9

squares, 282

Wren, Sir Christopher, 37

Parking, 91-95

facilities, 133

Parks and park systems, 168-184

administration, 182

Audubon Park, 175

Balboa Park, 170

Boston Common, 172

Bronx River Parkway, 180, 332

Central Park, 52, 357

Cook County Forest Preserve, 176

Denver, 176

Fairmount Park, 176

finances, 182

acquirement of parks, 182

Central Park, area over which cost was spread, 357

gain in valuations, $\mathbf{3 5 5}$

investment in parks and recreation, 182

Golden Gate Park, 176

Jackson Park, 52

Kansas City park system, 179

Lake Worth Reservation, 176

large parks, 174-176

medium-sized parks, 173, 174

minimum requirements, 180, 181

Minneapolis, 179

neighborhood parks, 173, 174 
Parks and park systems, parkways, 177

Philadelphia, 172

Phoenix, 176

Playland, 178, 179

program, 182

Salt Lake City, 172

Savannah, 172

sites, 181, 182

small parks, 171, 172

valuation, gain in, 355

value, 168

variety in, 170

Westchester County Parks, 176, 179, 180, 332

Passenger stations, 111

Passenger travel, diagram of average speeds per hour, 102

Paying for city planning, 352, 362 bonds, 352

excess condemnation, 343, 360, 361

long-term financial programs, 361 special assessments, 353

areas of, 358

graphical analysis, 360

methods, 358

parks, 357

streets, 356

taxes, 352

Peace of Aix-la-Chapelle, 40

Peets, Elbert, 16, 51, 89, 222, 275, 316

Penal institutions, 287

People help to distinguish community, 8

Pepler, G. L., 69, 272

Pergamum, 27

Pericles, days of, 24

Philadelphia, arcades, 86 checkerboard layout, 9

Fairmount Park, 176

Independence Hall, 282

location, 6

names of streets, 10

Penn's Plan, 45, 172

Pennsylvania Station, 141

regional diagonals, 327

regional planning body, 324
Philadelphia, regional territory, 319 suburban trend, 321

subway, 107 traffic, multiple block, 96

traffic losses, 2

Phoenix, Ariz., 176

Physical characteristics, 6-16

types of cities according to architecture, 10

to function, 8

to growth, 13

to location, 6

to people, 8

to size, 12

to streets and street systems, 8

Piazza del Campidoglio, plan, 37, 38

Piazza Maggiore, 36

Piazza, Navara, 37

Piazza del Popolo, 36

Piazza of St. Peter's, 29, $3 \hat{o}$

Piazza di Spagna, 36

Piazza Trevi, 37

Piedmont, ancient royal park, 36

Pienza, civic group, 35

Pink, Louis H., 227

Piraeus, 28

Pittsburgh, 8, 118, 142, 291

Place de la Concorde, 40

Planners, Baumeister, Rheinhard, 49

Bernini, 37

Bramante, 36

Burnham, Daniel H., 59

Eliot, Charles, 58

Ford, George, 62

Haussmann, Baron Eugène, 49

Hippodamos, 28

Jones, Inigo, 41

Kessler, $\mathbf{5 9}$

L'Enfant, 45, 45-48

Lewis, Nelson, P., 59

Louis XIV, 39

Michelangelo, 38

Norton, Charles D., 61

Olmsted, F. L., $\mathbf{5 8}$

Palladio, 36

Pray, James Sturgis, 62

Robinson, Charles Mulford, 59

Sitte, Camillo, 49

Stübben. Joseph, 49 
Planners, Vitruvius, 32, 33

Wacker, Charles H., 61

Wood, John, and son, 42

Wren, Sir Christopher, 37

Planning commissions, establishment of, 54

Play movement, 185, 186

Playground and Recreation Association of America, 186

Playgrounds and playfields, 185-197 kinds and distribution, 187

locations to serve elementary school group, 189

intermediate school group, 191

pre-school group, 187

school group, 189

youth and adults, 192

sizes, 193, 194

space requirements for organized games and sports, 195, 196

Playland (Rye Beach), 178, 179

Plaza, business (Malaga Cove), 279

Plazas, European, collection of plans of, 276, 277

Police power, 255, 308, 344, 345

Pompeii, 32

Pond, Bremer, 64

Pontiac, Mich., 264

Popes, Clement VII, 38

Julius II, 38

Leo X, 38

Paul III, 38

Sixtus V, 38

Population, increase in cities, 1

Port Sunlight, 231

Portland, Ore., 128, 153

Ports, sea, lake, and river, 122-138

American, 122

efficiency of, 137

kinds of boats involved, 130

kinds of cargo, 130

location and city plan, 135

Los Angeles, 124

management of, 137

New Orleans, 123

New York, 123

Portland, terminal, 128

railroads and, 134

Ripetta on the Tiber, 36
Ports, streets and, 132

transfer movements, 131

waterways and wharves, 127

Power, heat, and light, 164, 165

Pray, James Sturgis, 62, 64, 121

Preparation of city plan, 67

President Hoover, 2, 4, 251

Priene, 26

Princeton, 8

Program of preparation of city plan, 67

Promenade at port, 134

Propper, Henry M., 222

Pullman, Ill., 235

Pumping Station, 160

Purdom, C. B., 247, 341

Purdy, L., 362

Purification building, 159

$\mathrm{R}$

Radburn, Frontispiece, 8, 75

central park area, 245

children playing in large parks, 245

closed-end street, 211

plan, 210

of group of houses, 244

under-pass, 246

Railroad in city plan, 110-121

consolidation of lines, 119

freight, 114

freight houses, 115

passenger stations, 111

planting and improving, 119

relation to vicinities served, 118

to waterfront terminals, 118, 134

and streets, 116

union stations, 113, 114, 303

yards, 116

Raphael, 38

Reading, Pa., 45

Reclus, E., 16

Recreation, 168-197

(See also Parks and park systems, Playgrounds and playfields.)

play movement, 185 
Recreation, types of, 169 value, 168

Recreational centers, Chicago, 186 Rochester, 186

Regional control of subdivisions, 335

Regional development, theoretical scheme, 322

Regional expansion, 323

Regional planning, 317-341 commission, 324

highways, 326

parks, 331-333

Westchester County Park Commission, 333

scope and character of region, 318-320

theory of population distribution, 320,323

transit and transportation, 328

value, 317

water supply and sewage disposal, 330

Regional planning projects in United

States, Boston, 337

Chicago, 337

Los Angeles, 337

Maryland, 339

Milwaukee, 338

New York, 338

Niagara, 338

Philadelphia, 338

Santa Barbara, 339

Toledo, 339

Washington, 339

Regional zoning, aims, 333

factors to be considered, 334

standards, 335

Renaissance, planning of cities during, 35-42

England, 40

France, 38, 297

Germany, 40

Italy, 35, 276, 277

Scotland, 40

Renaissance plazas, analysis of sections, 297

Reports, city plan, $\mathbf{5 4}$

Reservoirs, 160

Rheims, 63
Richelieu, town of, 38

Richmond, 6

River-front development, St. Louis, 79

Riverside, Calif., 88

Robinson, Charles Mulford, 54, 56, $59,60,90,301,316,367,372$

Rochester, 53

Rockefeller Foundation, 366

Rockefeller housing developments, 238, 239

Roland Park, 8

Rome, 10, 29, 31

aqueducts, 31

architecture, 10

Bernini, 37

Bramante, 36

Bridge of San Angelo, 37

Capitol, 29

Cloaca Maxima, 29

Coliseum, 31

Forum, Roman, 29

Trajan, 29

grouping of buildings, 281

imperial, 29, 30

Michelangelo, 38

Palatine, 29, 31

Palladio, 36

Piazza del Campidoglio, 38

Piazza Navara, 37

Piazza del Popolo, 36

Piazza di San Pietro, 29

Piazza di Spagna, 36

Piazza Trevi, 37

popes (see Popes).

Port of Ripetta, 36

Raphael, 38

St. Peters, 37

Spanish steps, 36

Trinita del Monti, 36

Vatican, 36

Via Clivus, 29

Via Nova, 29

Via Sacra, 29

Via Sistina, 36

Root, Elihu, 5

Rotterdam, 122, 137

Routings, diagrams of, 103, 104

Row of shacks, 227 
Ruhr Basin, 319

Runways (airports), 147

\section{$\mathrm{S}$}

Saarinen, E., 301

Sacred Way, 19

Saginaw, 8

Saint-Foy la Grande, 35

St. Francis Woods, 199

St. Gaul, 33

St. Louis, 6, 85

airport, 153

civic center, 282

court house, 79

elevated streets, 79

exposition of 1904, 53

location, 6

overhead wires, 314

parking of automobiles, 92

radius of metropolitan region, 319

river-front development, 79

sewers, 164

street widenings, 85

subway proposed, 107

through freight, 114

ten years' progress, "70

transit system, 104

zoning for height, 264

St. Paul, 6

St. Petersburg, Fla., 8

Salem, 10, 11, 374

Salisbury, 10

Salt Lake City, 8, 172

San Diego, 53, 87, 133, 153, 170, 173

San Francisco, airviews, 7, 124

automobile use, 102

belt line, 134

cable-car line, 101

civic center, 53,282

climate, 12

ferry terminal, 84

Golden Gate Park, 176

harbor, 124

location, $6,7,374$

market street, 84

Santa Barbara, arcades, 86

business district, 283, 284, 374

El Paseo, 207
Santa Barbara, regional planning commission, 324

regional territory, 319

Sante Fé, 171

Satellite cities of Los Angeles, 327

Savannah, 45, 172 .

Saville, C. M., $167^{\circ}$

School grounds, plan of, 190 playgrounds, 185-197

Schools, 189-196, 190, 207, 296, 298, 288-301, 366-367

Schulz, Walter F., 138

Sculpture, Wilson Park, Jacksonville, $\mathbf{3 0 5}$

Seaplane landing sites, 154

Selinus, plan, 27, 28

Sennacherib, 20

Setback lines, 345

Settlements of early America, 42

Sewerage systems, 161-164, 164

Sewage disposal works, 164

Seymour, H. L., 16

Shaftesbury, 10

Shacks, row of, $\mathbf{2 2 7}$

Shaker Heights (Cleveland), 199

Sheridan, L. V., 351

Shops, Arrow Head Lake, Calif., 280

De La Guerra Studios, 284

Shurtleff, F., 64

Shurtleff (Shurcliff), Arthur A., 184

Sidewalk and street development, $\mathbf{8 8}$

Signal-light systems, 96, 97

Simonson, Wilbur H., 184

Sitte, Camillo, 49

Slum commission, first efforts, 52

Smoke, 310

Sociologists, 57

Soissons, 63

Solon, Leon V., 376

Spanish steps, 36

Special assessments, 353-360

Spengler, Edwin H., 109, 362

Spider-web diagram, $\mathbf{7 2}$

Spokane, 8

Spoleto, 32

Spot Pond (Boston), 160

Springfield, Mass., 53, 282, 283

Squares, Buffalo, 173

civic centers, $53,279,280,281$ 
Squares, commons of New England towns, 172

court house squares of middle west, 172

Dauphine, 39

Erie, 173

Indianapolis, 173

old-world examples, 281, 282

piazzas, 29, 36, 37

Penn's plan of Philadelphia, 172

Plaza of Santa Fe, 171

Plazas in Europe, 276, 277

Roman Forum, 29

Royale, 39

Salt Lake City, 172

Savannah, 172

small parks, 171, 172, 173

sub-centers, 279

Trajan Forum, 29

Washington, 173

Standard (all-America) type of subdivision, 214

Standard City Planning Enabling Act, 55, 70, 218, 324, 325, 350

Standard State Zoning Enabling Act, 55, 253, 347

State participation, 369

Stations, 111, 112, 113, 114, 303

Stein, Clarence S., 244, 247

Stockbridge (first village improvement association), 52

Strayer, George C., 197

Street signs, signals, markings, 95

Streets, mapped, buildings in, 346

and port, 132

and street systems, 71-90

dominant types, 8

focal points, 73

major street plan, 77

minor streets, 78

movement of traffic, 71

segregation of traffic, 78

street trees, $75,85,87,88,89$,

208, 304

street widenings, 85,86

superhighways, 80

system and plan, 76

traffic flow, theoretical scheme of, 72,76
Streets and street systems, types of street patterns, 73,47

widths and cross-sections, 81, 82,83

Stinchcomb, W. A., 184

Studenski, Paul, 341

Subdivision control, 217-219

architectural board of review, 219

Palos Verdes, 219

Roland Park, 219

bond for provision of utilities, etc., 219

homes associations, 220

Palos Verdes, 221

Rancho Santa Fć, 221

regulations, 218

restrictions, 219

Standard City Planning Enabling Act, 218

Subdivision of land, 198-222

planning elements, 204

alleys, 217

blocks, 212

centers, 205

interior spaces, 216

lots, 213-215

parks, 216

streets, 207-210

site, 202

location, 202

physical conditions, 203

size, 203

Subdivisions, Coral gables, 200, 201, 202

Kansas City, Country club, 199

Palos Verdes, 8, 101, 199, 219, 220, 221, 309

Radburn, Frontispiece, 8, 75, 202, $210,211,244,245,246$

Rancho Santa Fé, 199, 221, 309

Roland Park, 199

St. Francis Woods, 199

Shaker Heights, 199

Suburban trend, 321

Subway, 101, 107

Sudborough, C. B., 121

Sunnyside, 236, 237, 238

Superhighway, 80

Swan, H. S., 222, 362 
$\mathrm{T}$

\section{"A Tale of One City," 364}

Taxes, 352

Technical Advisory Corporation, 69

Telephone systems, 165

Tempelhof, 141

Temple of the Sun (Palmyra), 23

Terminals, passenger, 135

Terre Haute, 6

Thirty Years' War, 40

Thompson, F. L., 222

Thompson, Warren S., 16

Tibbets Brook Park, 178

Tilton, L. D., 301

Time lost in traffic congestion, 1

Timgad (Africa), 32

Toledo, 314,319

Traffic control, 91-99

at intersections, 95

lanes, $82,84,85$

middle strips and islands, 97

parking, 91-95

segregation, 78, 96

signal lights, 96

Traffic flow, study, 106

theoretical scheme of, 72

Traffic movement, principles and character of, 71

Transfer movements, 131

Transit, and future cities, 101

rapid, 100-109

automobile, 102

development of transit, 101

high-speed lines, 105

motor bus, 104

routings, 103, 104

unified control and service, 105

relative reaches of one-half hour journeys by, 103

Transit "wall," 102

Transportation (see also Transit). passenger capacity, diagram, 106 urban and surburban, 100-109

Tratman, E. E. R., 121

Trees, 75, 85, 87, 88, 89, 208, 300, 304

Trends of city development, 13

Triggs, H. I., 16, 51, 90

Trinita del Monti, 36
Tunnels for utility mains, 166

Turin, 32

Turner, D. L., 109

Turning basins, 130

Tuttle, G. W., 222

$\mathrm{U}$

Ugliness, elimination of, 309

Union stations, 113, 114, 303

United States Department of Commerce, 55

United States Housing Corporation, 54

University, Harvard, 56, 62, 298, 299, 366, 367

University of Illinois, 56, 367, 368

University of Virginia, 8, 289, 290

University of Washington (Seattle), 298

Unwin, R., 5, 16, 51, 90, 222, 278, $301,316,341$

Utilities systems of, 158-167

power, heat, and light, 164

sewerage, 161, 162, 163, 164

telephone, 165

transportation lines and terminals, 100-109, 122-138

tunnels for utility mains, 166

water, 158

\section{V}

Veiller, L., 228, 248

Venice, 34, 79

Triumphal Arch, 36

Versailles, 39

Vertical transportation, 15

Verviers, Belgium, 230

Via Sistina, 36

Vicenza, Basilica, 36

bridge over Bacchiglione, 36

Piazza Maggiore, 36

Vicksburg, 6

Vienna, 9

Vieux Carré (New Orelans), 10, 45

Vignola, 33

Vitruvius, 32, 33, 51

Vitry le Francois, 38 
W

Wacker, Charles H., 3, 61, 372

"Manual," 56

Wacker Drive, 61

Wadsworth, George R., 121

War memorial, 307

War-time cities, 53, 54, 235

Washington, air view, 9

American Civic Association, 55

architecture, 10, 374

Arlington Cemetery, 46

automobile, use, 102

Burnham, D. H., 48, 59

Capitol, 46, 47

Civil War, 48

Custis home, 46

epithets, 47

Fine Arts Commission, 48

function, 8

L'Enfant, Major Pièrre Charles, $45,46,47$

Mac Millan Commission, 48

Mall, 46

McKim, Charles F., 48

National Conference of City Planning, first meeting, 56

National Park Commission, 48

National Park and Plan Commission, 48

occupied by British, 47

Olmsted, F. L., 48

Pennsylvania Ave., 47

plan, 44, 173

poles and wires, 314

Potomac River, 47

"Presidential Palace," 47

Regional Plan Commission, 324

regional territory, 319

St. Gaudens, 48

street system, 9

triangular properties, 47

union station, 114, 303

U.S. Department of Commerce, 55

White House, 46

Washington, University of (Seattle), 298

Water systems in city plan, 158

Waterways, 127
Weir, L. H., 184, 197

Weisburg, A. F., 70

Wells, H. C., 375

Welwyn, 232

Westchester County Parks, 176, 179, 180,332

Wharves, 127

Whitbeck, R. H., 16

Whitham, P. P., 138

Whitten, R., 90, 91, 222, 341

Wilcox, D. F., 16

Wilgus, W. T., 121

Williams, Frank B., 157, 273, 316, $343,351,353,362$

Williamsburg, Va., 42

Wilmington, 120, 235, 282

Winchelsea, 35

Winds, 12, 135, 147

Wires, overhead, 314

Wood, Dr. Edith Palmer, 233

Wood, F. A., 94

Wood, John, 42

Worcester, Mass., 2

Wren, Sir Christopher, 9, 37 replan of downtown London, 41

Wright, Henry, 213, 214, 222, 236, $237,244,248$

$\mathrm{Y}$

Yards, front, 265, 266

rear, 266, 267

side, 267

\section{Z}

Zenobia, 23

Zihlman, F. N., 64

Zion City, 8

Zoning, 249-273, 347

Board of Appeals, 270

control of extreme height, 262, $263,264,265$

districts for different degrees of land coverage, 265

for different heights, 261

eminent domain and, 255

Enabling Act, Standard, 55, 253, 347

establishment of zoning districts, 256 
Zoning, exceptions to side and front yards, 267

form and content of zoning ordinances, 269

gathering of facts in zoning survey, 256

illustrations, comparison of conditions, 250

Fisher Building (Detroit), 263

intermixture of buildings, 249

printing establishment overlooking Buffalo Drive (Houston), 260

setback principle applied to corners, 266

zoning ordinances according to states, 253

zoning in United States by years, 1904-1930, 254
Zoning, inner and outer courts, 268 movement in United States, prior to $1916,251,252$ since 1916, 252

other regulatory means, 254 population density, 268 program, 270 regional, 333-335 skyscraper, 261

transition, 269 use districts, 257

commercial, 259

industrial, 259

non-conforming uses, 261

residential, 257, 258

yards (see Yards).

Zug, Prof. G. B., 368, 372 


450 

